. 


\section{A REVIEW}

OF THE

SYSTEMS OF ETHICS FOUNDED ON THE THEORY OF EVOLUTION 
s 


\section{A REVIEW}

OF

\section{THE SYSTEMS OF ETHICS}

FOUNDED ON

THE THEORY OF EVOLUTION

BY

C. M. WilliamS

Xrew 19ark

MACMILLAN \& CO.

AND LONDON

I 893

All rights reserved

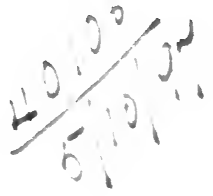


COPYRIGHT, 1892,

By MACMILLAN \& CO.

Typography by J. S. Cushing \& Co., Boston, U.S.A.

Presswork by Berwick \& Smith, Boston, U.S.A. 
TO MY FIRST TEACHER OF MORALS

MY MOTHER

THIS BOOK IS GRATEFULLY AND AFFECTIONATELY

DEDICATED 



\section{PREF A CE}

Of the Ethics founded on the theory of Evolution, I have considered only the independent theories which have been elaborated to systems. I have omitted consideration of many works which bear on Evolutional Ethics as practical or exhortative treatises, or compilations of facts, but which involve no distinctly worked-out theory of morals. On the other hand, I have ventured to include Professor von Gizycki's “ Moralphilosophie" among the theoretical systems founded upon the theory of Evolution, since, although the popular form of the work renders the prominence of the latter theory inpracticable, the warp of Evolution is clearly perceptible throughout it. In analyzing Höffding's work, I have made use not of the Danish but the German edition of his "Ethics," which was translated with his coöperation.

It is generally customary for an author to acknowledge, in the preface of his book, his especial indebtedness to those who have most influenced the growth of his thought in the line of research treated in the book. But I find this duty a difficult one to perform. Many of the authors whose work has aided me are cited in the text. But it is impossible, with regard to many points, to say to whom one is indebted, or most indebted, since much that one reads is so assimilated into one's organized thought, and changed in the process of assimilation, that its source and original form are no longer remembered. Besides this, much is always owed to personal influence and argument, and also to indefinite and minute forces whose workings it is impossible to trace. The 
growth of thought is, like any other growth, by imperceptible degrees and infinitesimal increments, and we breathe in ideas from our mental atmosphere as we breathe in perfumes or infections from our physical atmosphere. It is, of course, unnecessary to mention Mr. Spencer's name in this connection, since it goes without saying, that every one who writes on Ethics in their relation to the Theory of Evolution must owe much to him, even where he differs from him. But there is perhaps one name which it is fitting that I should mention here, since the influence of its bearer on my work, although one for which I have reason to feel peculiarly indebted, is not of a nature to determine its mention in connection with any particular theory. I refer to my first teacher of Philosophy, Professor M. Stuart Phelps, now deceased, whose life and labor all those who had the privilege of sharing his instruction and benefiting by his kindness must ever hold in grateful remembrance. 


\section{CONTENTS}

\section{PART I}

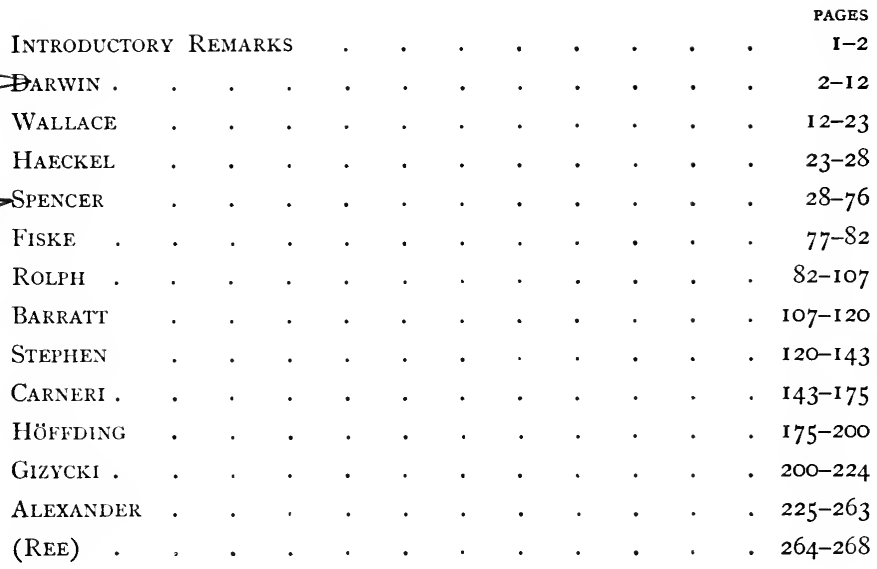

\section{PART II}

\section{INTRODUCTION}

Refutation of a priori objections to Evolutional Ethics, and a statement of reasons for supposing that an application of the theory of Evolution to Ethics must be of use . . . . . . 269-276

\section{CHAPTER I}

The Concepts of Evolution

Extension of the meaning of Darwinian concepts since Darwin - Lewes on the Struggle for Existence as internal - The mystery of "Varia- 
tion" according to Darwin not a metaphysical mystery, but one of the incompleteness of scientific knowledge-Rolph's criticism of the Darwinian conception of the Struggle for Existence criticised-General classification of the theories of Evolution - Fechner's theory of the Tendency to Stability - Petzoldt on Fechner - Petzoldt's concepts of Tendency and Competition - Zöllner and Du Prel - Examination of the concept of Absolute Stability, and of a full stability of the universe, in the light of the question as to the finite or infinite character of the material universe - Periodicity in Organisms - Criticism of the concepts of Cause and Effect-Criticism of Spencer's definition of Life - The concepts of Heredity and Adaptation - The point of dispute with regard to Variation - Darwin, Haeckel, and Eimer with regard to the inheritance of individual acquirements - Criticisms of Weismann - Habit in the life of the individual - Advantage of the method pursued by Avenarius in the "Kritik der reinen Erfahrung"Lamarck on the relation of Use and Function-Darwin on Habit and Instinct - Function and Tendency to Function - Relation of organism and environment - Theory of a special vital force - The relation of exercise to strength of Tendency - The concepts of Cause and Effect as applied to organism and environment - Relation of primary tendency to later-evolved function - Form and Function - The mixture of types in sexual propagation - Summary of conclusions .

277-306

\section{CHAPTER II}

\section{INTELLIGENCE AND "END"}

The question as to the extent to which Reason is diffused in the universeDarwin and Haeckel on Reason and Instinct - Du Prel on Reason as a fundamental property of all matter - Carneri on the automatism of animals - The dependence of theories on this question on the startingpoint assumed in the argument-Difficulties of assigning a limit-line to Reason - Schneider's criteria - Insectivorous plants - Knight, Darwin, etc., on the movements of plants - Race-habits - So-called reflex-action in man - From non-analogy no inference possible Arbitrary nature of the assumptions involved in the two starting-points of query - Reason = Cause or Effect ? - Further criticism of the concepts of Cause and Effect-The bias of the specialist - Attempted definition of the province of reason - Definition of "End"-Unreliability of inference as to the nature of ends in other individuals; in other species - Possible inferences from the analogy of the nervous system - Certain possible limiting assumptions as to the province of knowledge in animal species - The Law of the Variation of Pain 
and Pleasure in function - The ultimate dilemma - Examinations of Teleological conceptions with respect to the Tendency to Stability Criticism of Wallace on the Origin of Life, or of Consciousness Summary of conclusions

\section{CHAPTER III}

\section{THE WiLL}

Difficulties of definition - The Will and Consciousness - "Involuntary" action - Will in passivity - The concept of Choice - "Ends" and the Will - The Future and Will - The External and Will - Criticism of Barratt's axioms and propositions - Discussion of the relation of Thought and Feeling to Will - The argument of the Physiologist The argument of the Evolutionist - The argument from social statis tics - The argument from Psychiatry, Criminology, etc. - The argument from the psychological principles on which Evolutional Ethics is founded - Definition of Natural Law and Necessity - The positive factors of Evolution - The positive and active character of the organism as the result of evolution-The equivalence of Conditions and Results - The positive character of the organism as a part of Nature - The sense of Freedom as the sense of Activity - The theory of the Will as determined by Motives - As determined by Feeling - As determined by the desirability of the end or object - The argument of Concomitance and that of Sequence as used by both Materialist and Spiritualist - The endeavor to prove ( 1 ) the causal character of physiological process; (2) the causal character of Consciousness Inconsistencies of these attempts . . . . . . . 34I-359

\section{CHAPTER IV}

The Mutual Relations of Thought, Feeling, and Will IN Evolution

Hume on Reason and Passion - The constant connection of Thought with Feeling, and with Feeling as pleasure or pain - The question as to whether Thought or Feeling is primary $-A$ pplication of answer to previous considerations on the diffusion of Consciousness in Nature - The relation of the concepts of the Pleasurable and Painful to the concept of "End" - Will as a constant accompaniment of Consciousness - Absurdities to which the division of Consciousness into distinct faculties leads - Law of the growth of functional tendency and of pleasure in function - The New as a disturber of equilibrium - The pleasure involved in the overcoming of obstacles-The equilibrium of function as Health - Connection of the pleasure of food-taking 
with Health - Criticism of Rolph's principle of the Insatiability of Life - Further criticism of Rolph on the Darwinian theory of Growth - The coördinate progress of physiological adaptation with the advancement of knowledge, and with the variation of Feeling and Will - The pleasure of the strongest motive as relative, not absolute - The character of the End in view - The pleasure of anticipation and the pleasure of the event - Criticism of Sidgwick on Hedonism - Criticism of Rolph's theory of Want as universal motive - Suicide - Rest - The diminution of pain with lapse of time as adaptation Pleasure in pain as pleasure in function - The relation of Health to Happiness - The theory of the absolute Freedom of Feeling - The concepts of Cause and Effect as applied to the evolution of Thought, Feeling, and Will-Application of conclusions to the Teleological Argument .

\section{CHAPTER V}

\section{Egoism and Altruism in Evolution}

Prototypes in other animal species of what we term Egoism and Altruism in man; care for the young on the part of the parent-animal; mutual aid between the sexes; animal societies - Experiments of Lubbock showing the irregularity and caprice of action altruistic in form, among the ants - Benno Scheitz on maternal care among lower species Answers to the argument of automatism-Dependence of a theory of moral Evolution on the definition of Egoism and Altruism - The significance of the terms progressive - The possibility of differences in the form of the evolution of Altruism, in different species The possibility of the combination of different forms in the evolution of a single species - Discussion of the question of the first beginning of action prompted by altruistic motive - The argument of the illogical nature of a supposed development of Altruism from Egoism - The question as to whether Health, the Preservation of Species, or Pleasure, is the actual final end of action - The question of Heredity in relation to that of the moral evolution - Stephen's viewsArguments from Ribot, Dugdale's “Jukes," etc. . 383-422

\section{CHAPTER VI}

\section{CONSCIENCE}

The gradual character of the evolution of Altruism - Paul Friedmann on the genesis of benevolence - The observable growth of Altruism from Egoism in the individual - Human society as necessitated by increase 
of the species - Criticism of Darwin's form of statement on this point

- The mixed character of the motives which lead to advancement

- The necessity of evolution, primal organisms once having come into existence - General features of the moral evolution in the human race - Personal and Social Virtues - Racial evolution as subordinate to the evolution of the species - Criticism of Stephen - The theory of the connection of Intelligence and Morality - Testimony of Maudsley, Lombroso, Dugdale - The advantages of conformity to social standards - Definition of "advantage" - Arguments from the general direction of social advancement - The direction of evolution in the race as a whole and in the individual not always the same - Conclusion: the connection of Intelligence with Morality not invariable - Definition of Morality - Identification of Morality with Justice Special rules of morality - Morality as inward - The virtue of Truthfulness - Necessity of individual sacrifice - Dependence of Justice on certain general features of particular circumstances - Definition of Conscience - The mixed character of remorse - The theory of Conscience as a special sense - Criticism of Utilitarianism - Criticism of some forms of reaction against Utilitarianism - The terms "higher" and "lower" as applied to pleasures and "ends" - The idea of a "return to Nature"-The objection to Evolutional Ethics on the ground of degradation - Struggle as an element of virtue - The evolution of social rewards and punishments - Criticism of the objection to state-punishment on the ground of Determinism - Morality and the question of the Transcendental - Conscience in other species The contempt for "mere habit" - The concepts of Cause and Effect as applied to the moral evolution . . . . . . 423-465

\section{CHAPTER VII}

The Moral Progress of the Human Species as shown by HISTORY

The assimilative character of human progress - The character of our savage ancestors - Greek civilization - The Greek treatment of children - Of old men - Human sacrifices among the Greeks - Slaughter of prisoners - Slavery - The Greek attitude towards the fundamental virtues of trustworthiness - Athenian Democracy - Roman civilization - Treatment of children - Human sacrifices - Gladiatorial shows - Slavery - Moral character of the Middle Ages - Human sacrifice in England before the Roman conquest - Slave laws - State punishment in England: burning, hanging, and boiling, quartering and disembowelling - Women under the criminal law - Blood-money- 
The classification of crimes - Caste-favor in English criminal law Mutilation - Flaying - Ordeals - Punishment by starvation - The press - The rack — "Skevington's Daughter" — Benefit of Clergy The position of the English churl - The worship of rank - Hanging for petty theft - The pillory - Brutality of public feeling - Condition of the prisons - Jail-breaking, bribery, etc. - More concerning women under the law - Favor to rank - The logical consistency of human character in its various directions of action - General comparison of the past with the present - The evidence of literature-Modern philanthropy - Decrease of national prejudices - Growth of the democratic spirit - Lack of imagination a reason for the failure to realize the evils of the past - The Golden Age of Man

466-499

\section{CHAPTER VIII}

\section{The Results of Ethical Inquiry on an Evolútional Basis}

Criticism of Alexander's theory of the right as always absolute right and as the expression, on all planes of development, of an equal equilibrium The Moral Evolution as one involving the whole of humanity and the whole earth - Gradual relaxation of the Struggle for Existence - The final limitation of the increase in density of population - The increase of vitality - The habituation to progress - The gradual coördination of individual with social welfare through ( 1 ) Spread and increase of sympathy with the individual on the part of society as a whole; (2) Growth of individual predilections in the direction of harmony with social requirements - Decrease of punishment through (I) Increase in general sympathy; (2) Increase of amenability of the individual to influence - Increase of pleasure in pleasure - The possible egoistic element in sympathy with pain - Criticism of Rolph on Want as necessary to induce action - The moral evolution and emotionCriticism of Spencer on Altruism - Criticism of Wundt on Evolutional Ethics - The theory that Evolution adds nothing to Ethics - Criticism of Stephen on the impossibility of predicting the course of Evolution - The Moral Evolution as willed - The motives furnished by Evolutional Ethics - The theological doctrine of a "change of heart" - The doctrine of the Atonement - Divine forgiveness Theology and social evils - The prominence of the idea of self-salvation in Christian doctrine - Human sacrifice among the Jews Biblical authority for the killing of witches and heretics - The infliction of death for ceremonial offences among the Jews - The visiting of the sins of the fathers upon the children - Slave-holding, adultery, murder, etc., by God's chosen, bloodshed and cruelty of all sorts by 
God's express command-Animal sacrifice among the Jews - The original idea of Jehovah and of Heaven - The autocracy of the Jewish priesthood confirmed by Christ - Forced exegesis - The asceticism of Christianity - Slavery and the New Testament - Predestination, Hell, and the Justification of the Elect - The defence of Christianity as being a comforting belief . . . . . . 500-528

\section{CHAPTER IX}

\section{The Ideal and the Way of its Attainment}

Criticism of Stephen's assertion that the ideal cannot be determinedThe necessity of the choice between evils, under present social conditions - The argument for individual gratification of "natural desire" - Dangers of Utilitarianism - Moral right of the minority and the ethical demand for compensation to the minority - The contest between Individualist and Socialist - Criticism of Spencer on personal vice - Individualistic errors - Socialistic pessimism - The idea of a "return to Nature" - The Socialistic glorification of the laborer The agitation against machinery - The agitation against luxury - The abolition of luxury and the population question - The proposed change of social "environment" - Socialism at the present dateArbitrary character of many Socialistic ileas - Criticisms of Bellamy - The idea of a Revolution - Conclusions - The education of the child - The right of the child to state protection - The advantages of parental control - The education of women - The question of prostitution - Monogamy or polygamy? - Temporary contracts Divorce - The argument that the freedom of women must involve the forfeiture of chivalric feeling in men - The respect for ageDesirable changes in criminal law - Criticism of Bellamy on Crime - The question of Capital Punishment - Arguments for - Arguments against - Conclusions - The conflict between justice and mercy The supreme arbiter - The courage of Moral Sincerity - Heroic characters - The final destruction of the human species - The loss of belief in personal immortality - The human and earthly ideal .

$529-5^{81}$ 



\section{A REVIEW OF EVOLUTIONAL ETHICS}

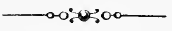

\section{PART I}

\section{INTRODUCTORY REMARKS}

IN the preface to the latest edition of his "Natürliche Schöpfungsgeschichte," Haeckel, writing of recent developments of thought on the subject of evolution, and the change of attitude observable in our later literature, says: "The vast mass of literature, yearly increasing in astonishing measure, on the theory of evolution in its various branches, best illustrates the remarkable change which public opinion has undergone. Twenty years ago, the greater part of this literature was in opposition to Darwin; to-day such opposition is not to be feared from wellinformed students of science. On the other hand, almost the whole literature of biology now gives testimony in Darwin's favor, for almost all zoölogical, and botanical, anatomic, and ontogenetic works are founded upon the principles of the development of species, and derive from Darwin their best and most fruitful ideas."

No science is a better exponent of this radical and important change than that which has to do with the principles of morals; for by no science was the theory of evolution assailed, in the beginning, with more vehemence and indefatigability. Not only did the zealous adherents of Christian dogma fear to find, in the destruction of all distinct barriers between the different forms of animal life, a ground for the denial of God's especial favor to man, and the worshippers of emotional morals become indignant at the unveiling of the divine Mystic (as if only ignorance were reverence, and only the Unknown worthy of homage), but even 
the less conservative schools of philosophy often showed themselves unfavorable or hesitant towards the new ideas, dreading their implications. All this is changed. If England's most popular living philosopher was among the first to declare himself for Darwin, and to revise his whole system in accordance with the theory of evolution, so that this theory early began to find adherents among students of philosophy in all lands where English is spoken, it was not long before the newer schools of France and Germany began to follow in their wake. Now every year, and almost every month, brings with it a fresh supply of books, pamphlets, and magazine articles on "The Evolution of Morality," "L'Evolution de la Morale," "Die Evolution der Sittlichkeit," "Sittlichkeit und Darwinismus," etc. So many are the waters which now pour themselves into this common stream that the current threatens soon to become too deep and swift for any but the most expert swimmers.

In a short review of Evolutional Ethics, it will be impossible to consider all the literature that has added to our knowledge on this subject; we must confine ourselves to the few books that are most prominent. The first laborer in this line, not only indirectly through general theory, but also directly through particular theory, is, as usual, Charles Darwin; and though Darwin was himself no psychologist, and moreover advances his ideas on the origin and development of morals only in the tentative manner that necessarily attaches to a first attempt when made by so conscientious a thinker, he doubtless suggested to all other writers in this field a very large part of that which was best in their work. A Review of Evolutional Ethics must, therefore, in order to start with the proper origin of the science, begin with

\section{CHARLES DARWIN}

In the essay on "Instinct" appended to G. J. Romanes' "Mental Evolution in Animals," 1 Darwin says: "The social instinct is indispensable to some animals, useful to still more, and apparently only pleasant to some few animals." The social tendency being thus classed as an instinct, it belongs to our work

1 P. 38I. This essay originally formed part of the chapter on "Instinct" in "The Origin of Species," but was omitted for the sake of condensation. 
to examine what are Darwin's theories as to the origin and nature of instinct.

In the chapter on "Instinct," in "The Origin of Species," Darwin premises: "I have nothing to do with the origin of the mental powers, any more than I have with that of life itself." 1 Again: "Frederick Cuvier and several of the older metaphysicians have compared instinct with habit. This comparison gives, I think, an accurate notion of the frame of mind under which an instinctive action is performed, but not necessarily of its origin. . . . If we suppose any habitual action to become inherited - and it can be shown that this does sometimes happen - then the resemblance between what originally was a habit and an instinct becomes so close as not to be distinguished. . . . But it would be a serious error to suppose that the greater number of instincts have been acquired by habit in one generation, and then transmitted by inheritance to succeeding generations. It can be clearly shown that the most wonderful instincts with which we are acquainted, namely, those of the hive-bee and of many ants, could not possibly have been acquired by habit." ${ }^{2}$ Of one of the habits of these last-named insects Darwin, however, writes: "I have not rarely felt that small and trifling instincts were a greater difficulty on our theory than those which have so justly excited the wonder of mankind; for an instinct, if really of no considerable importance in the struggle for life, could not be modified or formed through natural selection. Perhaps as striking an instance as can be given is that of the workers of the hive-bee arranged in files and ventilating, by a peculiar movement of their wings, the well-closed hive : this ventilation has been artificially imitated, and as it is carried on even during winter, there can be no doubt that it is to bring in free air and displace the carbonic acid gas; therefore it is in truth indispensable, and we may imagine the stages - a few bees first going to the orifice to fan themselves - by which the instinct might have been arrived at." ${ }^{3}$ Again: "Glancing at instincts, marvellous as some are, they offer no greater difficulty than do corporeal structures on the theory of the natural selection of successive slight, but profitable modifications. We can thus understand why nature moves by grad-

1 Vol. I. p. 319.

2 Pp. 320, 321.

${ }^{3}$ Appendix to "Mental Evolution in Animals," pp. 378, 379. The italics are my own. 
uated steps in endowing different animals of the same class with their several instincts." 1 And again: "As I believe, the most wonderful of all known instincts, that of the hive-bee, can be explained by natural selection having taken advantage of numerous successive, slight modifications of simpler instincts, natural selection having, by slow degrees, more and more perfectly led the bees to sweep equal spheres at a given distance from each other in a double layer, and to build up and excavate the wax along the planes of intersection; the bees, of course, no more knowing that they swept their spheres at one particular distance from each other, than they know what are the several angles of the hexagonal prisms and of the basal rhombic plates; the motive power of the process of natural selection having been the construction of cells of due strength and of the proper size and shape for the larvæ, this being effected with the greatest possible economy of labor and wax; that individual swarm which thus made the best cells with least labor, and least waste of honey in the secretion of wax, having succeeded best, and having transmitted their newly acquired economical instincts to new swarms, which in their turn will have had the best chance of succeeding in the struggle for existence." 2 And further, of instinct in general: "It will be universally admitted that instincts are as important as corporeal structures for the welfare of each species, under its present conditions of life. Under changed conditions of life, it is at least possible that slight modifications of instinct might be profitable to a species; and if it can be shown that instincts do vary ever so little, then I can see no difficulty in natural selection preserving and continually accumulating variations of instinct to any extent that was profitable. It is thus, as I believe, that all the most complex and wonderful instincts have originated. As modifications of corporeal structure arise from, and are increased by, use or habit, and are diminished or lost by disuse, so I do not doubt it has been with instincts"; though Darwin adds: "But I believe that the effects of habit are in many cases of subordinate importance to the effects of the natural selection of what may be called spontaneous variations of instincts; that is, of variations produced by the same unknown causes which produce slight deviations of bodily structure." However, "No complex instinct can possibly be produced through natural selection,

1 “The Origin of Species," II. p. 286.

2 Ibid. I. pp. 353, 354 . 
except by the slow and gradual accumulation of numerous slight, yet profitable, variations." 1 And of habit as connected with heredity, Darwin writes: "Changed habits produce an inherited effect, as in the period of the flowering of plants when transported from one climate to another. With animals the increased use or disuse of parts has had a more marked influence. . . . No breeder doubts how strong is the tendency to inheritance; that like produces like is his fundamental belief; doubts have been thrown on this principle only by theoretical writers. ... If strange and rare deviations of structure are really inherited, less strange and commoner deviations may be freely admitted to be inheritable. Perhaps the correct way of viewing the whole subject would be to look at the inheritance of every character whatever as the rule, and non-inheritance as the anomaly. . . If it could be shown that our domestic varieties manifested a strong tendency to reversion - that is, to lose their acquired characters whilst kept under the same conditions, and whilst kept in a considerable body, so that free intercrossing might check, by blending together, any slight deviations in their structure, in such case I grant that we could deduce nothing from domestic varieties in regard to species. But there is not a shadow of evidence in favor of this view; to assert that we could not breed our cart and race horses, long and short horned cattle, and poultry of various breeds, and esculent vegetables, for an unlimited number of generations, would be opposed to all experience." 2 Darwin recognizes, in instinct, the possibility for the play of a certain amount of imitation, as also of intelligence and experience, ${ }^{3}$ though denying to these the range attributed to them by Wallace. And summing up his theory in the essay given by Romanes, he writes: "It may not be logical, but to my imagination it is far more satisfactory, to look at the young cuckoo ejecting his foster brothers, ants making slaves, the larvæ of the ichneumidæ feeding within the live bodies of their prey, cats playing with mice, otters and cormorants with living fish, not as instincts specially given by the Creator, but as very small parts of one general law leading to the advancement of all organic bodiesMultiply, Vary, let the strongest Live and the weakest Die."

1 "The Origin of Species," I. pp. 321, 322.

2 Ibid. I. pp. 12-17.

${ }^{3}$ Appendix to "Mental Evolution in Animals," pp. 370, 383 ; see also "The Descent of Man," I. p. 102 et seq.; and "Nature" for Feb. 13, I873, introduction to a letter to the editor from William IHigginson. 
It will thus be seen that Darwin, while confessing a disability to account for the origin of Instinct,- beginning with some form of instinct as already existent, just as he begins with life as already existent, - does advance some perfectly definite views as to the probable origins of instincts, - namely, preservation, in the struggle for existence, of numerous slight but profitable variations. 'The assertion of the inadequacy of habit to account for the origin of more complex instincts, as in the case of the hivebees, when compared with the subsequent explanation, in the same connection, of the rise of these very instincts partly by habit acquired from experience and imitation, partly by accidental modifications of simpler instincts, both taken advantage of by natural selection, - would seem to limit the term "habit," as here used, to modes of action acquired during the life of the individual; this interpretation of the word being confirmed by the additional phrase "in one generation." But here, as everywhere in Darwin's work, an unknown quantity appears - namely, the cause of variation; i.e. of the differences, or tendency to differ, of offspring, from the parental type.

In "The Descent of Man," published twelve years later than "The Origin of Species," and "The Variation of Plants and Animals under Domestication," which appeared yet three years later, Darwin's views on instinct and habit are still further elaborated, and a definition of the relation of these to reason, pleasure, pain, and the moral sense, attempted. In Vol. I. of the former work, Darwin devotes two chapters to these subjects. Instinct he calls, pages I I6-122, "inherited habit"; and on page I68 he says: "But as love, sympathy, and self-command became strengthened by habit, and as the power of reasoning becomes clearer, so that man can value justly the judgments of his fellows, he will feel himself impelled, apart from any transitory pleasure or pain, to certain lines of conduct." Here, I take it, the word "habit" cannot be interpreted as referring to one generation of men, but to the race as a whole, a general continuity being thus ascribed to the inheritance of mental characteristics, and the important concept of progress as adaptation acquired. In contrasting reason with instinct, Darwin thinks that instinct and intelligence do not, as Cuvier maintained, stand in inverse ratio to each other, but that a high degree of intelligence is compatible with complex instincts - as in the case of the beaver; "yet it is not improba- 
ble that there is a certain amount of interference between the development of free intelligence and of instinct, - which latter implies some inherited modification of the brain. Little is known about the functions of the brain, but we can perceive that, as the intellectual powers become highly developed, the various parts of the brain must be connected by very intricate channels of the freest intercommunication; and as a consequence, each separate part would perhaps tend to be less well fitted to answer to particular sensations or associations in a definite and inherited - that is, instinctive - manner. There seems even to exist some relation between a low degree of intelligence and a strong tendency to the formation of fixed, though not inherited habits; for, as a sagacious physician remarked to me, persons who are slightly imbecile tend to act in everything by routine or habit; and they are rendered much happier if this is encouraged." 1 Darwin thinks instinctive action and action from habit may not be connected with either pleasure or pain, though he would seem to contradict this view in the latter part of the passage just quoted, and again where he says: "Although a habit may be blindly and implicitly followed, independently of any pleasure or pain felt at the moment, yet if it be forcibly and abruptly checked, a vague sense of dissatisfaction is generally experienced." 2

In writing of the social instinct, Darwin begins with it as already existent, and seems, moreover, to maintain concerning it a theory of purpose elsewhere denied in his works and, indeed, antagonistic to the whole principle of the struggle for existence. He says: "It has often been assumed that animals were in the first place rendered social, and that they feel, as a consequence, uncomfortable when separated from each other, and comfortable whilst together; but it is a more probable view that these sensations were first developed, in order that those animals which would profit by living in society, should be induced to live together, in the same manner as the sense of hunger and the pleasure of eating were, no doubt, first acquired, in order to induce animals to eat." ${ }^{3}$ If it were not for the expressions "should be induced" and "to induce," the words "in order that," taken in connection with what follows, might be interpreted as referring to mere sequence of time, as, on page I99, where Darwin refers to the "social faculties" simply as antecedent to society, they evidently do. For
1 P. 103.
2 Pp. I60, I6I.
3 P. I6I. 
he says: "In order that primeval man, or the ape-like progenitors of man, should become social, they must have acquired the same instinctive feelings which induce other animals to live in a body." The sentences referred to which follow the first quotation are as follows: "The feeling of pleasure from society is probably an extension of the parental or filial affections, since the social instinct seems to be developed by the young remaining for a long time with their parents; and this extension may be attributed in part to habit, but chiefly to natural selection. With those animals which were benefited by living in close association, the individuals which took the greatest pleasure in society would best escape various dangers, whilst those that cared least for their comrades, and lived solitary, would perish in greater numbers. With respect to the origin of the parental and filial affections, which apparently lie at the base of the social instincts, we know not the steps by which they have been gained; but we may infer that it has been to a large extent through natural selection." The passage may possibly be consistently explained by the idea of the Survival of the Fittest, but it is at least very unclear in its wording. At the beginning of Chapter IV. of the same book, Darwin also gives a synopsis of the development of the moral sense from the social instincts, through the pleasure of association and service, remorse being a result of the power of representation, regard for the approbation and disapprobation of fellows arising from sympathy with them until resulting habit plays a very important part in guiding the conduct of the individual. Another passage, however, again introduces an antagonism between habit, instinct, and reason, and natural selection: "It is impossible to decide in many cases whether certain social instincts have been acquired through natural selection, or are the indirect result of other instincts and faculties, such as sympathy, reason, experience, and a tendency to imitation; or again, whether they are simply the result of longcontinued habit." Darwin distinguishes between "the all-important emotion of sympathy," and that of love. "A mother may passionately love her sleeping and passive infant, but she can hardly at such times be said to feel sympathy for it"; but he includes both love and sympathy under the head of "sympathetic emotions"; and on page 163 he says: "With mankind, selfishness, experience, and imitation probably add, as Mr. Bain has shown, to the power of sympathy; for we are led by the hope of 
receiving good in return to perform acts of sympathetic kindness to others; and sympathy is much strengthened by habit." Again, on page r66, "instinctive love and sympathy" would seem to be contrasted with love and sympathy as habit, the increase of such - feelings in the race through habit, elsewhere more or less distinctly asserted, being here ignored: "Although man, as he now exists, has few special instincts, having lost any which his early progenitors may have possessed, this is no reason why he should not have retained, from an extremely remote period, some degree of instinctive love and sympathy for his fellows. We are, indeed, all conscious that we do possess such sympathetic feelings; but our consciousness does not tell us whether they are instinctive, having originated long ago in the same manner as with the lower animals, or whether they have been acquired by each of us during our early years." But again, on page 220 , sympathy is referred to as an element of the social instincts: ${ }^{1}$ "It should, however, be borne in mind that the enforcement of public opinion depends on our appreciation of the approbation and disapprobation of others; and this appreciation is founded on our sympathy, which it can hardly be doubted was originally developed through natural selection as one of the most important elements of the social instincts"; though, on pages I67, I68, the social instinct is again contrasted with sympathy, since according to Darwin the desire for the approbation of others and the consequent yielding to their wishes is the result of sympathy: "Thus the social instincts, which must have been acquired by man in a very rude state, and probably even by his early ape-like progenitors, still give the impulse to some of his best actions; but his actions are in a higher degree determined by the expressed wishes and judgments of his fellow-men." Again the social and the maternal instincts and sympathy are identified and classed as under the dominion of the moral sense, pages $168-170$ : "It is evident, in the first place, that with mankind the instinctive impulses have different degrees of strength; a savage will risk his own life to save that of a member of the same community, but will be wholly indifferent about a stranger; a young and timid mother urged by the maternal instinct will, without a moment's hesitation, run the greatest danger for her own infant, but not for a

1 See also p. 17r. And, p. I72, sympathy is designated as "a fundamental element of the social instincts." 
mere fellow-creature. Nevertheless, many a civilized man, or even boy, who never before risked his life for another, but full of courage and sympathy, has disregarded the instinct of self-preservation, and plunged at once into a torrent to save a drowning man, though a stranger. . . Such actions as the above appear to be the simple result of the greater strength of the social or maternal instincts than that of any other instinct or motive; for they are performed too instantaneously for reflection, or for pleasure or pain to be felt at the time; though, if prevented by any cause, distress or even misery might be felt. ... I am aware that some persons maintain that actions performed impulsively, as in the above cases, do not come under the dominion of the moral sense, and cannot be called moral. ... On the contrary, we all feel that an act cannot be considered as perfect or as performed in the most noble manner, unless it be done impulsively, without deliberation or effort, in the same manner as by a man in whom the requisite qualities are innate." Darwin defines the office of the moral sense as "telling us what to do," 1 that of conscience, - which includes remorse, repentance, regret or shame, fear of the gods and of the disapprobation of men,- as reproving us if we disobey it; ${ }^{2}$ conscience seems elsewhere to be defined as concerned with resolve to better future action; and in still another passage, the moral sense and conscience are identified. But again, in another paragraph, Darwin seems to ascribe remorse or regret, not to the baulking of an instinct, but to a judgment of having been baulked: "A man cannot prevent past impressions often repassing through his mind; he will thus be driven to make a comparison between the impressions of past hunger, vengeance satisfied, or danger shunned at other men's cost, with the almost ever-present instinct of sympathy, and with his early knowledge of what others consider as praiseworthy or blamable. This knowledge cannot be banished from his mind, and from instinctive sympathy is esteemed of great moment. $\mathrm{He}$ will then feel as if he had been baulked in following a present instinct or habit, and this with all animals causes dissatisfaction, or even misery." ${ }_{3}$ But, in spite of all indefiniteness in the use of terms and uncertainty as to the interrelations of "the social instincts," sympathy, reason, pleasure, and the moral sense, it is, after all, comparatively easy to gather, after a little deeper study,
1 P. 178.
2 Pp. I 74, 178.
3 P. 173. 
the general and more important feațures of Darwin's theory as to the origin of morality. We may state these as follows: The social instinct led men or their ape-like progenitors to society, ${ }^{1}$ this instinct growing out of the parental or filial affections through habit and natural selection. Virtue is, at first, only tribal, ${ }^{2}$ The social qualities of sympathy, fidelity, and courage implied in mutual aid and defence, were no doubt acquired by man through the same means. "When two tribes of primeval man, living in the same country, came into competition, if (other circumstances being equal) the one tribe included a great number of courageous, sympathetic, and faithful members, who were always ready to warn each other of danger, to aid and defend each other, this tribe would succeed better and conquer the other. .. Selfish and contentious people will not cohere, and
without coherence nothing can be effected. A tribe rich in the above qualities would spread and be victorious over other tribes; but in the course of time it would, judging from all past history, be in its turn overcome by some other tribe still more highly endowed. Thus the social and moral qualities would tend slowly to advance and be diffused throughout the world." Though in a warlike state, where courage is especially necessary to tribal existence, the bravest men would perish in larger numbers than other men, and the survival of the unfittest would seem thus to be secured, the influence of their bravery on others might excite the latter to imitation and do far more good than the begetting of offspring who would inherit their bravery. So, also, pity, though inciting modern society to the preservation of the weak, yet is useful in that it cultivates sympathy; and so, too, wealth, affording leisure for intellectual pursuits and a wider choice in marriage, tends, in the end, to the preservation of the fittest morally, by direct or indirect means. ${ }^{3}$ Altruistic action, followed from selfish motives, may become habit; habits of benevolence certainly strengthen the feeling of sympathy; and "habits followed during many generations probably tend to be inherited." Furthermore, melancholy tends often to suicide, as violence, and quarrelsomeness to a bloody end, intemperance to the destruction of individual life, and profligacy to disease and sterility; so that some elimination of the worst dispositions takes place. These are some of the probable steps of advancement, though the process is too

1 “Descent of Man," I. p. 199, etc.

2 Ibid. p. 179.

${ }^{3}$ Ibid. pp. 199-209. 
complex to be clearly followed out. The approbation of others - the strengthening of sympathies by habit - example and imitation - reason - experience and even self-interest - instruction during youth, and religious feelings - are the causes which lead to the advancement of morality. ${ }^{1}$ In the paragraph just quoted, Darwin says: "With civilized nations, as far as an advanced standard of morality and an increased number of fairly good men are concerned, natural selection apparently effects but little, though the fundamental social instincts were originally thus gained"; but he later writes: "Judging from all that we know of man and the lower animals, there has always been sufficient variability in their intellectual and moral faculties for a steady advance through natural selection"; and he further says: "No doubt such advance demands many favorable concurrent circumstances; but it may well be doubted whether the most favorable would have sufficed, had not the rate of increase been rapid, and the consequent struggle for existence extremely severe." ${ }^{2}$ The end or aim of morality is the general good, rather than the general happiness, though "no doubt the welfare and the happiness of the individual usually coincide; and a contented, happy tribe will flourish better than one that is discontented and unhappy. As all wish for happiness, the 'greatest happiness principle' will have become a most important secondary guide and object; the social instinct, however, together with sympathy (which leads to our regarding the approbation and disapprobation of others), having served as the primary impulse and guide." ${ }_{3}$ And with regard to the future, Darwin says: "Looking to future generations, there is no cause to fear that the social instincts will grow weaker, and we may expect that virtuous habits will grow stronger, becoming perhaps fixed by inheritance. In this case the struggle between our higher and lower impulses will be less severe, and virtue will be triumphant." 4

\section{ALFRED RUSSEL WALLACE}

"Whatever we may define instinct to be, it is evidently some form of mental manifestation," says Wallace in his "Contributions to Natural Selection" (I $87 \mathrm{I})$. We know little of the senses of animals; some animals may even possess senses which we have not, and by which stores of knowledge of the outside world may
${ }^{1}$ Ibid. p. 2 I 2.
${ }^{2}$ Ibid. pp. 219, 220.
${ }^{3}$ Ibid. p. 185.
${ }^{4}$ Ibid. p. 192. 
be opened that are closed to us. We do not know certainly, for instance, what is the office of the little stalked balls that are the sole remnants of hind wings in flies, or what is the office of the third joints of the antennæ in the same insects, though both these evidently correspond to some sense. How can we pretend to fathom the profound mystery of the mental nature of animals, and decide what or how much they can perceive or remember, reason or reflect? Defining instinct, then, as "the performance by an animal of complex acts, absolutely without instruction," Wallace refuses to accept the theory of such action, in any case where all other modes of explanation have not been exhausted; for " a point which can be proved should not be assumed, and a totally unknown power should not be brought in to explain facts, when known powers may be sufficient." He maintains that there is a possibility, for instance, of the instruction of young birds by old in the art of nest-building. It is quite likely that birds remember the form, size, position, and materials of the nest in which they were hatched, as it is also probable that young birds often pair with old ones who have experience in nest-building. Man's architecture is also chiefly imitative. "Birds brought up from the egg in cages do not make the characteristic nest of their species, even though the proper materials are supplied them, and often make no nest at all, but rudely heap together a quantity of materials." "No one has ever yet obtained the eggs of some bird which builds an elaborate nest, hatched those eggs by steam or under quite a distinct parent, placed them afterwards in an extensive aviary or covered garden, where the situation and the materials of a nest similar to that of the parent-birds may be found, and then seen what kind of nest these birds would build. If under these rigorous conditions they choose the same materials, the same situation, and construct the nest in the same way and as perfectly as their parents did, instinct would be proved in their case; now it is only assumed. . . . So no one has ever carefully taken the pupæ of a hive of bees out of the comb, removed them from the presence of other bees, and loosed them in a large conservatory with plenty of flowers and food, and observed what kind of cells they would construct. But till this is done no one can say that, with every new swarm there are no bees older than those of the same year, who may be the teachers in forming the new comb." 1

${ }^{1}$ For criticism of these arguments, see Romanes, "Mental Evolution in Animals," p. 225, etc.; also "Animal Intelligence." In his second edition of 
"Young birds never have the song peculiar to their species if they have not heard it, whereas they acquire very easily the song of almost any other bird with which they are associated." Moreover, there are failures and imperfections in the nesting of birds that are not compatible with the theory of instinct, which is supposed to be infallible, but are quite so with the theory of intelligence and imitation. Furthermore, in their manner of building, birds adapt themselves to circumstances and frequently alter and improve. The theory of instincts in man is likewise in the wrong. The sucking of the child, which is said to be instinctive, is merely one of those simple acts dependent on organization, like breathing or muscular motion. "So walking is evidently dependent on the arrangement of the bones and joints, and the pleasurable exertion of the muscles, which lead to the vertical posture becoming gradually the most agreeable one; and there can be little doubt that an infant would learn of itself to walk, even if suckled by a wild beast."

The theory of instinct "implies innate ideas ${ }^{1}$ of a very definite kind, and if established, would overthrow Mr. Mill's Sensationalism and all the modern philosophy of experience."

The reason why natural selection acts so powerfully upon ani-

this book (189I), Wallace notices a few of the instances cited by Romanes in objection to his theory: such as the recognition of the hen's call by a chicken hatched in an incubator, the fear shown, on the other hand, at the note of a hawk, and the fear exhibited by most young animals at the voice or presence of their natural enemies. Of these he says, however: "But in all these cases we have comparatively simple motions or acts induced by feelings of liking or disliking, and we can see that they may be due to definite nervous and muscular coördinations which are essential to the existence of the species. That a chicken should feel pleasure at the sound of a hen's voice, and pain or fear at that of a hawk, and should move towards the one and away from the other, is a fact of the same nature as the liking of an infant for milk and its dislike of beer, with the motion of the head towards the one and away from the other when offered to it." Of two authentic cases of the building of a nest by young birds, without instruction, he says that, in one case (that of ring-doves), the nest is a very simple one, and that the birds also received some assistance; and in the other case the nest was not built with the neatness ordinarily characteristic of the species. (See "Natural Selection and Tropical Nature," Pp. IO8-I I2.) The most of Romanes' instances and arguments he does not notice or answer.

${ }^{1}$ In his second edition, Wallace writes " not only innate ideas, but innate knowledge." 
mals, is to be found mainly in their individual isolation. "A slight injury, a temporary illness, will often end in death, because it leaves the individual powerless against its enemies. ... There is, as a rule, no mutual assistance between adults, which enables them to tide over a period of sickness. Neither is there any division of labor; each must fulfil all the conditions of its existence, and therefore natural selection keeps all up to a pretty uniform standard." But in man as we now behold him, this is different. $\mathrm{He}$ is social and sympathetic; and in society, a division of labor takes place that leaves the physically defective still something to do by which he may sustain life, and saves him from the extreme penalty which falls upon animals so defective. By his skill in constructing for himself tools and clothing and in planting his own food, man has an immense advantage over the animals, in whom a change of structure must take place in adaptation to changed conditions. Moreover, he not only escapes natural selection himself, but "is actually able to take away some of that power from nature, which, before his appearance, she universally exercised," establishing so his supremacy by means of that subtle force we term mind. "We can anticipate the time when the earth will produce only cultivated plants and domestic animals, when man's selection shall have supplanted natural selection."

We must, in future geological study, trace back the gradually decreasing brain of former races to a time when the body as well begins materially to differ, if we would wish to reach the startingpoint of the human family. Before that time man had not mind enough to preserve his body from change. From this point, however, we shall probably see that, while all other forms of animal life changed again and again, man's physical character became fixed and almost immutable, advance taking place only in his mental and moral characteristics, with which are united modifications of the brain, as well as of the head and face, parts that are immediately connected with the brain and the medium of the most refined emotions. By man's superior sympathetic and moral feelings, he becomes fitted for the social state. There is one feature, however, in which natural selection will still act upon him - namely, the color of the skin, which, as Mr. 1)arwin has shown, is correlated with constitutional peculiarities, liability to certain diseases being often accompanied by marked 
external characteristics; so that, in certain countries, certain tints would be likely to be weeded out, and certain other tints, with which, again, color and texture of the hair seem to be associated, would be established by natural selection.

Natural selection has no power " to produce modifications which are in any degree injurious to their possessor, and Mr. Darwin uses the strong expression that a single case of this kind would be fatal to his theory. If, therefore, we find in man any characters which all the evidence we can obtain goes to show would have been actually injurious to him on their first appearance, they could not possibly have been produced by natural selection. Neither could any specially developed organ have been so produced if it had been merely useless to its possessor, or if its use were not proportionate to its degree of development. Such cases as these would prove that some other law, or some other power, than natural selection, had been at work. But if, further, we could see that these very modifications, though hurtful or useless at the time when they first appeared, became in the highest degree useful at a much later period, and are essential to the full moral and intellectual development of human nature, we should then infer the action of mind, foreseeing the future and preparing for it, just as surely as we do when we see the breeder set himself to work with the determination to produce a definite improvement in some cultivated plant or domestic animal "; we should infer a creation by law. Skull-measurement shows that the brain of the savage was, and is, larger than it needs to be, and "capable, if cultivated and developed, of performing work of a degree and kind far beyond what he ever requires it to do." In evidence of this, Wallace cites the measurements of Esquimaux skulls and the testimony of Paul Broca to the fine form and capacity of the skulls of Les Eyzies, a race of cave-dwellers undoubtedly contemporary with the reindeer in Southern France. ${ }^{1} \mathrm{He}$ also argues that the loss, by man, of the hairy covering so long persistent in the mammalia, cannot have taken place on account of its lack of usefulness, since even the most savage tribes show a need of it, endeavoring to replace it by artificial coverings, especially on the

${ }^{1}$ In the second edition of this book, Wallace maintains the same position with regard to skull-measurement as a criterion of mental capacity. Nor does he notice distinctions in skull-form or the proportions of different parts of the brain to each other, except in the one case of the Eyzies. 
back. This naked skin is, however, of importance to civilization, since it leads to the adoption of both clothing and houses, and develops, through the former, the sense of modesty. The loss of the prehensile character of the whole foot, and especially of the pedal thumb, is a preparation for civilization. So, too, the capacity of the human voice for music, of little use to savages, since their singing consists only in a sort of monotonous howling, must be regarded as a preparation for the civilized man's delight in music, and probably also for a higher state than that to which we have yet attained.

Nor can the sanctity which attaches to virtue, even among savages, be explained by utility or natural selection. The "mystic sense of wrong," which, although few laws enforce truth, yet attaches to untruth, even among whole tribes of utter savages, is an example of such sanctity. Wallace adds, however, in the same breath: "No very severe reprobation follows untruth. In all ages, falsehood has been thought venial or even laudable under certain conditions." He asserts that "the utilitarian doctrine is not sufficient to account for the development of the moral sense," but seems, nevertheless, to adopt a utilitarian principle as the basis of the moral sense when he says: "Where free play is allowed to the relations between man and man, this feeling [i.e. of sanctity] attaches itself to those acts of universal utility or self-sacrifice which are the products of our affections and sympathies which we term moral"; and he adds: "while it may be, and often is, perverted to give the same sanction to acts of narrow and conventional utility which are really immoral, - as when the Hindoo will tell a lie, but will sooner starve than eat unclean food; and looks upon the marriage of adult females as gross immorality." The explanation of this inconsistency is, according to Wallace, that the strength of the moral feeling, in any case, will depend on the individual or racial constitution, and on education and habit; and the acts to which its sanctions are applied will depend on the extent of modification of the simple feelings and affections by custom, law, and religion. If a moral sense is an essential part of our nature, it is easy to see that its sanction may often be given to acts which are useless or immoral, just as the natural appetite for drink is perverted by the drunkard into the means of his destruction.

These phenomena of the preparation of the human being for civilization and morality can be explained only on the supposition 
of a superior intelligence which has guided man's development in a definite direction, just as man guides the development of many animal forms. By a superior intelligence is not necessarily meant the supreme intelligence. The modern cultivated mind seems incapable of realizing between it and the Deity other grades of intelligence, which the law of Continuity would, however, force us to infer: and rejecting first causes for any and every especial effect in the universe, except in the sense that the action of any intelligent being is a first cause, we can'still conceive that the development of the essentially human portions of man's structure may have been, in this sense, "determined by the directing influence of some higher intelligent beings acting through natural and universal laws." 1 "It is probable that the true law of this development lies too deep for our discovery." Wallace quotes, in support of his theory, some of Professor 'Tyndall's much-disputed statements, - to the effect that the chasm between the phenomena of mind and those of brain is impassable. "To say that mind is a product or function of protoplasm, or of its molecular changes, is to use words to which we can attach no clear conception. You cannot have in the whole what does not exist in any of the parts ${ }^{2}$ and those who argue thus should put forth a precise definition of matter with clearly enumerated properties, and show that the necessary result of a certain complex arrangement of the elements or atoms of that matter will be the production of self-consciousness. There is no escape from the dilemma, - either all matter is conscious, or consciousness is ${ }^{3}$ something distinct from matter, and in the latter case its presence in material forms is a proof of the existence of conscious beings outside of, and independent of, what we term matter.

"The merest rudiment of sensation or self-consciousness is infinitely removed from absolutely non-sentient or unconscious matter. We can conceive of no physical addition to, or modification of, an unconscious mass which should create consciousness, no step in the series of changes organized matter may undergo, which should bring sensation where there was no sensa-

1 See Wallace on "Miracles and Modern Spiritualism," "The Psychophysiological Sciences and their Assailants," and "The Scientific Aspect of the Supernatural."

2 Wallace omits this particular clause in his second edition.

3 The second edition reads " is, or pertains to." 
tion or power of sensation at the preceding step. It is because the things are utterly incomparable and incommensurable that we can only conceive of sensation coming to matter from without, while life may be conceived as merely a specific modification and coördination of the matter and the forces that compose the universe, and with which we are separately acquainted. We may admit with Professor Huxley, that protoplasm is the 'matter of life' and the cause of organization; but we cannot admit or conceive that protoplasm is the primary source of sensation and consciousness, or that it can ever of itself become conscious in the same way as we may perhaps conceive that it may become alive."

Wallace then reaches, without further preliminary discussion, the conclusion that "matter is essentially force" (arguing that we may draw this conclusion from the preceding considerations); that "matter, as popularly understood, does not exist, and is, in fact, philosophically inconceivable. When we touch matter, we only really experience sensations of resistance, implying repulsive force; and no other sense can give us such apparently solid proofs of the reality of matter as touch does." Wallace considers it a great step in advance thus "to get rid of the notion that matter is a thing in itself which can exist per se, and must have been eternal, since it is supposed to be indestructible and uncreated, that force, or the forces of nature, are another thing given or added to matter, or else its necessary properties, - and that mind is yet another thing, either a product of this matter and its supposed inherent forces, or distinct from and co-existent with it"; and to be able to substitute for this theory "the far simpler and more consistent belief, that matter, as an entity distinct from force, does not exist; and that FORCE is a product of MIND."

"If we are satisfied that force or forces are all that exist in the material universe, we are next led to inquire what is force." We are acquainted with two kinds of force - our own will-force, and the forces of nature. Freedom of the will cannot be disproved, for it cannot be shown that there is not one-thousandth of a grain's difference between the force exerted by the body and the force derived from without. "If, therefore, we have traced one force, however minute, to an origin in our will, while we have no knowledge of any other primary cause of force, it does not seem an improbable conclusion that all force may be will-force; and thus, 
that the whole universe is not merely dependent on, but actually is the will of higher intelligences, or of one Supreme Intelligence."

But though Wallace declares "natural selection, as the law of the strongest, inadequate " to account for man's mental and moral development, since the finer feelings and capacities could have been of no use to human beings in the early stages of barbarism, and further maintains that it is also difficult to understand how "feelings developed by one set of actions could be transferred to acts of which the utility was partial, imaginary, or altogether absent," he nevertheless has other passages like the following: "In proportion as physical characteristics become of less importance, mental and moral qualities will have increasing influence on the well-being of the race. Capacity for acting in concert for protection and for the acquisition of food and shelter; sympathy, which leads all in turn to assist each other; the sense of right, which checks depredations upon our fellows; the smaller development of the combative and destructive propensities, selfrestraint in present appetites; and that intelligent foresight which prepares for the future, are all qualities that, from their earliest appearance, must have been for the benefit of each community, and would, therefore, have become the subjects of natural selection. For it is evident that such qualities would be for the wellbeing of man; would guard him against external enemies, against internal dissensions, and against the effects of inclement seasons and impending famine, more surely than could any merely physical modification. 'Tribes in which such mental and moral qualities were predominant would therefore have an advantage over other tribes in which they were less developed, would live and maintain their numbers, while the others would decrease and finally succumb." "From the time, therefore, when the social and sympathetic feelings came into active operation, and the intellectual and moral faculties became fairly developed, man would cease to be influenced by natural selection in his physical form and structure. As an animal, he would remain almost stationary, the changes of the surrounding universe ceasing to produce in him that powerful modifying effect which they exercise over other parts of the organic world. But from the moment that the form of his body became stationary, his mind would become subject to those very influences from which his body had escaped; every slight variation in his mental and moral nature which should enable 
him better to guard against adverse circumstances, and combine for mutual comfort and protection would be preserved and accumulated; the better and higher specimens of our race would therefore increase and spread, the lower and more brutal would give way and successively die out, and that rapid advancement of mental organization would occur which has raised the very lowest races of man so far above the brutes (although differing so little from some of them in physical structure) and, in conjunction with scarcely perceptible modifications of form, has developed the wonderful intellect of the European races." "When the power that had hitherto modified the body had its action transferred to the mind, then races would advance and become improved, merely by the harsh discipline of a sterile soil and inclement seasons; under their influence a hardier, a more provident, and a more social race would be developed." And especially: "If my conclusions are just, it must inevitably follow that the higher - the more intellectual and moral - must displace the lower and more degraded races; and the power of natural selection, still acting on his mental organization, must ever lead to a more perfect adaptation of man's higher faculties to the conditions of surrounding nature and to the exigencies of the social state. While his external form will probably ever remain unchanged, except in the development of that perfect beauty which results from a healthy and well-organized body, refined and ennobled by the highest intellectual faculties and sympathetic emotions, his mental constitution may advance and improve, till the world is again inhabited by a single nearly homogeneous race, no individual of which will be inferior to the noblest specimens of existing humanity.

"Our progress towards such a result is very slow, but it still seems to be a progress."

In "Darwinism" (1889), Wallace advocates Weismann's theory of heredity. With regard to instinct, he uses arguments similar to those of his earlier work. He says of the hunting instincts of dogs: "At first sight it appears as if the acquired habits of our trained dogs - pointers, retrievers, etc. -- are certainly inherited; but this need not be the case, because there must be some structural or physical peculiarities, such as modifications in the attachments of muscles, increased delicacy of smell or sight, or peculiar likes and dislikes, which are inherited; and from these, 
peculiar habits follow as a natural consequence, or are easily acquired." So that he thus defines instinct, by implication, as he does also in his former book, as inherited habit which has no correlative in physical organization, and is unconnected with feelings of liking or disliking. He further says: "Again, much of the perfection of instinct is due to the extreme severity of the selection, any failure involving destruction "; and adds that, even if we admit the inheritance of the effects of the direct action of the environment on the individual, the effects are so small in comparison with the amount of spontaneous variation of every part of the organism, that they must be quite overshadowed by the latter. ${ }^{1}$ In his theory of a higher intelligence guiding human development, Wallace seems, in this book, to have abandoned all his former arguments except those from the mental and moral faculties, and it is perhaps due to a perception of the inconsistencies of his former utterances on the subject of the moral sense that he barely touches upon it in this book. On the other hand, he has elaborated his arguments from the mathematical and artistic faculties, and added an argument from wit and humor, none of which are found, he urges, among savages, except in their very rudiments, and none of which could have been developed by natural selection, since none could have been a cause of man's conquest in his struggles with wild beasts or with other tribes or nations. In answer to the objection that the law of Continuity, which he has quoted as favoring the belief in the existence of grades of supernatural beings between man and the Deity, tells against the introduction of new causes in man's development, Vallace maintains that there are certainly two other points in evolution where such new causes come into play, - namely, at the beginning of life and at the beginning of consciousness. "Increase of complexity in chemical compounds, with consequent instability, even if we admit that it may have produced protoplasm as a chemical compound, could certainly not have produced living protoplasm, - protoplasm which has the power of growth and reproduction, and of that continuous process of development which has resulted in the marvellous variety and complex organization of the whole vegetable kingdom, or, that is, vitality." 2

1 Pp. 442, 443.

2 This is contradictory of the passages on the subject of life above noticed as occurring in the "Contributions to Natural Selection," and retained in the second edition of that book. 
"All idea of mere complication of structure producing" consciousness is "out of the question." "Because man's physical structure has been developed from an animal form by natural selection, it does not follow that his mental nature, even though developed paripassu with it, has been developed by the same causes only." 1 Yet, in assuming Weismann's theory, Wallace asserts: "Whatever other causes have been at work, Natural Selection is supreme, to an extent which even Darwin himself hesitated to claim for it." "While admitting, as Darwin always admitted, the coöperation of the fundamental laws of growth and variation, of correlation and heredity, in determining the direction of lines of variation, or in the initiation of peculiar organs, we find that variation and natural selection are ever-present agencies which take possession, as it were, of every minute change originated by these fundamental causes, check or favor their further development, or modify them in countless ways according to the varying needs of the organism.." 2

In the opening portions of this book Wallace introduces a teleological argument to the effect that the pain which we ordinarily conceive as connected with the struggle for existence among lower species is mostly a figment of our imagination. Periods of suffering are comparatively short, since death speedily and without anticipation puts an end to those animals in any way incapacitated. Livingstone describes how, when seized by a lion, a sort of stupor succeeded the first shock, so that he felt neither fear nor pain; it is probable that terror induces this same condition in animals seized by beasts of prey, and that their end is therefore painless after the first shock. Cold is generally severest at night and tends to produce sleep and painless extinction. Hunger is scarcely felt during periods of excitement, "and when food is scarce, the excitement of seeking it is at its greatest." Nor is the gradual exhaustion and weakness of slow starvation necessarily painful.

\section{ERNST HAECKEL}

In his "Anthropogenie" (I874), Haeckel says: "The soul, or 'psyche' of man has evolved, as function of the cerebro-spinal nerve-chord simultaneously with the latter, and just as, even yet, brain and spinal column develop from the simple nerve-chord,

$$
{ }^{1} \text { P. } 463 \text {. }{ }^{2} \text { P. } 444 .
$$


so the human mind, or the soul-activity of the whole human race, has evolved, gradually and step by step, from the lower vertebrate soul. 'Spirit' and 'soul' are only higher and combined or differentiated powers of the same function which we designate with the general expression 'force.'" 1 In his essay on "Cell-souls and Soul-cells" (1878), Haeckel attributes to all animals the possession of soul, and adds that "we cannot wholly deny a soul to the plants also." The possession of soul he defines as the "capacity of sensibility in the organism to excitations of various sorts, and of reaction upon these excitations with certain movements." "This uniform character of protoplasm gifted with soul permits us the hypothesis that the ultimate factors of the soul-life are the plastidules, the invisible, homogeneous, elemental particles, or molecules, of protoplasm, which, in limitless multiplicity, compose the unnumbered cells." The soul connected with the higher developments of brain and spinal column is likewise a higher development, and differs from the soul connected with the uncentralized organization of lower species. In the latest edition of his "Natürliche Schöpfungsgeschichte" (1889), he further asserts that all matter is possessed of soul, and that "the antithesis which we have assumed between living and dead nature does not exist. When a stone, thrown into the air, falls to the earth according to fixed laws, or when a crystal is formed in a solution of salts, or when sulphur and quicksilver combine to form cinnabar, these phenomena are not more and not less mechanical phenomena of life than the growth and bloom of the plants, than the propagation and sense-activity of animals, than the perception and thought-processes of human beings." 2 And both in this work and in his "Anthropogenie" he quotes the words of Goethe, that "matter can never exist and act without soul, the soul can never exist and act without matter." This last statement is, however, rather a metaphysical one, in distinction from Haeckel's other statements on this subject, which are properly naturalistic.

In his lecture on "Cell-souls and Soul-cells," Haeckel says of instinct: "Unbiassed observation, applying its tests without prejudice, shows conclusively that the so-called 'instinct' of the animals is nothing else than a sum of psychical functions originally acquired by adaptation, fixed by habit, and descending from
1 P. 703 et seq.
2 Erster Vortrag. 
generation to generation by inheritance. Originally carried out with consciousness and reflection, many instinctive actions of the animals have become unconscious, as have, in like manner, the ordinary acts of intelligence in man. These too, may, with the same justice, be regarded as the expression of innate instinct, as often is the impulse to self-preservation, maternal love, and the social impulse. Instinct is not an exclusive attribute of the animal-brain, nor is reason an especial endowment of man; there is, on the contrary, for the unbiassed observer, a long, long scale of gradual improvement and evolution in psychic life, which may be traced step by step, from the higher to lower human beings, from the perfect to the imperfect animals, until we reach those simple worms, whose nerve-ganglia are the beginning of all the numberless brain-forms of the scale."

In his "Anthropogenie," Haeckel denies Free Will, maintaining that all phenomena are the result of mechanical causes causa efficientes, not causa finales. In an essay on the "Relation of the Theory of Evolution in its present form to Science in General" (1877), he says of Ethics: "By far the most important and the most difficult demand which Practical Philosophy makes upon the theory of Evolution seems to be that of a new theory of Morals. Certainly in the future, as in the past, the careful development of moral character and of religious conviction must be the chief problem of education. But until now the greater number of people have clung to the conviction that this most important problem could be solved only in connection with certain ecclesiastical articles of faith. And since these dogmas, especially as connected with ancient myths of the Creation, are in direct opposition to the facts of evolution, the latter have been believed to be, in the highest degree, inimical to religion and morality.

"This fear we believe to be erroneous. It has its origin in the continual confusion of the true, reasonable, nature-religion and the dogmatic, mythological, church-religion. The Comparative History of Religions, an important branch of Anthropology, teaches us the manifold nature of outward form in which different peoples and epochs have, in accordance with their individual character, enveloped religious thought. It shows us that the dogmatic teachings of the church-religion itself are subject to a slow, continuous evolution. New churches and sects arise, old ones disappear; at the best, a particular tenet of faith lasts but a few 
thousand years, an inconsiderably short space of time compared with the æons of the geological periods. Finally, the History of Civilization shows us to how small an extent true morality has been associated with any particular ecclesiastical form. The greatest rudeness and barbarity of custom often goes hand in hand with the absolute dominion of an all-powerful church; in confirmation of which assertion one need only remember the Middle Ages. On the other hand, we behold the highest standard of perfection attained by men who have severed connection with every creed.

"Independent of every confession of faith, there lives in the breast of every human being the germ of a pure nature-religion; this is indissolubly bound up with the noblest sides of human life. Its highest commandment is love, the restraint of our natural egoism for the benefit of our fellow-men, and for the good of human society whose members we are. This natural law of morality is much older than all church-religion. It has developed out of the social instincts of the animals. We meet with its rudiments among all animals, especially among all mammals. Following the laws of association and of division of labor, many individuals of such species unite to form the higher community of the swarm, herd, or tribe. The existence of the latter is necessarily dependent upon the mutual relations of the members of the community and the sacrifices which these make to the whole society at the cost of their own egoism. The consciousness of this necessity of self-sacrifice, the sense of duty, is nothing else than a social instinct. But this instinct is always a psychical habit, which was originally acquired, but which, becoming in the course of time hereditary, appears at last as innate.

"In order to convince ourselves of the wonderful power of the sense of duty among animals, we need only to destroy an ant-hill. Immediately we see, in the midst of the destruction, thousands of zealous citizens employed, not in the rescue of their own precious lives, but in the protection of the beloved community to which they belong. Brave soldiers of the ant-state prepare to offer strong resistance to our intruding finger; instructors of youth rescue the so-called ant-eggs, the precious larvæ, on which the future of the state depends; busy workers immediately begin with undiminished courage to clear away the ruins and to prepare new divellings. But the admirable state of civilization among these 
ants, among bees and other social animals, has been developed, just as has been our own, from the rudest beginnings.

"Even those finest and most beautiful forms of human emotion which we especially celebrate in poetry are to be found prefigured among the animals. Have not the tender mother-love of the lioness, the touching affection between male and female parrots, the self-sacrificing fidelity of the dog, been long proverbial? The noblest emotions of sympathy and love, which direct action, are here, as with human beings, nothing else than ennobled instinct." Beginning with this conception, the Ethics of Evolution has to seek for no new principle, but, on the contrary, to trace back the old rules of duty to their scientific basis. Long before the rise of all church-religion, these natural commandments regulated the lawful relations of human beings, as of gregarious animals. This significant fact the church-religions should utilize, instead of disputing. For the future does not belong to that Theology which declares war against the triumphant Theory of Evolution, but to that which makes it its own, acknowledges it, and turns it to advantage.

"Far, therefore, from fearing, from the influence of the Theory of Evolution, a subversion of all accepted moral law and a destructive emancipation of Egoism, we, on the contrary, look forward to a system of Ethics erected upon the indestructible foundation of unchanging natural law, since at the same time with the clear recognition of our true place in nature, the study of Anthropogeny opens to us the comprehension of the necessary character of our old rules of duty. Like theoretical science, Practical Philosophy and Pedagogy will no longer derive their most important principles from so-called revelations, but from the scientific truths of Evolution. This victory of Monism over Dualism opens to us a most hopeful prospect of an unending continuation of our moral, as of our intellectual evolution. In this sense, we welcome the Theory of Evolution in its present form newly stated by Darwin, as a challenge - the most important challenge of pure and applied science."

As touching on the idea of a nature-religion as conceived by Haeckel, may be noticed, however, a passage which occurs at the end of chapter XII. of the "Natürliche Schöpfungsgeschichte," as well as the passage before referred to in which it is asserted that we know only causa efficientes, never causa finales. The passage is as follows: "The general significance of the degenerated 
or rudimentary organs in the most important questions of natural philosophy cannot be over-estimated. On these may be founded a theory of Disteleology as opposed to the ancient, usual Teleolıgy."

With especial theories of Heredity advocated by Haeckel we are not concerned, except in one respect. Even in the first edition of his "Natürliche Schöpfungsgeschichte," Haeckel makes a distinction between conservative and progressive inheritance, and in the edition of 1889 he still maintains this division against Weismann and others, claiming the heredity of acquired habit, under certain circumstances, and showing conclusively that even wounds and blemishes received during the life of an individual may be, in some instances, inherited by descendants. ${ }^{1}$ The laws of progressive heredity he gives as four: (I) the law of the inheritance of adaptation; (2) the law of the surer inheritance of qualities fixed by continual operation of its causes on individual generations; (3) the law of homochronous inheritance or inheritance at a corresponding age; (4) the law of homotypous inheritance, which may be otherwise called the law of inheritance in corresponding parts of the body. ${ }^{2}$

Having thus glanced at the special theories by which the great original authorities paved the way for a system of Evolutional Ethics, we may direct our attention to the more purely philosophical writers who have turned these theories to advantage and elaborated them. The first on the list is

\section{HERBERT SPENCER}

In treating of Mr. Spencer's work, it is necessary to begin with a book which made its appearance before the publication of "The Origin of Species," namely, "Social Statics" (I85 I), Mr. Spencer's first noteworthy publication. In this are contained some remarkable statements, which are of especial worth as showing in what measure the thought of the time was already tending in the direction of the revelations of its greatest prophet, and science, in England as in Germany, was slowly coming to recognize the unity of nature in life and human progress. An analysis of the first and theoretical part of this work will be, therefore, of use, and with this we will begin.

1 P. 194 et seq.

2 For illustrations and proofs of these laws, see the "Natürliche Schöpfungsgeschichte," pp. I93-197. 
Mr. Spencer opens his book with some criticisms of Utilitarianism or the "Expediency Philosophy." Every rule, in order to be of value, must have a definite meaning. The rule of "the greatest happiness to the greatest number" supposes mankind to be unanimous in the definition of the greatest happiness; the standard of happiness is, however, infinitely variable, in nations and in individuals. For happiness signifies a gratified state of all the faculties; and no two individuals are alike in faculties. In endeavoring to fix a standard, we are met by such insolvable problems as: What is the ratio between mental and bodily enjoyments constituting the greatest happiness? Which is most truly an element in the desired felicity, content or aspiration? The conclusion we inevitably reach is that a true conception of what human life should be is possible only to the ideal man, - in whom the component feelings exist in their normal proportions. The world as yet contains no such men, and we are left with an insolvable riddle on our hands.

There is the same uncertainty as to the mode of obtaining the greatest happiness.

The Expediency Philosophy believes that man's intellect is competent to observe accurately and to grasp at once the multiplied phenomena of life and derive therefrom the knowledge which shall enable him to say whether such or such measures will conduce to the greatest happiness of the greatest number.

If without knowledge of terrestrial phenomena and their laws, Newton had attempted a theory of planetary and stellar equilibrium, he might have cogitated to all eternity without result. Such an attempt, however, would have been far less absurd than the attempt to find out the principles of public polity by a direct examination of that wonderfully intricate combination, Society. In order to understand Society it is necessary to comprehend Man.

Another mistake of the Expediency Philosophy is that it assumes the eternity of government, which marks a certain stage of civilization, but which will by no means necessarily last forever. Time was when the history of a people was the history of its government. Feudalism, serfdom, slavery, - all were forms of government. Progress means less government; constitutional. forms, political freedom, democracy, all mean this. Government is a sign of imperfection, an evil necessary against knavery; it must exist only so long as this exists. The Expediency Philoso- 
phy is, however, founded on government; takes it into partnership : but a system of moral philosophy professes to be a code of correct rules for the best, as well as the worst, members of society, and applicable to humanity in its highest conceivable perfection. Of the Expediency Philosophy it must, therefore, be said that it can claim no scientific character, since:

Its fundamental proposition is not an axiom but a problem to be solved;

It is expressed in terms possessing no fixed acceptation;

It would require omniscience to carry it into practice;

And, moreover, it takes imperfection for its basis.

The existence of society argues a certain fitness and desire of mankind for it; without this, it would not exist, as eating and drinking, and the nourishment and protection of offspring would not take place if there were no corresponding desires, but merely an abstract opinion in favor of the worth of the two. In the method of nature, there is always some prompter, called a desire, answering to each of the actions which it is requisite for us to perform. It is probable, therefore, that we shall find an instrumentality of this sort prompting us to morality. In objection to the theory of a moral sense, the want of uniformity in judgment as to what is right is often advanced. But none deny the importance of appetite, though all know that it is by no means an infallible guide in the choice of kind or quantity of food. The same may be said of parental affection. The foundation of the claim of any man that he has as great a right to happiness as any other can be found in the last analysis in feeling only; he feels that it is so.

None but those committed to a preconceived theory can fail to recognize the workings of such a faculty as the moral sense. It is clear that the perceptions of propriety or impropriety of conduct do not originate with the intellect but with the emotional faculties. The intellect, uninfluenced by desire, would show both miser and spendthrift that their habits were unwise; whereas the intellect, influenced by desire, makes each think the other a fool, but does not enable him to see his own foolishness.

This is a universal law: Every feeling is accompanied by a sense of the rightness of those actions which give it gratification. From an impulse to behave in a way we call equitable arises a perception that it is proper, 'and a conviction that it is good. 
There is, however, a perpetual conflict amongst feelings, from which results an incongruity of beliefs.

It has been said that codes derived from the moral sense have no stability since this sense ratifies one principle at one time and place, another at another. The same objection applies, however, to every other system of morals, and happily there is an answer to the objection. The error criticised is one of application, not of doctrine. The decisions of the Geometric Sense are conflicting; yet there are certain axioms upon which all agree; and in the same manner there are moral axioms to be found, upon which all must agree. Disagreement is to be looked for among imperfect characters. But nature's laws know no exception: Obey or suffer are the alternatives. A progress from entire unconsciousness of these laws to the conviction that law is universal and inevitable, constancy an essential attribute of divine rule, is the substance of the progress of man. The end of these unbending utterances is universal good; we have no alternative but to assume the law of constancy to be the best possible one. As with the physical, so with the ethical; all religions teach the inevitableness of punishment and reward, with which deeds are necessarily and indissolubly connected. It is of infinite importance to recognize and follow the laws of society. To the objection that one cannot always be guided by abstract principles, that there are exceptions where prudence must act, it may be replied that there are no exceptions to the laws of nature; that even if, in a particular instance, partial good may result, a far greater general evil is entailed by the opening of the way to future disobediences, and that we cannot, moreover, be sure that an exceptional disobedience will bring the anticipated benefits. Moral as well as physical evil is the result of a want of congruity between the faculties and their sphere of action. With regard to the results of varying conditions upon man, we have three alternative theories from which to choose: either man remains entirely unaltered by his surroundings, or he grows more unfitted for them, or else he grows more fitted for them. The first two suppositions being absurd, we are obliged to admit the remaining one. And since all evil results from non-adaptation, and non-adaptation is being continually diminished, it follows that evil must be continually diminishing. The evil in society shows that man is not yet completely adapted to a state which requires that each individual 
shall have such desires only as may be fully satisfied without trenching upon the ability of other individuals to obtain a like satisfaction. The primitive condition of man required that he should sacrifice the welfare of other beings to his own; the old attribute still clings to him in some measure; the belief in human perfectibility amounts to the belief that man will eventually become completely suited to his mode of life. Progress is not an accident but a necessity; and if, instead of proposing it as a rule of human conduct, Bentham had simply assumed the "greatest happiness" to be the creative purpose, his position would have been tenable enough. It is one thing, however, to hold that greatest happiness is the creative purpose, and quite a different thing to hold that greatest happiness should be the immediate aim of mankind. Truth has two sides, a divine and a human; or, it is for man to ascertain the conditions which lead to the greatest happiness, and to live in conformity with these.

The men who are to realize this greatest sum of happiness must be such as can obtain complete happiness without diminishing the activity and happiness of others. The first great condition of the attainment of the end is, therefore, justice, and, as a supplement to this, negative and positive beneficence, - abstinence from diminishing the spheres of activity of others, and further, a positive increase of their pleasure. For man is sympathetic, and the sympathetic pleasures increase the sum total of happiness.

The exercise ${ }^{1}$ of all the faculties in which happiness consists is not only man's right but also his duty. For the fact of pain, of punishment, proves that God intends and wills such exercise. But the exercise of all the faculties is freedcm; all men have, therefore, a right to freedom of action. This principle, however, implies a limitation of man by men, whereby we arrive at the general proposition that every man may claim the fullest liberty to exercise his feelings compatible with the possession of a like liberty in every other man. In the progress of mankind, or adaptation, the conduct which hurts necessary feelings in others must inevitably undergo restraint and consequent limitation; conduct which hurts only their incidental feelings, as those of caste or prejudice, will not inevitably be restrained, but if it springs from necessary feelings, will, on the contrary, be continued at the ex-

1 Spencer elsewhere says "due exercise," vide p. 76. 
pense of these incidental feelings and to their final suppression. Morality is not, therefore, to be interpreted as a refraining from the infliction of any pain whatever, for some sentiment must be wounded; and by much wounding it is gradually weakened. When men mutually behave in a way that offends some essential element in the nature of each, and all in turn have to bear the consequent suffering, there will arise a tendency to curb the desire that makes them so behave.

Questions of individual morality seem to present a difficulty to this theory of freedom. Thus, for instance, on the principle above adopted, the liberty of drunkenness cannot be condemned as long as the drunkard respects a like liberty in others; and here we fall into the inconsistency of affirming that a man is at liberty to do something essentially destructive of happiness. However, if we admit, as we must, that liberty is the primary law, no desire to get a secondary law fulfilled can warrant us in breaking this primary one; we must deal with secondary laws as best we can.

The first principle above stated may also be secondarily derived. The regulation of conduct is not left to the accident of a philosophical inquiry; the agent of morality is the Moral Sense.

In all ages, but more especially in recent ones, have there been affirmations of the equality of all men and their equal right to happiness. When we find that a belief like this is not only permanent but daily gaining ground, we have good reason to conclude that it corresponds to some essential element of our moral constitution; more especially since we find that its existence is in harmony with that chief prerequisite to greatest happiness lately dwelt upon; and that its growth is in harmony with the law of adaptation, by which the greatest happiness is being wrought out.

To assert, however, that the sense of justice is but the gradually acquired conviction that benefits spring from some kinds of action, and evils from other kinds, the sympathies and antipathies contracted manifesting themselves as a love of justice and a hatred of injustice, is as absurd as to conclude that hunger springs from a conviction of the benefit of eating.

The Moral Sense must be regarded as a special faculty, since, otherwise, there would be nothing during the dormancy of the other faculties, which must sometimes occur, to prevent an infringement on the freedom requisite for their future action.

As Adam Smith has shown in his "Theory of Moral Sentiments," 
the proper regulation of our conduct to others is secured by means of a faculty whose function it is to excite in each being the emotions displayed by the beings about him. The sentiment of justice is nothing but a sympathetic affection of the instinct of personal rights, a sort of reflex function of it. Other things being equal, those persons possessing the strongest sense of personal rights have, also, the strongest sense of the rights of others. There is no necessary connection between the two; but in the average of cases they bear a constant ratio.

It may be objected that if the truth that every man has a freedom to do all that he wills, provided he infringe not upon the equal freedom of others, be an axiom, it should be recognized by all, as is not the case. This difficulty seems in part due to the impossibility of making the perfect law recognize an imperfect state. It may further be answered that the Bushman knows nothing of the science of mathematics, yet that arithmetic is a fact; the difference in men's moral perceptions is no difficulty in our way, but rather illustrates the truth of our theory, since man is not yet adapted to the social state.

In further confirmation of the doctrine of the free exercise of function, it may be added that, since non-fulfilment of desire produces misery, if God is to be regarded as willing such nonfulfilment, he must be regarded as willing men's misery; which is absurd. If men are not naturally free, then a doctrine of the divine right of kings is easily reached, and whoever is king must be regarded as such by divine right, no matter how he reached the throne.

Spencer then proceeds to apply his first principle or axiom of freedom to prove the right to life and liberty, to the use of the earth, to property and free speech; and considers further the rights of women and of children, and the political rights of individuals; the constitution and duty of the state; commerce, education, and the poor-laws; government colonization, sanitary supervision, postal arrangements, etc. A remarkable feature of this part of "Social Statics" is that Spencer, while applying his principle with quite an opposite result to all other property, advocates the nationalization of the land, on the ground that the freedom of the individual is right only in so far as it does not hinder a like freedom in others; and that the monopolization of the privileges of land-ownership by individuals does prevent the enjoyment of the same privilege by others. 


\section{General Considerations}

The course of civilization could not possibly have been other than it has been.

Progress shows us that perfect individuation joined to the greatest mutual dependence will be reached in the future of the race. There will be an ultimate identity of personal and social interests, and a disappearance of evil. Spencer gives, however, a number of arguments to prove that the interest of society is, at present also, the interest of the individual.

The "Theory of Population" (published in I852), which is founded on the theory of an antagonism between the intellectual and the reproductive powers, and on the ancient theory of a direct relation between skull-capacity or brain-size and intellectual power, contains this passage: "From the beginning, pressure of population has been the proximate cause of progress. It produced the original diffusion of the race. It compelled men to abandon predatory habits and take to agriculture. It led to the clearing of the earth's surface. It forced men into the social state; made social organization inevitable; and has developed the social sentiments. It has stimulated to progressive improvements in production, and to increased skili and intelligence. It is daily pressing us into closer contact and more mutually dependent relationships. And after having caused, as it ultimately must, the due pcopling of the globe, and the bringing of all its habitable parts into the highest state of culture, - after having brought all processes for the satisfaction of human wants to the greatest perfection, - after having, at the same time, developed the intellect into complete competency for its work, and the feelings into complete fitness for social life, - after having done all this, we see the pressure of population, as it gradually finishes its work, must gradually bring itself to an end."

In a letter to Mr. Mill, published in Bain's " Mental and Moral Science" (p. 72I, 3d edition), Spencer repudiates the title of Anti-Utilitarian, which Mr. Mill, in view of the criticisms of Utilitarianism contained in "Social Statics," had applied to him. He defines his position in respect to Utilitarianism as follows: "I have never regarded myself as an Anti-Utilitarian. My dissent from the doctrine of Utility as commonly understood, con- 
cerns, not the object to be reached by men, but the method of reaching it. While I admit that happiness is the ultimate end to be contemplated, I do not admit that it should be the proximate end. The Expediency Philosophy, having concluded that happiness is a thing to be achieved, assumes that Morality has no other business than empirically to generalize the results of conduct, and to supply for the guidance of conduct nothing more than its empirical generalizations.

"But the view for which I contend is, that Morality properly so-called - the science of right conduct - has for its object to determine how and why certain modes of conduct are detrimental, and certain other modes beneficial. These good and bad results cannot be accidental, but must be necessary consequences of the constitution of things, and I conceive it to be the business of Moral Science to deduce from the laws of life and the conditions of existence what kinds of action necessarily tend to produce happiness and what kinds to produce unhappiness. Having done this, its deductions are to be recognized as laws of conduct; and are to be conformed to irrespective of a direct estimation of happiness or misery.

"Perhaps an analogy will most clearly show my meaning. During its early stages, planetary astronomy consisted of nothing more than accumulated observations respecting the positions and motions of the sun and planets; from which accumulated observations it came by and by to be empirically predicted, with an approach to truth, that certain of the heavenly bodies would have certain positions at certain times. But the modern sciencé of planetary astronomy consists of deductions from the law of gravitation - deductions showing why the celestial bodies necessarily occupy certain places at certain times. Now the kind of relation which thus exists between ancient and modern astronomy is analogous to the kind of relation which, I conceive, exists between the Expediency Morality and Moral Science properly so-called. And the objection which I have to the current Utilitarianism is, that it recognizes no more developed form of morality - does not see that it has reached but the initial stage of Moral Science.

"To make my position fully understood, it seems needful to add that, corresponding to the fundamental propositions of a developed Moral Science, there have been, and still are, developing in the race, certain fundamental moral intuitions; and that, 
though these moral intuitions are the results of accumulated experiences of Utility, gradually organized and inherited, they have come to be quite independent of conscious experience. Just in the same way that I believe the intuition of space possessed by any living individual, to have arisen from the organized and consolidated experiences of all antecedent individuals, who bequeathed to him their slowly developed nervous organizations - just as I believe that this intuition, requiring only to be made definite and complete by personal experiences, has practically become a form of thought, apparently quite independent of experience; so do I believe that the experiences of utility organized and consolidated through all past generations of the human race, have been producing nervous modifications, which, by continued transmission and accumulation, have become in us certain faculties of moral intuition, certain emotions responding to right and wrong conduct, which have no apparent basis in the individual experiences of utility. I also hold that, just as the space-intuition responds to the exact demonstrations of geometry, and has its rough conclusions interpreted and verified by them, so will moral intuitions respond to the demonstrations of Moral Science; and will have their rough conclusions interpreted and verified by them."

In "Recent Discussions in Science, Philosophy, and Morals" 1 (1871), Spencer, after quoting portions of the above letter as defining his position, continues with a consideration of the continual rearljustment of the compromise between the ideal and the practicable, the former of which prescribes a system far too good for men as they are, the latter of which does not of itself tend to establish a system better than the existing one; and he reiterates his law of the perfect man as follows:-

"Granted that we are chiefly interested in ascertaining what is relatively right, it still follows that we must first consider what is absolutely right; since the one conception presupposes the other." Spencer further expressly repudiates empirical Utilitarianism, and denies the assertion of Mr. Hutton that he by implication recognizes no parentage for morals beyond that of the accumulation and organization of the facts of experience. On this head he says: -

"In the genesis of an idea, the successive experiences, be they of sounds, colors, touches, tastes, or be they of the special objects

1 Essay on "Morals and Moral Sentiment." 
that combine many of these into groups, have so much in common that each, when it occurs, can be definitely thought of as like those which preceded it. But in the genesis of an emotion, the successive experiences so far differ that each of them, when it occurs, suggests past experiences which are not specifically similar, but have only a general similarity; and, at the same time, it suggests benefits or evils in past experience which likewise are various in their special natures, though they have a certain community of general nature. Hence it results that the consciousness aroused is a multitudinous confused consciousness, in which, along with a certain kind of combination among impressions received from without, there is a vague cloud of ideal combinations akin to them, and a vague mass of ideal feelings of pleasure or pain that were associated with them. We have abundant proof that feelings grow up without reference to recognized causes and consequences, and without the possessor of them being able to say why they have grown up, though analysis, nevertheless, shows that they have been formed out of connected experiences. The experiences of utility I refer to are those which become registered, not as distinctly recognized connections between certain kinds of acts and certain kinds of remote results, but those which become registered in the shape of associations between groups of feelings that have often recurred together, though the relation between them has not been consciously generalized " - associations which though little perceived, nevertheless serve as incentives or deterrents. Much deeper down than the history of the human race must we go to find the beginnings of these connections. The appearances and sounds which excite in the infant a vague dread indicate danger; and do so because they are the physiological accompaniments of destructive action.

"What we call the natural language of anger is due to a partial contraction of those muscles which actual combat would call into play; and all marks of irritation, down to that passing shade over the brow which accompanies slight annoyance, are incipient stages of these same contractions. Conversely with the natural language of pleasure, and of that state of mind which we call amicable feeling; this, too, has a physical interpretation."

Of the altruistic sentiments, Spencer says: "The development of these has gone on only as fast as society has advanced to a state in which the activities are mainly peaceful. The root of 
all the altruistic sentiments is sympathy, and sympathy could become dominant only when the mode of life, instead of being one that habitually inflicted direct pain, became one which conferred direct and indirect benefits; the pains inflicted being mainly incidental and indirect." Sympathy is "the concomitant of gregariousness; the two having all along increased by reciprocal aid."

"If we suppose all thought of rewards or punishments, immediate or remote, to be left out of consideration, it is clear that any one who hesitates to inflict a pain because of the vivid representation of that pain which rises in his consciousness, is restrained not by any sense of obligation or by any formulated doctrine of utility, but by the painful associations established in him. And it is clear that if, after repeated experiences of the moral discomfort he has felt from witnessing the unhappiness indirectly caused by some of his acts, he is led to check himself when again tempted to those acts, the restraint is of like nature. Conversely with the pleasure-giving acts, repetitions of kind deeds and experiences of the sympathetic gratifications that follow tend continually to make stronger the association between deeds and feelings of happiness."

Spencer continues: "Eventually these experiences may be consciously generalized, and there may result a deliberate pursuit of the sympathetic gratifications. There may also come to be distinctly recognized the truths that the remoter results are respectively detrimental and beneficial - that due regard for others is conducive to ultimate personal welfare, and disregard of others to ultimate personal disaster; and then there may become current such summations of experience as 'honesty is the best policy.' But so far from regarding these intellectual recognitions of utility as preceding and causing the moral sentiment, I regard the moral sentiment as preceding such recognitions of utility and making them possible. The pleasures and pains directly resulting, in experience, from sympathetic and unsympathetic actions, had first to be slowly associated with such actions, and the resulting incentives and deterrents frequently obeyed, before there could arise the perceptions that sympathetic and unsympathetic actions are remotely beneficial or detrimental to the actor; and they had to be obeyed still longer and more generally before there could arise the perceptions that they are socially beneficial and detri- 
mental. When, however, the remote effects, personal and social, have gained general recognition, are expressed in current maxims, and lead to injunctions having the religious sanction, the sentiments that prompt sympathetic actions and check unsympathetic ones, are immensely strengthened by their alliances. Approbation and reprobation, divine and human, come to be associated in thought with the sympathetic and unsympathetic actions respectively. The commands of a creed, the legal penalties, and the code of social conduct, mutually enforce them; and every child, as it grows up, daily has impressed on it, by the words and faces and voices of those around, the authority of these highest principles."

The altruistic sentiments develop, and altruistic action becomes habitual, "until at length these altruistic sentiments begin to call in question the authority of those ego-altruistic sentiments which once ruled unchallenged."

And Spencer sums up his objections to the interpretation of his theory of the development of the moral sentiment as follows: "What I have said will make it clear that two fundamental errors have been made in the interpretation put upon it. Both Utility and Experience have been construed in senses much too narrow.

"Utility, convenient a word as it is from its comprehensiveness, has very inconvenient and misleading implications. It vividly suggests uses and means and proximate ends, but very faintly suggests the pleasures, positive or negative, which are the ultimate ends, and which, in the ethical meaning of the word, are alone considered; and, further, it implies conscious recognition of means and ends - implies the deliberate taking of some course to gain a perceived benefit. Experience, too, in its ordinary acceptation, connotes definite perceptions of causes and consequences, as standing in observed relations, and is not taken to include the connections found in consciousness between states that occur together, when the relation between them, causal or other, is not perceived. It is in their widest senses, however, that I habitually use these words, as will be manifest to every one who reads the 'Principles of Psychology.' '

In his essay on Prison Ethics (I860), Spencer says: "The antagonistic schools of morals, like many other antagonistic schools, are both right and both wrong. The a priori school has its truth; the a posteriori school has its truth; and for the proper 
guidance of conduct there should be due recognition of both. On the one hand, it is asserted that there is an absolute standard of rectitude; and respecting certain classes of actions, it is rightly asserted. From the fundamental laws of life and the conditions of social existence are liducible certain imperative limitations to individual action - limitations which are essential to a perfect life, individual and social; or, in other words, essential to the greatest possible happiness. And these limitations, following inevitably as they do from undeniable first principles, deep as the nature of life itself, constitute what we may distinguish as absolute morality.

"On the other hand, it is contended, and in a sense rightly contended, that with men as they are, and society as it is, the dictates of absolute morality are impracticable. Legal control, which involves the infliction of pain, alike on those who are restrained and on those who pay the cost of restraining them, is proved by this fact to be not absolutely moral, seeing that absolute morality is the regulation of conduct in such way that pain shall not be inflicted. Wherefore, if it be admitted that legal control is at present indispensable, it must be admitted that these a priori rules cannot be immediately carried out. And hence it follows that we must adapt our laws and actions to the existing character of mankind - that we must estimate the good or evil resulting from this or that arrangement, and so reach a posteriori a code fitted for the time being. In short, we must fall back on expediency." Spencer then goes on to argue that an advanced penal code is as impossible to an early stage of civilization as is an advanced form of government; a bloody penal code is both a natural product of the time and a needful restraint for the time, and is also the only one which could be carried out by the existing administration.

The aim of morality is life, of absolute morality complete life; society is therefore justified in coercing the criminal who breaks through the conditions of life or constrains us to do so. Coercion is legitimate to the extent of compelling restitution, and preventing a repetition of aggressions; no further. I Less bloody systems of punishment, wherever introduced, have borne excellent fruit. It may be deductively shown that the best of all systems must be that best calculated to reform the criminal; too severe punishment, instead of awakening a sense of guilt, prevents the same, 
begetting a sense of injustice towards the inflicting power, which causes resentment; so that, even if the criminal, on reëntering society, commits no further crime, he is restrained by the lowest of motives - fear. The industrial system applied in prisons must have the best results - counteracting habits of idleness, strengthening self-control, and educating the will.

The principle of freedom, which runs through all Spencer's works, is especially enounced again, in his essay, "The Man versus the State" (I884), in which he combats "the great political superstition" of so-called "paternal government." He says: "Reduced to its lowest terms, every proposal to interfere with citizens' activities further than by enforcing their mutual limitations, is a proposal to improve life by breaking through the fundamental conditions of life." 1

In "The Data of Ethics" (published I 874), Mr. Spencer assumes a somewhat different standpoint from that of his earlier works bearing on morals. The course of reasoning contained in this book is as follows:

The doctrine that correlatives imply one another has, for one of its common examples, the relation between the conceptions of whole and part. Beyond the primary truth that no idea of a whole can be framed without a nascent idea of parts constituting it, and that no idea of a part can be framed without a nascent idea of some whole to which it belongs, there is the secondary truth that there can be no correct idea of a part without a correct idea of the correlative whole. Still less, when part and whole are dynamically related, and least of all when the whole is organic, can the part be understood except by comprehension of the whole to which it belongs. This truth holds not only of material but also of immaterial aggregates.

Conduct is a whole and, in a sense, an organic whole, and Ethics, of which it is a part, cannot be understood except through the understanding of the whole of conduct.

A definition of conduct must exclude purposeless actions, such, for instance, as those of an epileptic in a fit. Hence the definition emerges either: acts adjusted to ends; or, the adjustment of acts to ends; according as we contemplate the formed body of acts, or think of the form alone. And conduct, in its full acceptation, must be taken as comprehending all adjustments 
of acts to ends, from the simplest to the most complex, whatever their special natures and whether they are considered separately or in their totality.

A large part of conduct is non-ethical, indifferent; this passes, by small degrees and in countless ways, into conduct which is either moral or immoral.

The acts of all living creatures, as acts adjusted to ends, come within the definition of conduct; the conduct of the higher animals as compared with that of man, and of the lower animals as compared with the higher, differs mainly in that the adjustments of acts to ends is relatively simple and relatively incomplete. And as in other cases, so in this case, we must interpret the more developed by the less developed; human conduct as a part of the whole of the conduct of animate beings. And further: as, in order to understand the part of human conduct with which Ethics is concerned, we must study it as a part of human conduct as a whole, and in order to understand human conduct, we must again study it as a part of the whole of conduct exhibited in animate beings, so, in order to comprehend this too, we must regard it as an outcome of former, less developed conduct, out of which it has arisen. Our first step must be to study the evolution of conduct.

Morphology deals with physical structure, physiology with the processes carried on in the body. But we enter on the subject of conduct when we begin to study such combinations among the actions of sensory and motor-organs as are externally manifested.

We saw that conduct is distinguished from the totality of actions by the exclusion of purposeless actions; but during evolution this distinction arises by degrees. We trace up conduct to the vertebrates and through the vertebrates to man, and find that here the adjustments of acts to ends are both more numerous and better than among lower mammals; and we find the same thing "on comparing the doings of higher races of men with those of lower. These better adjustments favor, not only prolongation, but also increased amount of life.

And among these adjustments of acts to ends, there are not only such as further individual life but also, evolving with these, such as favor the life of the species. Race-maintaining conduct, like self-maintaining conduct, arises gradually out of that which cannot be called conduct. The multitudinous creatures of all 
kinds which fill the earth are engaged in a continuous struggle for existence, in which the adjustments of acts to ends, being imperfectly evolved, miss completeness because they cannot be made by one creature without other creatures being prevented from making them. This imperfectly evolved conduct introduces us, by antithesis, to conduct which is perfectly evolved, - such adjustments that each creature may make them without preventing other creatures making them also. The conditions of such conduct cannot exist in predatory savage life; nor can it exist where there remains antagonism between individuals forming a group, or between groups of individuals, - two traits of life necessarily associated, since the nature which prompts international aggression prompts aggression of individuals on one another also. Hence the limit of evolution can be reached by conduct only in permanently peaceful societies; can be approached only as war decreases and dies out.

The principle of beneficence is not derived by Spencer from the principle of freedom, in "Social Statics"; and here, as in the latter book, Spencer has difficulty with it. He says: "A gap in this outline must now be filled up. There remains a further advance not yet even hinted. For beyond so behaving that each achieves his ends without preventing others from achieving their ends, the members of a society may give mutual help in the achievement of ends. And if either indirectly by industrial coöperation, or directly by volunteered aid, fellow-citizens can make easier for one another the adjustments of acts to ends, then their conduct assumes a still higher phase of evolution; since whatever facilitates the making of adjustments by each increases the totality of the adjustments made, and serves to render the lives of all more complete."

Thus, then, says Spencer, "we have been led to see that Ethics has for its subject-matter that form which universal conduct assumes during the last stages of its evolution."

By comparing the meanings of a word in different connections, and observing what they have in common, we learn its essential significance. Material objects we are accustomed to designate as good or bad according as they are well or ill adapted to achieve prescribed ends. The good knife is one which will cut; the good gun is one which will carry far and true; and so on. So of inanimate actions, and so, also, of living things and actions. A 
good jump is a jump which, remoter ends ignored, well achieves the immediate purpose of a jump; and a stroke at billiards is called good when the movements are skilfully adjusted to the requirements. So too our use of the words good and bad with respect to conduct under its ethical aspects has regard to the efficiency or non-efficiency of the adjustments of acts to ends. This last truth is, through the entanglements of social relations, by which men's actions often simultaneously affect the welfares of self, of offspring, and of fellow-citizens, somewhat disguised. Nevertheless, when we disentangle the three orders of ends, and consider each separately, it becomes clear that the conduct which achieves each kind of end is regarded as relatively good; and conduct which fails to achieve it is regarded as relatively bad. The goodness ascribed to a man of business, as such, is measured by the activity and ability with which he buys and sells to advantage, and may coexist with a hard treatment of dependents which is reprobated. The ethical judgments we pass on such selfregarding acts are ordinarily little emphasized; partly because the promptings of the self-regarding desires, generally strong enough, do not need moral enforcement, and partly because the promptings of the other-regarding desires, less strong, do need moral enforcement. With regard to the second class of adjustments of acts to ends, which subserve the rearing of offspring, we no longer find any obscurity in the application of the words good and bad to them, according as they are efficient or inefficient. And most emphatic are the application of the words, in this sense, throughout the third division of conduct comprising the deeds by which men affect one another. Always, then, acts are good or bad, according as they are well or ill-adapted to ends. That is, good is the name we apply to the relatively more evolved conduct; and bad is the name we apply to that which is relatively less evolved; for we have seen that "erolution, tending ever towards self-preservation, reaches its limits when individual life is the greatest, both in length and breadth; and we now see that, leaving other ends aside, we regard as good the conduct furthering self-preservation, and as bad the conduct tending to selfdestruction." With increasing power of maintaining individual life goes increasing power of perpetuating the species by fostering progeny; and the establishment of an associated state both makes possible and requires a form of conduct such that life may be 
completed in each and in his offspring, not only without preventing completion of it in others, but with furtherance of it in others; and this is the form of conduct most emphatically termed good. "Moreover, just as we saw that evolution becomes the highest possible when the conduct simultaneously achieves the greatest totality of life in self, in offspring, and in fellow-men; so here we see that the conduct called good rises to the conduct conceived as best, when it fulfils all three classes of ends at the same time."

Has this evolution been a mistake? 'The pessimist claims so, the optimist claims not. But there is one postulate in which both pessimists and optimists agree - namely, that it is evident that life is good or bad, according as it does, or does not, have a surplus of agreeable feeling; if a future life is included in the theory of either, the assumption is still the same, that life is a blessing or a curse according as existence, now considered in both worlds, contains more of pleasure or of pain; and the implication is therefore that conduct which conduces to the preservation of self, the family, and society, is good or bad in the same measure. "Thus there is no escape from the admission that conduct is good or bad according as its total effects are pleasurable or painful." So that if self-mutilation furthered life, and picking a man's pocket brightened his prospects, we should regard these acts as good. Approach to such a constitution as effects complete adjustment of acts to ends of every kind is, however, an approach to perfection, and therefore means approach to that which secures greater happiness. "Pleasure somewhere, at some time, to some being or beings, is an inexpugnable element of the conception" of moral aim.

Here follow criticisms of the religious school of morals, which bases its system on the will of God, and of the school of "pure intuitionists," who hold "that men have been divinely endowed with moral faculties." "It must be either admitted or denied that the acts called good and the acts called bad naturally conduce, the one to human well-being and the other to human illbeing. Is it admitted? Then the admission amounts to an assertion that the conduciveness is shown by experience; and this involves abandonment of the doctrine that there is no origin for morals apart from divine injunctions. Is it denied that acts classed as good and bad differ in their effects? Then it is tacitly affirmed that human affairs would go on just as well in ignorance 
of the distinction; and the alleged need for commandments from God disappears." To affirm that we know some things to be right and other things to be wrong, by virtue of a supernaturally given conscience; and thus tacitly to affirm that we do not otherwise know right from wrong, is tacitly to deny any natural relations between acts and results. For if there exist any such relations, then we may ascertain by induction, or deduction, or both, what these are. And if it be admitted that because of such natural relations happiness is produced by this kind of conduct, which is therefore to be approved; while misery is produced by that kind of conduct, which is therefore to be condemned; then it is admitted that the rightness or wrongness of actions is determinable, and must finally be determined, by the goodness or badness of the effects that flow from them, which is contrary to the hypothesis. Spencer also repeats and enlarges upon his formerly stated objections to utilitarianism as superficial: "The utilitarianism which recognizes only the principles of conduct reached by induction, is but preparatory to the utilitarianism which deduces these principles from the processes of life as carried on under established conditions of existence."

Every science begins by accumulating observations, and presently generalizes these empirically, but only when it reaches the stage at which its empirical generalizations are included in a rational generalization, does it become developed science. So with Ethics; a preparation in the simpler sciences is presupposed. It has a biological aspect; since it concerns certain effects, inner and outer, individual and social, of the vital changes going on in the highest type of animals. It has a psychological aspect; for its subject-matter is an aggregate of actions that are prompted by feelings and guided by intelligence. And it has a sociological aspect; for these actions, some of them directly, and all of them indirectly, affect associated beings. Belonging under one aspect of each of these sciences, - physical, biological, psychological, sociological, - it can find its ultimate interpretations only in those fundamental truths which are common to all of them, as different aspects of evolving life. 


\section{The Physical View}

While an aggregate evolves, not only the matter composing it, but also the motion of that matter, passes from an indefinite, incoherent homogeneity to a definite, coherent, heterogeneity. It is so with conduct. 'The conduct of lowly organized creatures has its successive portions feebly connected. From these up to man may be observed an increase in cohesion. Man, even in his lowest state, displays in his conduct far more coherent combinations of motions; and in civilized man this trait of developed conduct becomes more conspicuous still. But an even greater coherence among its component motions broadly distinguishes the conduct we call moral from the conduct we call immoral. The application of the word dissolute to the last, and of the word self-restrained to the first, implies this fact. The sequences of conduct in the moral man are more easily to be specified, as implied by the word trustworthy applied to them; while those of the less principled man cannot be so specified; as is implied by the word untrustworthy. Indefiniteness accompanies incoherence in conduct that is little evolved; and throughout the ascending stages of evolving conduct there is an increasingly definite coördination of the motions constituting it, until we reach the conscientious man, who is exact in all his transactions. With this increase of definiteness and coherence goes also an increase of heterogeneity; the moral man performs more varied duties, adjustments of acts to ends in more varied relations, than does the immoral man.

Evolution in conduct is, like all other evolution, towards equilibrium, - not the equilibrium reached by the individual in death, but a moving equilibrium. His evolution consists in a continual adjustment of inner to outer relations, until a state of society shall be reached in which the individual will find his nature congruous with the environment.

\section{The Brological View}

"The truth that the ideally moral man is one in whom the moving equilibrium is perfect, or approaches nearest to perfection, becomes, when translated with physiological language, the truth that he is one in whom the functions of all kinds are duly ful- 
filled." Either excess or defect in the performance of function results in a lowering of life, for the time being at least. Hence, the performance of every function is, in a sense, a moral obligation. One test of action is thus given us. An action must be classed as right or wrong in respect of its immediate bearings, according as it does or does not tend either to the maintenance of complete life for the time being or the prolongation of life to its full extent. This is true even though the remoter bearings of the action may call for a different classification. The seeming paradoxy of this statement results from the tendency, so difficult to avoid, to judge a conclusion which presupposes an ideal humanity, by its applicability to humanity as now existing. In the ideal state, towards which evolution tends, any falling short of function implies deviation from perfectly moral conduct.

"Fit connections between acts and results must establish themselves in living things, even before consciousness arises; and after the rise of consciousness these connections can change in no other way than to become better established. At the very outset, life is maintained by persistence in acts which conduce to it and desistence from acts which impede it; and whenever sentience makes its appearance as an accompaniment, its forms must be such that in the one case the produced feeling is of a kind that will be sought-pleasure, and in the other case is of a kind that will be shunned-pain." So, in the case of the seizure of food, for example, "the pleasurable sensation," everywhere where it arises, must be itself the stimulus to the contraction by which the pleasurable sensation is maintained and increased; or must be so bound up with the stimulus that the two increase together. "And this relation, which we see is directly established in the case of a fundamental function, must be indirectly established with all other functions; since non-establishment of it in any particular case implies, in so far, unfitness to the conditions of existence." "Sentient existence can evolve only on condition that pleasure-giving acts are life-sustaining acts."

It is true that, in mankind as at present constituted, guidance by present or proximate pleasures and pains fails throughout a wide range of cases. This arises throughout evolution by changes in the environment, from which result partial misadjustments of the feelings, necessitating readjustments. This general cause of derangement has been operating on human beings in the changes 
from a primitive to a civilized condition through the direct opposition and struggle of the militant and the industrial spirit, in a manner unusually decided, persistent, and involved.

But there is a still further relation between pleasure and welfare to be considered. There are connections between pleasure in general, and physiological exaltation, and between pain in general and physiological depression. Every pleasure increases vitality, every pain decreases vitality. Non-recognition of these general truths vitiates moral speculation at large. "You have had your gratification - it is past; and you are as you were before,' says the moralist to one; and to another he says: 'You have borne the suffering - it is over; and there the matter ends.' Both statements are false; leaving out of view indirect results, the direct results are that the one has moved a step away from death, and the other has moved a step towards death."

However, it is with the indirect results that the moralist is especially concerned; since remote consequences of action are especially to be considered in ethical questions. But doubtless a better understanding of biological truths would be to the benefit of moral theory and society at large.

Spencer especially combats, in a note at the end of this chapter, Barratt's theory, stated in "Physical Ethics," that movements of retraction and withdrawal and movements that secure the continuance of the impression of any acting force, are the external marks, respectively, of pain and pleasure. A great part of the vital processes, even in creatures of developed nervous systems, are carried on by unconscious reflex action, and there is, therefore, no propriety in assuming the existence of what we understand by consciousness in creatures not only devoid of nervous systems but devoid of structures in general. It is more proper to conceive such feelings as arising gradually, by the compounding of ultimate elements of consciousness.

\section{The Psychological View}

"Mind consists of feelings and the relations among feelings." By compositions of the relations, and ideas of relations, intelligence arises. By composition of feelings, and ideas of feelings, emotion arises. And, other things equal, the evolution of either is great in proportion as the composition is great. One of the

1 Vide "Principles of Psychology." 
necessary implications is that cognition becomes higher in proportion as it is remoter from reflex action; while emotion becomes higher in proportion as it is remoter from sensation." 1

"'The mental process by which, in any case, the adjustment of acts to ends is effected and which, under its higher forms, becomes the subject-matter of ethical judgments, is, as above implied, divisible into the rise of a feeling or feelings constituting the motive, and the thought or thoughts through which the motive is shaped and finally issues in action. The first of these elements, originally an excitement, becomes a simple sensation; then a compound sensation; then a cluster of partially presentative and partially representative sensations, forming an incipient emotion; then a cluster of exclusively ideal or representative sensations forming an emotion proper; then a cluster of such clusters forming a compound emotion; and eventually becomes a still more involved emotion composed of the ideal forms of such compound emotions. The other element, beginning with that immediate passage of a single stimulus into a single motion, called reflex action, presently comes to be a set of associated discharges of stimuli producing associated motions; constituting instinct. Step by step arise more entangled combinations of stimuli, somewhat variable in their modes of union, leading to complex motions, similarly variable in their adjustments; whence occasional hesitations in the sensori-motor processes. Presently is reached a stage at which the combined clusters of impressions, not all present together, issue in actions not all simultaneous, implying representation of results, or thought. Afterwards follow stages in which various thoughts have time to pass before the composite motives produce the appropriate actions, until at last arise those long deliberations during which the probabilities of various consequences are estimated, and the promptings of the correlative feelings balanced; constituting calm judgment. That, under either of its aspects, the later forms of this mental process are the higher, ethically considered as well as otherwise considered, will be readily seen." ${ }_{2}$

"Observe, then, what follows respecting the relative authorities of motives. 'Throughout the ascent from low creatures up to man, and from the lowest types of man to the highest, self-preservation has been increased by the subordination of simple excitations to compound excitations, - the subjection of immediate sensations

$$
1 \text { P. 104. } 2 \text { Pp. I04, I05. }
$$


to the ideas of sensations to come, - the overruling of presentative feelings by representative feelings, and of representative feelings by re-representative feelings. As life has advanced, the accompanying sentience has become increasingly ideal; and among feelings produced by the compounding of ideas, the highest, and those which are evolved latest, are the re-compounded or doubly ideal. Hence it follows that, as guides, the feelings have authorities proportionate to the degrees in which they are removed, by their complexity and their ideality, from simple sensations and appetites. A further implication is made clear by studying the intellectual sides of these mental processes by which acts are adjusted to ends. Where they are low and simple, these comprehend the guiding only of immediate acts by immediate stimuli the entire transaction in each case, lasting but a moment, refers only to a proximate result. But with the development of intelligence and the growing ideality of the motives, the ends to which the acts are adjusted cease to be exclusively immediate. The more ideal motives concern ends that are more distant; and with approach to the highest types, present ends become increasingly subordinate to those future ends which the ideal motives have for their objects. Hence there arises a certain presumption in favor of a motive which refers to a remote good, in comparison with one which refers to a proximate good." 1

Out of the three controls of conduct, the political, the religious, and the social, the first and the last of which are generated in the social state through the supremacy of individuals in the midst of a control that is also, in some degree, exerted by the whole community, the moral consciousness grows; the feeling of moral obligation in general arising in a manner analogous to that in which abstract ideas are generated, out of concrete instances. As in such groupings of instances the different components are mutually cancelled to form the abstract idea, so in groupings of the emotions, there takes place a mutual cancelling of diverse components; the common component is made relatively appreciable, and becomes an abstract feeling. That which the moral feelings - the feelings that prompt honesty, truthfulness, etc. have in common, is complexity and re-representative character. The idea of authoritativeness has, therefore, come to be connected with feelings having these traits: the implication being that the

1 Pp. 108, 109. 
lower and simpler feelings are without authority. Another element - that of coerciveness - originated from experience of those several forms of restraint that have established themselves in the course of civilization - the political, religious, and social. By punishment is generated the sense of compulsion which the consciousness of duty includes, and which the word obligation indicates. This sense, however, becomes indirectly connected with the feelings distinguished as moral; and slowly fades as these emerge from amidst the political, religious, and social motives, and become distinct and predominant. The sense of duty is, therefore, transitory, fading as a motive as pleasure in right-doing is evolved.

\section{The Sociological View}

"Not for the human race only, but for every race, there are laws of right living. Given its environment and its structure, and there is, for each kind of creature, a set of actions adapted in their kinds, amounts, and combinations, to secure the highest conservation its nature permits." Yet in man we find an additional factor in the formula for life: for man is sociable to a degree not found anywhere else among animals. The conditions of the associated state have therefore called for an emphasizing of those restraints on conduct entailed by the presence of fellowmen. "From the sociological point of view, then, Ethics becomes nothing else than a definite account of the forms of conduct that are fitted to the associated state, in such wise that the lives of each and all may be the greatest possible, alike in length and breadth." "But here we are met by a fact which forbids us thus to put in the foreground the welfare of citizens, individually considered, and requires us to put in the foreground the welfare of the society as a whole. The life of the social organism must, as an end, rank above the lives of its units." These two ends are not harmonious at the outset, since as long as communities are endangered by rival communities, a sacrifice of private to public claims is necessary. When, however, antagonism between communities shall cease, there will cease to be any public claims at variance with private claims; the need for the subordination of individual lives to the general life will cease, and the latter, having from the beginning had furtherance of individual lives as its ultimate purpose, will come to have this as its proximate purpose. Between 
the commands of duty towards members of the same community and towards those of different communities as between the sentiments answering to these relations, there is, at present, conflict. In the course of evolution, however, the various forms of subjection countenanced by a warlike regime - slavery, the subjection of women to men, and paternal absolutism, become more and more unpopular, and are done away with. For each kind and degree of social evolution, there is an appropriate compromise between the moral code of enmity and that of amity; this is, for the time being, authoritative. ${ }^{1}$ But such compromise belongs to incomplete conduct; the end of evolution is in the annihilation of enmity between societies as between individuals. Nor is a mere abstinence from mutual injury enough. Without coöperation for satisfying wants the social state loses its raison d'être. In all efforts for coöperation equivalence of exchange is a necessary basis; all failure to fulfil such equivalence causes antagonism and thus a diminution of social coherence; in the social, as in the animal organism, waste without repair destroys the equilibrium of the parts; fulfilment of contract is, therefore, the primary condition of the welfare of society.

And even mutual punctiliousness in the fulfilment of contract is not sufficient to the moral ideal. Daily experience proves that every one would suffer many evils and lose many goods, did none give him unpaid assistance. The limit of the evolution of conduct is not reached until, beyond avoidance of direct and indirect injuries to others, there are spontaneous efforts to further the welfare of others. The form of nature which thus adds beneficence to justice, is one which adaptation to the social state produces. "The social man has not reached that harmonization of constitution with conditions forming the limit of evolution, so long as there remains space for the growth of faculties which, by their exercise, bring positive benefit to others and satisfaction to self. If the presence of fellow-men, while putting certain limits to each man's sphere of activity, opens certain other spheres of activity in which feelings, while achieving their gratifications, do not diminish but add to the gratifications of others, then such spheres will inevitably be occupied." ${ }_{2}$ But of beneficence, as well as of justice, sympathy is the root.

The assumption that feelings can be arranged in a scale of 1 Pp. I34, 148. 
desirability, against which Mr. Sidgwick especially argues in his objections to (empirical) egoistic hedonism, is not necessarily an element of such hedonism, although Bentham, in naming intensity, duration, certainty, and proximity as traits entering into an estimation of the relative value of a pleasure or pain, has committed himself to it. But if a debtor who cannot pay offers to compound for his debt by making over to me any one of various objects of property, will I not endeavor to estimate their relative value, though I may not be able to do it exactly; and if I choose wrongly is therefore the ground of choice to be abandoned? Mr. Sidgwick's argument against empirical hedonism must tell, moreover, in a still greater degree, against his own utilitarianism, since this is applicable, not to the individual simply, but to many classes of differing individuals. To this difficulty must be added, moreover, the future indeterminateness of the means for obtaining such universal happiness. Mr. Sidgwick's objection contains, however, a partial truth; for guidance in the pursuit of happiness through the mere balancing of pleasures and pains is, if partially practicable throughout a certain range of conduct, futile throughout a much wider range. "It is quite consistent to assert that happiness is the ultimate aim of action, and at the same time to deny that it can be reached by making it the immediate aim. I go with Mr. Sidgwick as far as the conclusion that "we must at least admit the desirability of confirming or correcting the results of such comparisons (of pleasures and pains) by any other method upon which we may find reason to rely'; and I then go further, and say that throughout a large part of conduct guidance by such comparisons is to be entirely set aside and replaced by other guidance."

The fact cited by Mr. Sidgwick as the "fundamental paradox of hedonism," that to get the pleasures of pursuit one must "forget " them, is explained by the fact that the pleasures of pursuit lie greatly in the consciousness of capability in the efficient use of means, and the sense of the admiration excited thereby in others. And so the "fundamental paradox" disappears. Yet the truth of the pleasure derived from means as distinguished from ends is of significance. Throughout the evolution of conduct we find a growing complexity of adjustment of acts to ends, the interposition of more and more complex means, each as a step to the next, and leading to the final attainment of even remoter ends. 
Of these means, each set, with its accompanying satisfaction, developed with the function, comes at last to be regarded as proximate end, and constitutes an obligation; and each later and higher order of means comes to take precedence in time and authoritativeness of each earlier and lower order of means. In this manner arises the authoritativeness of moral requirements, as designating the latest and highest order of means.

Such means are more determinable than the end - happiness - for any society. What constitutes happiness is more difficult of determination than what constitutes the means of its attainment. We may now see our way to reconciling sundry conflicting ethical theories, which generally embody portions of the truth, and simply require to be combined in proper order in order to embody the whole truth. The theological theory contains a part. If for the divine will, supposed to be supernaturally revealed, we substitute the naturally revealed end towards which the Power manifested throughout Evolution works; then, since evolution has been, and is still, working towards the highest life, it follows that conformity to those principles by which the highest life is achieved, is furtherance of that end. The doctrine that perfection or excellence of nature should be the purpose of pursuit, is in one sense true; for it tacitly recognizes that ideal form of being which the highest life implies, and to which evolution tends. There is a truth, also, in the doctrine that virtue must be the aim; for this is another form of the doctrine that the aim must be to fulfil the conditions to achievement of the highest life. That the intuitions of a moral faculty should guide our conduct is a proposition in which a truth is contained; for these intuitions are the slowly organized results of experiences received by the race while living in presence of these conditions. And that happiness is the supreme end is beyond question true; for it is the concomitant of that highest life which every theory of moral guidance has, distinctly or vaguely, in view.

Thus, those ethical systems which make virtue, right, obligation, the cardinal aims, are seen to be complementary to those ethical systems which make welfare, happiness, pleasure, the cardinal aims.

Spencer follows up this argument with a chapter on the relativity of pleasures and pains, and then proceeds with an argument against excessive altruism as, in the end, selfish, since it is destructive to 
the power for work and to individual life, diminishes the vigor of offspring, and finally results in the survival of the less altruistic as the fittest; this chapter is under the heading "Egoism versus Altruism." It is followed by a chapter on Altruism versus Egoism, in which is shown that some individual self-sacrifice, at least to offspring, is found far down in the scale of being; that altruism is, therefore, "no less primordial than self-preservation," 1 and hence no less imperative; that this altruism, at first unconscious, becomes, in higher stages of evolution, conscious; and that if often selfish in motive, it may be without any element of conscious self-regard, although it conduces greatly to egoistic satisfaction. Indeed, pure egoism defeats itself, since pleasure palls by overindulgence, is dulled by maturity, and almost destroyed by old age. He that can find pleasure in ministering to that of others has, however, a source of pleasure which may serve in place of personal pleasure. In the associated state, a certain altruism is, and must necessarily be, an advantage to each member of the community. Whatever conduces to the well-being of each is conducive to the well-being of all.

Here follows a criticism of utilitarianism as one form of pure altruism, since, according to the utilitarian doctrine, each individual is to count for one, not more than one, and the individual share of happiness thus becomes infinitesimal as compared with general happiness. Shall A, who has, by labor, acquired some material happiness, take the attitude of a disinterested spectator with regard to their use, as Mr. Mill recommends? And will he, as such, decide on a division of these means to happiness with $\mathrm{B}, \mathrm{C}$, and $\mathrm{D}$, who have not labored to produce them? From the conclusion that a really disinterested spectator would not decree any such division, Spencer seems to draw the conclusion that Mr. Mill's position is untenable. He further illustrates the untenability of utilitarianism (as pure altruism) by the figure of a cluster of bodies generating heat, each of which will have, as long as it generates heat for itself, a certain amount of proper heat and a certain amount of heat derived from the others; whereas the whole cluster will become cold as soon as each ceases to generate heat for itself and depends on the heat generated by the rest. Utilitarianism involves the further paradox that, to achieve the greatest sum of happiness, each individual must be more 
egoistic than altruistic. "For, speaking generally, sympathetic pleasures must ever continue less intense than the pleasures with which there is sympathy." And while the individual must be extremely unegoistic in that he is willing to yield up the benefit for which he has labored, he must, at the same time, be extremely egoistic, since he is so selfish as willingly to let others yield up to him the benefits they have labored for. "To assume that egoistic pleasures may be relinquished to any extent is to fall into one of those many errors of ethical speculation which result from ignoring the laws of biology. . . . To yield up normal pleasure is to yield up so much life; and there arises the question: - to what extent may this be done? . . . Surrender, carried to a certain point, is extremely mischievous, and to a further point, fatal." 1 After beginning, however, with this assertion that to assume that egoistic pleasure may be relinquished to any extent is to fall, from ignorance of biology, into an error of ethical speculation, Spencer reaches only the conclusion that, if the individual is to continue living, he must take "certain amounts" of those pleasures which go along with the fulfilment of the bodily functions, and that "the portion of happiness which it is possible for him to yield up for redistribution is a limited portion." $\mathrm{He}$ further argues that "a perfectly moral law must be one which becomes perfectly practicable as human nature becomes perfect "; but that the law of utilitarianism does not so become practicable, since opportunities for practising altruism, which originate in imperfection in others, will diminish and finally disappear in the ideal state. There is no addition to happiness by redistribution, and there is the additional labor and loss of time of such redistribution. The conclusion must be that "general happiness is to be achieved mainly through the adequate pursuit of their own happiness by individuals, while reciprocally, the happiness of individuals is to be achieved in part by their pursuit of the general happiness." The chapter on the conciliation of altruism and egoism is occupied with the development of sympathy, as the militant spirit grows less. The expression of emotion, as also the power of interpreting such expression, must become greater as the impelling cause to concealment found in lack of sympathy, disappears. When conditions require any class of activities to be relatively great, there will arise a relatively great pleasure 
accompanying that class of activities; the scope for altruistic activities will not exceed the desire for altruistic satisfaction. Such altruistic satisfaction, though in a transfigured sense egoistic, will not be pursued egoistically - that is, from egoistic motives. General altruism will resist too great altruism in the individual, and as the occasion for self-sacrifice disappears, altruism will take on the ultimate form of sympathy with the pleasure of others produced by the successful activities of these. And so there will disappear the apparently permanent opposition between egoism and altruism.

The last two chapters of "The Data of Ethics" deal with Ethics as the law of the ideal man in an ideal society, and treat of the attainment of general principles in this science as in other sciences by the neglect of conflicting factors, and the recognition of fundamental factors, in the gradually accumulated knowledge of society. On account of the diversity of men and societies, a code of perfect personal conduct can never be made definite; only certain general conditions of perfection can be pointed out. As life is now carried on, the conflict of claims is continual; and ethical science, here necessarily empirical, can do no more than aid in making least objectionable compromises. Absolute Ethics, which supplies the law of perfect right-doing possible only in an ideal state, does not greatly aid Relative Ethics, yet it aids somewhat, as keeping before consciousness an ideal conciliation of claims, and suggesting search for the best form of compromise possible under the circumstances.

"Justice," which constitutes Part IV. of "The Principles of Ethics," and to which "The Data of Ethics" belongs as Part I., was published ( $189 \mathrm{r}$ ) in advance of Parts II. and III. The argument of the book runs as follows:-

Ethics properly involves a consideration of the conduct of animals as well as of human beings, for the primary subject-matter of Ethics is conduct considered as producing good and bad results to self or others, or both, not, as most people believe, conduct as calling forth approbation or disapprobation. And even on this latter view, Ethics includes Animal Ethics, since we feel approbation or disapprobation with regard to many actions of animals.

Animal Ethics includes, as its two cardinal principles, the opposed classes of altruistic and egoistic acts. For preservation of the species, benefits received must be, during immaturity, inversely pro- 
portionate to merit or capacities possessed, merit being measured by powers of self-sustentation, and after maturity, directly proportionate to worth as measured by fitness to the conditions of existence. Furthermore, though the species is made up of individuals, many of these individuals may disappear and the species still be preserved, whereas its disappearance as a whole involves absolute fitilure in achieving the end, so that, where preservation of individuals conflicts with preservation of the species, the individuals must be sacrificed.

The principle that among adults benefits must be in proportion to merits, implies in its biological aspect survival of the fittest. Its violation involves double harm to the species by sacrifice of the superior to the inferior, and consequent increase of the inferior. "Interpreted in ethical terms, it is that each individual ought to be subject to the effects of its own nature and resulting conduct"; and throughout sub-human life this rule holds without qualification. The same principle is displayed in the mutual relations of the parts of organisms, every part being nourished in proportion to its use or function, a balancing of the relative powers of the parts being thus effected, and the organism "fitted as a whole to its existence by having its parts continuously proportioned to the requirements." In a parallel manner, the species as a whole is fitted to its environment by the greater prosperity to self and offspring that comes to those better adapted.

But sub-human justice is extremely imperfect, alike in general and in detail.

In general it is imperfect, in that the sustentation of multitudinous species depends on the wholesale destruction of others; so that, in the species serving as prey, the relations between conduct and consequence are so habitually broken that.in very few individuals are they long maintained. It is true the destruction of the species serving as prey is the result of their natures; "but this violent ending of the immense majority implies that the species is one in which justice, as above conceived, is displayed in but small measure." Sub-human justice is also imperfect in detail, in that the relation between conduct and consequences is, in such an immense proportion of cases, broken by accidents, - such as scarcity of food, inclemencies of weather, invasions by parasites, attacks of enemies, - which fall indiscriminately on the superior and the inferior. As organization becomes higher, sub-human justice becomes more 
decided ; as general superiority increases, there is less dependence on accident, and individual differences become more important.

With the beginning of gregariousness, we find the new element of coöperation, passive or active, which is an advantage to the species. This involves so much restraint of conflicting acts as will leave a balance of advantage ; else survival of the fittest will exterminate the variety in which association begins. The experience of the evils of not maintaining such limits to action results in an inherited tendency to maintain them. The general consciousness of the need for maintaining them results in punishment of their disregard. Self-subordination among solitary animals is found only in parenthood; among gregarious animals there is a further subjection of the individual to his kind, and where an occasional sacrifice of life furthers the preservation of species, sub-human justice may rightly have this second limitation.

In order of priority, the law of relation between conduct and consequence, the principle that each individual ought to receive the good and evil resulting from his own nature, stands first ; it is the primary law holding of all creatures. The law of the restraint, in gregarious animals, of interfering acts, is second in time and authority, and is simply a specification of the form which the primary law takes under conditions of gregarious life, since, in asserting restriction of the interactions of conduct and consequence, it tacitly reasserts that these interactions must be maintained in other individuals, that is, in all individuals. The third law, of the occasional sacrifice of individuals to their kind, is later and narrower in application, and a qualification of the first law. The first law is absolute for animals in general; the second is absolute for gregarious animals; but the third "is relative to the existence of enemies of such kinds that, in contending with them, the species gains more than it loses by the sacrifice of a few members; and in the absence of such enemies this qualification imposed by the third law disappears."

As human life is a development of sub-human life, so human justice is a development of sub-human justice. According to pure justice, the individual should suffer the consequences of his acts, and that such is the general opinion is implied in such common expressions as: "He has no one to blame but himself" ; "He has made his own bed, and now he must lie on it" ; "He has got no more than he deserved "; or, "He has fairly earned his reward." 
The truth that, with higher organization, danger from accident becomes less, longevity is greater, and so differences count for more, showing their effects for longer periods, and justice therefore becomes greater, applies also to human beings. The rate of mortality decreases with man, and according to his civilization.

More clearly in the case of human beings than in that of other animals is it shown that gregariousness establishes itself because it profits the variety. Where a variety live on wild food, they associate only in small groups; game and fruit, widely distributed, can support these only. "But greater gregariousness arises where agriculture makes possible the support of a large number on a small area; and where the accompanying development of industries introduces many and various coöperations." The advantages of coöperation can be had only by conformity to the conditions which association imposes - by such limitation of the pursuits of individuals as to leave a surplus of advantage to associated life. "This truth is illustrated by the unprosperous or decaying state of communities in which the trespasses of individuals on one another are so numerous and great as generally to prevent them from severally receiving the normal results of their labors." Mutual restraint being more imperative with human beings than with animals, there is with them a still more marked habit of punishment.

"Through all which sets of facts is manifested the truth, recognized practically if not theoretically, that each individual, carrying on the actions which subserve his life, and not prevented from receiving their normal results, good and bad, shall carry on these actions under such restraints as are imposed by the carrying on of kindred actions by other individuals, who have similarly to receive such normal results, good and bad. And vaguely, if not definitely; this is seen to constitute what is called justice."

In the highest gregarious creature, the necessity which we found, of an occasional sacrifice of the individual in defence of species, assumes large proportions, the defence being not only against enemies of other kinds, but also against enemies of the same kind. This obligation is less than that of care for offspring, or mutual restraint. It exists only as necessary to protect the society against destruction, hence only for defensive, not for offensive, war. It may be objected that war peoples the earth with the stronger, but this is not necessarily so, since the conquered may merely be 
fewer in number. And further, it is only during the earlier stages of human progress that the development of strength, courage, and cunning are of chief importance. But for an accident, Persia would have conquered Greece; and Tartar hordes once very nearly overwhelmed European civilization. The races best fitted for social life do not necessarily conquer, and there are injurious moral reactions on both conquering and conquered. Only defensive war retains a quasi-ethical justification. It belongs, however, to a transitional state, and is not justified by Absolute Ethics.

As the organs of inferior animals are moulded into fitness for the requirements of life, so, simultaneously, through nervous modifications, their sensations, instincts, emotions, and intellectual aptitudes are also moulded to these requirements, - in the gregarious animals to the conditions of gregarious life. Many evolutionists appear to regard the variability of man as ceasing with civilized life, but the whole analogy of nature is against such a theory; we must assume that man, like other animals, is moulded to suit his requirements, and that moral changes are among those thus wrought out. Aggressive actions often entail suffering on the individuals of a group performing them, as well as on the group as a whole, and on the other hand, harmonious coöperation in a group profits the average of its members; so that there is a tendency to survival of groups having such adaptation of nature. And just as a love of property, formerly gratified by possession of food and shelter, came later to be extended to the weapons for obtaining these, and, later, even to the raw materials, the pleasure in ownership becoming more and more abstract and remote from material satisfaction, so the natural impatience of animal nature at restraint of its powers becomes in man a sentiment of egoistic justice, for justice requires the free play of all forces in order that the results of character may fall upon the individual. It is more difficult to understand how the altruistic sentiment of justice comes into being. On one hand, its implication is that it can be developed only by adaptation to social life ; on the other, it appears that social life is impossible without the maintenance of those equitable relations which imply a sentiment of justice. These requirements are fulfilled by a pro-altruistic sentiment of justice, which takes its place. The first deterrent from aggression, among animals, is fear of retaliation; a further restraint, with man, is fear of reprobation or social disgrace. To these are to be added the feelings arising 
under political and religious authority - the dread of legal punishment and the dread of divine vengeance; and these four kinds of feelings coöperate, forming a body of feeling, which checks the primitive tendency to pursue the objects of desire without regard to the interests of fellow-men, and though containing nothing of the altruistic sentiment of justice, makes social coöperation possible. Creatures which become gregarious, tend to become sympathetic in degrees proportionate to their intelligence - by sympathy being meant the arousing of kindred feeling by the witness of a display of feeling in others, sympathy being fostered by common enjoyments and sufferings. The altruistic sentiment of justice is slow in assuming a high form, "partly because its primary component does not become highly developed until a late phase of progress, partly because it is relatively complex, and partly because it implies a stretch of imagination not possible for low intelligences." As, until pain has been felt, there cannot be sympathy with pain, so the altruistic sentiment of justice cannot be developed until the egoistic sentiment has arisen; moreover, the sentiment of justice is concerned, not only with concrete pains and pleasures, but also with their conditions, and hence this sentiment demands a development of the power of mental representation.

There is a close connection between the sentiment of justice and the social type. Predominant militancy affords no scope for the egoistic sentiment of justice, and at the same time sympathy is perpetually seared by militant activities. On the other hand, as fast as voluntary coöperation, which characterizes the industrial type of society, becomes more general than compulsory coöperation, which characterizes the militant type of society, individual activities become less restrained, and the sentiment which rejoices in the scope for them is encouraged; while simultaneously, the occasions for repressing the sympathies become less frequent.

The idea of justice is different from the mere sentiment of justice; the former gradually arising from the latter, in the course of generations, by experience of the limits to which action can be carried without causing resentment from others. But since the kinds of activity are many and become increasingly various with the development of social life, it is a long time before the general nature of the limit common to all cases can be conceived. A further reason for the slowness of development is, that the arising ideas of justice have been perpetually confused by the conflicting requirements of internal amity and external enmity. 
Two elements, a positive and a negative, constitute the idea of justice - that of man's recognition of his claims to unimpeded activities and the results they bring, and that of the limits which the presence of other men necessitate. The primordial ideal suggested is inequality, for since the principal is that each should receive the results due to his own nature, then, since men differ in their powers, unequal benefits are implied. But mutual limitations suggest a contrary idea, experience showing that the bounds to which one may pursue his own ends are, on the average, the same for all, so that the idea of equality arises. Unbalanced appreciations of these two factors in human justice lead to divergent moral and social theories.

Among the rudest men the appreciations are no higher than among inferior gregarious animals. Where war has developed political organization the idea of inequality predominates, but the idea is one, not of natural, but of artificial apportionment. And in general, we find that the primary or brute factor in justice is but little qualified by the human factor.

All movements are rhythmical, social movements included, and after the idea of justice in which inequality predominates comes a conception in which the idea of equality unduly predominates as in Bentham's ethical theory, where "one person's happiness, supposed equal in degree (with proper allowance made for kind), is accounted for exactly as much as another's"; and this is the theory which Communism would reduce to practice. It is an absolute denial of the principle of inequality, and must apply alike to the worthy and unworthy, as well as to the superior and inferior in physical and intellectual capacities, since moral inequalities are as much inherited as others. Here we have a deliberate abolition of that cardinal distinction between the ethics of the family and the ethics of the state emphasized at the outset - " an abolition which, as we saw, must eventuate in decay and disappearance of the species or variety in which it takes place."

The true principle shows an amalgamation of these two. "The equality concerns the mutually limited spheres of action which must be maintained if associated men are to coöperate harmoniously. The inequality concerns the results which each may achieve by carrying on his actions within the implied limits. No incongruity exists when the ideas of equality and inequality are applied, the one to the bounds and the other to the benefits. Contrariwise, the two may be, and must be, simultaneously asserted." 
"Any considerable acceptance of so definite an idea of justice is not to be expected. It is an idea appropriate to an ultimate state, and can be but partially entertained during transitional states; for the prevailing ideas must, on the average, be congruous with existing institutions and activities." During the thirty, or rather forty years' peace, and weakening of militant organization, the idea of justice became clearer; but since then the idea of regimentation has spread. It is predominant in the conception of socialism with its army of workers with appointed tasks and apportioned shares of products, and every act of Parliament which takes money from the individual for public purposes shows a tendency in the same direction. In the countries where militancy is most pronounced, socialism is most highly developed. "Sympathy, which, a generation ago, was taking the shape of justice, is relapsing into generosity; and the generosity is exercised by inflicting injustice. Daily legislation betrays little anxiety that each shall have that which belongs to him, but great anxiety that he shall have that which belongs to somebody else."

The formula of justice may be expressed thus: "Every man is free to do that which he wills, provided he infringes not the equal freedom of any other man."

This is not to be interpreted as meaning that aggression is permissible as long as retaliation is permitted ; for the formula means that interference with another's life is limited, that life shall not be impeded in one case further than is necessary to the maintenance of other lives; it does not countenance a superfluous interference on the ground that an equal interference may balance it. In earlier stages, the conception of justice was this erroneous one of a balancing of injuries - an eye for an eye and a tooth for a tooth. By oscillations which become gradually less, social equilibrium is approached; and with this approach to equilibrium comes approach to a definite theory of equilibrium.

In the reigning school of politics and morals, scorn is expressed for every doctrine which implies restraint of immediate expediency, or what appears to be such; - contempt for generalizations and abstract principles, with unlimited faith in political machinery. Strangely enough, we find this approval of political empiricism and disbelief in any other guidance, in the world of science also. The accepted scientific fact that causation holds of the actions of incorporated men as of other parts of nature, remains a dead 
letter; there is no attempt to identify the causation, and ridicule is visited upon those who endeavor to find a definite expression for the fundamental principle of harmonious social order.

Peoples with whom confusion is not caused by the conflicting disciplines of outer war and internal peace, early arrive at the principle of equity, and accordingly some uncivilized tribes show a stronger sense of it than is found among civilized peoples. Nevertheless, the conception of justice has slowly evolved to some extent, and is expressed in such formulæ as, "Do unto others as ye would that others should do unto you " (too sweeping a statement of the equality of claims, since it implies no recognition of the inequality necessary in the shares of good respectively appropriate), or in the Kantian rule, which is an allotropic form of the Christian rule. Jurists, too, have recognized a natural law of equity underlying human law. To the reproach that belief in such a law is an a priori belief, it may be answered that a priori beliefs are explained by the theory of evolution, as arising with determination of the nervous system and certain resulting necessities of thought, and that they differ from a posteriori beliefs merely in the circumstance "that they are the products of the experiences of innumerable successive individuals, instead of the experiences of a single individual." If we ask for the ground of the greatest happiness principle, we come to an a priori belief also ; for whence is the postulate? If it is an induction, where and by whom has the induction been drawn; and if it is a truth of experience derived from careful observation, then what are the observations, and when was there generalized that vast mass of them on which all politics and morals should be built? "Not only are there no such experiences, no such observations, no such inductions, but it is impossible that any should be assigned." The like is true of Bentham's rule: "Everybody to count for one, nobody for more than one," and also of the objection to this rule, that happiness cannot be divided, or greatest happiness obtained, by equal division of the means to happiness; they all lead, in the last analysis, to an a priori belief. Moreover, the rule of natural equity, the freedom of each limited only by the like freedom of all, is not an exclusively a priori belief, but although the immediate dictum of the human consciousness after subjection to the discipline of prolonged social life, it is deducible from the conditions to be fulfilled, firstly for the maintenance of life at large, and secondly for the maintenance of social life. 
Rights, properly so-called, are corollaries from the law of equal freedom, and "so far is it from its being true, as some claim, that the warrant for what are properly called rights is derived from law, it is, conversely, true that law derives its warrant from them."

In the application of this theory to practical questions, Mr. Spencer's "Justice " differs from "Social Statics," which it resembles in form and method, in general in the greatly increased conservatism of the views expressed. This is shown in all parts of the book, though perhaps most clearly in those parts relating to the Rights of Women, to the Land Question, and to the Limits of State-Duties. "Social Statics" advocated land-nationalization; but "Justice," though still asserting the original right of the aggregate of men forming the community to the use of the earth, as that from which all material objects capable of being owned are derived and so that on which the right to property is originally dependent, denies the expediency and the justice of a present redistribution of the land according to this principle ; and this because of the confusion of claims at the present time, the impossibility of ascertaining whose ancestors were the robbers and whose the robbed in the gradually arising monopoly, the wrong of making descendants responsible for the sins of their ancestors, and leaving those now dependent on the land without compensation for their loss, and the fact that any claim to the land is merely a claim to it in its original condition, not in its present state of drainage and cultivation effected by the labor of generations. Moreover, "under the existing system of ownership, those who manage the land experience a direct connection between effort and benefit, while, were it under state-ownership, those who managed it would experience no such direct connection. The vices of officialism would inevitably entail immense evils."

The whole of the practical part of "Justice" is especially directed against Socialism; in general, the course of history shows a less and less interference with personal freedom, and growing benefit from this cause. The practicality of woman suffrage and of universal man suffrage at the present time is denied. If earlier legislation was too much for the benefit of wealthy and ruling classes, recent extensions of the suffrage have resulted in still more injurious class-legislation of another sort.

In this book, Mr. Spencer seems to adhere to his theory of a "final perfect adaptation to the conditions of social life." Not 
only is the distinction between Relative and Absolute Ethics still drawn, but there are numerous references to an "ultimate state," though certain of these references might suggest the view that by such a state was meant only the attainment of so great a degree of civilization as would involve the cessation of wars. ${ }^{1}$ Other passages, however, seem to contradict this view. One may be especially cited ; it is as follows: "This law [of the gradual reëstablishment of deranged harmony, through adaptation and heredity], holding of human beings among others, implies that the nature which we inherit from an uncivilized past, and which is still very imperfectly fitted to the partially-civilized present, will, if allowed to do so, slowly adjust itself to the requirements of a fully-civilized future." And after some consideration of adaptation up to the present time, the paragraph concludes: "If, in the course of these few thousand years, the discipline of social life has done so much, it is folly to suppose that it cannot do more - folly to suppose that it will not, in course of time, do all that has to be done." ${ }^{2}$ But in the abridged and revised edition of "Social Statics" ( 1892 ), the following passage occurs as part of a note at the end of the chapter on "The Evanescence (? Diminution) of Evil." "The rate of progress towards any adapted form must diminish with the approach to complete adaptation, since the force producing it must diminish ; so that other causes apart, perfect adaptation can be reached only in infinite time." 3

Vol. I. of "The Principles of Ethics," including Parts I., II., and III., appeared in August, I892. In this volume, "The Data of Ethics," reprinted as Part I., remains unchanged, except for one or two unimportant sentences. To this Part I. is, however, appended a chapter which was, according to Mr. Spencer, written for the first publication of "The Data of Ethics," but was either put aside for some reason, or else overlooked, probably the latter, says the author, since it contains material which should have been embodied. The chapter is headed "The Conciliation," and seems to correspond to the two chapters on "Trial and Compro-

1 See pp. 71, 193.

2 Pp. 258, 259.

8 As the "revision" of the theoretical part of this book chiefly consists, like its abridgment, in the elimination of the references to Divine Will and other earlier views held before acquaintance with Darwin's theory of life, there is nothing in the book, in distinction from Mr. Spencer's other later works, that needs especially to be considered here. 
mise" and "Conciliation" which follow the chapters on "Egoism versus Altruism," and "Altruism versus Egoism"; for it begins with a consideration of the conflict of claims shown by "the last two chapters," the apparent impossibility of the establishment of an equilibrium, and the consequent apparent necessity of self-sacrifice. But this conflict between egoism and altruism is merely transitional and is in process of gradual disappearance, in the same manner in which the present degree of conciliation of the two has been reached, - namely, by the growth of such a constitution in each creature as entails pleasure in altruistic action. Even with the lower animals, the acts which are necessary to care for ova or young are the fulfilment of an instinct which is gratified by the act; and in the human race, conciliation between egoism and altruism, which goes hand in hand with evolution, has reached a high degree. In the evolution of the human race itself, from savagery to its present condition, there has been a marked increase of this conciliation; this is true not only in the family, but to a small extent also with regard to the larger groups of men constituting societies. There is decrease of cruelty, increase of justice, both in the form of state institutions and in their methods of administration, more active benevolence, and a public sentiment that leads large numbers of people to find egoistic gratification in the pursuit of the general good even to the neglect of private interests. Self-sacrifice thus ceases to be sacrifice in the ordinary sense of the word, since it comes to bring with it more pleasure than pain. The future must hold in store changes analogous to those of the past, but these must go on much more rapidly under the present comparatively peaceful organization of society than they have during the militant life of the past. This moral development is retarded, however, not only by the degree of militancy yet existing, but also by the necessity for a certain degree of bluntness of feeling, too great sensitiveness to the suffering of others entailing, while the pressure of population is as great as at present, a misery that would make life intolerable. It is likely that, with social progress, human fertility will decrease as cerebral activity increases, until a comparative balance of fertility and mortality is reached as "human evolution approaches its limit of complete adaptation to the social state" ; and sympathy will increase in proportion, no longer entailing on its possessor more of pain than of pleasure, but the contrary. "Sympathy is the root of every other kind of altruism than that 
which, from the beginning, originates the parental activities. It is the root of that higher altruism which, apart from the philoprogenitive instinct, produces desire for the happiness of others and reluctance to inflict pain upon them. These two traits are inevitably associated. The same mental faculty which reproduces in the individual consciousness the feelings that are being displayed by other beings, acts equally to reproduce those states when they are pleasurable or when they are painful."

The general corollary from the above-described process of evolution is that, with the increase of sympathy there arises the double result, that by its increase it tends to decrease the causes of human misery, and in proportion as it does this, it becomes itself the cause of further reflected happiness received by each from others. "And the limit towards which this evolution approaches is one under which, as the amount of pain suffered by those around from individual imperfections and from imperfections of social arrangement and conduct, becomes relatively small, and simultaneously the growth of sympathy goes on with little check, the sympathy becomes at the same time almost exclusively a source of pleasure received from the happiness of others, and not of pains received from their pains. And as this condition is approached, the function of sympathy is not that of stimulating to self-sacrifice and of entailing upon its possessor positive or negative pain, but its function becomes that of making him a recipient of positive pleasure." Thus altruism will overgrow egoism, becoming itself a source of egoistic pleasure, and eventually, with the diminution of the pressure of population, there will come a state in which egoism and altruism are so conciliated that the one merges in the other.

Among the social animals, with the ant and the bee, for instance, who cannot be supposed to possess a sense of duty, we see that this identification of egoism and altruism, as necessary to social life, has taken place to a considerable extent; and since pleasure of every kind is the concomitant of nervous structure, we can understand the pleasure in altruistic as well as in egoistic activities, as soon as there exists the nervous structure answering to these activities. As certainly as there yet exist in civilized men instincts of the chase inherited from savage ancestors, there are growing up and will continue to grow up in men, these other structures which will prompt to altruistic activities.

Part II. of "The Principles of Ethics" is concerned with "The 
Inductions of Ethics." It opens with a chapter on the confusion of ethical thought due to the fact that, conforming to the general law of evolution, "the set of conceptions constituting ethics, together with the associated sentiments, arise out of a relatively incoherent and indefinite consciousness; and slowly acquire coherence and definiteness at the same time that the aggregate of them differentiates from the larger aggregate with which it originally mingled. Long remaining undistinguished, and then but vaguely discernible as something independent, ethics must be expected to acquire a distinct embodiment only when mental evolution has reached a high stage." "Originally, ethics has no existence apart from religion, which holds it in solution. Religion itself, in its earliest form, is undistinguished from ancestor-worship," which passes, in the second stage, into worship of dead rulers, and is a method of propitiation, prompted by self-interest. Among some peoples, the idea of sin is limited to offences against the gods ; and in those other cases where there are ethical commands, the propriety of not offending God is the primary reason given for obeying them. This last phase of thought is illustrated by the religion of the Hebrews, among whom good and bad conduct was but little associated with the intrinsic natures of right and wrong. The popular belief is still that right and wrong become such by divine fiat.

The gods of primitive, warlike peoples were gods of war, and the belief in the moral virtue and honor of war still holds large place in the thought of the world. The ethics of enmity, thus taught at the same time with the ethics of amity necessary to the internal life of society, gave rise to utterly inconsistent and contradictory sentiments and ideas, which, in considerable measure, still exist side by side, in our churches and outside them.

But, together with these ethical conceptions, there have slowly evolved other, utilitarian conceptions, derived from a recognition of the natural consequences of acts. Authority has been introduced into these conceptions as the source of the duty of action in accordance with them; yet there has generally been also some perception of their fitness. Such utilitarian conceptions are to be found in the later Hebrew writings, among the Egyptians, Greeks, etc. "The divergence of expediency-ethics from theological ethics is well illustrated in Paley, who in his official character derived right and wrong from divine commands, and in his unofficial 
character derived them from observation of consequences. Since his day, the last of these views has spread at the expense of the first."

A still further simultaneous origin of moral dictates is found in the sentiments which have arisen with such habits of conformity to rules of conduct as have been furthered by survival of the fittest. We thus have a conflict of ethical ideas arising from the conflict of these various sanctions; and also from the further conflict that ensues where a later religion has been grafted on a more primitive one, as is the case everywhere in Christendom.

Among modern writers who assert the existence of a moral sense, there is a division between those who regard the dicta of conscience as supreme, and those who hold them to be subordinate to divine commands. The two are agreed in so far as they regard conscience as having a supernatural origin ; and, in that they both recognize the moral sentiment as innate and suppose human nature to be everywhere the same, they are also, by implication, alike in supposing that the moral sentiment is identical in all men.

But as a matter of fact, the moral sentiment is connected with entirely different rules among different peoples, prescribing monogamy among one people, polygamy among another; demanding faithfulness and chastity on the part of women among one people, encouraging adultery among another, etc.

Common elements in all codes of rules for conduct are the consciousness of authority, whether that of a God, of a ruler or government, or of conscience, the more or less definite sense of power or coercion on the part of this authority, and the representation of public opinion. These elements, combined in different proportions, result in an idea and a feeling of obligation, forming a body of thought and feeling which may be termed pro-ethical, and which, with the mass of mankind, stands in place of the ethical.

"For now let us observe that the ethical sentiment and idea, properly so-called, are independent of the ideas and sentiments above described as derived from external authorities, and coercions, and approbations - religious, political, or social. The true moral consciousness which we name conscience does not refer to those extrinsic results of conduct which take the shape of praise or blame, reward or punishment, externally awarded ; but it refers to the intrinsic results of conduct which in part and by some intellectually perceived, are mainly and by most intuitively felt. The moral 
consciousness proper does not contemplate obligations as artificially imposed by an external power; nor is it chiefly occupied with estimates of the amounts of pleasure and pain which given actions may produce, though these may be clearly or dimly perceived ; but it is chiefly occupied with recognition of, and regard for, those conditions by fulfilment of which happiness is achieved or misery avoided." It may or may not be in harmony with the pro-ethical sentiment ; but in any case it is "vaguely or distinctly recognized as the rightful ruler, responding as it does to consequences which are not artificial and variable, but to consequences which are natural and permanent." With the established supremacy of this ethical sentiment, the feeling of obligation retires into the background, right actions being performed "spontaneously or from liking." " Though, while the moral nature is imperfectly developed, there may often arise conformity to the ethical sentiment under a sense of compulsion by it ; and though, in other cases, non-conformity to it may cause subsequent self-reproach (as instance a remembered lack of gratitude, which may be a source of pain without there being any thought of extrinsic penalty); yet with a moral nature completely balanced, neither of these feelings will arise, because that which is done is done in satisfaction of the appropriate desire."

Where the really ethical sentiment conflicts with the factitious idea and sentiment of obedience to legal authority, the latter may rule at the expense of the former, as, for instance, in the case of a pedler condemned for selling without a license. "His act of selling is morally justifiable, and forbidding him to sell without a license is morally unjustifiable - is an interference with his due liberty which is ethically unwarranted."

The remainder of Part II. of the "Principles of Ethics" is occupied with data cited to show that the amount of internal aggression, of revenge and robbery, is greater among peoples much occupied with external aggression, and that these decrease, while justice, generosity (which Mr. Spencer defines as having a double root, in the philoprogenitive instinct and the relatively modern feeling of sympathy), humanity (including kindness, pity, mercy), filial obedience, and industry, increase as more peaceful habits are reached. A greater veracity is also indirectly the result of this evolution, since a coercive internal structure of society is connected with external enmity, and such coercive structure is unfavorable to 
veracity. Chastity also increases with the social evolution, though it does not necessarily characterize societies of the non-militant type. Its increase is connected with the growth of the higher moral and æsthetic feelings; romantic love plays a predominant part in our art. Intemperance, as causing, indirectly, social evil by a lowering of social efficiency, must, in like manner, decrease with social advancement.

In summing up his inductions, Spencer says: "Though, as shown in my first work, 'Social Statics,' I once espoused the doctrine of the intuitive moralists, . . . yet it has gradually become clear to me that the qualifications required practically obliterate the doctrine as enunciated by them. It has become clear to me that if, among ourselves, the current belief is that a man who robs and does not repent will be eternally damned, while an accepted proverb among the Bilochs is, that 'God will not favor a man who does not steal and rob'; it is impossible to hold that men have in common an innate perception of right and wrong.

"B't now, while we are shown that the moral sense doctrine in its original form is not true, we are also shown that it adumbrates a truth, and a much higher truth. For the facts cited ... unite in proving that the sentiments and ideas current in each society become adjusted to the kinds of activity predominating in it. . . . If the life of internal amity continues unbroken from generation to generation, there must result not only the appropriate code, but the appropriate emotional nature. . . . Men so conditioned will acquire, to the degree needful for complete guidance, that innate conscience which intuitive moralists erroneously suppose to be possessed by mankind at large. There needs but a continuance of absolute peace externally, and a rigorous insistance on non-aggression internally, to insure the moulding of men into a form naturally characterized by all the virtues." Complete exemption from war has already been attained by some few isolated peoples. "May we not reasonably infer that the state reached by these small uncultured tribes may be reached by the great cultured nations, when the life of internal amity shall be unqualified by the life of external enmity?"

Part III. of the "Principles of Ethics" is occupied with practical considerations concerning "The Ethics of Individual Life," under the headings "Activity," "Rest," "Nutrition," "Stimulation," "Culture," "Amusements," " Marriage," " Parenthood." Of 
the general ethical relation of the individual to society, Spencer says : - "Integration being the primary process of evolution, we may expect that the aggregate of conceptions constituting ethics enlarges at the same time that its components acquire heterogeneity, definiteness, and that kind of cohesion which system gives to them. As fulfilling this expectation, we may first note that while drawing within its range of judgment numerous actions of men towards one another which at first were not recognized as right or wrong, it finally takes into its sphere the various divisions of private conduct - those actions of each individual which directly concern himself only, and in but remote ways concern his fellows."

Ethics has been commonly regarded as merely a system of interdicts on certain kinds of acts which men would like to do and of injunctions to perform certain acts which they would like not to do. It says nothing about the great mass of acts constituting normal life, though these have their ethical aspect. The pleasurable has been too often regarded as outside the legitimate sphere of ethical approval, where not directly the rightful subject of ethical disapproval. But pleasure is an accompaniment of vitality, and furthers the vital activities; and if the general happiness is to be the aim of action, then the happiness of each unit is a fit aim ; and there is unquestionably " a division of ethics which yields sanction to all the normal actions of individual life, while it forbids the abnormal ones." There is an altruistic as well as an egoistic justification of the care for self, since the health of descendants and the ability to provide for offspring is directly concerned; and since such care is needful to exclude the risk of becoming a burden to others. And there is a further positive justification of egoism which results from the obligation to expend some effort for others, and to become, as far as possible, a source of social pleasure to others.

It will be seen, from the above analysis, that the chapter appended to Part I. still speaks of an ultimate state of complete adjustment to social life ${ }^{1}$; this chapter was, however, published from the original MS. without alteration. Some passages in Part II. seem to involve the same idea of a possible complete attainment of the ethical end, ${ }^{2}$ but Part III. closes with reference to "an approximately complete adjustment of the nature to the life which has to be led."

1 See, for instance, supra, p. 7 o.

2 See supra, p. 75 . 


\section{JOHN FISKE}

As Herbert Spencer's closest follower, John Fiske deserves to stand next him in order of analysis. Fiske accepts, though evidently with reluctance, what he terms "the terrible theory" of evolution, which establishes the fact of man's consanguinity with dumb beasts. In his book on "The Destiny of Man" (I884), he sets forth his theory of the evolution of society as foreshowing man's final destiny. With regard to the beginnings of psychical development in the course of evolution, he thus expresses himself: "At length there came a wonderful moment; - silent and unnoticed, even as the day of the Lord which cometh like a thief in the night, there arrived that wonderful moment at which psychical changes began to be of more use than physical changes to the brute ancestor of man. Through further ages of ceaseless struggle the profitable variations in this creature occurred oftener and oftener in the brain, and less often in other parts of the organism, until bye and bye the size of his brain had been doubled and its complexity of structure increased a thousandfold, while in other respects his appearance was not so very different from that of his brother apes. ... No fact in nature is fraught with deeper meaning than this two-sided fact of the extreme physical similarity and enormous psychical divergence between man and the group of animals to which he traces his pedigree. It shows that when humanity began to be evolved, an entirely new chapter in the history of the universe was opened. Henceforth the life of the nascent soul came to be first in importance, and the bodily life became subordinated to it. Henceforth it appeared that the process of zoölogical change had come to an end, and a process of psychological change was to take its place. Henceforth along this supreme line there was to be no further evolution of new species through physical variation, but through the accumulation of psychical variations one particular species was to be indefinitely perfected. . . . Henceforth, in short, the dominant aspect of evolution was to be, not the genesis of species, but the progress of civilization.... In the deadly struggle for existence, which has raged throughout countless rons of time, the whole creation has been groaning and travailing together in order to bring 
forth that last consummate specimen of God's handiwork, the Human Soul."

And further, of the genesis of this Human Soul: "With the growth of the higher centres, the capacities of action become so various and indeterminate that definite direction is not given to them until after birth." By the increase of cerebral surface, infancy, which is the period of plasticity, is prolonged, Man becomes teachable, and though inherited tendencies and aptitudes still form the foundations of character, yet the career of the individual is no longer wholly predetermined by the careers of its ancestors, but individual experience comes to count as an enormous factor in modifying the career of mankind from generation to generation.

The psychical development of humanity since its earlier stages has been largely due to the reaction of individuals upon one another in those various relations which we characterize as social.

Foreshadowings of social relations occur in the animal world. Rudimentary moral sentiments are also clearly discernible in the highest members of various mammalian orders and in all but the lowest members of our own order. But in respect of definiteness and permanence, the relations between animals in a state of gregariousness fall far short of the relations between individuals in the rudest human society. The primordial unit of human society is the family, the establishment of which was made necessary and took place through the lengthening of infancy. When childhood had come to extend over a period of ten or a dozen years, a period which would have been doubled where several children were born in succession to the same parents, the relationships between father and mother, brothers and sisters, must have become firmly knit; thus the family came into existence, and the way was opened for the growth of sympathies and ethical feelings. The rudimentary form of the ethical feelings was that of the transient affection of a female bird or mammal for its young. First given a definite direction through the genesis of the primitive human family, the development of altruism has yet scarcely kept pace with the general development of intelligence; the advance of civilized man in justice and kindness has been less marked than his advance in quick intelligence. But the creative energy which has been thus at work through the bygone eternity is not going to become quiescent to-morrow; the psychical 
development of man is destined to go on in the future as it has in the past. And from the "Origin of Man," when thoroughly comprehended, we may catch some glimpses of his destiny.

The earlier condition of things was a state of universal warfare, on account of the limitation of the food-supply. This warfare was checked by the beginnings of industrial civilization, which made it possible for a vastly greater population to live upon a given area, and in many ways favored social compactness. A new basis of political combination was now furnished by territorial continuity and by community of occupation. The supply of food was no longer strictly limited, for it could be indefinitely increased by peaceful industry; and, moreover, in the free exchange of the products of labor, it ceased to be true that one man's interest was opposed to another's. Men did not, it is true, at once recognize this fact, but have done so only gradually. When the clan had grown into the state, and the state into the empire, in which many states were brought together in pacific relations, the recognized sphere of moral obligation became enlarged, until at length it comprehended all mankind. The coalescence of groups of men into larger and larger political aggregates has been the chief work of civilization; and the chief obstacle to such coalescence has been warfare. Great political bodies have arisen in three ways. The first, conquest without incorporation, proved itself suicidal. The second way was conquest with incorporation, but without representation; and this lacking, the government retrograde dand gradually became a despotism. The third method, federation, has been the policy of the English government. The advantage of the habit of self-government has been shown in England's wide conquest and colonization. The federative method of political union, pacific in its very conception, is assuming an unquestionable sway and destined to become universal; the progress of the race will be, as it has been, with the gradual elimination of warfare.

In a race of inferior animals, any maladjustment is quickly removed by natural selection. But in man there is a wide interval between the highest and lowest degree of completeness which are compatible with maintenance of life; in all grades of civilization above the lowest, there are so many kinds of superiorities which severally enable men to survive, notwithstanding accompanying inferiorities, that natural selection cannot, by 
itself, rectify any particular unfitness. Hence, the action of natural selection upon man has long since been essentially diminished through the operation of social conditions. Therefore the wicked flourish. Vice is but slowly eliminated, because mankind has so many other qualities, besides the bad ones, which enable it, in spite of them, to subsist and achieve progress.

The fundamental difference between civilized man and the savage lies in the representative power, the imagination, by which men comprehend pleasure and pain in others. Use and disuse, in place of natural selection, have come to be paramount with man; and though the ethical emotions are still too feeble, they will be more and more strengthened by use, while the manifestation of selfish and hateful feelings will be more and more weakened by disuse. Man is slowly passing from a primitive social state, in which he was little better than a brute, toward an ultimate social state, in which his character shall have become so transformed that nothing of the brute can be detected in it. The "original sin" of theology is the brute inheritance, which is being gradually eliminated; and the message of Christianity: "Blessed are the meek, for they shall inherit the earth" will be realized in the state of universal peace towards which mankind is tending. Strife and Sorrow shall disappear. Peace and Love shall reign supreme. The goal of evolution is the perfecting of man, whereby we see, more than ever, that he is the chief object of divine care, the fruition of that creative energy which is manifested throughout the knowable universe.

We know soul only in connection with body. Yet nothing could be more grossly unscientific than the famous remark of Cabanis that the brain secretes thought as the liver secretes bile; the molecular movements of the brain and the phenomena of thought and feeling are merely concomitants related in some unknown way. It is not even correct to say that thought goes on in the brain. He who regards man as the consummate fruition of creative energy and the chief object of divine care, is almost irresistibly driven to the belief that the soul's career is not completed with the life upon the earth. Difficulties to this theory he will meet; yet the alternative view contains difficulties at least as great; nor is there any problem in the simplest and most exact departments of science which does not speedily lead us to a transcendental problem that we can neither solve nor elude. A 
broad common sense argument has often to be called in, where keen-edged metaphysical analysis has confessed itself baffled. The doctrine of evolution does not allow us to take the atheistic view of the position of man; the Darwinian theory, properly understood, replaces as much teleology as it destroys. In the Titanic events of the development of worlds from the nebular mist and their after-destruction, we may find no signs of purpose, or even of a dramatic tendency; but on the earth we do find distinct indications of a dramatic tendency; though doubtless not of purpose in the limited human sense. Are we to regard the Creator's work as like that of a child, who builds houses out of blocks just for the pleasure of knocking them down again? On such a view the riddle of the universe becomes a riddle without a meaning. "I can see no insuperable difficulty in the notion that at some period in the evolution of humanity this divine spark [the soul] may have acquired sufficient concentration and steadiness to survive the wreck of material forms and endure forever. Such a crowning wonder seems to me no more than the fit climax to a creative work that has been ineffably beautiful and marvellous in all its myriad stages."

Fiske gives some further definition of social evolution in man, in his "Cosmic Philosophy" (1874). He there denies the incompatibility of free-will with causation, saying that "it is the doctrine of lawlessness, and not the causationist doctrine, which is incompatible with liberty and destructive of responsibility." 1

He further postulates heterogeneity of the environment as "the chief proximate determining cause of social progress," and defines such evolution as "a continuous establishment of psychical relations within the community, in conformity to physical and psychical relations arising in the environment, during which both the community and the environment pass from a state of relatively indefinite, incoherent homogeneity to a state of relatively definite, coherent heterogeneity; and during which the constituent units of the community become ever more distinctly individual." 2 "'The progress of a community, as of an organism, is a process of adaptation - the continuous establishment of inner relations in conformity to outer relations. If we contemplate material civilization under its widest aspect, we discover its legitimate aim to be the attainment and maintenance of an equi-

$$
{ }^{1} \text { Vol. II. p. I } 89 . \quad 2 \text { Ibid. p. 223, } 224 .
$$


librium between the wants of men and the outward means of satisfying them. And while approaching this goal, society is ever acquiring in its economic structure both greater heterogeneity and greater specialization. It is not only that agriculture, manufactures, commerce, legislation, the acts of the ruler, the judge, and the physician, have, since ancient times, grown immeasurably multiform, both in their processes and in their appliances; but it is also that this specialization has resulted in the greatly increased ability of society to adapt itself to the emergencies by which it is now beset." 1 Religion, too, is adjustment; form after form has been outgrown and perished, yet the life of Christianity, incorporated in ever higher forms, is continually renewed. 'The omission of the moral feeling, as a factor, from Comte's interpretation of the progress of society, is a fatal defect, since moral and social progress depend more on feelings than on ideas. As Wallace shows, tribes which combined for mutual help and protection, restrained appetite by foresight, and felt sympathy, would have an advantage in the struggle for existence.

"As surely as the astronomer can predict the future state of the heavens, the sociologist can foresee that the process of adaptation must go on until, in a remote future, it comes to an end in proximate equilibrium. The increasing interdependence of human interests must eventually go far to realize the dream of the philosophic poet, of a Parliament of Man, a Federation of the World. "'When the kindly earth shall slumber, lapt in universal law,' and when the desires of each individual shall be in proximate equilibrium with the means of satisfying them and with the simultaneous desires of all surrounding individuals." 2

\section{H. ROLPH}

“Biological Problems" (“Biologische Probleme," r884)

For what purpose are we in the world? asks the philosopher, and lays, with this question, the foundation for later errors. In the effort to rescue from destruction the theory of a creative intelligence, teleology has adapted itself to many forms of scientific theory, not excepting that of evolution. It reads into evo-

1 Vol. II. p. 212.

2 Ibid. pp. 227, 228. 
lution progress towards what is, in one way or another, assumed to be an end. But we really know, in the universe, nothing but continuity, eternal change according to natural law, and so only causa efficientes, never cause finales; and organic development as well as processes in inorganic nature are to be explained in this manner. The assumption that the result of a process is an end towards which the process was directed is unwarranted. The question of science is not: Wherefore is any creature in the world? but: What is he? What is his actual aim, that is, his endeavor?

In the answer to this question, all philosophical schools have something in common. Happiness, in one form or another, is acknowledged to be the "end" of life in this sense. A follower of the utilitarian school may define happiness as the "sublime feeling that one has taken part in the continuous improvement of humanity, and the increase of human happiness," but his words are less a definition of the concept than a designation of the way in which happiness is to be arrived at. The "sublime feeling" can be represented only as a feeling of happiness, of joy. The religious theory, too, which represents the joys of religion on earth and in heaven, as compensating for the evils of this life, makes happiness the end of life, though in a different manner. Spencer is right in declaring that happiness, however it may be defined, always means, in the end, a greater amount of pleasure than of pain. At this point, however, the harmony of the schools ceases. The question as to the method by which this surplus of pleasure is to be obtained is answered in different ways. All say, indeed, by seeking good and avoiding evil. But opinion is divided as to what is good and what is evil.

Rolph here introduces a long criticism of the different schools. Against utilitarianism he urges that, in so far as it makes the happiness of the greatest number its principle, it asserts the right of the majority over a minority, and so advocates, by implication, an absolute subjection to authority.

Our whole moral education has for its aim to give the young as high a conception as possible of the happiness which springs from virtue and, on the other hand, to decry the pleasure which may result from forbidden acts. We seek, in this manner, to diminish the inward struggle and bring about the right result. He who has grown up under good influences escapes many temptations to which a man of less moral education falls a prey. According to Wallock, 
who makes the degree of inner struggle the measure of virtue, the man of better education in this case, the more moral man, must have less merit than the less moral man. Wallock thus founders on the rock which Kant so skilfully avoids; according to the former, the man whose lusts have been mastered by education could never equal the man of evil instincts, and the chastity of a Magdalen must be regarded as more moral than that of a pure woman.

Spencer's theory, that the conduct of the higher animals is better adjusted to ends than that of lower species, is erroneous; the lower animals are exactly as well organized for the ends of their existence as are the higher animals for theirs; the tapeworm is relatively just as perfect as the human being, in comparison with whom he possesses many superior qualities. The common judgment that the human being is superior does not accord with the real adjustment of things, but with our human conception of the ideal end of organization, our anthropocentric idea of the aim of life. We foolishly believe that the tapeworm and every other animal has the same end as the human being, and rank the animals according to this principle, instead of tracing the different genealogical branches to a like height and then comparing them. Not the fitness for ends, but the kind and multiplicity of the ends for which there is fitness, determine our judgment; and the ends by which we judge are those of our own life. We judge subjectively and absolutely instead of objectively and relatively. We are ever unconsciously influenced by the conception that nature, in creating the tapeworm, merely made a false step and a step backwards in her way towards the creation of man. That all animals are adapted, some in a greater, some in a less degree, to the ends of their existence, is proved by the simple fact of their existence, that is, of their survival in the struggle for existence; but which are in a higher, and which are in a less degree so adapted, is, in the individual instance, extremely difficult to determine. In any attempt at such an estimate, we must meet with peculiar difficulties, resulting from the fact that we judge of the adaptation to ends with less certainty the further from us any animal is in its organization. A comparison such as Spencer institutes is possible only with respect to like functions of similar organs in closely related forms.

The assertion that increase of ability for self-preservation leads to better care for the young, and makes of such care a duty, is 
likewise erroneous. For, up to the highly organized class of the crustacea, we have no example of care for the young. In the struggle for existence, the species which survive must be such as not only are in themselves best fitted for survival, but as also bring forth best fitted progeny. Nor has Spencer made clear on what ground natural process is to be regarded as identical with duty. In truth he has succeeded in showing only that care for the young is widespread in the animal kingdom, from which fact naturally follows that it is a quality which tends to the preservation of species.

It cannot be conceded that such a perfection as Spencer pictures, where each shall fulfil all the functions of his own life in the most perfect and complete manner without interfering with a like freedom in others, is possible. The assertion involves the extension to all living beings of that ideal principle of equal claims which Spencer repudiates with regard to man, - showing that not all men are capable of a like degree of happiness and that individuals desire, moreover, pleasure differing in quality. Furthermore, a world of beings which, like the animals and many plants, can support life only by means of organic material, must, in order to exist, destroy organic life, either animal or vegetable. The theory does not even hold with regard to individuals of the same species; Spencer himself acknowledges the truth of the principles of Malthus and of Darwin, according to which, even with the lowest rate of increase, a struggle of competition must soon arise between individuals of the same species.

Nor does Spencer's proof of the fundamental character of altruism hold, on investigation. He demonstrates that through the animal species up to man, there is less and less self-sacrifice of the mother animal in giving birth to offspring. But this physical sacrifice is not altruism; altruism lies in conscious care for the young after birth, and this is not lessened, but increased, the higher we ascend.

That morality is but greater adjustment of acts to ends cannot be admitted. If, in ordinary speech, the word good refers to greatest adjustment to ends, whatever the ends may be, that is no proof that it must have the same significance in Ethics. A good shot may be a good one in that it hits the mark; but what if it kill a man? The acts of criminals may be as well adjusted to their ends and as easy to predict as those of a good man. Spencer's theory would lead, consistently carried out, to the principle 
that the means justify the end, an assertion that is even more dangerous than its opposite. The fact is, that in Ethics it is the nature of the end which is of importance.

Spencer endeavors to show that only normal exercise of function is favorable to life, and so moral; - that excess and deprivation are both injurious. It is not true, however, that excess is always injurious; within certain bounds it is made up for by reserves in the animal organism. Or, if Spencer should answer to this objection, that his "normal" is not to be represented by a sharp line, difficult to keep to, but by a broad road within which excess is safe, such a representation would both burden his theory with two dividing-lines, and moreover would not save it. For he has not deemed it necessary to treat the concept "normal" to an exact definition, and we find him using it in his later deductions in an entirely new sense - not as equilibrium between capacity of function and its exercise, but in the ideal significance of a harmony between the claims of the individual on the one side, and those of the environment on the other. This normal is nowhere actually to be found and cannot, from the nature of things, be arrived at. By addition of this significance, the word normal becomes indefinite in meaning, and is used, now in one sense, now in the other. Normal exercise of function has, however, nothing to do with the claims of the environment, which generally demands, indeed, a deviation from the normal.

Nor is Spencer's analysis of the beginning of the process of food-seizure, adduced in support of the theory that happiness and morality are commensurable, confirmed by facts. According to this theory, the process of food-taking begins with the contact of animal and food, in which act the commencement of diffusion of food in the body of the animal causes a pleasure which leads to the seizure of its prey and the further act of devouring it. The theory might hold of the lowest organisms, but could not be true of any animal furnished with an impenetrable shell or skin. Nor would the seizure follow with sufficient promptness if it were left to the action of the pleasure caused by diffusion. Moreover, we should expect to find, according to this theory, a much more general and finer development of the organ of taste among the animals, - to find it as a special organ on the lowest planes of animal life; it is, on the contrary, the latest of the special senses to develop. It is the reaction on the sense of touch, the lowest 
and most general of the special senses, which causes the seizure of nourishment. We must, therefore, deny that pleasure is the motive to the seizure of food, and so, too, reject the conclusion that it is the motive to every other act.

Besides arguing that normal function brings pleasure, Spencer has attempted to prove that all pleasure has its spring in normal function, and is therefore moral. Could he succeed in so doing, hedonism would be proved. For since all schools agree in regarding happiness as the end of life, and since all these, in common, acknowledge happiness to be an excess of pleasure over pain, enjoyment might be regarded as the absolute guide. But if, as Spencer acknowledges, pleasure and morality are only in a perfectly adapted society commensurate, then in only such a society can pleasure be the criterion; and since we do not live in a perfectly adapted society, the theory is not applicable to us, and if practicably applied would be fatal to society.

Against Spencer's theory of the final spontaneity of morality, many objections may be urged, among others especially the one that such a morality ceases to be morality at all, virtue being possible, as Kant has demonstrated, only where a certain conquest of desire is achieved. Such a morality is, moreover, unattainable, an extravagant fancy.

\section{The Problem of Food-taking}

Rolph thinks Spencer's theory awakes the conjecture that it was not first arrived at through investigation, but rests upon a preconceived opinion, as do to a greater or less extent all theories on this subject. It seems as if the author had first attached himself to that theory which best accorded with his scientific bias, and then tried whether this theory might be proved or supported by facts of biology and psychology. One might surmise, from the very skilful, but often too artificial argument, that the author pursued the following train of thought. Pleasure, and indeed the greatest possible pleasure, is the end of endeavor in the organic world, that is, the psychical cause of endeavor. May it not also be the physical cause?

Rolph answers this question with a denial, and endeavors to show that the taking of food has its cause in the insatiability of all organic substance. The theory of Spontaneous Generation 
contains nothing impossible or improbable; is, on the contrary, a necessary logical assumption not to be disproved by the mere result of experiment under conditions of the laboratory. It is easy to imagine that organic elements, which are to be found in great quantities in inorganic nature, may come together by chance, or rather in the natural order of things, to the formation of protoplasm.

The movement of these masses of protoplasm seems, at first glance, to set the law of gravitation at defiance, but we may answer that an ascending balloon might seem, to an uninstructed observer, to do the same, although its movement is merely the natural result of that force; it is not necessary, therefore, to assume a free inner motive, the soul, as the cause of the one motion or the other. The first assimilation of food has its beginning in the process of endosmose and exosmose, in which the protoplasm, as in general the denser fluid, increases in volume, taking up more than it gives out; the process occurring, in detail, according to the special relations of attraction in the parts. The organism always takes up the greatest amount possible under the circumstances, exactly as, in the inorganic world, water takes up the greatest amount possible of salt or any other soluble substance; the growth of a crystal, and the oxidation of iron are illustrations of the same principle. Of the limit of this capacity to take up new matter into the organism we know nothing; all recent experiments go to show that the organism is capable, under propitious circumstances, of an enormous receptivity, such as, under natural conditions, it never reaches. The lower animals feed continually, and their whole lives are passed in this employment. In plants the tendency is seen still more clearly. Experiments with electric, violet, and ultra-violet light show an enormous growth in plants exposed to its action. But this can be only an indirect growth, namely, the exorbitant acceleration of organic change and assimilation. This fact is proved by experiments turning on increase of warmth in soil; from which is seen to result an unusual development of that part of the plant to which growth is especially directed at the time. When the warmth of an incubator is increased, the animal organ especially engaged in development at the time is affected in like manner. So that we may assume that the organism is capable of responding to every demand that nature makes upon it under normal conditions; and since the 
greatest possible assimilation under the existing conditions is thus removed from the control of the creature, the latter appears practically insatiable. This insatiability must appear to the observer an inner impulse of the organism, an effort towards increase of nourishment. It may be called mechanical hunger in distinction from psychical hunger, of which it is the basis. It is not necessary to take into consideration, in the question as to the degree of assimilation possible, the amount of excretion of substance by the organism; we must, on the contrary, assert that this is dependent upon the amount of assimilation. 'The measure of growth depends, theréfore, on the degree of assimilation of new material. This degree, however, like the degree to which the matter may be dissolved in a liquid in the case of inorganic matter, is especially affected by light and warmth. The creature which comes into existence in the sun will experience a decrease of organic change when placed in the shade; and the creature which comes into existence in the shade will experience an increase of such change under the influence of the sun, a decrease again with a return to the shade. This decrease means hunger, - harm. Experiments with zoöspores throw an interesting light upon these relations. They show that the zoöspores, although suited to very different degrees of light, all shun darkness. Although when in the light they soon come to rest, divide, and copulate, they remain, in the darkness, in a state of continual unrest and motion. They grow so thin "that they almost excite pity" (Strassburger), and finally perish of hunger. Only such zoöspores as are distinguished by sex and copulate come to rest, or those of such sorts as prey upon others. It is easy to perceive that the unrest of the zoöspores in the darkness springs from lack of nourishment, from hunger; they seek feverishly for the light, without which assimilation follows with insufficient energy to satisfy need and render life possible. In darkness, copulation alone can do this; copulation takes, then, the place of normal nourishment.

Or let us consider the case of an organism which has originated in the shade. Heat, as we know, increases chemical change, in inorganic as well as organic matter; it hastens the disintegration of certain compounds, and alone renders it possible in many cases. In general, we may assert that increase of temperature within certain limits increases assimilation; that is, capacity to assimilate. Therefore, if an animal is placed in the sun, its 
capacity, that is, its need, to assimilate is increased, although assimilation is much more energetic than before. Need to assimilate or hunger is, therefore, dependent upon the supply of food, although, doubtless, also on other conditions, especially those of light and temperature. If this is true, the hunger of a simple organism that assimilates energetically must be more intense than that of one which assimilates slowly, in spite of the consumption of an enormous quantity of food in the case of the former. Botanists know (Sachs, "Lehrbuch der Botanik," p. 613) "that growth may be so hastened by too high a temperature that assimilation (especially under scanty light) does not suffice to provide the necessary material for it. The transpiration of the leaves may be so increased that the roots cannot repair the loss. And on the other hand, a too low temperature of the soil may so diminish the action of the roots that even a small loss by transpiration cannot be repaired."

At what stage of organization psychical hunger is added to mechanical hunger, or whether it may be identified with it, we cannot say. In any case, the former appears exceedingly early, for excitations of hunger may be observed in creatures very low in the scale of being. Certainly hunger is never absent where there is movement.

Hunger, a sense of pain, is, therefore, the first impulse to action. ${ }^{1}$

With a like effort in the attempt to obtain food, that organism will be best nourished which commands the best means of obtaining and preparing its food, - the best apparatus for the seizure and grinding of food, and the best salivary gland. And finally, greater surface of skin, of lungs, of gills, or of intestines, causes greater capacity for assimilation, and since this surface is increased by cell-division or propagation, the capacity of the organism for assimilation grows with its capacity of propagation. ${ }^{2}$ Protoplasm is never entirely homogeneous, and we must suppose some difference even in the beginning; such difference is, indeed, fundamental through the very composition of protoplasm from

1 For further arguments in support of this assertion, see "Biologische Probleme," pp. 64-66, etc.

${ }^{2}$ Und da diese Fläche durch Zelltheilung oder Fortpflanzung vergrössert wird, so wächst die Aufnahmefähigkeit des Organismus mit der Fortpflanzungsfähigkeit desselben (p. 67). 
the four fundamental elements, and this or that other element. These different elements must be held together by forces of attraction, and the direction of these forces must have some common centre represented by some differentiation of the protoplasm, whether as clearer spot, or as nucleus. This spontaneously generated organism, neither animal nor plant, is nourished, as we have seen, by diffusion, by the transformation of inorganic into organic substance. The lowest organisms possess no definite organs for taking food; they manifest, however, phenomena of movement which are exactly like those of the animal organism, for they appear unconditioned and hence voluntary. Locomotion is, in the lowest animal forms, the only means of obtaining nourishment. The amœba surrounds and takes in whatever is by chance met with. Animals a little higher in the scale swim about and seek their food; or, remaining in one place, they cause, by means of cilia, a movement of the water towards a certain part of the body, a sort of mouth where the protoplasm is open and can take up the prey in the same manner as does the amoba. Ascending the scale of life, we find more and more complicated apparatus for the seizure of food, for its preparation and digestion, and the beginning of a nervous system, first as the differentiation of certain muscle-cells, then in connection with a special sense, that of hearing. If we assume any pleasure to be connected with the earliest acts of assimilation, it must be that of the satisfaction of a want, the stilling of pain in the form of hunger.

\section{The Problen of Perfectibility}

In the earliest forms of propagation, the younger organism is a true copy of that from which it springs, the trifling differences being due, as Schmankewicz has shown, to outer influences. The differences of male, female, worker, and soldier are due to such outer influences. The differences in the younger organism, where propagation takes place through copulation, may be explained by the mixture of types, through which, by action and reaction, some qualities are intensified, while some others become latent or are entirely destroyed. To these mutual influences are to be added such as come from without, especially those of warmth, and of quantity and quality of food. Under too great an increase in temperature, the young organism may even be 
destroyed, the process of assimilation not being able to keep pace with it. Those variations which have led to the development of existing forms, that is, which were favorable to life, are chiefly such as could be brought about by relative or absolute increase of assimilation. This is true of mental, as well as of physical, qualities.

It is a fact established without doubt, that the most common and most widely distributed species show the greatest variability, and that those species, on the contrary, which are now rare, although they were, perhaps, at earlier periods, the most common and extremely variable, vary, at the present date, the least of all. Following Darwin, one generally draws the conclusion that the severity of the struggle for existence favors the formation of varieties. For, it is said, the most common species fight the severest battle with one another, while the scanty representatives of rarer species come the least into competition and continue unchanged. But this theory is, in two ways, erroneous. In the first place, no attention is paid to the fact that a rare species may be exposed to a severe struggle against another species for the same nourishment, while a common species may, on the other hand, be exposed to no such struggle, and, supporting life from a generous supply of food, be subjected to but slight pressure. The conception of the Darwinians means nothing more or less than that the individuals of a species vary the more, the less favorable the conditions of nourishment; and this cannot be conceded. Again, the fact is to be taken into consideration, that the species at present common must have passed through a favorable period in which food was so plentiful that it not only afforded an abundance to individuals past the dangers of infancy and youth, but allowed, in addition, the existence of an everincreasing number of individuals. And it is this period of increase, of abundance, not a period of struggle, which has developed the variations we now have before our eyes. In the same manner one must conclude, with regard to the rarer species, that the formerly existing numerous varieties were destroyed during the period of decline, that is, of overpowering pressure. We have abundant proof of this in the fact that domesticated species, which are carefully tended and fed, and so wholly withdrawn from the struggle for existence, vary enormously, and produce the most wonderful monstrosities.

To what direct causes the appearance of a variety is due, is a 
question as yet unanswered. But Weismann's investigations have shown us that climate plays a large part in their development. Embryology teaches us, moreover, that the development of the young organism does not take place with the same uniformity in all organs, but that, on the contrary, in one period one organ, in another, another, undergoes a more rapid growth, which may be influenced by variations in food or temperature. Through such variations the development of monstrosities is explained. We know that influences of nourishment are operative in the development of the larvæ of bees to workers or to queens, and we can easily conceive that other organs besides the sexual are subject to these influences. The field in which such influences may be operative is, indeed, boundless.

All these considerations lead us to the conclusion that variability in general, but especially that variability resulting in a so-called improvement of the varieties producing it, is an accompaniment of prosperous conditions. This is a conclusion not yet reached in zoölogy, although botanists long ago recognized, in abundance of food, the most essential condition for the develop-
ment of variations.

Darwinism fails to account for any need of nourishment beyond that necessary for the maintenance of the status quo of life. According to Darwin, the animal can acquire only sufficient for the repair of loss. The struggle for existence is, therefore, according to him, a struggle of self-defence, and its results could be, at the best, only the maintenance of species in their present position or, in a less favorable case, their decline, and finally their destruction. But this view is wholly false. The animal acquires not only enough to repair loss, but much more. How could the first amoba have propagated itself, if it consumed no more than it needed for mere self-maintenance, and how could evolution have taken place? We have seen that, even in the inorganic world, there is not an equality of loss and repair, but that, in osmose, the denser fluid takes up more than it gives, while the fluid that is less dense loses more than it receives, and the mutual exchange reaches the maximum possible under the existing circumstances. It is this characteristic which renders the involuntary and forced tendency of the organism to satiation independent of the amount of waste; this mechanical hunger is the spring of the insatiability of organisms, and explains to us 
their increase in number, the process of increasing perfection, and individual development. Without it, an eternity would not have sufficed for evolution; we should still have only a world of primitive amœbæ.

This theory of development is, then, the opposite of that ordinarily assumed. The latter asserts that increase of growth demands increase of nourishment, whereas this asserts the fact that increase of nourishment determines growth. The struggle for existence is not a struggle for the mere necessaries to maintain life, but a struggle for increase of acquisition, increase of life; it is not a struggle of defence, but an attack which only under certain circumstances becomes a defence. The rule with which we advise our friends is, "Forward! strive to better yourself!" though we may endeavor, in hypocritical spirit, to persuade to contentment those who come into competition with our interests.

The chief points, therefore, in which this theory differs from that of Darwin, are as follows:-

"The struggle for existence is really a struggle for increase of nourishment, of life; and independent of the supply of the moment, it goes on at all times, hence even in a state of abundance.

"Limitation of supply by competition leads to fixation of the species and, in the end, to its decrease and disappearance.

"Sickness, climate, and direct enemies are the destructive agencies, and must secure more propitious conditions for survivors, the stronger their effect.

"Only under conditions of prosperity can the survivors propagate largely, and perfect themselves, separating into varieties and species.

"The increase and differentiation of the organic world shows us that conditions of prosperity have been the rule, those of want the exception."

Rolph's extremely interesting chapter on Propagation traces the sexual instinct to the "mechanical hunger." The earliest example which may be adduced in support of this theory is that of the zoöspores which, by copulation, sustain life for a time under the unfavorable conditions of darkness, the thinner male representing, as does also the spermatozoön, the seeking individual suffering from want, the female representing a means of sustenance. The sex of the young organism is in like manner referred by Rolph to conditions of nourishment during development. We now come to the chapter on 


\section{Animal or Natural Ethics}

The existence of morality presupposes the existence of commandments of duty, and of an authority. Among animals, as well as among human beings, we find recognized authority and can discern the principles of action which constitute the duty of any particular animal. Authority among the lower animals is based on might, which is, indeed, the universal source of authority, without which no authority can exist. Personal authority is but a particular form of the authority of circumstances; and to this authority every creature must be subject. It consists of two factors: the outer authority of the environment, and the inner authority of impulse. Duty is obedience to authority. The duty of the organism consists in action that corresponds to these two authorities, following the direction given as the resultant of the mixture of the two components. That is, that manner of life is right or moral which renders the life of the organism the fullest possible under the circumstances. The unreasoning organism is unconsciously drawn to seek this maximum, while the reasoning being seeks it through reflection. The impulse to happiness includes, therefore, for the reasoning being, the impulse to morality; or, ideally expressed, the relative morality equals the relative happiness; morality and happiness are the same thing.

An authority without the means of enforcing itself is a selfcontradiction. The means by which nature makes its authority felt is organic excitation. In proportion to its strength, an excitation produces sensation, in case it is not too weak to make itself felt at all. Every excitation has a definite significance and may come from without or within. Pleasant excitations are always, primarily, the feeling of the stilling of pain, though there are pains, such as, for instance, that of a wound, the toothache, headache, an aching corn, which have no corresponding feeling of pleasure. Nor is pleasure the only offspring of pain, since pain may bring forth pain. Pleasure depends, in its character as pleasure as well as in its strength, on the feeling preceding it in the organism; that is, its quality is the result, not of the degree of organic excitation, but of the order of succession of the feelings. For this reason, the same feeling which brings pleasure to one individual may bring pain to another. 
This whole deduction is at variance with Spencer's theory that pleasurable excitations are favorable to life, painful ones injurious. And since observation is in direct opposition to his assertion, his followers have been obliged to supplement it with the conception that pain is gradually weeded out by natural selection. On the contrary, we need pain at every instant, since it is the impulse to action; persistence in the same condition through lack of excitation, must result in death; pleasure can never originate action, it can only cause persistence in action already begun. The fact has been too often overlooked, that the motive and the "end" of an action are by no means the same. The motive is pain, and the end is either simply the stilling of pain or an additional positive pleasure. There are, therefore, many actions which are directed to no concrete positive end, but only to the purely negative end of escape from pain without consideration of the further results; a striking example of such action is suicide. Even where positive pleasure appears as an end, it is never in itself the motive to action. In order to become a motive, it must first be transformed into an excitation, into desire for pleasure; and this desire for a definite or an indefinite pleasure is, in its essence, pain - the pain of the absence of pleasure. ${ }^{1}$

The pleasure sought may be one already known through experience, or it may be one not yet experienced. In the latter case, the desire is awakened by instruction or reflection, or else induced by instinct. But the motive is always the same, namely, a seeking after pleasure, hence a feeling of pain.

This view furnishes us with a psychical explanation of the association of ideas, the mysterious so-called transferrence of the feeling of pleasure from the end to the means. Pleasure begins as soon as we have begun the action which will bring us with certainty to the end desired, and this pleasure may reach such a degree of strength at some point of the process as to conquer the desire for the real end, hem further action, and dispose to continuance at the point reached. The action of the miser may be thus explained.

The objection that, if pain is the motive, the organism is nothing but a bundle of pains, is by no means valid, for it overlooks the fact that pain remains, in an immense number of cases, below

1 Und diese Begierde ... ist ihrem innersten Kerne nach, eine Unlust, ein Leid: das Leid des Entbehrens des Genusses (p. 176). 
the threshold of consciousness; as in the case of organic action, where it is rhythmic. The same is true of reflex action. To any close observer of the lower organisms, it seems most probable that these possess consciousness (see Wundt, "Physiologische Psychologie "), nor is it by any means proved that the plants do not possess it likewise. It is certainly remarkable that exactly the lowest plants, which stand so near the animals in the phenomena of their life, exhibit movements closely resembling those of animals. And it is, moreover, a fact that automatic and reflex actions increase with the degree of organization, and are most numerous in human beings. With increased exercise, one chain of movements after the other is withdrawn from consciousness; and through this removal from consciousness action gains in certainty and rapidity, and in energy also, since the part of the force which was before lost in inducing consciousness is now released. Such removal from consciousness is, therefore, a benefit to the organism, as an adaptation to the increased demands of circumstances. Movements which thus become unconscious are each and every one of them movements which have but one definite end and an interruption of which either kills or seriously injures the organism, or at least brings disorder into its life for the time being. An easily excited consciousness would be an exceeding danger to the animal. Conscious action is directed to the attainment of variable ends by means which are also variable. It cannot, therefore, astonish us that consciousness disappeared in plants after the loss of free motion.

By the regular exercise of certain actions or of trains of thought, either through necessity or by habit certain tracks are worn or taken possession of, so that the whole process, from the excitation to the action resulting upon it, takes place with such rapidity that we are no longer conscious of its separate phases and so of the growth of the result.

The first commandment of animal ethics is, therefore: "Flee pain "; and closely associated with it is a second commandment furnished by the insatiability of the organism, the impulse to happiness, to increase of life. The principle of Spencer's ethics, according to which normal living is right living, would result in stagnation. Right living consists, on the contrary, in pregress, in passing beyond the normal. No educator would hesitate for an instant to pronounce the continuance of a pupil upon a present 
normal immoral, and to oppose it with all his powers. From day to day the developing organism advances the line of its normal activity. And as in the individual, so in the species: every new generation exceeds in a certain measure the activity of the last. Not rest, but motion, constitutes the normal; not rest, but motion, is happiness, and the spring of happiness. Not that being which has no wants, but that which develops and satisfies the greatest possible number of wants, is the happiest, leads the most pleasurable life. When we apply these principles to the animals, we reach the conception that all such as lead a solitary life live morally when they endeavor, with all their powers, to better their own condition. That they injure plants and other animals in so doing need not trouble us, since they are forced to do so in order to maintain life. The principle on which animal life is based is hence preëminently egoistic and acknowledges no other right than that of might. Spencer, in speaking of altruism on the lowest plane of animal life, makes the fundamental and quite fatal mistake that he does not first sharply and distinctly define egoism. Had he done this, he would certainly have found that, for egoism, as for altruism, the criterion of consciousness, of will, is indispensable. In his definition of altruism as consisting in those acts which in any way benefit others, he does nothing less than get rid of egoism altogether, since there are no acts which do not, in the end, benefit others than the performer. The greater number of the young brought forth by lowest organisms serve as food for other species, and hence the parent animal, in bringing forth such numbers, favors these species rather than her own flesh and blood. The fly would act altruistically, according to Spencer's definition, in being caught in the net of the spider.

A creature which gets its food, as do many of the lower species, without exertion of its own, does not act egoistically, nor does the animal which, in the natural course of its growth, brings forth young by spontaneous division; but that animal may do so which acquires its food by means of any voluntary actions, however insignificant, or which voluntarily protects and cares for its young; and such voluntary action increases rather than decreases with greater organization. Real egoism begins with the voluntary acquisition of food, a process continued in the forced excretion of the young. But since this action benefits the second genera- 
tion, we may regard it as the connecting link between egoism and altruism. It is not purely altruistic; altruism proper begins with the nourishment and care of the young. And to what degree we have a right to consider even this as really altruistic can be determined only by further investigation. The emptying of the milkglands is combined with pleasure; it may therefore be regarded as primarily egoistic, and furnishes us with a further example of the development of altruism from egoism. Altruism increases, not only with higher organization, but also with a higher development of social life.

The beginnings of society are to be found in the family life of animals; the most primitive form of this is the temporary, voluntary association of male and female among the higher species; that is, the anthropoids and vertebrates. On this merely temporary association follows, as a higher stage, the lasting family union, which exists among comparatively few animals. The so-called "states" of the animals are, in their most typical instances, nothing but families living in a condition of polyandry.

Closer association gives opportunity for a misuse of the powers and aims of the individual, before impossible. Examples of this are the theft of honey from one hive of bees by the workers of another, and the carrying off of the young by wasps and ants, as also the slaughter of the drones. Since the robber of yesterday may be the robbed of to-day, such acts are harmful to individuals, to the family, and to the species. They diminish the degree of life, and are opposed to animal ethics. The association of male and female, since only temporary, affords little opportunity for immorality, and the duties of parents to their young are, for the most part, faithfully performed. In striking contrast to the natural morality of wild animals is the immorality of clomestic animals, which give themselves up to every sort of vice when not restrained. The moral conditions of any associated animals not under control, whether in zoölogical gardens, in the town, or in the country, is, in fact, monstrous. Immorality increases with the closer association of animals. The closer the contact and the looser the bond between the individuals of a species, the greater the opportunity for immorality, and the worse the resulting habits. The careless life of plessure led by animals that live in solitude, is interfered with, in a state of association, by certain cluties. How far the performance of such duties springs from a concealed 
pleasure, or from instinct, or follows upon the command of authority, we, unfortunately, cannot say. The limitation of gratification signifies, however, decrease of pleasure. The needs of different animals differ according to differing organization; higher organization means greater and more complicated desire, the satisfaction of which is often impossible, but it means also the attainment of capacity for greater pleasure in form and intensity. Hence even the partly attained pleasure of the higher animals is, in intensity as well as in fulness, much greater than the completely attained pleasure of the lower animals.

\section{Humane Ethics}

Rolph contests Lubbock's theory that the early type of man lived in a condition of sexual promiscuity, and gives as a reason for his opinion the "strict" monogamy of those animals which are most closely related to man. The customs of such animals should have as much weight, as evidence, as those of any of the present tribes of savages, since these tribes are as old as civilized races, and their customs cannot, therefore, be unhesitatingly regarded as primary ones.

The real needs of men, those the gratification of which is indispensable to the maintenance of life, are few. By experience, and by experience alone, can man learn that present gratification may mean future pain, and so be withheld from such gratification; for only disinclination to one form of pleasure can induce inclination to another form. In the simplicity of primitive social conditions and the uniform character of action under such conditions, rules of experience must have been early formed, which, inherited by succeeding generations, became the rules of conduct. $^{1}$ With the development of authority, - first the paternal authority, then that of the family, and finally that of the elders of the tribe, - the possibility of establishing rules of action, and inducing morality, increased. The very nomination of elders, to which primitive authority may almost everywhere be traced, shows how great was the respect for experience.

1 Bei der Binfachheit der primitiven socialen Verhältnisse und der Einförmigkeit der Lebenstätigkeit müssen sich bald Erfahrungsregeln gebildet haben, die nun durch Vererbung übertragen und damit zu Lebensregeln vertieft wurden (p. 195). 
Spencer remarks, in one place in his "Data of Ethics," that human beings first banded themselves together because they found it more advantageous to coöperate. This is only conditionally true. Before human beings could find association advantageous, they must have accumulated experience of it. That they did this by their own inclination is certainly not true. Wherever we find two solitary beings coming together by chance, enmity is the first feeling excited, and war the result. Everything new, everything unknown, causes aversion, and this aversion must lead to misunderstandings and war the more surely because each of the opponents feels himself disturbed in his supposed right to limitless possession. Human beings must first have warred with one another before they came to the knowledge, not that social life, that is, mutual forbearance, was more advantageous, but that more closely associated individuals gained in power against a common enemy by their association. Man did not choose society, but was, on the contrary, forced into it, for good or evil, through increase of his kind. The discovery of the first tools must have had an immense influence upon increase in the number of individuals, which was before limited by struggle with wild animals, and by the restriction of food to fruit. We must conclude that, under such circumstances, a lasting contract was inevitable, and that, with it, vices suddenly appeared which had before existed only potentially, as predisposition. War or theft must have followed the mutual limitation of rights, but against this disturbance of the peace other members of the society must have banded themselves together. The weaker must soon have been driven from their possessions by the stronger, and must then have united for the purpose of obtaining, by association, what they were unable to acquire otherwise. The growing children settled near their parents, with whom they entered into a family union, in which the father represented the authority. In this arrangement is the germ of civil order, - of the ideas of right and wrong. Inner conflicts can at first scarcely have occurred, since the possessions of the family were in common, and a conception of theft between members of the family could not exist. Furthermore, there was scarcely anything worth stealing, for the implements must have been so primitive that each individual could easily manufacture them for himself. Only women could have been, in the beginning, an object of conflict, and for avoidance of this conflict laws 
and customs arose, which are, to our modern minds, inexplicable. Real polyandry may doubtless be explained by the idea of the common right of possession among brothers; it has, in most cases, this significance. It is extended, indeed, later, to more distant relatives, and gains finally a solemn significance, the presentation of the wife, or of one of a number of wives, being a symbol of fraternity by which the guest is honored.

With the manufacture of better tools and weapons, temptation to theft was increased, and authority began to be directed inwards to the society itself, since inner conflict injured the family in its contests with outer enemies. What is true of the family in this connection, is true of the tribe. A joint egoism of the society as a whole must thus have been developed, as soon as the first step of association was taken. The earliest law is always negative, a prohibition, not a positive command.

War had its good as well as its evil side, since it made different peoples acquainted and gave them knowledge of each other's tools, weapons, and customs. War was, at first, the only means by which peoples learned to know each other. The establishment of peace led to the union of different peoples, or at least to peaceful intercourse by exchange, which united the tribes by common interests, corrected ideas, and tempered customs.

The egoistic impulses, the feeling of unconditional right to possession, are the impulses with which the child is born; morality is not inborn, but must be developed by education, as is shown by the example of such children as are neglected in education. $^{1}$ Or, if there is anything innate in the direction of morality, it is merely a certain inherited predisposition acquired in the course of the thousands of years of social intercourse, which makes it easier for us to respond to education. If this is not so, and the impulse to morality is innate, why has it required so many centuries for man to make the simple connection of ideas, that what is just towards one man is just towards another. In this feeling of justice, acquired through an extension of egoism, is the root of all virtue. It is the spring of sympathy or benevolence, which can be developed only where the feeling of the like rights of others is strong.

But an unconsidered over-estimate of this feeling is the source of Spencer's Utopia, as it is of that of present socialism. We

1 Compare supra, p. Ioo, note. 
have seen that authority is a primary and necessary factor of society. Authority, virtue, and duty are interdependent, and must be of about the same antiquity. From all compulsion imposed by authority, the creature, by its nature, attempts to escape, and the feeling which prompts this attempt has been falsely called the instinct of freedom. Authority exceeds its bounds, where it issues commands not demanded by the general conditions existing in the society. But though these conditions may demand a limitation of personal freedom, their requirements must, nevertheless, in general, be enforced.

Natural and Humane Ethics may thus be at variance in some things; may in others, coincide. There is no necessary conflict and no necessary agreement between them; therefore the theological theory of an absolute contradiction between them is false, as is also the teleological theory of their coincidence. The latter theory, not being able to deny that the moral and the natural do not always coincide under present circumstances, endeavors to avoid the difficulty by calling these conditions abnormal. The theory falls into two errors: in the first place, it ignores the fact that we have our organs, not for use but $b y$ use; and that our inherited characteristics may be regarded as an adjustment to the conditions of our ancestors, but not an adjustment to our own; and in the second place, there are no abnormal conditions. There are new or changed conditions, but either there are no abnormal ones, or all are abnormal.

But although increase of life means also increase of desire, although the organism is insatiable, yet there is, as we have seen, an increase of happiness, both in quantity and quality, with higher organization. The absolute amount is increased, but not the relative amount, the amount realizable in proportion to desire.

Want does not lead to improvement, as Darwin maintains, and the individual cannot be just or sympathetic in a condition of want. The freer he is from the direct care of the acquirement of necessities, the more manifold capabilities will he develop, and the greater will be his happiness.

The task which authority must set itself, in order to secure greater justice in society, and so greater happiness, is twofold, a positive and a negative task. The positive task consists in such an education of the young as will enable them by their own effort to advance towards their individual ideal of happiness, and in 
the inculcation of such an ideal as corresponds to their individual talents and means, and is attainable under the existing circumstances. The negative task, already implied in the positive one, is the imposition of necessary restrictions in the means used for the attainment of happiness. Within the limits set by justice, the individual has a natural right to seek his own pleasure, and for each individual an attainable maximum may be reckoned. This is not saying, however, that the individual has a just claim to this maximum, in case he cannot, or will not, be sufficiently energetic to gain it by his own efforts. It is an error of modern times to suppose that the realization of happiness rests in any other hand than that of the individual himself - that the state can make and decree happiness. Happiness cannot be secured by means of decrees, by a division of goods, or by gifts. Division is always unjust, since it leaves out of consideration that individuality of character which is the only measure of sensibility to pleasure. The negative part of the task is to be accomplished less by inculcation of many special virtues than by the continual direction of the attention to the fundamental virtue of justice. The positive task is to be accomplished by the most thorough education of the intelligence of the individual, through which he shall learn to inquire the reason of moral precepts, to judge for himself, and then to act on the decision he arrives at. We have seen that the ethical education of the present time tends to reduce inner struggle, rendering the results of wrong-doing as repellant as possible. One in whom has been instilled a very terrible conception of the sufferings resulting, in the present and future life, from wrong-doing, will perhaps automatically avoid the evil; and the means for a moral education seem thus attained. However, it is not so; for when the individual accustoms himself to being directed in action, not by his own carefully won experience, but by feelings instilled by others, concerning the ethical character of which his own insight does not, and cannot, afford him any explanation, he opens the way to every chance influence, and becomes the plaything of unknown forces; while he at the same time divests himself of that personal responsibility without which no society can exist. The true ideal of education is such as sharpens the judgment and accustoms the individual to consider his action from all sides, in the consciousness of personal responsibility. Only through such action is man the possessor of free- 
dom. He who acts without reflection, from unreliable emotion, is not free. The freest possible decision is that which is reached as the result of such a careful consideration of all the single components of reflection that no one of them exceeds in its influence its real worth. The ideal of education is not, therefore, the production of spontaneous decision and action, but of reasoning, conscious action. That this principle is the only right one is shown by our former observations, according to which, as society develops, more and more actions are the result of reflection. And in case a state of moral perfection is attainable, it can be arrived at only as each member of the society acts from perfect reflection, not from impulse or instinct. In attempting social improvement, we must take example by the chemist, who does not attempt a chemical combination by force but endeavors to attain the conditions under which the elements will unite, through their own inner laws, to the desired, homogeneous body. This is a wearisome process; but it is the shortest and swiftest, for it leads us to the desired end.

The single virtues cannot be regarded as ideal principles. They contradict each other, and whether the one or the other should have the preference depends on the individual case and can be decided only by reflection. The formulation of these general rules of conduct under the name of virtues has, practically, only the advantage of reducing the numberless possibilities of action to a few; but such principles can never be exhaustive. Wherever the individual forgets this fact and is led to regard virtue as an end, instead of as the means to an innocent happiness, virtue ceases to be virtue and becomes its opposite. 'Thus thrift becomes avarice, generosity extravagance, courage foolhardiness, openness want of consideration, gentleness weakness, and chastity celibacy. The single virtues are only abstractions from special circumstances generalized to an ideal of action. But in practical life, we have to do with individual cases whose conditions are by no means ideal, and cannot be treated as ideal. We must act, in each case, for the relative best, not for absolute good; and what is best for one sex or in one society may not be best for the other sex or in another society. A compromise between idealism and realism is everywhere necessary; and such a compromise is made, despite all fine words to the contrary, by every one, - by one only more openly or consciously than another. It is comfort- 
ing to remark that mankind shows itself, and always has shown itself, instinctively taking the road to the attainment of the end.

Through an extension of relations, authority, at first represented by a single individual, the head of the family or tribe, reaches the point of development where the one ruler is unable to rule all parts, and decide all questions, alone, so that he is obliged to call in help. He naturally chooses men near to him, with whose character he is acquainted. But there arises, by this division of authority, the danger of its misuse to the disadvantage of the ruler himself. Since despotic government depends on might alone, and the voice of the people has no influence, every person in any way related to the ruler represents a danger. Nevertheless, the establishment of new powers to assist the ruler was the startingpoint of constitutional government. For by this division of power the ruler rendered it impossible for himself to govern without help from others, and opened the way to a contract of compromise with the people. The influence of individuals upon the state spread, thus, to the people itself. Self-government, pure parliamentarism, is the ultimate end to be reached by the process.

We have seen that neither pleasure, nor utility, nor virtue, nor, finally, religion, can be regarded as the absolute means, but only as the relative means to the attainment of happiness. Both the hedonist and the utilitarian need to correct and further define their principle, as well in respect to the end to be attained, as in respect to the means proposed. Their principles are not to be rejected, but fanaticism is to be condemned. Principles may have exceptions; but fanaticism recognizes no exceptions.

As to man's final end. Though he has attained to the power of shaping, to some extent, his own environment and means of existence, yet he does not occupy an exceptional position in the animal kingdom, and must cease to exist unless he submits to adapt himself. It has been almost the rule that the highest animals of an epoch have later died out and been replaced by some new aristocracy, developed from somewhat lower forms. It is to be supposed that man, also, will be destroyed, whether by a new ice-age or by a period of heat. By the very fact of his supremacy, he disturbs the primal equilibrium, and originates conditions which, even now, press hard upon single lands and may easily become dangerous to all civilization. Destruction may also threaten mankind morally, for the development of morality 
hitherto gives no surety of its continuance. Every advancement brings with it some evil, every virtue contains the germs of some vice. Modern humanity has given us an unreasoning softheartedness, with an extravagant malady of forgiveness which is nothing less than immorality itself, since it on the one hand undermines the general sense of justice, while on the other it prompts and encourages wrong-doing.

\section{ALFRED BARRATT}

Alfred Barratt's "Physical Ethics" (ז869) deals with First Principles, "Pure," as distinguished from "Applied," Ethics, the aim of the science, as stated by the author, being "to try to establish the first principle which is the condition of further progress. If we can establish a principle a priori, and then verify its universality by an appeal to mental phenomena and to philosophical theories, its existence as a fact will be made certain; if, in addition to this, we can connect it with laws still more general and with the family of natural sciences, it will be no longer a fact, but become a scientific law, a section of the universal code; and the title of this essay will be justified."

Part First of "Physical Ethics" is occupied with the statement of axioms, definitions, and propositions "derived from general experience." 'They are as follows:-

"Axiom 1 . - Actions, like objects, are capable of being classified according to their properties, and of being measured by a definite standard.

"Obs. - This axiom merely means that the qualities of actions, like those of objects, are fixed and constant, so that the same action has always the same properties and moral value, and, under the same circumstances, always produces the same effect. . . . It follows from this axiom that it is possible to act so as to attain a definite object, and thus a general end of action may be arrived at. ... .

"Axiom 2. - The end of action (being some common property or effect) is a possible object of knowledge.

"Axiom 3. - We are capable of being affected by any external object only through our faculties, or (in other words) as a part of our consciousness.

"Axiom 4. - Faculties are known only by their action, or (in other words) so far as they are portions of our consciousness. 
"Axiom 5.- The sphere of action lies in the adaptation of 'inner' to 'outer' sequences, of faculties to the laws of nature.

"Axiom 6. - The constitution of man and other animal beings is an organism consisting of a number of parts, each having its appropriate function, and the end of each part results from the performance of its function.

"Axiom 7.--Approbation is the standard whereby we judge of the moral value of actions, and is the universal mark of the due performance of a function and of the attainment of an end."

\section{Definitions}

" $\mathrm{I}$. Good is the object of moral approbation. The highest good is, therefore, the ultimate object of such approbation, the end of action.

"2. Pleasure is that state of consciousness which follows upon the unimpeded performance (as such) of its function, by one or more of the parts of our organism."

\section{PRoposition I}

"The Good is relative to our faculties. For no object can affect us except through our faculties (Axiom 3 ); but to be known by us is to affect us;

"Therefore, nothing can be known except through our faculties, or (in other words) except in relation to our faculties;

"But the Good, or End of Action, is a possible object of knowledge (Axiom 2);

"Hence the Good is relative to our faculties.

"Corollary $I$. - The highest good of man at any time is relative to his faculties at that time.

"Corollary 2. - Since ideas derive their elements from experience, the idea of perfect Good, or God, can only be an idealization of humanity.

\section{Proposition II}

"The Good is a state of Consciousness. For, the Good is a possible object of knowledge (Axiom 2); but all objects of knowledge are states of consciousness;

"Hence the Good is a state of Consciousness. Or, the Good 
exists (or is capable of being known) only by affecting our faculties, or, in other words, only as an affection of our faculties (Proposition I);

"But an affection of our faculties is a state of consciousness;

"Hence the Good exists only as a state of consciousness.

"Obs. _ . . . To speak of anything existent external to our consciousness, is, as we saw, a pure hypothesis, incapable of proof, perfectly unintelligible and void of utility. When, therefore, we make use of the ordinary dualistic phraseology, we must remember that the two worlds there distinguished are merely two divisions of the universe of self considered as distinct for convenience of language, but differing only as two classes comprehended under a common genus.

\section{Proposition III}

"The Good is relative to circumstances. For, the Good is determined by, and therefore lies in action (Axioms 7, 6, Obs.); but Action is relative to circumstances (Axiom 5). Hence the Good is relative to circumstances.

\section{Proposition IV}

"The Good depends upon the adaptation of faculties to circumstances.

"For, the Good is identical with the end (Def.); which results from the performance of function by each part of the organism (Axiom 6).

"But the function of each part is its adaptation to circumstances (Axioms 5, 6): Hence the Good depends upon the adaptation of faculties to circumstances.

"Corollary. - Since man is an organism composed of parts (Axiom 6), the whole good of man is the sum of the goods of his parts, and therefore depends upon the adaptation of all his parts to their corresponding circumstances.

\section{Proposition V}

"The Good is Pleasure.

"For the good results from the due performance of functions (Prop. IV); but the Good is a state of consciousness (Prop. II), 
therefore the Good is the state of consciousness which results from the due performance of functions (as such). Hence (by Definition), the Good is Pleasure.

"Obs. - By our definitions of Good and Pleasure it was evident that they were coextensive, being both marks of the same thing; to prove their identity it was necessary to show that Good is a state of consciousness."

Of these propositions Barratt says that I and II are perhaps the most important, since they assert the impossibility of Transcendentalism.

Part Second of "Physical Ethics" is a "Verification by Special Experience."

\section{The Origin of the Moral Sense}

The assumption of a moral sense has already been made in the definition of Good as the object of Approbation.

Our previous reasoning would lead us nevertheless to guess that this sense is not, in its nature, a simple and indecomposable faculty. How, then, did this sense arise, and what is its nature and composition?

In the lowest animal organization, there are merely vague and indefinite states of consciousness corresponding to the undeveloped state of physical function. With the development and specialization of advancing evolution arises Perception; by which likeness and unlikeness among sensations are distinguished, and classification is begun.

"At first only the most obvious resemblances are noticed, but as experience progresses, wider and wider classes ever tend to be formed, till at last we arrive at those highest ideas which are coextensive with experience. These, though the last in order of birth, become the starting-points of science - just as men formed the idea of stones falling long before they discovered the law of attraction, yet by that law they afterwards 'explain' the former fact. Thus we trace the whole of Perception or Knowledge to this power of comparison and noting likenesses, and this we see to be coincident with the organization of consciousness into central meeting-places or ganglia, in which different sensations are presented to a common tribunal and so compared together. We see, therefore, that Perception does not originate consciousness; it only organizes and develops it. We cannot, therefore, agree 
with Mr. Herbert Spencer, who will not allow consciousness to the lowest animals." 1

The process of perception or Knowledge works, not only on states of consciousness themselves, but on the changes from one state to another, or, in other words, on relations. 'Thus results, on the one hand, recognition of objects; on the other, argument and reasoning, for the most abstruse reasoning is nothing more than a classification of relations.

"We have now, therefore, two distinct divisions of Consciousness: Sensation, which as before consists only of pleasure and pain, though now of different kinds; and Pereftion, which classifies states of consciousness and their relations, and is therefore concerned only with change. Knowledge, therefore, has originally no other object than different pleasures and pains, but eventually it attends so much to the differences and resemblances that it ceases to remember the pleasure or pain; in its absorption in the relation it well-nigh forgets the things related. 'This process is furthered by the fact that, as the medium gets more extended, each part of it has less average effect upon the organism: the primary pleasures and pains being spread over a larger surface are less intense, and so obtrude themselves less. This is exemplified by the common observation that sensation and perception tend to exclude each other. . . . Nevertheless pleasure and pain ever remain indissolubly connected with consciousness, though their presence is often unheeded, and only the more violent forms force themselves on the attention.

"What is true of these simple forms of consciousness, is true of their later development. 'The relation of sensation to perception is the same as that between the faculties of which these are respectively the germs, emotion and intellect. For emotion is associated sensations of pleasure and pain; and intellect is associated perceptions of change and relation. Hence by their very nature these are at once mutually exclusive and inseparable. A strong emotion drives out reason, and much reasoning chills emotion. ${ }^{-}$. . Yet we can give some reason for any emotion; and we feel some emotion in working a mathematical problem. . . . In every intentional act it is evident that both are involved; the end being given by emotion, the means by reasoning. Reasoning can give no end, it can only arrange, elicit, suggest; emotion can 
give no means, for it cannot classify or observe relations. In the building up, therefore, of any moral faculty, both these elements must take a part. Hence it will be well to trace, a little more closely, their mode of formation, and their connection with muscular activity.

"When in the course of experience a certain sequence of sensation frequently recurs, the consciousness becomes habituated to it, and the return of the first sensation is followed by an idea or associative image of the others. . . . Hence the idea of pleasure or pain not actually felt comes to be associated with objects, which, if placed in certain different positions, would effect us in the way imagined. . . . Pleasure may thus be associated through a train of ideas of any length. . . A After a time this process becomes organic, the intermediate terms are lost, and pleasure is directly connected with sensations and ideas that are in themselves not distinctly pleasurable.

"Now by various trains of association, various pleasures and pains are connected with the same object. These different combinations of pleasures and pains, some of which arise, before reasoning, by unintentional association, but the higher of which are the results of automatization of reasoning, form the different emotions. ...

"Action in its origin is simply the correlative of sensation. Contractility and irritability are the two general properties of vital tissue, or rather are two sides of one fundamental property which is also known under the name of sensibility - the power of contraction under irritation, or of expressing impressed force. Irritability means merely the phenomena of consciousness, the development of which we have hitherto been tracing, though we have been throughout obliged to express ourselves in the language of the inner, and not of the outer experience. . . . This internal development we have already examined; we must now turn to the obverse external development which takes its origin in contractility.

"The connection between these two fundamental properties is exceedingly intimate, that of ultimate identity or at any rate inseparability. For not only is contraction universally the result of irritation, but the only evidence that we have of irritation is the contraction which follows, and in their early stages the two represent one and the same process

When, however, the expres- 
sion, in action, of force impressed in sensation, becomes indirect and immediate, the name of irritability is given to the immediate, internal results of its impression, while contractility expresses the action ultimately expressed. Hence the seat of irritability is preeminently the nervous system, while contractility, or the $i$ is musculosa, is the name of the special property of the muscular tissue.

"Considering them however in their origin, they together represent a certain form of the transmission of force. . . . Some kinds of impressed force are followed by movements of retraction and withdrawal, others by such as secure a continuance of the impression. These two kinds of contraction are the phenomena and external marks of pain and pleasure respectively. Hence the tissue acts so as to secure pleasure and avoid pain by a law as truly physical and natural as that whereby a needle turns to the pole, or a tree to the light. . . . Hence, the law of Self-Conservation, or of the direction of Action, is merely another mode of expressing the fundamental property of animal tissue, which we have every reason to believe is derived from the more elementary physical properties of matter. The course of action is just as dependent on physical laws as that of a stone which falls to the ground. The belief in external consciousness makes no differ-
ence either way; the earliest phenomena of such consciousness are those of pleasure and pain, therefore we can suppose it to exist only as pleasure and pain. In the one case we say that action aims at, or naturally results in, the phenomena of pleasure; in the other case that it aims at the actual consciousness of pleasure.

"The expression of impressed force, or the connection of action and sensation, is at first in the unorganized tissue direct and immediate, without the agency of nervous communication, or to return again to the ordinary psychological language, is unintentional or involuntary. . . . The earliest modification is due to association, whereby secondary sensations, or (as they are called later when they become perceived) idleas are produced. These manifest themselves as weaker repetitions of the primary pleasures and pains, and, therefore, are naturally followed by like results. ... The process is this: the force originally impressed by the first sensation, instead of being all expressed in action, is partly induced by habituation into an internal channel, 
and so transformed into the kind of force which generally impresses the second kind of sensation, and this now produces its appropriate action. Hence part of the original force has undergone two transformations instead of one; the immediate antecedent of action being the force produced by association, or in other words, the associated pleasure. This is the rudiment of motive, which, however, is not generally called by that name till it is perceived. The same process may go on through two or more links of association; the first transformed force being again transformed internally instead of expressed, and the second again in its turn, until eventually a transformation is reached which finds its easiest way of escape in action; the immediate motive power being that transformation of force, or that associated pleasure, which immediately precedes the action. Actions of this kind constitute the lower phenomena of instinct: and we see therefore that they may depend on any number of links of unperceived, or, as we say, unconscious reasoning; and that their motive is also 'unconscious.' These actions stand half way between Reflex and Voluntary Actions. ...

"We now come to the third and last development of associated action. Here not only is each associated idea perceived, but the change, in each case, is also a fresh centre of association; whereby similar changes are connected with it, and it is referred to a class. Hence the whole train is perceived, not only by the classification of each of its parts with similar previous sensations, but by the classification of each of its sequences with previous like sequences: in other words, it is now a chain of reasoning from the past to the present. That associated pleasure from which this reasoned train commences is now called the motive (though really the immediate motive power lies in the last transformation which directly precedes the active expression) and the series of ideas intervening between this and the action is called the means. Hence the motive associates the means, and the motive power is transmitted through them till it is finally expressed in the action which is appropriate to the attainment of the pleasurable state whose idea is its source. This association of means with ends is at first sight opposed to the natural direction, which is from antecedent to consequent; but when a line of nervous connection is formed, a current may be transmitted indifferently in either direction. An effect may lead us to think of its cause, as easily 
as a cause associates its effect. By the sequence of action and sensation, a connection is established between their ideas, which is independent of the order of excitation. This last kind of action is that which we call voluntary, and the series of classified ideas and relations which lead to it is called Reasoning. If at any point the current is attracted in two or more directions by different trains of association, deliberation is the result; and the eventual victory of one and the consequent transmission of the force along it is entitled Will.

"We have therefore distinguished four kinds of action: Reflex Action, which is purely physical and independent of association, and which is the last link in all the derived varieties; Lower Instinctive Action, which is caused by the first introduction of association, and is hardly to be distinguished in its phenomena from the last; . . Higher Instinctive Action, which involves perception of qualities or objects; . . . and finally, Voluntary or Intentional Action, such as we find it in man. . . . Though we have separated these classes from each other for clearness of description, there is no distinct line to be drawn anywhere between them. Each fades insensibly into the next. . . . Evolution, we must remember, does not advance by stages; these are merely marks that we make ourselves, like the constellations in astronomy, for convenience of study.

"Finally, we must remark that the last two kinds of Action ever tend to relapse into the second, which subjectively is a mere form of the first. Association of all kinds tends to become organic. By this we mean that, as the connection becomes more definitely marked and easy, the perpetual radiation which occurs as the current passes the different points on its path, disappears; and the whole current passes unimpaired. First, the radiation caused by the changes disappears, and reasoning becomes instinct, as in doing a mathematical example from mere memory of the different steps. Secondly, the radiation from the different nervous centres also disappears, and the current which ends in action becomes not only unreasoning but unperceiverl, as in walking or reading aloud while thinking of something else. . . .

"Long habituation has two effects: it increases the number of trains connected with each object, and also the length of each. If we suppose the simpler emotions to have, by this time, become organic or apparently simple states of consciousness, a continu- 
ance of association tends to connect them together in bundles, as they themselves were originally bundles of elementary pleasures and pains. Hence the emotions become organized in their turn so as to form higher emotions, and eventually, when association has completed its work, .. . this organization ends in one supreme emotion, which is the head of the emotional or sensitive side of the consciousness. . . .

"Turning next to the second effect of prolonged habituation, we find that, with objects or actions with which pleasure was at first associated and which so were called pleasurable, further association often connects a subsequent pain which increased experience has shown always to follow upon the immediate pleasure. This pain often more than counterbalances the preceding pleasure; hence when it is taken into the emotion, that emotion becomes one no longer of appetition but of aversion, and the object or action is remembered as one not to be sought after but avoided. It cannot, however, be called painful, because it causes immediate pleasure, so a new name has to be invented, and it is called Bad, or Evil. Similarly, many thirgs which are immediately associated with pain are found to be eventually followed by pleasure which more than counterbalances the pain, and as this experience becomes consolidated by the power of association, they attract rather than repel, and for a name whereby to distinguish them, are called Good; so that Good and Evil are correlative terms like Pleasure and Pain, and mean respectively the greatest total Pleasure, and the greatest total Pain. Now this experience when once acquired is never lost, but by virtue of hereditary transmission descends from parents to children. But, as in the case of the simpler emotions, only the results survive, and not the means whereby they were arrived at; so that, in a short time, the words Good and Evil come to be quite separated from Pleasant and Painful; nay, as might be expected from their origin, they tend to acquire exactly opposite meanings; for Pleasure and Pain come to signify only immediate pleasure and pain; and the final reckoning is often considerably at variance with the first item; as in a race the man who leads for the first lap seldom wins in the end. . . .

"This, then, is the origin of the Moral Sense. . . . The Moral Sense, therefore, is merely one of the emotions," though the last of all in the order of evolution; it can only claim a life of some 
two or three centuries; and there are even some who still doubt its existence. "Man at any rate is the only animal who possesses it in its latest development; for even in horses and dogs we cannot believe that it has passed the intentional or conscious stage. ... Good, with them, has no artificial meaning; it is simply identical with the greatest pleasure."

Only by complete and perfect obedience to all emotions can perfect freedom from regret be obtained in the gratification of all desire. Man is at present passion's slave, because he is so only in part; "for the cause of repentance is never the attainment of some pleasure, but always the non-attainment of more: not the satisfaction of one desire, but the inability to satisfy all. The highest virtue, therefore, consists in being led, not by one desire, but by all; in the complete organization of the Moral Nature."

\section{Of the Social Relation of the Individual}

When we assert the end of Action to be Pleasure, do we mean the pleasure of the individual, or universal happiness? "Good has been shown to follow immediately on the adaptation of an organism to circumstances; it is evident that external objects can affect it only in so far as they form part of these circumstances. Hence it follows that the pleasure and pain of others can come in only incidentally; from the fact that each man is not an isolated unit, but a member of society. But further, this social medium itself is, after all, nothing but a part of the individual affected by it; it is one division of that primary side of his nature, by which the other side, the emotional, the intellectual, the moral, is being continually moulded and fashioned; and even if we take the narrower meaning of self, the pleasures and pains of others cannot possibly affect a man's actions or emotions except in so far as they become a part of his. If man aims at pleasure merely by the physical law of action, that pleasure must evidently be ultimately his own; and whether it be or be not preceded by phenomena which he calls the pleasures and pains of others, is a question not of principle but of detail, just as the force of a pound weight is unaltered whether it be composed of lead or of feathers, or whether it act directly or through pulleys.

"The principle, therefore, is clear enough, that the happiness of others can have only an indirect influence upon the good of 
each individual. But it is equally clear that this direct influence must be of no mean extent, and that it is now our duty to trace its history." Here follows a scheme of the development of the state from the family, which last was necessitated by the helplessness of infancy, and from which arose the habit of human association. We have no evidence from history or science that mankind has not always existed in a state of society; there is no warrant for assuming an earlier condition of isolation. "Hence to the human race the earliest Good was inseparably bound up with what we now call the Family Virtues." 1 The state, thus originated, developed as a social organism, with ever greater integration, heterogeneity, and complexity of parts, and "the End or Good of each individual became largely modified by the extension of the medium to which his actions had to be adapted "; man became a member, not only of the family but of the state, and the conceptions of his nature and duty became wider, "so that at last the more perfectly each attains his own interest, and the more pleasure he gathers to his own store, the more certainly does he secure the universal happiness of mankind." If a man aims, as Spinoza remarks, at doing real good to himself, he will be sure to do most good to others.

\section{The Unselfish Emotions}

Under this head is traced the genesis of sympathy through representation of the pains and pleasures of others and interpretation of them by individual experience in the same environment; and the genesis of benevolence, the active side of sympathy, through habit associated with the ideas of the pleasures and pains of others. Love is defined as "originally the association of many pleasures with one individual." From the wider experience of man as a member of a state is developed justice or the sense of equality of right, patriotism, etc. All these feelings are hereditary.

\section{Of the Relation of Man to Nature}

This portion of the book treats of the gradual development of knowledge to wider and wider generalization; of the extension of sympathy from man to the animal world also; of the universality 
of consciousness, which exists in the inanimate as well as the animate world; of the perfection of morality through the perfection of knowledge, since "knowledge moulds emotion, and absolute virtue is nothing but absolute correspondence with nature in action resulting from thought"; and of the evolution of religion, through knowledge, to a religion of knowledge of the real universe or of humanity.

\section{OF THE WILL}

Under this heading the metaphysical doctrine of freedom of the will is combated as a contradiction of the laws of Cause and Effect. Praise and blame, reward and punishment, are desirable because of their effect on action.

\section{Of Obligation}

Barratt defines obligation as a "violent motive." Paley says: "If a man finds the pleasure of sin to exceed the remorse of conscience, of which he alone is the judge, the moral-instinct man, so far as I can understand, has nothing more to offer." What, then, asks Barratt, has he himself to offer if a man finds the pleasure of $\sin$ to exceed the pain entailed by disobedience to the external command? It may, indeed, be the fact that particular kinds of motive only come from particular sources, but unless we can prove that those coming from a command are always the strongest, we cannot claim for them a position such as that implied by the word obligation, of being the highest or most universal motives. In a contest between two motives, it is not the kind but the quantity which decides. For if two pleasures or pains be equal, what does it matter where they came from? And if they be not equal, the greater, whatever its source, will always be the stronger motive.

"Hence obligation is nothing more than a 'violent motive.' Prudence and duty are both the following of the greatest pleasure; but so far as in ordinary language we make a distinction between them, the pleasure aimed at in prudence is proximate and only slightly greater than the pain, whereas in duty it is not only very considerably greater, but the greatness is further glorified by a dim aureole of magnificent generalities and the halo of an unfathomable future. . . 
"And as the result of a motive is in no way dependent on its external source, so neither is it influenced by its mode of internal operation. A motive may be strong either by its own natural force as a large excess of associated pleasure in one direction, or by the facility artificially given to its expression by the long-continued custom, either in ourselves or in our fathers, of acting in a certain way on certain occasions. In other words, the strength of a motive is not absolute, it is relative to the habits and predispositions of our organisms; but the strongest motive, whatever its kind, prevails in all cases.

"Obligation is often, again, confounded with compulsion: but submission to physical force is not morally an act at all, because its $\dot{\alpha} \rho \chi \grave{\eta}$ or immediate antecedent is external to us, and therefore independent of our moral laws."

\section{Of Pleasures that are called Bad}

"We saw that Good differs from Pleasure simply by a widening of the field of calculation; whereby the pleasure of the moment is often found to entail future pain greater than itself (allowance being made for perspective), and is therefore condemned as Bad. When, therefore, we speak of Pleasure as opposed to Good, we always mean the pleasure of the moment; or very often by a still further narrowing of the term, sensual as opposed to intellectual pleasures."

\section{LESLIE STEPHEN \\ “The Science of Ethics" (I882)}

While with regard to the matter of Ethics, - the general classifications of right and wrong conduct, - moralists are almost unanimous, with regard to its form, - the essence and criterion of right and wrong, - there is great disagreement. All widely spread opinions deserve respect by their mere existence; they are phenomena to be accounted for. On the subject of morals, as on all other subjects, opinions gradually modify and approach each other; but a perfect agreement will probably not be arrived at.

Leaving aside metaphysical questions, however, we may be able to find, as in physical science, some constants or ultimate elements which, though they, according to the metaphysician's view, re- 
quire further analysis, yet constitute, within their sphere, scientific knowledge independent of metaphysics. The follower of Hegel means, in all probability, precisely the same thing as the follower of Hume, when he says that a mother loves her child; though, when they come to reflect upon certain ulterior imports of the phrases used, they may come to different conclusions. The formula remains the same; for all purposes of conduct it evokes the same impressions, sentiments, and sensible images, and it therefore represents a stage at which all theories must coincide, though they start, or profess to start, from the most opposite bases. "Mothers love their children" is not unconditionally true; some mothers do not love their children; but the statement is of worth as approximating scientific truth. It may be well to attempt to ascertain in how far it may be rendered scientific.

In the physical sciences, the statements of laws arrived at by the labor of generations are ideal statements, in which a mass of modifying circumstances are disregarded for the sake of simplification. Even in these sciences, the power of prediction is small. Of the complicated conditions of human action we have even less accurate knowledge than of those of physical phenomena, though this does not lead us, any more than in the physical sciences, to suppose that prediction would not be possible if we knew the conditions. So far as man is a thing or an animal, it is comparatively easy to determine his conduct. Given a starving dog and a lump of meat in contact, you can predict the result. But to determine the behavior of a human being with a glass of water presented to his lips, you must be able to calculate the action of human motive and to unravel the tangled skein of thought and feeling in its variation in the individual under consideration. Moreover, much of the life of the individual is ruled, not by conscious motive, but by automatic habit, acquired through education. The prediction of action in society as a unit is not less difficult than the prediction of individual action, for if individual differences neutralize each other, so that a certain uniformity in the influence of circumstances is shown by statistics, it is not the less difficult to predict what these uniformities will be. Society as an organism, not a mere aggregate, presents, in the interaction of more complicated conditions, greater difficulties than does the individual as such; and it may be said that prediction of the course of history, even in general terms and for 
a brief period, would require an intellect as much superior to that of Socrates as the intellect of Socrates is superior to that of an ape.

And yet mankind does possess knowledge of conduct, which does not differ in kind from scientific knowledge; there is, in fact, but one kind of knowledge, which passes into scientific knowledge as it becomes more definite and articulate. The knowledge that mankind possesses consists in what we have thus far taken for granted, that under the same circumstances of outward environment and inward character, human conduct does not change. Of society, as of an organism, we cannot say a priori that it is so and could not have been otherwise; we can only show, a posteriori, how different parts mutually imply each other, so that, given the whole, we can see that any particular part could not have been otherwise. Our gain from such knowledge is the recognition that there may be discoverable laws of growth essentially relevant to our investigation of conduct. So long as reasoning was conducted upon the tacit assumption that social phenomena can be satisfactorily explained by studying their constituent elements separately, attention was diverted from the important principles of the interrelation of parts to the whole. The theory of evolution brings out the fact that every organism, whether social or individual, represents the product of an indefinite series of adjustments between it and its environment. Every race or society is part of a larger system, product of the continuous play of a number of forces constantly shifting with an effort towards general equilibrium, so that every permanent property represents, not an accidental similarity, but a correspondence between the organism and some permanent conditions of life. To solve the problem of existence by calculation is an impossibility; but our own lives are working it out; the evolution of history is the solution of our problem. And when we fully recognize that a problem is being solved, we have only to gain some appreciation of its general nature and conditions, in order to reach some important, though limited, conclusions, which may fairly be called scientific, as to the meaning of the answer. These conclusions are not scientific in the sense of giving us quantitative and precise formulæ, but they may be so far scientific as to be certain and reliable.

Thus we may be able to show how a given set of instincts 
corresponds to certain permanent conditions under which they were developed, and (returning to the problem of differing theories of morals with which we started) to show what is the cause of differing opinions. Our investigations of the problem of morality have nothing to do, in the first instance, with moral principles which are, or profess to be, deduced from pure logic, independent of any particular fact; they deal with actual moral sentiments as historical facts. The word moral, as used in our considerations, does not, therefore, refer to an ideal moral code, but to the one actually existing in the case considered.

Ethical speculation, as thus understood, must be concerned with psychological inquiries - inquiries in regions where the vague doctrines of common sense have not yet crystallized into scientific coherence; we must therefore proceed with caution.

The contention between materialist and idealist is irrelevant to our discussion. The fact that mechanical processes underlie all mental process does not make the latter the less a fact; nor can the mechanical statement ever supersede the psychological statement. The proposition that hunger makes men eat will express truth, whatever material implications are involved in the statement.

Conduct is determined by feeling; we fly from pain, we seek pleasure; life is a continuous struggle to minimize suffering and lay a firm grasp upon happiness. "Good" means everything that favors happiness, and "bad" everything that is conducive to misery; nor can any other intelligible meaning be assigned to the words. The difficulty of proving these propositions lies in the fact that they are primary doctrines, for proof of which we must appeal to the direct testimony of consciousness. But critics oppose, not so much the propositions themselves, as certain supposed implications. By pain and pleasure is here meant every conceivable form of agreeable or disagreeable feeling. The assertion that conduct is determined by pain and pleasure is not meant as a denial that it is also, in some sense, determined by the reason; but a state of consciousness which is neither painful or pleasurable cannot be an object of desire or aversion. The reason is often contrasted with the feelings in its determination of conduct, the reasonable man being defined as one who, instead of being the slave of immediate impulse, is capable of adapting means to ends and following, thus, courses of conduct not in 
themselves agreeable but promising a greater total of happiness. The fact is, however, that all happiness that determines the will is future; conduct is determined, in every case, not by a future feeling of pleasure, which, as future, does not yet exist, but by present. feeling. It is therefore more accurate to say that conduct is determined by the pleasantest judgment than to say that it is determined by the judgment of what is pleasantest. The intention of the agent is defined by the foreseen consequences of his conduct; his end is defined by that part of the foreseen consequences which he actually desires; and the end defines the motive, that is, the feeling, which actually determines conduct. The pleasantest end is adopted because the foretaste of the pleasure is itself pleasurable. The intellect and the emotions are in reality related as form and substance, and cannot be divided.

In the action of pain and pleasure, it seems to be an obvious fact that pain, as pain, represents tension, that is, a state of feeling from which there is a tendency to change; pleasure represents equilibrium, or a state in which there is a tendency to persist. The worm writhes on the hook, and the mind may be said to writhe under a painful emotion in the effort to writhe into some more tolerable position. In the act of choice, each mode of action is tried ideally, and the individual settles into that which is, on the whole, the easiest. The analogy which naturally offers itself and seems to give the best account of the facts is the mechanical principle of least resistance. It is not, perhaps, superfluous to remark that the volition may exercise a very small influence, even when the limiting conditions are in a great part ideal. The more painful is not necessarily the less permanent condition. It is one in which there is an additional chance against permanence. Terror sets up so disturbed a condition that the mind cannot settle into any definite course. We can no more alter arbitrarily the circumstances of our microcosm than those of the external world. It is as difficult to avoid brooding in vain regret as to evade a physical constraint.

Reason and feeling are bound together in inseparable unity. But reason, whatever its nature, is the faculty which enables us to act with a view to the distant and the future. A great part of conduct is automatic; it is either not determined by conscious motives, or it is determined by motives which, though they rise 
for a moment to the surface of consciousness, are forgotten as soon as felt. Of our conscious conduct, again, part may be called instinctive and part reasonable. These modes of action pass into each other by imperceptible degrees. The instinctive may be converted into reasoned as the consequences become manifest, and the reasoned become instinctive as the consequences are left out of account. So, again, the instinctive action becomes automatic when it is performed without leaving any trace upon consciousness. It may still be voluntary in the'sense that the agent may be able to refrain from it if his attention happens to be aroused. Habitual actions pass through all these gradations. When the reason is called into action, it is not in virtue of a purely logical operation that it conquers if it does so; it is in virtue of the fact that it reveals a new set of forces ready to spring into action to the necessary degree.

We may be said to feel by signs as well as to reason by signs. The sight of a red flag may deter us from crossing a rifle range without calling up to our imagination all the effects of a bullet traversing the body. If the motive which prompts us to run the risk be strong, it may be necessary to convert a greater volume of latent, into active emotion; and as we frequently fail to do this, we often run risks which we should avoid were the consequences distinctly contemplated.

The development of the whole nature implies a development of both the emotional and the intellectual nature; new sensibilities imply new sentiments; and increased range of thought is associated with an equal growth in complexity and variety of emotion. The more reasonable being acts with emotion, but his emotions have more complex and refined methods. The reasonable man is a better mirror of the world without him, his conduct shows a better adaptation to ends and a greater logical consistency in its parts; more harmony of action between the different instincts. The important question is not solved by these facts. We may still ask: How is the relation between the different instincts, the influence exerted by each member of the federation, determined?

We start with certain fixed relations between our various instincts; and however these may change afterwards, our character is so far determined from the start. Again, it is plain that this inherited balance varies greatly with different peoples and gives rise to different types. In one man the sensual passions 
have a greater relative importance than in his neighbor, and so forth. And the question arises, whether we can determine which of these types is most reasonable.

In the construction of the bow, we may suppose that, from rude beginnings, through discovery of better and better forms as adapted to ends in view in its construction, a form of bow would finally be reached which would represent the maximum of efficiency. This bow may be called the typical bow. As exquisitely adapted to its purpose, it arouses in us æsthetic satisfaction. Like the bow, every organism represents the solution of a problem, as well as a set of data for a new problem. As the bow is felt out, so the animal is always feeling itself out. The problem which it solves is how to hold its own against the surrounding pressure and the active competition of innumerable rivals. Though we cannot apply an a priori method, cannot define the materials of which men are made or the end which they have to fulfil, we can determine to some extent their typical excellence. Recognizing the general nature of the great problem which is being worked out, we can discover what is implied in some of the results. The process of evolution must be, at every moment, $a$. process of discovering a maximum of efficiency; though the conditions are always varying slowly, and an absolute maximum is inconceivable. At every point of the process, there is a certain determinate direction along which development must take place. The form which represents this direction is the typical form, any deviation from which is a defect. It is conceivable that the highest efficiency in different departments of conduct may imply consistent conditions. The greatest philosopher may also be the greatest athlete and the greatest poet. It is equally clear that there is no necessary connection. What, then, is the relative value of different kinds of efficiency? A complete answer to the question might bring out the fact, which seems on other grounds probable, that it is an advantage to a race to include a great variety of different types. It is enough, however, to say that, in speaking of a type, the assertion is not intended, that there is one special type conformity to which is a condition of efficiency, but that evolution is always the working out of a problem, the solution of which implies the attainment of certain general qualities.

We have changed our point of view from the consideration of 
pain and pleasure to that of the conditions of existence. The fact is simply, that the constants in one problem are variables in the other. Given a certain character, the agent does what gives him pleasure. But if we ask how he comes to have that character, the only mode of answering is by referring to the conditions of existence. His character must be such as to fit him for the struggle for existence. There must therefore be a correlation between painful and pernicious actions on the one hand, and pleasurable and temporal on the other. The useful in the sense of the pleasure-giving must approximately coincide with the useful in the sense of the life-preserving. All conduct may be considered as a set of habits, to each of which there is a corresponding instinct - the word habit being used to designate any mode of conduct, automatic or voluntary, which may be brought under a general rule, instinct denoting all conscious impulses to action, whether including more or less reasoned choice, and whether innate or acquired. Habits graduate from the essential processes which constitute life rather than maintain it, and which are, for the most part, automatic, to the most superficial and transitory. In order that the proposition "This habit is a bad one " may have any real meaning, we must assume that the organism can exist without it. A habit cannot be removed as one takes off a coat, as has been too often assumed; the whole character of the man is affected by its removal.

A capacity is essential if it is essential under normal conditions of environment. The quality which makes a race survive may not always be a source of advantage to every individual, or even to the average individual. Since the animal which is better adapted for continuing its species will have an advantage in the struggle, even though it may not be so well adapted for pursuing its own happiness, an instinct grows and decays not on account of its effects on the individual, but on account of its effects upon the race. The qualities of the individual and those of the race mutually imply each other, since the individual can no more be considered apart from society than the apple can be considered apart from the tree on which it grows. It remains true, however, that certain qualities of the apple may vary whilst the relation to the tree remains approximately the same, as also that the individual may vary in his qualities to some extent, his relation to society remaining approxi- 
mately constant; and qualities thus variable may be regarded as, in so far, independent of society.

Social development takes place without corresponding change of individual organization. We cannot interpret the changes from savage life arrived at in present civilization, as representing an essential, great, or corresponding difference in the innate faculties of the civilized man from those of the savage, but must regard them rather as representing the accumulation of mental and material wealth. The child, learning, with the words of his language, their implicit meanings, has his feelings modified by them, is thus a philosopher and metaphysician in the cradle by the associations given him, and is educated from infancy by the necessity of conforming his activities to those of the surrounding mass. All organization implies uniformities of conduct, and therefore continuous discipline. Society is an organism in this sense, not in any mystical sense. It is not an organism with a single centre of consciousness.

An organization implies organs; and these are to be found in the various organizations, political, religious, etc., by which, through a greater or less division of labor, certain special functions are relegated to particular associations. We thus have not only to go beyond the individual and refer to the organs in order to determine the "law" or form of any instinct developed through the social factor, but we have also to classify the various social instincts by reference to the complex structure of society, which implies a distribution into mutually dependent organs. Moreover, such organs, though primarily directed to a specific end, acquire a vitality independent of any special end, become organs discharging a complex function, and imply the existence of a correspondingly complex set of instincts. We come really to love an organization because it supplies us with a means of cultivating certain emotions and of enjoying the society of our fellows; it would be an entirely inadequate account of the facts if we regarded it simply as the means of attaining that pleasure which has given the pretext for its formation.

The organs of society are not, however, distinct from each other as the physical organs are distinct; the same individuals may be members of various organizations. The race is not, in fact, analogous to the higher organism, which forms a whole separated from all similar wholes, but to an organism of the lower 
type, which consists of mutually connected parts spreading independently in dependence upon external conditions, and capable of indefinite extension, not of united growth. We may consider the race, thus, as forming social tissue, rather than constituting an organism. The tissue is built up of men, as the tissue of physiology is said to be built up of cells. The laws of growth and vitality of the organs of society are always relative to the underlying properties of the tissue; although, in particular cases, the more civilized race may be supplanted by the less civilized, we may assume that these accidental and contingent advantages will be eliminated on the average, and the general tendency will be to the predominance of those races which have intrinsically the strongest tissue. Not the state as such, and (as we have seen) not the individual, is the unit of evolution; the state may develop when the external pressure is little or nothing; the social tissue is that primary unit upon which the process of social evolution impinges. The family is not, itself, a mode of organization coördinate with other social organs, but rather represents the immediate and primitive relation which holds men together. It is quite possible to suppose men living together without any political and social organization; but some association between the sexes, however temporary and casual, and some protection of infants by parents, are absolutely necessary to the continuance of the race beyond a single generation. A change in family associations implies a corresponding change of vast importance in the intimate structure of society itself, in the social tissue. The state may make a marriage law, but it cannot create or modify the family tie beyond certain narrow limits. It can bestow privileges upon some one kind of association, but it cannot originate it, cannot enforce fidelity and chastity.

The social tissue is its own end, or depends upon the whole system of instincts possessed by man as a social and rational creature.

The development of society as an organic structure implies the development of customs in the race, and habits in the individuals forming it. There must be certain rules of conduct which are observed by all, in order that corresponding rules may be observed by each.

Custom in the civilized society may be distinguished from positive law. In primitive states, the distinction is impercep- 
tible. The authority of law itself must rest upon custom, - the custom of obedience. But physical force alone, or the dread of its application, cannot produce obedience; the application of such force is so little essential that a state of society is conceivable, in which it should disappear altogether; men might be willing to obey their rulers simply from respect and affection. The power of applying coercion in case of need must no doubt increase as the strength of the social bond increases; but that bond is also the stronger, in proportion as the need of applying it becomes less. The whole social structure, then, must rest, in the last resort, upon the existence of certain organic customs, which cannot be explained from without. They depend, for their force and vitality, upon the instincts of the individual as modified by the social factor; they correspond to a given state of the social tissue. A legal sanction may be added to any custom whatever, and thus it may seem that a state can make its own constitution and define its own organic laws; in reality, however, the power of making a certain constitution presupposes a readiness to act together and accept certain rules as binding, and thus implies a whole set of established customs, essential to the life of the society and giving rise to special types of character in its members. Every law of conduct more or less affects the character of the persons subject to it, so long as it is enforced; and necessarily, every variation in the character more or less affects the sentiments from which the external law derives its force. The correspondence, however, is not so intimate that one mode of statement can always be rendered into the other. For laws, indeed elaborate codes, are developed without seriously affecting the general character of the underlying customs, and in the same way instincts may vary widely without producing any normal change in the external order, though they affect the mode in which it works. The essence of any law is in the mutual pressure of the different parts of the social structure. Any association with a given end will have laws determined with reference to that end. When we pass, however, from the organ to the tissue, we still have an organic structure with certain rules of conduct and corresponding instincts, but we no longer have a definite end or a fixed material. The material, that is, is to be regarded as developing and determining the development of the subsidiary organs. And since the most efficient society normally survives, we may 
inversely infer from the survival of a society that it has developed the properties on which its efficiency depends. 'The actual laws existing at any period may not represent the greatest degree of efficiency possible; but they must be an approximate statement of the essential conditions.

The moral law, as applicable to all members of a society, defines some of the most important qualities of the social tissue. It is as independent of the legislature as are the movements of the planets. This is true whether you resolve morality into reason or make it dependent upon utility. The action of any set of people can no more change the nature of facts than that of logical necessities. This is, however, fully true only of morality as it ought to be in correspondence with facts. Actual morality corresponds to men's theories about facts, and it may, therefore, deviate from what the code would be if they were incapable of error. But it is plain that, though it varies, it must vary within incomparably narrower limits than other systems of law, because its variation is determined by far more general conditions; it maintains itself, so to speak, by the direct action of the organic instincts. The doctrines of the greatest moral teacher, though somewhat in advance of prevailing standards, are successful only in proportion as they are congenial to existing sentiments, give articulate shape to thoughts already obscurely present in the social medium. Like Socrates, the reformer must be something of a midwife. Morality grows, and is not made; that is, it is the fruit of a gradual evolution of the organic instinct continued through many generations. The ordinary mind resists any change in principles instilled into it from birth; the great masses are sluggish in movement.

The moral law has to be expressed in the form: "Be this," not "Do this." The existence of a character such that variations of circumstances will cause no deviation from morality is the only security for morals. The legislator is forced to classify conduct by its objective manifestations. But the cunning of the man who desires to evade the code can still devise innumerable methods of accomplishing his end indirectly. Law permits what it does not prohibit, and is, therefore, in danger of producing hypocrisy instead of virtue.

The process by which the moral law (or rather, the law of conduct which includes, but is not coincident with the moral law) is 
developed, is a process of generalization. It corresponds to a vast induction carried on by the race as organized in society. Beginning with modes of conduct which are seen to be bad, society gradually perceives that the ultimate principle of classification must be by the primary feelings, that rules of conduct must be expressed in terms of character, and other rules which concern the application of these to more special cases must take a subordinate position and be regarded as only of conditional value. All these rules must necessarily correspond, within very narrow limits, to a statement of the conditions of vitality of the tissue which they characterize. In an ideal state of society, every general principle would also be recognized in every particular rule. This is a result a gradual approximation to which, rather than its actual attainment, must be anticipated.

Morality implies action for the good of others in some sense. Society may be regarded both as an aggregate and as an organism. There are certain qualities which we may suppose to vary in the individual without necessarily involving a change in the social structure. How is the general rule, as distinguished from other rules, deduced from the general principle of social vitality?

The law of nature has but one precept, "Be strong." But when we regard the individual in his relations to society, the law takes on different forms. This may be expressed by saying that the law "Be strong," has two main branches, "Be prudent" and "Be virtuous," the first applying to cases in which the individual is primarily affected, the other to those in which the units are affected through society and the social factor must be taken into account.

To find a classification of the virtues that will not run into infinite detail or be a simple affirmation of the general principle, the internal development of moral character under its emotional and intellectual aspects may furnish a sufficient method. The general formula of primary individual virtues is: "Be strong." The condition of vitality of the individual as a complex of instincts, is expressed by the formula: "Be temperate." And the class of virtues referring to the conditions of intellectual efficiency, has the general rule: "Be truthful."

Ceteris paribus, an increase of individual energy is an advantage to society; and, as a matter of fact, we find that civilized society differs conspicuously from the ruder in stimulating more 
vigorously and systematically the various energies of its members. The most conspicuous virtue of this class is the virtue of courage. In more primitive conditions, courage, as necessary to the preservation of society, is regarded as a virtue in itself; later, some mixture of judgment and reason is required in its exercise; and finally, since it may be combined with other anti-social qualities, it is not approved in the same manner as the more directly social virtues. Courage is now regarded merely as one manifestation of a character which is fitted for all the requirements of social existence.

The courage of the bulldog is blind instinct. Where such an instinct exists, the animal survives by reason of it, not because he forms any conscious judgment of its advantages. It seems necessary to suppose that races owed their survival to military prowess when reflection was still in the most rudimentary stage. The utility of courage must have been a very obvious discovery as soon as reflection became possible; but the quality must have existed, in some degree, before it could be discovered, although the existence of a distinct moral sentiment doubtless implies some reflection. Moreover, the instincts which imply a perception of utility must themselves comply with the conditions of existence, must themselves be useful. Increased intelligence might act to the disadvantage of the race by increasing selfish cowardice through a keener perception of personal, as distinct from social, risk; but this cannot be true ultimately, since we perceive that intelligent races have an advantage; we may suppose that those races are most successful in which a perception of the vitality of courage goes along with an increase of courage. This principle must be regarded, therefore, as working, not only through the less conscious instinct of the lower races, but also upon the judgments of a highly civilized society. The like is true, mutatis mutandis, of other qualities (such as industry, energy, and so forth) which belong to the same class.

The estimate of courage differs with respect to the two sexes, as does also that of chastity. The historical explanation is simple; courage was necessary in men in early social stages, to racepreservation; to women, on the other hand, has been given, from early times, a class of social functions not requiring courage. The estimate, once fixed, survives even when some of its early conditions disappear. The savage acquired his wife by knocking 
her down; to him the ideal feminine character must have included readiness to be knocked down, or at least unreadiness to strike again; and, as some of the forms of marriage recall the early system, so in the sentiments with which it is regarded there may still linger something of the early instinct associated with striking and being struck.

The virtues of chastity and temperance occupy an intermediate position between the virtues of strength and the directly social virtues. Some of them are a part of the prudential, and others of the directly moral code. Temperance is primarily prudential, but the sexual and parental instincts concern the most intimate structure of society. Our instinctive classification of temperance as higher than courage has good reason; the classification of it as a personal virtue cannot be maintained. A man whose vice injures only himself in the first place, becomes incapable of benefiting others. As we condemn the man whose character is bad, whether external circumstances do, or do not, give him an opportunity of displaying it, so we object logically to the man who is destroying his social qualities, whether the immediate effect of his conduct tells upon himself or upon others. Another element, an instinctive disgust at sensuality, seems to precede judgment upon intemperance, with a strength not to be accounted for by a mere summing up of consequences. The human hog revolts us as the smell of the sty turns our stomach. The justification of the instinct is not that it implies a judgment of what is useful, but rather that it is a useful judgment. As men become more intellectual, sympathetic, and so forth, they gain fresh sensibilities, which are not simple judgments of consequences but as direct, imperative, and substantial, as any of the primitive sensibilities. To get rid of the sensibility you must lower the whole tone of the character. Asceticism, which has arisen chiefly at times of great indulgence, may have been of use if only as a demonstration of the possibility of conquering the prevailing passions. In a similar manner, we may think a great reformer, a Howard for example, admirable, though he neglects duties which must be performed in the ordinary case. We thus admit that the general moral code of benevolence prescribes different conduct according to a man's opportunities and talents.

Truth is a virtue of slow growth; the savage, like the child, is unable to distinguish clearly the difference between imagination, 
hypothesis, and historical statement. The perception of the utility of truth first takes the external form: "Lie not," which corresponds approximately but not perfectly to the internal rule: "Be trustworthy." The internal rule, as such, is the higher; the external may have exceptions.

We come, at last, to the directly social virtues of justice and benevolence. So far as truth and temperance are strictly virtuous, they may be classed, the one under justice, the other under benevolence. There is no real conflict between justice and benevolence; so far as a man is really benevolent, he will not wish to benefit some to the injury of others. Justice seems to consist in the application to conduct of the principle of sufficient reason.

It is not safe to infer altruistic intention merely from altruistic consequences. The sexual appetite appears to be the most selfish of impulses, in that it prompts to conduct often ruinous to its objects. On the other hand, it is the root of all social virtues. We cannot be sure that the hen who covers her chicks regards them as more than comfortable furniture in the nest. Altruism begins with the capability of benevolent intention; where the conferring of pleasure upon others becomes a possible motive. The generation of pleasure in others' happiness has been traced to association; but, though the pleasant association doubtless prepares the way for the higher sentiment, the latter is something more.

It is true that all conduct is egoistic, in the sense that all conduct has its source in the pain and pleasure of the doer; but there is great difference between conduct that regards human beings as mere means to personal pleasure and that which takes into account their feelings as sentient beings. Sympathy springs from the primary intellectual power of representation. I cannot properly know a man without knowledge of his thoughts and feelings. Cruelty is, in many cases, simple insensibility, incapacity for projecting ourselves into the position of other beings. We may desire the pain of others when it is useful as a deterrent, or secures our own safety; yet to think about other beings is, in general, to stimulate our sympathies, our sensibility being thus quickened by the same power which implies intellectual progress.

To believe in the existence of sentient beings is to take into account their feelings, to believe that they have feelings, which 
may persist when I am not aware of them. A real belief, again, implies that, at the moment of belief, I have representative sensations or emotions corresponding to those which imply the actual presence of the object. To take sentience into account is to sympathize, to feel with. The only condition necessary for the sympathy to exist, and to be capable, therefore, of becoming a motive, is that I should really believe in the object, and hence have representative feelings. Systematically to ignore these relations is to act as I should act if I were an egoist in the extremest sense and held that there were no consciousness in the world except my own. But really to carry out this principle is to be an idiot; for an essential part of the world as interesting to me is constituted by the feelings of other conscious agents, and I can ignore their existence only at the cost of losing all the intelligence which distinguishes me from the lower animals. It is true that this vicarious sympathy, this pain at another's pain, may result in our simply getting rid of our own pain by going away from the sufferer, removing him, or dismissing him from our mind; as a fact, these methods are often pursued. But in many cases, such a course is impossible without the renunciation, at the same time, of many pleasures. If a man is to live with his friends, he must share their joys and sorrows; the choice is not between a particular pain and its absence, but involves the whole question of the renunciation of companionship. Emotions are inevitable, whether sympathetic or not, in proportion, not simply to the pain and pleasure at the moment, but to the intensity and degree in which they form part of the world of the individual, - the world constituted, not by mere sensations, but by the whole system of thoughts and emotions sustained by the framework of perception. The existence of pure malignity must, it is true, be admitted; it may be partly explained as love of the "sensational," the novel; the full explanation must be left to the psychologist. Sympathy is the natural and fundamental fact. If intellectual progress carried with it inferior sociability, it would tend to be eliminated; the world would be to the stupid; it must carry with it something which counterbalances the anti-social tendency. Reason is that which enables a human being to take account of future, as well as present pleasures. The working of the instincts or feelings, which dictates conduct, approximately coincides with the prevision as to the maximum of happiness obtainable by the 
agent; normally, it is prudent to be virtuous; and the sympathetic motives, so to speak, always develop within the framework provided by the other motives. To become reasonable is to act on general principles, and to act consistently; and this includes the condition that a statement of the real cause of my action should equally assign the reason of my action. The law which my feelings actually follow must coincide with the principle which commends itself to my reason. In order, then, that a being provided with the social instincts should act reasonably it is necessary that he should take that course of conduct which gives the greatest chances of happiness to the organization of which he forms a part. As the pain or pleasure in another's pain or pleasure is direct, so the end willed is willed as pleasurable to the subject, and the statement that altruism involves the contradiction of aiming at something else than the real end - the pleasure of the subject - in order to secure that end, is erroneous. The fact probably is that the mind "flickers," taking into consideration various consistent and mutually dependent ends, some of which may be primarily egoistic, some altruistic. The physician is not benevolent enough to cure me unless he expects a fee; but he may act also out of sympathy; he need not be always thinking of his fee. Our sympathies would be stifled, if it were not for the coöperation of motives of a different kind.

Altruism is the faculty essentially necessary to moral conduct; but the altruistic sentiment is not to be identified with morality. The elementary sympathy must be regulated and disciplined, in order that it may give rise to true morality. Virtues, for instance, which belong to the type of truthfulness and justice, generally imply a severe restraint of the immediate sympathetic impulses.

We recognize the internal motive as desirable, and recognize a difference between the man who acts only from prudential motives and the one who acts from moral motives. We consider the latter meritorious, that is, that he has a certain claim upon society, inasmuch as he has done for nothing what another man will only do for pay, or has refrained from action from which a less moral man can be restrained only by coercion. Wherever society finds sacrifice of the individual necessary, it pays for it in terms of merit. Merit is the value put upon virtue; it is a function of the social forces, by which our characters are moulded.

Every character is developed under circumstances, and depends 
upon mutual adjustment with these; we cannot disentangle the - two factors. Upon the power to infer future action the science of Ethics depends. The action of the individual is not a matter of chance; in this sense it is caused. But the instinct from which the action springs is not something external to the man, which moves him; there is not the man plus the instinct; the whole man, including the instinct, acts in a certain way, in which he would not act if he did not possess the instinct. We are accustomed to say that a man has inherited certain qualities; but the man is not one thing and the inherited qualities another; the whole man is inherited. Merit implies effort. This does not mean that effort, taken absolutely, is the measure of merit. Such an assumption would lead to our excusing men for the very qualities that make them wicked, - the murderer because of his spiteful disposition, for instance. The man is most meritorious who is virtuous with the least effort - provided always that he has the normal passions of a man. By these, however, since they are morally neutral, he is accessible to temptation and to a certain struggle.

Conscience appears, historically, as a development of simpler instincts; it is not a primary or a separate faculty; material morality makes its appearance long before the conscious recognition of a moral law. The existence of conscience is undeniable. Yet moralists are much given to exaggerate the sorrow which it actually excites. In almost every case, the pain which we feel for a bad act is complex, and due only in part to our conviction that we have broken the moral law. If we regard conscience as a separate faculty judging of action by some inherent power, we have to attribute to it reason and feeling. It is not a primary attribute of the agent (to borrow Spinoza's language), but a mode of the attributes.

There is, indeed, a sensibility which seems to have as good a claim as any to be regarded as elementary, and which is clearly concerned in most of our moral judgments: the sense of shame. This is excited by the consciousness of the judgment of others. It operates, however, not only in cases of a breach of morality, but often more strongly even in cases not concerned directly with morality; and may even operate against the moral code. But the variation is clearly not indefinite. Social development implies the development of a certain type of character, which includes, 
as essential, certain moral qualities; the consciousness of the code and of the condemnation of certain classes of acts, which it would cause, is implied in the sense of shame. The sense is closely connected with the instinctive disgust before noticed. It seems to have especial reference to decency and indecency. The value of the sense of decency cannot be measured by a consideration of a particular set of bad consequences from indecent actions other than the shock to decency; we must consider the whole difference between a state of society which does, and one which does not, possess it; it is an essential symptom of refinement and delicacy. Again, the judgments of conscience may be compared to æsthetic judgments. The difference between the æsthetic and other pleasures depends upon the form of gratification, not upon the instincts gratified, and seems to correspond to the difference between work and play. The artist may appeal to our moral emotions, giving us imaginary ideals; but emotion at the contemplation of such types is in the æsthetic phase when we simply enjoy their contemplation, and it passes into the practical phase as soon as it begins to have a definite relation to the conduct of our lives. Only in so far as the moral law has become internal, is the delight in heroic or benevolent energy spontaneous; in so far, we may speak of the existence of a moral, as of an æsthetic, sense. A man of fine moral sensibility may, indeed, like the artist, perceive finer moral discords than can be measured by formulæ; and may thus supply a more delicate test. But the complex problem of a difference in moral judgment may yet be solved approximately by reference to the test of social welfare; the highest type is that which is best fitted for the conditions of social welfare. The collective experience of the race is always progressing towards a more accurate solution of the problem.

The utilitarian theory, which makes happiness the criterion of morals, coincides approximately with the evolutionist theory which makes health of the society the criterion; for, as we have seen, health and happiness approximately coincide. The utilitarian theory fails, however, in one or two respects. It gets rid, as much as possible, of a priori truths, and rejects intuitions; it bases its argument on the assumption that all knowledge is empirical and the ethical problem to be solved by a summing up of the consequences of action. It thus neglects the truth which is implied by evolution, - that the organism itself is solving the 
problem; it neglects the instinctive sense generated by social evolution. Moreover, it considers society as an aggregate of similar individuals, taking little account of the variability of human desire. And, further, the utilitarian theory lays its stress upon morality as extrinsic; according to it, love of morality for its own sake, as love of the means to the end, must be as unreasonable as the miser's love for his gold. Association, in this sense, means illusion; and the more reasonable we become, the more we should deliver ourselves from the bondage of such errors; the theory fails just at the point where true morality begins. Furthermore, in substituting the external rule: "Do this," for "Be this," it seems to fall into the error of expediency. Though lying is assumed to be, on the whole, detrimental to happiness, truth is maintained to be desirable only where it contributes to happiness. The utilitarian destroys, to some extent, the force of the objection to this by asserting the danger of trusting ourselves. The force of this objection is only seen, however; when it is applied, not to the external, but to the internal code; we instinctively feel the danger to character in the lie, and hesitate to trust human nature in the establishment of such a precedent, just as we object to permitting the taking of life even in cases where prolonged life means prolonged misery, because we cannot trust human nature with the decision as to life and death. We make binding laws of morality, and leave it to the man of exceptional qualities to break them; for the generality of mankind, the stricter code is safer.

What is the sanction of morality? Why should a man be virtuous? The answer depends upon the answer to the previous question: What is it to be virtuous? If, for example, virtue means all such conduct as promotes happiness, the motives to virtuous conduct must be all such motives as impel a man to aim at increasing the sum of happiness. These motives constitute the sanction, and the sanction may be defined either as an intrinsic, or as an extrinsic, sanction; that is, it may be argued either that virtuous conduct leads to consequences which are desirable to every man, whether he be or be not virtuous; or, on the other hand, that virtuous conduct as such, and irrespectively of any future consequences, makes the agent happier. The problem is, thus, to find a scientific basis for the art of conduct. The "sanction " must supply the motive power by which individuals are to 
be made virtuous. This is, for the practical moralist, the culminating point of all ethical inquiry. Now there is, by our theory, a necessary and immediate relation between social vitality and morality. But it does not follow that there is the same intimate connection in the individual case. The sacrifice of some of its members may be essential to the welfare of the society itself.

We have, then, to answer three questions: first, whether the 1 virtuous man, as such, is happier than the vicious; second, whether it is worth while, on prudential grounds, for the vicious man to acquire the virtuous character; and third, whether it can be worth while, in the same sense, for the vicious man to observe the moral law.

If any man outside the pulpit were to ask himself what were the main conditions of happiness, the answer would certainly include health as the first, most essential, most sufficient condition. But the whole process of nature, upon the evolutionist doctrine, implies a correlation between the painful and the pernicious, and thus the elaboration of types in which this problem is solved by an ever-increasing efficiency and complexity of organization. Hence we may infer that the typical or ideal character, at any given stage of development, the organization which, as we may say, represents the true line of advance, corresponds to a maximum of vitality. It seems, again, that this typical form, as the healthiest, must represent not only the strongest type - that is, the type most capable of resisting unfavorable influences - but also the happiest type; for every deviation from it affords a strong presumption, not merely of liability to the destructive processes which are distinctly morbid, but also to a diminished efficiency under normal conditions. However, the typical man, though he is, on this theory, the virtuous man, is also much more than is generally understood by that name. Happiness is the reward offered, not for virtue alone, but for conformity to the law of nature, "Be strong." Beauty, strength, intellectual vigor, æsthetic sensibility, prudence, industry, and so forth, are all implied in the best type, and are, so far, conducive to happiness. If virtue be taken in the narrower sense as implying chiefly the negative quality of habitual abstinence from forbidden actions, there is no reason to suppose that it coincides with happiness. You can raise a presumption that moral excellence coincides closely with a happy nature only when you extend "moral" to include all 
admirable qualities. It is chiefly practical reasons which cause an attempted evasion of this conclusion; the practical moralist holds that the non-social qualities may be left to take care of themselves, but that stress must be laid upon the social qualities as the more important, in order to obtain them in society.

Sympathetic motives may lead to self-sacrifice; but this is also true of selfish motives; gin is a more potent source of imprudence, even in a moderate sense, than family affection; and the sympathetic motives have on their side the far greater intrinsic advantage, that they promote ends more permanent, far richer in interest, and giving a proper employment to all the faculties of our nature, besides the intrinsic advantages that spring from friendly relations with the society of which we form a part. It is, however, true that higher activity of any sort may cause pain in an uncongenial medium, and that, hence, the man who is morally in advance of his age may suffer through his morality; every reformer who breaks with the world, though for the world's good, must expect much pain. "Be good if you would be happy," seems to be the verdict even of worldly prudence; but it adds in an emphatic aside, "Be not too good." We must acknowledge that excessive virtue cannot be recommended to the selfish person upon grounds intelligible to him. There is, however, a general advantage in possessing more varied possibilities of enjoyment, and in being on the side of the strongest forces, those of progress.

Extreme self-sacrifice is sometimes demanded of a man by his moral principles. Is the sacrifice worth making? Would Regulus have suffered, from remorse, pain worse than death, had he chosen life at the cost of honor, or would he have found, as many do, that remorse is amongst the passions most easily lived down? To these questions can only be answered that morality must often involve pain, but that the virtuous man nevertheless chooses it.

We must thus conclude, leaving one great difficulty unsolved; and this is because this difficulty is intrinsically insoluble; there is no absolute coincidence between virtue and happiness. The scientific moralist has to do with facts; beyond these he cannot go. From the scientific point of view, we may hold that evolution implies progress, and that progress implies a solution of many discords and an extirpation of many evils; but there is no reason for supposing that all evil will be extirpated and perfect harmony attained. New sensibilities bring with them new dangers; even 
sympathy, when not guided by knowledge, may lead to rash changes productive of evil as well as good. To improve, whether for the race or the individual, whether in knowledge or in sympathy, is to be put in a position where a new set of experiments has to be tried, and experience to be bought at the price of pain.

It is true that beyond the science lies the art; we must incite the intrinsic motives to good through the pressure of the social factor. A certain disadvantage to the individual cannot form a reason for our not endeavoring to make him moral as far as possible; the good of society as a whole is involved; and even the man who is himself immoral sees the advantage of living in a moral medium, and would prefer that the world at large should not be guided by his own principles.

\section{B. CARNERI}

Carneri begins his book on "Morality and Darwinism" (Sittlichkeit und Darwinismus," I87I), with the rejection of the older Spiritualism in favor of Idealism, on the ground that modern investigation has made it impossible for philosophy to assume any foundation but one sanctioned by science; and with a rejection of dualism in favor of monism, on the ground that the investigations of Wundt and others have shown the psychical and the physical to be identical.

Instinct is defined by Carneri as thought upon the standpoint of mere sensation, but following the laws of the same logic as governs conscious thought. There is, thus, according to his view, no exception to be taken to the conception which represents instinct as the action of mental force, the difference between it and human reason as one of degree only. It is nevertheless a confusion which ascribes reason to the animals. Even their intelligence is one-sided, since it does not reach self-consciousness, and it is not to be regarded as an unqualified improvement upon instinct, since the latter loses both in intensity and in certainty of action when it no longer governs undisturbed by other influences: only such animals as are endowed with intelligence ever eat of injurious food. In human beings instinct has almost disappeared; - almost, we say, since savages do many things in an instinctive manner, and even civilized men at times perform acts which, on account of the exceeding rapidity of their execution, 
cannot be regarded as the results of reflection. Instinct may be compared to polarity in magnetism, according to which opposites are attracted. Instinct was evolved by natural selection. But intelligence and judgment are doubtless also to be found even far down in the scale of species. The brute consciousness is, nevertheless, only a transition-stage, in which the individual is still lost in the species; and, as such, it is not to be confused with human reason. Consciousness in the brutes is purely subjective, a consciousness "für sich"; while in human beings it is consciousness "an und für sich," consciousness that becomes subject-object through the concepts developed by language.

Man is as unconditionally subject to the law of causality, psychically and physically, as the merest atom. There is no such thing as chance; but in this very fact lies a consolation. In the concept of individualization in its broadest sense, is included the conception of freedom, and in the very nature of man there is an indestructible impulse to freedom; his being, as self-conscious, is identical with the latter impulse. This increases with increasing civilization, and has finally become the problem by the solution of which alone man can attain to self-satisfaction. It is true that the power of choice is inconsistent with the law of causality; but in the manner in which the man, as a thinking being, takes his stand over against the species, he becomes a person, an individuality. As one of the species, he shares the characteristics of the species, is an expression of the species-idea, and his action is determined outwardly by things; but it is so determined only mediately by means of thought, of concepts; these are the immediate determinants. Hence, man's relation to things is a different one according to the grade of his knowledge. In so far as this is adequate, that is, corresponds to the truth of actuality, his relation is an active one; in so far as it is, on the contrary, inadequate, the relation is a passive one.

Character is inborn and can never be effaced but only clarified, though this least through the bitter experience of the results of action. As the horse loses his sure-footedness after one fall, and falls again more easily, so we lose, through many a deed, the motive furnished by the consciousness of never having committed it, and have a greater tendency to repeat it. If an act has bad results, it is more likely that an attempt to avoid these results by cunning will be made at later opportunities for the act, than that 
the act itself will be avoided. And even if it were to be avoided, such avoidance would not constitute an improvement of the character; the latter would but hide itself under a mask to reappear at the first prospect of exemption from punishment. That which alone can modify character is a considerable extension of knowledge. For, since all things influence us only in proportion to the worth we attribute to them, their power over us must differ according to the correctness or incorrectness of our judgment. Therefore, the more we regard things in the light of their actual worth and hence also in their relations to each other, the more our character, beholding in these relations the general as the true, will incline to avoid extremes in action. A preponderantly sensual character remains such through life; but there is no doubt that a careful education, which makes it acquainted with nobler principles and develops a sensibility to true beauty, may ennoble it; while, if the education is, on the contrary, neglected, it must sink deeper and deeper into the mire of coarseness and vulgarity.

Character is the sum of its "affections," that is, of all states and motions of the disposition. These are divisible into "passions," - included under selfishness, which is the general, all-embracing passion, - and the active conditions of existence. These two divisions are also identical with pain and pleasure, passion with pain, and activity with pleasure. All desires have their root in the primary instinct of self-preservation and self-propagation, the instinct of self-propagation being only the racial form of the instinct of self-preservation. The instinct of selfpropagation is the highest of all the passions, yet, as Spinoza says, every form of love which recognizes another cause than mental freedom is easily turned to hate, - if it is not already a sort of madness, nourished rather by discord than concord. The various forms of family love, the love of country, and friendship, noble sisters of love in the narrower sense, result in desirable activity only as they exist in the form of concepts. Civilization is nothing but the struggle of inadequate and adequate concepts, in which, as in the struggle for existence in nature, only that is triumphant which, instead of assuming a position of separation, makes the general and the conditions of existence its own; so that charity in the widest sense of the term is, of all humane feelings, that to which the palm has been given. In this feeling, the dialectic movement of the concept "man" is completed and per- 
fected, the single man, instead of perishing in the struggle of all against all, first working his way upward out of his species and then taking up, in his own being, the whole of mankind through the medium of benevolence. By this evolution he raises himself to the level of the general. Far higher than that confused sympathy which, in lending temporary aid to one, brings lasting harm to many, is this adequate concept; true benevolence is founded upon the clearest reasoning, and is the activity of the mind's fullest power. The discord which self-consciousness has caused in man can be done away with only by the greatest possible clarification of self-consciousness: man returns mentally to the bosom of the universal, when every living thing causes him to exclaim in the words of the Indian philosopher: "Behold thyself."

Ethics ranks higher than morals, the latter merely comprising a collection of particular rules of conduct which, as particular, bear the stamp of the individual, the non-universal. The details of morality change according to epochs and peoples. This change has been regarded as an argument that there is no absolute but only relative good. But the concept of the Good is, like the concept of the Beautiful, the fruit of education; that is, it is the product of mind, which, through its own evolution, arrives at Knowledge. When we do away with all concessions to one-sided, extravagant desires, abstain from placing mind above the universal law of causality, and are content with the facts made known to us by science, we perceive that the absolute True, Beautiful, and Good, bears the character of the Universal. In this universal character it has always finally found expression in human life, and in this character it will always find expression. The idea which reaches perfect expression in the dialectic movement of these three concepts, the True, the Beautiful, and the Good, has come into existence by the mediation of the self-individualizing selfconsciousness, just as the evolution on the earth, which reaches its completion in man, is the outcome of the first chemical process. Not only have the two one law, - (mind is only in so far realized ${ }^{1}$ as nature is expressed through it, and the actuality of nature is its expression in mind) but both are, in fact, one, the succession in their development on the earth being a succession only in relation to the earth, and for us in this respect. Although to our notion of time, thousands of millions of years lie between the two, their

1 Wirklich. 
separation does not represent a second for the univarse and its eternity, for the comprehension of which it must be disregarded.

The good man is he who does good for its own sake, without effort, not out of momentary caprice, but out of perfect knowledge and conviction. He is free, since he acts out of his own character, the law of nature appearing as the law of his own mind; freedom lies in the absence of discord and strife in the mind. The good man has strength of soul, just as the man who lifts a weight without effort, not he who lifts it only with the greatest effort, possesses strength of body.

There is no absolute Evil in contrast to the absolute Good. Evil is negative. The perfection of man is identical with the attainment of absolute Good through evolution.

Morality knows nothing of either reward or punishment; for it there are only causes and effects. This truth, on which morality is based, lends to the freedom out of which its activity proceeds a deeper worth. The eternal law's of mind point the way by which mankind has to proceed; it is the same way by which man has become man and by which he must proceed, even if he did not will to advance thus. In the struggle for existence, which knows only victory or destruction, progress is a necessity of nature, but it is less painful and more rapid the more clearly these laws come to be perceived by consciousness. Yet, however clear they may be, it is only by a tireless endeavor which shrinks from no sacrifice, that progress takes place. The end which morality has in view is distant, for it is high; but only with its attainment will mankind fully deserve its name when "struggle has been transformed to labor, when no insignia are recognized but those of right, no weapon used but intelligence, no banner raised but that of civilization."

In the volume, "Man the "End' of Man" (Der Mensch als Selbstzweck," I 877), "a positive criticism of Hartmann's Philosophy of the Unconscious," Carneri defines instinct as no form of real thought, nothing dependent upon perception, but merely an inherited, mechanical dexterity dependent upon sensation. For the assumption that thought is the source of instinct must lead us naturally, on account of the existence of the latter where the centralizing organ of thought is absent, to the theory that thought is universal in nature; that is, we shall arrive at a theory of atomsouls. It is evident here that not Carneri's definition of instinct 
so much as his conception of thought is changed from the one adopted in "Sittlichkeit und Darwinismus," thought being now limited, as it was not in the former book, to self-conscious mental activity, assumed to be dependent upon nervous centralization in the brain. In this book also, the author defines the idea as something having mental existence, though not, he says, in any metaphysical sense. His idealism is not of such sort that he recognizes any other way to the attainment of ideas than that of science; and to him "the service of the materialist who gives us information concerning the function of the smallest nerve-fibres is of more worth than that of the idealist who originates a whole philosophical system." The work of philosophy lies in the rejection of all that is contrary to science, and the clarification of ideals.

The will may be defined, not as a definite, separate power, but as the self-conscious impulse to action resulting from excitation. Any other definition is inconsistent with the theory of evolution, according to which that individuation which is the first condition of the struggle for existence, is nevertheless but the expression of all previously existing oppositions. To make of the will or of the impulse to self-preservation anything separate and individual, is as childish as to personify death. 'The individual is totality as unity. Darwinism teaches us, not that the world together with man has been created according to any teleological principle, but that it has developed by virtue of motion. The human being moves by virtue of reciprocal action and reaction with the world. Yet only by virtue of his unity as feeling does he think and will. Individuality is that which stamps all our activity with the mark of the ego, which causes us to recognize every impulse that moves in us as our impulse, to call all our willing ours. The psychical, the summation of functions to which we give this name, reaches consummation in the clarification of feeling to consciousness, in which the desire of an action or of abstinence from an action appears to us as our will. As thought is based on perception, so will is based on impulse; and since thought and will appear as the two highest opposites of feeling, and this, according to our definition, springs from sensation by way of perception, the will, including action and abstinence from action, arises out of the general sensitivity. The progress of science authorizes the expectation that the close relation of sensitivity to simple reaction will one day be discovered. 
The conceptions of teleology are groundless. The so-called "ends" of nature have the peculiarity that they are according to the means. It does not rain in order that there may be vegetation, but vegetation exists because it is conditioned by the rain. Only with thinking man, in his struggle for existence, arises the concept of ends; man has not attained to civilization by help of a friend; rather has he wrung civilization from nature as an enemy; compelled by it to the exertion of his whole strength, and growing in cunning by exercise, he has learned to use the weaknesses of his foe to his own advantage. To want he owes the greatest things that he has accomplished. By way of labor alone can victory over nature be achieved and salvation won.

The standpoint of faith is childlike. Faith does not reason, and may not do so if it wishes to remain faith. The child can comprehend nature and man's relation to it only by the language of faith, and there are large classes of people who, for a long time, will be accessible to no other language but this. But faith must decrease in the same ratio as mankind outgrows intellectual childhood. In the same measure, the worth of the philosophical solution of certain problems must increase; and among the most important of these problems must be reckoned that of bridging the chasm between the individual and the world, which has grown wider with the awakening of consciousness. It lies in the nature of self-conscious thought to reach out beyond itself, just as it lies in the nature of sense-perception to regard this "beyond " as the world to come. Hence the endless longing which seeks the ruler of the world to come, and despairs without him; until the supposed right to a future life is perceived to be the right to the Only Whole, and an end is set in the attainment of this whole. For the thinking man an aimless life has no meaning; there is only one means of bridging the chasm; namely, that mankind shall set itself an end.

A final destruction of life upon the earth must surely come, whether it be in the shape of a sudden catastrophe or as the result of a slow process. But such an end can no more be regarded as the "end" in the philosophical sense than death can be regarded, in the same sense, as the "end" of the individual life. By the development of ideas, which are concepts of reason in distinction from concepts of the understanding, we arrive at a notion of the ideal as end. 
In the ethical ideal, there is contained more than the empiricist can offer. The enthusiasm with which the true artist starves for his art, or the martyr perishes for his conviction, can never be fully explained from the empirical standpoint. One does not even need to be an idealist in order to act thus; but the materialist or the realist who possesses true love of beauty and a heart framed for great deeds, merely deceives himself when he refuses to acknowledge the All-embracing which therein overwhelms him. Sociology and the History of Civilization can only point out how man has attained to the ideas of the Beautiful and the Good; what these are and wherefore their influence is so powerful, - the real worth of the Beautiful and the Good, - thought by concepts alone can show.

The Idea of Man, as he has already developed and may yet develop, is, as far as our knowledge reaches, the highest of human thoughts. We are therefore formulating no metaphysical theory in personifying mankind, and pointing out that the perfecting of which it is capable is the great end which it has set itself. We know, by our knowledge of human nature, that mankind will always endeavor to be happy, and that it will approach nearer perfection the more real and general its happiness becomes.

The particular rules of morality may and must change; but the highest principle of all morality is changeless. From the purest moral feeling came Schiller's words: "Live with thy generation, but be not its creature; serve thy contemporaries, but in that which they need, not that which they prize. Without having shared their guilt, share with noble resignation their punishments, and yield thyself freely to the yoke which they both illy could do without and illy bear. By the steadfast courage with which thou refusest their pleasure, thou shalt prove to them that it is not cowardice which causes thy submission." In these three sentences there lies a whole system of ethics.

In the will to good, indivisible from a feeling of freedom, of which no power on earth can rob us, lies true happiness.

For mind, as for matter, the law of the indestructibility of force, of work, is true. That which appears as force or energy is motion; every impulse to motion is motion, and only in so far as it appears, can the quantity of motion, force, energy, increase or diminish; as a matter of fact, it always remains the same. But just as the activity and force of matter increase with 
its differentiation, so the activity and energy of the mind increase with intelligence. It is through intelligence that we come to a comprehension of the distinction between good and evil, and through intelligence that we are able to increase social prosperity, and so morality.

There are no innate, primary human rights; there are only acquired rights which man has gained for himself in the process of development.

If we were to express negatively the end which mankind sets itself, we should define it as the greatest possible reduction of pain. Conscious existence is accompanied by a feeling of pleasure; but the general progress heedlessly overrides the individual being, and we therefore have to erect barriers against the stream which thus turns pleasure into pain.

Pain and pleasure are relative to the individual. Every sensation is pleasurable as long as it does not exceed in strength a certain limit corresponding, in each case, to the nature of the individual. Since, however, every sensation becomes, by perception, feeling, thought appears as a modifying factor in all pain which does not arise from too extreme physical injury. The manner in which our perceptions, thought-images, are formed, the store of thought-images and concepts which we possess, and hence our thought-capacity, combined with the extent and clearness of our knowledge, are decisive not only with respect to the avoidance of pain and attainment of pleasure, but also with respect to our attitude towards pain and pleasure in general; every pain and every pleasure has, in the last analysis, such worth alone as we attribute to it. The universalization of true education, the increase of intelligence, is, therefore, the means by which man's lot may be bettered.

Through the conditions of the earth's atmosphere, man has grown to be the glorious creature that he is. If we gradually give him, by education, an advantageous love of life and pleasure therein, and at the same time do not neglect the cultivation of ethical principles, virtue will become, with the increase of happiness, a necessity.

If intelligence is to bear the fruit which we thus demand of it, its nature must be such as not only to be nourished by actual life, but also to uplift by its increase the whole man. And this is, in fact, the case; where it is not so, we have to do with a one- 
sided development such as existing circumstances often condition, but which cannot be regarded as normal. This point of view is the necessary consequence of the unity which we postulate of man. If thought and will have their origin in feeling, and if will clarifies itself through the clarification of thought, then all advance in thought leads, in general, to an advance in feeling, and true intelligence is inseparable from true love. We use the word "love" here, as designating intelligence in its highest sense, and declare, moreover, that we would desire to see this meaning alone attached to love. Over against the conception of love which we find in Hartmann and Schopenhauer, we place the conception of Spinoza, who designates it as a free, reasonable activity, and says of it as distinguished from passion that "the love of both man and wife has for its cause, not a pleasing exterior merely, but especially freedom of soul."

If we regard intelligence and love in their highest antithesis, the one appears as the appropriative, the other as the self-devoting conception of things. But since we form a conception of things and make them our own only in proportion to our intelligence, our attitude towards them must be according to this measure; and since there is no action without reaction, intelligence must be broadened by love as well as love clarified by intelligence. The highest of all is intelligence; but it is love that first lends it creative power; without love it cannot create, but only destroy. Everything great and noble that man can point out as his work is due to love - love of mankind, love of country, love of knowledge, love of art, love of labor in general. If the devotion is deficient in purity, determined by extraneous motives, the work will bear marks of the deficiency. The reason why the power of love is so much greater than every other power is that its all-embracing, boundless character reacts upon it as a feeling of eternity, enabling it to undertake all things, as if it might conquer even death. Life, considered in its parts, is cheerless; but love, regarding it in its totality, points out to it the way of salvation through itself. Love is the concrete element which exalts the abstraction of Intelligence to incarnate Idea; therefore is love the idealizing principle from which intelligence draws belief in its own aims. And if one questions whence comes the conception of immortality, impossible to be won from experience, love must confess itself guilty of originating it, being unable to exist without this selfdelusion. 
Carneri thus places himself in direct opposition to Schopenhauer's and Hartmann's notion of love, which, he says, "falls like a deep shadow over their whole conception of the world"; and he pleads in favor of a standpoint which shall make selfperfection the aim of existence for woman as for man. He propounds a theory of education for woman which, according to his own statement, places him at one in spirit with Mill; but he avers that he cannot follow the latter in his more extreme views, which, he says, were evidently assumed by Mill only in view of the strength of the enemy with which he had to contend. The book ends with the following paragraph:

"We do not run after ideals; hence no plan floats before us, according to which the world should be shaped anew. He who understands how to read the book of History knows that, in no one place does the identity of form and content come more clearly into view than in others, and that, with every new content, there is always a new form also. The modern state has by no means outlived itself yet, and those who endeavor to do away with it know not what they are about. Instead of thinking upon a new form, let us devote our care to the clarification of the content. No one deceives himself as to the suffering in the world; but he deceives himself who thinks that he alone can bring about a better condition. Only the action of all can better things. Therefore, that which remains for us to do can be summed up in these few words: Let us make every effort possible to place every one in a position to help himself. This is the only ethical conception of universal reform. Let us prize knowledge above all things, and let us show that we so prize it by increasing it and diffusing it as much as lies in our power; let us prize it above all things, and prove that we do so by using it for the good of mankind. By knowledge we have become human beings, because knowledge has brought us to a comprehension of the Beautiful and the Good. It is knowledge that sets life an end in the attainment of the Good, and knowledge that glorifies our path to that end. Let us educate for ourselves wives that shall not merely dimly feel what we think, but such as will bring to the execution of our will a clear understanding. Let us educate for ourselves wives who, fired by the same feelings as our own, will unite their efforts with ours in the education of a generation that shall take morally the stand upon which the science of the century finds itself. Let us 
seek true happiness if we would find virtue. It is to no wisdom, but it is likewise to no foolishness that we owe the existence of the world. Man can be foolish; but he can also be wise; and if he is wise, then the world too is wisely arranged."

Carneri begins his "First Principles of Ethics" ("Grundlegung der Ethik," 1881) with an investigation of the origin of primary concepts and our knowledge through these. In order to bring light into our conception, we must first of all learn the way to the concept; for then only can we see how the concept completes itself in the judgment, and becomes, in reasoning, the criterion of its own worth.

The problem which first presents itself to us is that of Life in general. The problem is inseparable from that of corporeality. If we follow phenomena to their last conceivable reduction, we finally pass from the perception of mass to the concept of matter; but further than this we cannot go. At least, we can perceive only material things, and that which we call the spiritual in distinction from the corporeal has always something corporeal as its basis; and if we do not wish to dispense with the reliable guidance of experience, we shall not overleap this barrier. Science cannot reckon with supernatural factors.

What matter is we cannot know; that it exists, however, that the phenomena of nature are no empty seeming, sensation, as the felt result of the mutual relation between us and the outer world, testifies. Sensation is the basis of our self-consciousness, of the only full and irrefutable certainty that we possess. As to what true Being or Existence is, there is disagreement; but there can be none regarding the fact that we are conscious of our sensations; and upon this consciousness rests the postulate of the materiality ${ }^{1}$ of all existence. In order to assert the materiality of all phenomena, we are forced to distinguish between a corporeal and a non-corporeal action of matter; matter operates mentally when its division or differentiation proceeds so far that the resulting phenomena can no longer be perceived by the senses, but only conceived by thought. The indivisibility of mind from corporeality follows directly from this definition of the mental side of nature. We distinguish between the two only for convenience' sake. The newer Psychology knows nothing of Sensuality in the

${ }^{1}$ Stofflichkeit; by this word Carneri designates "das Gemeinsame aller Gegenständlichkeit." 
old sense of the word, since the basis of all psychical effects is physical.

For matter operating mentally, as for matter operating corporeally, there are no specific energies; it is, as Wundt expresses it, functionally indifferent. The differing results of a high differentiation of centralized organisms arise in accordance with the changing combinations of elementary parts and nerve-activities. These results are not, however, to be regarded as the mere effects of matter, but as phenomena of the same, in fact, as the consummation and crown of the whole evolution of nature. Even in the sense-organs we see the differentiation of matter advance beyond the sphere of sense-perception. Therefore, in distinguishing between mind and matter, we are still in the realm of the natural, and follow the path of experience, if by experience is understood not alone immediate experience, but also the conclusions which directly or by strict analogy may be drawn from it.

The theory of an atom-soul and the theory of an organizing principle must be abandoned as teleological, and so inconsistent with the facts of evolution. The theory which holds force to be a transcendental existence, a something outside of matter, must also be rejected. With the endless divisibility is given an endless motion, inward or outward; the endlessly divisible matter exists in endless motion, or what is the same, the endless motion is the endlessly divided matter. Hence motion, like matter, can never diminish; only the form of its appearance changes.

The order in nature cannot be used as the basis of a teleological argument; what we call order of nature is necessity as distinguished from chance. For example, the statement that the life of the earth requires the alternation of day and night means merely that, since day and night alternate upon the earth, only such beings could arise and continue in existence thereon as flourish under this alternation.

The first appearance of protoplasm introduces no strictly new thing, but only a new form of matter with life-motion; and the formation of germs is only a further step of the process. The most important characteristic of all life is sensation. This is the form in which, in all living things, that which in the rest of nature we call reaction, appears. That it is so easy for us to say in the same breath, the animal possesses sensation; and, by this particular excitation we produce in him this particular sensation, has 
its reason in the fact that the animal is not only capable of sensation, but is, moreover, continually in a state of sensation. By the fact of its continual reaction upon sensation, it keeps itself alive. Hence the two concepts coincide, so to speak; sensation is to life what divisibility is to matter. We express with these words more than a similitude, since all sensation is based upon motion, is, indeed, motion, and every motion may be reduced to a division or differentiation in the broadest sense of the word. All further distinctions, as, for instance, with respect to the mode of sensation (which belongs, without doubt, to plants as well as to animals), we leave unnoticed; all differences in the forms of life are but those of degree, though they may be wide differences of degree; they are to be ascribed to the influence of outer circumstances.

Sensation develops in the direction of least resistance. In the animal world, we have to distinguish between outer and inner factors, with the latter of which a new element seems to be introduced. The difference between the two is not, however, one of essence, since the will, too, is determined by outward circumstance. The inner factors of evolution are comprised in the germ, from which the individual is produced; while the environment constitutes the outer factors. The individual enters the world with a certain reserve quantity of force, which represents his power of resistance to outside forces, and he passes the more rapidly from youth to age the more rapidly this force is consumed. This accumulation of force is, therefore, identical with the impulse to self-preservation, which, as modified by various inner and outer excitations, manifests itself in various forms. But he who, as unimpassioned thinker, desires progress, desires also retrogression; he who desires youth desires age, since the two concepts are correlative and the one includes the other; old age, and finally death, must come to our planet as a whole, as well as to the human individual. The original tendencies of the total character determine, for the most part, the manner in which the individual sustains the struggle for existence; yet the environment is in no less degree active in this determination. Not less important than the manner of reaction is the differing susceptibility to particular kinds of excitation; the character resulting from the mutual action and reaction of individual and world depends upon the manner in which the individual adapts himself to circumstances, ennobles and disciplines himself. 
In idealism, as long as it remains within proper bounds, there is certainly truth; he who derides it, derides himself. But realism has also its truth, as long as it does not misjudge the worth of concepts, by which alone we clearly recognize what things are to us, what their relations to us are, and so how we have to deal with them. Concrete concepts inform us as to what is true and what is not true in phenomena. There is no greater mistake than to suppose that what things are in themselves, not what they are for us, is of importance to us; as if we could have an interest in that which things are not for us. The decisive point is the fact that, not things as they appear to us, but their rightly conceived appearance, their appearance as understood by adequate concepts, is the beginning and end of knowledge. Hence the true student of nature can no more do without the concept than the true philosopher can leave material perception out of account. Stiff-necked Materialism is as one-sided as old-time Metaphysics; the one has no meaning for its form, the other no form for its content; the one is a corpse, the other a ghost, and each strives in vain to attain the warmth of life. Natural Science and Philosophy must tread different paths, in so far as division of labor requires them to do so; but they labor at the two sides of one whole. Nature is not a machine, but life in its fullest form, and the task set us is to understand her as she is, not to patch together a nature out of disconnected scraps.

Carneri adopts the definition given by Claude Bernard, to whom life is neither a principle nor a result, but a conflict. To the chemical synthesis, from which protoplasm results, is added, through mechanical integration, morphological synthesis, to whose special form inherited characteristics are related as elements. Through the conflict within living forms, and between these and the rest of the world, motion, attaining to the character of function, appears as continuous consumption. Destruction and renewal are inseparable correlative concepts. This fact is contained in the concept of the conservation of force, work, and motion. We may distinguish between ( I) latent life, such as that accumulated in the germ, (2) the merely oscillating plant-life, and (3) free animal life. With this distinction, we place ourselves upon the standpoint of the individual, for whom there is both beginning and end, and to whom renewal is subordinated to destruction; for consumption, death is the characteristic of liv- 
ing in distinction from non-living matter. If, therefore, we regard life as identical with death, we merely assert that we consider death identical with life, and that, in the broader sense of the word, for the universe as a whole, there is no death. That which Claude Bernard designates as Construction is the differentiation and division of labor arising in the process of integration. The cell constitutes the first integration of protoplasm. In it, motion takes place in a particular form, organizes according to this form, causes division and synthesis, and impresses features of character that, by their action and reaction with the environment, either effect their own destruction, or else maintain their existence, propagate themselves, become fixed, and undergo further evolution. In this manner species arise and vary: and the more primitive the form, the more variable it is; the more advanced, the more fixed. Hence the invariable character of the germ-cells. In bone-formation, it is clearly shown that special structure begins very early, - in the cell, namely; but it is preserved only where it is aided by the necessary action and reaction. Autonomic in itself, life submits itself to the general laws of evolution. ${ }^{1}$ As the direction of motion is determined for whole groups of cells by the direction of the motion of the protoplasm in the single cells, so organic function is determined by the grouping of the irritable, contractile, sensible cells. From the first origin of life up to its most perfect development, everything is formed at the cost of other forms. If life is, therefore, to be conceived as a conflict, it is a conflict as wide as the universe itself, and we say, with Claude Bernard, that "life may be characterized, but not defined."

Everything that has sensation lives. As life depends upon particular combinations of particular elements, so sensation is the characteristic mark of such combinations, and a higher form of that simple reaction common to nature in general. Reaction has its reason in the motion arising from the endless divisibility of matter, through which the most different combinations and reactions are produced. Since we have before us, in our contemplation of corporeal nature, not abstract matter in general, but some sixty or more special chemical elements, we must, in thinking of atoms, have in mind atoms of these particular elements,

${ }^{1}$ An sich autonom, unterwirft sich das Leben den Cesetzen, die aus der allgemeinen Entwicklung sich ergeben. 
and not atoms of abstract matter in general; of such atoms of matter in general, or, if one will, of primordial matter, we can know only that they would in general attract and repel. Only by degrees can a particular reaction of the elenients have been developed; and since our known elements have particular different reactions, they must be the product of different combinations. Sensation is due to certain combinations of these elements; when the combinations no longer exist, the atoms of these elements still react according to their characteristic method as atoms of particular elements, but the sensation dependent on their peculiar combinations is destroyed. The atom as such is devoid of sensation, and we may convert our earlier proposition, making it read: Only that which lives is sensible. We know quite well how much of this course of reasoning is of hypothetic nature; but the strictest consistency cannot be denied it. The method which explains life by the assumption of sensible atoms is a much shorter and easier one; but is it not likewise a method of greater risk? And is there no danger that, in rejecting a method by which all changes in phenomena are referred to functions of combinations of elements, we may seek, in matter itself, something that is not matter? 'The above theory of life, also, takes its departure from the assumption that all was, originally, in the formation of the world, living in the broader sense of the word. But here we are concerned with life in the narrower sense of the word, as distinguished from what we call dead nature.

Soul is, therefore, according to our definition, equivalent to animal life, in contrast to the life of the plant. The significance of the distinction lies in the intermediation of the general organic unity, not in a qualitative division. The elements are the same; only their connection is different, and that which distinguishes the animal is a centralization of the organs. In referring to the possession of soul by the animal, we simply point out the independent manner in which, by reason of sensation, its impulses govern, and develop, through the scale, up to consciousness and will. Of course the gradations are very numerous, inasmuch as the functions of the soul are determined by the development of the organism. The difference between animals whose sensation attains clear consciousness and such as do not attain to more than a mechanical action, does not concern us, as long as we regard the psychical phenomena in their most general form. Every 
animal possesses soul; we avoid the expression " $a$ soul," as giving the soul the significance of something by itself. In like manner, we do not say that $a$ life, but that life belongs to the animal. The chief condition necessary to soul as to life consists in union to a whole, and soul represents the gradation by which life lifts itself to the plane where it becomes a mirror of the world.

Sensation, as centralized in the brain, becomes perception, the sensation of a part becoming the sensation of the whole, a feeling of the individual. It is perceptions which cause movement. To find a connection between perception as generally understood and the action of the muscle would be as difficult as to show the connection between body and soul in the sense of Spirit. But if we regard perception as feeling, then the awakening of a corresponding impulse, and the transformation of this into will, which finds expression in a corresponding motion, is something so natural that it needs but a glance at the nerveapparatus in order to comprehend the rapidity of the whole process. With regard to the unconscious character of the greater part of the process, and its corresponding rapidity, we have to consider the gradual nature of the development of the nervous system, the gradual drill of the parts, until the whole process becomes perfect. By feeling is here not meant necessarily feeling as pain or pleasure. This quality of feeling does not necessarily belong to every perception, else thought, as a train of perceptions, would be unbearable; a certain strength of feeling is necessary in order that it may attain the character of pain or pleasure; as we recognize a boundary at which sensation begins, so we recognize one at which feeling begins to attain the character of pleasure and from which, up to a second boundary-line, it continues to appear as pleasure; beyond this line it appears as pain. Noderate feeling is beneficial to the organism, immoderate feeling harmful; hence the appearance of the one as pleasure, and of the other as pain. We say expressly "moderate," not "weak" feeling, because too weak feeling may also, under certain conditions, be painful. Horwicz rightly protests against any attempt to arrange the feelings in an exact scale, since a particular feeling may lead to quite different phenomena of emotion, according to the particular circumstances and the particular development which it undergoes in the organism, and since it is furthermore nothing 
changeless and distinct, but merely an energy that necessarily leads to activity. Hence it is that the excitation which does not pass the stage of sensation remains localized, but when it attains to the stage of feeling takes possession of the whole individual, and brings the essential tendency of his being ${ }^{1}$ to expression.

As Carneri tends to interpret the sensation which he predicates of the lower animals as a mere higher reaction of living matter, and thus wholly mechanical, so he tends to regard the activity of all animals which lack brain (under which he understands especially the nervous developments found in the gray matter which contains Haeckel's "soul-cells") as devoid of pleasure and pain, and due to mere inheritance and force of habit. So the action of the ants is not to be attributed to intelligence, but to mere reaction upon sensation due to inheritance and exercise; and so the movements of a butterfly impaled upon a red-hot needle would be attributable to the hindrance of its flight, not to pain. ${ }^{2}$ Thus, with Carneri, the words "sensation," "soul," "perception," and "feeling," lose their ordinary significance; and this fact must be held in mind in the interpretation of his assertions that "all animals have soul," and "all animals have sensation."

Carneri further cites Haeckel's definition of the organism as a cell-monarchy, in which different individuals, and different groups of individuals, having different duties, are guided by a central power. He does not intend thus to assume special centres for consciousness and will, but only to assert that, through such centralization, the expression of the whole individual, as total consciousness and total will, takes place.

Not only the brain, but other parts of the nervous system, are affected in perception; and the same parts are operative in remembrance. Thus the association of ideas is explained.

As long as the animal remains upon the plane of mere instinct, it has only blind impulses. ${ }^{3}$ Only in the most highly organized animals do we find the first traces of conscious, though not yet of self-conscious, will. In that the animal knows what it will, it distinguishes clearly the objects of its will, and hence its own impulses. Upon the earlier plane of mere self-preservation, the beneficial, harmful, and indifferent were not yet made inward, but only distinguished outwardly by nature in the struggle for existence, in which the fittest survived; in consciousness, how-
1 Daseinstrieb.
2 Pp. I I 2, II3.
${ }^{3}$ Dunkle Triebe. 
ever, the harmful and advantageous become inward, taking the form of pain and pleasure. But the animal never gets beyond the concrete case, - in which his inherited instincts, working with a rapidity and freedom we often see imitated in the passions of men, sometimes act so advantageously as almost to deceive us into believing them the result of reflection; yet sometimes, again, bring most disastrous results. The animal never attains to a notion of the Whole. Associations and general perceptions the higher animal species have, but not concepts.

Impulses appear, in their primary form in the animals, as passions. $^{1}$ The first beginning of the ethical may be found in the passion of love in the broadest sense of the word, as sexual love and the love of offspring. The first is chiefly exacting, the second is higher, in that it gives.

That which divides man physically from the brutes is merely the union of qualities, all of which, but never all of which united, we find among the animals; that which divides him mentally from them is self-conscious thought, developed by means of speech. Through the development of attention, which arises in connection with a greater and greater centralization, sensation becomes perception, this develops further to general perceptions, and is still further perfected to concepts.

Carneri believes primitive man to have been, not more benevolent than the animals, but less so. Leaving out of account the carnivorous animals, the brutes seem to satisfy their own wants without interfering with the satisfaction of others, and, except where the possession of females is concerned, to live in peace with each other. On the other hand, the influence of man upon the domestic animals may be seen in the greed of the dog, who, as capable of instruction, takes on himself all the evil qualities of his master. The cat, who is not so intelligent as the dog, is not thus influenced.

For nature there is no good and evil. The animal which tears and devours its prey is no worse than the swollen stream, that uproots the trees in its course. With consciousness, intention awakes; yet in the brute this is only secondary; the brute distinguishes between pain and pleasure, but not between these as the result of its own action in distinction from that of nature outside itself. Only the self-consciousness of the human being knows good and evil; nature does not know evil, for she does not 
know the opposition on which it is based. There is wisdom in the story of Genesis, which sees in the beginning of knowledge, the commencement of evil. The awakening of self-feeling is the beginning of a chasm, through the full development of which the individual is at length separated from nature. With self-consciousness and the feeling of boundless isolation that therein comes over him, man begins his ethical development.

But the ethical does not begin with the human being known to us by natural history; even yet there are races of man which stand lower than many species of animals; and the early development of moral activity was of necessity much more of the nature of that which we call evil than of that which we call good. The mind is a sort of light; and as warmth is indivisible from the motion which we call light, and the first warmth of the sun could only burn, so the motion which we call mind could at first only have destroyed; self-consciousness, in its earliest stages, can have produced only the intense feelings which lie nearer pain than pleasure. As man came to have intention, and gained new wants in development, he could regard the intentions of his fellow-men only with distrust. Envy, hatred, dislike, were developed long before the family, and, later, the tribe furnished opportunity for love. Self-consciousness could, at first, interpret good and evil only as having reference to self, just as it also conceived its freedom as that of its own caprice. The desire for happiness and endeavor to attain it is the primary incentive to all human undertakings. It is erroneous to suppose that man is nearer to the brutes by this impulse; the animal does not possess it, has only the impulse to self-preservation.

The idea that man and wife together first constitute the complete human being, and that the real future of this human being lies in the children - the idea of the family is, certainly, of all ideas, primordial, though it probably came late to consciousness. From the family developed the tribe with the eldest at its head. The more peaceful the tribe, the more others combined against it, and by their combination compelled it still further to strengthen its resources. The feeling of power awakened by the growing concord extended further and further, and finally made its way to the individual with the full force of the Idea. This development, but more especially the compelling power of the struggle for existence, soon called the bravest to command in place of the eldest of the tribe. 
It is by the agency of no other being that, in the mutual relation of physical and mental activity, consciousness is attained; man himself comes to a feeling of himself. In the being endowed with soul, who on the one hand attains, through integration, an independence that appears as the impulse to selfpreservation, on the other hand becomes conscious of this impulse to self-preservation through a centralized nervous system that raises the part-sensations to feelings of the whole, sensation divides into two chief functions, which appear as passion and thought. We are not concerned, in thought and passion, with opposites, but with an opposition which a single phenomenon develops through manifold action and reaction with the rest of the world of phenomena. The distinction is merely a convenience in finer investigations; there is, in fact, as little thought without emotion as emotion without thought. And since emotion always manifests itself as will, this highest opposition is best defined as that of thought and will. In order to understand the human being, we must analyze these two sides of consciousness.

Carneri's examination of the primary laws of thought can be only touched upon here. In the law of Identity, or, negatively speaking, the law of Consistency, ${ }^{1}$ there comes to our consciousness a more general Species which includes a determinate species. "The adequate, clear, correct, corresponding ${ }^{2}$ concept is consistent with itself," means, the adequate concept finds itself again in every object which it includes. The law of Identity expresses, therefore, not entire sameness, with which the cessation of all thought would be reached, but simple consistency. It affords us, thus, the means of recognizing the Untrue in that which is not what it is called, hence also the means of recognizing the True. The law of Excluded Middle contains an extension or doubling of the law of Identity, in that the identity here appears, not in the form of consistency, but in that of contradiction; as, "either - or." Not one, but two cases are supposed, only one of which can exist or be true. The disjunctive proposition which corresponds to it is not less determinate than the categorical proposition which corresponds to the law or judgment of Identity, but is rather, on the contrary, a more forcible affirmation of it. In this determinate nature lies the

1 Widerspruchslosigkeit.

2 Entsprechend. 
worth of the Excluded Middle. Du Bois Raymond's address on the Limits of Knowledge has caused much joy to conservative thinkers; but these have made much more out of it than it really means. There is either for us a transcendental, or there is not; and if not, then we are limited to the knowledge of nature. The scientific limit set to our knowledge by our hypotheses and theories is, however, merely a limit set for the purpose of rounding knowledge to a whole, not of closing it to a further advancement; but such hypotheses must be consistent with experience and founded upon it; otherwise we leave knowledge behind us and abandon the hope of it. We cannot say what, within the province of science, man will not know, except that he never will know everything.

The law of Causality is the most important law of thought, after that of Identity. Reason and result are often confused with cause and effect. The reason on account of which we do a thing is not, however, the cause by which it occurs. The cause is the complexity of all conditions which make it possible, and the reason of its performance coincides with a conscious design on our part that constitutes our purpose. Causality has nothing in common with the concept of purpose. The principal of Sufficient Reason has been made the bridge between Causality and Design. Probably human experience reached first the conception that nothing occurs without sufficient reason, and only later, by a further mental step, the conviction that everything for which the necessary conditions exist takes place. With this conviction, the concept of causality became clear; but, at the same time the bridge which connects it with the theory of design in the succession of events was destroyed, so that only a logical leap can restore us to this incomplete conception of earlier experience. Causal necessity excludes purposed necessity. That which takes place may be regarded as, in one direction, conformable to an end, but may, on the other hand, conform to no end in any direction. A succession of events conforms to purpose only in so far as it is regarded by a particular consciousness which combines it in thought with ends of its own or such as it ascribes to another consciousness. In the law of Causality, as in the law of Identity, the necessity of self-consistency and the self-consistency of Necessity reaches expression. The sufficient reason is simply the completeness of the conditions, with the existence of which the event takes place, and with the absence of which the event fails to take place. 
Spinoza's "Will and intellect are one and the same" is the ethical law of Identity. All thought is willed; that is, indivisible from a certain coloring which it has in virtue of its identity with the will, just as all will is connected with thought; there is, indeed, a will-less thought, which might, however, just as correctly be called "unthinking thought," ${ }^{1}$ just as "unthinking willing" is, in reality, will-less willing. In all mental operations, the identity of the two functions is found. A will is unthinkable without something willed - an end, given by thought. It is the fact that, in his practical life, man recognizes purpose as a necessity, which causes him to read purpose into nature.

"At the basis of identity lies a concept which throws light upon the teleological principle. This is the concept of the General. The basis of the principle of identity is a concept of species which embraces the general in contrast to the singular and particular; just as the judgment of Identity constitutes an advance to still greater Generality. The concept of the General which reaches expression in species coincides with the concept: Law of Nature. The Law is, for a particular circle of events, what the Species is for a particular circle of objects. As in the Species, the characteristics are expressed which an object must exhibit in order to belong to it, so in the Law the conditions are expressed which much exist in order that the instance included under it may take place. The relation of Identity to Causality is unmistakable. Species and Law include no mere plurality of objects and instances, for as often as the instance comes to pass the law is fulfilled, and the number belonging to a species is, in conception, limitless. Worlds like our earth may come into existence again and again; hence specimens of a certain species, eternally destroyed, may eternally renew themselves, and instances which fall under a certain law may eternally occur. Simply their conditions must exist in order that they may occur. Such cases form, therefore, a whole; and this is Totality in Little." The importance of every whole which sets itself over against the greater whole has already been noticed. The former whole constitutes the concept of Individuality which, as Undivided Unity, becomes independent. "The limitlessness which we claim for the whole is one of conception; we thus seek to make that which is incomprehensible conceivable." The concept does not need to be

${ }^{1}$ Gedankenloses Denken. 
imagined; it may be thought. "Every one knows what he means when he opposes the whole to the part. The whole is not a larger part, but the opposite of the part, as 'all' constitutes the opposite of the many and the particular."

What we aim at, in this analysis, is a true Realism in the conception of the Purposeful. 'The Purposeful is that which conduces to an end, the Useful. From Individuality follows the individual nature of ends. Every man has his own ends, and in the attempt to attain his ends does not hesitate to set himself in opposition to all the rest of mankind. If he is sufficiently energetic and cunning, he may even succeed, for a time, in his endeavors, to the harm of humanity. Yet to have the whole of humanity against oneself is to endeavor to proceed in the direction of greater resistance, and the process must, sooner or later, result in the triumph of the stronger power. In the struggle for existence, in its larger as well as its smaller manifestations, the individual seeks, with all his power, to satisfy the impulse to happiness which arises with conscious existence; while the species, as the complex of all energies developed by its parts, has an impulse to self-preservation of its own, which, by its action as type, has originated and preserved for centuries the conception of changeless kind.

"Here is the beginning of the dawn, whose sun, however, in order to become visible and impart warmth, must rise still higher. The certainty afforded in the law of Identity in positive form, in the law of Contradiction in negative form, in the law of Excluded Middle in the form of an opposition, and in the law of Sufficient Reason in conditional form, is based upon Causality, Community of Species, or Totality. For this reason, deduction and induction are only then to be relied upon when the first form of reasoning has for its middle proposition one that expresses causality, community of species, or totality, and the latter form of reasoning takes these for its point of departure. The analysis of Deduction is of worth as clarifying and confirming thought, and thus extending its field as often as the syntheses of Induction stand the proof of the process of clarification. The supernaturalism of Dualism leads to a dead, the natural character of Monism to a living, dialectic, - to the dialectic of Becoming. The concept assumes a concrete form, and, as higher and higher rising sun, enables us to conceive what it will be to us as Idea. The 
understanding knows nothing of ideas; their realm is that of the reason; yet since the reason is but a higher development of the understanding, the commencement of this dawn must be perceptible in it. Moreover, the division which we make between the two originates in our genetic treatment of the subject, which seeks to explain the concept by showing the course of its development. Yet the distinction is no empty abstraction which may not claim life and form to a certain extent. The human being is always the whole human being; but he is not always uniformly developed, either physically or mentally. In one individual the understanding, in another the reason, manifests itself more plainly in thought. This is also true of the race, the people, and the epoch, as of the individual. Modern development has turned more and more from the ideal to material interests; we seem to be progressing towards a reaction," but what that reaction will be, we cannot say; it may be a reaction in the worst sense. The mistakes of the understanding cannot be predicted. With the point of culmination, the extreme is reached, and in Spiritualism may be found traces of a touching of extremes. Yet the influence of the understanding is to be relied on in so far as it is the clear mirror of Necessity. The understanding may err, just because it is conscious; but experience always corrects these mistakes. Nature, as gifted with mind, is no new nature; the laws of thought are the natural laws of the mind. In their mirror the will sees the accomplishment of the first mental development, and learns to comprehend this, on higher mental planes, as Common Weal.

The opposition of the individual to the rest of the world which arises with self-consciousness and individuality is greater, the greater the individuality. To the struggle for existence is added the struggle for happiness, which, separating into numberless desires that gain in attractiveness with every obstacle opposed to their satisfaction, is the origin of all the passions, - of greed, jealousy, envy, hatred, etc. Through passion, which is the exaggeration of activities that, in a normal form, are good, man is led into a struggle for false happiness, just as the concepts under which his passions arise are false. The individual against the world cannot attain happiness for himself. The greatest good, peace of soul, freedom from passion, is attained only through knowledge, by which the concepts of the individual are corrected; it is attained, not as dead incapability of emotion, but only as 
clear enjoyment of life after past storm. Labor and education are the path to true happiness and, through true happiness, to virtue. The passions are not separate existences; the whole man is the passion of his heart; the whole man feels, just as the whole man thinks. But just for this reason, because of the identity of will and understanding, the correction of the concept is the correction of will. This is not saying that will and understanding are never in opposition to each other; the apparent opposition is, however, merely a hesitation of the will, which does not know what it really will. It is true that one passion can be conquered only by another; we cannot will an emotion that leads to a certain course of action; but we can fix our attention on the objects which produce it, and by thus reaching a clear recognition of their actual and necessary relations, affect our own action. It is true that man does as he wills; but he wills necessarily as he does. According to the doctrine of freedom, it must be exactly those who act without knowing wherefore they act, and who are thus driven by blind impulse, who are the most fully self-determined. A real freedom and conquest of necessity can, on the contrary, be attained only by obedience. Just as, in the animal, the summation of impulses and desires reaches a focus in feeling, so in man, in proportion to his development, the summation is in consciousness, the focus of which is the point of concentration of the will's activity. Spinoza's "Will and understanding are one" means: the activity of the will is the realization of the activity of thought. Every one, the more self-sacrificing, as the less selfsacrificing man, does that which is to him the pleasantest; egoism turns the scale in both cases; only in the one case the egoism has a basis of broader love. And since we act according to our conception of things, the question of our responsibility is the question of our full possession of consciousness. The necessity of nature must take away our desert, as far as a future life and its reward are concerned; but from the standpoint of a being who desires happiness and attains to it through evolution, necessity gains a new aspect. Natural Selection is Natural Necessity.

Yet not in the understanding, as such, but in the reason, is the reconciliation of the same with will. Reason in the narrower sense is a higher development of the understanding, constitutes its completion and perfection, and presupposes a high degree of culture; though in a wider sense, as the half-unconscious modifi- 
cation of the impulses by adjustment to the needs of the species, it develops early in man. By it alone man becomes man in the full sense of the word. The activity of the mere understanding is an analytical, that of the reason a synthetical one, the return of cold consciousness to warm feeling, of abstract mind to concrete nature. Truth lies, for the reason, in Totality; hence, to it, the General alone is comprehensible. It has to do, not with abstract concepts, to which nothing in the realms of the mental or physical corresponds, but with concepts of species, concrete concepts, which we call, in distinction from abstract concepts, ideas. By ideas is not meant existences in the Platonic sense, but the Typical in species.

The impulse to happiness which arises with consciousness as thought and will, calls itself "I." It is the individual who, with every nerve-cell and every drop of blood, attempts his own realization. But all individuals are alike in this, that they reach, at last, a point where they recognize the fact that their ego is but a miserable half which needs a Thou to its completion. In the union of the Thou and the I, the first I becomes a complete and perfect I. Man and woman both realize that only together do they represent the whole human being. I and Thou together constitute a We. The ego remains after, as before the union, the axis upon which the whole world turns. But the egoism of mere understanding is, by a broader thought, elevated to the altruism of reason. As the highest union of thought and will, the reason becomes Idea in and for itself, actual, absolute Idea. With the We was born the Saviour who should reconcile the sharply opposed factors of awaking consciousness. The light of his gospel spread in wider and wider circles; man and woman no longer beheld, each, merely his own happiness in the other; they saw their mutual happiness in their children, and their own and their children's happiness in friends, and their own and their children's and their friends' happiness in their fellow-men. The I of the reason is the self-conscious We.

The struggle for happiness has brought forth, out of the privileges and endeavors of individuals, civilization in its present form. Want and the necessity for labor have been the spur to endeavor and advance. Through the concepts of ends and of intention, the self-conscious will further evolved ideas, which themselves undergo a struggle in the activities to which they give 
rise; and this is no longer the struggle for existence, but the struggle for civilization.

There are three Ideas which, arising out of the extension of the I to Thou and We, are the spring of all ethical conceptions; these are Love, Humanity, and Public Spirit. ${ }^{1}$ Love is the passion of passions and is the spring of all capacity to altruistic emotion. Love is life in its highest degree; ${ }^{2}$ and by the manner in which a human being loves one may know what manner of man he is, and what will be the nature of his feelings towards his fellow-men in other relations of life. A man's conduct towards women is the surest test of his character. That which Spencer calls Integration, that which has created all nature, from the first germ to the perfect human being, and, as preservative cell-labor, still continues to create, - this infinite Something comes to consciousness in the human being, as Love. On the lowest plane it can appear only as simple impulse; but what, developing from stage to stage, it can accomplish, the history of Love shows us.

'To these three ideas of Love, Humanity (or Benevolence), and Public Spirit correspond three outward phenomena, which bear such relation to them in the development of morality as the body bears to the soul. These are: the Family, the State-form, and the Representatives of Great Ideas. These latter, the men who have been pioneers of civilization, we do not need to pity or regard as victims, though life was to them a mighty struggle and a restless labor; in their suffering was their pleasure; and that which impelled them and compelled them to attain their end was the impulse to happiness. Therein lies the wonderful secret of the clarified impulse to happiness, that it finds its highest satisfaction in itself. Such representatives of great ideas are those in whom the species orercomes the individual, and out of the species "man" the species-man is developed. That which they express is the True, if only the True for, and in, mankind. In this lies their worth; as worth in Science also, and in the Beautiful, lies in the truth of the Idea that is therein expressed. The True becomes practical in the Good.

The reason is thus the first condition of happiness, and freedom of the will lies in the ethical ennoblement of reason, which is

${ }^{1}$ Gemeinsinn oder Gemeingeist, pp. 340, 410. Carneri explains this word as equivalent to the English "common-sense," but defines the latter as feeling for the general, the universal.

2 Potenz. 
nothing more nor less than obedience, as the total result of all natural causes; by it the individual is lost in the species as a whole. This ethical height does not consist in impulse, but in the self-conscious activity of will. Its mental expression is an Ethical Sense, in distinction from the Moral Sense of the Intuitionists. Through it man is at one with himself as with his kind.

The Ethical Sense is not the common property of the species. Just as it has, however, reached expression in a few, so it is more and more realized in the many by the process of evolution, through which a common will, purpose, and good are necessarily finally evolved from all striving of individual wills after happiness. Ethical ideas arise as the result of experience, and in them man gradually attains reason.

For the Reason to which Love, Public Spirit, and Humanity are the natural element, the General (Common) as truth, is no empty conception, but a promise whose fulfilment is the Good and the Beautiful. The faithfulness of this Reason never swerves, since it depends on no fear, but springs from the clearest conviction, and therefore is one with the love which it feels and inspires. Its friendship is as strong as it is unselfish, for it does not call anything "friendship" that is based on other relations than those of mind. Its generosity is always strength, its mercy never weakness. As far as its power reaches, so far and no farther do its remorse and pity extend; for all passions which reduce or dim the activity of the soul are unreasonable. The way to the attainment of the ethical spirit is pleasure, which guides, though it often misguides us; fortunately, on the wrong paths we sooner or later meet with pain, while on the right path we are ever accompanied by pleasure as "transition from less to greater perfection," to quote Spinoza. The feeling of Responsibility consists in the soul's recognition of all its action and omission of action as its own, and in the courage to endure the consequences of these.

The ethical Ideal, which the ethical imagination as "scientific" conceives, is the truly happy man, the man fully in harmony with himself. This idea is to be regarded as a star by which we are to shape our course, not as an end to be fully attained. Through labor mankind approaches this ideal, attains knowledge from experience, and clarifies the concept of happiness. The "I" extends itself to an "I" of mankind, so that the individual, in making self his end, comes to make the whole of mankind his 
end. The ideal cannot be fully realized; the happiness of all cannot be attained; so that there is always choice between two evils, never choice of perfect good, and it is necessary to be content with the greatest good of the greatest number as principle of action.

This is an ideal which is actually and necessarily evolved. Benevolence has become more general, and has attained a degree not conceived of in former times. The ideal of a happy humanity has gained definite outlines, and has become an earnest aim towards which we steer with filling sails. The end is not to be reached by force, which brings in its train evil that cannot be gotten rid of for generations, but must be attained within the bounds prescribed by the state, through education and increase of intelligence. Nor can the state declare and ensure happiness; the duties of the state are chiefly negative, as Bentham has said. Each individual sacrifices a portion of his happiness in order that the rest may be secured to him by the state; the first-named part comprises his duties, the rest constitutes his rights; the office of the state is to hold each to his duties and secure to each his rights. There is no perfect state, just as there is no perfectly good individual; but there is progress in states as in individuals.

The merely Useful can never furnish a full solution of the problem of Ethics, any more than Mathematics and Mechanics or Physics and Physiology can do so. The Perfect is much more than the merely Useful. Spencer finds the condition of happiness in the exercise of function. But he regards happiness as the final end of morality, while, according to our system, the latter is the product of the former.

Carneri again pleads, in this book, for the like right of woman with man to mental culture, and to labor which shall make her independent of the caprice of man; the good of the family alone to be regarded as the limiting factor.

The extent of Carneri's work on the subject of Ethics makes it impossible to consider minor points of his theory, such as are included, for instance, in his criticism of Hartmann, of Schopenhauer, Feuerbach, and others; or to define more clearly than has been done his relation to Spinoza, Kant, Hegel, etc. His book "Entwicklung und Glückseligkeit," published in r886, is a collection of essays which first appeared separately in "Kosmos," and which, as such, do not hold to each other the relation of parts 
of an organic whole. They are chiefly a recapitulation of the views already expressed in the "Grundlegung der Ethik," with some extensions and possibly some modifications; - these last, however, chiefly of an extraneous character. In these essays Carneri demands a systematic moral training in the common school, to the end of the development of conscience, such training to be non-religious, though not anti-religious excepting in case the religion itself be seen to transgress the laws of right established by humane reason; he protests against the error of Materialism, as likewise against that of the Apriorists and the "Ideologists" or Idealists in the narrower sense of the word; and he reaffirms, defines, and further defends his standpoint as that of a "Real-idealist"; that is, of one to whom Kant is the point of departure in a farther evolution of theory. He reaffirms the oneness of the universe, so of man with nature, restates the self-identity of the individual in will and thought, limits the knowledge of man to nature as it is for us, but invests it with certainty within these bounds, and reasserts the necessity of the progress of the whole through the efforts of the many for happiness. He lays further stress upon the absence of morality, not only among the animals, in whom at least general ethical feelings, in distinction from those towards individuals, are not found, but also among savages; morality being not the incentive to, but the product of the state. From this standpoint, he combats Socialism as proposing impossible ideals, since it presupposes ethically perfect men as governing and being governed by the laws, and since it disposes of the freedom of the individual. The theory of compulsion reckons without the will of man as he is and must be. Man has no primordial rights (except, perhaps, the right to get and keep all he can); he has only rights that he has gained by the help of the state. There is no one commandment in which man's whole duty may be expressed, unless it be, perhaps, some such new rendering of Kant's words as this: Act always in such a manner that the maxims of thy will might be taken as the principle by which to render happy the greatest possible number of human beings. But this can never become a categorical imperative for all men. Morality lies in the Will to Good, which becomes in the moral, or according to Carneri's phrase, the ethical man, a second nature: his sense of duty is joy in duty, highest satisfaction of his desire for happiness. It might perhaps be claimed 
that Carneri, in his theory of the Conscience, has in this book laid more stress on feeling than in his others; however, it is to be recollected that, with him, thought and feeling are no distinct faculties, but that conscience means less an impulse unconscious of final ends than a self-conscious attitude or readiness of the will as the result of conviction.

Carneri's latest book, “Die Lebensführung des modernen Menschen" (I89I), is practical rather than theoretical, a consideration of general problems and rules of action.

\section{HARALD HÖFFDING \\ “Eтнics" ("Ethik," I887)}

Ethical judgments contain an estimate of the worth of human actions. Every such estimate presupposes the existence of a need, a feeling which spurs us on to the judgment of the action, as also the existence of a standard, an ideal, according to which we judge. The motive to the ethical judgment may be called the basis of Ethics. The standard involved in the ethical judgment determines the content of Ethics, in that it decides which actions, which directions and modes of life, are to be called good in the ethical sense. The ethical basis is the subjective, the standard the objective, principle in Ethics; the character of an ethical conception depends upon this presupposed basis, the applied standard, and the relation between the two.

The feelings and impulses of the individual are not only influenced by his own experience, but bear also a character derived from the experience of the whole species; hence the ethical judgments delivered by the individual are the result of the whole experience of his kind. It is by virtue of this circumstance that the ethical system of the individual gains its power; as ethics of the species, it is a condition of the health and vitality of human life.

This actual working Ethics of the species and of life has been named Positive Morality. Such Positive Morality manifests itself in the every-day judgments and principles of men, often in the form of proverbs, and may express either the enduring worldly wisdom of a nation, a tribe, or a religious society, or the less enduring "public opinion" of a century or an epoch.

Is it well to treat such Positive Morality to a criticism, which, 
arousing, as it must, doubts and questions, will interfere with the certainty and energy of action that characterize unreflecting instinct? Is it well to examine the principles of such a system from a scientific standpoint? We may answer: Life itself leads naturally to such questionings; only where the view is narrow and the problems simple is there full security from doubt. With the growth of experience begins a comparison of the different laws and ideals, the differing institutions of different epochs and peoples of which one learns; or new experience presents problems which cannot be solved by means of the system handed down; or the individual seeks some orderly arrangement of the great multiplicity of ethical judgments which he himself pronounces or hears others pronounce, for the purpose of distinguishing between the more and the less important ones. It is certainly a serious point in an individual's or a nation's development when reflection and criticism begin; but where life leads naturally to such questionings, we must either find some answer to them or else some reason why they shall not be answered. Moreover, it is to be noticed that certainty and force of action are not absolute Goods. The greatest energy may take a most disastrous direction, and must then be checked. To a new and better insight, when attained, one must endeavor to secure all the energy possible. All evolution consists in the diversion of energy from lower to higher ends.

A scientific system of Ethics does not, and cannot, take the place of Positive Morality; it only supplies the latter with a basis of reason, broadens, and develops it. Such a scientific system only endeavors to discover in accordance with what principles we direct our life, and to secure for these, when ascertained, greater clearness and inner harmony. In the mental life of the human being, a continuous action and reaction of the conscious and the unconscious takes place, as well as of perception, feeling, and will. What is won in the one province may profit the others also.

Two tasks of Scientific Ethics, as Historical Ethics and as Philosophical Ethics, are to be distinguished. Historical Ethics has to do with the description and explanation of the development of Positive Morality. Philosophical Ethics has to decide upon the worth of the various forms assumed by the latter. Philosophical Ethics is a practical science, and is based upon the supposition that we set ourselves ends which may be reached through human 
action. Every ethical judgment presupposes such an end, for feeling is set in motion by the sight or the thought of an act only when the latter promotes, or stands in the way of something, the existence and success of which are desired by us. Not all that is developed as practical morality can be pronounced good. On the other hand, customs which were at first assumed from motives which must be condemned by Philosophical Ethics, may yet prove themselves good, and may be practised, later, from higher motives; and such customs cannot then be condemned on account of their origin. Hence, Philosophical Ethics is both conservative and radical; it respects nothing simply because it exists; but since it endeavors to furnish guidance beyond present standards, it attempts to show how that which has been developed historically may be given new forms and thus used for further progress. It is difficult, from a broader view, to distinguish perfectly between Historical and Philosophical Ethics; the historian has an ideal which he applies more or less in his researches; and the philosopher in Ethics is more or less ruled by the prevailing opinions of his time. This necessitates a continual re-discussion of problems. Yet it does not prevent the existence, in any system, of lasting principles among the less enduring ones.

Theological Ethics is directly opposed to Historical Ethics as well as to Philosophical Ethics. It builds upon tradition, upon truth as something historically revealed. So far, it might appear as if Theological Ethics were related to Historical Ethics. But the system of the former does not recognize the method of scientific research, since the revelation on which it is based is due, according to its doctrine, to an interposition of supernatural forces not to be explained by the physical, psychological, and social laws that serve as the foundation of historical science. It demands a unique position for its historical basis, and asserts that this must be looked at in an entirely different light from that in which the rest of the history of the world is regarded. It appears to approach Philosophical Ethics in instituting an examination of the worth of historic acts and modes of life. But it undertakes this examination, not according to any principle that can be found in nature, but from the point of view of a supernatural revelation of an ideal. Its foundation is an absolute principle of Authority; its good is that which is God's will. But how is the individual to be sure as to what, in the single case, is God's will? By the inward 
testimony? How is he to distinguish certainly between such and his own natural thoughts and feelings; what means of distinction can be applied? In passing thus to the province of Psychology, we assume a human means of distinction, and the principle of Authority loses its force. Or if it be said that we should receive this principle of Authority because it answers to a need of our nature, we may ask how we know that the need is one that should be satisfied? Its mere existence cannot guarantee that. Or how, then, are we to distinguish which of other wishes and needs of our nature should, and which should not, be gratified? Is the principle of Authority to decide this? Then we argue in a circle.

A similar circle is adopted by such theologians as attempt to combine the two assertions: "The good is good because God wills it"; and "God wills it because it is good." If the good is identical with God's will, this means that he wills it because it is his will; if he, however, first recognizes something as good, and therefore wills it, then his will bows to a law and rule, and is not, in itself, the cause whereby the Good is good.

Have we not, as a fact, already broken with the absolute principle of Authority as soon as we begin to reflect, to endeavor to bring the various commandments of Authority into harmony with each other, thus applying the measure of our own reason to them?

But it is not these inner contradictions alone which hinder Philosophical Ethics from making use of theological assumptions; that which has called Philosophical Ethics into existence and lends it interest, is the conviction that the ultimate reason of the ethical must lie in man himself. However lofty may be the ideal, it can become man's ideal only through his own recognition of it as ideal. For this reason Socrates was the founder of Ethics by the command: "Know thyself!" In this command is expressed the principle of free investigation, the opposite to that of blind obedience. The desire to make Ethics as far as possible independent of assailable assumptions is likewise active in the establishment of a system of Philosophical Ethics.

In the great, sometimes too great, regard paid to the distinction between the subjective and the objective worth of actions, and the contest as to the relative importance of the two factors, the fact is often overlooked, that the standard by which ethical judgment is pronounced is itself of subjective nature. The question arises as to wherefore we seek a general and objective standard. 
It is a fact that human beings reflect upon their own acts, pronouncing them, according to the result of this reflection, good or bad. How are such judgments as these possible?

We will suppose, first, the simplest conceivable case, namely, that the acting subject pronounces judgment on his own act without consideration of the existence of other beings. Such a judgment must presuppose memory; but it presupposes something more, namely pain or pleasure through memory; an end is aimed at only because the thought of a result causes pleasure. In the simple case supposed, the feeling which determines the end can be only that of the individual himself, and the latter will judge the act as good or bad according as it has affected his own life. The character and significance of the judgment will depend on whether the feeling of pain or pleasure is determined only by the single moment or has reference to the life of the individual as a whole. The lower the life of consciousness, the more isolated and independent are the single moments of time in relation to each other, and the less is the significance of the memory and the thought of the ego as a whole embracing the single moments with their content. Only a half-unconscious instinct hinders the individual from losing himself in the moment; the instinct of self-preservation leads him to consider the future and to make use of the experience of the past. The more he loses himself in the moment, the less is the power of judgment, since comparison and action and reaction of the different states cannot take place. The single moment bears to all others the relation of an absolute egoist, who does not wish to relinquish any part of its satisfaction for their advantage.

And here we may perceive the possibility of a standpoint upon which all judgment is dispensed with. Such a standpoint is represented by Aristippus of Cyrene, who asserts the sovereignty of the moment. It is not without its justification. Ethics itself must show cause for the relinquishment of the satisfaction of the moment in favor of other moments.

If the principle of the sovereignty of the moment could be practically carried out, no reasoning could overthrow it. However, there can scarcely be a conscious individual in whom there are not instincts and impulses which reach beyond the moment. When a momentary state of feeling, as the effect of an act of the subject, comes together in consciousness with the feeling deter- 
mined by the conception of the life as totality (the result of memory and comparison), a new feeling arises which is either one of harmony or one of discord. The standard by which judgment is pronounced is determined by this feeling. The capacity for such feelings is conscience, as this may manifest itself in entirely isolated individuals. Conscience, in the broadest sense of the word, is a feeling of relations, and requires only a relation between central and peripheral feelings, - feelings of wider, and feelings of narrower thought-connection. The single moment and the single act are judged according to their worth as parts of the individual life as totality.

And here the individual is confronted by the necessity of bringing the single parts of his life into harmony. The problem is certainly never solved by any individual involuntarily. The estimation of earlier acts according to the assistance they give in this task is, therefore, at this point, of great importance to the individual. The judgment pronounced is thus not only made possible through the central feeling which corresponds to the life as totality, but is determined by it. An acute sense for that which benefits the individual life whose single members are the moments, is a condition of the continuance and development of the life; it is a higher sort of instinct of self-preservation, and need not be confined to the continuance of physical life, but may also refer to the ideal needs.

And here we come upon the standpoint of Individualistic Ethics. From such a standpoint, the problem is to determine, not only how much energy may be used in the single moments of time, but also in what manner it should be used in order to secure as great variety and many-sidedness as may be consistent with the interests of the life as totality. Nor are the interests of the life to be summed up in physical self-preservation; the individual acquires, in the natural course of things, interests of increased ideality and complexity, through which the life gains in content.

The ethical law, from the standpoint of Individualism, is expressed by a formula which requires harmonious relation between the interest of the life as totality and the impulse of the moment; it consists of two chief mandates: (I) The single instant should have no greater independence than corresponds to its significance in the life as totality; (2) but, on the other hand, the single moments should be as richly and intensely lived as is consistent with the preservation of the life's totality. 
Of Individualism, or the principle of the Sovereignty of the Individual, the same is true as of the sovereignty of the moment, that no reasoning can overthrow it; if the individual recognizes no end but his own life, there is no logical way of transition to another standpoint. A change of aim can take place only through such a change in the central feelings which determine the standard of the individual that a wider circle of conceptions enter into his reflections. Until this takes place, there is no use in appealing to conscience.

The science of Ethics has often claimed to be a science of pure reason. This claim is opposed to its character as a practical science, since action can be judged only according to the ends it had in view, and ends presuppose feelings of pain and pleasure. On the other hand, there is, in the mere capacity for pain and pleasure, no limitation of the extent of the circle of conceptions with which the feelings of pain and pleasure are connected.

Individualism can be carried out in practice only approximately; the individual has his origin in the species, and lives his whole life as a part of the life of his kind, with an organization in which the results of the action and passion of earlier generations are inherited, and in a mental atmosphere which has induced the development of his species. And just as the instinct of self-preservation did away with the isolation of the single moments of the individual life, becoming, thus, the basis of feelings determined by the interests of the life as totality, so the sympathetic instincts do away with the isolation of the single individuals and determine the conditions of the life of the species in the minds of its individuals. The most primitive form of the sympathetic instincts is exhibited in the family. Here, however loose and variable the relation of man and wife may be, that of mother and child cannot, by its nature, be done away with or essentially changed. In this case, the sympathetic feeling springs immediately from the natural instinct, and the relation is the nucleus which makes possible the higher forms of family life. In the family circle, the sympathetic feelings are cultivated, and arrive at such strength that they come to include ever wider and wider circles of human beings. Indeed, the mother-love remains forever the image and criterion of all sympathy, as well in respect to strength as to purity.

When sympathy has reached full purity, it is a feeling of pain 
or pleasure determined by the fact that other beings feel pain or pleasure. The most important point of its development was when it so broadened as to include all mankind. The Peripatetic and the Stoic schools of Greek philosophy led to this idea of love to all humanity and the natural union of all men in one great society. But this idea acquired greater historic importance when it became a chief commandment of a great religion, - of Christianity. To this sympathetic feeling the criterion of good and evil is no longer to be found in the individual life, but is dependent on the life of the whole society of which the individual is a member.

Yet sympathy is not, from this standpoint, identical with the ethical feeling, conscience. Conscience is here, too, a feeling of relations determined by the relation between the ruling or central feeling of the individual and the results of action. When the individual feels his own interests subordinate to the good of the whole of which, through sympathy, he regards himself as a part, the ethical feeling appears as the feeling of duty. A feeling of duty may be spoken of, likewise, from the standpoint of pure Individualism, for the concept of duty expresses only the relation of a lower, narrower consideration to a higher; and this is represented, in Individualism, by the relation of the single moments to the life as a whole.

From another point of view, the ethical feeling appears, in its higher development, as the feeling of justice, which, while regarding the good of the whole as the chief end, considers also the peculiarities of individuals. Sympathy in its active form is impulse to share. This sharing must be carried out according to fixed principles; where sympathy is universal, differences of division can be justified only by the fact that the Goods divided, if otherwise divided, would not be in so high a degree Goods to those to whom they reverted, or would not conduce to so great progress of the society as a whole. The ethical law upon this standpoint, the standpoint of Humane Ethics, can be no other as to content, than that action shall conduce to the greatest possible welfare and the greatest possible progress of the greatest possible number of conscious beings; and this law includes two chief mandates, a negative and a positive mandate: (I) The individual may not receive more than befits the position which, in consequence of his peculiar qualities, he occupies among his kind; (2) but, on the other hand, the capacities and impulses of every individual 
shall be as fully and richly developed and satisfied as is consistent with the demands of the life of the species as a whole. These two mandates follow with logical necessity from the concept of society as a multiplicity of conscious beings united into one whole. It is contrary to the unity of society, that an individual, or that individuals, should be wilfully preferred to others; every exceptional position must be justified by the demands of the general conditions of life; on the other hand, a society is the more perfect the more freely and more independently the single members move, and the larger the number of different possibilities it realizes, if, at the same time, unity is preserved and attains an ever higher character and ever increasing validity.

When the ethical feeling develops, upon the basis of sympathy, to the feeling of duty and justice, the principle included in the above law becomes the standard according to which the individual judges his own actions as well as those of others, and pronounces them good or bad. The good is that which preserves and develops the welfare of conscious beings.

The ethical principle now arrived at applies to the deeds of conscious beings, presupposing an end in view. Unconscious nature affects man's life, but its workings have no ethical charactei. The ethical judgment is itself determined by the principle on which it is pronounced, and hence it serves to produce greater welfare. This is especially to be seen where the judging and the acting individual are one and the same person; in other cases, it becomes a special problem to bring the acting individual to the recognition of the principle; this is a problem of psychologicpedagogical nature.

The word "welfare" is used in preference to utility or happiness in order to prevent misunderstanding, and may be defined as including all that serves to satisfy the needs of man's nature. Ethics must take into consideration all the gradations of life, and cannot, therefore, distinguish in the beginning between outer and inner, higher and lower, welfare. Such a distinction is already an ethical judgment, and can be made only after determination of the ethical criterion. Another mistake is the stress often laid upon momentary feelings of pain and pleasure. Pain signifies, it is true, the beginning of the disintegration of life, and pleasure its normal and harmonious development; yet each must be considered in its relation to the whole consciousness, the whole 
character, and the whole social state. So-called utilitarianism has injured its own cause by resolving consciousness into a sum of feelings, and society into a collection of individuals. The significance of single feelings of pain and pleasure for the welfare of society cannot be determined as if the problem were a simple arithmetical one.

The reasoning of Philosophical Ethics must not be confused with practical reflection. In the last we are led by instincts and impulses, by motives of which we are, for the most part, wholly unconscious, by thoughts and feelings the first origin of which we cannot designate. We follow the "positive morality" to which we have accustomed ourselves and which is, in part, an inheritance of our species. Ethics as an art precedes Ethics as a science; the aim of the latter is partly to show by what principles the former is guided, and partly to correct these principles.

The ethical principle broadens out, thus, from the single moment of the individual life until it embraces the whole of mankind; but there are many points in the course of the development at which we can make a stand, and there may, therefore, be as many philosophical systems as there are larger or smaller totalities. The position of the man who holds fast consistently to a principle that determines the criterion by the family, the caste, the nation, a sect, as highest totality, is as unassailable as we have seen that of the individualist to be. The psychologichistorical evolution alone can bring us, through the changes which it produces in the feelings, beyond these criterions. In other words, every criterion has a psychologic-historical basis. $\mathrm{He}$ who is to recognize and carry out practically the principle of the greatest possible welfare, must be no egoist or individualist, no fanatical patriot or sectarian; this is the subjective condition necessary to the objective principle. The conscience which is to be regulated by the objective principle is always itself the condition of the recognition of this principle. A system which leaves this fact out of consideration takes on a dogmatic character. The basis of all ethical judgments is feeling. By this is not meant, however, that the standpoint of an individual cannot be influenced by argument; the feelings are always connected with concepts, and discussion of these concepts is both possible and must react upon them even if only very gradually.

Conscience is not infallible in its application of the objective 
principle; a wider experience may show it to have erred. Conscience is highest authority, but still an authority which may continually perfect itself. The objective principle makes possible the mutual correction of different consciences and the self-correction of the conscience of the individual through self-judgment.

The difference between Subjective Ethics and Objective Ethics, as here explained, does not coincide with the difference between Individual Ethics and Social Ethics. Objective Ethics includes both the latter, since it recognizes individual peculiarities. It has yet to be decided whether, within the bounds of Objective Ethics, Individual Ethics and Social Ethics are dependent upon each other, or whether one, and if one then which one, determines the other. It has to be decided whether, according to the principle of welfare, the free self-development of the individual is to be limited by the conditions of social life, or vice versa. Within the limits of Objective Ethics, there may arise an Individualism of another sort than that before mentioned, founded, not upon the sovereignty of the individual, but upon the principle of welfare, which demands as many independent and peculiar points of departure for action as possible. 'The like is true, also, of the question of smaller organizations within larger ones.

The history of Ethics shows us that the ethical judgment of actions at first regarded the outer act itself and its results, but was gradually extended to include the motive, the disposition, the character of the acting subject. It is perfectly natural that regard should first be attracted to that which is the object of sense-perception. Moreover, action at an earlier stage of development is essentially reflex action, and the expression of instinct; the motives are simple and transparent, and interest does not linger long with them. The great revolutions in Ethics appear as essentially progress with regard to the importance accorded, in ethical judgment, to the inner factors of action. This greater inwardness is combined with a generalization; for the rejection of a motive is the rejection of all action occasioned by it, and the ethical acceptance of a motive the acceptance of all action springing from it. Hence the transference of regard to inner conditions represents a great simplification of the ethical law. Examples of such a transference may be found in the rupture between Christianity and Judaism, and between Protestantism and Catholicism. 
In this way, too, Objective Ethics leads to Subjective Ethics. The objective judgment not only presupposes a subjective basis, but also finds some of its best objects in actions which spring from the same mental constitution which is the basis of the judgment. Here, the basis of mental constitution and the motive coincide; the ethical law demands the existence of the moral disposition by which it itself exists in the species. This Kant expresses in the assertion that it is a duty to possess conscience. Since the recognition of duties presupposes the existence of conscience, it might seem as if here were an argument in a circle. But that this is an illusion may be seen from the fact that the basis of ethical judgment and the motive do not necessarily coincide and that it is not necessarily an imperfection when they do not coincide. It may be necessary in some cases, in accordance with the principle of welfare, that other motives than the sense of duty shall guide the action; it may be necessary and healthful, for example, that in some cases man should be led by the instinct of self-preservation, or by an immediate sympathy, to labor for the welfare of others, and that conscience should not be aroused in every single act. It may even be a sign of perfection when actions that demand exertion and sacrifice are carried out without the intervention of a sense of duty. Indeed, mental drill in the end renders that which at first took place by means of a long psychological process of reflection and will, direct and without special consciousness of its reason.

All Ethics is practical Idealism. All systems assume an end, and an end is not anything at present existing, but something which ought to be. All systems assume, therefore, strong feeling, impulse, and endeavor, combined with the image of that which is the object of the endeavor. But the ideal must have points of contact with actuality, so that at least an approach to it is practicable; it must be physically, psychologically, and historically possible.

Ethical ideals deviate from the actual in three ways. In the first place, there is often in actual willing and doing something directly opposed to the principle of welfare. In this case, the office of Ethics is to restrain and forbid. To this function corresponds, in the practical life of the will, the hemming by which involuntary, original, or acquired impulses and inclinations are repressed. Again, actual willing and doing often exhibit only 
a weak and imperfect realization of that which Ethics demands. Here there must be an increase in the degree as well as in the extent of the realization. To this corresponds, in the practical life of the will, effort and attention, the power of the will, through its influence upon conceptions and feelings, to react upon itself. And finally, there may be, in willing and doing, a lack of unity and harmony; various opposed tendencies and impulses may make themselves felt. Here a process of harmonizing and concentration is necessary. And to this corresponds, in the practical life of the will, a drilling in connected action and trains of thought, and in the power to make an end of reflection by decision. In all three cases, the principle of welfare is to be followed; and the three processes are to be applied not only in the development of the individual but also in that of societies, and of the species.

That which manifests itself in conscience is a species-instinct. In the feeling of judgment, the relation between central and peripheral factors finds expression, neither of which, and least of all the central factors, are developed by individual experience, but both of which are, on the contrary, the product of the experience of the species. What Kant called the Categorical Imperative is, in fact, an instinct; and every instinct speaks unconditionally, categorically, gives no reasons and admits of no excuse.

No instinct finds expression without the existence of conditions which call it forth; but all manner of individual and social circumstances may furnish such conditions.

When conscience begins to be conscious of its office, it manifests itself as an Impulse. ${ }^{1}$ The thought of actions which the instinctive judgment has recognized, or to the performance of which it has perhaps incited, is combined with pleasure, the conception of actions of the opposite nature with pain. The tendency arises to linger with the former and to repeat them, and to turn from the latter, if no stronger impulses of another sort make themselves felt.

Conscience may develop, without losing entirely its instinctive or impulsive character, to practical reason. This takes place through the development of the conceptions which determine the conscience as impulse, to greater clearness and distinctness. When conscience acts as instinct, the individual does not know what he does. If it acts as impulse, he has a dawning conscious- 
ness of his acts. And when it becomes practical reason, there arises a clear consciousness of ethical laws and ethical ideals. In different individuals, conscience may appear in very different forms and degrees, as instinct, impulse, practical reason, sense of duty, sense of justice. Sometimes it appears as mainly negative and restraining, sometimes again as chiefly positive, partly harmonizing and partly increasing. Here it appears as enthusiastic devotion, there as quiet and continuous tendency. It would be impossible to name even the principal forms in which it may manifest itself, but it is of great importance to call attention to the fact of these individual differences, since we suffer at present from a dogmatism that has but one measure for all these different manifestations.

We must go a step farther still. There may be men who possess no strictly ethical feeling and who do not need it. Such men do what they can with their whole heart without applying any reflective standard to their own or others' acts. They entirely absorb themselves with unflagging zeal in a work that perfectly corresponds to their capabilities and impulses, without any doubt of its rightfulness and import. They may devote themselves to art and science, to the service of society, or to their family. Or they belong to the class of happy natures who spread light and joy by their mere existence. They act in accordance with the law, without being in possession of the law, and what objection can Ethics have to offer to this? Ethics is for the sake of life, not life for the sake of Ethics.

Since all ethical judgments have conscience for their psychological basis, conscience is highest authority, highest law-giver, in comparison with which every other authority is subordinate and derived. To wish to go beyond one's conscience is to wish to go beyond oneself. When I yield to another human being whose judgment I trust more than my own, this can be justified only as it takes place through my conscience. Conscience is infallible, if one understands by infallibility that it is, at every instant, the highest judge; this infallibility does not mean, however, that it does not err. Every earnest conviction takes the form of conscience; the truth is not, however, secured by the mere form. Was it not from conviction that Aristotle asserted the right of slavery, and Calvin, with Melancthon's approval, sent Servetus to the stake? 
Not less dogmatic than Fichte's assertion that conscience never deceives us, is the view which regards a system of Ethics as merely the science of the forms of society and of outward acts, and thus declares conscience to be without authority in comparison with outer circumstances and their demands. The law which we obey must always express itself in the form of conscience. The light which illumines for us all other things must be within ourselves.

Here we perceive the possibility of a conflict between Subjective Ethics and Objective Ethics, between the two principles upon which Ethics is founded. There can be no other solution to the problem than that we shall follow the command of conscience, provided it speaks clearly and after sufficient deliberation. It may be added that conscience can correct and control itself, the later and more experienced conscience criticising the earlier. As long as the individual acts according to his best conviction, he is morally healthy; hence, from an ethical point of view, a pernicious action carried out under the conviction that it is good is to be preferred to a good action performed with the conviction that it is bad. In the former case, the spring is pure; in the latter it is corrupt. Only he who has courage to make mistakes can accomplish anything great. It is not the cold and narrow, but those who are zealous for the true and good, who thus err.

The power of self-correction can be developed only when some definite principle or criterion may be found. Such a principle is that of welfare. The problem of the application of this principle to action is, however, like that of the application of the principle of causality to actual phenomena, an endless one.

In close relation to the concept of Authority stands that of Sanction. The Authority commands or forbids, the Sanction enables the command or prohibition to remain in force. The sanction consists in the pain or pleasure connected with the observation or transgression of the command, in the reward or punishment which one brings on oneself through one's action, in the heaven or hell which one approaches by the action. It is only, however, when the authority itself is an, outward one that the sanction holds this outward relation to the action. In this outward form it has no immediate ethical significance. The ethical character of an action is dependent, in subjective regard, on its origin in the intention of the performer, in objective regard, on its harmony with the principle of welfare. What 
ethical significance could it have that here a feeling of pain or pleasure not arising from the action itself, is added to it? The outer sanction of reward and punishment is thus but an educating sanction. The inner sanction consists in a feeling of harmony and unity with one's own highest convictions, of consistency between one's ideas and one's actual willing. Thus arises an inner peace that may be stronger than all contradiction and opposition from without.

Such an inner sanction is not only an effect of the action, but a feeling already present before the action. It was the preservation and full development of this feeling that led to the decision and made it possible. Blessedness, says Spinoza, is not the reward of virtue, but virtue itself.

The manner in which the ethical is so often made dependent upon certain fixed religious or speculative assumptions must be, from an ethical point of view, matter for great solicitude. In the first place, it is easy to suppose that the man who no longer respects these dogmas may have emancipated himself also from the ethical maxims dependent upon them, and would be most consistent if he acted in accordance with the principle: "Let us eat and drink, for to-morrow we die." In the second place, action is reft of its ethical character when the attention is directed to things outside its essence and origin, and considerations of reward and punishment are declared to be a necessary motive. Not even a belief in progress within the world of experience can have any absolute worth for Ethics. It may be theoretically difficult to maintain such a belief; and even if the victorious direction of evolution were shown to be unfavorable to Ethics, ethical principles would not be destroyed. Simply the problems would be different; pity and resignation would acquire greater importance. Wherever the ethical disposition were present, it would take the side of the conquered and remain upon that side though the gods themselves were with the conquerors. Ethical worth does not depend upon mere might.

The birth-hour of conscience is the time when, through the difference between ideal and actuality, a certain feeling arises. Its death-hour would be the instant in which the difference forever disappeared. Such a disappearance might occur in two ways, either through the conquest of the ideal by actuality or through that of actuality by the ideal. The objection has beer made to 
the theory of evolution that it fulfilled the first of these possibilities, and so left no room for Ethics. But the very fact of the existence of ethical impulses as the actual result of evolution would seem to belie this theory. And indeed, we see that evolution is not physical growth alone, but mental as well; and that the important feature of man's development consists in his aspiration through desires and impulses, which act as moving forces in his life. Aspiration is necessary to his evolution, and indifference and lack of sensibility an obstacle to it. The theory of evolution leads directly to Ethics, in that it shows that the struggle for existence becomes, in its higher forms, a common struggle for the continuance and development of human life. The theory of evolution takes us, indeed, not only to, but beyond, Ethics; for, according to Spencer, the ethical sense is but an intermediate condition in a development toward a state of "organic morality," where right-doing will be involuntary and natural, and a special ethical sense no longer existent or necessary. Such a state would constitute the realization of the second alternative mentioned above, with which Ethics would come to an end. This state is conceivable, and Ethics could have no objection to offer to it. Yet we are still far from such a condition, and though we may strengthen our courage and hope with the thought of a continual progress of human nature, yet the assumption of such an end to evolution cannot have an essential influence upon the method of Ethics.

We must, in fact, suppose that progress will bring us new problems and new ideals, that, as the Ethics of the civilized man includes whole provinces unknown to the savage, so many relations will certainly present themselves in the future whose ethical significance our present thick-skinned condition, our ignorance and egoism, prevent us from comprehending.

Can one do more than one's duty? From the standpoint of ethical systems which are founded on authority or any outward principle, this question may be answered in the affirmative. The Roman Catholic Church distinguishes, for instance, between that which is commanded and that which, beyond the command, is merely advised. But he who follows an inward sanction cannot but feel that he has done no more than his duty when he has done all that lies in his power for the welfare of mankind. It may be right, from a pedagogical standpoint, to give especial praise to actions that tower above the usual; he who performs them, how- 
ever, only then possesses the right spirit when he feels that he has done no more than his duty, and could not have done otherwise. Even from a pedagogical standpoint, the difference between duty and merely counselled action, beyond the duty commanded, can be only a relative one; that which is, upon a lower plane of development, merely advised, becomes, upon a higher plane, one of the most elementary duties; mercy to the conquered may be a high virtue in a savage, but to the civilized man it is a primary rule of morals.

It is of the highest importance to keep in mind the fact that conscience itself is a cause, and that ethical judgment, arising as a feeling, takes part, by its influence upon the will, in the ethical evolution towards highest welfare. Keeping this in mind, it is easy to see that Ethics not only calls for no limitation of the law of Causality, but that such a limitation would be pernicious, even destructive, to Ethics.

There are at least six different significations in which the expression "freedom of the will" may be used.

It may be used to denote absence of outward constraint; but this might rather be called a freedom of action than a freedom of the will.

It may be used to denote absence of inner constraint; the will which springs from pain or fear is often called unfree in distinction from the will which springs from pleasure or hope.

It may refer to energy and vitality of the will. Here the stress is laid upon the amount which the will can accomplish, not, however, upon its independence of causes. One can be a determinist and yet concede that the will plays an important part in the world; or one can be an indeterminist and yet assume that free will plays but a small part in the world.

By freedom of the will is often meant the power of choice. This freedom is not opposed, however, to causality, but to blindness of action, subjection to momentary impulses. "Free will" denotes, in this case, self-conscious will.

Or the word "freedom " may refer to the will as ruled by ethical motives. In this sense, only the good man is free. This significance of the word is the oldest, comes down to us from Socrates, and is used by Augustine, Spinoza, and many others.

But the sense of the word "freedom" with which the strife between Determinism and Indeterminism has to do is that in 
accordance with which a free will is not subject to the law of Causality, is not, like other phenomena, a link in the chain of causes, but is, on the contrary, a cause, without being an effect. To be free in will is, according to this definition, to will without cause, - independent of all that has gone before.

Indeterminism destroys the bond between the individual and his kind, between the individual and the rest of existence. Indeterminism is hence unable to regard existence as a totality. Every deeper philosophical or religious conception becomes, thus, impossible; the only religious conception consistent with Indeterminism is Polytheism, since every being that can form the absolute beginning of a chain of causes is a little god, an absolute being. This fact is to be noted, for the reason that Determinism is sometimes designated as a godless doctrine.

The assertion that the will is without cause, and the assertion that we ourselves are the cause of our willing, are two different assertions. The last finds a cause in our nature. Thoughts and feelings, tendencies, instincts, and impulses arise in us, and in these the origin of the acts of the will is to be sought.

If the will, or a part of it, is not subject to the law of Causality, it stands in relation to the whole personality as something isolated and accidental. The Indeterminist who asserts that Determinism makes man a mere machine, himself makes of him something much meaner, something incoherent and accidental. Ethical judgment is based upon the assumption that my action is mine; it is, therefore, clear and certain only when motives and the decision they cause are known. The less my actions can be understood by knowledge of my character, the more easily I may be regarded as irresponsible. Although law regards, by its nature, action and not motive, yet even the judge must gain an insight into the motives, the outer and inner relations from which the deed originated, both in order to determine the degree of punishment necessary, and in order even to be fully persuaded that the action really took place.

Many recent Indeterminists designate the freedom of the will as exceedingly small. They thus extend the dissolution of the unity of existence and of the unity of personality to the act of willing itself. Moreover, if responsibility depends upon freedom, it is impossible to see how reward and punishment are to be justified upon this standpoint; since the individual can say with 
reason that he is not guilty with respect to the whole, but only with respect to a very small part of his act.

The words Responsibility, Guilt, Accountability, are taken, like so many other ethical expressions, from Jurisprudence, or rather they come to us from a time when the distinction between the province of Jurisprudence and that of Ethics had not yet been recognized. That I am made accountable for my action means that I stand as the one to whom reward or punishment for the deed is meted out. For what reason the action is rewarded or punished is a question by itself.

In relation to Ethics, the feeling of guilt, of responsibility or accountability, signifies that my act is subjected to the judgment of conscience. If I find discord between my act and that which I recognize as good, remorse arises, - a feeling of inner disharmony, unworthiness, and self-contempt which may increase until it becomes the greatest psychical pain. This feeling may be defined, from a deterministic standpoint, as dissatisfaction with oneself because one has not acted otherwise, and the wish that one had done so. This wish arises in the moment of reflection, when one weighs one's act. From the present wish is not, however, to be concluded that one could just as well have acted otherwise at the moment the act took place. Such an illusion dates the experience dearly bought with mistake and remorse back to an earlier period. According to the theory of retribution, remorse must be greatest in him who has committed the greatest crime. This is not so, however; since remorse arises from a contrast between ideal and act, which contrast can take place only when the conception of the ideal is strong; the purest and best characters often have the strongest feelings of remorse.

Remorse first arises when a new attitude of mind is attained different from that which ruled at the time of the action. Time is necessary for this new feeling to replace the old, if it is to be more than a momentary passion, and during this interval the two feelings are both active in consciousness. This is the time of the birth-pains by which the new character comes into being. The significance of remorse lies in the fact that it urges forward, that it gives birth to impulse and endeavor after a higher plane. Only because remorse is a motive, is it of ethical nature.

If the law of Causality were not active in the realm of the psychical, this ethical endeavor would be hopeless. Only where 
order reigns can the will accomplish anything. Only as we know the law of outer nature, and know what conditions must be produced in order to bring about a certain result, can we serve our own ends in this province; and the like is true in our relation to human nature. Here the problem is to find motives of the right sort and of sufficient strength. Of what use were all possible exertion if, under given conditions, the same motive were followed by now this, now the other entirely different decision. I am master of my future willing only in so far as a causal relation exists between my present and my future will. We find, therefore, that the reason why responsibility goes no further back in the causal chain than the will, is this: that it is the will which is to be acted on and altered. That which precedes the act of the will interests us, ethically, only in so far as it influences the will.

It is a strange assertion, sometimes made, that the consistent Determinist must be a mere spectator of his own and others' lives. As if one could feel no pain or pleasure and no desire to interfere, because one believes life to be subject to law. It is true that theoretical study may weaken practical interest; but Indeterminism is a theory as well as Determinism.

What the ethically bad is follows from what has already been said. It consists of a more or less conscious isolation of the single moment in the life of the individual, or of the single indi. vidual in the life of the species, such that not only a hindrance to the welfare of individual or species arises, but also a relaxation of energy and a diminution of the coherence of individual or species. In most such cases, inertia is at work. The one moment demands to be lived without any consideration of others, the individual will not move outside the circle of his own interests. Such a resistance to influence may be unconscious. It may be authorized in so far as it is a condition of the development of real willing that action shall not immediately respond to impression. In this resistance lies, therefore, the germ of the ethical as well as the non-ethical life of the will. The clearer consciousness becomes, the more this inertia takes on the character of defiance. Or the discord felt through consciousness of the good may be so painful that the individual desires to free himself at any price. In this case, no remorse is felt; on the contrary, the individual seeks to dull the awakened consciousness, or to get rid of it. 
It is important to note that conceptions develop, in this connection, faster than feelings. And as long as the former do not find points of connection with the existing feelings, they will have no practical influence. The bad consists in the persistence, from inertia or defiance, upon a lower plane of development after the consciousness of a higher has arisen. Evil is the animal in man, the remains of an earlier plane of life. From the instincts of self-preservation and self-propagation in their most primitive forms, the ethically bad is produced, and offers fierce resistance to harmonizing influences.

Evil is, furthermore, a sociological phenomenon; the general psychological elements take on different forms under different historical conditions; society, in its different forms and functions, is always one of the determining factors of its development. The criminal is, like the saint, the child of his time.

It appears, therefore, that the term "bad" is applied from a standpoint not shared by him to whom it is applied. If the man who stands upon the lower plane of morals possessed the full and clear consciousness that the predicate of badness applied to his conduct, the corresponding feelings and impulses must arise in him, and his conduct be altered. It is psychologically impossible to act against our fixed and full conviction, if this is not blunted by other impulses.

The definition of the good must be, on different ethical planes, a different one. But when a disinterested and universal sympathy determines the ethical judgment, only that can be good which preserves and adds to the welfare of conscious beings, increases their pleasure or diminishes their pain. Every action which tends in this direction without producing further results of an opposite nature, is authorized; every action of which the opposite is true is to be rejected.

Since, in general, pleasure is connected with the healthy and natural use of the powers, with that which preserves and benefits life, and pain is connected with the opposite of this, Ethics merely continues the work begun by nature, in aiming at human progress, at as rich and harmonious a development of human powers as is possible. The problems of Ethics concern, therefore, the pleasures of the moment as well as those of the whole life, the pleasures of the individual as well as those of the whole species. This remains true even if we accept the pessimistic 
view that all life is pain; the good would consist, from this point of view, in as great alleviation of pain as possible. Even the ascetic tortures himself only in order to gain greater good.

The ethical end as welfare is not to be conceived as a state of continuance on the same plane. Such a continuance is impossible; evolution does not stand still; every step of progress creates new needs, the satisfaction of which again demands endeavor; perfect satisfaction is impossible. Even the development of sympathy makes it easier to wound us in many ways and brings us larger duties. The need of variety alone would make continuance upon one plane impossible; we labor not only in order to arrive at conscious ends, but also in order to relieve ourselves of accumulated energy. The highest end that we can conceive is a progress in which each step is felt as a good because it affords scope for action without over-exertion.

Activity is also welfare. But it is so only in so far as it is healthful activity; when the powers are over-exerted or dissipated in action, having no common end, or when their application in one direction is at the cost of other more important directions, progress ceases to be welfare. The evolution of civilization contains an element of blindness and heedlessness which is bound up with both its excellencies and its faults. But civilization is not an act of choice; it is the continuance of the evolution of nature. Progress is necessary; it is impossible to remain upon any level attained. Ethics must, therefore, accept progress as a fact. It does not feel an admiration for an order of nature in which no advance appears possible without one-sidedness and dissipation of energy. It is not so hard-hearted that it could forget, in the seeming splendor of outward results, the anxiety and pain, the sweat and blood, with which these were won. It demands, therefore, that the heavy burdens be lightened, the scattered forces united, and all capabilities that are of worth developed. On the other hand, Ethics is not so sentimental and short-sighted that it could forget that progress can take place only through exertion and suffering. Its chief task with regard to progress is to impress upon the mind the fact that life should not be made a mere means to the solution of impersonal problems. Civilization is a means for the individual, not vice versa.

The natural division of Ethics is into Individual Ethics and Social Ethics. It has sometimes been assumed that the whole 
duty of man could be summed up in Individual Ethics. However, it is not necessarily true that that which assists the best development of the individual serves society as a whole also. When the attention is directed so excessively to oneself, the general welfare is likely to be forgotten. On the other hand, a too great subjection of individual interests makes a man a mere parasite, robbing him of all self-dependence. When Ethics condemns the instinct of self-preservation, it condemns its own means. If the impulse to self-preservation, self-assertion, and self-development were evil, then our essential nature would be evil, and Ethics would be impossible. The right relation of the two principles is given in the principle of welfare. Mill's book "On Liberty" denies the ethical significance of self-development and forgets the individual's oneness with his kind, in declaring personal vices of no importance to the general welfare. That which Mill wished to defend was the freedom of the individual, the loss of which through the compulsion of society and the "moral police" he feared. But he might have accomplished this purpose without denying the ethical value of self-development. There is nothing that is a ground for greater solicitude than the mistake that public opinion and Ethics are one, and that a condition of things is no longer a subject for ethical condemnation when no outer power has the right to denounce it.

The first question which presents itself in Individual Ethics is: How is the individual to educate himself to an ethical personality? Here the development and strengthening of the ethical principle as governing and determining the life of the individual is concerned. The problem is one with the determination of the chief virtue which includes all other ethical qualities. This virtue is justice, which includes in itself the two groups contained under Self-assertion and Self-sacrifice. ${ }^{1}$

In the application of this general theory of Ethics, Höffding maintains the radical-conservative and individual-social position already stated. The principle of welfare demands the reconciliation of the free development of the individual and the progress of society as a whole; the individual does not live to himself alone, hence the state has a right to demand sacrifices; but it must always be able to show good reason for such; the burden of proof lies with the side which would take away the most valuable posses-

${ }^{1}$ Selbstbehauptung und Hingebung. 
sion of the individual, - the right to free self-development in the ever-shifting direction of his need. This very characteristic of change makes it impossible for the state to decide for the individual what are his needs, and how they may be satisfied; hence the best course of the state is a chiefly restrictive one. The relation between state-help and self-help must be exactly the reverse of that which Socialism, in remarkable agreement with Bureaucracy anil Absolutism, asserts. Socialism presupposes not only perfection in the governed but also perfection in the persons. to whom the government is entrusted. It assumes, moreover, that pleasure in activity and its resulting power of originality and invention would not be weakened if men's right of initiative were taken from them and their needs determined by others. Much of the good even now accomplished by the state in its functions is due to the competition with individual undertakings.

Philanthropy, on the part of individuals as on that of the state, will best follow this same principle of indirect aid, in order to obtain the best results through education of character. Organization is desirable on the part of individuals, but the state will achieve best results by acting through smaller organizations which afford a wider field and the possibility of more intelligent work. In its methods of punishment, also, the state must have regard, not only to prevention through fear, but also and chiefly to the bettering of the criminal character; capital punishment and lifelong imprisonment cannot be justified from a higher ethical standpoint. Freedom should be allowed and tolerance shown the various religious sects as corresponding to various needs. The more liberal education of woman, which will make her capable of greater independence of thought and action, is one of the chief means to the solution of the marriage-question. The ideal of marriage is free monogamy; in polygamy, the purely physical must always rule; that part of self which one can surrender to many can be only the animal; long association and sympathy alone admit to the sanctuary of love. It belongs to the nature of true love to believe in its own endlessness; it is, therefore, incompatible with its nature to arrange for a mere temporary union. Yet where an unhappy union exists, divorce should be permitted. Strict divorce laws have always fettered and burdened nobler natures, while light-minded people have easily found means of escape.

The view that the artist occupies a peculiar position in his 
ideal world, must free himself from the actual world, and live only for his ideal, is ethically false; art should lend form to actual life, defining and clarifying it, broadening the view and educating sympathy. A great artist is, at the same time, half a prophet; his whole people and epoch must learn to know themselves through him. Freedom is to be regarded as both means and end. A representative government is not only an education for the people, who through freedom alone can learn to use freedom, but affords the state, moreover, a firmer foundation in the consciousness of its citizens that they are responsible for the existing condition of things.

The development of conscience in force and extent takes place through thought and imagination. Knowledge alone is not enough; it must be fixed by exercise, - made a persistent thought, until it becomes, by means of the laws of association, such a thought as will easily come in play whenever the case requires it.

\section{GEORG VON GIZYCKI}

“Moral Philosophy" (" Moralphilosophie," I889)

Moral Philosophy has a scientific and a practical office. Its scientific task is to supply the human being with a clearer, more thorough understanding, founded on ultimate reasons, of his moral life. Its practical task is to answer the important question: How am I to act? How shall I order my life?

It was not left to science first to direct human action. Custom and law seek to order the doing and leaving undone of the members of society. Ethical philosophy ascertains means of testing the actually existing ideas of morality, and thus enables us to better law and custom.

A highest criterion, one only, is necessary, by which to judge of the morality of a deed. If there were more than one, the judgment might fall out differently from the different standpoints furnished by these.

When I regard the qualities which I consider morally good, I perceive that they all have a direction conducive to the generai welfare or happiness; and when I regard the qualities which I consider morally bad, I find that they all have an aim prejudicial to the general welfare or happiness. 
When I attempt to convince any one that certain conduct which he considers right is wrong, by showing him that it is opposed to the general welfare, my final appeal is to his conscience. And in the same manner, when I correct some of my own moral conceptions, it is my conscience which determines me to the proof of them, and my conscience which is the standard that determines my decision. Conscience is the principle underlying my moral convictions. But I do not possess, in conscience, a moral power which never errs; hence it behooves me to judge carefully. Body and mind both have their laws on which depend the welfare and happiness of society; the last results of science and human experience give us these laws.

There are few things in regard to which there is so great unanimity as there is in regard to the right and good. In the fundamental questions, all the more highly civilized peoples are, for the most part, agreed.

On the lowest planes of civilization, only the narrowest tribal association is taken into consideration in morals, but gradually, with the growth of experience, growth of the understanding, which permits the recognition, in a much higher degree, of the results of action and the power of sympathy, ever larger circles of human beings are regarded, - the tribe, the nation, the whole of mankind, all sentient beings. In this development of conscience and benevolence, there is nothing to cause moral uncertainty or contempt of conscience; for, in that case, the fact that there was once a time when human beings were not on the earth must be a reason for contempt of everything human.

We call various different things good, of worth, others bad, evil; there must be something common to all these, on account of which we apply the common term to them. That which is thus common to them is their relation to a consciousness for which they are good or bad, and not to a merely perceiving consciousness, but to one that feels and wills. As true and false relate to the intellectual side of human nature, so do good and bad relate to the side of feeling and will. Such things are good as are the mediate or immediate cause of agreeable states of consciousness or of the prevention or removal of disagreeable states; and on the other hand, such things are bad as are the cause of pain or the hindrance of pleasure. We say of these things that they are agreeable or disagreeable. Or we may use, instead of "agree- 
able," the term "object of desire," and instead of "disagreeable," the term "object of aversion"; for all that is agreeable has an attractive influence upon the will, and all that is disagreeable or painful has a repellant one. Joy is that condition of consciousness which we seek to attain and preserve, whose existence we prefer to its non-existence; and pain is that state of consciousness which we seek to avoid and destroy, whose non-existence we prefer to its existence.

The good is often defined as that which conduces to some end; but an end is nothing other than something willed; that which conduces to an end is the cause of something that is willed, so that this explanation also refers back to a consciousness.

Whatever is existent for us must be existent in us, in our consciousness. Our states of consciousness are either painful, or indifferent, or pleasant. We must turn, therefore, in the last analysis, not to things, but to the mind, if we wish to distinguish what is good and what is bad; and according to the differing constitution of different minds, the same things may be good or bad. There is good and bad with respect to our body or senses, and good and bad with respect to our mind. A moral good is one which causes conscious states of moral satisfaction.

The good has often been divided into the useful and the agreeable. The agreeable is that which causes immediate, the useful that which causes mediate pleasure. A thing may be both useful and agreeable; and the like is true of the disagreeable and the harmful. The useful and the harmful in this, as it were inner, (subjective) sense, are to be distinguished from the useful and the harmful in an objective sense; in the last sense, that is useful which tends to the preservation of life. Between the useful and harmful, and the pleasurable and painful, in this sense, there must exist, as the theory of evolution teaches us, a wide-reaching correspondence. Living beings do that which is pleasurable to them; they avoid that which is painful; they continue alive when they do that which is conducive to life and avoid that which is harmful to life. This continuous process of exterminating those beings to whom the harmful is agreeable and the useful painful, must tend to make the harmful coincide with the painful, and the useful with the pleasurable. The agreement is, however, far from being a perfect one; and it is the less so, the more complicated are the conditions of life. It is the most imperfect in human beings. 
Good is that which causes pleasure or prevents pain; that is better which causes more pleasure or prevents more pain. A thing may cause both joy and pain; in this case, the excess decides whether a thing is good or bad; and the greater the excess, the better or the worse is the thing. The greatest possible excess of satisfied states of consciousness in the life of a human being one may call his greatest possible happiness. The greatest possible happiness is hence the standard by which good and evil are determined.

From these reflections is to be seen that a distinction is to be made between that which is desired and that which is desirable. All that is desired is pleasurable, yet much that is pleasurable has pain for its result, - pain that is far greater than the momentary pleasure.

The good is often considered as opposed to the agreeable, and the bad as opposed to the disagreeable or painful. In this case, by pain and pleasure are understood feelings of the moment, by good and bad are understood enduring, or at least long-continuing causes of lasting or oft-recurring pain or pleasure; momentary pleasure may be bought at the expense of long suffering; and short pain may be the condition of the prevention of greater evil.

A thing may be good as regards one individual, bad as regards another. A thing is truly good as regards a society when its total effect has for the society lasting beneficial results, that is, accords with the happiness of the society during its whole existence; and that is for mankind truly good which is, in its total effect, beneficial to present and future humanity.

In general, we may say that, when we order our conduct by the thought to serve mankind to the best of our ability, we have a satisfied consciousness, a good conscience. In so far, therefore, a noble deed is good for ourselves as well as for society. The question whether or not the performance of our duty corresponds to our greatest possible happiness, is a different one. But the good man does not allow this thought the chief rôle in consciousness; he is filled with the thought of doing his duty in devoting himself to the happiness of mankind, and there is but one form of his own happiness which he will not forego, namely, the blessedness of a good conscience. This consciousness, this blessedness which unites the human being to mankind, he should 
regard as his highest good; for it is a moral good; and the dissatisfaction which lies in the consciousness of having violated his duty towards mankind he should regard as the greatest evil.

It may be objected that this morally satisfied consciousness, this sort of joy, cannot be called a good. A good is the cause of pleasurable states of consciousness. But it would appear strange to claim that joy, happiness, are not goods, and pain, unhappiness, not evils; the terms "good" and "evil" and "worth" refer not only to joy and suffering, but also to desire and will; and no one doubts that happiness is an object of desire, and pain an object of aversion.

From what has been said it appears that happiness cannot be defined as "satisfaction of the desires." Such satisfaction may have unhappiness as its result. Not all desires are to be satisfied simply because they are desires.

The study of the history of moral conceptions appears to show us that most changes in this province are the result of a change of views concerning the effects of actions with regard to the welfare of society; hence, that they were the fruit of experience. This process of change takes place, however, very gradually; the rules which are the result of experience are handed down, for the most part, without statement of reasons; and only in a very limited measure do the new generations labor for a progressive development of moral conceptions. We cannot wonder that a clear consciousness of the highest reasons of moral precepts is seldom to be found. Yet in civilized societies, the conviction is general that at least an average conformity to rules of morality is the indispensable condition of the safety and the good of society. The answer to the question: What would happen if every one were to act thus? has been regarded, from earliest times, as decisive with regard to the moral quality of an act.

When we recognize that actions which we call good and bad are so called because of their causal relation to pain and pleasure, the belief must arise in us, that the worth of qualities of character depends on the promise they contain of future action. The most important power for the happiness or misery of humanity is the character of human beings. Hence the morally good, excellence of character, is to be regarded as preëminently Good. And so it appears that our instinctive judgments are justified by the deliberations of calm reason. 
The question: Why shall I act in accordance with the general welfare? is answered by these considerations; because such action is right and reasonable, enjoined by conscience and reason, by human nature itself in its higher development. He who does not recognize this fact, who does not find in it the highest and holiest of commandments, and who yet desires to act reasonably and well, recognizing duties to all men, does not see what he himself really will.

The conception of right-doing is the motive of the human being, in so far as he is good. The teacher who desires to have moral influence will endeavor to awaken this motive in his hearers or readers. For this purpose he must appeal to their actual characters. And it is as much a petitio principii to assume, in Ethics, the existence of moral feelings, as to assume, in Optics, the existence of sight. Just as there are blind persons, so there are persons without moral feelings. These are, however, comparatively few; some trace of moral feeling, of conscience, is to be found in almost every member of society.

The general welfare, that is, the greatest possible true happiness of all, not the greatest happiness of the smallest number which is often the ruling principle of state laws, nor the greatest happiness of the greatest number without consideration of the minority, - is the highest ethical criterion. It may be difficult to ascertain wherein this happiness consists; Bentham demands, for the determination of the worth of an action, a calculation of the intensity, duration, certainty, fecundity, and purity, of the feelings produced by it. But the happiness and misery of mankind is surely the most important object of mankind; it must be, therefore, our highest care to ascertain the results of an action as far as we are able. And, in fact, the most important results of any form of action are generally ascertainable.

To make endeavor after one's own and others' perfection the criterion of morality is to set up a false standard, a form without a content, since "perfection" designates merely a state that accords with some preconceived concept or end. The question is: What end shall human perfection realize? The criterion of general welfare alone can define human perfection. It is such a constitution of man's bodily and spiritual characteristics as conduces in the highest degree to general happiness.

Too long and detailed a consideration of possible results is not 
desirable in every case where action is called for. There is seldom time for a consideration of the intensity, duration, etc., of resulting pain and pleasure. It is well, in most cases, to follow the general moral rules we have attained to through previous reflection. In cases of doubt, we need to appeal to our highest criterion. Often such doubt may be caused by selfishness, by the hidden desire to act, after all, for our own benefit; we need, therefore, to put to ourselves the question: How would we judge the action of another in our own position? Thus we arrive at the highest moral commandment, which is: So act that thy conduct, if made general, would be for the good of mankind. And the force of example is here one of the factors to be considered.

It has been asked what right one has to assert the rule that each one is to count for one, and no one for more than one, in moral decisions. May not one human being's capacity for happiness be greater than another's, and his happiness, therefore, more to be considered? It may be answered that bad men have never been embarrassed for an excuse for selfishness, but that the arrogance of regarding one's own happiness as of greater worth than that of others has brought incalculable harm into the world, and that the only safe method of calculation for the purpose of furthering the general welfare, is the rule above given, - that each one shall count as one and no more.

The rule that the greatest possible happiness of all is to be striven for, is an assertion that the happiness of every one is to be considered, that not that of the lowest human being is to be interfered with unless such interference is necessary in order to prevent still greater harm to others; and that no such interference shall be greater than is positively necessary in accordance with this aim. The highest moral law is thus nothing more than the Christian commandment of love to all men. And the rule "To count each as one, no more," may receive the restrictive clause "in so far as the good of the whole of society is not diminished by so doing."

Some Darwinians are inclined to regard the preservation of existence as the criterion by which to judge the moral quality of action. "Aim for the preservation of the species" would be, from their standpoint, the moral law. But mere existence is not happiness; that is shown by the fact of suicide. However, it is true that health is one of the conditions of happiness. Pessi- 
mists are generally men of an unhappy temperament, often of morbid physical constitution; medical science must, in its progress, help to prevent the development of such morose dispositions. Want of love may also be a cause of pessimism; most pessimists have been lonely men. And want of employment may also lead to pessimism. If we follow Rousseau's advice not to listen to those who are in exceptional abnormal positions, but appeal to those who constitute the great majority, we shall conclude that, in general, the happiness of men greatly exceeds their misery. The increase of suicide is often used as an argument that civilization has not caused an increase, but a decrease, of happiness. To this argument it may be answered that the religious scruples which formerly withheld men from this extreme step have diminished, that men have grown more self-conscious and independent in action; and that, moreover, our age is one of unrest, a transition-period such as no other period has been. When we examine the lives of tribes on a low plane of civilization, we find their existence full of uncertainty and of superstitious fear, and at the mercy of the forces of nature. Without doubt, much misery exists; a great part of it, however, is caused by the disappointment of too extreme demands for happiness; the individual must not require that life shall be continuous rapture.

The recognition of what right action is, is not its accomplishment. Pain and pleasure determine the will, - the pain and pleasure of the person who wills, since he cannot feel with the feelings of others or will with their will any more than he can move with their limbs. He may have a conception of the welfare or suffering of others, but a mere mental image does not determine the will. Only when such a conception arouses pleasure or pain in the subject himself, are will and action possible.

Love consists in joy in the thought of the beloved person, with joy in his joy, and pain in his pain. He who seeks to render happy one whom he loves does not, as a rule, consider the fact that he will himself have a joy in the happiness of that other; his aim is to give pleasure, not to himself, but to the other. But the thought of doing for him is combined with pleasure, the thought of not doing for him is combined with pain; and these present feelings determine the will.

That which distinguishes the moral from the immoral man is that, in the former, the notions of the right and good rouse strong 
feelings, - feelings of pain at the thought of acting contrary to them, of pleasure at the thought of acting in accordance with them, feelings which may overpower all others; while in the immoral man these conceptions call forth no feelings or only such weak ones as offer no sufficient opposition to the influence of other feelings. Both men act from feeling, but not from the same feelings.

Do we, by proving that the moral, as well as the immoral man is determined in his action by feelings, show that the one approximates to, or is identical with the other? By no means. In that case, the proof that both the moral man and the immoral man will with their own will, and act through their own limbs, that both possess arms, hands, senses, feelings, understanding, in short, that both are human beings, must show, in the same manner, an approximation of the moral to the immoral man. A perceptive, intellectual, objective side, and an emotional, inner, subjective side are to be distinguished in all action; and only the confusion of the two has led to the fancy that, with the proof that all action proceeds from the pain or pleasure of the person who wills, it is shown that all action, every human being, is selfish, and that unselfishness is a figment of the imagination. It is not the expected pleasure that moves the will; it is only when the conception of future happiness or misery awakens present feelings stronger than other present feelings which would move the will in another direction, that willing and action can follow in accordance with that conception. Hence, there is nothing so remarkable in the sacrifice of one's own happiness. It is not morally desirable that self-love should be weak, but only that conscience and general benevolence should be stronger still.

Many who have recognized the reality of sympathy and benevolence have not regarded them as primary but as evolved from egoism. However, if the word egoism is to have a distinct meaning, it must be interpreted as the conscious preference of one's own good to that of others. But with self-consciousness is likewise developed the consciousness of other beings, and the latter, as the former, clothes itself with feelings - with egoistic feelings, and with sympathetic feelings as well.

It is further to be remarked that the proof that an action is disinterested, is no proof of its moral worth. The worst action, - an action of pure cruelty, envy, or hatred, may be disinterested, 
that is, it may have for its end the pain of another without consideration of the advantage of the doer.

The effects, as pain or pleasure, of conduct opposed to, or in harmony with, civil or moral law, in so far as such effects can be predicted and, as thus predicted, they influence the will, are called Sanctions. One may distinguish between a physical, a political, a social, a sympathetic, and a moral sanction. Doubtless the conduct recommended by self-love, as a result of these sanctions, coincides, to a very large extent, to a larger extent than egoists in the rule perceive, with that which the good of society demands; but it is just as certain that, in many cases, the way of selfish cunning and that of virtue diverge. The outer sanctions do not insure the coincidence of duty and one's own happiness; nor does the sympathetic sanction secure this, for sympathy is often on the side opposed to duty. There is but one sanction which is ever on the side of action in accordance with duty: the moral sanction, the peace and joy which accompany the knowledge of having done right. Duty and self-interest coincide the more nearly, the better and more unanimous the various sanctions are, and, especially, the more strongly the moral feelings are developed in a society; one of the tasks society has to set itself is to labor for the greatest possible concord of duty and selfinterest. But this harmony will never become an absolutely perfect one and self-sacrifice impossible. Man needs, therefore, some end which shall depend upon himself alone, if he is to be kept from discouragement and despair. Such an end is the consciousness of right-doing. He who chooses this as highest end must devote himself to the service of mankind, as well as he who makes the advancement of the good of mankind his end. The thought of this end will prevent him from being blinded by selfinterest in answering the question as to what right and duty are, and will also preserve him from permitting himself one or the other pet sin under the excuse that he will atone for it by other good actions; it will compel him to the endeavor to fulfil every duty. And though he may not be perfectly happy, he will be happier than the man who makes the good of humanity his end; since he is less dependent upon outer events. Benevolence and conscience are not the same. The latter constrains us to do right, that is, to perform actions the expected results of which are in harmony with the general welfare; it has attained its end 
when the right action is performed, and it has failed to attain its end when this aim is frustrated. Man has a deep inner longing for happiness of some sort. When he does not find it upon earth, he seeks it in some other world. He has of ten a deep inner yearning for holiness, and a secret dissatisfaction in his own conduct. Ethics satisfies this double longing in commanding him to renounce his greatest happiness and endeavor to attain moral blessedness, the happiness of holiness.

Perhaps some one may object that this is a selfish view of the moral life. Is it selfish to renounce one's greatest happiness in order to attain only peace of conscience? That no one were without such selfishness! He who sets himself this end will act better, more in accordance with the good of humanity, than he who makes the advancement of human welfare his ultimate aim. Hence the human being should choose this end. 'Therefore, the highest moral commandment, the Categorical Imperative, receives this form: "Strive to attain peace of conscience in devoting thyself to the service of mankind."

By "right" we understand what is in conformity with a standard of action which we recognize, by "wrong," what is in opposition to it. The recognition and application of the standard belong to the reason. But not to reason alone; every rule is the outcome of feelings; and this is the reason why ideas of right possess the power of motives.

Judgment of action may take place in two ways: immediately, through the feeling; and mediately, through moral rules, the adoption of which, however, presupposes feeling. According to the disposition, the education, the circumstances, of a man, the one or the other form of judgment prevails. The words "obligation," "commandment," "duty," "law," express the fact that something lies without the mere free pleasure of the acting individual, is withdrawn from its sphere.

It has been said that a distinction is to be made between duty and the sense of duty - that an objective duty still exists, even when no corresponding inner sense of duty is present. This merely means that some one else in distinction from the acting person recognizes a moral law, by which he may blame the action. Duties are actions sanctioned by one or another sort of punishment. The moral sanction is self-blame. But not the performer of an act alone, others also, pronounce judgment on his action, 
and in the rule there exists a greater or less harmony between his judgment and that of others. To self-condemnation is added the consciousness of having deserved the blame of others.

Human actions are not only an object of displeasure or of indifference, but also of praise, gratitude, love, admiration. Actions which reveal a character above the average are regarded as meritorious according to the measure of their superiority; they deserve recognition, respect, praise, honor.

Three classes of actions to which public opinion applies its sanction may be distinguished: actions blamed; those the neglect of which is blamed; and those which are praised. The first two classes, sanctioned by a punishment, are regarded as duty; the last class, sanctioned by at least mental reward, are actions of desert. Actions the omission of which is punished or blamed are not actions of desert, but of duty and obligation.

The boundary-line between duty and desert is not fixed and definite; in the measure in which the moral condition of a society is perfected, the province of that which is regarded as duty is extended into that which was formerly regarded as desert. The distinction between duty and desert has, in general, only an outward significance; it has regard to the relation to others, to the socia! sanction. 'The moral human being does not inquire what entitles him to praise, but simply what is right; and he does not compare himself with others but with his moral ideal. Hence he recognizes, with regard to himself, only duty, not desert. $\mathrm{He}$ aspires to attain, not the approbation of others, but his own, and he attains this only when he has done that which he holds to be the best possible.

The moral significance of the outward sanction lies in its educating influence; it acts as counterpoise to inclination to action opposed to the moral law, and facilitates, thus, the victory of the moral motives, which increase in strength through use. If it is true that a condition of "heteronomy" always precedes that of "autonomy," then the outer sanction is the indispensable condition of the evolution of moral feelings.

It has sometimes been said that the human being is under obligation to others only. But it seems that this view has proceeded from a confusion of the moral with the juridic significance of the word "duty." It is not to be doubted that the consciousness of duty would not develop in an individual who grew up in 
solitude, - but speech and reason likewise would not become his. The law of morality applies not only to social conduct but also to conduct having reference to self.

By "moral law" is not meant a law in the sense that it is imposed on human beings from without, by another; it is exactly the peculiarity of the moral law that it is self-imposed as the voice of conscience.

Virtue is related to duty as the enduring characteristic to the single action, or the lasting will to obligation, to the "ought"; virtue is a disposition to act in accordance with duty. Vice is a characteristic which continually determines actions opposed to duty.

There may be exceptional cases where vice is innate, as is idiocy or insanity, but the records of prisons and reformatories where a moral influence has been attempted, show us that germs of good may exist even in those apparently wholly given over to vice. It is true that the capacity for moral education is narrowed with every added year of life; but it is impossible for us to say, with certainty, how great this decrease of capacity may be. ${ }^{1}$

The most essential influence for moral betterment is that which the personality of an earnest human being exerts by example and precept. The awakening and strengthening of good impulses is not, however, the immediate destruction of the bad; and struggle is often necessary if the good shall conquer. The more frequent the victory, the easier it becomes. Every virtue can be acquired at least in some degree, if the wish to acquire it be sufficiently strong and persistent.

But although such struggle as this is often necessary, exactly the sign of the attainment of virtue consists in the absence of self-compulsion; by this absence, its perfection is measured.

The assertion, occasionally heard, that virtue is in proportion to struggle, amounts to the contradictory assertion that the more perfect the man is, the less is his virtue. The truths which, imperfectly comprehended, lead to this opinion, are these: We distinguish by the name of virtue that moral constitution which rises above the average. It is presupposed, however, that its possessor has, in general, the impulses and capacities belonging

1 The references here are to Lounbroso, “ Der Verbrecher," deutsche Ausgabe, S. I 29 u. f.; H. v. Valentini, "Das Verbrecherthum im preussischen Staate," S. 226 u. f. 
to human nature; he could not be called temperate in any particular direction, if he did not possess the capacity of enjoyment which leads many to intemperance. Moreover, the control of strong impulses from a desire to do right presupposes a strong sense of duty; and it is on account of this sense of duty that we respect a man. But if an individual distinguished by a strong sense of duty gradually succeeds in tempering his impulses and ridding himself of his faults, his virtue is not less, but more perfect. And finally, the fact is also to be taken into consideration that, while one cannot necessarily conclude, from a man's innate love for some especial class of good actions, that he will do his duty in other directions also, this is an inference which can be drawn where actions are performed from a sense of duty.

A certain degree of intelligence is a condition of virtue; a being without reason is not a moral being, as the animal is not; but morality requires only average human intelligence.

There is no greater error than the opinion that virtue is not concerned with action; for virtue is excellence of character which leads to right action; action is the test of moral worth.

In olden times, an attempt was often made to set up one especial form of character as universal ideal. Such an attempt is injustifiable, since the nature and circumstances of individuals. differ. In morality, too, there may be originality.

In the judgment of an action, two questions must be distinguished: the question whether the action is right or wrong, and the question as to what inference shall be drawn from it with regard to the character of the performer.

In the action, there must be distinguished the following points: the movement of the body; the results of the act; the act of the will; the intent; the presence or absence of a conviction that the action will not have evil results; the part of the intent willed, not merely as means but as end; and the incentive, or feeling from which the action springs. The chief end and the incentive together are often called the motive. The movement of the body is not an object of moral judgment, as are not, also, the outer results of the action as such. Nor is a mere act of the will as such, but its nature, of moral importance.

No human motive or incentive is, in itself, bad. Not even anger and hatred are in themselves evil; since wrath against wrong is justifiable. Yet motives are by no means morally of the 
same worth; while where motives directed to the good of the individual are at work, the action will be, in nine cases out of ten, in accordance with the general good; it will be, let us say, in nine cases out of ten, contrary to the general good where motives of malevolence are active. And for this reason the motive in the single case gives us a clue to the character. There exists a certain stability of character which makes it likely that the individual who acts out of good motives on one occasion will do so again. Of greatest worth are the motives which spring from desire for the general good; these are moral motives. Actions may be right, yet immoral, and moral yet wrong. Yet the theory that the objective judgment of an action, and the judgment of the character of the doer have nothing in common is erroneous; for in both cases the highest ground of reasonable judgment is the same; namely, the general good.

Blame is not merely for the sake of prevention through fear; since we may blame a deed and not its doer. When a man does what we consider wrong under the impression that he is acting for the general good, we do not endeavor to frighten him from his conduct by blame, but to convince him of his error.

But the significance of the motives of an action does not lie merely in our inference from them to the character of the doer; from the actual, or inferred, motives of the action spring its most important results; namely, its influence upon the morality of human beings. Every moral action reacts for good upon the performer, strengthening his tendency to such conduct; and it is, besides, an inciting example.

It is not necessary for morality that all actions should take place directly from desire for the general good, but only that the belief be present that they are in harmony with the general good; duty need not be the only motive, but simply the ruling one; one may act immediately from other motives.

The æsthetic judgment of a character is to be distinguished from the moral judgment of it. Much that pleases one æsthetically in character is morally indifferent; and much that is morally of the greatest worth has little or no æsthetic value. The talk of an identity of the beautiful and the good has caused much confusion.

Things have particular qualities according to which they affect us and are affected. All that I can predicate of things, all their 
being is their effect. And when I say that a certain thing, as long as it does not change, will, under the same circumstances, operate in the same way, I assert merely that this certain thing, as long as it remains unchanged, is this certain thing. It may often be difficult or impossible to determine whether or not the thing has changed, but if it has not changed, it must, under the same circumstances, operate in the same manner as formerly. As everything is, at each moment, a definite thing, so is also every human being; he has definite qualities, and if these do not change, neither does his action under the same circumstances; if it could change, he would act according to that which he is not.

Different individuals have different innate tendencies; and differing circumstances develop similar tendencies in different ways. The history of the human being is his character, if we add what he has inherited to his own history. To reflect upon human nature is to assume its conformity to law; to deny such conformity involves ceasing from thought on it; for thought means the conclusion of like from like. Though the action of the human being depends, in a high degree, upon circumstances, we can often predict, from a knowledge of his character, the general nature of his action. And if our expectation should be, for once, disappointed, we do not say that his character has suddenly passed into its opposite, but that we had an insufficient knowledge of the circumstances, or that we imputed to him a character which he did not really possess. We have thus to distinguish two groups of facts in the contemplation of a particular action: the present constitution of the doer of the action, and that of the outward circumstances concerned; if a change occurs in either, the conduct will also change. Criminal statistics are evidence of the effects of similar circumstances upon similar characters.

Those who deny the action of cause and effect in the conduct of men as contradictory of freedom, cannot refer to physical or political liberty, since the absence of these does not involve the absence of cause and effect. The free will which is said to be peculiar to the human being and not possessed by the animals, is an absence of subjection to the impressions of the moment, and this has been regarded as an activity of pure reason. But, as Höffding says, the contest of the reason with the passions is really a contest between feelings combined with reflections of 
reason and other violent feelings that are combined with few thought-elements. This free will is the capacity of reflection gained by experience. It is not a negation of cause and effect, for the act of the will is determined by the feelings, thoughts, inclinations, which precede it; it may be determined by reflection as opposed to the impressions of the moment. The word "freedom" is also used to denote moral freedom, or the freedom from determination by immoral motives; in such case, however, moral motives determine.

But it must be remembered that the natural law of cause and effect is not like a law in the sense of the political law; it is not something imposed from the outside. Natural laws are rules formed by men to express the regularity of events in one sentence; things do not obey the laws, but the laws are according to things. When we say: Gunpowder "must" explode when it comes in contact with a flame, the explosion is necessary; we do not mean that the gunpowder is compelled, under certain circumstances, to explode; it explodes of its own essential nature. "Necessity" designates, not a state of things, but a state of the understanding regarding them. The same is true of the words "possible" and "accidental." The accidental is the unintentional. The bullet which accidentally killed a man was not sent with the intention of killing him. Or "accident" is used of that with regard to which we are ignorant and cannot predict; the word does not, in this sense either, denote an absence of cause. Objectively, nothing is "possible"; either it is, or it is not. Great confusion is, however, caused by a want of clearness in the interpretation of the words "possible," "impossible," "necessary," etc., with regard to the will. When I say: "It is possible for the good man to perform even the worst action, he can perform it"; and: "It is not possible for the good man to perform a bad act, he cannot do it"; I use the words "possible" and "can" in two quite different senses. The first sentence means: "Even the best man can perform the worst act if he will"; the second: "The good man never has the will; it follows from his nature that he does not possess it; it would be a self-contradiction to say that he has it." The human being can do this or that if he wills, provided no outer force opposes his will; but whether he wills or not depends upon his character. His will is not uncaused.

It has been said that "one should not allow himself to be deter- 
mined, but should himself determine his act." This assertion makes self something distinct from one's thoughts and feelings. Free will has also been interpreted as choice between motives. The human being does not, however, choose between motives but between acts, and his choice is free in that he can, as has been said, choose this or that act if he will; but his choice is not the less caused. When, in reflection on a past act, the human being says to himself: "It was possible for me to act otherwise," he means, as a rule, simply: "If I had thought as I do now, I should not have acted thus; but I did not think as I do now." The delusion that he might have acted differently under the same outer circumstances and with the same thoughts and feelings, arises from the difficulty of realizing, from his present standpoint, his position at the time of action. It may, indeed, seem to us, after we have chosen a certain course, that another was the easier; but can it be possible that one preferred the former course when he yet really preferred the latter? It is the strongest motive that determines the action. Or, if it be objected to this assertion, that our only criterion of the strength of motives is their effect as overcoming other motives, the assertion that the will follows the strongest motive would still exclude accident in choice; the assertion would amount to this: that the motive which determines the will in the one instance will always, under the same outer and inner circumstances, determine it. So Mill remarks that, when we say that the heavier weight will weigh down the other, we understand by "heavier weight," merely the one which will weigh down the other. Nevertheless, the sentence is not senseless, since it means that there is, in many or most cases, a heavier weight, and that its action is always the same. Education by others, and self-education would be useless, if the same thoughts and feelings could, under the same circumstances, produce now this, now that totally different result, and not always the same one.

Kant's doctrine of freedom includes practical freedom (which is not, according to his definition, opposed to causality) and transcendental freedom; he seems, however, not always to have kept the distinction between the two clearly in view. His theory of transcendental freedom is grounded upon the doctrine of the pure ideality of time. The only method of saving the doctrine of freedom is, according to Kant, the theory that the law of 
necessity applies to things as phenomena but not to things in themselves. If phenomena are not to be regarded as things in themselves, but as mere thought-images, they must themselves have reasons which are not phenomena. Such a cause for pure reason $^{1}$ is not determined by phenomena, although its effects appear as phenomena. The causal action of reason does not have a beginning in time, but is the constant condition, outside time, of all free action of the will.

Kant failed, however, to prove the pure ideality of time, as Riehl has sufficiently shown. Moreover, were the intelligibile character of reason the cause of action as phenomenon, there would be no possibility of moral improvement, since the noumenon is not affected by phenomena, - an inference which Schopenhauer makes in adopting Kant's theory. Moreover, if space has, as Kant also assumes, transcendental ideality, plurality is not conceivable; hence, the moral difference of characters, and the science of Ethics itself, could have no transcendental significance. It is evident that Kant argues from the standpoint of an assumption of a "soul-thing," a constant "substratum" of psychical phenomena, - a standpoint which he himself criticizes. He identifies this thing-in-itself, moreover, with the reason, although he himself declares that the concept of the thing-in-itself is but a concept limiting reason. ${ }^{2}$ He makes the reason a thing-in-itself outside time, although it is an activity, a process of consciousness in time. The thought of duty, of the categorical imperative, is a phenomenon, and if the will is determined thereby, it is determined by something in time. Kant takes but little account, moreover, of the fact of birth. Is the intelligibile character born? If so, it is preceded by something in time; if not, it must be eternal, existing before birth as well as after death. And how can he assert, too, that an action might have been other than it was, if it depended upon the constitution of the intelligibile character, and this is as it is, and operates as it is?

Schopenhauer's argument for transcendental freedom contains many self-contradictions, and is founded on the fiction of a first free choice of character. Schopenhauer asserts, however, that character is innate. If so, how is it chosen? The theory assumes that one is before he is. An act of choice presupposes a chooser, and, according to his own words, "Every existentia

$$
{ }^{1} \text { Intelligibile Ursache. } \quad{ }^{2} \text { Grenzbegriff. }
$$


presupposes an essentia"; that is, every existence must have a particular being, essence.

Accountability assumes that some one is held answerable for an action or event, and is, as answerable, amenable to punishment. The punishment may be one of law, of society, or a moral punishment. The concept of responsibility is closely allied to that of accountability; it assumes, in general, that a person is the author of a deed. Responsibility may be immediate, when the author of the deed was also its performer, or mediate, when the performer was another person.

Remorse is pain at the recognition of the immorality of a past action. With the pain is often connected the wish that the action had not been performed. This wish is naturally unreasonable, since it is directed to the impossible. Yet it is not idle, as Schopenhauer asserts, since it has an effect upon future action. There is often also an egoistic regret, or one not called forth especially by the conscience, for a past action. This may or may not be moral, according as it is or is not in harmony with the general welfare.

The friends of the theory of chance as regards the will have asserted that shame, remorse, would be impossible, if the human being recognized the fact that his act was necessary. They have neglected, however, to give any reasons for this remarkable assertion. If a man recognizes that the constitution of his mind was such as to lead unavoidably to vicious acts, this is the strongest motive for condemnation of his own moral constitution, for pain at it, and an endeavor to better it. But if the act had no necessary foundation in his character, if it was merely an accident that his will chose thus, then, since the act is past and there is no reason for drawing conclusions from it with regard to future action, how does it concern him?

Blame and punishment, as well as self-blame, have regard to character and so to the future. Acts are not blameworthy and punishable if they have no cause. Punishment is inflicted from two motives: as a preventive, and as an expression of the felt need of retribution. Originally, mankind punished from a desire for revenge. This is not the moral motive. Not the criminal alone, but the whole constitution of society, is responsible for his crime. If, then, punishment is allowable for the sake of prevention, it cannot, as an evil, be permissible further than is in 
accordance with this end. Punishment of the insane could be justified only in case it could prevent insanity.

Nor is desert based upon an uncaused character of the will. We do not admire, praise, and reward great genius the less because genius is inborn; nor do we admire the moral man the less because his father before him was distinguished by deeds of philanthropy. We admire him for what he $i$.

The doctrine of causality in human action is far from being what it is sometimes called, a doctrine of fatalism. Fatalism assumes that, whatever a man may do, a power outside him determines the event; but the recognition of cause and effect in human action is the recognition of the fact that the actions of human beings are never without result.

It is often said that morality is founded upon religion. Assuming that, by religion, is meant the belief in a personal God and in the immortality of the soul, is this true?

If a mighty tyrant commanded a man to do what was contrary to his conscience, if he promised rich reward for obedience and fearful torture for disobedience, would obedience therefore be moral? Why is it represented as wrong to follow Satan's commands and right to follow God's will? Evidently not because God is mighty but because he is good, and Satan is bad. But if it is, thus, a matter of duty, and not merely one of selfish cunning, to obey God's will, then his will must be directed to the good; and this presupposes the good to be something in itself, without regard to the fact that God wills it. If God is a moral being, this must be so.

This is, in fact, an assumption which the moral members of society have, in general, made. They boast of the morals of their religion, comparing it, in this respect, with other religions; and thus they subject it to the test of morality. Moreover, when we examine the Christian gospel, we find that it in general assumes the moral laws as already existent and only urges obedience to them. The good is, as we have seen, that which conduces to the general welfare. The earliest religions had no connection with rules of morality; these have developed with the social life of human beings and have, in it, their root.

As to the belief in immortality, cannot the human being do right without the thought of the reward and punishment of another life? As a matter of fact, many good men have not possessed 
such a belief. The distance of such an end often makes its effect a weak one, and the motive may easily become selfish. Yet it is true that a loss of faith may include a loss of morality, in case the belief exist that there is no basis for morality outside religion; the responsibility of such a loss of morality lies with those who teach this latter doctrine. Through love to others and the thought of the immortality of influence, the moral man gains a larger life and loses the fear of death. He who has thus faced the thought of death finds life more earnest but not less happy. Each hour has not the less its own joy because there is an end, at last. Nor, in spite of the deep pain the loss of friends causes us, do we lose them wholly, since the memory of all that was best in them may remain with us. Our own pain may bring to us a deeper sympathy with, and love for, others.

If we are able to love the good in God, we may also learn to love the good in those about us, and be incited, by it, to emulation. The love of the good in men has always had stronger effect than love for a distant God of whom but little was known. It was the thought of the man Buddha which exerted an ennobling influence upon thousands, and it was the thought of another human being that moved the "christians" more strongly than did that of a Father in Heaven. Do we love father and mother, brother or sister, wife or child, or our friends, for God's sake? Why may we not love all men, as we love our friends and children, for their own sake?

It has been said that there is no accountability, if not to God. But if God is the author of the world, he must himself be the cause of evil, either by direct influence or by neglect to avert. Where, then, is the justice of his punishment? It does not suffice to answer that God's justice is not our justice; for in that case, what right have we to apply the word to him at all?

History demonstrates the fact that morality is by no means necessarily connected with religion. In the name of religion millions upon millions of human beings, and these often the most upright and conscientious men of their nation, have been put to death, and thus the civilization of whole peoples has been retarded. Slavery in America had no stronger friends than the churches. How is the forgiveness of sins by God to be justified? Are the evils which they caused any the less existent because of such forgiveness, and is it well for the doer to escape, in this way, the 
sense of responsibility? Only labor for the good of humanity is the way of atonement. We ourselves are the creators of the kingdom of righteousness.

Many claim that Ethics is not indeed based upon Theology, Dut that it needs a metaphysical, a teleological, foundation. For it presupposes that human life has an "end." If we wish to ascertain how our life should be conducted, we must ascertain what is the end Nature has in view for us.

But an end is an effect imagined beforehand and willed, which we cannot bring about immediately but only through a chain of causes. These causes we call the means to the end. They too are willed, but only indirectly and because the end is attainable only through them. These processes to an end are sometimes treated as if the causal succession in them were reversed, so that the last effect appears as the beginning, and the future determines the present; in this sense, the end has been called the end-cause, because the final link of the process causes the beginning. But this is a senseless conception, since the future, that which does not yet exist, cannot now operate. In fact, the succession of causes and effects is no more broken into in the processes leading to an end than in any other processes. When a human being imagines to himself a result and endeavors to bring it about, these mental processes are not future but present; and they are not determined by an influence of the future upon the present, but by an influence of the past upon the present; they follow from experience, that is, from that which has already occurred. They are causal processes in which the activities of understanding and will have part. Hence "ends" exist in nature in so far as they exist in man and the higher animals; but outside these, ends cannot be predicated, unless Nature is regarded either as gifted with imagination and will or as the creation of a being possessing these. But imagination and will require, according to all our experience, a highly developed nervous system, and to assume their existence where such a centralized system does not exist is scientifically injustifiable. Moreover, the laws of thought by no means determine us to inquire after a cause of the whole world, since the concept of cause is applicable only to changes, not, however, to enduring existences and their qualities.

Or let us assume that we had discovered an end set by Nature. Then, either it would appear useless to interfere with its attain- 
ment and unnecessary to assist in it, or it would appear to us possible to oppose this end. In this latter case, cause must be shown why we should assist, or should resist, the process of Nature.

Many philosophers have said that man should live according to his own nature. If the word "nature" here denotes the totality of his characteristics, it is evident that the worst actions are not less natural than the best. Therefore, the word nature cannot, as here used, have this sense; the natural in this sense is not identical with the moral. Nor can the term as here used refer to the usual, for in that case the greatest moral excellence, as unusual, must be rejected. Nor can it be used to designate the more primary, for in that case, again, the later developments of benevolence and truthfulness should be rejected.

The word can have but one other sense, namely, as opposed to artificial. But what is in man artificial and what is natural? It seems that the natural is understood as that which is not the work of human intention and reflection, of labor, and of education. Innate impulses would be, according to this definition, natural. But it is evident that one cannot abandon himself to his blind impulses; society could not exist under such circumstances.

Or if it be said that, since all organs and impulses of the human being tend to preservation of the species, and that this must, therefore, be the end, then let us say "the preservation of the species," or "the good of mankind " but not "the natural life," is the end for man to attempt.

Nature as a whole is neither good nor bad. Her cruelty in the struggle for life is continuous. Yet this is not "cruelty," in so far as it is not willed. She has often selected the best men for her sacrifices. Yet this is not all that is to be said of the relation of Darwinism to Ethics. 'The law of natural selection regulates not only the life of the individual but also that of peoples and nations. Evil may arise and prosper in society. But it has no permanent existence. The chances that the descendants of human beings possessing evil characteristics will long survive, that they will not, sooner or later, perish as the result of conflict with the mandates of health, or the laws of the state, or the demands of society, are not great. In the life of nations, it appears more clearly than in the life of the individual, that "Death is the price of sin." Should in any society the opinion gain power that the struggle for existence authorizes or demands a 
regardless pursuit of one's own interests, an oppression and robbery of the weak by the strong, an annihilation of pain through the annihilation of the suffering individuals, an outrooting of conscience, and the natural voice of pity which raises protest against such a course; should selfishness be bred, and physical strength and refined cunning become the highest ideal; such a community would be on the verge of its own destruction; it would have labored for this result by justifying the struggle of all against all, permitting this the moment that a conflict of interests arose. Let times of need and danger, times of national war, come, and we shall see what is the fate of a society in which love of country, self-sacrifice, a sense of the ideal, respect for truth and justice, are only subjects for scorn. "The world's history is its judgmentday."

All positive human authorities are subject to the authority of the conditions of life. If they do not take note of the nature of things, if they disturb the foundations of social life, their endeavors must finally suffer shipwreck on the rock of this powerful impersonal authority.

Natural selection is therefore a power of judgment, in that it preserves the just and lets the evil perish. Will this war of the good with the evil always continue? Or will the perfect kingdom of righteousness one day prevail? We hope this last but we cannot know certainly.

We ourselves shall decide our future, by our acts.

In an essay written for the Society for Ethical Culture, and read October I0, I89 I, before the London branch of that society, Gizycki reconstructs his theory of the right final end of life, advocating as such the General Welfare, instead of Peace of Conscience in the pursuit of the same. The objections to his own former theory offered are, chiefly, that if peace of conscience is. regarded as the final end, the individual is likely to take too little account of the outward effects of his action, to be too little impressed by the evil results which should teach him greater care. The good of society is regarded by the virtuous man as more important than his own happiness, as that for which he is willing to sacrifice his own peace. 


\section{S. ALEXANDER}

\section{“Moral Order and Progress" (I889)}

The proper business of Ethics is the study of moral judgments - or, if we say of human conduct, then of conduct as submitted to the praise or blame of moral judgments. But these judgments are not mere opinions; conduct is not that which is "judged" to be right in distinction from that which is right; and thus the analysis of such judgments is a systematization of both conceptions and facts.

The task of Ethics falls into two parts. It has (I) to supply a catalogue raisonné of the moral observances of life, the various moral judgments which make up the contents of the moral consciousness, and (2) to discuss what it is that the moral judgment, as such, expresses.

Nothing is more striking at the present time than the convergence of different schools of Ethics - English Utilitarianism developing into Evolutional Ethics, on the one hand, and the idealism associated with the German philosophy derived from Kant on the other. The convergence is not, of course, in mere practical precepts, but in method also. It consists in an "objectivity" or impartiality of treatment, commonly called "scientific." There is also a convergence in general results which consists in a recognition of a kind of proportion between individual and society, expressed by the phrase "organic connection." The theory of egoism, pure and simple, has been long dead; Utilitarianism succeeded it and enlarged the moral end. Evolution continued the process of enlarging the individual interest, and has given precision to the relation between the individual and the moral law. But in this it has added nothing new; for Hegel, in the early part of the century, gave life to Kant's formula by treating the law of morality as realized in the society and the state. The change in ethical conception is not due to biological research alone, but to the study of history also, and to other general changes in the practical data on which its principles are built. The social and political history of the century represents the growth of the idea of freedom, which has properly two sidesthat of individual liberty of healthy development, and that of the 
solidarity of society and the responsibility of the individual to it. With the increasing complexity of interests and the growth of individual freedom, has come, however, a certain sense of loneliness to the individual in the midst of modern competition, and this explains, to a great extent, the increase of suicide in the present century.

The convergence of dissimilar theories affords us some prospect of obtaining a satisfactory statement of the ethical truths towards which they seem to move.

Our inquiry falls into two parts, according as we analyze the conceptions which relate to the existence of the moral judgment or those connected with its growth, maintenance, and change the statics or the dynamics of morality. To these two divisions is to be added a third, preliminary division, more closely allied with the statical examination of morality. These three parts are represented by the questions: (I) What is it that is good? To what are the terms good and bad applied? (2) Why is it good? What does its goodness mean? (3) How does goodness come into being; how is it maintained; how does it advance?

Moral judgments apply to voluntary action, that is, action distinguished by the presence of an idea of the end to be attained " not merely in consciousness but to consciousness," and the conversion of the idea into the actual reality of presentation. The terms good and bad, indeed, are applied, not only outside the realm of morals, but also, within it, to desires and thoughts; but to these only as they are the objects of volition, in that the will at present allows them to persist in consciousness or in that their present occurrence is regarded as the result of past willing.

The conduct to which we apply moral judgment is a whole made up of many parts - and actions, consequences, and internal feelings have value for morality only in so far as they are its elements.

External action concerns conduct only in so far as the object of volitions (which may be either internal or external) is derived from this source. Voluntary external action is not external only, but has also an internal side; and not whether I succeed in performing a certain action or am prevented in the middle of it, but whether I willed it, is of importance to moral judgment. Conduct is sometimes considered separately from character; but this separation results from confusing conduct with mere action. 
character exists only in its conduct, and all moral actions issue from character.

The consequences cannot be separated from conduct in the moral judgment, except in so far as they could not have been foreseen. The consequences of conduct are a most important part of action, in that they should be considered by the person willing, and should influence the nature of his conduct.

The internal side of conduct is represented by the moral sentiments. These are to be distinguished from the mere motives, which, defined as something that has propulsive force, whether a feeling or a passion, does not enter into moral action except as absorbed into volition. No emotion is, in itself, right or wrong, but is only indirectly judged as such as it makes a difference to the action - as an aptitude of mind which tends to this or that predominating form of conduct. Moral sentiments, on the other hand, as moral aptitudes effective for particular conduct, contain an additional element. Moral sentiments, thus defined, being equivalent to conduct, it follows that the mere possession of sentiments cannot constitute the difference between intrinsic or internal, and customary morality; customs are themselves a matter of sentiment. Thus "conduct as a concrete whole has an inward element of sentiment and an outward element of action, and these are different, on the one hand from mere given feelings, on the other from mere action." "Conduct is this unity of feeling and action in which mere feeling is modified by the idea of action, and mere action becomes a mental, or, if we like, a spiritual thing." "Conduct and character are the same thing facing different ways." "Think of a man's conduct in relation to the mental conditions from which it proceeds, and you think of his character; think of his character as it produces results beyond these sentiments themselves, and you have conduct."

There are no morally indifferent acts; when viewed in general and broader lights, all acts are either good or bad; though there are some cases of really indifferent means arising from the mechanism of action; as, for instance, that I am to go to London is not indifferent, but we may suppose that the fact that I may go by the road or by the river makes no difference to my volition. There is no distinction between virtue and prudence as regard for self, but prudence, in so far as it is compatible with social requirements, is a duty and a virtue. 
Ethics, then, has to do with conduct as a whole in its external and its internal aspects. In distinction from Psychology, it has to do with it not merely as a fact to be analyzed, but with reference to its nature, quality, or content, judged by a standard of value. It is not dependent upon Metaphysics, but precedes it in order of time, whatever may be said of the order of importance; Metaphysics examines, properly, the ultimate questions left over unanswered by the other sciences. From the purely physical method, Ethics has advanced to a biological method; and the doctrine that pleasure is the end of right action has been replaced by the idea of social vitality as the end.

\section{Statical Analysis - Moral Order}

The recognition of the reference in morality to society has been implied in all ethical theories; theories of selfish pleasure themselves recognize the social element in individual gratification, even Cyrenaic theories recommending selection and refinement of pleasures, and containing a reference to personal dignity which implies a conception of man as typical of a perfection that others may sympathize in and attain. Individualism and Universalism in morals differ only in the order in which they take their terms. "To the former, the individual comes first and is the measure of the law; to the latter, the law or society comes first, and is the measure of the worth of the individual." Nevertheless, the ethical problem is very differently conceived by the two schools. But the History of Philosophy shows a tendency to harmonization of the two; we find that Individualism becomes more and more socialistic, while Universalism becomes more and more conscious of individuality. We may trace this movement, in the case of Individualism, in the development of the philosophic theory of morality as true benevolence from the theory of benevolence as merely another form of self-love. The earlier conceptions of Universalism, emphasizing the good as something binding irrespective of the inclinations of the individual, issue in particular formulæ of virtue; later conceptions recognize the differences of individual cases while still insisting on the universal or authoritative character of morality. The problem receives its definite shape when the explanation of authority is sought, not in some categorical imperative, but in the very nature of society 
itself, which, if a whole, is yet a whole made up of individuals. Ethical inquiry thus naturally breaks up into two parts, according as we consider the meaning of right and wrong for the individual, or for society as embracing many individuals.

As far as morality concerns itself with the individual, the good act implies a certain adjustment of functions to one another, too much in any one direction implying a defect in others. "The good life as a whole is a system of consecutive acts, where each function has its limits prescribed for it by the demands of all the other functions." And the good character is "an order or systematic arrangement of volitions." The goodness of an act is thus a matter of equilibration or adjustment of the elements of an individual's nature. In this proportion or adjustment consists

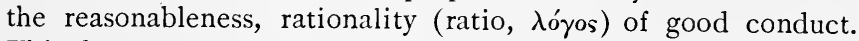
This does not mean that the principle of morality is the result of reason, for moral adjustment is no more specially the work of reason than of any other mental faculty.

This account of good character uses ideas which apply, mutatis mutandis, to the life of any organism, as well as to the mind of man; it merely explains, in terms of human experience, the elements involved in the conception of organization; the difference lies simply in the nature of the elements involved in the adjustment, the elements being, in the case before us, conscious acts. To the question whether such a definition of morality would not apply rather to conduct than to character, and whether, the volitions being conceived as a series in time, it does not dissolve the unity of character, may be answered that conduct and character have already been shown to be identical, and that unity can no more be denied to the series of acts involved than it can be denied to the growing plant or animal whose functions are successive. The unity conditioned by time is a unity characterized by succession, as that of space by extension. The objection, as it gathers its strength from a persuasion that the good character should be described by the feelings or sentiments of any one time, is legitimate; good conduct is built upon a man's needs or desires and is defined as satisfying every part of his nature in its proportion; so that an equilibrium of the emotions and the moral sentiments is involved in morality, and any sentiment is moral which can be equilibrated with the rest. "The good man may be described either as an equilibrated order of conduct, or as an equilibrium 
of moral sentiments or of the parts of his nature. Nevertheless, the order of conduct is a prior conception to that of structural equilibrium." In a machine, the combination of parts is made in order to produce the motion of the engine, and the equilibrium is maintained by the motion. "In the organism, the bodily structure retains its proportion only in so far as it is in physiological action, and this physiological action subserves the conduct of the organism," while "in like manner the equilibrium of moral sentiments exists only through conduct and is determined by the requirements of conduct." The equilibrium is effected simultaneously both for conduct and the moral structure. The ideal is a plan of conduct, ideal in that it is never fully attained. The ideal is hypothetical in two senses. It supposes that every member of the order is good, whereas no life contains good acts only; and that the order itself remains permanent, whereas morality is necessarily progressive. Nevertheless, it is to be observed that the ideal is a realized ideal. It is realized in every good act, since the good act is the act which has the shape it would wear in the ideal order. "Though it is adjusted to imaginary elements, it realizes the whole so far as its own particular share is concerned."

Morality implies the existence of society. It is useless to inquire what would be moral in case the human individual were an isolated being; the fact is that he is not so, and that all moral judgment implies not only the judgment of other individuals besides the acting individual, but also the function of the acting individual as a member of a society. Yet each member of a society has his special individual work, so that duty varies according to individual circumstances, and so far from its being true that morality is not a respecter of persons, it is a fact that it is always a respecter of persons. This does not deny that there are certain common bounds of morality, which allow the formation of some general propositions; nor does it mean that each individual is at liberty to construct his own moral precepts. The individuality of morality, which finds a place or vocation for each individual, involves an equilibrium between the members of society, in which consists the morality of the whole.

The so-called self-regarding virtues are social as well as selfregarding; their disregard involves evil, not to the individual alone, but to others also. It may be objected that acts and thoughts which can never be known to others are condemned by conscience. In answer it must be observed:- 
(I) That the knowledge of others is a matter of degree; my friends know my actions; and in order to judge an action, it is not necessary to suppose the whole nation looking on.

(2) That as personal morality becomes more and more complex, and hence knowledge by others less and less possible, we leave the judgment of an act more to the conscience of the individual, as vicegerent of the moral law. "Acts which are wrong when nobody knows them have come to be so by a process beginning with simple acts which are known, that is, known in their outward appearance." The act, known or unknown, leaves its impress upon character, raising or lowering the efficiency of the agent; and hence is judged good or bad. The study of art and science has, thus, moral value, as influencing character.

Good and bad acts and conduct are thus to be distinguished by their adjustment or non-adjustment to the social order. The adjustment takes place in a similar manner as in a trial of strength, and the compromise between the different individuals must be taken as measuring the actual forces which were engaged.

The social organism has both its morphological, or structural, and its physiological or functional aspect; and here, once more, the order of functions is a prior conception to the structural order; in the society, conduct bears to structure the relation which physiological action in the body bears to the bodily structure. The social ideal is doubly hypothetical, implying that all members of the society are good and that society is statical.

That to which moral judgment applies with regard to the individual's relation to society, is the adjustment of individual wills regarded either as directly appearing or as latent and capable of acting, the occasion being given. The moral principle in society as a whole is thus, as in the case of the individual, a rational one, and Aristotle rightly gives the same name (ojptos $\lambda$ ó $_{0}$ s) to it as to the principle of individual action. The moral individual is the reproduction in small of the social order. But "the two conditions that the individual must be a harmony within himself, and that he must possess all the powers that are required of him for the purposes of society, are not different, but identical." For the absence of such powers implies the absence of adjustment to his conditions, failing which adjustment the inner harmony is impossible, although life may be continued, just as it may be continued under diseased physical conditions. 
Good men may thus be said to conform to a certain type or ideal; but this type is not merely something to which they are fashioned, but to which they themselves are the contributory elements. Hence the social ideal is a species of which all good men are the individual instances; and the species exists, not, as in the case of natural science, as a generalization in the mind of the observer or as an identical plan upon which the members are organized, not as a mere collection of individuals, but as in itself an organism. "Let it not be objected that, since no society is in perfect equilibrium, and the ideal exists only in good men, the ideal is therefore as much a creation of the observer's mind as a natural species. An ideal implies no contrast of observer and observed: conduct is something mental: the ideal is a reality of mind, existing in the minds of those who act upon it. The social ideal has thus a concrete existence in the collective action of good men."

In this manner, the supposed independence of the tendencies towards Individualism and Universalism disappears, the harmony of the individual and his harmony with society being identical - a true independence being equivalent to true coöperation.

Morality implying adjustment to the ideal order, a realization of the bearings of our acts is important. But we need no special moral faculty to teach us morality; it is prompted by thoughts and feelings that, as the result of a process of compromise, are thoughts and feelings adjusted to a social order.

Obligation "expresses that an act is the act required." "It is that relation in which the single part of the order stands to the whole order, when it is confronted by the whole," whether we consider the single act in relation to the whole character of the individual, or the single individual in his relations to society. "Duty in the abstract is the name which comprehends obligation in all its details; a duty in the concrete is any good act regarded in its relation to the whole. On the other hand, the whole has authority against its parts, and every particular duty is said to have authority just so far as it is backed by the whole mass of duties," as the command of a sovereign has authority because it gives expression to the will of the whole society over which he presides. Obligation "corresponds to the necessity under which an organism lies of acting in a certain manner in order to conform to its type." Duty is thus not necessarily antagonistic to 
inclination, as Kant conceived it, since, in the good man, inclinations are adjusted to the requirements of social life; and obligation is thus different from compulsion, which, as attendant on authority, applies to the bad, not the good, man. The negative side of compulsion is responsibility, which implies that, in the case of transgression, the person will be called to account. Duty, though thus free from the idea of antagonism, is itself always negative, implying subjection of the individuai to the larger order. It is from this negativity that duty lends itself to the legal idea of compulsion, and in general wears a legal garb.

In law, rights and duties are correlative, the right of one implying duties of others, and vice versa; but in morals, rights and duties are not merely correlative but identical; it is a duty to insist on rights in so far as these rights are moral, not merely legal, and the individual has a right to the performance of duty.

The moral judgment is a judgment on a fact, but expresses, nevertheless, a fact also; it expresses an adjustment to an ideal order, which, if ideal, is yet a fact, although never realized in its entirety. Thus morality is not a mere matter of opinion. Opinions may differ with regard to a fact of morality as different individuals differ in the apprehension of a physical fact. An action is not right simply because I think it is so ; but the opinion of the good man represents what is really good.

Goodness is a mental fact; the apprehension of goodness, as the passing of judgment upon it, is different from it; but it is nevertheless, in another sense, the goodness of the good man which approves or is the approbation of the good act; and "badness exists in the mind of the good man and is known as disapprobation." The quality of an action is that which excites approbation; its goodness or adjustment is nothing but the approbation of the good man, but not of other men. In like manner, duty and the sense of duty are the same thing. When the act judged is presented to the mind only as idea, the feeling of approbation or disapprobation is that which we know as the working of the moral sense or conscience.

It is this truth that goodness and approbation are identical that Intuitionism builds upon. Intuitionism, however, regards goodness as some new quality of action, peculiar and inexplicable; while a true analysis looks upon goodness as no new quality, the moral judgment merely placing a mark upon any action as conforming to a certain order or equilibrated system wanted. 
There is in the good man a vague mass of moral sentiments and emotions; and when the idea of any act comes in contact with these, a feeling of satisfaction or dissatisfaction arises, according as the idea fuses with this mass of sentiments or fails in adjustment to them. Moral promptings are merely promptings which have been adjusted on one side and the other until they have come to be in harmony with social conditions; they grow out of the natural feelings by the process of adjustment. The word "conscience," as it is more generally used, seems to emphasize the element of reflection in a greater degree than "moral sense." The explanation of the apparent independence of conscience is merely that, in the good man, the moral order is realized, and action from moral principle takes place spontaneously. In so far as this is true, he is, in the ethical sense, free, yet not free in the sense that he is to be bound by his own conscience alone in opposition to the judgment of all other consciences; "on the contrary, the conscience sits as a tribunal on a man's acts or intentions, just because it is the representative of the moral order."

In speaking of a "perverted conscience," morality condemns the isolation of a man's ideas about right conduct, from the judgment of his fellows.

The conscience, by reason of the element of reflectiveness, is higher than the moral sense; and the cultivation of a refined conscience is the basis of all morality. Yet this very reflectiveness involves danger, in that, attaching itself as it does to the negative side of duty, it tends to associate the latter with the idea of painfulness rather than of pleasure, and to induce fear, and also in that it tends to develop a morbid subjectivity of feeling through too much self-examination.

Good conduct, as good in virtue of the equilibrium it establishes between the various parts of conduct itself, should contain within itself the whole justification of morality. As such, it is the end of morality, in that it is both the object and purpose, the aim or desire; and in that it is also the standard, criterion, or result by which conduct is measured.

Good conduct involves a common good as part of the moral order, and so creative of a tie between all members of society. The common good is thus not to be conceived as something that might be, as it were, cut up and distributed, but as common in 
that it involves an adjustment of claims. The common good is thus, in a sense, objective, or objectively valid, though not objective in the sense that it exists outside the minds of men, but in the sense that it is a compromise between wills, in which each mind surrenders merely personal whims for a common agreement.

Since there seems a discrepancy between my own good and the good of others, how do I make the good of others my object, going beyond myself in the range of my interest? And how is self-sacrifice possible? The answer to the first question is that morality reconciles the likes and dislikes of individuals, so that self-love and love of others describe the moral relation from opposite ends; every act of respect for others is an act of selffurtherance.

We are entitled to assume, as not needing proof, that the instincts of altruism are as fundamental and original as those of self-love. But if we use stricter reasoning, we can see how, in either case, we identify ourselves with others. Altruism is merely a form of conduct in which the egoistic element, though present, retires into the background; while in all right egoism, we aim at the good of others as well as our own good, though our own good appears as the more prominent feature in the act of willing. We must not be understood as willing, in altruism, another's good in any mystical sense, in the sense of any identification of self with others; we will the good of others in quite a different sense from that in which we will our own good, the idea of their good being a representation in our mind from the analogy of our own experience; and the good attained by each party to the transaction is different and incommunicable. Neither must egoism or altruism be interpreted in the sense that, in either, reflection on the end as distinctively the good of self or of others is involved; the moral agent in general throws his energies into this or that course of action, because it is felt to be what is wanted, without further reflectiveness.

Human beings, as plastic shapes, moulded by contact, adjust themselves to each other, and thus it comes about that certain personal claims are waived. Self-sacrifice is a real fact, a fact attested by the existence of the bad, to whom such sacrifice involves a loss of happiness and is impossible. It means the abandonment of a real good which the individual would seize under other circumstances. It is sometimes contended that real 
self-sacrifice is impossible, either (I) because the sacrifice is really pleasanter to the agent, or (2) because he is compensated for his loss. But the evident fact that self-sacrifice is pleasanter to the agent does not involve the seeking of his own pleasure by the agent, and even if it be admitted that there is always the forecast of compensation in the mind of the agent, yet part of the forecast is the picture of happiness foregone. But here, as before, it may be said that the element of reflection, the weighing of one's own and others' happiness against each other is read into the act by the onlooker, and is not necessarily involved. 'That his own self-sacrifice, the compensation of his own consciousness of right-doing outweighs, to the moral man, the pleasure of lower aims, does not mean that the individual is selfish in seeking selfsacrifice. And, in fact, that any ulterior aim of self-satisfaction beyond the act itself is sought, in self-sacrifice, by the moral man, is false; the greatest acts of heroism are characterized by complete absorption in the impersonal end sought, the good of the agent thus not lying beyond, but consisting in his action. Acts characterized by another spirit than this we do not term selfsacrifice.

As all conduct is a matter of will, so morality is concerned not merely with the virtues, the practical dealings of men, but also with all that strengthens or weakens the will and, in general, conduces to character. In judging a man, the significance of his individual gifts, and the responsibility which attends the cultivation of these gifts must be recognized. Not special virtues alone must be considered, but the whole man must be judged and the significance of his self-cultivation in this or that direction observed. This does not mean that the exceptional faults of exceptional men are to be condoned. On the contrary, there is no reason to suppose that special gifts confer a special privilege rather than a special responsibility. Judged in the entirety of their character, such men may not be worse than others, and this fact should be regarded; but we should not defend their sins as such. The neglect of self-cultivation in one direction may be necessary to action in another direction; but the moral criterion of such self-cultivation or action is to be found in morality as an equilibrium of powers.

Perfection is not itself sufficient to define the end. Perfect is that which is the best possible; perfection as a perfect activity 
rather than a perfect state (as we must conceive it) is equivalent to the best possible conduct. But the moral end can be understood as perfection only when by the best possible conduct is understood that which is the best possible under circumstances determined by morality itself. The fullest development as demanded by morality is not necessarily the perfection of development in any particular case, that is, with regard to any particular gift or individual. Or, in other words, perfection in both its absolute and its comparative meaning, is a conception which belongs, not to morality as such, but to the materials out of which morality is constituted. Take "perfect" as equivalent to "best," then perfection is equally involved in every good action. The good is always the best; what is right is perfect; morality discards degrees of comparison. But the degree of perfection to which any power or individual is to be developed is determined, morally, by the principle of equilibrium. Moreover, we may recognize degrees of perfection in individuals who are, nevertheless, not to be classified as of less or greater moral value.

There are two different conceptions of merit, the one as applied to magnitude of actual achievement, the other to magnitude of effort. The apparent discrepancy vanishes on reflection, since both conceptions apply to what passes beyond the average and measures the distance between the two.

Against the hedonistic doctrine, it has been urged by Green that pleasure as such is not the end of action, for even where the single pleasure is desired there is always the thought of a permanent self whose good is supposed to lie in the direction of this pleasure; while a sum of pieasures cannot, as such, be an object of desire, since pleasures, as separate and transitory in contradistinction from the permanent self, cannot be added together in fact, but only in thought; and with regard to a greatest sum of pleasures the difficulty is still greater, since pleasures admit of indefinite increase, and their sum can never be the greatest possible. In so far as desire is supposed to be for pleasures and nothing else, the argument that a sum of pleasures cannot be desired must be admitted. The transiency of the pleasures has, however, nothing to do with the question; the reason why a sum of pleasures cannot form a single pleasure is that they are pleasures with a higher idea - that of a series involving a plan. This does not prove that a sum of pleasures might not be the criterion of conduct. It must be admitted that 
"sum" is an unfortunate word, since it seems to imply that the pleasures must be combined in one total result ; but such an interpretation of the word is not necessary. A series of pleasures is properly nothing more than an aggregate or combination of pleasures, partly successive, partly coëxistent. Nor does the greatest possible happiness mean a happiness than which no greater is possible, but the greatest possible under the given conditions. The polemic is directed against the individualistic psychology, which regards mental states as a mere succession of events. So far the arguments enforce a great principle; a mere succession of feelings or sensations could never yield a conception of a sum apprehended as a sum. But this is irrelevant. For such an idea we require much more than sensation: we require memory, perception, the idea of a self. But this is only saying that morality requires more than mere sensation, and the argument assumes the standpoint it is fighting, treating mental states as mere events. It, moreover, introduces the idea of a permanent self as something superior to mere sensations, whereas perhaps this self is elaborated from sensational elements. Furthermore, if the proposition means that a mind which had only sensations could not have a sum of sensations, this may be denied. A sum is possible from three positions - that of the conception of a spectator, that of a reflecting consciousness, and that of a feeling consciousness which feels its states continuously, though it may not feel them as continuous, for such a feeling would argue comparison and reflection. The polemic, therefore, while in so far right as it is directed against individualistic psychology, seems to assign wrong reasons for a rejection of hedonism ; Utilitarians, while speaking of pleasures in the language of psychology, treat them really as something more than mere events - treat them as we really combine them by processes much higher than sensation. A refutation of hedonism must consist in showing that pleasures really differ in kind, and cannot, therefore, be compared in intensity. "Pleasure" is often used as equivalent to a pleasant sensation; such pleasures differ in kind, as in the case of gratified hunger, ambition, and the like, and cannot be actually added, either in thought or in enjoyment, because incommensurable. "Pleasure" is often used, also, to refer, not to the sensation itself, but to its pleasantness, and here the same thing is true; if we distinguish the quality and the tone of feeling, as usual in psychology, the classification of tones 
as pleasurable and painful is insufficient. "The tones of colors and sounds, for instance, are more naturally represented by the mood of mind they suggest : red has a warm tone, black a sad, gray a sober, the organ a solemn tone." 1 The tone of some feelings is too indefinite for description, - a vague comfort or discomfort, - while the tone may rise to a condition to be described only by "bliss " or " rapture." Pleasure and pain depend, moreover, not only on the quality and quantity of the feeling, but on the whole condition of the mind, pleasure indicating agreement with the mind, pain non-agreement. Every pleasure being a function of the sensation in which it is an element, the supposed sum of pleasures must be made up of pleasures every one of which is qualified as that which is produced by a certain activity. "The sum of pleasures, therefore, re-introduces the distinctions and contents of the moral order, and, though an expression of the criterion of conduct, is therefore, like perfection, not an independent criterion." The element of quality in pleasure may be verified more easily as what may be called preferability. The term preferability does not mean that there is an inherent moral value in every pleasure, in virtue of which pleasures may be distinguished as higher or lower - obviously an erroneous view, for higher and lower is an antithesis established by morality itself; the value depends on the kind of pleasure, and the preferability is that in the good man's mind.

It might be objected that even though pleasures differ in kind, a comparison and summation of them might be possible, just as comparison and summation of weights is possible, although weight depends not on bulk alone but also on specific gravity. It cannot be denied that some numerical expression for qualities of pleasure may yet be found, by which they may be compared. But it is to be noted that, the higher we go in the scale of existence, the more distinct becomes the growth of a principle of selection or distribution which the members of a combination must follow in order to produce a given quantitative result. In chemistry we may obtain the atomic equivalent of sulphuric acid (98) in many ways, but we can obtain the acid itself only by specific combinations in specific proportions. In determining what food to give an animal, we must consider not bulk alone but the nutritiousness of various sorts. We might express the nutritiousness of various

${ }^{1}$ The reference is here to Wundt, "Phys. Psych.," I. p. 485 (ed. II.). 
foods by numbers, but the numerical equivalent would tell us nothing, unless we knew the kinds of food to be combined. And in the same way we might express the sum of pleasures as end numerically, but until we know the kinds of activities and so of pleasures to be combined to this sum, the formula is useless to inform us as to the end or method of attaining it. The popular conception of happiness avoids all the difficulties and perplexities caused by setting up pleasure as the end, because in that conception pleasures and pains are never considered apart from conduct and character. Thus, though the end involves pleasure, the criterion is good conduct. The good conduct necessarily involves pleasure, for conduct which only outwardly conforms to the moral rule, and in which the agent does not take pleasure, is not really good.

The pleasure-formula thus represented as the standard of conduct is to be distinguished, as actual ethical pleasure in the act, from the pleasures attendant on the act as results, and which may be termed pathological in a Kantian sense. The ethical pleasure need not be unmixed, for the act which satisfies one part of a man's nature does not necessarily satisfy all the other parts. But the ethical pleasure must be present as the total reaction of character considered apart from the incidentals of result.

Pleasures and pains may be divided into two classes, active and passive ; active pleasures being those attendant on an act, as gratification of an impulse, passive pleasures those which come to us as enjoyments, not as the gratification of the impulse producing an act, though perhaps resulting from our act. Active pains are those of want, passive those of suffering. The pleasures accompanying an act as pleasures of attainment are always pleasures of gratification, but not of gratification merely, for they gratify a sentiment directed towards an object previously present to the mind in idea; and it is because the volition realizes the idea that the pleasures are called pleasures of attainment, and in this fact lies also their ethical value. The ethical pleasure in the action itself is not to be confused with the mere pleasure in the explicit consciousness of right-doing, which argues special reflectiveness. The ethical pleasure meant is identical with the feeling of approbation, not as a reflection on the act as idea, but as present in the act itself. But the ethical pleasures are not independent of the incidental pleasures, but depend upon 
them, the latter themselves being considered in determining what acts are to be performed.

The pleasure-formula of the end represents the end in terms of all the ethical pleasures secured by good action; and now we can see how morality can be expressed in terms of all the pleasures and pains involved in action, the purely ethical pleasures being reckoned among the rest. Every pleasure is an inducement to persistence, every pain an inducement to change; hence, since the society of good persons, or the kingdom of powers within a man's own mind acquiesce in the moral order as the equilibrium in which all their claims are gratified as far as may be, it follows that the order of good conduct represents the maximum of happiness. The end thus involves the greatest happiness of the greatest number.

If pleasure is but a part of the standard of morality, is it, then, the object of conduct? If the idea before the mind to be realized in action is called the object of the action, then in the same sense the pleasure connected with the idea, which must be pleasant, is the object of conduct. The difficulty in agreeing that the pleasure of the idea is part of the object of desire arises from two causes: (I) confusion of the object of desire with the character or criterion of the object; (2) a misunderstanding of how the ideal object is related to the result. As to the latter cause, it may be said that the idea is only in this sense an idea of the result, that the result is the idea as it is realized; the elements of the idea are derived from the past, and the desire is not for the prospective pleasure of the end. As to the first cause, though it is false that the prospective pleasure must necessarily be part of the idea, the opposite conclusion is not necessarily legitimate that desire is not for pleasure at all. It is true that, in order to distinguish one object from another, we need to know what kind of an object it is ; but to conclude that, therefore, the desire is not for pleasure, is to confuse the actual idea before the mind in desire with its quality. That we do not make pleasure an object in the sense that the pleasantness of the object itself is what we have before us in desire, is obvious. Such a desire would argue a reflectiveness which has been shown not to be necessarily characteristic of action. Nor is it the pleasure of an act which is the cause of the desire, even if we suppose this not in the sense that reflection apprehends it as cause. To suppose this is to confuse the cause 
with its sign. The pleasure is a function of the quality of the object. The element of reflectiveness may enter into a consideration of the object, and the prospective pleasure thus become an element of the object of desire. But it is only a part ; the pleasure alone cannot be the object of desire. The pleasure which is thus a part of the object is not a future pleasure, but that which is actually present in our minds, belonging to the ideal object as part of it - the represented pleasure of attainment. To call the pleasure desired the prospective pleasure is to confound the reflection of the spectator with the actual fact in the mind of the agent to an act. 'The pleasure is, moreover, not pleasure in general, but the pleasure of the agent; but this is not stating that the act is necessarily selfish.

Since every object of desire and will includes pleasure, the socalled "paradox of hedonism" - that pleasure is lost by seeking after it - cannot be explained by holding that pleasure is not itself the object of desire, and that consequently pleasure is never, in enjoyment, what it is in idea. This last is true, for no idea is in reality what it is as idea. But the explanation lies rather in pointing out how foolish it is to seek for what is a sign or effect rather than for its cause.

In the good man, the pleasure of attainment is the ethical sense of approbation, and this is also goodness. It may, however, be asserted that it is not this ethical pleasure, this goodness as such, that is desired by the good man; again, it is only in exceptional cases of reflectiveness that goodness or the right action as such is distinctively desired; and herein lies Kant's mistake in asserting that a moral act must be done from a sense of duty.

Active pains, as wants, are what prompt to action, and are, so, the conditions of conduct. Though in themselves evil, as pain, they cannot be considered by themselves apart from the action to which they lead. As for passive pains, in so far as they are the result of evil action on the part of others, they ought not to have occurred, and we try to prevent their repetition by punishment. Those sufferings incidental to right conduct are to be borne, in so far as they are inevitable, as a necessary evil in that which, considered as a whole, is good. As soon as they cease to be inevitable, they are to be removed. We do not imagine, however, that pain may ever be wholly removed. But the statement that pain is inevitable to right conduct is not to be interpreted as an assertion that it is for 
the sake of goodness, as a discipline, - a metaphysical conception depending on the idea of a divine purpose.

Morality is thus a kind of optimism, not ignoring the reality of pains in right conduct, but treating them as part of the given conditions which it has to turn to the best account, by the creation of a conduct and character involving ethical pleasures. Pessimistic theories do not ignore this optimism of morality ; but in such theories the fact of pain is emphasized and dwelt upon, and morality is regarded only as a means of lessening pain, or, as in the case of Von Hartmann, finally getting rid of it altogether by a universal suicide. It is impossible to determine whether existence represents an excess of pain or of pleasure, since the answer to the problem is a matter of individual temperament; and, moreover, pleasures and pains cannot be (as yet) merely quantitatively compared. Another error of pessimism consists in comparing pleasures and pains in detail and supposing the result to hold good in the general sum; but even in cases where pleasures are greatly outweighed by pains, the pains may sink in value considered in connection with the rest of life. The desirability of non-existence could be maintained only as a race should be developed desiring it ; but the whole course of history is in the opposite direction.

The question, Is life worth living? involves two: (I) Is it actually preferable to the creature who lives it? (2) Can any life be said to have a real value; is any life subjectively, is any objectively, preferable? The answer to the first question is the fact of life, for the mysterious instinct of self-preservation called in to account for the continuance of existence is one of the elements to be considered in the problem, cannot be excluded. It is true that only certain kinds of life are preferable, but the very meaning of the principle of selection is the securing of the life that is worth living.

Having arrived at this answer, we can no longer compare existence and non-existence in respect to preferability, and the second problem presents itself to us as the question as to what existence is of value. The answer is the moral life, goodness, as including all the activities of character.

The moral end has sometimes been defined as social vitality. Vitality is, in strictness, the energy to live, and has two aspects. It is (I) the force which keeps a creature alive, or (2) the force which keeps it well. As implying the keeping up of vital func- 
tions, the notion of continued existence represents the end, but represents it in its lowest aspect, its least and poorest significance, and is an insufficient description; for not existence can be the end, but existence of a certain sort. "Existence, in fact, is an abstraction to which nothing corresponds in experience : nothing exists except upon certain terms. Given the type, the end of the creature is to continue the existence of that type ; but continuance of existence is nothing more nor less than the performance of those functions which constitute the type of life in question: it is not separated from those functions as something which they subserve." If the functions in man or animal are said to be determined by the need of maintaining his existence, it may be answered that his existence is these functions. In this sense of continued existence as the repetition of vital functions in their order, it is true, but only secondarily true, that the end is to preserve life. But the doctrine of evolution implies much more than such preservation. It means the victorious continuance of life. But because a type is victorious, we cannot infer that the end of the type is to maintain its victorious existence in the sense of aiming at victory. To do this is to read into the end a theory of how the type came into existence. The end of a type is to act according to the type; the victory over rivals affords the opportunity of this. The preservation of existence is a condition of the end, not the end itself; to regard it as such is to confuse cause with effect.

Vitality as health, on the other hand, implies the equilibrium which constitutes good conduct good. It must, however, "be observed that health is not a further specification or a limitation of continued life, but is coëxtensive with it."

But health, as applied to morals, is a $\mathrm{m}$ taphorical term. Morality does not consist in mere physical vitality; on the contrary, some sacrifice of such vitality may be necessary, the perfect physical vitality may be inconsistent with the development of higher and finer mental functions. "With this proviso, vitality as health is simply another name for the character of good conduct which wins it the title of good."

There is often a distinction made between virtue and duty, the former word seeming to include the latter and go beyond it. However, it is not only virtuous to do one's duty, but it is also the duty of the individual to do his best. In fact, the two, virtue and duty, 
are coëxtensive, the term "virtue" describing conduct by the quality of the agent's mind, the term "duty" by the nature of the act performed. Nevertheless, there are actions to which it is more natural to apply the term "virtue," "duty " being colored by legal implications. In the legal sense, duty fixes, not the highest line of conduct, but the lowest limit, beneath which conduct must not fall. Virtue, as contrasted with duty in the legal sense, seems to be coëxtensive with merit. Negative merit, however, where a man is good in spite of some great disadvantage, does not make an act virtuous in distinction from dutiful conduct. It is the duty of a man with a passion for drink to repress it; but we do not term his performance virtuous, though it may be meritorious. Merit, that is, implies a scale within the range of good acts themselves. Virtue and duty coincide, however, only so long as the moral value of actions are considered. For we distinguish two different classes of virtues, or two senses of the word "virtue," corresponding to the distinction of ethical and pathological, the pathological virtues being certain gifts of emotion or sentiment, which are sometimes thought to make action more virtuous, but do not alter its real character. "Thus, for example, the virtue of benevolence may be thought imperfect without kindly feeling, though a man may be benevolent without any such spontaneous movement. Chastity, again, may in some natures be accompanied by, and flow from, a delicacy of feeling which makes all unlawful suggestions impossible. Now, if these emotions were necessary to their respective virtues, we should have to admit that duty was less than virtue. But we must maintain that they are excellences which do not alter the moral character of conduct, and may be absent altogether and leave the agent as virtuous as if they were present. Some persons, indeed, would say that there was less virtue in characters which possessed these emotional endowments. ... In themselves, they are not virtues in the ethical sense, but only ' add a lustre' to habits of will. They may even be ineffectual, as often happens with very good-natured persons, or they may be positively bad. Courage, for instance, we admire even in a villain. We may conclude, then, that these excellences of disposition are only valuable in so far as they are helps to virtue, and we praise the brave villain on account of a quality which is of the utmost importance for actual goodness. They enter into our ideal of the perfect or complete character, though, if we estimate our ideal of 
perfection, we shall find, I think, that we attach less value to them when they are native than when they have been produced by a constant discipline."

It might seem, then, that we could classify duties under virtues. To a considerable extent such a classification is possible. But it must be imperfect, because there are duties - for example, filial duty, or the duty of casting one's vote in a political contest which do not correspond to any general head of virtue, or may be ranked under several heads : and again, we may rank along with virtues which stand for duties qualities of conduct which do not correspond to duties in the same sense ; as, for instance, in a list of heads of duties, wisdom and self-control. The enumeration mixes up two classifications, in the one of which we group observances together under certain heads, in the other of which we enumerate certain elements of good action in general, certain aspects which every good action presents, and we exhibit them as qualities in the agent's mind. The two classifications are combined in the ancient description of morality under the heads of wisdom, courage, temperance, and justice. The better classification is by moral institutions, where the moral life is already mapped out for us into its different parts. Such a scheme of classification will consider $(a)$ the Individual, $(b)$ the Family, $(c)$ the Society, $(d)$ the State; the fourth division including international duties, the third not being necessarily limited to a particular society, but extending to all mankind.

\section{Dynamical Analysis - Moral Growth and Progress}

The previous description of morality supposes it to be stationary, and is like a section taken across the path of morality at any one time. It gives us no idea of the process and progress of morality. We have yet to show how the moral order is produced, and to examine the meaning and the law of moral progress.

As the moral organism may be compared to a species of which the various moral individuals are the members, so the moral ideal may be regarded as a species of which the various ideals in the minds of good men are the different individuals. We should thus expect to find the origin and growth of morality analogous to or, more strictly speaking, identical with, the growth of natural species. 
"If an ultimate ideal were admissible, it would be impossible to assert that morality is essentially progressive." Morality, in the sense of an equilibrium, has at every stage a certain finality, in the sense that it is, for that stage, the ideal adjustment. But we cannot conceive of any ideal as final in the sense of stationary. The good is always ultimate but always in motion. "Moral progress admits of only two degrees of comparison, the superlative being identical with the positive." By "best" we do not imply a greater rightness in the ultimate condition, but only a highest development. Spencer's conception of the distinction between Absolute and Relative Ethics involves the conception of an ultimate "ideal congruity," or complete adaptation of man to his conditions, a mobile equilibrium including perfection as well as goodness, present choice being never between wrong and an absolute right, but always between two wrongs, the lesser of which is to have the preference. The picture is, in itself, perfectly legitimate; and in so far as Spencer "conceives that the only ideal is the absolutely right conduct, his conception is not only legitimate, but true." There is always, however, an absolute right that may be chosen; and "using the conception of a mobile equilibrium, we found it to be, not a goal of progress, but the meaning of goodness at any time." "The distinction of good and bad (right and wrong) arises within the limited range of conditions that are to be met by good action." That, as Sidgwick asserts, there is always some course of conduct which is right, the moral consciousness declares with certainty, and is thus against the relativity of morality. Mr. Spencer holds that any concomitant of pain makes an action wrong, therefore it is natural for him to regard all present morality as only relative. But to the good man the pleasure of doing right exceeds the possible attendant pains of an action; and except upon the understanding that, in a society of good men, every one will adjust himself with equanimity to the needs of others, not even the acts which are declared to be typical of absolutely right conduct can be free from concomitant pain. "Will the ideal state exhibit no competitions, such as rivalry in love, which can be ended indeed with the contentment of all persons, but assuredly not without attendant pain?"

The general error in theory on this subject lies in a misconception of the idea of "adjustment" to environment, the fact not being noted that the environment is not itself fixed and permanent. 
What the environment is depends upon the nature and faculties of the individual, the same environment being a different one for amœba and human being, for the blind man and the man possessing sight ; and what environment is and what the individual does are settled at one and the same time, the process of selection being one from both sides, and the variation of both. The adaptation "wherever it exists and so far as it exists" is, hence, perfect adaptation; if the lower organism is adapted to its environment, its adaptation is as perfect as that of the higher organism to its environment.

Every successful life means adaptation. "Every animal which can maintain its life is in adaptation to its environment." The bare formula of adaptation means nothing more than the fact of existence. "Adaptation to the conditions as such teaches us nothing as to the nature of the organism; for all functions are reactions upon the conditions, and therefore, so far, adaptations. But it points to something behind. It means that all the functions of the animal are adapted to the conditions, and this means that its functions are adapted or adjusted to one another under the conditions."

"The moral ideal consists in a certain equilibrium established on the basis of certain conditions - wants and sentiments in moral agents." It involves advance just for this reason, because the act of adjustment implied in good conduct itself alters the sentiments of the agent, and creates new needs demanding a new satisfaction. The change is not always in the same direction, however; for cultivation in one direction may cause the individual to become aware of capacities or wants in quite another direction, or the advocacy of one side of a question, persevered in, may so open up the other side as to end in complete change of view. In any case, however, there is an enlargement of experience, and the old facts are themselves changed by it as well as are the individuals subject to it.

This change or adjustment leads to a maladjustment requiring a new adjustment. 'This maladjustment is to be distinguished from the reärrangements which are contemplated by the statical ideal and due to the mere rotation of wants in society; the latter are within the moral system as a system of mobile equilibrium. The maladjustment is of another sort. "The good act ceases to be good by its performance. The moral ideal ceases to satisfy." 
The two forms of change may be compared respectively to a shifting of position on the same locus, and to such a shifting of position as involves a shifting of locus. Thus, by change after change of this sort, a new variety replaces its parent, and this variety in time producing a fresh variety, there is finally reached a new species. Progress thus becomes a necessary fact, and the difference of so-called stationary societies from progressive ones can lie only in the comparative slowness of change.

"As there is a difference between different societies in rate of change, so there is a similar difference as between different parts of conduct." Law, a part of morality, lags behind in moral progress. However, there is nevertheless always advancement, otherwise legislators would be unnecessary. And the direct outward change of form is preceded by other change, laws which fall into disfavor by means of moral progress being modified, in application, within the possible limits of interpretation, and less and less rigidly enforced. There is good reason why law should have a certain permanence.

The moral standard appears to have a similar more or less fixed character, while morality itself is in continuous change. There are two reasons for this appearance: (I) the changes in the moral order are infinitesimal and not perceived by us except as accumulated through some period of time; and, moreover, what is commonly called the moral standard is only a kind of generalization from the extremely various opinions of different persons as to what is right, and differs from the real standard which " registers the conduct constituting equilibrium, and is possessed by the good man. Perfectly good men are impossible. The standard current is therefore nothing more than a common understanding, which every one, even every good man, expresses differently; it is no more an exact expression of the truth than is, let us say, a great scientific conception (like development) which regulates all knowledge, but is amongst the educated little more than the name of a general way of thinking, while the thing itself is becoming, at the hands of men of science, modified or even transformed." (2) The mistake is often made of describing morality, not by institutions, but in terms of virtues, and while the name applied to different virtues remains the same, their content changes from age to age.

This idea of variability affects the statical conception of order 
with regard to habit - the moral requirement being that the fixed habits of morality should not be so fixed as to be incapable of advancement; and with regard to conscience, of which it might be said that, instead of representing the moral order, it was more occupied in changing than in maintaining it, but which in reality thus represents the moral order, to which the ideal is a changing one.

Two difficulties or objections may arise with regard to this idea of a changing ideal. The progress has been represented by personifying the ideal and supposing the person to change with each new ideal. Again, "goodness consists, we saw, of a system of conduct in the individual himself or in society, and this system forms a series in time. It would seem to follow that, if goodness is always progressive, no second act would be performed under the same law, although the very idea of the law means a series of acts." But we are not to suppose that, if fifty good men in a society act rightly, fifty new ideals are established, for the ideal represents the equilibrium of the members of the society, and it depends on whether the new ideals of the fifty men represent the new equilibrium whether we shall call the persons good or bad. Again, the ideal at any moment would be in fact realized in a series, supposing the conditions did not alter meanwhile; and while the system of conduct is serial, it is realized at any one moment in the mind of the man whose sentiments correspond to its requirements.

"In this process we see exhibited the interplay of the element of goodness or rightness with that of perfection. In all actual goodness, we have perfection attained as well; but in the statical notion of goodness perfection is subordinate - only that exercise is perfect which is legitimate. But in the notion of progressive goodness, perfection regains its rights. For goodness, having secured perfection, creates new materials which destroy the old equilibrium and call for a new one. Goodness determines perfection, but change in perfection determines, therefore, changes in goodness." Morality is the creation of a better; this better is change from a lower to a higher development, not the growth of a greater rightness. All good conduct is absolutely good, and the good man of former days was as good as the good man of to-day, although he performed acts not allowable by the higher moral standard attained as highest development. Accord- 
ingly, there is no such thing as an absolute morality, in comparison with which other conduct is variable and relative. The relativity of good conduct, instead of being a reproach, is in reality its highest praise, for it implies that the conduct takes account of exactly those conditions to which it is meant to apply. This conception of morality as absolute runs into that of morality as an eternal and identical law: eternal, for the morality of given conditions remains eternally true for those conditions; identical, for although it cannot be called identical in the sense that virtues do not change with institutions, it is identical in form, - as an equilibrium of social forces in an order of conduct. The more important conception of the moral law is its unity in which, as the stages of one continuous law, its identity consists. "Progress is not mere destruction of the lower, but fulfilment."

In considering how morality arises, it would be erroneous to suppose that it comes into existence by an actual compromise. It arises through a process of continuous change, parts of which may be an insensible growth, parts the self-conscious adoption of a proposed new scheme. In the latter case, a slight reform may be adopted with but little opposition from members of the society other than the proposer, as meeting a recognized, common want; or, in the case of a more extended reform, the idea as first proposed may be long contended against, and only finally adopted after much alteration by reason of contact with such opposition. In its acceptance innumerable forces are combined, innumerable different motives determine its acceptation by different persons. Whatever the motive, however, the conduct of the person accepting it alters in accordance with its acceptation.

The chief importance of pleasure and pain lies in the part they take in such choice. They are "the tests of the act being suitable or the reverse to the character (in the widest sense) of the agent." If a reform does not suit the character, it will cause pain and urge to removal of the pain by resistance; and on the other hand, when the reform is accepted, it must be that it gives pleasure to the persons concerned. But in saying this we have to remember the distinction between ethical (or effective) and pathological (or incidental) pleasures and pains. The total reaction of character on a stimulus may be pleasurable, but this pleasure results from a mixture of pleasures and pains weighed against one another. This balancing of pleasures and pains is not reflective, but takes 
place by a kind of intuitive act in which only subsequent reflection may be able to distinguish the elements. The pleasure or pain involved in acceptance or rejection is not the ground of acceptance or rejection. The cause of the acceptance or rejection is the nature of the reform itself, its congruity or incongruity with the natures of the persons accepting or rejecting it. "When the new ideal is definitely established, those who do not obey it are bad, those who do are good." Those who were good under the old may thus be bad under the new ideal, and vice versa.

The gradual reform through the choice of individuals who act upon their feelings without knowing the whole aim or bearing of their conduct is similar to that where a definite reform is the end in view. It is a gradual adjustment of wills under new conditions and represents the position of equilibrium which would be completely realized if all the society were good.

The new ideal is not to be defined as merely the will of the majority, the possession of a majority being nothing but the fact of its prevalence. The ground of prevalence is that it represents the equilibrium. "There is no virtue in mere preponderance; it is not that reforms follow the majority, but that a majority is attracted by a suitable reform."

A new ideal arises by a struggle of varieties analogous to that in the organic world, - the word "struggle" being metaphorical in both cases, since actual conflict is not necessary to either. "The distinction of good and bad corresponds to the domination of one variety . . . which has come to prevail in virtue of its being a social equilibrium," and thus representing suitability to all the conditions of life. Evil is simply that which has been rejected and defeated in the struggle with the good.

The reformer, as not representing the predominating ideal and so the social equilibrium, and the man who turns out to be bad by the new ideal, thus stand originally upon the same level. "Each is an instance of a variety of the original species, but the former is the successful variety"; his ideal "represents the real forces of society and can be adopted by the whole." The struggle is one of character and conduct, and results not necessarily in the extinction of life, but in the extinction of unsuitable ideals.

"The distinction of the formally bad from the materially good rests upon the transition from the old ideal to the new, though sometimes we use those terms as describing what is only legally 
wrong though morally approved. A reformer, until his reform is established, is formally wrong. He can be considered materially right only prospectively; . . . time only can prove whether he had really forecast the movement of his society." "Sometimes a society may be so divided, as in our civil war, that neither variety is predominant. In such a case we must say, not that there was no rule of right, but that there was a different rule for each of the two halves of the nation." "There does not arise any need for the distinction of formally and materially right conduct, until the limits have been overstepped, within which it is in any age considered right for a man to act upon his own conviction. These limits are placed very differently in different ages."

Does good action, then, depend on the bad man as well as on the good? "Good and evil arise together, and good is therefore always relative to evil, but we do not therefore take our morality from the bad. We cannot, in fact, know who is bad until the standard is created, but once created, we maintain it against bad men by punishment. But, on the other hand, the moral standard does depend upon the forces which, when allowed free play, are distinguished as bad. . . . A large part of conduct consists of precautions which it is not only legitimate but incumbent to take, but which we should dispense with under happier conditions. And in a second way, morality depends on 'badness,' for when a habit of action which we dislike and call bad comes to be strong enough to make itself felt, we seek to satisfy its claims as reasonable. There is . . . no external standard by which we can settle once and for all what claims are legitimate and what are not. We derive our conception of the reasonableness of things from our experience of their vitality and effective powers. A wise man who thinks the feelings and beliefs of his neighbors ridiculous will, by persuasion or force, resist them with all his energies, but when he finds them persist in spite of all his efforts, he will recognize that there are more things in human nature than stir within the narrow limits of his own breast. If what we now call bad conduct, murder, adultery, theft, could be conceived to become predominant under greatly changed and of course impossible conditions, it would cease to be bad and would be the ideal of life."

From the view that morality depends upon victory, miscon- 
ceptions may arise. The question may be asked: Should one, in case of doubt, follow one's own conviction, or join the side it is thought will prevail? But that good is created by predominance is a theory of the means by which ideals come into existence, not a statement of the motive of those who participate in the struggle. The struggle is between characters and their forces, and not victory is the end, but the assertion of certain principles.

"Interest or good in general is a different conception from the right or the morally good. Interest means what is good for an individual considered from his own point of view, and without regard to similar claims of other individuals. It is the maximum of happiness or satisfaction which he can secure under his conditions. By 'maximum happiness' is meant that distribution of satisfactions or of the energies which produce them, any deviation from which on either side implies a less fulness of life." It refers, however, to his good as a social, not as an isolated individual.

As a general rule, interest is in agreement with goodness; misdeeds are unprofitable. But there are instances where goodness and interest do not coincide, though not in the case of the good man. That virtue and interest are in general identical means, statically, that morality is a reconciliation of interests by which wants are satisfied, and is established by the creation of a new type of character, which has wants of only certain kinds; and, dynamically, it represents the fact that forces are arrayed on the side of the good which are too powerful for the bad. "Good is the victorious ideal"; and though we may say that it would really be to the bad man's interest to be bad, if circumstances were such that his variety could maintain itself, we may add that such hypothetical interests cannot be secured. However, interest does not coincide with morality -

(I) Where the individual does not care for punishments and social censures. (2) Where a man, by reason of certain superiorities of force over others with whom he is more directly in contact, is able to obtain power and suppress their resistance, or where the moral weakness of others leaves him unpunished. In these exceptional cases, we have the contradictory phenomenon that an ideal which can maintain its existence is yet declared to be bad. "Such cases mark a stage of transition in the process 
by which the distinction of good or bad is established.' In the struggle of animal species, the same phenomenon may be found; an exceptional individual of a vanishing variety maintains his existence for a time by reason of his exceptional endowment or of coming in contact merely with the weaker members of the successful variety.

There are two ways in which the moral ideal is maintained,by education and by punishment. Punishment is the condemnation of wrong-doing by censure or by legal penalties. The unpleasant consequences of neglect of the self-regarding virtues are not punishment; but the reaction of the good forces of society against wrong-doing is as natural as the unpleasant physical effects of imprudence.

"If the question as to what moral sanction is means, "What reason is there why morality exists?' the answer lies not in enumerating the penalties of wrong-doing, but in tracing the origin of morality as an equilibrium of the forces of society. .. . But the question, 'Why should I be moral?' means, most naturally and usually, What inducements are there to me to do right?" The answer is that motives differ for different individuals. With some, outer social inducements, with others, the approbation and disapprobation of conscience are stronger. These latter ethical pains and pleasures which are felt at the idea of an action stand on a different footing from feelings having regard to external rewards and punishments and also the prospective pleasures and pains of conscience. The man who does right because he shrinks from prospective pains of conscience is not a good man, but intermediate morally between the bad man who seeks only to escape legal punishment and the good man whose pains of conscience felt at the idea of a wrong act prevent his performing it.

Punishment wears different shapes according to the point of view from which it is regarded, but, in the distinctively moral view, is reformatory. All punishment is retribution, but not in the sense that it is personal vengeance. The value of this idea of retribution lies in the fact that it places punishment on a line with the process of self-assertion by which species maintain their life; it is a part of the reaction of the organism against anything which impedes its vitality. If, however, punishment avenges the evil deed, it is a confusion to say that it is for the sake of 
vengeance. The purpose in the mind of those punishing is not necessarily vengeance, and the idea of mere retribution is repugnant to the good man. From the juridic point of view, the object of punishment is prevention; from the moral point of view, reformation. The reformation seeks to destroy a bad ideal, and does not necessarily destroy the individual in whom it is found; but in some cases the wrong-doer's mind is so perverted that only death, it is judged, will suffice. "Here, too, paradoxical as it may seem, though perhaps the chief object of our punishment is the indirect one of bettering others, we punish with death in order to make him a good man and to bring him within the ideal of society. . . The penalty of death is thought necessary to bring home to him the enormity of his guilt."

The object of punishment is not always achieved, but this matters not for its moral character, which lies in its conscious object. The idea of punishment as reconciling the criminal with society includes the aspect of retribution or expiation, under which punishment may be viewed from without; but it is only when the suffering is attended by reformation that it can be considered in a proper sense expiation or atonement.

Responsibility differs from obligation by introduction of the element of punishment. Obligation is the necessity of good conduct which arises out of the relation of the act to the order of which it forms a part. "Responsibility is the negative aspect of this relation. When I think of conduct as required of me, I think of it as my duty; when I think of it as conduct which if I do not perform, I shall be rightly punished, I have the sense of responsibility." The sense of responsibility is thus a knowledge of the requirements of the law, and it is only as we have lawabiding instincts that we feel it; and we feel it differently according as we think of the authority of the law as derived from its mere enactment or as founded upon the social good, or as established in our own conscience and self-respect, which represent the social good. As including recognition of certain conduct as right, the sense of responsibility is more than the mere knowledge and fear of punishment. "It is only those who can appreciate that punishment will be deserved to whom the idea of responsibility applies. There is, therefore, no difference between the fact of responsibility and the sense of responsibility, any more than there is between goodness and the feeling of approbation, 
or duty and the sense of duty. When we declare a bad man responsible, we mean that the good man holds him to be justly punished."

Responsibility depends, then, on two things, - that a man is capable of being influenced by what is right, and that whatever he does is determined by his character. This capacity depends on his being aware of the meaning of his acts, and so of their connection with other acts, and contains thus an element not present in the relations of animals.

"Except for the authority of one or two great names, there seems to be a general agreement that the will is determined by character." If character means the principle of volition, as it is regarded in our analyses, the assertion is a truism. It is no less true if character is defined as disposition; all our dealings with our fellow-men reckon on their acting in accordance with their character. The distinction made by Green that the mind acts from its own nature (the motive and the whole process of willing being within the mind) is no more and no less true of the action of other bodies. The emergence of new sentiments in character might be urged as an argument for free will; but this is of no more significance than the budding of trees in springtime. The sense of freedom is the sense of choice between two motives; but this merely depends upon the intellectual property that the object willed is present to consciousness, - in case of choice two objects being present to the mind. "So far is the consciousness of freedom from being a ground for assuming an arbitrary or undetermined power of volition that it is exactly what would be expected to accompany the process of determination when the object concerned was a conscious mind. Pull a body to the right with a force of twelve pounds and to the left with a force of eight; it moves to the right. Imagine that body a mind aware of the forces which act upon it; it will move in the direction of that which, for whatever reason, appeals to it most; and in doing so it will, just because it is conscious, act of itself, and will have the consciousness of freedom." But which motive is chosen is fixed and dependent upon character, that cannot choose otherwise than it does; and the sense of freedom is a sheer delusion. The feeling that one ought to have acted otherwise implies another sort of freedom, according to which he only is truly free who chooses the right; in such choice it is, however, the character 
which acts, and though a man is free, in this sense, if he chooses, his choice is determined. The argument of free will in regard to punishment does not explain punishment, but renders it inexplicable. It would be senseless to punish except as, by so doing, we can influence a man's character. Determinism does not make punishment wrong; it is not cruelty, but kindness to punish: it saves a man from worse, from degradation of character, enabling him to change his ideal, and thus bringing himself into equilibrium with his kind. The reason of certain doubts which are beginning to be felt to-day with regard to punishment is the larger knowledge of the dependence of men on their surroundings, hence of the culpability of society as a whole; it is not an objection to responsibility as such, but to the distribution of responsibility.

Education, the second means by which the moral ideal is defended, is not identical with social progress, by which the moral ideal is itself changed, but is the individual progress included within each definite moral ideal. Education and progress are, however, inseparably bound together, in that education goes hand in hand with punishment, and in that it leads to the discovery of new ideals. If we take only the irregular line which includes the good, and discard the ideals which are exterminated or left behind, the movement of ideals is continuous with education, and progress may therefore be described as an education of society. The education of children has to put them in possession of the present moral achievement, and to make them independent individuals, - so to penetrate them with the moral order that it shall appear in them as spontaneous character. It is an evolving of an ideal already present; for, to be capable of education, a person must have already set foot on the right path.

As in the physical world, so in the moral, we have the survival of many different genera and species, - various ideals of conduct or institutions of life, some of which may be grouped together by strong resemblances, others of which stand to each other in the relation of lower to higher organisms; the survival of archaic institutions in the higher as well as their history of progress showing their affinities with the lower. "History is the palæontology of moral ideals," and provides us with a better means of studying the growth of morality than exists for the study of the growth of species. As in the organic world, varieties develop 
from species by a gradual and continuous movement of sentiment, each successful variation forming the basis of a new variation, and the differences of the varieties from each other and from the original species increasing with their distance from the original species, until the difference amounts to a difference of species. We may call these modifications "accidental," but, as in the physical world, they are so only as we regard them from the position occupied by a person before the event; they have their causes if we can find them. These causes are to be found in the contact of different minds. Variability depends to a considerable extent on the size of a genus, but only in so far as greater size involves greater complexity and variety of interests; the vast but homogeneous societies of the East being less progressive than the smaller but more complex ones of the West. "Where freer scope is left to individual inclinations or aptitudes, there the friction of mind against mind is more intense. New ideas are generated in the more vivid consciousness of the people, and life becomes more inventive."

Species developed from a common genus will show some common traits and some rules of mutual observance, savage peoples which have divided into tribes being an exception to the latter part of the statement, for the reason that lower societies have very little moral cohesion; they may be compared to lower organisms which reproduce themselves by fission, or to homogeneous colonies of animals, like sponges. Under the generic institutions we must not include those which arise merely as the result of similar circumstances. Ideals once formed advance at very different rates, though the tendency to divergence is always being corrected by the diffusion of ideas. But where one nation takes ideas from another, these ideas are not borrowed, in the sense that they come wholly from the other nation; there must have been, in the borrowing nation, a development of ideas up to the point that makes the borrowing possible,- a similar development to that of the nation from which the borrowing takes place, due to similar circumstances. The communication of moral ideas does not depend upon race-community, as is shown by the ready adoption of Western ideas by such nations as the Hindoos and Japanese.

In general language, we identify development and progress; and this is true also in the case of morality. Goodness means 
progress; wickedness, retrogression or else stagnation, which, compared with advance, is retrogression. "In changing from one form to another, morality changes from what is right under one set of conditions to what is right under another set, and such change from good to good is what we mean by becoming better. To deny this is to find some other standard of advance than in the actual movement which has taken place, to put an a priori conception of development in place of the facts." "The moral ideal is always, therefore, a progress, for either the society is single, and goodness represents the law of its advance, or if the society is part of a larger one, its ideal can be retrogressive only because the society is so far bad." "And since goodness and badness exhaust the field of moral possibilities, if the propositions that goodness means progress, and badness regress, are both true, we must be able to convert them, and maintain that all progress is due to goodness and all regress to badness." To do this, we must distinguish between degradation and a mere degeneration which involves a return to simpler conditions as an adaptation to changed environment. Such degeneration as adaptation to circumstances, in an individual or a society as a whole, is progress. Fish who become blind by living in the dark become thus better fitted to their circumstances, and the like is true of moral degeneration under simpler conditions. Old age and death are characteristic of the higher type of organism, in distinction from the lower types which, multiplying by fission, are practically eternal; they are conditions of the advantage of type, in which the individual is partaker. So a good society under simpler conditions is on the side of progress, though it may lie outside the main line of advance.

It is true that bad persons often help on progress, but the good they do lies in their representation of the will of society for progress, the evil lies in their use of this will as means to their own ends. It may be objected, too, that the good man is sometimes a hindrance to progress through stupidity; but to this is to be answered that intellect itself becomes morally characterized in action.

All events and institutions are thus determined by their conditions; but there is a movement forward distinguishable from the delay of stragglers and the resistance of enemies, and this distinction is enforced by the moral predicates of good and bad.

Our theory does not imply that whatever is, is right; such a 
statement involves the use of the word right in the sense of "correct," or "intelligible," "accountable by reflection." Nor is the doctrine fatalistic. Fatalism implies that men act at the impulse of some force which they do not understand; "but the history of mankind is the history of beings who, through their own gift of consciousness, subdue circumstances to their own characters." In judging a nation's development, we must not interpret it according to our own likings, as progression or retrogression; nor must we imagine retrogression from relaxation of duties in some certain directions, but must regard the society and its institutions as a whole.

The test of higher organization usually given is that of increasing differentiation of parts with corresponding specialization of function. But the main course of progress is not linear, or in one continuous direction; apparent reversions to former types are only apparent; the new type stands higher than the old. In other words, history moves in cycles. It follows, from this, that mere differentiation is insufficient for definition. While the differentiation advances, its significance alters, or, let us say, the relative places of specialization and of unity alter. Along with differentiation goes a process of integration. Great revolutions simplify. The result of greater and greater heterogeneity is to produce a new principle, which combines the warring elements. The definition of progress by increased differentiation is lacking in two ways: It tells us nothing of the forces by which progress is produced, and it gives no connected view of the actual facts of historical development. A general statement of progress in its formal sense is found in the conception of a struggle of ideals. But as in this struggle the survival of the fittest does not necessarily mean the destruction of those who represented the defeated ideal, but the supplanting of their ideal by another, the movement is one of comprehension, and we should expect to find, and do find, the history of morality exhibit the gradual development of a universal moral order, good not for one group of men but for all. It would be a misapprehension to regard this change as merely quantitative, as if the virtues were the same whether they applied on a larger or a smaller scale. "The quantitative extension is parallel with, and in reality proceeds from, a change in the conception of the human person himself." In primitive communities, the individual is so limited that he can 
hardly be called an individual at all. First among the Greeks do we find the person the embodiment of the social order, but in a limited sense. "When this limitation breaks down, and the individual stands forth as independent and self-conscious, the author of the laws he obeys, we have at the same time the extension of the area of persons with whom he is in moral relation."

"It matters little that the Western ideal of a society of humanity is realized to so slight an extent. The ideal exists and implies the inclusion of mankind." The principle of democracy, which we are engaged in working out, "continues, or perhaps supersedes, under much more complex conditions and over a wider range of institutions, the same principle as Christianity introduced." It is not merely an identical element in many individual states, but a comprehensive ideal. The power of naturalization, extradition laws, international action among the working classes, etc., imply this.

This "comprehension" is not merely one of breadth, but of depth as well: the ideal includes not only the present of mankind, but its whole future also. Duties have always been recognized to posterity, but the range of generations to whom they applied was small, and the interests which it was believed could be secured were limited also. Après moi le déluge describes a form of selfishness of all ages, but different ages have understood the après moi quite differently. At the present day, the range of responsibility is extending indefinitely.

A common political ideal does not mean a universal peace. Coarser forms of dispute disappear, but, on the other hand, as nations grow more refined in their ideals, they grow more susceptible. What a political humanity, or a political community of Europe, would mean, is the substitution of international punishment for the self-willed conflicts of irresponsible nations.

We cannot say what the future of society and of morality may be, - whether mankind will be able to take mechanical means against a period of ice, or whether human society may not, as a whole, be destroyed, to be replaced by a higher type of existence, which may arise on the earth from the development of humanity, or may, on some other planet, take up the tale of human civilization as we take up that of the civilization of Greece and Rome.

Two things follow from the progressive character of the moral ideal: ( $\mathrm{I}$ ) that the classification and description of duties will 
vary with each age; (2) that, as the ideal changes from age to age, the highest moral principle or sentiment will change with it.

At the present time, a belief has gained great authority, that the sense of duty is transitory and will finally disappear; but whether we, with Spencer, identify obligation with coercion, or understand it as the relation of a part of conduct to the rest, in neither sense is the proposition true as it stands. If duty means constraint, it by no means follows that constraint will cease with progress; for constraint arises from confronting one inclination with a higher idea, and its disappearance would mean that inclinations had become constant; this is, however, impossible. The fiction of a final stage of mobile equilibrium is an unwarranted conclusion from the fact that all morality involves a cycle of conduct in mobile equilibrium. But the theory represents a truth, - the truth that morality at no time implies in itself the sense of duty. The sense of duty, as involving the hard feeling of compulsion, of subjection to authority, and bound up with the sense of sin, a sense stronger in proportion to merit or the interval between first inclination and final moral willing, may and is giving place to a higher conception. In the family, this may already be found, where self-sacrifice and aid are matters of affection and rendered freely. In the higher ideal, we have that love of man for a higher and larger order than himself which morality represents as solidarity with society, a continually progressive society of free individuals; which religion represents as the love for and of God.

And at the last two questions may be asked: (I) whether the difficulties in which Christianity is placed at the present day do not arise from absorption of its highest idea into the conceptions and the practice of morality, so that the religious sentiment is starved; and (2) whether the ideal of a free coöperation in the progress of humanity may not be used to interpret the belief in immortality, putting in the place of individual immortality the continuance of life in the persons whom the individual may affect. In "The International Journal of Ethics" July, 1 892, Alexander combats some misinterpretations of " Natural Selection in Morals," which he says are partly due to Spencer's Indivilualism. Natural Selection in social life does not mean necessarily destruction of individuals, but is a struggle of ideals, such as that between Individualism and Collectivism, - in which Selection seems to favor Collectivism. 


\title{
APPENDIX TO PART I
}

\author{
PAUL REE
}

DR. PAUL ReE's "Source of the Moral Feelings" ("Ursprung der moralischen Empfindungen," 1877), is written from a pessimistic and mechanical standpoint. The connection of thought and feeling in the region of morals is, according to Ree, a purely, or very nearly a purely, outward one, moral judgments not being the result of sympathy or antipathy, or related to these feelings in more than an external manner, but arising from associations of ideas engendered by education; the Sense of Justice being, in this manner, the effect of Punishment. A definite distinction is likewise made by Ree, between vice, which affects the individual only, and badness, which affects society, the profligate who satisfies his lust in the most unrestrained manner being regarded as perhaps unwise, but not bad, as long as he does not seduce the pure. The author fails, however, to show us how vice can be practised without social injury, and necessarily fails also-since his position takes into account no organic relations of characteristics - to notice the significance of profligacy as an inherent feature of character. He touches at one or two points, only, on Habit, and at one point alone on Heredity, where he raises the question of the hereditary character of Vanity, but arrives at no conclusion. $\mathrm{He}$ also makes the division of Egoism from Non-egoism a definite one, fully identifying the Good with the Non-egoistic, the Bad with the Egoistic. The Nonegoistic really exists; a man may relieve another's suffering in order to free himself from the sight of it; or he may relieve it for the other's sake. Nevertheless, non-egoistic action is rare; men are much more egoistic than the apes, who are rivals only with regard to food and sexual desire, while men are rivals not only with respect to these primitive wants, but with respect to many others besides, especially since they not only regard the present but provide for the future also.

Vanity, according to Ree, gives rise to envy, hatred, and malignity. But, the action of these passions being opposed to the safety of society, some persons ${ }^{1}$ introduced punishment for its protection, and fear of punishment and exchange of labor united men in peace. Deeds and never motives were at first considered in the infliction of punishment, but, outer compulsion not securing safety, the ideal of an inner condition of character which should secure it arose. "Good" and "useful" are synonyms, but men of later generations, receiving laws without explanation of their origin, fail to understand that the Good was, in its origin, simply the Useful, that the Bad was, in like manner, the Harmful, and that Punishment is for the purpose of prevention and not in the nature of a return for things done. The knowledge of this truth takes from life some of its grandeur; but the truth remains the truth, nevertheless. 
The will is not free; the mistake of regarding it as free is the result of the failure to perceive that punishment looks to the future, not to the past, - is a means of prevention, not a requital. The right to punish does not rest, therefore, upon the Sense of Justice; but punishment is justifiable as a means of prevention. Its choice, like that of other evils as the alternatives of greater ones, is the practice of the principle, The end justifies the means. Those who repudiate this principle have not generally looked deeply into its meaning; moreover, it has been misused. In putting it in practice, several things must be observed :-

I. The end to be served must be a good one;

2. The choice of means causing pain is permissible only when no other means are possible;

3. The pain must be reduced to the least possible;

4. The pain must be less than would be involved in the omission of this particular choice.

The doctrine of eternal punishment is untenable, because :-

I. It presupposes the existence of a God.

2. Supposing a God to be existent, we cannot name him either good or bad. "God is good" means "He does good to the world and its inhabitants"; but of the world we know only the little earth, and of God we know nothing.

3. If we will, nevertheless, predicate goodness or badness of God, we must call him bad, since all beings known to us suffer much pain and have little pleasure. The gods of the savages, who are not yet led away by theological hair-splitting, are evil.

4. But if we still persist in naming God good, then we cannot suppose him to be also cruel, and even more cruel than the hardest-hearted of mortals.

5. The doctrine of eternal punishment assumes the existence of a soul; but the difference between human beings and the higher animals is not so great that one can ascribe an especial soul to men.

6. But if a soul exists, it cannot be tortured, since it is immaterial.

7. And the deeds which God will thus punish deserve, on the theory of punishment as prevention, no requital.

It is not immaterial to us whether men have a good or an evil opinion of us.

I. Because we hope for advantages from a good opinion.

2. Because we are vain.

Vanity arose, in the first place, because admiration was useful to men, just as it is useful to the birds at pairing-time, and habit rendered it agreeable in itself. Men therefore desire it, even when it has no especial use, because "they know that all admiration is followed by a strong feeling of pleasure." 1 The difference between man and the peacock in respect to vanity is merely that he desires to be admired for other things than outer appearance alone, for courage, strength, cleverness, the tools of battle, and many other things. Since, among human beings, men and not women choose their mates, endeavoring to obtain one or more of the most beautiful women possible, women 
endeavor to render themselves beautiful, expending greater efforts as the stake is greater in their case than in that of the peacock. They endeavor to supplement their outward attractiveness by amiability, cleverness, household industry, and, in our days, wealth; but beauty always makes the strongest impression upon the man. Men desire to be admired rather for other things than outward appearance, though for this, too, to some extent.

But vanity may be objected to ( $I$ ) on the ground that it is a desire to create envy, and envy is pain and gives rise to hatred; (2) on the hedonistic ground that the vain man more often suffers pain from not being admired than experiences pleasure from admiration; (3) on the intellectual ground that vanity renders a man incapable of impersonal interest in Nature, Art, Philosophy, and Science. Entire freedom from vanity could, however, be attained only by a life of complete isolation. Because of these reasons for blame, men do not confess that they act from vanity, but give other reasons for deeds prompted by this feeling. ${ }^{1}$

Ambition may be blamed on grounds similar to those on which vanity is blamed. However, this feeling urges to many useful acts, and without it few would find interest for great effort. And since, because of its usefulness, ambition is less blamed than vanity, men are more ready to acknowledge that they possess it.

We desire to appear well in the eyes of others, therefore we conceal our envy and hatred, and affect high courage, great honesty, and charity. Such hypocrisy is bad; but it is necessary. For if men were to show themselves as they are, with hearts full of hostility, they could not at all associate. In order to make frankness and peace both possible, men must become what they now pretend to be; but this does not lie in their power.

Malignant pleasure in others' pain arises from a comparison with our own more agreeable situation, or from the pleasure in our own superiority in any respect.

When a woman is seduced, it is in the interest of other women to ostracise her, since, if marriage were to be abolished, women would lose in position; the man who seduces her is blamed for bringing shame on her, but not for unchastity, for men have no interest in maintaining chastity in their own sex.

Caprice arises, not from change of mood, but from the pleasure of power experienced in now charming by amiability, now causing gloom by coldness, and again inspiring fear through anger.

If one desires anything from another, one should not say, "It is a little thing," but "It is very much that I ask"; since he who is asked gives more readily when he thinks he will appear very kind.

Natural Selection does not prefer the individual as far as morals are concerned, but only nations. Moral rules are variable, but not steadily progressive. Man is by nature selfish; simply habit tames men and makes them, by change in nerves and muscle, more amenable to rule.

The good man is probably worse off than the bad man. Pain exceeds pleasure in all beings. Everything, love included, becomes worthless when

1 See, in contradistinction to Ree's theory of vanity, Sigwart's admirable essay on this subject, contained in his "Kleine Schriften." 
attained, and labor begins again for new attainment. Man is, moreover, the most unhappy of all beings, for he feels most strongly, and in his complicated organism there is almost always something out of order. For this reason, sympathy ${ }^{1}$ brings more pain than pleasure. The bad man has only pangs of conscience to disturb him, and, if he is superstitious, the fear of punishment after death. It is difficult to say whether the bad man or the good man is happier. In fact, happiness depends rather on temperament, power of selfcontrol, and health. Possibly these truths may seem harmful; and if the good man is higher than the bad man, and goodness should be sought, only so much of the truth should be revealed as is not antagonistic to this end. But the good man is not the higher, although, because goodness is useful, our education has attempted to make us believe this. The animals may be unselfish as well as man; on the other hand, the disinterested search for truth is not found among the animals. The attainment of truth is, moreover, pleasurable to the searcher, turning painful desire for truth to pleasurable fulfilment.

Dr. Ree's later book, "The Origin of Conscience" ("Die Entstehung des Gewissens," I 885), does not add anything distinctly new in theory to this first book; it is rather noticeable for what it omits of the pessimism of the earlier book, for a more moderate, thoughtful, and less assertive tone, than for additional theories or even much further elaboration of the old theories, except as regards the derivation of the Sense of Justice. It traces the savage custom of the revenge of death through its displacement by the payment of blood-money, up to the final substitution of state punishment. Punishment does not grow out of revenge, but succeeds it. It is not revenge, though the desire that the guilty may be punished and the desire for revenge may be mixed, in some cases. Pain, not the Sense of Justice, drives the savage to revenge. Punishment does not grow out of the Sense of Justice, but the latter out of the former. The interference of the state with the revenge of the individual is at first a mediation between the two parties for the maintenance of peace in the interest of the community; later, the state arrives at a method of punishment for the purpose of prevention.

Hume's theory of the origin of religion has been confirmed by Anthropology. The savage sees in natural phenomena the action of living beings endowed with mental faculties like his own, and he gradually comes to transfer this action to beings not in, but, according to his new idea, behind, phenomena. The gods of primitive religions are moral only as the peoples whose gods they are, are moral. As society progresses, religion falls behind, and a new interpretation of old doctrines must be introduced in order to bring it up to the later standard. Then the gods, as moral with the morality of this later date, are imagined as commanding the later standard, and to the fear of punishment by the state is added, as a preventive force, that of the punishment of the gods. The gods command what men command, forbid what men forbid. The God of the Old Testament, Jahveh, was, like Zeus, a nature-god, and took revenge as men did. When a later date demanded a standard of greater

1 Dr. Ree appears to depart from his general theory here and identify sympathy with morality. 
humanity, Christ came, and he represented the God of the Old Testament, no longer as revengeful and passionate, but as possessing the attributes of sympathy which he felt in himself. The later standard of the New Testament takes into consideration motives as well as deeds, and commands positively as well as forbids. But the God of the New Testament is not wholly love; if his love is unreturned, he becomes angry, like men.

The Categoric Imperative in the individual is merely the result of his individual education. Conscience alone accomplishes little; other motives than the desire to do right — fear of punishment, etc. - are stronger. Nothing is, in itself, good or bad, but only so far as it is useful or harmful.

Sympathy is to some degree innate, - how it arose we cannot say; but it has been preserved by natural selection. 


\section{A REVIEW OF EVOLUTIONAL ETHICS}

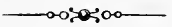

\section{PART II}

\section{INTRODUCTION}

Twenty years ago, any one about to deal with moral science from the standpoint of the Theory of Evolution, might have deemed it necessary to preface his work with a statement of cogent reasons for the assumption of such a standpoint. At a time when Theology saw in Darwinism only a weapon of the anti-theological party, and when even many scientists were not yet decided as to the worth of the new ideas, the right of the student to make use of them in psychological and ethical investigations might have been a subject for dispute. Yet even in the beginning the attitude of apology was assumed oftener without, than within, English-speaking countries, for the very reason that exactly among the race from which Darwin sprang, the warfare of his conception of animate nature with older systems was fiercest. At the present date, the attitude of opinion is changed in all countries. The Theory of Evolution has few, if it can be said to have any, enemies among the students of science. "With Louis Agassiz died the last opponent of Darwinism deserving scientific notice," says Haeckel. ${ }^{1}$ 'Theology itself has ceased from extreme hostilities, and many theologians have even found in the idea of Evolution an argument with which to defend teleological doctrine. The present opponents of Darwinism as applied to psychology and ethics rather contest its special worth for these provinces than deny its validity in them. Nevertheless, a universal acceptance cannot be claimed for the theory; and since

1 "Natürliche Schöpfungsgeschichte," 8th ed., p. Io9. 
ethics is, above all other sciences, the one that should most desire to persuade rather than to alienate, - and this the more, the stronger its conviction of its own truth, - it may be well to state or restate some of the reasons which justify, from almost all modern standpoints, at least a tentative application of the ideas of Evolution to ethical theory. Such a statement, or restatement, must be an attempt to demonstrate the validity of the theory in this province, and to give some good reasons for supposing, a priori, that a survey of ethical questions from the point of view it furnishes may be of ethical utility. The proof of such utility can be found, ultimately, only in the results of the investigation itself.

There is but one phase of the theological doctrine of Creation with which the mere idea of an evolution of life, by itself considered, is directly at variance; this is the doctrine of Creation as taught by the older Theology, which accepted the opening chapters of Genesis as literal history, not as, by any possibility, an oriental allegory. Between the theory of Evolution and the idea of Creation as a primal formation of matter with force or motion in accordance with fixed laws, between it and the idea of an initial application of force from without, - an impulsion which set the universe in motion, - between it and the conception of a transcendental guidance through natural law or of a pantheistic order of development, there is no such necessary contradiction as could justify the denial of Evolution from the standpoint of any of these theories. It is, therefore, with the defenders of the older theological doctrine of creation only that an a priori defence of Evolution has to deal.

The argument which this doctrine has always regarded as one of its strongest defences is that of the universality of the notion of a Creating Spirit. But this defence is no longer available; modern research has proved the idea to be by no means universal. Sir John Lubbock says, "The lower races have no idea of a Creation; and among those somewhat more advanced it is, at first, very incomplete." "The lower savages regard their gods as scarcely more powerful than themselves; . . . they are not creators; they are neither omniscient nor all-powerful; far from conferring immortality on man, they are not even in all cases immortal themselves." 1 "Stuhr, who was, as Müller says, a good

1 "Origin of Civilization," p. 39 I. 
observer of such matters, reports that the Siberians had no idea of a Creator. When Burchill suggested the idea of creation to the Bachapin Kaffirs, these 'asserted that everything made itself,' and that trees and herbage grew by their own will." 1 "As regards Tahiti, Williams observes that the "origin of the gods and their priority of existence in comparison with the formation of the earth, being a matter of uncertainty even among the native priests, involves the whole in the greatest obscurity." 2 "When the Capuchin missionary, Merolla, asked the queen of Singa in Western Africa who made the world, she, 'without the least hesitation, readily answered, "My ancestors." ", 3 "The Bongos of Sudan had no conception of there being a Creator," ${ }^{4}$ the Adipones, the Californian Indians, before they came in contact with white men, the Crees, the Zulu Kaffirs, the Hottentots, had no idea of a creation. "Even in Sanscrit, there is no word for creation, nor does any such appear in the Rigveda, the Zendavesta, or in Homer." 5 The idea of a creation in any sense is not, then, universal, and cannot be asserted to be innate, a priori, primordial, or essential to human nature. Nor, assuming the standpoint of belief in a Creator, is there any ground for supposing that he would have chosen the one rather than any other method of creation. The internal as well as the external diffculties in the way of a too literal exegesis of the Old 'lestament are rapidly causing the abandonment of dogmatism with respect to this point; and any other interpretation than a literal one cannot, as has been said, logically object to a theory of Becoming based on scientific grounds.

It is in the nature of many of our greatest scientific theories that their simplicity and naturalness in the explanation of facts fill us with a sense of wonder that they had not long before suggested themselves to scientists. If, for instance, we were to attempt, in a Cartesian spirit, to free ourselves from all the prejudice of previous dogma and regard only the general course of nature, we could not logically avoid the conclusion, even from a superficial view, that a theory of the gradual development of existing forms has far more probability on its side than that of a creation from without which broke in upon natural process, and placed ready-made suns and planets in the heavens, and finished beasts and men upon the earth. Everywhere in the organic world
1 "Origin of Civilization."
2 Ibid.
${ }^{3}$ Ibid.
${ }^{4}$ Ibid.
${ }^{5}$ Ibid. 
we behold the process of growth, the development of germs, the passage of the inorganic into the organic, and of the organic into the inorganic again, - change and transformation under natural law.

The difficulty which difference of form and function in the various species offers to a theory of Evolution is by no means so large as has often been claimed; as great difference exists between the oak and the acorn, from which we know it, nevertheless, to spring; as much contrast is exhibited between the brown twigs of the trees and shrubs in winter and the brilliant foliage and flowers which they put forth under the warmer sun of spring; quite as great contrasts may be found, in the life of every human being, between the single cell and the individual completeness attained at birt'l, between infancy and morally characterized manhood and womanhood, between the vigor of full maturity and the deterioration of age. Even the chasm between the organic and the inorganic is not logically impassable. The necessity of nourishment is the natural bridge between the two, and the equivalence of conditions and result, the indestructibility of matter and motion, establish at once the necessity of the inference that the organic can exist only at the ultimate expense of the inorganic, from which it is continually renewed. Were our senses such that, having before been closed, they were suddenly opened to the perception of the daily observable facts of growth, these would probably appear to us very nearly as strange, anomalous, and impossible as the changes which, according to the Darwinian Theory, have resulted in the existence of different species; and it is obvious that the public mind, becoming gradually accustomed to the conception of the latter changes, does not now regard them as so wonderful and anomalous as they appeared to it in the beginning.

Processes involving complete change of form may be observed, at the present time, everywhere in nature; but they are observable, everywhere in the organic, as growth without breaches; even a primitive science has always recognized the gradual character of motion, the absence of gaps in the causal chain, at least outside of the initiative action of human will. Such a natural hypothesis of creation as we have above supposed, formed upon crude and superficial, but as far as it goes, logical reasoning from facts of observation, could not regard the process as other than a gradual one, in which simpler forms and conditions must be supposed to 
have preceded more complex ones; in other words, it could not logically conceive the process as other than an evolution.

Traces of an idea of Evolution may be found in various crude forms in nearly all the earlier Greek philosophers, especially in Anaximander, Heraclitus, Democritus, Empedocles, and later in Aristotle. Such traces may even be found in many heathen mythologies in contradistinction from the Judaic. The progress of investigation, establishing the universality of natural law and, in every province, the gradual character of change was, before Darwin, as it has been since his work, in the direction of such a theory, as was shown by the ready acceptance with which Darwinism met, if not by the world at large, at least by the majority of scientists. In England, France, and Germany, there were others at work under the influence of thoughts similar to if not identical with those that inspired the researches and experiments of Darwin; and the nebular theory of Kant had already claimed in Astronomy what the Darwinian claimed in Biology. "When Kant, in his Natural History of the Heavens, which has become the fundament of modern Astronomy, says, 'Give me matter and I will make you a world,' what he intended to express was that the natural laws of matter are perfectly competent to render comprehensible to us the development of our well-known solar system." 1

In the very beginning, the theory of Evolution may be said to have had three distinct branches, represented by the Nebular Theory in Astronomy, Haeckel's Ontogeny, and the Biology of Lamarck, Darwin, Wallace, and Huxley; and to these should properly be added the Sociological Ethics of Spencer, which was not, however, worked out to a complete system. But Du Prel says of later research: "In the progress of modern science, no principle has proved so fruitful as that of evolution. All branches compete with one another in its use, and have brought about by its aid the most gratifying results. Geology interprets the significance of superimposed, hardened strata of the earth's crust in the sense of a history of the earth's development; Biology, in union with the study of fossils, arranges the living and petrified specimens of plants and animals in their order, and constructs a history of the evolution of organic life; Philology prepares a genealogical tree of languages, and finds in it signs which throw

${ }^{1}$ Du Prel: “Die Entwicklungsgeschichte des Weltalls." 
light on prehistoric times, and reveal facts forgotten for thousands of years; Anthropology discovers in the form and expression of human beings rudimentary signs that point to a theory of development from lower forms; and, finally, History reveals the evolution of civilization in far-distant historic times; and in all these branches it becomes apparent that we only then understand phenomena when we have comprehended their Becoming." 1

It is due to the gradual perception of the fact that some. such theory as that of Evolution is implied in the very conception of the constancy of nature that there has been a continual decrease of that negative form of criticism which has made much of the gaps in the direct proof. Modern science has so grown to, and by, the theory of Evolution that the overthrow of the latter means nothing more nor less than the destruction of science itself in its highest results. Even those who reject the conclusions of Evolution are found to make use of its methods, and must do so perforce. As the breadth and depth and height of the theory come to be perceived, it is seen that the demand for complete proof is nothing more nor less than a demand for the perfection of all branches of knowledge, the refusal of credit without such proof a refusal to place any confidence in the first principles of scientific theory until it has fully explored the universe and left nothing further to be discovered. But science would have less ground for complaint, if the opponents of Darwinism consistently refused, on the ground of the incompleteness of our knowledge, to form any theory whatever on the subject of man's nature and development, permitting the worth of the evolutional theory to be determined by its future results in application as hypothesis. But the peculiar spectacle is afforded us of a party rejecting a theory supported by numberless facts in all branches, and whose very breaches the direction of discovery continually tends to bridge, in favor of a dogma which cannot point to one scientific fact in its support, - a party demanding absolute perfection of proof as the condition of its acceptance of one theory, while it at the same time fiercely defends a conception of nature of which it cannot furnish the most imperfect proof. It is true that mankind has not beheld the evolution of the whole vegetable and animal kingdom. But neither had any human eye ever yet beheld the planet Neptune when Le Verrier prophesied its existence and calculated

1 "Die Entwicklungsgeschichte des Weltalls." 
its size and position. The theory of Evolution is a reasoning from the constancy of nature, as was that of Le Verrier, only, in the case of the former, we have the observation and calculations of not one scientist alone, but of thousands, on which to rely. To demand of the scientist that he shall produce the organic from the inorganic, and practically demonstrate the change of form and function, and the process of separation of species, before the possibility of such development is conceded, is on a par with demanding of him an actual reproduction of the Glacial Period before the theory of its previous existence shall be accepted. There is no reason for supposing that, if spontaneous generation once took place, the peculiar complication of conditions which produced it will ever again recur or can be artificially constructed.

But science has no desire to be dogmatic. - It readily acknowledges the total absence of direct and established proof at this particular juncture of the beginning of life. It can only point to the indirect testimony of Physiological Chemistry and Crystallogeny, to the simplicity of structure and movement in certain forms of life, and finally to the observed constancy of nature. But an exaggerated significance has been given to this chief flaw in the theory of Evolution, by those who, starting with the intention of defending Theology or the dignity of the Human, have been driven back, step by step, to this point, and fail to perceive that, arrived here, they have already abandoned the ground on which contest was possible. What significance a primal creation merely of lowest organisms can have, for either a defence of human dignity or for Christian Theology, it is difficult to perceive. As a matter of choice, it would seem to be more consistent with the omnipotence and dignity of a Creator to suppose that these very simple organisms arose, like other forms, under the action of natural law than that special interference was necessary in just their case. But, supposing such a special Creation, the following questions immediately present themselves from the theological standpoint: Are these special creations endowed with soul? If so, they must be immortal; if not, then soul arises in the process of evolution; if it arises as do all other things, qualities, functions, by growth, - that is, by the addition of infinitesimal increments (as we must, indeed, suppose it to arise if we regard it as "evolved") - then whence come these increments? If they come direct from a Creator, then surely no special favor towards man in the bestow- 
ment of soul can be alleged; and if they arise by natural causes, out of nature, then why may not their first beginning, their first infinitesimal appearance, also be supposed to be due to such causes?

The proof of an increase, a growth, of what have been called distinctively the mental faculties, throughout the animal kingdom, is every day stronger. No one believes, at the present date, with Descartes, that the animals are automata. Differences of mental power would seem to be but differences of degree; the facts all point to such a theory. The more scientific theologians have, indeed, abandoned this with the other minor points of contest above discussed, and devoted their efforts to argument from the moral nature of man. Philology, Anthropology, and Geology testify to mental progress, even in the human species; and if such a progress is a fact, it cannot have been without influence upon the moral nature of man, even supposing the latter to be Godgiven. Indeed, a merely physical progress or change cannot have been without such influence; for the most conservative theologians admit the strong action of the body upon the mind. It would seem, then, for all reasons, that an investigation of the process of mental evolution, or of evolution in general, ought not to be without results significant for any system of morality. If it is true that we learn wisdom and morality from human history, this can be so only because history gives us increased knowledge of the constancy of nature in those of its manifestations which specially concern the human, and thus enables us better to judge the present and predict the future. We should suppose that a still wider knowledge of our mental and physical evolution must be of yet greater worth to us in the same manner, - that the disclosure of more extended fields of nature to our vision must afford us new and valuable lessons with regard to ourselves; just as the telescope makes no discovery in the most distant regions of space that does not prove to have, in the end, its peculiar significance for our own planet. If our investigations should prove fruitless, as all such investigations have been said by some to be, the fact, established a posteriori, could not be disputed. But, considering all the points above noticed, such a result could not but astonish us; and we should even be inclined, after all that has been said, to suspect that the fault lay rather in the particular method than in the direction of our research. 


\section{CHAPTER I}

\section{THE CONCEPTS OF EVOLUTION}

THE preceding considerations have made it evident that the idea of Evolution has undergone a broadening process since Darwin first brought it before the world. It is necessary to glance briefly at some of the chief phases and the general significance of this process in order to define the extent and intent of the concept as far as science has made such definition possible.

To Darwin himself the struggle for existence was always between the unities represented by complete organisms whether as isolated individuals, or in family, tribal, or national groups. Everywhere in his calculations, appearing unchanged in his results, is found the unknown quantity of variation from ancestral type, the known factors being heredity, and natural and sexual selection in the struggle for existence. Wallace's ideas as to color in birds deprive the theory of sexual selection of one of its most important points of application in Darwin's work. It is, in fact, easy to see that sexual selection cannot neutralize natural selection, that any particular form of sexual selection can arise and finally survive only by a harmony with the direction of natural selection, and that the two must therefore appear, even from any standpoint of freedom of the will, as continually attaining coincidence. It has been said, above, that the struggle for existence was, for Darwin, between the organisms as unities. This consistent position of the specialist has been criticised, from a more general point of view, by Lewes in his essay on the Nature of Life, ${ }^{1}$ in which he asserts that we must logically "extend our conception of the struggle for existence beyond that of the competition and antagonism of organisms - the external struggle; and include under it the competition and antagonism of tissues and organs - the internal struggle." "Mr. Darwin," he says, "has so patiently and profoundly medi-

1 " Problems of Life and Mind," second series, chap. on Evolution. 
tated on the whole subject, that we must be very slow in presuming him to have overlooked any important point. I know that he has not altogether overlooked this which we are now considering; but he is so preoccupied with the tracing out of his splendid discovery in all its bearings, that he has thrown the emphasis mainly on the external struggle, neglecting the internal struggle; and has thus, in many passages, employed language which implies a radical distinction where - as I conceive - no such distinction can be recognized. 'Natural Selection,' he says, 'depends on the survival, under various and complex circumstances, of the best-fitted individuals, but has no relation whatever to the primary cause of any modification of structure.' 1 On this we may remark, first, that selection does not depend on the survival, but $i$ s that survival; secondly, that the best-fitted individual survives because of that modification of its structure which has given it the superiority; therefore, if the primary cause of this modification is not due to selection, the selection cannot be the cause of species. The facts which are relied on in support of the idea of 'fixity of species' show, at any rate, that a given superiority will remain stationary for thousands of years; and no one supposes that the progeny of an organism will vary unless some external or internal cause of variation accompanies the inheritance. Mr. Darwin agrees with Mr. Spencer in admitting the difficulty of distinguishing between the effects of some definite action of external conditions, and the accumulation through natural selection of inherited variations serviceable to the organism. But even in cases where the distinction could be clearly established, I think we should only see an historical distinction, that is to say, one between effects produced by particular causes now in operation and effects produced by very complex and obscure causes in operation during ancestral development. . . . Natural Selection is only the expression of the results of obscure physiological processes."

The last statement is one to which Darwin himself would certainly not have objected. It is an extension of the principle implicitly involved in all his work and explicitly stated in his later work, although the chief emphasis is laid on outer conditions. The extension of the idea of competition from the outer condition of organisms to the more ultimate physiological unities

1 "The Variation of Plants and Animals under Domestication," I 868, II. 272. 
of organ and tissue is a philosophic gain. It is evident, however, that that for which Darwin is seeking is not a philosophical generalization which shall include outer and inner change under one highest law, but, first of all, the particular causes of particular variation interesting to the specialist in biology. It is made too clear for mistake in "The Variation of Animals and Plants under Domestication " that the uncertainty with regard to such particular forms of cause is the spring of his declaration of our ignorance as to variation. The possibility of an inclusion of lower in higher generalizations he would not deny; though the special laws first occupy his attention. Doubtless, his work is not, as is no man's, wholly free from inconsistencies and contradictions, - which are due, in part, to the fact that every scientific theory is, even in the thought of the individual, an evolution. But the declaration of mystery in the question of variation is not equivalent to a theory of accident, of transcendental mystery, or of some special organic or vital force, such as Claude Bernard especially opposed; it is merely and simply a statement of the mystery of present ignorance. This fact is expressly stated in Darwin's later work. We find, for instance, in the introduction to a letter to the editor of "Nature," written in 1873 , the origin of many instincts referred to "modifications or variations in the brain, which we, in our ignorance, most improperly call spontaneous or accidental;" and we have, in "The Variation of Animals and Plants under Domestication," " such passages as the following: "When we reflect on the individual differences between organic beings in a state of nature, as shown by every wild animal knowing its mate; and when we reflect on the infinite diversity of many varieties of our domesticated productions, we may well be inclined to exclaim, though falsely, as I believe, that variability must be looked at as an ultimate fact, necessarily contingent on reproduction. Those authors who adopt this latter view would probably deny that each separate variation has its own proper exciting cause. Although we can seldom trace the precise relation between cause and effect, yet the considerations presently to be given lead to the conclusion that each modification must have its own distinct cause." It is "probable that variability of every kind is directly or indirectly caused by changed conditions of life. Or, to put the case under another point of view, if it were possible to expose all the

1 Vol. II. Chap. XXII. 
individuals of a species during many generations to absolutely uniform conditions of life, there would be no variability. . . . The causes which induce variability act on the mature organism, on the embryo, and, as we have good reason to believe, on both sexual elements before impregnation has been effected." Darwin further considers, in this same book, some of the probable particular causes of variation, as given in climate and food. And it may be remarked, in this connection, that Rolph's criticism of the impossibility of progress under conditions of want is irrelevant as applied to Darwin, since the latter himself says expressly: "Of all causes which induce variability, excess of food, whether or not changed in nature, is probably the most powerful "; ${ }^{1}$ again: "We have reason to suspect that an habitual excess of highly nutritive food, or an excess relatively to the wear and tear of the organization from exercise, is a powerful exciting cause of variability." 2 Rolph's criticism is probably due to forgetfulness of the fact that Darwin limited the struggle for existence to that of complete organisms with one another, and that, under such a limitation of the conception to external struggle, a condition of want cannot be conceived as necessarily precluding a monopoly of abundance by best-fitted individuals.

Theories with regard to the special outer causes and resulting physiological conditions of variation have been gradually added to, as facts on this score have accumulated. But, as investigation advances, the question is seen to involve all the problems of the intricate chemical and mechanical nature of physiological structure in its manifold forms and degrees of organization. The field stretches out in this direction, under our contemplation, to an indefinite distance; and science appears as yet to have passed only the outer limits of its territory.

It is certain that the comparatively recent science of Physiological Chemistry will have many of the decisive words to say on this score, in the future. "When we see the symmetrical and complex outgrowths caused by a single atom of the poison of a gall-insect, we may believe that slight changes in the chemical nature of the sap or blood would lead to extraordinary modifications of structure," says the great seer of evolution himself. ${ }^{3}$

1 "Variation of Animals and Plants under Domestication," II. p. 257. See also "Origin of Species," 6th ed., I. pp. 7-9, etc.

2 "Variation of Animals and Plants under Dumestication," II. p. 418.

${ }^{3}$ Ibid. 
Among special theories of Evolution, a distinction may be made between: (I) such special theories as aim at biological simplification by reduction of all organic variation to one primary form of cellular process; (2) such theories as are content with less ultimate laws, by which the various ascertained forms of change are included in one general statement not involving special physiological or physical theory but applicable to all forms of life; (3) such theories as aim to give distinctive philosophic expression to a generalization like the last named, including in this statement both psychical and physiological phenomena; and (4) such theories as aim at an ultimate expression of the direction of evolution that shall include the phenomena of life, both physiological and psychical, under one head with all other natural phenomena. To the first class belong only "provisional" hypotheses, among the best known of which are those of Pangenesis, Perigenesis, and the Continuity of the GermPlasm. To the second, which are not merely tentative but have a broad foundation in known fact, belongs Haeckel's theory of Inheritance and Adaptation, a theory restated in substance, from independent research, by Eimer, whose ultimate general factors of analysis are the same with Haeckel's, though he deals, beyond these, with special facts and special theories of his own. Phases of the second class often entitle them to inclusion in the third. An example of the third class is found in Spencer's definition, "Life is the continual adjustment of inner relations to outer relations." The fourth and last class includes Fechner's "Tendency to Stability" and Spencer's theory of the rhythm of motion (see his "First Principles"), similar to which are certain ideas of Zöllner, Du Prel, and others; and similar elements to which are to be found in Haeckel's "Plastidule-Theory." In connection with this class, reference may be made to an article by Dr. J. Petzoldt in the "Vierteljahrschrift für wissenschaftliche Philosophie" under the title "Maxima, Minima, und Oekonomie," in which, among others, Fechner's views especially are discussed with reference to an ultimate principle of evolution. The first pages on the "Tendency to Stability" in Fechner's "Ideas concerning the Evolution of the Organic" ("Einige Ideen zur Schöpfungsund Entwicklungsgeschichte der Organismen ") are as follows:-

"For the sake of brevity I call relations of position and motions recurring at regular periods, that is after like intervals, in the 
particles forming a material system or in the centres of whole masses conceived as forming a larger system, 'stable relations.' Among such relations is to be reckoned the condition of rest of the particles or masses in relation to each other, as the extreme case, which we may call the state of 'absolute stability'; while a dissipation of the particles or masses, to infinity, in different directions, constitutes the other extreme of absolute instability. "We do not speak of 'absolute stability,' but of 'full stability,' in cases where motion still takes place, but this brings continually, in exactly the same periods of time, the same relations of particles or masses, not only as regards position, but also as regards velocity and direction of the motion and change of velocity and direction.

"To absolute and full stability may be added, as third case, that of greater or less approach to full stability, which we may term briefly 'aproximate stability' . . . and of which we have an example in the chief bodies of our solar system.

"It may serve as a simplification of the consideration of stable relations of motion to remark . . . that, in an isolated system or one under constant outer conditions, exactly or very nearly the same relations of velocity and direction recur when exactly or very nearly the same relations in the position of the particles or masses return. As regards the velocity, this follows directly from the principle of the conservation of energy; as regards the direction, it is indisputably possible to assume the connection of its recurrence with that of the other relations, although I cannot remember that a direct general proof of this has been found.

"With these introductory specifications in mind, let us assume any number of material particles to be restricted, by forces of some sort, to motion within limited space, and the system either withdrawn from outer influences or under such as are constant; let us, moreover, suppose the system undisturbed by the interference of psychic freedom, or the latter impossible. In such case, certain initial positions, velocities, and directions of the parts of the system being assumed, all following states will be determined by these. And now, if there are among these conditions, either present at the beginning, or attained in the course of the motion, any such as have for their result a return of the same states after a given time, then the motion, and so also the positions of the parts conceived as at first undergoing alteration in form and 
velocity, will, unless they contain the immediate condition of periodic recurrence, continue altering until those of all the possible states are reached which contain the condition of recurrence; until this point is attained, the system will, so to speak, know no rest. Has the recurrence once taken place within a given time, then it must always take place anew within the same time, because the same conditions are there to determine it. And since these conditions are determinative of the whole course of motion from one recurrence to the next, the same course must be repeated; that is, in every like phase of the period a like state of motion will exist. But this gives us full stability of the system, a change, a deviation from the attained stability being possible only through changes in outer influences, the assumed constancy of which rendered the attainment of stability possible.

"This principle appears at first purely a priori; but the assumption should not be overlooked that there are among the conditions determining the motion such as lead to their own recurrence, and this is to be taken for granted, since it is necessary to assume that a system must continue to change until, but only until, the conditions of full stability are attained, in case it is attainable; and that this full stability, when once reached, cannot be again destroyed by the action of the system itself. The question presents itself as to how far calculation and experience permit us to lay down a more general principle.

"In a system in which only two particles or masses, withdrawn from outer influences, are determined to motion by mutual attraction and the influence of a primary impulse in another direction, calculation shows us that, motion to infinity being excluded, the attainment, and indeed the immediate attainment, of full stability is a necessity; and for swinging pendula and vibrating strings it may be calculated, from the nature of the moving forces, that they would remain in a condition of fully stable motion if outer resistance were removed; for, such obstacles present, they pass through an approximately stable condition to one of absolute stability. The power of purely mathematical calculation does not go beyond such comparatively simple cases. . . .

"But if we call experience to our aid, it may be asserted, in accordance with very general facts, that, in a system left to itself or under constant outer conditions, and starting from any conceivable state, if not full stability at least a greater or less 
approximation to it is reached as final condition, from which no retrogression takes place through the inner workings of the system itself. The tendency to approximately stable conditions appears, or the actual state is attained, according to the measure in which variable outer influences are withdrawn. So that so little is lacking to our hypothesis, that, although it has at this point to make up for the impossibility of perfect demonstration, we are nevertheless justified in laying down the following law or principle:-

"In every system of material parts left to itself or under constant outer influences, so, then, in the material system of the universe, in so far as we regard it as isolated, there takes place, motion to infinity being excluded, a continuous progress from more unstable to more stable conditions, up to the attainment of a final condition of full or approximate stability."

From the union of the principle thus stated and that of the conservation of energy "it follows that no unlimited progress of the universe to absolute stability, which consists in perfect rest of the parts, can take place. ... The energy manifested in the universe cannot be altered, in general, in its amount, but only in the form in which it manifests itself." "It cannot be asserted that the attainment of full stability in the universe would be the attainment of an eternal rest, but only of the most perfectly adjusted motions, and therefore such motions as would give rise to no variations. . . . But a condition which brings with it eternal repetition cannot be reached in finite time."

"To elucidation of this principle of the Tendency to Stability," says Dr. Petzoldt analyzing Fechner's work, "we have only to call to remembrance a number of natural phenomena, such as the ebb and flow of the tide, the circulation of moisture, periodic changes of temperature, and so forth, which exhibit great periods of approximate stability and in which we notice in general no retrogression.

"Not less does the constitution of organisms which are, "so to speak, constituted dependent upon periodicity of their functions, and so upon stable relations of their life,' serve to confirm the theory. Only the concept of stability must be extended in their case, since not always the same, but only substitutive parts of the organic systems tend towards stability.

"Experience never gives us an example of an isolated system; on the contrary, every system is a part of higher systems. The 
inner relations of its stability are not conditioned by its own parts only, but also, more or less, by those of other systems, so that the destruction of one part-system is always only in the direction towards the stability of a higher, ultimately of the highest, system; that is, of the system of the universe."

"Thus the teleological principle coincides with the principle of the Tendency to Stability, and at the same time the latter constitutes the link between the former and the law of Causality. Though, in truth, this manner of looking at the matter signifies a generalization of the concept of 'end,' since it defines all stable conditions as ends. The view is justified, however, by the fact that the greatest possible physical satisfaction - for us, the criterion of teleology - is always bound up with the longest possible preservation or slow change of a stable organic condition. The physical Tendency to Stability 'bears with it a psychical tendency to the attainment and conservation of just those conditions' towards which the physical tendency is directed."

Of the fact that Lange "feels the lack of the proof of this 'Tendency to Stability,', Dr. Petzoldt says: "But how is there a need of proof here? To prove is to refer back to known facts. But what is there in Fechner's remarks that stands in need of such a reference? They simply draw our attention to the result of evolution as a state which bears, in itself, the guarantee of some continuance. Can any one contest this? Is there anything further to prove? It is said that Gauss once remarked that Lagrange's equations of motion are not proved, but only historically stated. The case is exactly the same here. The fact is attested, merely, that evolution ends in a stable condition; and herein lies the pith and the great merit of the theory of the Tendency to Stability."

Dr. Petzoldt criticises, among other things, especially Fechner's concept of approximate stability, in that no distinction is made by the author between three different cases. The first case comprises forms of motion in which periodicity is only approximate, but in which, nevertheless, no retrogression in stability takes place; this case is illustrated by our solar system. The second case comprises forms of motion in which the stability increases up to a certain point, but beyond this, despite relative constancy in outer conditions, decreases again until complete destruction of the system supervenes; an illustration of this form 
of motion is found in all organisms. The third case comprises forms of motion which we cannot concede to be stable. "For, if we ascribe periodic motion to pendula and musical strings which vibrate in a resisting medium, this is nevertheless a periodicity, which continually changes in the same sense, and we certainly cannot say that pendula and strings approach, in a resisting medium, a condition of absolute, through a condition of approximate, stability. We recognize in these vibrations, decreasing in amplitude, merely unstable changes which tend toward a final stable condition, - namely that of rest."

The author finds a further ground of criticism in Fechner's assertion that organisms are entirely dependent upon the periodicity of their functions. Only a part of such functions are periodic. Periodicity is not conceivable without stability, but stability is conceivable without periodicity.

In the process of evolution towards a stable form of movement, Dr. Petzoldt recognizes briefly two factors, "Tendency and Competition." 1 Tendency is defined, in general, as the direction, actual or potential, of material parts or of mental or physical function; competition, as the conflict of tendencies, from which a tendency of a higher order results. "The concept of Competition is, like that of Tendency, to be taken in a general significance. A number of forces which act upon a single point compete. Different mental images, observations, concepts, laws, come into competition, from which result concepts and laws of lower and higher orders. The struggle for existence is only a special case of competition. Though this often ends with the immediate or gradual destruction of systems entering upon it, nevertheless only a middle worth between all the competing tendencies can be ascribed to the resultant. Even the conqueror is, after the struggle, other than what he was before it; a part of the tendency destroyed by him lives on in him, has combined with his original tendency to a resultant. 'Tendencies can as little disappear without compensation as can forces, whether the compensation consists in a strengthening or in a weakening of others, and the conseriation of competing tendencies might be regarded as a further qualitative addition to the law of the conservation of force. Hence, in the examination of the effects of

1 For elaboration of definition and theory, vide the article in question, “Vierteljahrschrift für wissenschaftliche Philosophie," I89o. 
the struggle for existence, the like claim of all tendencies taking part in it is not to be left out of consideration. Each makes its full force felt. But not all attain to competition; of the numerous tendencies bound up in one organism, only a few unite, in the single case, to a resultant, which has a direction towards a definite issue." The less the opposition of competing tendencies of concepts or laws, the less the deviation of the resultant from its components, and the less the change these have to undergo. The higher concepts and laws are, the less are the number of distinguishing marks which they take from all single conceptions; for they are the resultants of very strongly opposed components. ${ }^{1}$

Fechner's views are related to, and, to some extent, dependent upon, certain ones of Zöllner adduced in connection with a consideration of sun-spots. ${ }^{2} \quad$ Du Prel, who also acknowledges special indebtedness to Zöllner, attempted in his "Struggle for Existence in the Heavens" ("Der Kampf ums Dasein am Himmel") to demonstrate the fact of a struggle and selection among the hearenly bodies analogous to that claimed for life upon the earth. The title of the book was afterwards changed to "The History of the Evolution of the Universe," ${ }^{3}$ its scope having "grown far beyond the limit of the former title." Du Prel finds one of the chief advantages of an application of Darwinian ideas to astronomy in the fact that, unlike our earth, the heavens in their immensity afford us existing, or to our eye existing, examples of the various stages of their evolution, in nebular mist, comets, suns, fixed stars, planets, rings, and moons, - all subject to processes of development, which we may to some extent observe. In the first chapter of this book, Du Prel says: "The existing condition of the Cosmos with respect to all forms of the Purposeful ${ }^{4}$ whether we regard the realm of the organic or the inorganic can be looked upon only as an attained, moving equilibrium of forces. Immanent in Nature lies the capacity to develop from chaotic conditions to teleologic forms; for, in the ceaseless play

${ }^{1}$ As confirming this analysis of evolution, reference is made to Mach: “Die Mechanik in ihrer Entwicklungen," p. I28, and "Beitrage zur Analyse de Empfindungen," pp. 25, 154; also Avenarius : "Kritik der reinen Erfahrung."

${ }^{2}$ See above essay by Petzoldt.

3 “Die Entwicklungsgeschichte des Weltalls," I 882.

4 "Gestaltungen des Zweckmässigen." 
of forces, all other than such combinations are by their nature given over to destruction, while it lies, on the contrary, in the essence of all purposeful combinations to be preserved. In every system of mechanical forces an adjustment of the same must finally be arrived at through the removal of all immanent oppositions." "It is impossible for nature to remain in chaotic conditions." "Every system of forces tends to a state of equilibrium. This is as true of the conflict of images in a human brain, from whose mutual accommodation the resultant of a unified theory of the universe arises, as of oppositions in the social organism, of the conditions of power and civilization of neighboring peoples, of the meteorologic states of the earth, of the mechanical forces of a solar system, or the atoms of a cosmic mist. Every war of the elements ends with an adjustment of ideal justice, for every 'moment' of force has influence proportioned to its power and the duration of its activity." 1

There is one portion of Fechner's theory as above stated (its metaphysical phases being beyond the scope of the present chapter have not been touched upon) that raises a question which may perhaps appear to have in itself no special significance, but which nevertheless opens up, by its implications, new fields of inquiry, and may possibly lead to further theory. The condition of stability which evolution in the universe as a whole gradually approaches but can never attain to in finite time is declared, namely, to be one not of rest, but of motion. A question might be raised, here, as to the definition of the "infinite time" asserted to be necessary to the attainment of such full stability, - whether the phrase be used in the mathematical or the philosophic sense; and the question would be found, I believe, to involve the unanswerable problem of the finite or infinite character of the universe in space. Of a universe conceived under the philosophic concept of spatial infinitude, obviously no final state as the result of evolution can be predicated, the evolution supposing a progress which, as involving infinite matter, cannot be acconplished in finite time. If we, however, conceive the universe as occupying finite space and undergoing continual evolution as a whole in the direction of equilibrium, it is a question whether the end must not be attained in finite time. For a universe conceived as finite, however immense, there must be a finite number,

1 “Die Entwicklungsgeschichte des Weltalls," chap. I. 
however great, representing the changes necessary to the attainment of final equilibrium; and if progress in the direction of such equilibrium is of necessity continual, the final equilibrium must be attainable in finite time. The question of the nature of such a state of final, universal stability is bound up with the problem of motion through a perfect void, and of the possibility of the formation of such a void through the concentration of matter. Leaving out of consideration the problem in its metaphysical form, which concerns the possibility of conceiving intermaterial space, it may be said that it is not now supposed that the heavenly bodies move through an absolute void; and the existence of any medium opposing resistance, however slight, is a condition rendering impossible the attainment of absolute stability of motion or a full stability which suffers no diminution and is, therefore, in effect, an absolute stability. It may be questioned whether the very nature of motion is not coincident with change, and this with action and reaction, or competition. Such a view would reduce evolution to a single ultimate principle, in place of Darwin's Variation and Selection through struggle, or Petzoldt's Tendency and Competition. We should have left, instead of these, only the final principle involved in moving matter considered in its ultimate parts. The metaphysical problem of the infinite divisibility of matter need not here concerr us; the ultimate parts of an organism could not be, however, its organs as Lewes defined them, but rather, from a positive standpoint, the ultimate units recognized by science in cell and cell-parts. We may, indeed, since we know no beginning of motion, legitimately regard all tendency as itself resultant. Just as we cannot separate matter and motion, except by abstraction from reality, so, too, we cannot conceive of motion except as having definite direction; and thus we arrive, by a final analysis, at the ultimate philosophic principles of matter and its motion. I use these terms in no metaphysical sense, but merely as generic terms including under one head specific forms of material combination and the specific forms of motion of their wholes or parts.

'The question of the character of a conceived state of final equilibrium may be approached from a somewhat different side, though the emphasis falls, as before, on the solidarity of the universe and the nature of motion as change. We may, for 
instance, regard the earth as an isolated system whose isolation makes possible the continual progress of the evolution taking place on its surface. But this whole evolution is, on the other hand, dependent upon the light and heat of the sun. Again, the sun is undergoing an evolution whose continuous progress may be regarded as in a certain sense dependent upon isolation; but we see, on reflection, that this very process is the result of the cooling nature of the sun's surroundings, and that it is sending its motion in every direction through space. The moon, which has passed through both the evolution that the sun is undergoing and that which is in progress upon the earth, is now passing through another stage which the earth must reach in time by diffusion of its atmosphere, in case its destruction is not accomplished by some catastrophic event before the arrival of that distant period. Suns and planets, all the heavenly bodies, are sending their influence in every direction through the unfathomable depths of space; and just as the capacity of the earth to be warmed by the influence of the sun involves its reciprocal capacity to act as a cooling medium for that body, so the conditions throughout the universe must be regarded as everywhere interdependent and mutually implying one another. Thus we again arrive finally at a universal action and reaction among the parts of the universe, all motion implying change of the direction of motion. Or, since we may and are, in fact, obliged to regard every direction or form of motion as a resultant, - for of motion as of matter we know no absolute beginning,- - even this simple assumption may supply us with the conclusion which we have reached in a more roundabout way. We may regard motion in any direction as counterbalanced by a resistance in every other direction sufficient to produce it in this one; in other words, motion takes place at every instant, in the direction of least resistance, even though this direction may represent, in the next instant, through the action of new "moments" of force, the greatest resistance. Any direction as well as any change of direction implies, then, resistance; resistance is equivalent to the interference of force, or, in other words, to competition; and competition may, at any moment, become catastrophe. The difference between competition and catastrophe is one merely of degree, or rather it is a subjective difference depending upon the point of view of the observer. In other words, all that we can testify to is a certain periodicity 
of motion, all motion meeting with resistance, the accumulation of which finally induces motion in another sense. Larger periodicities are made up of smaller periodicities, and, according to the point of view taken, any period of such motion may be regarded as an evolution, that which Fechner terms "full" stability being only the maximum towards which motion during that period tends. Absolute stability can be conceived only as perfect rest, whether we conceive it as merely an abstraction, its realization as rendered impossible by the conservation of energy, or whether we conceive it as possible in a universe regarded as finite; an absolute stability of motion is a self-contradiction, and a full stability which knows no retrogression is equally a selfcontradiction. Periodicity is, then, all into which the Tendency to Stability resolves itself for nature as we know it.

We perceive, in the actual universe, the fact of a certain imperfect periodicity. This wave form of movement in great and little plays, as Spencer has shown far more elaborately than Fechner, a large part in the universe.

But the evident fact of a present periodicity of imperfect form suggests another possible conception. We are under no necessity to regard the universe as finite either in space or time. On the contrary. We tend naturally to conceive of it as finite after the analogy of particular things which we perceive continually to arise and perish; but as concerns space, we have no knowledge of any limit, and, as concerns time, the conception of any actual beginning or end to the universe as a whole is only the ancient naïve idea which science has disproved in showing that neither matter nor motion ever perish. An infinite universe is conceivable, in which not exactly the same but very similar forms, or forms of which the successive ones closely resemble each other though those widely separated may be very dissimilar, continue to arise and be destroyed to all eternity. The conception of a primal nebular mist is not a necessary inference from astronomic phenomena; it is as easy and as logical to regard the various phases of planetary development revealed to us by the telescope as so many phases of an evolution and dissolution continually recurring in different parts of the universe, one extreme of which is represented by the nebular mist, the other by the cold and lifeless remains of planets gradually suffering dissolution as they revolve through space. The greater the immensity of the uni- 
verse is conceived to be, the nearer our conception of it must approach to this type. But the term Tendency to Stability is misapplied when applied to such infinite and imperfect periodicity - to the motion, thus conceived, of the universe as a whole.

The periodicity in the life of organic species may be compared to the wave-motions of light and heat as distinguished from those of water, the individual representing the single wave-length. 'The analogy is not, however, intended - to speak with Bacon as one of nature, but merely as one of mind. And just here it may be questioned whether Fechner may not have been right, after all, in his assertion of the dependency of the organism upon periodicity of function, whether the periodic character of the individual life, dependent, as it must be supposed to be, on adaptation to a medium to some degree resisting, does not sacrifice its stability in so far as the increments of resistance lack uniformity. This is evidently the case in large relations; is it not logically necessary to suppose it so in minute relations, though the fact may not be so evident to the coarse measurement of the senses? Experience seems to prove that an approximate periodicity in larger relations, is most consistent with health; and it must be remembered that the non-periodic relations are subordinated to periodic ones, that not only in the case of waking and sleeping, working and eating, but also in those of rest and labor, a certain uniformity is necessary to the best mental and physical condition. A close observation will, I think, reveal a greater periodicity than was at first suspected; since much of it is of so-called "automatic," "unconscious," or "half-conscious" nature. It is to be noticed, here, that the termination of individual lives is often in the nature of a catastrophe, and a uniform periodicity of individual development and decay cannot be assigned, except in the form of an average that falls much below the figure attained by the thoroughly healthy individual. There is every reason to believe that if we could sleep, rise, eat, bathe, exercise, work, and rest with the regularity of a clock, we should be the better for it physically. But the irregularities outside the province of our will-power render it impossible for us to order our lives in this manner. Nor do we desire to do so. For these very irregularities, as representing greater or less change to which adaptation is necessary, are, in many 
cases and within certain lines, the conditions and signs of progress; though they may constitute in other cases and beyond these lines - that is, where they are of too great intensity or duration - conditions of retrogression, the imperfection in periodicity becoming catastrophe, which may extend beyond the individual to his offspring. We may thus infer that the final destruction of the individual organism is conditioned by its own progress and the progress of its species, but that on the other hand, when the destruction of the individual is too abrupt, it may mean catastrophe to the species also, or at least to a part of it, through heredity.

Our considerations so far have been of a nature to convince us that not isolation, but a constancy in the continual action of like relatively small increments of force in the same directions, is the condition of steady evolution. The less constant and the larger the increments, the nearer the changes involved resemble catastrophe, though the catastrophes themselves may be regarded in another light as forming part of an evolution of a higher order. The changes the sun is undergoing may be regarded as evolution in so far as the influence of the cooling medium is a constant one. The earth as a whole and in its parts may be regarded as passing through a process of evolution towards full stability in so far as the sun's heat is a constant quantity, the periodic changes of seasons and of day and night the same. The relation would seem, therefore, to be one of time - the timerelation involved in the duration of outer conditions as constant with reference to the period required for the attainment of stability. Thus the sun's influence upon the earth might appear approximately constant to the human individual, but might represent a rapid change in relation to some stupendous and long-continued evolution in some other part of the universe. Considerations which we have already noticed forbid our regarding any conditions of "full" as distinguished from absolute stability as anything other than peculiar states single in the system and thus unenduring maxima succeeded by decrease, although the process may be, with reference to any other particular process, so slow, the retrogression from the culminating point so gradual, as to be, with respect to this other process, inappreciable.

And while we are busied with matters which involve the whole multiplicity of relations in the universe, just a word with reference 
to cause and effect. Which one of these myriad material parts interacting at any moment shall we single out as the cause of the succeeding state? The solidarity of the universe as far as the complete interdependence of all its parts is concerned is clear to us. It is true we cannot reckon with all factors of the universe at once; and the concept of cause and effect is therefore a useful one. But the cause of anything must be, from a positive point of view, just what the methods prescribed for its discovery in any particular case shows it to be: namely, a factor, merely, in the manifold conditions determining a following state, the removal of which means the prevention of the succession of exactly that state. Which, for instance, shall we regard as the cause of an evil act - the character of a man or the temptation offered by circumstances? The change or removal of either means the change or removal of the act. Neither is complete without the other, and both are involved in the whole complexity of the universe, through heredity on the one hand and the action of nature external to life on the other.

And just here we may glance at Spencer's definition of life as "the continual adjustment of inner relations to outer relations." Though emphasizing an important side of evolution, it is evidently incomplete. Evolution is not only the adjustment of inner relations to outer relations, it is also the adjustment of outer relations to inner relations as well as of inner relations among themselves; or it is a process of mutual adjustment of all the parts engaged in it.

Our analysis, though crude and imperfect, may now be regarded as complete. Our scope will not allow of a more elaborate one. It is fitting, therefore, that we proceed to synthesis. The first matter which presents itself to us, in this connection, is the theory of Heredity and Adaptation mentioned above.

The theory is not a new one, wholly outside Darwin's conception of evolution. The concept of Adaptation represents simply the generalization of all those special causes with which Darwin more particularly occupied himself, and is, in essence, only a proclamation of that universal subjection to natural law which Darwin himself plainly asserted. As such a generalization it is, however, a useful one; it furnishes us with an expression, for the organic world, of that universal action and reaction through which opposing forces move towards stability by mutual adjustment. 
The law of Heredity, again, may be regarded as an organic expression of the more general principle according to which motion that, in the sense defined above, suffers only a minimum of interference, that is, motion which, by a certain equilibrium of mutual relations, is "approximately" or "fully" stable, tends to continue to take place in nearly the same directions, or nearly to repeat itself. It is thus apparent, also, that Heredity is closely related to the more special principle of Habit, or also of Use and I)isuse, if only we remember that, whatever the metaphysical truths of Freedom or Determination, the psychical is always accompanied by what may be called equivalents of the physical under natural law. The special laws of Heredity are still enveloped in mystery; I refer, not to that mystery which may be regarded as surrounding all ultimate facts, if we choose to conceive them as expressing or concealing something further unknowable, but to the scientific mystery of ignorance, which time may dissolve. Biologists disagree on this question, the ultimate decision of which must be left to them. Still some general criticism on the results of research in this direction may be allowable from a philosophic standpoint.

The chief point at issue between various theories of Heredity seems to be the degree of importance to be attached to Adaptation: however we may express the question, this is the ultimate form to which it is reducible. Now it is obvious, from the foregoing analysis, that the form of theory which would be most useful to us, if such were attainable, would be one in which the degree of tendency to inheritance as well as the strength of inherited tendency is expressed in terms of the intensity and duration of exercise, use, function, habit, or form of motion or action (however we may choose to term it); and variation is regarded as the resultant of such tendency and change in the environment, or, in other words, deviation from constancy of influence. It may be useful to inquire to what extent such a general theory is authorized by special ones.

We have the testimony of two of the acknowledged greatest authorities - Darwin and Haeckel - as well as that of a score of other biologists, and specialists in related branches, to the inheritance of peculiarities acquired during the life of the individual. ${ }^{1}$

1 See especially Darwin: "The Variation of Animals and Plants under Domestication "; Hatckel: “Natürliche Schöpfungsgeschichte,” 8th ed., I889, p. 179 et seq. 
Eimer lays especial stress on the fact, long witnessed to by one class of specialists, of the hereditary character of brain-diseases, among which may be reckoned some that are without doubt due to direct influence of the environment. ${ }^{1}$ Haeckel and Eimer even instance cases in which mutilation has been inherited. ${ }^{2}$ One such instance would be sufficient, in overthrowing the general denial of the inheritance of individual adaptation, to make probable the direct influence of the environment in other cases, the uniformity discoverable in the workings of natural law leading us to suppose that the one instance would not be isolated. It must have weight, too, as an argument, in the judgment of many doubtful cases. Not one such case alone is furnished us, however, but many well-authenticated ones. And it is to be remarked that even Weismann has gradually parted from his original theory, recognizing more and more clearly the element of adaptation in inheritance. It seems open to question, indeed, whether Weismann's theory, in withdrawing the germ-plasm from the direct influence of the environment with which the parent individual is in contact does not exempt it from the universal law of action and reaction. Eimer designates such an opposition as Weismann postulates of the germ-plasm to the rest of the organism as a "physiological miracle," and the artificial line thus drawn between the germ-cells before and after the beginning of development as "opposed to that conformity to law shown in the morphological and physiological unity of living beings." 3 Ancient ideas seldom conceived of a universality of action and reaction; and ancient belief, isolating phenomena, invested each with some special guiding power. This belief was maintained as the conception of a special vital force long after the increasing knowledge of nature had caused it to be abandoned with regard to inorganic phenomena; and the theory of the continuity of the germ-plasm seems to be a survival, with regard to the comparatively unexplored province of Embryology, of the idea of such a force.

The elements of which the organism is composed are not strange essences or entities peculiar to the organic; they are the same with those of inorganic matter, though their combinations

1 "Die Entstehung der Arten auf Grund von Vererben erworbener Eigenschaften," p. 204 et seq.

2 Ibid. p. 190 et seq. 3 “Entstehung der Arten," p. 15. 
differ somewhat from these, both in chemical composition and in the morphological arrangement of the composites. We can easily conceive these differences as coördinate with differences of general form and function; but it is inconceivable that the continual assimilation of matter in growth should be at any time without result in function, however comparatively small this result may be in higher forms representing an accumulation of energy from previous conditions. The separation of form and function is an abstraction, as is that of matter and motion; we cannot suppose the connection of particular functions with particular forms, - particular organization, - to be accidental, any more than we can suppose the particular properties of particular inorganic composites and elements to be accidental or these particular properties to be without result in the organic matter into which the particular composites and elements are taken up.

The environment must contain complementary conditions of function in order that the individual may even come into existence and survive at all. The great question is, then, how much is to be allowed for original tendency in primal organisms and how much is to be reckoned to the account of the action of the environment in the course of evolution. Even if we go back beyond the organic, assuming a development of the organic from the inorganic, we must come, in the last analysis, to irresolvable elements whose motion, as distinct and particular action and reaction, must have definite form. If we begin with a supposititious simple organism conceived as lowest, - the primal form to which the name "organism" may be applied,-we must likewise conceive of this as embodying motion distinctive as its form, which may be regarded as concomitant and coördinate with that form, - or, that is, as function. The ultimate elements of this organism represent positive factors and the primal organism itself must be regarded as a positive factor (or positive composite) without which the evolution of highest organisms would be impossible. We may, therefore, regard it as in this sense embracing the potentialities of evolution. But are we to regard it as representing potentiality in a further sense - in the sense that, beyond the particular life-motion coördinate with its particular composition and form, it represents an independent force that prefigures the whole animate evolution? To such an assumption the analogy - which is something far more than a mere analogy - 
of Embryology logically reduces us, on Weismann's theory, unless we assume a fixity of species that practically does away with the whole theory of Evolution and returns to the original darkness that on which Darwin threw light. Or, if we leave out of account this analogy and begin with sexual propagation, the problem, on Weismann's theory, is very nearly as difficult. Are we to look upon the conditions involved in the environment as mere negatives and simply developing the positive potentialities lof the germ-plasm? If we resolve the environment into its elements, even the ultimate analysis must show it composed of positive factors of matter and motion, each one of which has its full worth in any resultant of incidence. The positivity of these elements takes from the primal germ-plasm any superiority of potentiality; the potentiality lies also in the environment. That the organism is in constant contact with the environment is evident; and that this contact, involving incidence of force, cannot be without result, and result representing a full equivalent of all the factors, is also evident. It may seem as if we could understand human progress, or progress in other species, in the limited province open to direct observation, on Weismann's theory; but evolution as a whole becomes, on this theory, a mystery, and indeed, as Eimer terms it, a miracle. Logical consistency thus tells against the theory; and undeniable exceptions to its fundamental conception, furnished by such authorities as Darwin and Haeckel, raise a further presumption against it, that, taken in connection with the logical inconsistencies noticed, constitutes the strongest probability against its truth.

The general experience of mankind has recognized, in a thousand ways, that the individual is "a creature of habit." The strength of the muscle, the cunning of hand or eye or ear, mental acuteness, and even liability to temptation in any direction, or, on the other hand, moral strength, all are coincident with exercise within the bounds set by the normal of the organ, - that is, within its ability to repair its waste in labor, an ability defined by the food-supply and its power of assimilation; for even the moral struggle that is so great as to exhaust physically ends in a weakness which may represent the very condition of conquest by the temptation opposed, if this present itself again before the system has had time to repair its loss. We may regard this weakness as a lessening of force in one particular direction, 
the resultant of action deviating in favor of the other of the opposing forces or tendencies manifested in the struggle. In this connection I cannot do better than refer to the "Kritik der reinen Erfahrung" already mentioned, in which the influence of the environment on the individual is minutely traced. The special feature of the work is its entire freedom from the thousand metaphysical implications which have gradually gathered about our philosophical vocabulary and which render it well-nigh impossible to write from any new standpoint without danger of misunderstanding. This perspicuity and exactness are secured by a new vocabulary which may seem at first glance, on account of its unfamiliarity, elaborate and incomprehensible, but which is, when mastered, the greatest possible aid to understanding. Nevertheless, the terminology of the book and the exceeding closeness of its analysis, while rendering it peculiarly valuable to the expert in Philosophy, place it beyond the grasp of the average reader; and Ethics is a science which concerns, not the specialist in Philosophy alone, but all thinking minds.

The influence of exercise even beyond the individual has long been recognized. Lamarck advanced the theory that the development of organs and their force of action is in ratio to their employment. Darwin also laid stress, particularly in his later works, on Use and Disuse, but he often defined the term more specifically than many other authors, Lamarck among them, seem to have done. The very mass and magnitude of I)arwin's knowledge made it, as Huxley has said, somewhat unwieldy, and, in diverting the attention to minute features, sometimes prevented distinctness in broad generalizations; the very virtue of Darwin's work conditioned also its defect. If we begin with the general theory of use and disuse, we may regard each present form of organic action or function, whether conscious or unconscious, as in some manner the result of exercise, the processes of foodtaking, digestion, repair of waste, being classed, not as, in any case, mere negative reactions, but as positive organic functions. If we apply the term "habit" to all these, it is evident that we must, in so doing, extend the significance of the word beyond its ordinary interpretation. From our present point of view, such an extension of meaning might be claimed to be legitimate; the question here is, in reality, only one of expediency, namely, whether it is not better to retain the more specific significance of 
the word. It may be useful, at least, to indicate the relations of Habit to Use and Disuse. In its ordinary interpretation, the term "habit" refers more particularly to a form of action acquired during the life of the individual, and may be used to imply the action of the will in its formation, or may simply have in view the organic concomitants of whatever mental action is included in such formation. Since our present standpoint supposes a certain equivalence of the mental and physical, that is, uniformity in their connection (without entering into the question of their dependence or independence, or considering which, in case of dependence, is to be regarded as dependent, which as fundamental and independent), we may leave for the moment the mental side of function out of account, to take it up later. Darwin's definition of habit was, as we have seen, no distinct and invariable one, and while he speaks of "inherited habit," referring both to forms of action acquired during the life of the individual and to such acquired through use favored by constancy of environment during several generations, it is not always plain whether he has in mind the action of the will, or only its organic equivalents. He inclines, like many other authors, to give prominence to the physical side of action in lower species, to the mental side in higher. If we use the term "habit" in the sense of tendency to function acquired by use, we employ what is certainly a useful terminology, yet we are in danger, if we do not carefully define our terms, of elevating to the position of a reality an abstraction that has none. Function and Tendency to Function are not separable; the distinction is not an inner, but an outer one, of favorable or unfavorable environment by which tendency to function becomes function or vice versa. To habit, then, we can attach, from our present standpoint, no distinctive implication beyond that of individual acquirement, — an implication obviously not fundamental in a theory of organic function. Use and disuse are rather the fundamental concepts with which, in a consideration of function under Heredity and Adaptation, we have to do.

But, in this connection, it is also obvious that, when we, from our point of view, distinguish between the organism as acted on by the environment and the environment as acting, we make a distinction that may be both useful and necessary for many purposes, but that is yet an arbitrary one. The organism is not the dependent, passive, the environment the independent, formative 
factor in the process of development, the organism is not purely reactive, the environment active, but the two are interactive; and from their interaction arises change, as resultant, in both organism and environment. So, too, if we return to Fechner's conception, the separation of function as effect from use and disuse as cause is an arbitrary one. Every function, as representing a state of more or less perfect, moving equilibrium, may be regarded either as the final form issuing from a long process of action and reaction or, as determined at present, by such a comparative constancy of all its conditions as makes the line followed by the resultant approximately a repetition of that which it has followed before; and we may lay stress upon either the inferior resistance in this line or the continual application of superior force, the accumulation of energy, in its direction. Use or exercise is function; long continuance of the same or approximately the same form of function may be regarded as concomitant with a certain constancy of environment, sufficient to furnish the complementary condition always necessary. The present form of function may be regarded as the result of an evolution of function in the sense that it is the end-form assumed by the same, but not in a sense that separates it from previous forms of function by a distinction of kind; since each of these may be regarded, in like manner, as the result of the preceding evolution. As in the ciefinition of Habit, so in that of Use, the element of animal will or of a distinct vital principle is likely to be consciously or unconsciously included, lending it thus a superior significance to that of mere organic function regarded as its result. Again it must be said, however, that, whatever the metaphysical truth of freedom, will does not interfere with the equivalence of physical conditions and results or prevent perfect uniformity of relation between the physical and the psychical, and that a special vital force cannot be demonstrated. Disuse may be defined either as the mere discontinuance of Use or as Use in a sense opposed to the form of function particularly under consideration.

The idea of some special vital principle doubtless has its origin in the mysterious tendency of every organic form to develop along certain lines. The mystery involved is here, again, besides that of ultimate fact on which the metaphysician lays stress, the lack of the ability of present science to furnish such a description of the process as shall resolve it into its elements and demonstrate 
the uniformities of relation among these elements in this last analysis. But it is to be remarked that the metaphysician is apt to confuse these two meanings of the word "mystery," and regard the mystery of the organism as a greater metaphysical one than that of simpler processes whose elements are better known; and this in spite of the fact that he himself does not at all deny the uniformity in natural process which we term Law, or expect to find it less in an ultimate analysis than in a more superficial one. We understand the simple parallelogram by which the physicist represents to us the action of two forces at incidence, we may represent to ourselves the motion of any one of the heavenly bodies as the resultant of the centrifugal and centripetal forces, but when we come to consider the formation of a crystal, and watch the regularity of shape and grouping, this very uniformity which had been before an explanation now seems all at once to represent an insoluble mystery separating the process forever from those others. The more complicated the process becomes, the more the mystery appears to increase, until we build up, out of a negative ignorance, some positive new entity to baffle us. And yet neither do we deny, as has been said, the constancy of nature in its most final elements, nor can it at all be shown or supposed that those simpler processes we seemed to understand were less along fixed lines than the more complicated ones. If we grant, then, the insoluble mystery of the transcendental meaning of things claimed by the metaphysician, we cannot admit the presence of this mystery in the organic more than in the inorganic, nor discover in the science of the former any further element lacking than in that of the latter, except a remediable ignorance which, when remedied, can only reveal in new particulars the workings of natural law. It may be remarked, in this connection, that those who are so ready to claim the workings of some special force or power in the developmeri of the organism make no assertion of such in the so analogous growth of the crystal. The passage of the inorganic into the organic and back into the inorganic is, in fact, no more (if the metaphysician will, no less) mysterious than the evaporation of water and its recondensation, the propagation of animal form no greater mystery than the continued flowing of a stream in spite of evaporation, or the growth of a crystal to the form of its kind. The propagation of species is, in one sense, an isolated fact; but so, in like sense, is the 
evaporation of water or the formation of the crystal of a particular chemical: but none of these phenomena are isolated in any other sense, as less or more than a part of a universal whole. We carry our notion of human importance into all our science, and so invest with greater weight and mystery ignorance that concerns our own life and that of allied forms. As we have seen, a connection of use, or of duration and intensity of function, with its strength is evident in the individual, and we are compelled to suppose the connection a constant one even where such constancy cannot be directly demonstrated. There is evidently a relation likewise between degree, or duration and intensity, of use or exercise of function, and strength of tendency in the species, which we must also suppose to be constant. Darwin distinctly recognizes this, everywhere in his work, in asserting that such function as is favored by the environment for several generations is more likely to be transmitted. But though the separation of organism and environment into cause and effect may be useful in the solution of some problems, it is yet to be kept in mind that the distinction is an arbitrary selection of some factors as dependent, others as independent variables, while all are, in fact, interdependent. Function may be regarded as at every moment determined by the factors given in environment and organism, in which either may seem the more important, according to the particular case or the point of view from which it is regarded. 'The tendency of the organism may represent such an accumulation of potential energy that a slight favorable element in the environment may be like a spark in a magazine of gunpowder, followed by results seemingly most disproportionate to its own significance; yet the accumulation of energy in the organism can have taken place only under previous favorable circumstances of the environment; and if we regard the organism in its relation to the whole environment, that is, to the universal conditions outside it, the primary importance may seem to attach to th:se. But yet, which is, in the last analysis, the more important to the explosion of the magazine - spark or powder? Either is insufficient without the other; the two are simply complementary and both indispensable to the result. So too habit, use, or exercise of function and influence of the environment cannot be held distinct; exercise of function is impossible without a sufficient complementary factor in the environment, but this is evidently sufficient only 
with the existence of that tendency in the organism of which it is the complement. Regarding strong tendency as the result of a long process of evolution in which the environment has presented sufficient complementary elements to condition its development, the strength of tendency being coördinate with the duration and intensity of the process of evolution, we can understand that any such change in the environment as shall prevent such function may be of so much significance, the suppression of the function represent so great departure from what was previous resultant, that even the destrucrion of the organism may supervene in cases where longest exercised and strongest functions are prevented; and we can understand, from the same standpoint, the slight comparative importance of the experience of individuals as influencing their descendants, except under especially favorable conditions of the organism.

All biologists make much of the mixture of types in sexual propagation; and Rolph, perhaps, lays especial stress on it in connection with progressive heredity. He calls attention to the intricacy of interaction of forces at once introduced by it in its action and reaction with the environment, and shows, in this connection, the extreme similarity of the younger generation to the parent where propagation is non-sexual, that is, does not involve such mixture of types. It may be said that every new factor in development introduces a complexity greater as the complexity of the conditions already attained by the organism is greater, since its influence on the different elements and combinations of elements varies; or (if we choose to put it thus) since the possible chemical compounds and especially the possible combinations and permutations of elements and parts increase enormously with the increase of the latter in number. But the importance of the presence of any particular new element in these complexities depends, further, on its particular nature.

The final decision of the principal question of progressive heredity which our argument concerns must be left to Biology; but biologists themselves have as yet discussed these questions chiefly from a philosophical standpoint, - on general, as distinguished from specific, grounds. All theory is at this point tentative. But if only for this reason we have a right, in assuming a working theory, to select that which seems best to 
accord with philosophic principles of universal application as well as with general biological fact. For the rest, it has at least been made evident, by all that has been said above concerning the constant contact and interaction of organism and environment, that the selection of one of these two factors as the positive and one as the negative, one as the formative the other as the formed, one as the active the other as the passive factor, one as independent the other as dependent, one as invariable the other as alone variable, is an arbitrary one. In dealing with the complexity of the universe, whether mathematically or logically, we cannot grasp all factors at once, and so are obliged to regard some sides to the exclusion of others, to disregard the variable and dependent nature of some factors in the consideration of that of others. The method is useful as well as necessary, useful because necessary; but we are too apt to forget that we are dealing with half-truths, devices of reason, and come to regard them as whole truths. Thus the abstraction of Natural Selection is too often elevated to a separate entity, a particular power residing in the environment as such. It is, on the contrary, a mere fiction, a device for assisting our comprehension of complex action and reaction. Not only does the action of the environment alter the organism, the action of the organism also alters the environment; or, to put it more plainly, the state of organism and environment at any moment is the result of the interaction of preceding states of organism and environment. Material combinations, whether organic or inorganic, when fitted to their environment, survive; those best fitted, where perfect fitness does not exist, thrive best; this is only another method of saying that absence of resistance is coördinate with the preservation of form and its inherent motion to the extent of the non-interference. As organic forms survive only to the extent to which they are in harmony with each other and with inorganic conditions, so inorganic forms or combinations survive unaltered only when they are in harmony with other inorganic conditions and uninterfered with by organic forms. Matter and motion in some form must survive, both being indestructible. Natural Selection in this sense, as at each moment regulating inorganic combinations and motions.and organic form and function, is either ultimately the origin of variation, or else it is not its preserver. It is to be remembered that the organism is, from the physical point of view, simply form 
(that is, organization) and function; when we have subtracted these, we have subtracted the organism.

The inability of the reason to grasp all sides of the complexity of natural processes at once, even where these are known, is a thing to be kept in mind in our future investigations; we are apt to take our analyses for the syntheses of nature.

In the preceding considerations, an "equivalence of the Physical and the Psychical" has been assumed, which, though already in a measure defined, should have been, perhaps, more fully explained. It may be repeated that, in such equivalence, no materialistic assumption is made of the dependence of the Psychical on the Physical; nor is the intention to assert that the Psychical can be measured by the weights and measures of the Physical. The assertion is intended in the sense that there is always a physical function connected with the psychical, and that the relation of the two is not an accidental or variable, but a . constant one. All that is claimed is, in other words, that, whatever the metaphysical truth as to the freedom of the will, such freedom cannot interfere with the constancy of nature. But, in fact, all that is postulated by physical science in the assertion of the equivalence of physical forces is such a uniformity or constancy of relation as we postulate of the Psychical and Physical; for the different forms of physical force can no more be measured by the same standards than can thought and brain-process.

It may be added, further, that by "force" as used in the above arguments, no metaphysical entity is implied; the word simply serves as the generic term embracing different forms of motion and the equivalent of motion in resistance, and enables us to deal with motion regarded as potential as well ar with motion actually existent. 


\section{CHAPTER II}

\section{INTELLIGENCE AND "END"}

IT is interesting to notice the opinions of different scientists and philosophers as to the extent to which reason is diffused in the universe, where the point lies at which the boundary line is to be drawn between reason and an automatism of instinct or organic action, or whether any such point can be found at all, whether reason, at least as consciousness and will, is not inherent in all life, or at least in all animal life, or whether it is not, indeed, to be regarded as the cause of motion even outside life, in the inorganic as well as the organic. There is no need to remind ourselves of the philosophic conception of the World as Will, the Philosophy of the Unconscious, or the Theory of Monads. The theories that specialists in physical science have arrived at, through the results of wide-reaching investigations in their own peculiar branch, are as various as those of philosophers. Darwin carefully avoids drawing any distinct limit-line between reason and instinct, but remarks that "A little dose of judgment or reason, as Pierre Huber expresses it, often comes into play, even with animals low in the scale of nature." 1 Haeckel says: "Unbiassed comparison and unprejudiced test and observation place it beyond doubt that so-called 'instinct' is nothing else than a sum of soul-activities which, originally acquired by adaptation, have been fixed by habit and carried down from generation to generation by inheritance. Originally performed with consciousness and reflection, many instinctive actions of the animals have become, in the course of time, unconscious, exactly as is the case with the habitual activities of human reason. These, too, nray, with like justice, be looked upon as the workings of innate instinct, as, indeed, the impulse to self-preservation, maternal love, and the social instinct often are regarded. Again, instinct is neither distinctively an attribute of the brdin

1 “Origin of Species," 6th ed., Vol. I. p. 320. 
of the animal, nor is the reason an especial endowment of human beings. On the contrary, an impartial doctrine of soul recognizes a long, long, descending scale of gradual evolution in the life of the soul, which leads from higher to lower human beings, from more perfect to more imperfect animals, step by step, down to those forms whose simple nerve-ganglion furnishes the starting-point of all the cell-less brain-forms of this scale." 1 The lecture in which this passage occurs not only argues further that the soul is composed of soul-activities as the brain is composed of cells, but finds in all living cells, "all protoplasm, the first element of all soul life, sensation in the simple forms of pain and pleasure, movement in the simple forms of attraction and repulsion. Only the degrees of development and combination of soul are different in different beings." Du Prel, impressed with the evolution of order from disorder in the heavens as on the earth, ascribes this to universal sensation as a fundamental quality of all matter, which makes it continually tend towards a state of equilibrium in which collision is reduced to a minimum. ${ }^{2}$ Some biologists ascribe sensation, or consciousness, to animal life alone; some ascribe consciousness to such animals only as possess a nervous system; some philosophers make a distinction between sensation, consciousness, and self-consciousness, as shown in the scale of animal life; some, again, approaching the problem from another side, lay emphasis on the difference between automatic and organic action, instinct, "blind impulse," and will. Carneri, as we have seen, ${ }^{3}$ holds that even the action of an animal so high in the scale as the butterfly may be pure automatism, its fluttering when impaled merely the motion of a continued attempt at flight.

These differences in opinion seem to depend, in great measure, upon the end of the scale of being chosen as the starting-point in the development of theory. If we begin with man and assume intelligence to be the cause of design, - of the purposeful, the self-preserving, - in his action, we shall be likely to infer intelligence as the cause of self-preserving function in all animals, and we shall find great difficulty in drawing any distinct line between intelligence and automatism. If we are not students of inorganic nature, the evolution to be found also in it, up to the attainment

1 “Lecture on Cell-souls and Soul-cells," I 878 .

2 " Entwicklungsgeschichte des Weltalls," p. 349 et seq.

3 See Part I. p. I6r. 
of preservative forms of motion, may escape our observation, preoccupation with man and the self- or rather human-interested bias of observation blinding us to it; but if we carry our considerations, in an unprejudiced spirit, on beyond the province of life, we may, like Du Prel and others, arrive at a theory of intelligence as a universal property of matter. On the other hand, if we begin with inorganic matter and assume automatism to be the cause of its motion, we are likely, ascending the scale of organic existence, to interpret much of its function as due to material action and reaction, and may again, from this side, find so great difficulty in drawing the line where intelligence begins, that we may fall, as Carneri has done, into the opposite extreme to that last noticed, and interpret nearly all animal action as unintelligent or even insentient.

Let us look at the dilemma a little more closely. Might it not seem, from one point of view, as if the harmonious movements of the stars, by which they avoid their own destruction, must be referred to desire and will to avoid it? If all systems of material parts, without exception or distinction, tend, as Fechner, Du Prel, and Petzoldt assert, towards harmony of the parts such that the motion of these parts will become self-preservative, does it not seem logically necessary to assume that this self-preservation, arising in inorganic matter in the same manner as in organic matter, must be due to the same causes as those to which we ascribe action towards an end, action that involves self-preservation, in the broadest sense of the word, in man? May not the heavenly bodies, learning from experience in some way, as man does, gradually come to choose, though still in accordance with natural laws (as man also invariably chooses) that orbit which preserves them from collision? True, they must finally suffer destruction, but so, also, must the human individual, and the race of human beings. The difference of evolution and dissolution in the two cases is only one of time. Among different species of nervously organized beings, the duration of life also differs. Or, if we deny the existence of intelligence in inorganic nature, can we, at least, descending the scale of organic being, find any point of which we can say, "Here intelligence ends and automatism begins"? Shall we deny the existence of intelligence in plants, and if so, how shall we find that dividing line between the plant and animal kingdoms which the advancement of science in many directions 
is rendering, not more distinct, but less and less so? G. Th. Schneider says, in his book on "The Human Will": "The movements of touch and locomotion in the search for food are the first movements in which the specific animal-life may be recognized. In no plant is the groping caused by hunger to be observed." 1 But is this true? The insectivorous plants, for instance, open their leaves when their prey is digested, waiting for fresh prey; and they close them again when prey has again entered, thus practically grasping their victim and holding him fast. Although the nature of the plant prevents its moving from the spot where it grows, are these movements less a search for and capture of food than those of the animal? T'o say that the closing of the leaves depends upon the beginning of some chemical process in the plant furnishes us with no mark of distinction between the two, for it is equally true that chemical processes underlie animal motion; and to object that the reopening of the leaves is the result of the completion of assimilation gives us, also, no distinctive mark, since the animal's search for food is likewise the result of hunger and so connected with a particular state of the digestive organs. The action of insectivorous plants draws our attention because the process of assimilation involved so resembles animal digestion; but, as a point of fact, the opening of petals to receive the air and sun is as much a search for food as the opening of leaves to receive insect prey.

Schneider adds to the passage above quoted, "A further difference between psychical and physiological movements is this, that the latter always remain the same, however the excitation changes, while the former have, now the character of attraction, now that of repulsion." It may be questioned whether this difference either can be demonstrated to be a distinctive mark. We have only to go into a dark cellar where the potatoes have begun to sprout, in order to see how plants that ordinarily grow upward will take every curve and angle in order to reach towards the light of some distant window. And if we turn one of the tubers about, we may watch the pallid sprout again turn to grow towards the far-away sunlight. Thomas A. Knight relates experiments in which plants of the Virginia creeper (Ampelopsis quinquefolia) were removed from one side of the house to the other, being, in each case, screened from perpendicular rays of the sun, and

1 "Der menschliche Wille," p. I 3. 
records that, in all cases, the tendrils turned in a few hours in a direction pointing to the centre of the house. One plant after being thus experimented with, was "removed to the centre of the house and fully exposed to the perpendicular light of the sun; and a piece of dark-colored paper was placed upon one side of it, just within reach of its tendrils; and to this substance they soon appeared to be strongly attracted. The paper was then placed upon the opposite side, under similar circumstances, and a piece of plate glass was substituted; but to this substance the tendrils did not indicate any disposition to approach. The position of the glass was then changed, and care was taken to adjust its surface to the varying position of the sun, so that the light reflected might continue to strike the tendrils; which then receded from the glass, and appeared to be strongly repulsed by it." 1 Darwin writes of the insectivorous Drosera rotundifolia: "If young and active leaves are selected, inorganic particles not larger than the head of a small pin, placed on the central glands, sometimes cause the outer tentacles to bend inwards. But this follows much more surely and quickly, if the object contains nitrogenous matter which can be dissolved by the secretion. On one occasion, I observed the following unusual circumstance. Small bits of raw meat (which acts more energetically than any other substance), of paper, dried moss, and of the quill of a pen, were placed on several leaves, and they were all embraced equally well in about two hours. On other occasions the above-named substances, or more commonly particles of glass, coal-cinder (taken from the fire), stone, gold-leaf, dried grass, cork, blotting paper, cotton-wool, and hair rolled into little balls, were used, and these substances, though they were sometimes well embraced, often caused no movement whatever in the outer tentacles, or an extremely slight and slow movement. Yet these same leaves were proved to be in an active condition, as they were excited to movement by substances yielding nitrogenous matter, such as bits of raw or roast meat, the yolk or white of boiled eggs, fragments of insects of all orders, spiders, etc. I will give only two instances.

"Minute flies were placed on the discs of several leaves, and on others balls of paper, bits of moss and quill of about the same

1 On the Motions of the Tendrils of Plants; among the essays of Knight published under the title, "A Selection from Physiological and Horticultural Papers," $184 \mathrm{r}$. 
size as the flies, and the latter were well embraced in a few hours; whereas after twenty-five hours only a very few tentacles were inflected over the other objects. The bits of paper, moss, and quill were then removed from these leaves, and bits of raw meat placed on them; and now all the tentacles were soon energetically inflected.

"Again, particles of coal-cinder (weighing rather more than the flies used in the last experiment) were placed on the centres of three leaves: after an interval of nineteen hours, one of the particles was tolerably well embraced; a second by a very few tentacles; and a third by none. I then removed the particles from the two latter leaves, and put on them recently killed flies. These were fairly well embraced in seven and one-half hours, and thoroughly after twenty and one-half hours; the tentacles remaining inflected for many subsequent days. On the other hand, the one leaf which had in the course of nineteen hours embraced the bit of cinder moderately well, and to which no fly was given, after an additional thirty-three hours (i.e. in fifty-two hours from the time when the cinder was put on) was completely reëxpanded and ready to act again." 1

From these and many other experiments Darwin concludes that inorganic and some organic substances not attacked by the secretion of the leaf act much less quickly and efficiently than organic substances yielding soluble matter, which is absorbed.

He also writes of the curvature of radicles which come in contact with obstacles at right angles:-

"The first and most obvious explanation of the curvature is that it results merely from the mechanical resistance to the growth in its original direction. Nevertheless, this explanation did not seem to us satisfactory. The radicles did not present the appearance of having been subjected to a sufficient pressure to account for their curvature. Sachs has shown that the growing part is more rigid than the part immediately above, which has ceased to grow, so that the latter might have been expected to yield and become curved as soon as the apex encountered an unyielding object; whereas it was the stiff, growing part which became curved. Moreover, an object which yields with the greatest ease will deflect a radicle: thus, as we have seen, when the apex of the radicle of the bean encountered the polished surface of extremely

${ }^{1}$ See "Insectivoruus Plants," Chaps. I. and II. 
thin tin-foil on soft sand, no impression was left on it, yet the radicle became deflected at right angles. A second explanation occurred to us, namely, that even the gentlest pressure might check the growth of the apex, and in this case growth could continue only on one side, and thus the radicle would assume a rectangular form; but this view leaves wholly unexplained the curvature of the upper part, extending for a length of $8-10 \mathrm{~mm}$.

"We were therefore led to suspect that the apex was sensitive to contact, and that the effect was transmitted from it to the upper part of the radicle, which was excited to bend away from the touching object. As a little loop of fine thread, hung on a tendril or on the petiole of a leaf-climbing plant, causes it to bend, we thought that any hard object affixed to the tip of a radicle, freely suspended and growing in damp air, might cause it to bend if it were sensitive, and yet would not offer any mechanical resistance to its growth. . . Sachs discovered that the radicle a little above the apex is sensitive and bends like a tendril towards the touching object. But when one side of the apex is pressed by any object, the growing part bends away from the object." 1

Acting on this idea, Darwin found, in many experiments, that the radicles of plants freely suspended in bottles, when brought into contact with the most yielding substances, bits of paper, etc., were deflected, in a very few hours, from their original course, and often at right angles to this. He says, further:-

"As the apex of a radicle in penetrating the ground must be pressed on all sides, we wished to learn whether it could distinguish between harder, or more resisting, and softer substances. A square of sancied paper almost as stiff as card, and a square of extremely thin paper (too thin for writing on) of exactly the same size (about one-twentieth of an inch), were fixed with shellac on opposite sides of the apices of twelve suspended radicles. . . In eight out of the twelve cases, there could be no doubt that the radicle was deflected from the side to which the card-like paper was attached and towards the opposite side bearing the very thin paper.

"This occurred, in some instances, in nine hours, but in others not until twenty-four hours had elapsed. Moreover, some of the four failures can hardly be considered as really failures: thus, in one of them in which the radicle remained quite straight, the 
square of thin paper was found, when both were removed from the apex, to have been so thickly coated with shellac that it was almost as stiff as the card; in the second case, the radicle was bent upward into a semicircle, but the deflection was not directly from the side bearing the card, and this was explained by the two squares having become cemented laterally together, forming a sort of stiff gable from which the radicle was deflected; in the third case, the square of card had been fixed by mistake in front, and though there was deflection, this might have been due to Sachs's curvature; in the fourth case alone, no reason could be assigned why the radicle had not been at all deflected."

Darwin found, moreover, by experiment, that, when the tip of a radicle is burnt or cut, "it transmits an influence to the upper adjoining part, causing it to bend away from the affected side." This deflection resembles, in a very striking manner, the avoidance of sources of injury and pain on the part of animals.

And at the end of his book on the Movements of Plants, which contains very many other experiments bearing on the question of sensitivity in plants, the author writes, "It is hardly an exaggeration to say that the tip of the radicle thus endowed, and having the power of directing the movements of the adjoining parts, acts like the brain of one of the lower animals."

It is true that the plant does not react with the rapidity which characterizes the animal; Darwin found that radicles are not sensitive to temporary contact, but only to long, though to slight pressure. It is also true that the physical basis of the movement is more simple, and so more easily traceable in the plant than in the animal organism; yet why lay such especial stress upon this side of plant-life, since it is acknowledged that the physical basis is by no means peculiar to it, but that, on the contrary, all lifeprocesses, in the animal as well as in the plant, have their physical side, although greater complexity of organization may make this more difficult to follow in the one case than in the other?

But we may begin at the other end of the scale and examine the facts presented from the opposite point of view. The physicist demonstrates that force is indestructible; that is, that the sum of the motion and resistance to motion residing in indestructible matter is also imperishable, that all present motion must be regarded as the resultant of previous conditions of motion and resistance, as far back as we may go, until we reach some assumed 
primal state (which is only assumed and cannot be proved to have existed) in which the matter composing the universe is supposed to have been at complete rest; and that every resultant bears relations to its component factors of force that are constant, every component finding its full value in the resultant. What evidence has the present state of our solar system and the other systems of heavenly bodies revealed to us by the telescope to offer us in proof of their consciousness or sentience? How are the whirl and concentration of nebular mists, the crash and collision of elemental bodies, from which, by simple action and reaction, after ages of disharmony, only a comparative harmony is arrived at as inevitable result, evidence of aim, intention, will, consciousness, in the matter subject to this evolution? Do we find anything here except blind law? The movements of plants, often directly favorable to self-preservation, may be explained by the arrangement of the cells and their chemical action. Or, if sentience must be assumed to be the cause of movement attaining ends of self-preservation in plants, how are we to account for organic and instinctive action in animals? How is it, for instance, that the new-born infant sucks, and the chicken but a few hours old, even though it has been hatched in an incubator apart from its kind, picks at the food strewn before it, aiming, too, with considerable precision? ${ }^{1}$ How does it happen that the process of breathing and digestion, the beating of the heart and the circulation of the blood, all so necessary to life, go on with regularity, though not directed by reason? Has the newly hatched chicken any experience to teach it what food is, and how it is to be seized; or does the caterpillar, which spins itself a cocoon, do this with the understanding that it is about to enter a new phase of existence? Or, if such important and, at first view, seemingly intelligent action can be explained as unreasoning instinct, why cannot many other actions of the lower animals be thus explained? Why may not nearly all, if not all of them, be thus explained, and consciousness be regarded as the exclusive property of man?

But how much of the action we term automatic, instinctive, or organic, reflex or "merely functional," can be positively asserted to have no admixture of consciousness? If we examine our own action closely we shall often find that we were, in fact,

${ }^{1}$ See experiments made by Eimer: "Entstehung der Arten," etc., p. 263 et seq. 
conscious of much that seems, at first glance, purely automatic. It may appear to us, for instance, that reflection on the notes of a musical composition which we have known for a long time "by heart" hinders rather than helps us, even causing us sometimes to fail completely in our performance. But if we examine our condition at the time of such a failure, do we not usually find that, when we began to think about what we were playing, we were suddenly seized with a fear of failing and that the fear confused us? Or do we not find, at least, that withdrawal of our attention from the music by conversation that requires any concentration of thought is as likely to confuse us as too great attention to it? A friend of mine one day related to me the following experience: Having a felon upon his finger, he submitted to a surgical operation, for which the operator preferred to administer an anæsthetic. When he awoke to consciousness again, he was pleased to find the painful operation completely finished and the hand newly dressed. Asked whether he had experienced any pain, he answered, "Not a twinge," whereat the surgeon remarked that he had screamed and groaned during the operation. To this he replied that his action must have been merely reflex. An hour or so later, however, as he was at work, a sudden recollection of the whole operation came to him. Persons undergoing dental operations under the influence of laughing-gas often scream and make convulsive movements as if in pain, though they declare, afterwards, in like manner, that they have felt nothing; but may not this be due, as in the case just cited, to a mere lapse of memory? Why, indeed, should the patient scream if not in pain? Again, there is a poison - curarine, the Indian arrow poison - which has power to deprive its victim of all motion, while leaving him, as has been ascertained in cases in which it has been used as a medicine, a consciousness that is more or less dimmed. May not the seeming dimness, however, be due to the incomplete function of memory when turned to events that transpired under its influence? And may not the action of socalled anæsthetics of all sorts involve simply a paralysis of action similar to that caused by the Indian arrow poison, together with a more complete lapse of memory than that ensuing upon the latter? To answer that anæsthetics affect the brain, and that therefore consciousness is not possible, is begging the question, for it is by just such experiments and experience of the apparent 
mental effects of anæsthetics in connection with peculiar brain conditions that theories of non-sensibility under these conditions have been arrived at. States of somnambulism generally used to be classed as outside the sphere of memory and were therefore sometimes called unconscious; but recent experiments in hypnotism have shown that similar states to these may be remembered or not remembered according to the individual case, and that persons who, when awakened, ordinarily recall nothing of that which has passed in the hypnotic state may be made to recall all the events of that state if commanded to do so before awakening. Pfliger has attempted to demonstrate, by many experiments, that consciousness is not confined to the brain but is also connected with the spinal cord; ${ }^{1}$ why, however, draw a line at the spinal cord? Is not nerve substance the same with that from which the spinal cord and the brain develop, are not all nerve cells primarily mere modifications of cells of the outer skin?

Of unconsciousness in ourselves we can have no more an immediate and direct knowledge than of unconsciousness outside ourselves, since, in order to be immediately known, it would have to be present in consciousness; and a conscious unconsciousness is a self-contradiction. We can only witness to a failure of memory at certain points (which failure has already been shown to be untrustworthy as evidence) or to movements of our body to which we can supply no corresponding conscious states as premeditation. But our inability to testify to such is merely negative. A great deal has been made, in one way and another, of the fact that there are links in premeditated action which do not come into consciousness, there being no knowledge, for instance, of the processes in nerve and muscle between the movement of the arm in writing and the premeditation of such movement. As a fact, however, none of the physiological processes which accompany the psychical are present to our consciousness except as given through the senses or through nerve-transmission similar to that of sense-perception. The conscious elements of any present state of thought do not include the changes in brain-matter concomitant with them. But the question may be raised, as Haeckel raises it, - though perhaps somewhat differently, - in his essay on Soul-cells and Cell-souls,

${ }^{1}$ E. Pflüger: "Die sensorischen Functionen des Rückenmarks der Wirbelthiere," I 853 . 
as to whether the brain-cells themselves are not endowed with consciousness; and any answer in the negative is, evidently, an assumption, of which we can give no proof. Indeed, the question may be asked, and has been asked, whether the remarkable white blood corpuscles which traverse our body, and are so similar to certain lower forms of life, are not to be regarded as distinct beings, or whether, in fact, all the cells whose combined life and movement make up our own are not endowed with distinct being and consciousness. Again an answer in the negative is evidently a mere assumption. And why stop, in this case, exactly with the cells of animal life; why not apply our question to those of plant life also? Why not, indeed, suppose all forms to be endowed with consciousness, all harmonious motion to be accompanied by pleasure, all dissolution and conflict by pain? From analogy we may conclude something, but from mere non-analogy nothing. Our experience may entitle us to the assertion that all beings possessing a nervous system are endowed with consciousness, but we cannot conclude, therefore, that all beings not possessing a nervous system are not endowed with consciousness. We have associated consciousness with acts peculiar to man, and hence inferred its presence in similar movements of animals similarly constructed. But if we could examine the physiological accompaniments of our own thought and feeling and their issue in action, if we could look on at all the details, the chemical and mechanical changes of the physiological processes, what hint should we find in these more than in any other physical processes, from which to infer consciousness? They are not the less rigidly in accordance with natural law than any other. But our observation of all other processes than those of our own organism is a mere extraneous one, like this we have imagined of the processes of our own body; if there were consciousness in other forms we could not enter into it; and how can we prove extraneously its non-existence? Our own "stability" of function and the stability of all life-motion has been developed in a perfectly similar manner to that by which the stability of the heavenly bodies has been developed, the physical side of the process being just as fully a matter of action and reaction, and our action towards ends the slowly progressive result of this course of action and reaction, just as is the case with the harmonious movements of the systems of the heavens. It would, moreover, be perfectly 
easy to formulate a purely physical and mechanical explanation of our action, as Carneri does of the action of ants and other species, - to explain the plucking of a rose, for instance, as mere reaction upon the sense of smell and sight, or as the mere mechanical action of cell-matter.

But, again, on the other hand: If it is true that the nervous system is developed from cells of the outer covering of the body, it is, nevertheless, not true that those primary cells are the nervous system, any more than it is true that the lowest forms of life, from which man has developed, are human beings. Rudimentary eyes exist in some animals in the form of mere pigment spots, but we do not suppose these pigment spots to endow the animal with sight as we understand it. Sight is not a function of all forms of life, neither is hearing, and these powers have developed out of forms of animal life in which they did not exist; why then is it necessary to suppose consciousness to be a property of all forms of life because we know it to appear in some higher developments of life? Why may it not arise, as do sight and hearing, by gradual evolution, as a function of special organisms? Have we any direct knowledge of consciousness except in connection with certain normal conditions of our own brain? And, this being said, have we any means left by which we can prove the existence of consciousness, except in connection with a brain similar to our own?

What grounds have we for assuming the existence of consciousness where the analogy of our own organization does not furnish us with an argument? If we argue from the analogy of our own experience to the existence of consciousness in animals whose organization is similar to our own, and then, following down the scale of life, find no pause or gap at which to draw an exact line, we must not the less forget that with the diminishing analogy the force of our inference diminishes in like degree. Or where is the logical necessity of inferring that consciousness must exist in the inorganic either because the organic originally developed from the inorganic, or because it suffers continually a renewal by nourishment, which is, in effect, as much a development from the inorganic as the supposed primal one? The pigment spot from which the eye arises is not the eye, simple protoplasm is not the organized human being; whence does the physical organization arise? Are we to suppose it, too, as 
preëxistent, "in a weaker form," or in any form, in the inorganic? Whence have we any grounds for assuming that that which we know only in connection with a certain peculiar organization exists elsewhere? Are we to suppose the color blue to be present in certain chemical elements because their chemical compound is blue? Or how is it that even isomeric compounds may exhibit different qualities? Shall we regard the color as not essentially connected with the chemical constitution of the supposed compound? As a matter of fact, color is one of the chemist's means of recognition. Or shall we "explain" the color by the length of light-waves or the construction of the eye, correcting, thus, one part of our experience by another, and assuming one as fundamental and essential, the other as non-essential? We "explain" sound as wave-movement in some outer medium and in the ear, correcting, thus, the hearing by sight or touch; does this mean that that part of our experience given us through the eye or hand alone is truth, and to be relied on and recognized as such, while the experience given us through the other senses is non-essential and not to be accepted or relied on? But if the eye gives us the truth, then why do we, in the case of color, correct it again by another phase of our experience? How are we to decide which is essential, the wave-movement that is (or may be made) perceptible to our eye, or the sound heard by our ear, the color directly seen or the length of the light-wave concluded from experiment? As a matter of fact, we emphasize one or the other according to the end we have in view in our experiment. Is it the length of the wave which causes the color, or the color which causes the particular wave-length? If we analyze brain-action as chemical action, do we prove thereby that the consciousness concomitant with this peculiar chemical action under these peculiar conditions must exist elsewhere under other conditions? Are the characteristics of one chemical compound the same as those of another because both compounds are matter and motion? If we prove that the brain contains cells similar to cells in other parts of the nervous system, that the whole nervous system arises, in the first instance, from epithelium cells, that the whole animal is descended from some primal protoplasmic cell, and that the cells of plants are similar, in many ways, to those of animals, do we thereby prove that consciousness exists except as coördinate with the peculiar cells and arrangements of cells in the brain? 
We have no precedent from which to argue, since consciousness is to us a unique feature of the universe; we know it immediately only as existent in ourselves, and in order to obtain any precedent must be guilty of assuming it in order to prove it.

The dilemma seems, thus, as we analyse and inquire into it more closely, to increase rather than decrease in significance. How is any solution to be arrived at?

If we return to the beginning of our considerations on this point, we shall find that, in coming at the question from either side, we have made an assumption. Our first premises were as follows: Assuming that consciousness is the cause of movement by which man attempts to arrive at his ends, what reason have we for supposing consciousness to exist outside man? and, on the other hand: Assuming mechanical action and reaction to be the cause of movement in inorganic nature, what reason have we for assuming this to be the cause of action in organic existence? Let us examine these assumptions more closely.

We may return to the theory of the gradual development of stable out of unstable conditions as stated in different ways by Zöllner, Fechner, and Du Prel. As has been shown, the principle applies to organic as well as to inorganic nature, and is only a broader principle including that of the Survival of the Fittest. There is a physical side to all psychical functions, and everywhere our investigation shows us the physical following unchanging laws. The development of the Stable from the Unstable explains to us the evolution of function in the direction of the preservation of the organic forms of which it is the function, as well as the evolution of harmonious movement in the heavenly bodies. The explanation of the natural and necessary elimination of the inharmonious covers the whole ground, and seems to assign a cause for every form of preservative action, for the harmonious conduct which preserves the state or the family as a collection of individuals, as well as for the harmony of function that preserves the individual. As long as reason can change no smallest detail in the workings of the laws of nature, as long as it can never render any motion other than the exact resultant of the forces represented in it, what room remains for reason as a cause? Ought we not rather, though from a much broader and therefore more convincing, in fact from the broadest and hence most convincing view of the matter, to regard consciousness, as do 
many physiologists on narrower grounds, as the mere accompaniment of material processes?

But this brings us again to a consideration of the concept of cause. What do we mean by cause? Above, we spoke of the "cause of motion"; do we designate by this term those factors of preceding motion which, continued, produce it as composite resultant? If so, why not substitute for the term "cause of motion," "component factors of motion"? But is this, in fact, all we meant by cause? Was there not, in our mind, as we made use of the term, a vague half-conception of some additional force beyond those so exactly summed up in the resultant, which, in some indefinable manner, guided the process? As has been sufficiently demonstrated, no such additional force can be shown to exist, or be logically assumed in theory, except in some transcendental sense; nature gives us only perfect equivalence of forces. A cause of motion except as the mere sum of its preceding components is, therefore, a natural impossibility. Hence the reason or consciousness cannot be assumed to be such a cause. But if consciousness cannot be regarded as such a cause additional to the component factors of motion, neither can anything outside consciousness be regarded as such a cause. Natural laws are often treated as if they constituted a cause; but they are not entities which control nature: they are merely forms by which we express nature's constancy, uniformity. Neither is constancy or uniformity a controlling entity: it is simply a generalization, if a universal one, whether we regard it as a priori or as a posteriori. It appears, then, that we have no greater reason for regarding the constancy of nature or natural law as cause than we have for asserting reason to be such.

In this connection the question may be in order, as to why the student of the natural sciences, who is in the habit of proclaiming, so loudly, the necessity or at least the constancy of everything in nature, should yet elect to assign to consciousness the character of the non-essential, that is the accidental. Action and reaction are, according to him, essential inherent properties of brain matter as such, but consciousness is merely a dependent. But who shall decide what part or form of force, what factors of the universe are accidental and what essential? If our assertion of constancy in natural phenomena means anything at all, it means that nothing is accidental, but that all factors of phenomena 
are essential. Is the bell the less silver to my eye because it appeals to my ear with sound, or the ball the less round to touch because my field of vision is flat? Even if we suppose forms of matter, and organic forms, to exist without consciousness, can we therefore assert consciousness to be any the less essential, any the less inherent in the nature of things, any the less existent and actual, where it appears? If so, what physiological function can we call inherent and essential, since these all also arise with evolution? Heat may exist without light, but is light therefore less essential than heat, where it arises? The very constancy which psychical phenomena exhibit would show their essential character as factors of the universe. Perhaps it is the attempt of the spiritualist to assign to consciousness something more than such a character which has led his adversary into the opposite error of asserting it to be something less; but the two extremes of doctrine are quite equally far from that scientific method which holds to given phenomena. Materialism is as much metaphysics as Spiritualism is; and the materialist who condemns metaphysics condemns himself. Consciousness belongs to the Actual; and the Materialism which assigns it a place subordinate to that of other actual phenomena is as much dogmatism as is any theory which subordinates the other phases of the Actual to it. The fact that consciousness bears constant relation to certain physiological phenomena is no ground for pronouncing it the effect and the physiological phenomena the cause, it the dependent and the physiological phenomena the independent factors; the relations of all forms of force to each other are constant. Heat is constant in its accompaniment of light; and yet who shall say the one is dependent, the other independent, the one cause, the other merely effect?

We have only to regard the theories of specialists in order to discover how easily habitual occupation with one particular side, form, factor, or phase of phenomena inclines one to regard that side as the only essential one, and all others as non-essential, dependent upon it, mere effect of which it is the cause. The physicist tends to interpret everything by mechanical action and reaction; the chemist lays more particular stress on the chemical properties of organic as of inorganic matter; the physiologist emphasizes cellular structure and combination, and makes much of brain cells, the spinal cord, the nervus sympathicus, and the 
special sense-organs; the biologist often regards the attraction and repulsion involved in the so-called sensibility of all forms of living matter as the cause of all life phenomena; the anatomist calls attention to the arrangement of organs with respect to each other, the mechanical adjustment of parts for function, the size and shape of bones as caused by weight and the angle of its incidence, etc., etc.; while the psychologist on the other hand refers everything to mental causality. For complete science, however, we need the aid of every special science, - of Physics, Chemistry, Biology, Physiology, Anatomy, Psychology, and all the other branches which can contribute to any side of our knowledge of nature. The desire within us for unity is strong, the impulse to simplify by referring everything to a single principle almost irresistible; and in so far as we do this through a conviction of the oneness of the universe as consisting of interdependent parts we are in a certain sense justified; but until we can grasp this unity in its totality, our one-sided reductions must remain false in so far as they make claim to include the whole of truth. It may be most useful to choose out that side or phase of phenomena for any particular investigation which is most accessible to such investigation; where the links of the psychical fail, it may be necessary to scientific completeness or clearness to complete the chain with the aid of the physical, but it should be borne in mind that this is a device of reason for convenience' sake. It may be possible to imagine two worlds, one in which the physical evolution alone takes place and all phenomena peculiar to organic function arise through the action and reaction of organic matter $;^{1}$ but the question is not what we can imagine but what is: we can imagine many things which do not exist and are impossible to nature. The human reason has also found it possible to conceive of spirit unconnected with body.

The materialist calls triumphant attention to the constancy of material phenomena, and proves, by careful comparison with coördinate psychical phenomena, the uniformities in the latter. Disease of every kind, but particularly those forms of disease which attack especially the nervous system - brain and spinal cord and the nerve endings - furnish the strong points of his argument, which is thus based on facts no lover of truth desires

${ }^{1}$ See Lange: “Geschichte des Materialismus,” II. Theil, p. 486. 
to gainsay; but when the materialist has shown us all these facts, has he not proved, with regard to the psychical, exactly that constancy which entitles it to consideration as a part of the actual universe subject to natural law?

The materialist objects that if the physical side of nature is the essential one, the psychical cannot be essential. On what grounds is this claim based? Is the color of an object not essential to it because its shape is essential, or do the actual existence and change of color according to natural law interfere with the actual existence and change of shape according also to natural law? Does only one of our senses give us truth?

Logic is very ready with its definitions of "things" and their "properties" and "accidents," as Physics is very ready with its analyses of light and color and sound, and Physiology with its analyses of the sense organs and their relations to color and sound. But shall we accept only the physiological analysis of cell form and action, and reject the sense-synthesis of sight or hearing as less important, less actual? Or are we to believe that the sensefunction alone is essential and not also some actuality in its object, as of this or that color? Are we to believe that any property or accident of a thing may change, and the thing remain yet actually the same thing? What are our essences as separated from their properties and accidents? As a matter of fact, we know nothing except we know it as some particular thing, every change in which leaves it something different from what it was before. Changes of particular form or color are changes to some other particular form or color, unless they are such changes as withdraw the object from the reach of the special sense of sight before appealed to, as for instance in the case of evaporation. That one form of force may accompany or pass into another makes neither one of the concomitants and neither the preceding nor the succeeding form less real. As a fact, however, much superstition still remains with us as unconscious result of just such withdrawals from the perception of one sense and analogous new appeals to some hitherto unaffected sense, although we are accustomed to flatter ourselves that science has long overcome this superstition. There is no change that is not a particular change, that is not according to constant laws of nature, and, as such, essential to nature. There is no phase of nature that exact science can consistently regard as non-essential. So that, even if reason does 
not exist in combination with all matter, we have no ground for regarding it as non-essential where it does exist, and no more reason for defining it as effect than we have for defining it as cause. Result it may be, as physiological function is result, that is, an end-form of processes of change which we call evolution.

But we have found our disproof and also our proof of the existence of reason outside the human species fail us wherever the direct evidence of extreme analogy is wanting, as soon as we cease to regard reason as a cause of physiological change. Perhaps it will be well for us to define more closely the province of reason, before we proceed further in our considerations. An exhaustive analysis is not necessary to our purpose and it would be useless to attempt it at this point of our argument. The relation of reason to action is what chiefly concerns us here, and in this connection Mr. Leslie Stephen's definition of it as that faculty which enables us to act with regard to the distant and future might seem to designate its important function. 1 Simple reaction on the present action of force belongs to all matter. However, when we consider further, a certain doubt may rise as to the exact correctness of this definition or description, for does not that which we call instinct often perform the same office for the animal as that which we have designated as the office of reason? Let us look into this question a little more closely. We may take, for instance, the case of those insects and other animals which, though never caring for or indeed seeing their offspring after the hatching of the-latter, make provision at the laying of the eggs for their nourishment during the helplessness of the first period of their life; are we to suppose that these animals have any means of knowing that they are providing for their offspring? Can they have learned the fact from their own parent whom they never saw, or from others of their own species who are in the same predicament as themselves? As Schneider points out, ${ }^{2}$ the human infant must have sucked before it could have had any ideas, as individual, of the act of sucking. 'The newly hatched chickens of Eimer's experiments above referred to could scarcely have had any conception of the act of eating before they picked at their food. How happens it that the young of many of the lower animals which

1 "The Science of Ethics," p. 60.

2 " Der thierische Wille," p. I6I. 
give no care to eggs or offspring yet know how to care for themselves after the peculiar manner of their kind? Once it is admitted that any acts which attain results that constitute desirable ends for the acting subject need not be regarded as caused by knowledge of the ends, there is no reason to suppose that the principle may not hold of many acts in which a distinct knowledge of the end seems to play a part. But what do we mean by end?

Let us take, for instance, the act of eating. The biologist and the physiologist tell us that the end which eating serves is the preservation of life; and the biologist may further add - not the life of the individual, alone, but that of the species. The very consistent physiologist may principally have in view, in eating, the preservation of his own health, and may even take into consideration, in a degree, his possible future offspring, guarding his own health with a view to theirs. With a minority of other men these more general and distant results may to some extent be kept in view as ends. But it is evident that, with the majority of people, they are, where ends at all, subordinate ones, the immediate satisfaction of hunger, the pleasure of eating, or the relief of physical depression, appearing of tener as chief end. And what is to be said of the new-born infant, which sucks when the breast is placed between its lips? what is the end which it has in view in taking nourishment? Shall we suppose it, as individual, to have any definite conception of the contrast between states of hunger and states of satisfaction, and to possess the knowledge that the act of sucking is the proper means to the attainment of satisfaction as an end? As the infant becomes the boy seating himself at table with a distinct conception of pleasure to be attained by the gratification of a vigorous appetite, so the boy may become the physiologist eating with a view chiefly to his own health and to the further end of health in his offspring. How does it happen that, thus, the same act, the significance of which remains the same, may be performed and by the same individual yet with quite different ends, or perhaps in some cases (that of the infant) no end at all, in view?

When we perceive the sphex providing its eggs, as is its wont, with living and yet motionless and helpless insects, we can scarcely refrain from believing that it is inspired by parental affection thus to provide for its future young; and yet we might, with quite 
equal reason, suppose that the act of copulation, in the case of the sphex, must have ir view the propagation of offspring and the preservation of the species, since this is its result also; we refrain from so supposing, simply because a common experience furnishes us with the knowledge that the act of copulation, most necessary to the propagation of offspring and the preservation of the species, may yet be performed with no direct view to either of these ends, the birth of offspring being even regarded, in many cases, as something to be avoided if possible. With respect to all manner of acts, we continually fall into error by imputing what would be our own end, in case we performed the act, to another individual of our own species performing it; and the danger of error is doubtless increased when we attempt to judge the ends of an entirely different species by ends in a degree common to our own species. There is no reason why we should not suppose that some less ultimate end than that of the preservation of offspring may be present to the consciousness of the sphex placing food about its eggs, just as some nearer end than preservation of the species, health of offspring, or even individual health may be present to the human individual in the acts of copulation or of food-taking. And there remains still the further question as to whether the care of the sphex for its eggs may not be, and continue forever, on the plane of the first act of food-taking in the human infant; and then the question again arises as to what the nature of that plane of action may be.

These questions must remain, I believe, in great part unanswered, considerations such as those noticed above making the inference even of like ends from like acts very untrustworthy, the inference of similar ends from similar acts still more so, and the inference of the existence of no end or consciousness at all a logical impossibility. However, a certain general clew is given us in the constant coördination of our own nervous system with psychical processes, from which we may infer psychical processes in some manner and degree similar to our own in species whose nervous system greatly resembles our own; the similarity need not be that of ends, however. The decreasing similarity of nervous organization as we descend the animal scale may be supposed to be coördinate with some decrease of psychical similarity. Wherein this increasing dissimilarity consists, however, we have yet to inquire. 
If we return to the act of food-taking in the individual, we perceive that, avoiding any exact assumption as to the definite nature of the act in its first appearance in the infant, we may make the general assertion that, as in the case of the supposed physiologist who finally comes to eat with a direct view to the preservation of health in his offspring as well as his own preservation and health, the act itself, while remaining unchanged in nature, connects itself, in the process of development, with various ends. As the individual becomes conscious of farther and farther reaching and more and more complicated results of the act, he postulates these as ends, not forgetting, however, important ends earlier postulated. He may eat, as a boy, for the pleasure of eating, later with his health and the capacity for useful work in view, and finally to the end also, or perhaps primarily, of securing healthy offspring; but he eats, in all these cases; and it is even supposable that he may eat the same kinds of food, healthful food being, from the beginning, agreeable to him. The widening of knowledge by experience, in the case of the human individual, furnishes him with more distant and more complex ends, which were earlier impossible to him, since he knew nothing of them.

Something similar appears to be the truth in the case of the mental progress of the human species as a whole. The growth of knowledge is, in fact, a growth of consciousness of the constant connection of particular processes with particular results, and of human acts as affecting these; with which increase of knowledge a further coördinate development in the sense of a postulation of further and further and more and more complex ends keeps pace. We are continually making "discoveries," - performing or observing operations some or all of the observed results of which are unforeseen by us, though these very results may be later sought as ends. We are often able to predict the results even of entirely new experiments; but we foresee, and can therefore assume as end, no results the elements of which in their connection with their conditions have not first come, in some way, within our knowledge. Nothing is a discovery which does not involve some new element or new combination of elements. The growth of knowledge, in individual and species, and the increase in distance and complexity of ends never attain completeness, not all results become known; new discoveries are 
constantly being made which show us that we have hitherto been blind to results continually before our eyes, action in accordance with which would have been most advantageous to us.

With all these facts before us, how are we to decide as to the end in view in any non-human act? How can we be sure whether the bird which covers its eggs is acting with a view to the production of offspring or merely, as some authors have assumed, to the more immediate end of cooling its own breast. ${ }^{1}$ How do we know whether any feeling which we might term mother-love is active in the sphex's care for her eggs, whether they are, as some authors have suggested, a part of her own ego and therefore cared for, or whether the act of caring for them has not finally come to have some immediate pleasure connected with it, such as accompanies the satisfaction of hunger or the sexual instinct, the pleasure itself being sought as an end? How do we know even whether the impaled butterfly is endeavoring to escape pain or merely attempting to continue its flight?

There appear to be some general lines that we may draw. Thus, for instance, all facts seem to justify the assumption that the possession of a nervous system involves sensibility and susceptibility to pain and pleasure; and thus it is hardly consistent to suppose that the struggle of the impaled butterfly can be without pain. It might be at times more agreeable to our selfishness to suppose animals insusceptible of pain, but I think we can scarcely lay that flattering unction to our soul, and must face the assumption of their sensibility and feeling. The question as to whether the butterfly has any distinct idea of escape as an end to be striven for is a different one and not so easily solved. Yet as regards conscious ends, too, we may be able to arrive at some general conclusions with respect to the acts of animals, even of those low in the scale. Some such conclusions have already been reached in our considerations. But it is to be noted that all these are purely negative - exclusions not inclusions. We may be able to say, for instance, after careful experiment and observation, that this or that act takes place where there is no possibility of previous knowledge, on the part of the animal performing it, of this or that result (which we may, however, regard as an end that should especially be desired by the animal), and that this particular result cannot, therefore, be an end present to

${ }^{1}$ See, for instance, Eimer: “Entstehung der Arten," p. 283. 
the animal mind, as such, in performing the act. Lubbock believes that the passive state of the caterpillar in its cocoon during its transformation to a butterfly is a necessary condition of its preservation, since the mouth while undergoing change to an organ adapted to sucking, and the digestive organs during their preparation for the assimilation of honey, must be useless, and therefore the animal in an active state must perish of starvation. It is scarcely to be supposed, however, that the insect is aware of these ends of self-preservation involved in the state of passivity in the cocoon and knowingly seeks them as ends. Since the metamorphosis takes place but once in the individual life, the insect has no means of learning anything about it beforehand from his individual experience (though, even if this were not true, there would still remain the first instance of cocoon-spinning to be explained); and it is both difficult to suppose that the caterpillar has always had opportunity to be instructed in some way by butterflies of his kind, as well as unnecessary to suppose this, since we see, in other cases, that acts useful to the individual may take place without previous instruction or experience. In the case of the sphex, too, as in that of many other lower species that provide for offspring they will never see, it is not to be supposed that the welfare of the offspring but rather some result nearer than this is the end in view, if any end be present to consciousness.

With regard to primary acts of instinct such as those of the newly hatched chicken, and the new-born infant, it would seem as if an argument like the following might hold; it is, in fact, often made use of in a somewhat different form. We have seen that not only the progress of the individual but also that of the human species as a whole has involved an ever increasing knowledge of the connection of processes with their results and the coördinate assumption of these increasingly distant and complex results as ends. The ends which animals with a less extensive knowledge of natural processes may postulate, must be nearer and less complex than our own, the ends of those whose experience affords them least extensive knowledge being nearest and simplest, until we arrive thus at those lowest forms of animal life which cannot be supposed to have any knowledge that may be termed such, whose action and reaction, in its psychical aspect, can be figured only as vague sensation. 
But first as to this vague sensation. Among our own acts, in which "blind instinct" seems to play a rather larger part than reason, there are those in which the gratification of the instinct involved is attended with a peculiar pleasure, while the denial of gratification to a sufficient degree is correspondingly painful; these are the acts connected with the gratification of the primary appetites of hunger, thirst, and sex. The strength of the appetites, the degree of emotion involved in them, seems to be directly coördinate with their character as connected with primary functions. This being the case, why may we not suppose the functions of the simplest forms of life, which we believe to have been passed on from generation to generation almost unchanged, for the whole period of time occupied in the evolution of the human race, to be connected with feelings equally as strong as any of our own, or even stronger since function has been exercised on these few lines only? Feeling changes direction with the growth of man's knowledge, with the development of reason; it may be connected with new and more complex processes; but it would be difficult to prove that strength of feeling has increased except as connected with increased exercise of particular functionthat is, it would be difficult to prove that the whole sum of feeling has increased. And if we may assume that it has not increased, then we must suppose as great a degree of feeling to be possible in the lowest animals as in man; and no reason appears why we should not suppose it to exist also in as great a degree in the plants and in the inorganic matter from which both these forms of the organic have sprung. ${ }^{1}$

1 Carneri's instance, cited in support of his theory of the possibility of sensation without pleasure or pain, that certain nerves connected with fine senseperception, may yet be cut without special pain to the owner, is a poor one, first, because highly developed nerves, the media of fine perceptions, are especially inapt examples for citation in support of any theory of primitive sensation in lower organisms, and, second, because the problem of pain and pleasure in such cases is very different from the problem of pain and pleasure in connection with ordinary excitation of nerve endings or the outer covering of the organism from which the nervous system has developed. The fact that, in highly developed organisms, some parts are less susceptible of pleasure and pain might as easily be construed into an argument that corresponding parts of lower organisms differ, in the same manner, in susceptibility. Furthermore, sensation being admitted, as Carneri admits it, or rather asserts it, of all forms of animal life, it is difficult to conceive how he can interpret the phenomena of appetition and repulsion as devoid of feeling. Most authors have argued, 
And we have to notice a second fact: If the ends present to human reason are nearer ones according as the knowledge of the individual performing them is narrower, these nearer ends and the means of their attainment may yet be very clearly and thoroughly known, the narrower knowledge including the minute, often the minutest particulars, as far as it goes; and why may we not suppose the so-called "instinctive" movements of animals very low in the scale of being, which exhibit a most perfect adaptation as far as it reaches, to be connected with a like perfect, if very narrow, action of reason? Or why should we draw a line here between the movements of animals and all other movements?

We are thus brought face to face with a dilemma to which there appears to be no solution. If the solution is impossible, however, why attempt it? In this case, anything we may term solution can be only dogmatic assertion or else mere speculation. If the question is unanswerable, it is unanswerable, and there is no use in further endeavor in this direction. But, in reviewing our arguments, we shall find, I think, that that which led us astray at every turn and induced us to hope for an answer, now on this side, now on that, was the tendency to look for some independent cause, some essence, effecting change rather than being effected, or of which phenomena were only the properties. It was this which made us believe that we had found the means to an answer in reason as the cause of action towards ends, as also, again, that we had found it in the development of the higher organism from the lower, and of the organic from the inorganic. We know no such independent cause, no such essence. We know only variables, preceding conditions and succeeding conditions, all of which preceding and succeeding conditions we must regard as equally essential since they are equally actual; and we know in all variation a certain constancy of relations, which we, by abstraction, term law.

The argument which starts with the dependence of "ends"

with much more reason, that pleasure and pain are primordial. Carneri's further argument that he who conceives the lower species as feeling pleasure and pain introduces an immense amount of pain into the world (p. II3, "Grundlegung der Ethik") is quite aside from the question as to the facts of the case. Nor can man create pain by his conception of its existence, or destroy it, if it exists, by a refusal to acknowledge its existence. 
upon reason, and so infers a necessary intervention of reason where motion is such as to attain results regarded by the onlooker as ends to be desired, is often applied in a still wider form in Theology. Of course if we start with a definition of ends as results actually desired and premeditated, then we may infer reason from the assumed existence of "ends" in any case; but such a form of argument is evidently a gross case of petitio principii; we assume that which is to be proved, - namely, the desire and premeditation of the results attained. 'This fallacy ordinarily escapes the eye through the double significance of the word "end" as it is generally used; in the premises of the argument the use of the word is justifiable if no implications of reason and will are associated with it; but, with such a non-committal definition of the word, the conclusion noticed could never be reached, we should find ourselves at the end of the argument no nearer it than we were at the beginning.

The gradual development of stability from instability, harmony from disharmony, a state where collision is at a minimum from one where it was at a maximum, may be regarded as furnishing the best phase possible of a teleological argument. Even the dissolution of any system is part, according to the theory, of the evolution of some higher system of stability, that is, of one including more elements. This leads us, however, to the question of the definition of "higher"; the friends of theological Teleology are very ready to define the development of life up to man as the development of higher from lower forms, but are they willing to regard a succeeding stage of still greater stability, a state of barren and lifeless rest like that of the moon's surface, which our earth will probably one day attain, as a yet higher stage of development, the destruction of man and of the earth as part of a higher evolution? We have to consider, further, that, unless we assume some final state of absolute stability for the universe, we can suppose only an asymptotic evolution towards it, in which higher and higher systems of stability are developed only to be again destroyed. We know nature only as involving such processes of evolution and dissolution; we know no enduring stability. If we regard merely the side of evolution in these processes, we may seem to have a strong argument for design; but if we give attention to the dissolution succeeding every evolution, the argument loses its force. And, again, if we assume the continual 
order of destruction, reconstruction, and re-destruction finally to give place to a condition of absolute stability, the question may be recurred to whether this state could be one of motion, whether it must not rather be conceived as one of absolute rest, some frozen peace of which the moon's is but an imperfect type. We may ask, then, whether the friends of the teleological argument would agree to designate this state, which is highest from a mathematical point of view since it includes all the elements of the universe, as highest in any point of view favoring a theological theory of design. The teleological argument is accustomed to take into consideration only the evolution side of natural process; the pessimistic argument lays emphasis, on the other hand, on all forms of dissolution, - both views corresponding thus, as a matter of fact, to but half the truth. Even if we do not look beyond the evolution upon the earth, it is evident that each step in advance is marked by wide-spread destruction, each survival of the few bought at the expense of the slaughter of the many. We may overlook the slaughter, but it does not the less exist; we may egoistically shut our eyes to the pain, when it is not our pain, but it is not the less a fact.

But further than this: Our previous investigations have shown us difficulties on every side, when we have attempted to assume reason in matter as the cause of stability or harmony, preservative action, or the survival of the fittest. We may argue that mere matter and motion cannot have produced such results as these; but how do we know this? How have we such an intimate acquaintance with the nature of matter and motion that we can assert this? Where were we at the origin of the universe (if we suppose such) or where were we at the origin of life, that we should be able to be assured of this? Or how do we know in any case, from an origin, what might evolve with time? We obviously cannot argue from the analogy of man's action, since he is a part of the problem itself, included in the question, and such an analogy is a petitio principii. If we have found it impossible to assume reason as cause in his case, how can we, by the analogy of his action and by a universal generalization, assume it as a Universal Cause? We have, in fact, absolutely no precedent from which to argue, and may answer, - when Wallace asserts that combinations of chemical compounds might produce protoplasm, but that no such combinations could produce living or conscious 
protoplasm, ${ }^{1}$ - How do you know that they could not? We have, indeed, no evidence to the contrary: we do not know. If we assume the creation of protoplasm or the creation of the world to have been analogous to any of the phenomena of our experience, in which we find only certain constant results of the forces resident in matter, then certainly we have no precedent for asserting the necessity of divine creation; and if we assume the creation to have been essentially different from any of the phenomena of our experience, then certainly we have no data upon which to base any theory whatever concerning it. But the assumption that the creation of protoplasm, of the earth, or of the universe, was essentially different from any of the processes that we know, is a mere assumption, without basis: we have no data from which to argue in this direction; any hypothesis of such sort is made purely and absolutely a priori. A first appearance of protoplasm upon the earth we must infer from the facts furnished us by Geology and Astronomy; but a creation of either matter or motion is a mere assumption. As we know matter, it can neither be created nor destroyed. We cannot draw any inference from man's will, for man creates nothing; his action is itself a part of nature. Advanced theological doctrine tends more and more to limit the creation to the first communication of motion to matter or to assume sorne transcendental government of the universe, known, according to the assumption, transcendentally, or inferred from the existence of moral tendency or from desire for the transcendental in man. With Transcendentalism we have, as yet, nothing to do; and with moral principle in its bearings on this matter we cannot deal until later. But as for the hypothesis of a first communication of motion to "dead" matter, we may remark, as before, that this is a mere hypothesis with no facts to support it. We know nothing of motion apart from matter, or of matter except through motion; the two cannot be separated in fact, and there is no reason for their separation in hypothesis or theory. Du Prel says: "Whether causeless motion is scientifically conceivable, depends on whether we have to regard rest or motion as the natural condition of matter; for a motion that is not primary must, as newly appearing change, be preceded by a cause. But though experience might incline us to regard rest as the original condition of matter, and therefore to seek a cause for every 
motion, this is, nevertheless, only the result of an incomplete induction. For if it is true that we never see a motionless body pass into a state of motion without a cause, on the other hand, it is just as certain that a moving body can never pass into a state of rest without cause; and if this axiom can never be directly proved in processes on the earth, we can, nevertheless, show reason for it: motion on the earth cannot be imagined without resistance from obstacles, since the attraction of the earth and the moments of friction can never be removed. But the axiom is indeed indirectly proved by the fact that we see the velocity of a body decrease in proportion to the resistance of obstacles; the body can only then attain to a condition of rest when the moving force is consumed to the last remnant. Hence, if we subtract the whole sum of resistance to the motion, we have again the former condition, the motion with its original velocity... Which condition of matter is the original one, rest or motion, experience cannot inform us. We have as good reason for regarding rest as arrested motion, as for regarding motion as disturbed rest. The requirement of an outer cause for the first impulsion of matter therefore has meaning only in so far as rest is claimed to be the original, natural condition of matter; but this claim cannot be substantiated, and the opposite is just as conceivable, namely, that rest is only arrested motion, and that all cosmic matter had motion from the beginning." 1

Wallace practically abandons his own ground, not only in his later works in ascribing much to natural selection which he was at first inclined to believe the effect of some supernatural cause, and omitting from his chapters on the application of the conception of evolution to man several arguments for supernatural intercession employed in his earlier work, but even in his first book, by admitting that natural selection takes advantage of mental superiority just as it does of physical superiority. We may notice at this point, however, a consistent inconsistency of his, in that, though he denies the existence of consciousness in matter, he leaves no logical room for the opposite theory of a gradual development of consciousness, since he asserts that all instinctive actions were at first self-conscious. This position is held by others also.

We may note here an objection of Wallace's that "because 1 “Die Entwicklungsgeschichte des Weltalls, p. 350 et seq. 
man's physical structure has been developed from an animal form by natural selection, it does not necessarily follow that his mental nature, even though developed pari passu with it, has been developed by the same causes only." The question may be again repeated as to what is meant by cause; and it will be well to keep distinct, in our thought, transcendental cause and cosmic conditions. We must admit that we have no proof of the absence of transcendental causes. Neither the constancy of nature nor the inseparability and indestructibility of matter and motion can prove the absence of such causes, which might be entirely consistent with these things; we have no data from which to argue that they are not so.

But though the law of Excluded Middle must hold good here as elsewhere, it is also to be noticed that the absence of proof in the natural order of things, with respect to the non-existence of transcendental causes, is not equivalent to the presence of proof of the opposite. We cannot infer, from the fact that no proof can be given of the non-existence of transcendental causes, that therefore proof can be given of the existence of such causes; or, from the fact that transcendental causes may be, that therefore transcendental causes are; they may also not be. There is, in fact, absence of proof for either view. Of the transcendental, if it exists, we can know by definition absolutely nothing. The man who endeavors to prove its existence generally bases his argument on this very fact in order to disprove the validity of any argument of his opponent from natural facts; when he, therefore, after legitimately silencing his opponent, goes on himself to prove the transcendental, he is guilty of self-contradiction. When Fiske asserts that there is no problem "in the simplest and most exact departments of science which does not speedily lead us to a transcendental problem that we can neither solve nor elude," 1 we may admit the point, but surely it does not follow, because we cannot solve it, that therefore we must solve it, far less that we must solve it in one particular way. If we cannot solve it, we cannot solve it, and there is an end to the matter, unless we find new proof. We may not be able, as Fiske says, to elude the problem, but we certainly are able to elude the answering of it, and must do so perforce if the first part of the assertion,namely, that we cannot answer it, - be correct. When Fiske urges

1 See Part I. p. 8 . 
us to accept one view because "the alternative view contains difficulties at least as great," we fail to perceive any grounds in this position for such acceptance. To Fiske's question as to whether we are to regard the work of the Creator as like that of the child, who builds houses just for the pleasure of knocking them down again, we may answer that the existence of a Creator must first be proved before we, from a scientific basis, may make any inference as to his purpose; and that we certainly cannot use an assumption of his existence in order to protest against a theory of Disteleology, - as Fiske seems to do,- if we use the teleological argument to prove his existence.

We may furthermore protest against the elevation of any negative term, as, for instance, Spencer's "Unknowable," to a term signifying a positive existence. We do not know whether there is any positive Transcendental that is to us unknowable; this mere negative term is admissible only on the assumption that it expresses such an absence of knowledge. The Unknowable assumed as existent entity is the Unknowable known,-a selfcontradiction.

A similar criticism may be applied to Spencer's use in his "First Principles" of the word "Force," spelled with a capital, and defined as designating "Absolute Force," an "Absolute, Unconditioned Reality," "Unconditioned Cause," 1 etc. The attribution of reality to a mere mental abstraction is a survival of old conceptions repudiated by Spencer in their older form. Of forces we know much, but of abstract Force nothing, - except as an abstraction from reality; and the dangers in the use of such a term are made manifest by Spencer's elevation of this concept to the character assigned it by the other terms quoted.

To sum up. We have found in nature only variables, no constant and invariable factor, no independent one according to which the others vary; we have found no cause that was not also an effect; that is, we have discovered nothing but a chain of phenomena bearing constant relations to each other, no causes except in this sense. We have no precedent or data from which to assert that chemical combinations could not have resulted in protoplasm and in living protoplasm, no data from which to assert that mere evolution could not have produced consciousness. As a matter of fact, however, we find the relations of conscious-

1 Pp. 170, 192d. 
ness and physiological process as constant as those of the different forms of material force, and while discovering no grounds upon which to pronounce either consciousness or physiological process the more essential, find none, either, for pronouncing one more than the other independent of what we call natural law. The logic of all our experience leads us to believe that neither protoplasm, nor the earth, nor any of the parts of the universe, could have originated otherwise than under natural law, that is, as the result of preceding natural conditions which must have contained all the factors united in the result, and would thus explain to us, if we knew them, in as far as any process is explained by analysis, the results arising from them. We know matter and motion only as united; we know no state of absolute rest, and we have no grounds for supposing any initial state of such absolute rest, or any state in which motion not previously existent in the universe entered. On the other hand, we have no proof of the absence of consciousness outside animal life, and no proof of the non-existence of transcendental causes, though likewise no proof of their existence. 


\section{CHAPTER III}

THE WILL

IN any discussion of the will, we are met at the outset by the difficulties of definition, on which whole chapters might be, and have been, written. But one great difficulty has already been considered in the discussions of the previous chapter, in the questions as to the existence of consciousness in inorganic nature, in organisms which differ from our own in not possessing a centralized nervous system, and in connection with actions of our own body known to our centralized consciousness only as results. Leaving these questions open, as we have found it necessary to do, and confining ourselves, in speaking of consciousness, to consciousness as we immediately know it, or as we may, with some degree of probability, infer it in animals constituted similarly to ourselves, we find one obstacle to our definition removed. For by will is generally meant a psychical faculty; and to speak of "unconscious will" is either a self-contradiction or a mere figure of speech.

We shall also find, I think, that the most essential characteristic of the will as a psychical faculty is that it is connected with action which has in view some end consciously sought; action to which there corresponds no conscious end, whether a long premeditated end or an end instantaneously comprehended and assumed in the moment of need, we term reflex. The question may arise as to whether there are not acts which we name merely "involuntary," which must be classified, from a pyschological standpoint, as midway between the voluntary and the reflex. But it may be answered that here, as everywhere in connection with the organic, there is difficulty in drawing distinct lines; there are psychical conditions in which some strong emotion, for instance, terror, so takes possession of the mind as almost to exclude plan of action, and the individual appears to act, as we say, "unconsciously"; but I think this very adverb solves, for us, to all prac- 
tical purposes, the question we have put. When we analyze such psychical conditions, we often find that, besides emotion, there was some degree of preconception of action, though the emotion so absorbed our attention at the time that the other appeared subordinate and was easily forgotten; but the fact that we term action of this sort, where we fail to discover preconception, "unconsciously" performed, would go to confirm the definition with which we began, though we may have difficulty in deciding whether or not a particular action comes under the head of willed action, that is, action to a preconceived end.

Another question which has been frequently asked, in analyses of the will, is whether mere abstinence from action, the negation of action, can be classed as an instance of willing, willing being, by definition, an active, not a passive state. It may be answered that, from the physiological point of view, a point of view not to be wholly disregarded even by the conservative psychologist, the arresting action of the will as the control of lower by higher centres, is its most important function. And to this physiological fact corresponds the psychological fact that no stronger exertion of will-power is known to us than that sometimes necessary to the attainment of mere passivity. A definition that would exclude such passive states from the province of the will must exclude, on the same principle, all other willing not issuing in muscular action, and so all voluntary control of thought. The choice between activity and passivity may be as real and as difficult as between two different forms of activity.

We have here introduced the concept of choice, and it may be well to define this, and its significance in our definition of will, more exactly. Voluntary action is, we say, often preceded by long deliberation and severe struggle, ending finally in the choice of one of the many modes of action deliberated. We can conceive of this struggle as not so long, as shorter and shorter, until it occupies so little time and attention as to be scarcely perceptible. But we can conceive, also, of a premeditation which includes no struggle, in which one motive appears so strong as to exclude consideration of any but the one end, and the deliberation has reference only to the best means of attaining that end. The murderer, inspired by a desire for revenge, may seek his end with the same directness, if not the same instantaneousness, or with the same directness and instantaneousness, as the dog 
who snaps at a piece of meat; yet we call his action voluntary, whatever we may think of the dog's action, our conception of which may be rendered indistinct by our uncertainty as to the nature of instinct and the part it plays in the action of other species. We call the action of the murderer voluntary because we conceive that he consciously sought the end involved. We are even inclined to call it voluntary in cases where the criminal is moved by momentary passion, since we conceive that he might have exerted self-control.

Our conception of will is, therefore, closely bound up with the conception of conscious end, distant or near. Our association of choice with the act is not always exact; we may conceive of the choice as actually taking place between one of several ends deliberated upon, or as involved in the conscious determination of any end, even though no other was deliberated upon, even though all others were excluded from consciousness by passion; since we conceive that as all definition is, in fact, exclusion, so the determination of one end is in effect the negation of others that might have been sought, if only in the form of the contrary of action, inaction.

We are thus brought, first of all, to a consideration of the meaning of the term "end." As we have seen in the last chapter, an end is that part of the results of an action which consciousness especially holds in view in the performance of an act. The end in view has sometimes been called the cause of the act, but it is evident, as both Gizycki and Stephen have shown, that a future state, that is, something which at the time of willing does not exist, cannot move the will; though the representation of a hopedfor end is concerned in action, - in just what capacity we have yet to determine. It has also been urged that nothing external can act upon the will, but only internal states of consciousness. All depends, here, upon the definition of external and internal. The distinction between the two is a legitimate one where it calls attention to the difference between that which is at present perceived and that which is only remembered, or imagined from the elements given by memory. But what is an object, as present to me, beyond what it is to my consciousness? My knowledge of a thing is made up of various elements contributed through the different senses; and this assertion is exactly the same as the statement that a thing is the sum of its qualities. My idea of 
the fire, the lamp, or any other object as external, arises from the fact that it appeals to more of my senses than one, that, if withdrawn from one or from all but one, it may still be perceived by the other or others, or that, if withdrawn from all of them for a time by some obstacle, it may be perceived again when this obstacle is removed; but beyond perception or memory of perception, in any case, I have no consciousness of the object. The perception is not, however, something distinct from consciousness, but is consciousness. The error above noticed arises from the conception of consciousness as a sort of place, another space into which we cannot get objects from external space; the conception is a crude one, yet it often enters into psychological speculation. The perceived, that is the external, does, as a matter of fact, affect our will.

There may thus be two definitions of the term "internal" and two of "external," as the words are generally used. Internal may mean either within the body or within consciousness, external may mean external to the body or external to consciousness. The two meanings are, in both cases, commonly confused, - that is, consciousness is looked upon, as has been said, as a sort of internal space within the body to which external things cannot get admission. "External to consciousness" should refer simply to that which the individual or individuals considered do not perceive, of which they are unconscious. That of which we are conscious is in consciousness. But all manner of ingenious jugglery is played with the help of the metaphysical dualism implied in the other definition of the terms. The objection of a possibility of this duality of meaning applies to Barratt's use of the term "external" at the opening of his book on Ethics, and the objection of a possibility of a similar duality applies to many other expressions in the propositions and definitions with which he begins, - to such expressions, for instance, as "relative to our faculties," "state of consciousness," etc. ${ }^{1}$ Objection may also be taken to such quantification of the predicate as is found in Cor. I of Prop. I.

To return to the question of the will. The thought-image, memory or perception, with its associations, has been termed the excitation or the motive and said to move or determine the will to some end. Thus the perception of the burning house is 
said to be that which leads me to give an alarm, or the perception of the smoking lamp that which moves me to turn it down. To this form of statement is often objected that mere thought or perception can never move the will, but that feeling is required to do this. A further discussion may arise as to whether it is feeling in the form of pleasure or of pain which moves the will. Many authors regard anticipated pleasure as a constant motive; Rolph, on the contrary, as we have seen, inclines to the view that it is always some present pain by which we are moved to action. And it is argued that, since the direction of the will is determined by pleasure or by pain, that is by motives, the will is not free.

Again, the physiologist calls attention to the fact that the so-called free action of the will has for its basis physiological processes, all of which are in accordance with the strict uniformity of nature, all subject to law, and all, as we must believe, capable of exact prediction from the conditions which produce them, if we but comprehended these conditions. There is no gap in these processes where free will might interpose; the whole thought-process, the deliberation preceding decision, the moral struggle if there is one, the decision itself, and its realization in action, have for their foundation physiological function, which is as much determined by necessity as any of the processes in inorganic nature. 'The results of past experience, not of the experience of the individual only but of that of the whole species inherited as inborn tendency and capacity and modified by individual circumstances, are stored up in the organism, the point of centralization being the brain; any single excitation sets this whole complicated machinery in motion and the result is the act. The individual, not understanding this complicated process of reaction, not being able to trace the results of experience to their source, to descend the whole scale of being to the beginnings of life and note the gradual development of tendency, and seeing the inadequacy of the excitation in itself to account for the action following, attributes to this a peculiar character, regarding that which is really result as absolute beginning, independent cause.

We may consider the matter from still another point of view. We may inquire whether the freedom predicated of the human will is predicated of that alone, or of will in the whole range of 
animal life. And if it be predicated of the human will alone, we may ask at just what point of the evolution this is supposed to arise, whether, in the gradual development, any particular point can be found or assumed to exist, of which we can say: Here the animal ceases and man begins. Or if freedom is asserted of the whole range of animal will, not, however, of plant movement or the motions of the inorganic, we may again inquire as to the point of exact division between the animal and the plant. Evolution is, by definition, a gradual process, a growth in which there are no gaps, and of which our finest and most minute calculations by infinitesimals can give us only a faint conception. Where is there any point of such a process at which we can suppose the entrance of a totally new principle that cannot be regarded as another expression of force or merely a new form of animal function, but as directly opposed to developed function and to the force that is subject to natural law?

The Evolutionist may state the problem in still a new form, as follows: The survival of any organism at a given period is determined by the fitness of that organism for the conditions of the environment at that period. The form and function of the animal are thus, at each moment, determined by the environment. And since only functions in harmony with the environment render the organism capable of survival under that environment, the functions of surviving organisms are in a direction favorable to the preservation of the form of which they are the functions. Since, moreover, self-preservation in some form, whether as preservation of the whole organism or as preservation of a part through satisfaction of its function (rendered possible only through harmony between the function and the environment), always constitutes the end sought by the will, the individual appears to himself to will ends, whereas these are all determined for him by the survival of the fittest, whose function he inherits and carries out subject only to the modification of the peculiar elements of his own environment. If we suppose, at any point of development, an action not in accord with that which the laws of nature necessitate decided upon by the will, such an action cannot be carried out. But even a decision is impossible contrary to natural law, since in preceding evolution there has been no point at which nature has not in like manner determined action, and the present decision, being the expression of function attained as the result 
of evolution, must be as much determined as the action which follows.

Or if we return to our conception of the development of stable from unstable conditions, we may consider all evolution of higher function as increased adaptation, that is, as harmony with an ever wider circle of nature, the reason appearing as corresponding concomitant knowledge of this widening circle, to which the function of the organism is adjusted. The reflection preceding decision on an end consists in the imagination, by aid of the memory of past experience, of some of the constant results of particular function, to which function, however, the organism is irresistibly moved. Thus that which is generally regarded as the greatest independence of nature is, in reality, the greatest subjection to nature considered as a whole, although this wider subjection means an increasing independence of the mere excitation of the moment. The ability to weigh all sides of a question, sometimes termed Freedom, is rather the widest adaptation, which means the widest determination by nature. The lower organisms may be, as Rolph and Alexander assert, as well adapted to their particular environment as the higher; but the higher are adapted to a wider environment, to more of the variations of the conditions on the earth's surface. Man is the most widely adapted of all animals. This is a fact which we express when we say that man's power of adaptation is greatest, - that is, that there are latent tendencies in him, the result of former adaptations, which may correspond sufficiently to new environment, i.e. to environment involving many new elements, to enable him to survive. This wider adaptation expresses itself especially in the higher development of the nervous centres, to which man's higher reason corresponds; it is through the reason especially that his adaptiveness comes to light.

The statistician often has considerable to say against a doctrine of freedom of the will. He calls attention to the necessary character of human action as evidenced by its uniformities under uniform circumstances, in the various important relations of life. These uniformities are not less than those which statistics reveal in disease and death and other events classed as not under the control of the will.

And to all this evidence we may add that of the history of the mental life of the species, derived from the combined labors of 
the geologist, the ethnologist, the philologist, and the historian. Everything goes to prove an evolution in the mental life of man, as gradual, and as much subject to the influence of the environment, as his physical evolution has been. Carneri says, "The eternal laws of mind point out the way upon which man has to proceed; it is the same way by which man has become man, and by which mankind must go forward even if it does not will thus to proceed." 1

And again, the authorities on mental disease demonstrate the constant relations, not only of general health of brain to health of mind, and of disease of brain to mental unsoundness, but also of particular physical symptoms to particular mental symptoms. This constancy of relations is revealed with more certainty and distinctness by every step in the progress of medical knowledge. The specialist in mental disease inquires with reason how we can acknowledge the physical processes of the body to be governed by natural law, yet assert the emancipation from law of the psychical processes which vary concomitantly with these in a manner that science shows to be perfectly constant. To the testimony of Psychiatry may be added that of the comparatively new science of Criminology.

And, finally, Evolutional Ethics demonstrates the constancy of character, the persistence of habit, and the uniformity of its change under the influence of environment. If there is no persistence of character and uniformity in its action, we have no reason, as various authors have shown, for trust or distrust, for praise or blame; and, I think we may add, none for love or dislike, reverence or contempt, enthusiasm or coldness, in the contemplation of character or conduct. If the fact that a man acts honorably, kindly, nobly, in one instance is not a warranty that we may with reason expect him to act similarly again under similar circumstances, allowance being made for error in our interpretation of motive (which may have been merely selfinterested where we thought it disinterested) and for changes produced in character by the environment between the first act and the opportunity of the second, then character is merely a jumbled chaos of chance, and the name "habit" a contradiction in terms. We may, perhaps, respect the single act, but we have

1 "Sittlichkeit und Darwinismus," p. 363 . See also, however, the "Grundlegung der Ethik," p. 289. 
no reason for respecting the individual performing it, since the "individual" cannot be regarded as coextensive with a single act of his life, and least of all when the act gives no clew to a permanent basis issuing in uniform action of which law can be predicated. In this case, the noble deed, or any number of noble deeds, afford us no security that the next act of the person performing them, or all the rest of the acts of his life, may not be wholly ignoble, base, and vile.

In the face of all the considerations thus offered us, we cannot well find reason for accrediting the will with a peculiar position in the universe, as emancipated from the natural law which we Idiscover in all other phenomena. But it behooves us, in this connection, to inquire as to just what is the significance of the term "natural law." It has already been implicitly defined in our previous considerations. Lewes and several other modern philosophical writers have given excellent definitions of the expression. Lewes writes as follows: "Law is only one of two conceptions, ( I) a notation of the process observed in phenomena, which process we mentally detach and generalize by extending it to all similar phenomena; (2) an abstract Type, which, though originally constructed from the observed Process, does nevertheless depart from what is really observed, and substitutes an Ideal Process, constructing what zould be the course of the process were the conditions different from those actually present. The first conception is so far real that it expresses the observed series of positions. It is the process of phenomena, not an agent apart from them, not an agency determining them, but simply the ideal summation of their fositions. . . . Phenomena, in so far as they are ruled, regulated, determined in this direction rather than in that, and necessarily determined in the direction taken, ... are determined by no external agent corresponding to Law, but by their coöperant factors internal and external; alter one of these factors and the product will be differently determined. It is owing to the very general misconception of the nature of Law, that there arises the misconception of Necessity; the fact that events arrive irresistibly when their conditions are present is confounded with the conception that the events must arrive whether the conditions be present or not, being fatally predetermined. Necessity simply says that whatever is, is, and will vary with varying conditions." 1 Neither Natural Law nor Necessity

1 "Problems of Life and Mind," Ser. I. Vol. I. pp. 308, 309. 
is an entity extraneous to phenomena which governs or compels them; the two are generalizations merely by which we express a certain uniformity that we find universal.

Let us return to our analysis of the organic as matter and of function as its motion. Go as far as we like in our analysis, and we still have left positive entities of matter and force, or matter, motion, and the equivalent of motion in resistance; moreover, we cannot suppose either matter or force to decrease by our analysis. Here, therefore, we have indestructible entities, and these, not Law and Necessity, are the positive factors. But if the final divisions of matter leave us still positive factors, then the combinations of these must be positive also; not only the theoretical atoms of the chemist, or the organic cells with their motions and functions, but the combinations of these in organisms, must be positive.

It is said that the organism answers to its environment "as the clay to the mould"; that it is formed by the environment and adjusted to it. Here we may inquire whether the adjustment referred to is present adjustment or that of the whole development of the organism. If present action of the environment is all that is had in view, it may be objected that not anything in the environment, and not the whole environment, is more positive than the organism. The one of the two factors cannot be regarded as positive, the other as merely negative, the environment as the active and formative, the organism as the passive and formed, the environment as determining, the organism as determined.

But we may also consider the organism in the process of development. In this case, we seem to find reason for regarding it as purely the product of the environment in which it has arisen. The product it certainly is in one sense; that is, it is the endform of a series of changes which we may suppose originally inorganic matter, or (if we prefer to begin with the lowest form of life) simplest forms of organic matter, to have undergone. But the present forms of matter everywhere are, in like manner, the products of the past changes of matter; if we trace these changes which have produced present forms, in the case of the inorganic as well as that of the organic, back to any point of time which we may choose as a beginning, we shall find in neither case more matter or a greater amount of force than at the present 
period; we shall find the same matter in different combinations, the same force in other forms. Present forms are not greater or less than past ones, but their exact equivalents; the beginning was not greater than the end; the producing forms and forces were not greater than are their products. By a backward course of thought comprehending evolution we may bring unity into our conception of the organic, but we find no new factors of force, and need to avoid laying stress upon the process to the depreciation of the importance of the product. We may be led to suspect that our search after new and more important factors was only another form of the search after an independent cause according to which all other phenomena may be said to vary. Our mathematical habit of selecting some one side of natural process as independent, in order to trace, by its variation, the variation of the others, leads us to regard the one side, phase, or portion, of phenomena as actually thus independent; although we forget, in this assumption, that we may select any phase for our mathematical independent, and are not confined to any particular one. The organism is itself a part of the environment regarded as conditioning, when we consider the development of other organisms, or change in inorganic matter, with which it is in contact. Our minds are unable to comprehend the whole of nature as variation only, and we fasten on some one part of the process as independent of the general change or as holding a unique position in it, from which to consider the variation of the rest. And the conception of some one part of phenomena as cause disappointing us, on closer investigation, as far as merely present phenomena are concerned, we remove the conception farther back into a dim past which we fail to analyze in thought with the same completeness with which we analyze the present. We are not, however, in the habit of tracing back any other than just the organic forms to an arbitrary point which we call the beginning, and emphasizing this in distinction from present conditions; in considering the inorganic, we simply notice present conditions and mark the result of action and reaction between this and that other form of matter with which it comes in contact.

The action of the animal at any moment may be said to be determined by the tendency or potential energy inherent in it at the moment, and the influence exerted by a particular excitation; this is a matter of action and reaction; but the force represented 
by both sides, by that of organism and by that of environment, is equally positive and equally represented again in the result. Particular emphasis has been laid, now on the positive activity of the organism by one school of writers, now on the activity of the environment as moving the organism to action by another school; but both sides contribute to the result. Where action and reaction in inorganic matter are considered, we do not regard either of two incident forces as alone positive; nor do we regard one as overcome by the other in the sense that it is not fully represented in the result.

Again, if we return to the dispute as to the importance of the physiological "basis" of action, the remark may be repeated, that it is mere dogmatism to select some one phase of phenomena as the only essential phase, while all other phases are regarded as non-essential or subordinate. The materialist who derides the idea of a "Ding-an-sich" is himself assuming something very like it, when he endeavors to prove matter to be the cause, essence, or independent, of which consciousness is the mere effect, property, or dependent.

Even if it could be said with truth that the brain secretes thought as the liver secretes bile (and the analogy does not hold), it should be borne in mind that the bile is no mere dependent creation of the liver, but that, before it became bile, it existed in another form, was, in fact, a part of the liver of which it is regarded as the dependent creation. Matter and force have simply changed form; that is all. The later form is not rendered secondary in importance or less positive by-the fact of its sequence upon the other form. The conditions equal the result; they are not greater than it. Where is there, on closer analysis, passivity as distinguished from activity? All force is, by definition, active; and all matter represents force. We find simple equivalence, that is, a uniformity of relation between preceding conditions and succeeding conditions. Our "Natural Law" and "Necessity" resolve themselves into this. Yet the conception of law as something extraneous to things, something without them not included in their primary nature but controlling them, is a very common conception. Thus Du Prel, though rejecting other forms of teleological argument, bases a whole course of teleological reasoning upon the mere fact of law. ${ }^{1}$ However, we

1 “Die Entwicklungsgeschichte des Weltalls," pp. 352 et seq. 
know of natural law merely as an expression of uniformities, a generalization from the relations of things; we have no reason for treating it as extraneous to the nature of things themselves; and nature itself furnishes us with no reason for supposing the relations of things to be of more significance than things themselves; relations are not entities.

If man be part of nature, it is strange that the force within him should be regarded as so shaped and compelled, the force without him, on the other hand, as so compelling and mighty. No part of nature is, as a matter of fact, compelled. All things act and react spontaneously from their own nature, and man in the same manner acts from his. Law cannot be defined as determining action and reaction, nor can Necessity; they are not entities. Force is sometimes called the determining factor, but an abstract Force we do not know; we know force only as motion or the equivalent of motion in resistance, or as the conceived potentiality of motion. The concept of potentiality of motion is, however, again only a device of reason for bringing unity into our conception of things by accounting for the appearance of motion where before it was not. Potentiality is no existence, no reality; actual potentiality is a contradiction in terms. Nature contains only actualities. Force is the abstract term by which we include motion, resistance, and the conceived potentiality of motion, under one head. Motion again is often defined as the cause of movement; but such a conception makes the abstract notion of a thing the cause of the thing itself, unless by motion as the cause we understand the preceding motion, and by movement as the effect we mean the succeeding motion, in which case we have to bear in mind the equivalence of conditions and results. Nor do we know motion as something apart from matter, moving it; we know no abstract motion; we know only things as moving, changing, and resisting motion. There is no outside cause given us in our experience as the mover, from which things are to be distinguished as the passive moved. Things move. And in correspondence with the activity of things is doubtless the sense of freedom in the exertion of the will. Outer compulsion, resistance to the carrying out of a course decided upon or desired, has sometimes been interpreted as the negation of freedom of the will; but it has with reason been objected to this definition that the very strongest sense of inner freedom may exist in connection 
with such compulsion. It may be supposed that, as long as there is action in the brain, the corresponding sense of freedom will exist; or, lest this statement be interpreted as materialistic, we may say instead: As long as consciousness exists, it must by definition exist as activity, with which the sense of freedom is indissolubly connected.

But we may look at the matter from the more purely psychological side. The opponents of a theory of freedom make much of the determination of the will by motives. In their argument, the will is treated as if it were some separate material thing, the motive another equally separate thing which, when brought into contact with the will, sets it in motion in somewhat the same manner as the powder in the gun drives the ball. But the motive is not something external to consciousness, something foreign, that, introduced, impels the will to action; nor can the will be compared to an organ of the body, the motion of which is given us through our senses as the motion of a part, not of the whole body. The functions of the body are, in this sense, a part of the material world to us. But the will is no material thing, no separate organ of consciousness in this sense. In the will, consciousness expresses itself; and we cannot say that it is only a part of consciousness that thus expresses itself. The motive, as conscious, belongs to that consciousness which finds expression in the will.

A similar form of theory to that just noticed regards the will as determined especially by feeling. But feeling belongs as evidently to consciousness as does will, nor can we say that one part of consciousness feels and another wills, the one part being the active mover, the other the passive moved; the division into parts is a material one applicable to things occupying space, but not to consciousness. The notion here of mover and moved is very similar to that noticed above, of motion as cause, movement as effect.

It is sometimes said that the desirability of an object moves or determines the will. Here arises the question as to whether the desirability of an object lies in the object or is only dependent upon consciousness as a quality of feeling. Thus we come, by closer analysis, to the fundamental problem of the connection of consciousness with the external world. It is often said that desirability is a mere predication of consciousness and does not 
lie in the object or end itself. That desirability is a predication of consciousness is true in a sense. And yet it is evident that this predication corresponds to actualities existing in the thing or end, on account of which it is pronounced desirable or, under proper conditions, desired. When we analyze the state of consciousness itself, we find it impossible to separate the desirability as predicated by consciousness and the desirability as predicated of the end, the excited feeling and the feeling as excited by the object. From one point of view, excitation and consciousness are the two sides of the conditions, both of which are essential to the result; but, from another point of view, it is equally true that the desire of the end is always a part of consciousness, which expresses itself in the will according to its own inherent nature.

The act of the will, as following excitation, is sometimes treated as its mere result, hence subject to it, subordinate and passive; on this principle, we could also define brain-action as subject to nerve-action and passive in comparison, wherever it follows. The mere conception of the conservation of force would make it impossible to suppose a result of force to be less than preceding force of which it is the result. We do not call the evolution of organic life on the earth subject or subordinate to the motion of the nebular mists, or passive with respect to them. The mere sequence of one event upon another in time does not justify our pronouncing the one subordinate to the other or passive with respect to it, the whole sum of matter and force remaining always the same, and a resultant in any particular instance exactly representing its factors.

From our examination of the above arguments, we perceive that the materialist uses both the concomitance of consciousness with material processes, and, again, the sequence of particular conscious states upon material processes, as proof of the subordination and passivity or dependence of consciousness, as proof that the latter is effect of the material as cause; indeed, we are not at all sure that he does not often confuse the two arguments from sequence and from concomitance. On the other hand, the argument of sequence is often used to prove the greater importance and activity of consciousness in contrast to matter, consciousness being regarded as antecedent to excitation in general or to some particular excitation. But consciousness is not the "prius" of its excitation in time, since its very definition includes 
activity and this is not possible without excitation; consciousness is always the consciousness of something. To regard consciousness as the "logical prius" of matter or of excitation by matter may be possible, but the standpoint is either a purely fanciful or a purely dogmatic one. With regard to its priority in respect to a particular excitation, the remarks made above hold good, that mere sequence does not prove subordination or passivity as distinguished from activity. The fact of concomitance is also sometimes treated as a part of theories of the causal nature of consciousness, the brain being regarded as the mere organ of mind, the passive instrument upon which it acts. In this case, however, as in the opposite argument that consciousness is dependent upon brain-action, there is probably some indistinct idea of sequence at work. The argument applies equally well, indeed, in either direction, the materialistic or its opposite, and merely this fact would lead us to suspect that it can be conclusive in neither.

Thus, in hunting for some cause and effect in the activity of the will, we bring to light, in the end, only a certain concomitance and sequence. That which we call "explanation" of natural process is, in fact, in all cases, merely a finer analysis of concomitance or sequence, or the analysis of some new phase of it. We have only the finer elements of the process analyzed before us in any case, although we are often inclined to treat these elements as if they were the essence and cause of the process to which they belong. We explain, for instance, the green color of the leaf by the continually renewed presence of a certain chemical combination; yet the green color is not less real and essential than the chemical composition which constantly accompanies it. The musical note is not the less real to our ear because we can make the vibrations of the string and the air perceptible to our eye, or because we can observe to some extent, and infer further, vibrations of parts of the ear that are the physiological accompaniment of the note heard. The light of the fire is not the less real because of the heat that I feel from it, nor is either less actual because I can analyze the process of combustion in the case. The shape of the leaf to my touch does not make its greenness of color the less real to my eye, nor does change of form prevent change of color or prove it less essential in any case. The smell of the rose does not render its color less real 
and essential, and, vice versa, the color does not render the smell less an essential part of reality. Neither does the activity of the brain render the activity of consciousness less real, or interfere with its freedom, any more than the activity of the consciousness renders that of the brain less actual or interferes with its free action and reaction. My knowledge of a thing given me through one sense is totally different from the knowledge of it given me through other senses; yet I do not find this various knowledge contradictory or irreconcilable. Why, then, do I find such great difficulty in reconciling the simple facts of consciousness and brain-activity? And why should there be such an inclination to give greater prominence to physiological process than to mental process, to regard the only method of reconciling the two that of proclaiming the dependence of consciousness?

The solution of the question is not so difficult to find. In the first place, our knowledge of the concomitance of brain-process and consciousness, or at least of the constant uniformity of this concomitance, is only comparatively recent. Further, this knowledge is not given us immediately, but is the conclusion of a process of reasoning. While such concomitance as we immediately perceive - the concomitance of certain impressions on one sense with certain other impressions upon other senses - appears to us so natural as to need no comment, the newness and mediate nature of our knowledge of this other concomitance incline us to regard it as strange and needing some especial "explanation." While the concomitant impressions upon the senses, wherever they are constant, become united in our conception to a single whole, we fail to unite the elements of this mediately known concomitance to such a whole; doubtless, however, if a perception of all the details of our own brain-activity were the invariable accompaniment of thought, we should thus unite them. We can no more "explain" why the two activities are concomitant, except as we show it to be a fact and analyze it into its elements, than we can show why just Prussian blue should be the characteristic of one chemical compound and the green of plant-life of another, why the connection of the colors should not be the reverse. The importance we accord the physiological accompaniments of mental process is partly accounted for by the significance which attaches to more recent knowledge as constituting scientific progress; in the effort to bring together in our 
conception the two elements of consciousness and brain-action, to whose association we are not accustomed by immediate perception, we are led to lay especial weight upon the facts of recent discovery, which are connected with so great advance in science and have done away with so many superstitions. And, finally, in the rebound from the old superstitions, the tendency is to exaggerated views in the opposite direction. The attempt to correct spiritualistic ideas of a soul superior to the rest of nature and no part of it has resulted in materialism. And by the physiological basis we now think to "explain" the facts of psychology. "Notable enough," says Carlyle, "wilt thou find the potency of Names; Witchcraft, and all manner of Spectre-work and Demonology, we have now named Madness, and Diseases of the Nerves. Seldom reflecting that still the new question comes upon us: What is Madness, what are Nerves? Ever, as before, does Madness remain a mysterious-terrific, altogether infernal boiling-up of the Nether Chaotic Deep, through this fair-painted Vision of Creation, which swims thereon, which we name the Real. Was Luther's Picture of the Devil less a Reality, whether it were formed within the bodily eye or without it?"

If the connection of physiological and psychological processes requires "explanation," beyond that of analysis, why should we not feel ourselves equally required to explain, in like manner, the connection of light with heat and sound, and form with color? Why is it more comprehensible that the ball can be at the same time round to my touch and red or gray to my eye, and that the rose can both smell sweet and be yellow in tint? Why should we, in this particular instance, make such a strenuous effort to find reasons which can never be given in this case any more than in the others, and which we do not, moreover, demand in the others? Why cannot we accept the simple fact of concomitance in this case also? Our attempts to show the reason of brain-activity by means of mind-activity, or, vice versa, to explain mental activity as caused by, and dependent upon, physiological activity, must end equally in failure, in a one-sided dogmatism. It is the concomitance of the two, to the thought of which we are not yet used, that thwarts us. And yet Zeno, the sceptic, found as great difficulties in sequence, and proved, to his satisfaction and that of his followers, the utter impossibility of many things which we accept as simple facts without troubling ourselves to solve his problems. 
We have seen that any explanation of facts beyond analysis, except as we assume some transcendental intuition, is impossible. The search for some further explanation embodies the last remnant of the idea of some special separate agent behind each single event and process, with which early superstition was animated. Driven by the gradual spread of knowledge to more and more obscure details in concomitance, and to ever greater distance of time in sequence, it has reached the final shadows of the one, and the furthest ends of evolution, whither thought seldom travels, in the other. That we expect other explanation than analysis, or read into analysis more than its real worth, is the result of an indistinctness and confusion in our thought, which has not yet. lost the habit of infusing into generalizations and abstractions a vitality of their own apart from reality. We continually hope and strive for some explanation that shall give us more than nature, and yet, strange to say, we endeavor to found our theories in and on nature. We acknowledge the scientific truth of the indestructibility of matter and force, the constancy of their sum, and yet we nevertheless continue to construct our many-storied theories of causes and essences, failing to notice that we are bringing all our concepts from a time when the equivalence of results and conditions, of results and their factors, was not yet comprehended. 


\section{CHAP'TER IV}

THE MUTUAL RELATIONS OF THOUGHT, FEELING, AND WILL

IN EVOLUTION

Hume, in his essay on the Passions, writes: "What is commonly, in a popular sense, called reason, and is so much recommended in moral discourses, is nothing but a general and calm passion which takes a comprehensive and a distant view of its object, and actuates the will, without exciting any sensible emotion. A man, we say, is diligent in his profession from reason; that is, from a calm desire of riches and fortune. A man adheres to justice from reason; that is, from a calm regard to public good, or to a character with himself and others. The same objects which recommend themselves to reason in this sense of the word, are also the objects of passion, when they are brought near to us, and acquire some other advantages, either of external situation, or congruity to our internal temper; and by that means excite a turbulent and sensible emotion. Evil at a great distance is avoided we say from reason; evil near at hand produces aversion, horror, fear, and is the object of passion." We know no state of consciousness from which elements of thought are excluded; consciousness is not a state of rest, but a continual passage from percept to concept, or from concept to percept, or if from percept to percept even then with the intervention of concepts. Judgment, exclusion and inclusion, has part in all consciousness; and thus pleasure and pain must be regarded as always accompanied by thought-elements, though the thought-factors may escape notice because of the prominence of violent emotion, just as, in like manner, feeling may draw less attention when of a less turbulent nature. This is not equivalent to saying that emotion must always be accompanied by a representation of its object. To this last statement might be objected that emotion may not be, at first, connected with its proper object, just as so-called purely physical pain may not be, in the beginning, combined with any 
perception of the object producing it, may not even be localized, in fact. But to this objection may be answered that our conception of "its" object, in the case of emotion, is similar to our conception of "the" end of any particular act; that which we regard as "the" object of the emotion may be entirely different from the object in the consciousness of the being subject to the femotion. That is to say, emotion speedily connects itself with some object, or even if felt for some time as vague want is yet combined with thought, in that we make mental search for its object or, where it is too faint to induce this action, tend to turn to memories or imaginations sad or joyful, according as the feeling tinges our mood with exhilaration or sadness; but the objects with which it connects itself in thought may be quite other than those which onlookers regard as its proper object. Into many/ an emotion of childhood and growing adolescence, for instance, the adult reads a meaning and object of which he is aware the individual subject to the emotion has no thought. Physical feeling may not be connected with any distinct perception of the object producing it (as, for instance, when one bruises oneself in the dark), but it is never unconnected with thought-images. The intermediate links between this outwardly stimulated physical feeling and so-called purely mental emotion are represented by localized organic feelings, passing by imperceptible degrees into non-localized feeling experienced as mood. But feeling on any plane is not, as conscious, uncombined with thought.

It follows that, as connected with the human will, emotion is never uncombined with thought. This fact is implied in the definition of will as the conscious determination on some definite course of conduct which, as definite, is an exclusion of other courses, and thus involves judgment. Where action takes place without conscious predetermination, we call it "organic," "automatic," "reflex," or "involuntary," the pain or pleasure connected with the act rising into our individual, centralized consciousness when the action has already taken place or during its progress. In the latter case, part of the act rises into consciousness as result, as already performed, and the will may then interpose to check and prevent the elements not yet performed.

The question as to whether thought is always accompanied by feeling, at least by feeling as pleasure or pain, may appear more difficult than the previous one. That thought is not always con- 
nected with violent emotion as pleasure or pain is evident. But, as Höffding says, "feeling may be strong and deep without being violent." If we examine carefully any train even of abstract and apparently, at first glance, wholly unemotional reasoning, we can generally trace a distinct vein of varying feeling accompanying the thought, - perhaps extreme interest in the problem involved and pleasure in its solution, hope as we seem to be on the point of finding the key to it, disappointment when the hope proves a delusive one, shame or impatience at our failure, or pride in our readiness, and exultation when we have finished our work. All these feelings may relate to the mere solution of the problem as end, or may pass beyond it to ends more or less distant and complicated, to which the solution of the problem then appears as means. Even if we could suppose all other feeling to be excluded, we cannot conceive of a train of thought untinged with mood,interest or weariness, exhilaration or depression, - the dim complex of perhaps many elements, but admitting of general classification on the side of either the pleasurable or the painful, the agreeable or the disagreeable.

Is feeling the result of thought, or thought the result of feeling? which of the two is to be accorded the greater importance with regard to the will? and what is the significance of feeling as pleasure and of feeling as pain with respect to the will? These are some of the questions generally considered in one form or another in the discussion of the relations of mental functions. The first question may be interpreted in any one of several different ways. It may be regarded as referring to particular excitations, objects, or ends, or to precedence at the earliest beginning of consciousness in general, or to the initial state of consciousness in the case of the individual organism. Since we are not able to determine as to where consciousness does begin, either absolutely in nature as a whole or relatively in the individual, whether there is, indeed, any such thing as an initial state, and since we can predicate nothing certainly as to the nature of such a state if there be one, the interpretation of the question which has reference to this relative or absolute beginning of consciousness cannot be answered. If we regard the question, however, as having reference to particular excitations, objects, or ends, it is evident that sometimes one, sometimes the other of the two functions appears more prominent in the beginning; pain or pleasurable excitation 
sometimes makes itself felt before it is connected in consciousness with any distinct object, and again perception may give us thought-images which only consideration renders painful or pleasurable. But there is no real beginning in either case; in consciousness as we know it, thought and feeling are continually intermingled, and only their direction varies with varying excitation, now thought, now feeling, assuming the greater prominence.

This last consideration has important bearings on a question which we have previously discussed and to which we may, at this point, revert for a moment. The fact alone that we know nothing of a beginning of consciousness, but only its variation, is sufficient to make us doubt whether we are in possession of any data from which to pronounce dogmatically on the absence of consciousness in the case of organisms differing from our own, or even in the case of inorganic matter. Why may we not equally well suppose merely a difference in the direction of consciousness corresponding to differing organization and function in the one case and differing composition or constitution and corresponding motion in the other? Our error begins in assuming no ends possible in action except such as we ourselves would set, and so in assuming no end to be present in cases where no end would exist for the human being, or where the end which would be involved for us cannot have come within the experience of the organism performing the act. In the latter case, we speak of "blind instinct " or of "automatism." We forget that an "end" is merely some one of such constant results of function as are brought within the circle of our experience; which end may come to lie farther and farther away, for the same act, as the circle of experience widens and varies in direction, even in beings as similar as individuals of the human species. With the attainment of manhood and womanhood, whole regions of thought and feeling, whole classes of motives, are opened up which are wholly unknown to the child and would be incomprehensible to him; the ends of the scientist, the man of letters, the idealist in morals, the sensualist, and the boor, may differ radically in performing the same or very similar acts. However, there is a certain community of ends in human beings, due to common organization and experience, which enables them to judge to some extent of each other's ends. But these data of organization and experience fail 
us when we come to judge of beings not human, and hence we are liable to error in their case. A superior being of an entirely different species from our own might be greatly puzzled to discern the motives which could govern some of our acts, - those, for instance, which incite the miser to starve in misery with a fortune hidden in the cellar. A superior being of another species gifted with pessimistic views, if we can suppose such, regarding our action externally as we regard brute-action and plant-function, might imagine our whole action to be directed to the attainment of our own death, since that is what we finally achieve as the result of action, and sometimes with most purposeful rapidity; and he might suppose the suicide, and the miser, and the opiumeater, and the drunkard, and the glutton, to be only the more intelligent members of the species, the others to be led chiefly by blind instinct. It is a fundamental mistake to suppose that there can be no "ends" but those of which we are conscious.

The question as to the existence of any causal relations in the old sense between thought and feeling has already been answered in previous considerations; all we can assert is sequence or simultaneity. Indeed, as psychology has rarely troubled itself with any direct question of this sort, its introduction may appear foolish. Yet feeling is sometimes, by imputation, treated as a mere attribute of thought, while again, as we shall see, it is often considered as an independent, directing, if not perception, at least the subsumption of percepts in thought. And, indeed, it is difficult to perceive why, if feeling and thought be regarded as two quite distinct yet simultaneous activities, the same problem as to precedence might not arise, under the concepts of cause and effect, as in the case of physiological process and consciousness as a whole.

But a question with which Psychology and Ethics have occupied themselves as a most important one is that of the relation of pleasure and pain to the will. A point around which strife particularly rages is the problem as to whether it is the pleasurableness of the end which moves the will to seek it; and on the view taken as to the truth on this point theories of freedom or determination of the will are often based, the advocate of free will arguing that the power of choosing the painful proves his theory, the determinist declaring that the invariable might of the pleasurable over the will shows the subordination of the latter. But I cannot, for my own part, see how the demonstration of the fact that the will may be 
moved by the imagination of a painful end rather than, or as well as, by that of a pleasurable one is a proof of its freedom; as I also fail to perceive how it is proved that the will is determined because it invariably chooses the pleasurable rather than the painful end. In either case, choice may be said equally to depend on motive, and in either case the will may be said equally to choose. It is true in either case that the strongest motive moves; it is true in either case that the will decides upon the act with a feeling of its own spontaneity and freedom, and guides the movement of the body in the performance of the act. That which is shown in an invariable connection of the will with pleasurable motives is a constancy which we find elsewhere in nature and which forbids us to regard will as something outside and above the rest of nature. As we have seen, however, the theory of a compulsion of nature anywhere by constancy or law, or of the compulsion of one particular part by the rest, is untenable.

In speaking of the pleasurable and painful, we have introduced the conception of ends into our considerations, and may emphasize, in another form, the fact that we cannot consider indefinite feeling alone as the mover of the will to an end. The pleasurableness or painfulness is predicated of some definite object or event, and corresponds to definite actualities perceived in the object or imagined with the help of former experience. Thought and feeling are thus inextricably commingled in the state of consciousness leading to choice, and the nature of the acting individual and that of the external objects concerned are equally essential to the result.

We have hitherto treated thought, feeling, and will, as separate parts of consciousness, defining each, by implication, much as we would define wheel, tongue, and whitfletree, as parts of a wagon. But the three are indissolubly connected in the act of the will, and thought and feeling are not, as we have seen, ever disconnected. Nor can we say that it is one part of consciousness that feels, another that thinks, and still another that wills. Further, a closer analysis may render it doubtful whether that which we call will is only an occasional act of consciousness, or whether it is not rather involved in all operations of consciousness as we have seen thought and feeling to be. The identity of will and that which is often called involuntary attention has already been asserted by some authors, and not the identity of will and outward 
attention alone, but also of will and attention to the inner process of consciousness. Here, however, the dividing line generally sought between willed and unwilled, involuntary, or, as we say, drifting thought, becomes dim and uncertain. But it is evident that attention is given to that which interests us for one reason or another; and the question logically presents itself as to whether thought ever follows a direction wholly uninteresting to us, or whether it does not the rather always turn from such direction to one which has for us at least some degree of interest, whether, in short, the will does not in this manner, as the innervation of attention, accompany and direct all mental process. The sense of effort involved in choice, in the struggle of interfering impulses, may bring into prominence mental activity at points where such obstacles and interferences occur; but is not the mental force which we, in this case, especially notice the same with that involved in all processes of consciousness? Just as the physiological process in nerve and muscle with which the limbs are moved in action, or eye or ear innervated in the effort of attention, is only the outcome of the processes which are constantly going on in the brain, so the concomitant process of will or attention is but the expression, in another form, of the activity involved in all consciousness.

The division of consciousness into separate entities or parts has often been carried much further than this threefold one; the division has varied with the particular theory and fancy of the student, until some one has suggested that we might, on the principle used, assume a distinct faculty for dancing, for eating, sleeping, dressing, reading, writing, and so on, ad infinitum,- the faculty, in each case, being defined as the special activity that discharges the particular function assigned to it by the name. Only by abstraction and by the investiture of our abstractions with a life of their own do we arrive at a theory of thought, feeling, and will, as separate entities, or parts; in the mental process itself, they are indissolubly united.

We have seen that thought acquires new directions with the evolution of the individual, that pleasure and pain attach themselves to new objects, and that will is directed to new ends. If we can discover in these changes any uniformities of relation everywhere manifest as far as experience extends, the constancy of nature may admit of our conclusion that the relation is funda- 
mental, and we may be able to formulate thus a general law of evolution with respect to the mental processes. Such a law must, of course, be interpreted, not as governing the changes which it regards, but simply as the expression of general facts of their development. Our considerations on this point are in a line with those of Chapter I; indeed, they are only a more special application and more careful derivation and expansion of points there noticed.

If we begin with our own experience, and study the growth of this or that particular habit gradually acquired, we notice that it not only becomes stronger with time, acquiring an intensity less and less easy to check, but also that this increasing strength of tendency is accompanied with a corresponding increase of pleasure in the performance of the act. 'The drunkard may have derived no especial pleasure from his first glass; he may, indeed, have found the taste little to his liking, and the slight succeeding dizziness disagreeable; but, with habituation, both gradually become agreeable. The first fit of intoxication may be felt as unpleasant, not only in the succeeding shame and physical depression, but in itself; though it is also conceivable that the state of thorough intoxication may have been led up to so slowly, by such imperceptible degrees, that it may be combined, even in the first instance, with a certain degree of pleasure. It is, however, evident that this pleasure increases with further lapse of time. If we study the habits of individuals, we shall find a thousand little peculiarities of habit in which others than their performers would be puzzled to discover anything attractive, and in which, indeed, the latter themselves would find difficulty in pointing out the source of the gratification that they nevertheless experience. Our habits are things we are loth to break with; and we grow more loth as time passes, until finally no consideration, no shame of scorn or pain of punishment in any form, can suffice to counterbalance the craving of desire and the fierce pleasure of satisfaction, or the less turbulent but not less strong impulse that carries us steadily in the course which past custom has worn for us. Customary acts are themselves agreeable to us, though their results may bring with them disagreeable factors.

Again, this same principle is directly traceable in heredity. We say, for instance, of the drunkard whose father and grandfather were drunkards before him, that he has inherited a "taste" 
for intoxicants, meaning, not that he can feel their attraction before he has tasted them and experienced their influence, but that the habit of drunkenness is one more easily formed in him than in the average individual, constitutional peculiarities corresponding to a pleasure derived from the alcohol. We often notice striking resemblances, not only in general appearance but also in mental characteristics and habits, extending even to attitude and gesture, between children and parents deceased when the children were yet infants. I have known very peculiar physical habits to appear, in one instance in three, in another in four, generations, with the avowal of satisfaction in their practice on the part of the persons subject to them, although neither they could explain, nor onlookers comprehend, the pleasure derived from them. Imitation is not always possible in such cases; in one case of these two just cited, it was, in the third generation at least, impossible; and even where there is imitation, it is by no means proved that an innate tendency does not lend readiness to the formation of the habit. It may here be objected that we are venturing on too uncertain ground in endeavoring to formulate any general law of the growth of habit in relation to heredity, opinions differing so much as to the relative importance to be accorded to environment and innate tendency in the formation of character, and especially as to the possibility of the inheritance, by succeeding generations, of new peculiarities not common to the species as a whole but acquired by individual parents. As far as the former question is concerned, it may be said that the whole development of plant or animal in organization and corresponding functions must be regarded as directly dependent upon present environment, never independent of it; but that, while it must be conceded that the environment is greatly concerned in the development of habit, and that no innate tendency can manifest itself unless the complementary conditions of its appearance are presented by circumstance, it may likewise be claimed that the influence of environment no more excludes heredity than heredity excludes the influence of the individual environment. We tend, generally, to emphasize heredity in the case of the plant and the animal, and environment in the case of the human being. This is because our knowledge of species other than our own is merely an outward one, while the ideas of heredity in our own case are confused by our consciousness of the influence that even 
minute circumstances may have upon our inner life and character. And yet just those who are inclined to lay most stress upon the power of good influences are generally, strange to say, the very ones who would most protest at the assertion of the superiority of outer conditions over inner ones. It can scarcely be supposed that any law of heredity which applies to the rest of the animal kingdom does not apply to man also. With respect to the second of the two questions noticed above, something has already been said from one point of view, and more will be said later from another. At present it will be sufficient for our purpose to notice some generally admitted facts. Darwin uses a certain caution when he comes to the consideration of the conditions of inheritance, and makes the general statement that the tendency to inheritance of any function is increased by the continuation of the action of the inducing conditions of environment for several generations. But it may be questioned whether an innate tendency may not have favored and assisted the action of the environment in the later of these generations, whether, indeed, the continuity everywhere supposed in evolution does not compel us to assume, between the first appearance of any function, trait, or habit, and its attainment, after several generations, of sufficient strength to render its hereditary character noticeable, intermediate degrees of strength in the intermediate generations. On the same principle on which we accept the theory of evolution as a logical necessity, despite the gaps in the proof, we must also, I believe, consider development of any sort to be continuous increase.

But even the theory of the increased probability of the inheritance of any mark, function, trait, or habit, after several generations of inducing environment, is sufficient for our present purpose. It still remains true, if we regard the development of function or habit in its broad features, that the tendency to inheritance, the organic significance of any function or habit is increased with increased exercise. Merely in the one case we regard the increments of increase as infinitesimal, while, in the other case, we regard them as of much greater than infinitesimal value. Even the theory of Weismann, which regards everything as present in the germ, must formulate some such theory as this of the environment as the condition of the development of germinal possibilities. 
Not only are the strongest and most infallibly recurring functions those which have been most strongly and longest exercised, but these strongest functions, those to which, as we say, the tendency is strongest, are connected with the strongest pleasures of gratification and the most extreme pain of denial. The sexual appetite is an example of such a function fundamental to all the higher forms of animal life. Hunger and thirst, if long unsatisfied, are connected with intensest suffering and, if not dulled by general ill-health or too great satiety, involve a keen pleasure of satisfaction. Muscular exercise is a source of keen enjoyment, and physical inaction results in general depression that may become extreme if the inaction be long continued.

In this pain of inaction, a new conception has been introduced into our considerations. The converse of this pain is that involved in the over-exercise of any function. We thus perceive that the pleasure involved in the exercise of function lies between two extremes, beyond either of which is pain, discomfort. Such pain is connected with the vacillations in the relations of foodassimilation to the use of accumulated energy. These two general processes or functions of all organic matter are reciprocal or complementary, and the too much or too little on either side which involves pain may be looked upon as a disturbance of equilibrium. Excess on either side means want on the other. ${ }^{1}$

And this brings us again to the conception of normal function as a stable form of motion. Long-exercised function, fundamental functions of animal or plant life are forms of motion that for a very long period have found their sufficient complementary conditions in the environment, have met with but little interference in this environment. And thus we attain a conception of pleasure as that form of feeling accompanying forms of physiological motion with which there is a minimum of interference. Pleasure appears as the accompaniment of unimpaired and unimpeded function everywhere as far as our knowledge extends. Function and habit are essentially the same; habit is merely function. The functions of the species furnish the foundation of the habits of the individual, which vary according to individual surroundings and the family peculiarities acquired through peculiar circumstances. The degree of pleasure in the exercise of

${ }^{1}$ See Avenarius' formulae of "complete vital maintenance": $f(R)=$ $-f(S) ; f(R)+f(S)=0$, " Kritik der reinen Erfahrung." 
any function or habit bears constant relations to the strength of the acquired function, while this again bears constant relations to degree of exercise, in which the time relation plays a prominent part. Here we have, too, by implication, the explanation of the disagreeable character of the strange and new except as it corresponds to some tendency of the organism, some capability not yet exercised, in which case it appears as nothing strictly new but only as pleasing variety. From a physiological point of view, the new appears as that which demands a readjustment involving the fresh action of natural selection, and the possible destruction of the organism in case the readjustment demanded is too great. From the physical and mechanical view, the new may be regarded as a disturber of equilibrium.

To this analysis the objection may possibly be urged that obstacles often increase pleasure. If, however, a definition of obstacle be demanded, it will soon appear that what is meant by an obstacle that increases pleasure is not anything that interferes with function but rather that which is exactly its occasion and opportunity. To a man in health and vigor who sets off for a walk through the fields, a hedge or fence in the way is no real obstacle, but furnishes rather an agreeable diversion, a new method of trying his strength and getting rid of superfluous muscular secretions; it adds but the spice of some slight variety to his exercise. That which is an interruption of one function, may be the opportunity of another; and if the demands of the first function for satisfaction are not too imperative, the interruption of too great duration, the obstacle may not be felt to be disagreeable. But pain and pleasure are often mixed, since the satisfaction of one function may be the prevention of another. If, in this case, the function which is satisfied is a fundamental one, the function which is prevented a subordinate one, the pleasure exceeds the pain. If, on the other hand, the function prevented is a fundamental one, the function satisfied a merely subordinate one, the pain exceeds the pleasure.

With the ideas of unimpaired and unimpeded function as pleasurable, and of the new as demanding readjustment, we arrive at the consideration of health and disease. The free performance of any particular function is the first condition of the health of the organ of which it is the function, the regular performance of all physical functions according to the mutual adjust- 
ment of the organs of the body the condition of the health of the organism as a whole. And thus again we come round to the conception of pleasure as connected with the action that accords with the health of the organism. And this leads us to some remarks concerning the act of food-taking which may answer a possible objection to the statements made above with regard to the pleasure involved in the act. The moralist and idealist are wont to protest against any theory that may seem to give prominence to "the purely animal" side of human life. But first, we have to do, at present, merely with facts on which ethical theory may be founded, not as yet with such theory itself. Furthermore, the selection of the appetites of hunger, thirst, and sex, as illustrating the general theory of the relations of pleasure and pain to function is not made in order to lay special stress upon these appetites but because they afford, as fundamental, especially good examples. And, finally, it may be noticed that the pleasure connected with the stilling of hunger and thirst is not that of taste alone, though doubtless there are many with whom this pleasure is one of the most important of life; on the taking of sufficient and proper nourishment depends the pleasure involved in the general health of the body; the pain of non-satisfaction in this case is not simply that of a single organ but that of the whole organism. Even the deferment of a single meal beyond the usual hour often lowers the "tone" of the whole body, and the variations of too much or too little strongly influence the mood and general happiness of the individual. On the right use of nourishment depend, in great measure, the ability to cope with circumstances and the moral power of cheerfulness.

In connection with the idea of a certain equilibrium between exercise and nourishment, waste and repair, as normal, healthful, and pleasurable, Rolph's principle of the Insatiability of life may be considered. Evidently the facts of evolution demonstrate the power of the organism to advance by slow degrees beyond its original normal. But the progress is an exceedingly slow one, and the power of advance in the individual organism, at any particular point, by no means limitless, but very definitely limited. The limitations of the power of assimilation are evidenced by the evil results of over-eating, of over-satiety of function in any direction. Even at an early period of life, when growth is most marked, the capacity for assimilation is by no means limitless. 
The idea of insatiability is advanced by Lewes $^{1}$ in a somewhat different form. It may possibly be an aid to the comprehension of the process of growth to regard one factor, namely the organism, as the active side of the development tending to indefinite growth in all directions, and the other factor, the environment, as the regulating, resisting factor, limiting such growth; the conception may, perhaps, be legitimately resorted to as we resort to various other devices which bring into prominence some one side of a process to the neglect of others but to the simplification of our concepts and calculations. A similar device is used by Zöllner in his consideration of sun-spots. ${ }^{2}$ But these representations should not be mistaken for actuality. The limitless expansion of the organism is as much a fiction as a theory of the limitless coercion of the environment resisted by the organism would be. The latter fiction is involved in one interpretation of the Struggle for Existence. Either view is one-sided; environment and organism both alike represent active forces, of both which combined, growth is, at each moment, the exactly conditioned resultant.

We may notice another assertion of Rolph's, namely, that growth is produced by increase of nourishment rather than that it demands ${ }^{3}$ increase of nourishment as the Darwinians state. I do not know how the Darwinians come to be accredited with this statement in the sense which is evidently criticised by Rolph. In so far as the statement may be interpreted as meaning that growth takes place first, and without nourishment, and that the demand for nourishment then ensues on this growth, the criticism is evidently valid. But the word "demands" may be interpreted in quite a different way as designating the need of growth for its conditions, or rather (for this is the ultimate significance of the word in this sense) the logical demand of the reason, which cannot suppose anything to take place in the absence of its conditions. Any other signification of the word is contrary to the whole spirit of Darwinism, and would accord much better with a theory of Insatiability or with other forms of theory that imply a special vital principle of some sort. If, when Rolph makes the assertion that increase of nourishment produces growth, he

1 "Problems of Life and Mind," Ser. II. p. ro3.

2 See essay by Petzoldt above considered.

3 "Biologische Probleme," p. 96; " erfordern." 
refers, by "increase of nourishment," to the mere act of mastication, it is true that growth must be regarded as following upon this as its condition; but growth and the assimilation of nourishment are identical. And, in fact, assimilation begins in the action of the saliva in the act of mastication. Analysis of assimilation gives us sequence in one sense, since the parts of the act follow upon one another; but any interpretation which tends to draw a distinct line at any point in the physiological process, or to distinguish between assimilation as active, performed, and growth as passive, suffered, should be avoided.

We may return to the consideration of pleasure and pain as connected with function in general, with a view to a solution, if possible, of the problem of its especial connection with the will. The brain may be defined, from the point of view of the theory of evolution, as the organ of centralization through which the unity of the organism is established, and the adaptation of parts or the development of special function becomes the adaptation or function of the whole. With this physiological adaptation, an increasing breadth of knowledge by experience, the deviation of feeling from old into new channels, and the attainment of new ends of action, are associated. Just as past adaptations must have their physiological representation in brain-organization, so psychical experience is stored up to be remembered on sufficient suggestion, and finds, thus, its expression in conscious will, just as its physiological concomitants must be supposed to find their expression in nervous and muscular action. As we have seen, pleasure follows the line of evolution of function, strongest pleasure appearing in the direction of most strongly developed function, so that, just as any conflict of tendencies to function in the brain must result in conquest by the strongest tendency, the line of action must always correspond with that of the greatest pleasure. And just as the most strongly inherent function is combined with the greatest pleasure, so the representation of the performance of this most strongly inherent function is, in the conflict of tendencies before action, combined with the greatest pleasure of anticipation. This statement coincides with Stephen's remark that it is not the representation of the greatest pleasure, but the pleasantest representation, which furnishes the decisive motive to will. Contingent circumstances may introduce into the actual carrying out of the act determined upon an element of 
pain not before experienced, in which the wish may arise that the act had not been performed; and the strength of the tendency to action in this direction is thus diminished.

With regard to this analysis, several things are to be noted. (I) It is no more claimed that the strongest pleasure of anticipation is unmitigated pleasure than that the pleasure involved in the attainment of the end is necessarily unmitigated. Wherever there is interference, there is also pain. Where any struggle is involved, where any conflict of tendencies and wishes precedes choice, the struggle itself and the relinquishment of one or more courses in favor of the one chosen involve disagreeable elements, and the fiercer the struggle the greater the pain. Where two extremely strong tendencies thus come into collision, the pain involved may amount to agony. Our statement that the more pleasurable end or rather the one the imagination of which is the more pleasurable is the one sought by will needs therefore to be put into a somewhat different form, since, among all the methods of action open to choice in any case, there may be none the thought of which involves any positive pleasure, though there is in all or most cases some one which promises at least a negative excess of pleasure, that is, least pain. (2) No assumption is made as to the particular kind of representation or the particular kind of end with which the greatest pleasure of anticipation or of realization is combined, whether these are "higher" or "lower," sensual or intellectual, moral or immoral. It is not by any means asserted that the most moral end may not be that which is chosen. (3) It is not asserted that any direct calculation of the pleasure to self involved in any course of action necessarily contributes to choice. (4) The pleasure or pain connected with the imagination of a future event is not to be confused with the actual pleasure or pain of the event itself. The feeling experienced in the event may be wholly different from that of anticipation.

In connection with the second point, reference may be made to an assertion of Sidgwick's in his attack upon Hedonism. $\mathrm{He}$ writes as follows, "We have to observe that men may and do judge remote as well as immediate results to be in themselves desirable, without considering them in relation to the feelings of sentient beings." 1 The question for us here is, first, whether the emphasis of the assertion is on the word "considering," 
- a question the context does not answer. It is certainly true that decisions are reached, judgments pronounced, without introspection and self-analysis, and without long reflection of any sort. It is true that, even where reflection does take place, there is not necessarily any distinct attachment of the concept "pleasurable " to results considered, whether with relation to self or to others. The dog who snatches at a piece of meat does not probably waste any time in reflecting on the pleasure he will experience in eating it; and yet we do not the less believe that if the act were not pleasurable to him he would not perform it. It may also be true that a man often pronounces results to be desirable without noting or caring for their relations to other sentient beings; but if these results are regarded by him as desirable, then they must be in some way desirable to himself, that is, must have a pleasurable relation to his own feelings. Desire appertains to sentient beings and to sentient beings as such; a thing which is desirable must be desirable to a sentient being; the desirable which is not desirable to a sentient being is the desirable which is not-desirable, a self-contradiction.

In connection with the third of the points above noticed, Rolph's assertion that not pleasure but pain is the motive to action, may be considered. The author does not mean anything else than that action is in the direction from "want," "hunger," "pain," to ends involving pleasure, so that this theory does not, when analyzed, differ fundamentally from theories which assume the motive to will to be furnished by the most pleasurable end or by the most pleasurable representation of an end. The chief point of difference is the conception of the state of consciousness preceding will as invariably one of pain, the want of the end willed as invariably painful. Now it is evident that the satisfaction of a function may be so long deferred as to involve the severest pain; hunger, thirst, may reach a degree of intensity that is frenzy, muscular inaction, in an ordinarily active individual, if long persevered in, may be combined with extreme discomfort and depression. And it is also true that all desire involves want in the sense that an end is sought because its absence is felt as undesirable. But want in this sense means merely desire, and is not necessarily combined with any real pain of deprivation. The state of consciousness preceding action may be, on the contrary, one of exhilaration, of exceeding joy of anticipation; the grati- 
fication of a desire may take place so soon after the first appearance of the desire, or the gratification of the desire become so certain so soon after the desire is first felt, that no pain of want is felt at all. Rolph, indeed, finds great difficulty in demonstrating his theory, and finally resorts to the definition of the pain which, as he asserts, furnishes the motive to action as "the pain of the absence of pleasure." He says, moreover, that not all pain is felt as such, since much feeling is below the threshold of consciousness." But "unconscious pain" and "feeling below consciousness" are mere self-contradictions. Specification of that of which, as unconscious, we know nothing is a very easy way of delivering oneself from the necessity of positive proof, but it is a very unscientific one. With respect to Rolph's assertion that pain can not be dispensed with, since it is everywhere the motive to action, it may be remarked that this statement seems to accord ill with Rolph's other theory that never the struggle for existence but always states of plenty and comfort are the conditions of growth, and the lengthy demonstration that periods of want must condition decline, retrogression, and finally the extinction of the species suffering the want. From the standpoint of Darwin, the struggle for existence is not inconsistent with the possession of plenty on the part of favored individuals and species, but Rolph expressly denies the compatibility of the two principles.

In his theory of want as the universal motive to action, Rolph cites suicide as an extreme case of this want. Our analysis has already taken into consideration some of the cases of mental struggle and postponement of the satisfaction of desire involving pain. But where one end greatly desired is unattainable, choice may yet be possible of another end affording partial satisfaction of the function corresponding to the desire, and, in cases where choice is necessary between two or more conflicting ends, the gratification of one may be attended with a sufficient degree of pleasure to cause partial forgetfulness of the disappointment in the necessary relinquishment of the other ends. Where, however, the function denied is one of the most fundamental of the organism, its denial may be combined with intensest pain and a gradual physical degeneration, or even a sudden collapse of the organism, ending in death; or it may induce an act that secures this end through the mediation of self-conscious will. What is true, in 
this case, of the denial of some one fundamental function, is true also of an accumulation of coincident denials of a number of lesser ones. Our desires are, indeed, in all cases, more or less complex, and involve the fulfilment of various functions; but we can easily imagine such an accumulation of small ills as to lead to desperation. Where no choice of action seems left us by which we may attain some one end deeply desired, or where a coincidence of obstacles makes it appear as if there were no choice of action towards any desirable ends, death may be chosen as a lesser evil than life, the equivalent of a lesser pain in the absence of feeling altogether. It may be noted, however, that where suicide is prevented in the first moment of desperation, the individual planning it may not only never again attempt it, but may afterwards even find much pleasure in life. As there is a high degree of pleasure connected with the performance of deeply rooted function or habit, so the performance of all function is attended with some modicum of pleasure, except in such isolated moments as render suicide possible. Every end desired is one of function, and all function furnishes ends to the will. The pessimist lays emphasis upon the fact of the speedy loss of pleasure in ends attained. But herein lies the higher pleasure of life, that it is not rest but progress. The pleasures we attain may be continually renewed if rightly sought, but they cannot be unintermittently sustained. We cannot rest at ends attained and find unlessened rapture in them. Rest is not an attribute of life; life is essentially motion, that phase of it which we term rest being mere change of function for a time. The intimate relation between pleasure and an equilibrium of waste and repair renders it impossible to obtain pleasure except as occupation is varied in order to afford opportunity of recuperation to organs and cells before used. Proper variation, however, may enable us to return to old pleasures with ever renewed and even increased enjoyment. But it is conceivable that the pleasures of gratification and the pains of disappointment may be so nearly balanced as to make life possible and yet endow it, at least for a period, with but little joy. It is to be noticed, however, that intense pain cannot endure, unmodified, for any great length of time. As pleasure follows the line of customary action, so pain diminishes with long-continued lack in any direction, unless this direction be that of too fundamental function, in which case the organism 
succumbs entirely and perishes. Either we grow gradually used to our disappointment and forget it to a great degree in other gratification, or we die under it. Certainly there are losses the pain of which is never entirely forgotten, after which life is never quite the same again; but the first agony of such losses is materially modified with time; and many of the losses which have seemed worst to us at the time they occurred are later looked back upon without regret. We progress to another stage, and the ends we desire to gain are changed. The habitual misanthrope, indeed, generally derives a great deal of satisfaction from his own misery; and this leads us to the apparently anomalous remark that even pain as function may come to be combined with pleasure; we feel a satisfaction in our own capacity of emotion. The sensitivity of the poet to pain as well as his sensitivity to pleasure is a source of often very keen gratification and pride to him. Of the weak and aged who have no especial pleasure in life, it may be said that they have also, in general, no fierce pains, at least seldom such as bring desperation in youth. Having learned from experience, they are not subject to such exaggerated expectations, and hence disappointments, as accompany youth, vigor, and ignorance of the realities of life; and often they derive enjoyment from things which would have no attraction for the young.

The old question as to the relation between health and happiness may be answered by the statement that the two coincide. The statement is not meant, however, in the sense that the happiness which we at present attain is coincident with health in an absolute sense or that, vice versa, perfect happiness is, or can be, coincident with that which we ordinarily term health. The two terms are generally very ill-defined; sometimes the one, sometimes the other, is used in an absolute sense in connection with the discussion of the parallel term in a comparative sense. Perfect happiness must coincide with perfect health; for perfect health must coincide with perfect fulfilment of all function, and this coincides with the gratification of all desire. At present desires conflict, and the gratification of one is bought at the expense of others. This partial gratification corresponds to a partial health; but we too often forget, in the discussion of health and happiness, that health is no more perfect than is happiness. The individual is not yet in harmony with himself. But this means that he also is not in harmony with the environment. 
In the development of thought, feeling, and will, we have noticed a certain parallelism, the attainment of new knowledge, the deviation of feeling into new channels, and the direction of will to new ends; indeed, our analysis must bring us to regard this development as something more than a parallelism, since, as we have seen, thought, feeling, and will, cannot be defined as separate organs of mind. And we are here led to notice a theory sometimes advanced, that the feelings of one individual can never be changed by another. You may present a man with arguments, say the advocates of this theory, but this is all; you cannot bring him to act on the arguments unless his feeling is already of the right sort before you present your arguments; if it is not, you cannot in any way alter it. Now a certain general foundation of character, of fundamental feeling, must always be conceded; but this is not what these theorists mean when they say that arguments can never alter feeling. "Of what use would it be to argue with my child and tell her that this or that act of hers is selfish," said a man to me not long ago of his three-year-old daughter; "if she is selfish, arguing with her will not make her less so; showing her that she is selfish will never have any effect upon her selfishness; you may change opinions by argument, but not feelings." The theory reminds us of the old idea of the will as something above other phases of nature and so supreme above their influence; it replaces this theory of the uncaused nature of the will by one of the like absolute independence of feeling. And yet, strange to say, this theory is oftenest advanced by just those who assert the variability of will in accordance with law, under the influence of the environment, and unite with these already incongruous theories the wholly contradictory one that it is feeling which furnishes the motive to will. To appeal to any one except through the medium of thought is certainly impossible; the feelings cannot be influenced except by representation and argument. Feeling cannot be taken by itself and so influenced. But the person endeavoring to convince does not desire to arouse indefinite feeling; he invariably wishes to excite it with regard to some definite end. To change opinion is also to change feeling in some degree. Whether an appeal to another is successful or not depends on the nature of the appeal and upon the consciousness of the individual to whom the appeal is made; but this means that not the nature of consciousness alone decides the result. In 
any excitation by the environment, the result is conditioned, not by the one factor alone but by both; and no excitation can leave the individual entirely unchanged; the multiplication of infinitesimal single excitations constitutes the whole of evolution. A first appeal or argument may be felt only as disagreeable interference; but an accumulation of appeals at first disagreeable and met only with rebuffs may eventually result in total change of both ends and feelings. The amount of appeal necessary differs with the person appealed to; it may be large or small, excessively large or excessively small, but the general fact remains, that feelings vary as thought widens, and that an accompanying change of ends takes place. Thought and feeling are not two separate and independent things, but are, on the contrary, vitally united.

We may put our old familiar question with regard to cause and effect in a new form in respect to the development of thought, feeling, and will. In considering the process of evolution, will, and, therefore, the conscious exercise of function, is ordinarily treated as the effect of pleasure; but our course of analysis identifies function and its exercise and rather brings function into the foreground, though the assertion of precedence in importance has been avoided. The course was chosen partly because it affords an opportunity of propounding the following questions: Is lapse of time, amount of exercise, or pleasure, the cause of habit? Or is habit the cause of function? Or is pleasure the cause of continued exercise of function? Or is function the cause of pleasure? Or is a minimum of interference the cause of pleasure and of function in a particular direction? Or is not, rather, continued exercise of function the cause of the absence of interference wherever and as far as it exists? We find all these various suggested theories advocated, by direct statement or by implication, in the treatment of the evolution of function by different authors, and indeed we frequently find several of the theories included, by implication, in the work of the same author. The vital connection of unimpeded function and pleasure is apparent, and the necessity of the time element in the development of function may also be asserted; but there is not, according to our theory, any reason for introducing the concept of cause into the relations.

Our analysis of the development of thought, feeling, and will, has an important bearing on the teleological argument. If all habit comes, in time, to be pleasurable, if pleasure merely fol- 
lows the line of exercise of function, whatever that line may be, and ends are thus mere matters of habit, and habit, exercise, is a matter of the action and reaction of all conditions, then it is evident that the force of the teleological argument is at once destroyed. We cannot pass beyond nature, by this route, to the inference of a transcendental cause. Man's action being a part of nature and the result of all conditions as much as is the motion of the wind or the waves, the results he produces, like theirs, only change and never creation, the only inference we could make from his will to other will must be an inference to will that is a part of nature, a result if also a condition, a link in the chain of nature, its ends coördinate with habit but not the cause of it, and no more determining than determined. 


\section{CHAPTER V}

\section{EGOISM AND ALTRUISM IN EVOLUTION}

Carneri, in consistency with his scepticism as to feeling in animals, remarks that, with man, the struggle for happiness is added to the struggle for existence. Wallace and others regard man as comparatively withdrawn from the struggle for existence and the operation of natural selection. Much depends on definition in any statement; but it may be repeated that the analogy of nervous organization does not permit us to suppose the absence of pleasure and pain in many species, and that man is no exception to the rule that the disharmonious is the unstable, and doomed, by its nature, to destruction.

However, analogy does not, as we have seen, carry us far in deciding upon the presence or absence of consciousness, or in determining the exact nature of the ends it posits even where we may suppose it to be present and conscious of ends. If, then, we apply the terms "egoism" and "altruism" to the action of plants or even of other animal species, meaning, by these terms, that, in the action referred to, such ends are sought and willed as render human conduct what we call altruistic, we may be falling into error. However, in considering egoism and altruism in their relations to human development, it may be useful to note their prototypes, as far as external form is concerned, in life on lower planes, without making any assumption as to the internal meaning of these prototypes, except in so far as, in special instances, we may be warranted by further particular examination of facts.

It is evident that the action of animals is of a sort that has as its immediate and most prominent result their own protection and preservation, and that they show themselves generally hostile to other kinds and even, in many cases, if not hostile, at least indifferent, under most circumstances, to their own kind. Yet a certain amount of mutual support may occasionally be observed 
even among lower species. One of the forms of such aid most common in the whole range of animal species is the care of the parent animal for its offspring. This care is more usual on the part of the female than on that of the male, and where it is exercised it is not the exception, but rather the rule, that the mother will sacrifice life itself in the defence of her young. Such care and self-sacrifice, especially marked in mammals and birds, are too well known to need illustration here.

Mutual aid between the sexes is not so common or so strongly marked as the care of parent animals for their young. There is often no companionship at all between the sexes, and even at the time of mating male and female may show themselves hostile to each other. It often happens with certain Epeiridae the males of whom are smaller than the females, that, after copulation or sometimes even before, the female seizes upon the male and makes a meal of him. Sometimes, also, during the battle of two males for the possession of a female, the latter throws her web about both and devours them. ${ }^{1}$ Female deer wandering in the company of a male have been observed to watch with indifference the contest of the latter with some newly arrived male, and on his death to lick the wounds of their new suitor and follow him as they before followed his predecessor. The relations of male and female among the birds, especially among some sorts of birds, have, on the other hand, often been made the theme of the poet.

But mutual aid among the animals is not confined to the relations of parents and offspring, and male and female. Whether or not we explain the societies of animals as merely huge families, as some authors are inclined to do, the fact of the association remains, and it continues to be true that, in this association, much mutual assistance is given. In this connection, however, may be cited the experiments of Lubbock, showing the exceeding irregularity and apparent caprice with which such assistance is rendered among even such creatures as the ants, with whom organization is generally regarded as having arrived at an unusual degree of development. Lubbock found that, wherever a regular battle was in progress, the ants gave aid to each other, but that where a single ant was attacked by an enemy, the others of the nest generally took no part in the matter. In many cases,

${ }^{1}$ I am indebted for these facts to Dr. Auguste Forel. 
they passed by wounded or helpless members of their own colony, leaving them to perish where a very small amount of help would have saved them. In some cases, they cared for the slightly wounded; but those who were severely wounded they threw from the nest. In their hostility to their enemies, they were merciless and more persistent than in their help of friends. ${ }^{1}$ Lubbock, arguing from such facts as these, differs in opinion from Grote, who regards it as necessary to the maintenance of any society that some moral feeling should exist. Indeed, that which Carneri asserts with regard to the care of offspring might be claimed in this case, namely, that the assistance reaches exactly so far as is necessary for the preservation of species. The implication is that all this apparent altruism is mere automatism.

In support of a view similar to this, Benno Scheitz quotes the following case, " "which Dr. Altum relates from his own experience ": " "In the Gens d'Armes Market in Berlin, I saw several larks and a robin in a cage; the former cowered sorrowfully, with somewhat roughened feathers, in a corner, but the robin was in full activity. It ran to the food-cup, seized as many ant-larvæ as it could grasp in its bill, and hastened with these to the nearest lark. The latter, however, did not honor the solicitous robin and its food with as much as a look. But scarcely had the robin offered its disdained food than it let this fall and hastened after fresh food, offered this, let it fall, fetched fresh again, - only to begin the same performance anew. As long as I watched this interesting spectacle, the robin was thus employed, and very soon the greater portion of the ant-larvæ had been carried from the food-vessel and lay scattered before the different larks. And what was here the motive of the redbreast in permitting itself no nourishment (I did not see that it ate a single one of the ant-larvæ itself), but carrying it all to its fellow-prisoners, - sympathy and love for the larks, who disdained all food, and who could have taken the same food for themselves, in the same manner, and with exactly the same amount of trouble? The redbreast had been caught and carried away from its young; the impulse to feed was strongly awakened and had before been strongly active, but not satisfied; the bird

1 "Ants, Wasps, and Bees," Chap. V.

2 "Zur psychologischen Würdigung der darwin'schen Theorie." 
was obliged, therefore, to continue to bring food, although there was no longer anything to feed." " The care which female animals of many species, when deprived of their young, often show for the young of other animals of the same or other species that come in their way is well known. Among domestic animals, the cat appears particularly susceptible in this respect, though comparisons here are perhaps scarcely fair, since, of all domestic animals that are habitually deprived of their young, the cat is about the only one that has the chance of coming in contact with young animals near the size of its own kind. The cat has been known to adopt young rats, chickens, puppies, ducks, and will generally, during the time of suckling, take up readily with kittens of another litter. Galton, in his "Inquiry into Human Faculty," mentions that the records of many nations have legends like that of Romulus and Remus, these being surprisingly confirmed by General Sleeman's narrative of six cases where children were nurtured for many years by wolves, in Oude. The working ants of certain species show as great care for the slave-larvæ robbed from other nests as do many parent animals for their own offspring. Again, the care for their eggs shown by many animals who give no care to their young may be cited as evidence in favor of the theory of automatism. In the vegetable world also, similar protection is afforded flower and fruit, the most wonderful instances of such protection being, perhaps, those of the insectivorous plants.

But to all these arguments in favor of automatism may be answered: (I) that functions which are preserved and inherited must evidently be, not only in animals and plants, but also and equally in man, such as favor the preservation of the species; those which do not so favor it must perish with the individuals or species to which they belong; (2) that it cannot, indeed, be assumed that a result which has never come within the experience of the species can be willed as an end, although, with the species, function securing results which, from a human point of view, might be regarded as ends, may be preserved; but (3) that, as far as we assume the existence of consciousness at all in any species or individual, we must assume pleasure and pain, pleasure in customary function, pain in its hindrance; and (4) that, as far as we can assume memory, we may also feel authorized to assume that a remembered action may be associated with 
remembered results that come within the experience of the animal, some phases of which may thus become, as combined with pleasure or pain, ends to seek or consequences to avoid. There is no reason to be given why care for the young should be more pleasurable than care for eggs; the one may be as pleasurable to some species as the other is to other species. If we assume consciousness in Dr. Altum's robin, we may assume pleasure in the care of its young and also, as a possibility, pleasure in the results of such care, the preservation and prosperity of the young; whether the consciousness of the robin includes abstract concepts of preservation and prosperity, is another question. The human mother, too, is wont to be peculiarly tender to children in general, but we do not for that reason infer that her kindness towards them is mere automatism. There is no necessary opposition between reason and instinct, and certainly none between emotion and instinct. To the very functions from which we derive the most pleasure we are impelled by an irresistible innate tendency. In any particular case, it may be very difficult to determine the amount of reasoning power possessed by the animal, the exact relation of ends to means in its consciousness; but it may be remarked that there are human mothers who reason little with regard to the preservation of the species or other so-called ends secured by the care they give their offspring; the care is spontaneous, but may not be the less a matter of warm affection. It appears strange, therefore, that exactly that constancy and strength of tendency, with need of satisfaction by other channels if the usual ones fail, which we use as proof of extreme mother-tenderness in the case of human beings should, in the case of other species, be turned into an argument to disprove the existence of this feeling.

It is sometimes argued that the feeling of the parent animal in the care of its young is, in any case, merely one of pleasure in the activity, and has no connection with the good of the offspring. In such a case as that of the robin, where the effects of the care come within the experience of the mother, this is a mere arbitrary assumption, although direct proof of the contrary may be impossible. Naturally, in the case of an animal which cares for its eggs, but never comes in contact with the offspring that are hatched from them, it would be impossible to suppose any affection for the offspring as such; their existence does not 
come within the range of the animal's experience. With regard to an animal whose connection with its young is constant, the theory that pleasure in their care has no reference to their welfare, has no evidence to support it and is unjustifiable. If we cannot directly disprove it, we have, at least, the evidence of many facts unfavorable to it. The distress manifested not only by many mammals (who might be supposed to find physical discomfort merely in the absence of the means of relief of the milkglands), but also by other animals and notably birds, in the loss of their young and even in any danger that threatens them, - the indescribably mournful sounds at deprivation, the after depression, and the capacity for self-sacrifice in their defence, would lead us naturally, from an unprejudiced standpoint, to a belief in something very like what we term mother-love in human beings. From Letourneau's "Sociology based upon Ethnography," 1 I quote the following: "A female wren, observed by Montagu, spent sixteen hours a day in looking for food for her little ones. At Delft, when there was a fire raging, a female white stork, not being able to carry away her young ones, allowed herself to be burnt with them.... J. J. Hayes tells us of a female white bear forgetting the Esquimaux dogs, the huntsmen, and her own wounds, in order to hide her own little bear with her body, to lick her and to protect her. In Central Africa, a female elephant, all covered and pierced with javelins, hurled at her by the escort of black men attending upon Livingstone, was all the while protecting her young one with her trunk which her own large body enabled her to cover. . . . In Sumatra, a female orang-outang, pursued with her little one by Captain Hall and wounded by a gunshot, threw her infant on to the highest branches of the tree on to which she had climbed, and continued, until she died, exhorting her young one to escape. In Brazil, Sphix saw a female of the stentor niger who, wounded by a gunshot, collected her last remaining strength to throw her young one on to one of the branches close by; when she had performed this last act of duty, she fell from the tree and died." In Romanes' "Animal Intelligence," occurs the following quotation from Dr. Franklin: " " 'I have known two parrots,' said he, 'which had lived together four years, when the female became

1 Pp. 141, 142, translation by Henry M. Trollope.

2 Eng. ed. Internat. Scientific Ser., p. 276; quoted from “The Zoölogist." 
weak and her legs swelled. These were symptoms of gout, a disease to which all birds of this family are very subject in England. It became impossible for her to descend from the perch, or to take her food as formerly, but the male was most assiduous in carrying it to her in his beak. He continued feeding her in this manner during four months, but the infirmities of his companion increased from day to day, so that at last she was unable to support herself on the perch. She remained at the bottom of the cage, making, from time to time, ineffectual efforts to regain the perch. The male was always near her, and with all his strength aided the attempts of his dear better half. Seizing the poor invalid by the beak or the upper part of the wing, he tried to raise her, and renewed his efforts several times. His constancy, his gestures, and his continued solicitude, all showed in this affectionate bird the most ardent desire to relieve the sufferings and assist the weakness of his companion. But the scene became still more interesting when the female was dying. Her unhappy spouse moved around her incessantly, his attention and tender cares redoubled. He even tried to open her beak to give her some nourishment. He ran to her, then returned with a troubled and agitated look. At intervals, he uttered the most plaintive cries; then, with his eyes fixed on her, kept a mournful silence. At length his companion breathed her last; from that moment he pined away, and died in the course of a few weeks.' "

Moreover, care of animals for other animals shows itself often where neither the relation of parent to offspring, nor the relation of sex, nor even that of species, furnishes the basis. Aside from the friendship and self-sacrifice of domestic animals for man, friendships, under domestication, between individuals of all manner of ordinarily most hostile species are reported. Such friendship is not at all infrequent between $\operatorname{dog}$ and cat. In the family of a relative of my own were once a quail and cat who were most devoted to each other. 'Ihey would spend hours playing together, and were often left alone together for long periods. The cat never manifested any tendency to regard the bird in the light of food; she seemed, however, well aware of the danger it might be under from other cats, and invariably drove these away when they endeavored to approach the house. This cat was also friendly to a tame robin which preceded the quail as pet in the same family. 
And furthermore, assistance is frequently given spontaneously where there has been no association before the act. There are a number of instances on record, and supported by good authority, where dogs have brought suffering individuals of their own kind to places where they had themselves received aid. Romanes cites from Mr. Oswald Fitch the story of a domestic cat who "was observed to take out some fish-bones from the house to the garden, and, being followed, was seen to have placed them in front of a miserably thin and evidently hungry stranger cat, who was devouring them; not satisfied with that, our cat returned, procured a fresh supply, and repeated its charitable offer, which was apparently as gratefully accepted. This act of benevolence over, our cat returned to its customary diningplace, the scullery, and ate its own dinner off the remainder of the bones." 1 Romanes says further: "An almost precisely similar case has been independently communicated to me by Dr. Allen Thomson, F.R.S. The only difference was that Dr. Thomson's cat drew the attention of the cook to the famishing stranger outside by pulling her dress and leading her to the place. When the cook supplied the hungry cat with some food, the other one paraded round and round while the meal was being discussed, purring loudly." "Mr. H. A. Macpherson writes me that in 1876 he had an old male cat and a kitten aged a few months. The cat, who had long been a favorite, was jealous of the kitten and 'showed considerable aversion to it.' One day the floor of a room in the basement of the house was taken up in order to repair some pipes. The day after the boards had been replaced, the cat 'entered the kitchen (he lived almost wholly on the drawing-room floor above), rubbed against the cook, and mewed without ceasing until he had engaged her attention. He then, by running to and fro, drew her to the room in which the work had taken place. The servant was puzzled until she heard a faint mew from beneath her feet. On the boards being lifted, the kitten emerged safe and sound, though half-starved. The cat watched the proceedings with the greatest interest until the kitten was released; but, on ascertaining that it was safe, he at once left the room, without evincing any pleasure at its return. Nor did he subsequently become really friendly with it." " 1883 .

1 " Mental Evolution in Animals," p. 345; cited from an article in "Nature," 
I cite still one other instance of animal affection from Romanes: "One of a shooting-party under a banian tree killed a female monkey, and carried it to his tent, which was soon surrounded by forty or fifty of the tribe, who made a great noise and seemed disposed to attack the aggressor. They retreated when he presented his fowling-piece, the dreadful effect of which they had witnessed, and appeared perfectly to understand. The head of the troop, however, stood his ground, chattering furiously; the sportsman, who perhaps felt some little degree of compunction for having killed one of the family, did not like to fire at the creature, and nothing short of firing would suffice to drive him off. At length he came to the door of the tent, and finding threats of no avail, began a lamentable moaning and by the most expressive gesture seemed to beg for the dead body. It was given him; he took it sorrowfully in his arms and bore it away to his expecting companions. They who were witnesses of this extraordinary scene resolved never again to fire at one of the monkey race." 1

As to the changeable and capricious appearance of the assistance rendered in animal associations, by one member to another, it may be said that any being of a different species who could look into our towns and cities might easily find as great problems of caprice here as among the ants and bees. We, too, leave our fellows to perish unaided; we, too, kill off, by neglect and hard usage, often not only or chiefly our drones, but even some of our most industrious, useful members of society. With us, too, there is very often greater hostility towards enemies than kindness towards friends. Many savage tribes, that we certainly concede to be endowed with intelligence, could learn of the ants, rather than teach them, with regard to the duties of mutual aid. With regard to other species than his own, even so-called civilized man is often eminently selfish and cruel. Among the savages the most extreme cruelty is often shown. Bain, in an essay entitled "Is there Such a 'Thing as Pure Malevolence?" cites from a book, "Siberian Pictures," together with mention of the pleasure shown by onlookers in the drowning of a man, an instance where boys seemed to find a genuine and peculiar delight in slowly roasting a dog to death. ${ }^{2}$ And Bruce describes in his travels the feasts of the Abyssinians, where the

1 “Animal Intelligence," p. 472.

2 " Mind," Vol. VIII. 
flesh was cut from an ox alive and bellowing with pain. But our police courts frequently bear witness to the possibility of the most wanton cruelty performed by people within our own most enlightened societies, although we may claim that cruelty is not so general in civilized societies. I personally have known of a case where, a horse becoming suddenly ill and falling upon the road, it was prodded by its owner with a pitchfork until it died of its wounds; and of another case where a man fastened to a tree a harmless kitten that had wandered into his yard, and deliberately stoned it to death. Surely we have very little right to criticise the slaughter of animals by other species, while we ourselves name the taking of life "sport." Our criticism of the play of the cat with the mouse as "cruel" is humorous-if there can be any humor connected with cruelty - as long as we ourselves find delight in the prolonged struggle of the trout and the torture of the fox-chase. Perhaps the cat may be under the impression that the mouse takes pleasure in being played with; certainly we can believe that this is possible, when beings who claim to possess so much higher intelligence can gravely assert that the fox enjoys the chase.

Amongst so-called civilized human beings, too, the care of parents for offspring is by no means universal, and mothers are known whom not even the fear of the law can hinder from sacrificing their children by the slow torture of starvation for the gain of a few pounds or for even simple relief from the trouble of their rearing. The reports of the Society for the Prevention of Cruelty to Children show that not strangers but parents are the most frequent sinners against the child. Nor is infanticide and neglect confined to the poorer classes. I repeat, if a being of some other species enabled to obtain only such external knowledge of us as we have of other species, some being beholding us, for instance, from distant planets, should endeavor to form a theory of our inner egoism and altruism, of sentiment and motive, he might be as puzzled as we are when we study the conduct of bees and ants. Even the helplessness of the ant species, Polyergus rufescens, at which we often wonder as stupidity, has its parallel in some of the former slave-owners of the southern states of North America, who live in the utmost poverty and ignorance because they have lost the habits of industry and consider work beneath them. Mother-love is certainly the rule 
amongst us; but it is not more constant or self-sacrificing than with some other species, though it, in general, accompanies the child farther in his career. This rule is not, however, universal. Human mothers of a lower type, who show fondness for their children when they are little, often exhibit little or none for them after they have grown out of arms.

It is claimed that altruism was, in its origin, egoism. Everything depends, in theory on this point, on our definition of the terms "origin" and "altruism." If we regard the life of animals in general or the life of any particular species as having been non-social before it was social, and as having become social through increase of numbers, the "chance" association which arose naturally in this way being favored by natural selection, we must assume function fundamentally advantageous to self without regard to the results to other beings to have been primary, whether or not we call this function egoism. With regard to animal life in general, we cannot avoid adopting some such view as this, since we find few species forming lasting bonds of association, a large number forming only exceedingly short ones, and some forming none at all, and since we must furthermore suppose a scarcity of living individuals to have preceded their multiplicity. Moreover, we cannot suppose consciousness to have been absent, in the case of many of the animal species, during the whole of this development. And where there is consciousness, pleasure must be a concomitant along the line of development, and customary forms of action come to present ends, whether or not the individual has the abstract concept of "ends."

But we need to remember that even the human race has not yet arrived at perfection, and that even moral altruism (for not all altruism is necessarily moral) is not yet absolutely attained in any species. Our ordinary use of the term is progressive; that which is altruistic at one period of history is often looked upon, at a later period, as merely a higher form of egoism. This fact should be borne in mind when, in Ethics or Political Economy, we inquire whether man was, in the beginning, altruistic. What do we mean here by "altruism," and what by "beginning"? A similar criticism may be made on the rather more usual question as to whether man was, in the beginning, social; what is the beginning of our species, and what degree of association is necessary in order that the individuals associating may be termed 
"social"? The question is a difficult one to answer from any point of view. While the majority of human beings, even the most savage, show some degree of gregariousness, there appear to be some tribes that are even less social in their habits than the most of our ape-cousins. Mr. Daiton says of the savages of Inner Borneo that they live in the most perfect state of nature, do not cultivate the earth or live in huts, do not eat either rice or salt, and do not associate with each other, but wander like wild animals in the forest. "The sexes meet in the jungle, or the man carries away a woman from some campong. When the children are old enough to shift for themselves, they usually separate, neither one afterwards thinking of the other." 1

As to just what form the development of altruism from egoism may have assumed in the case of any particular species, or how the individuals of the species may first have been led to association, the state of science does not, at present, enable us to say. Most authors, indeed, incline to class all social development as having its origin in some one form of family relation. Rolph, for instance, refers it to the necessary association of the sexes, at certain times, for the purpose of copulation. Others regard the care of the female for its young as the primary form from which all social organization has developed. Inasmuch, however, as the line of ascent from primitive protoplasm to man cannot be regarded as straight, but has very many branches, it is quite conceivable that the development may have taken place in different ways in different branches or different species; and the very various forms which social organization shows in different species is direct evidence in favor of such a supposition. 'Thus it is not, for instance, in some species, the mother animal, but the male, who cares for the young, and again, in other cases, affectionate relations of the sexes are not a prominent feature of the social structure. The attitude of a swarm of bees towards the queen, her progeny, and the drones, presents aspects entirely different from those of ant-nests or human tribal or state organization. In some species where the female exhibits considerable care and concern for her eggs or offspring, there is no especial friendliness between the sexes, and in other cases, where no care is given to offspring, there is still apparently some degree of friendliness, or at least of physical attraction, between male and female.

${ }^{1}$ Lubbock: "The Origin of Civilisation," pp. 9, 10. 
It is not only conceivable that the habit of association may have been developed by different means in different species, but it is also conceivable that, in some cases, several forms of family relation may have assisted equally, and in other cases have united, even if not in equal measure, in producing the result. The association of parent with offspring, for instance, is in most cases impossible without some degree of association between the offspring.

However we may suppose social relations to have originated in the case of any particular species, whether through the sexual or the parental relations or through both combined, and whether we trace these relations themselves back, in the one instance, to the original union of the sexes in the individual, and propagation as self-division, in the other to the unity of mother and offspring before the individual life commences, or whether we simply begin with some non-hostile contact of individuals as already existent, it is evident that, with increasing competition, coöperation must be to the advantage of those coopperating. Those individuals whose single strength is supplemented by the aid of others must succeed best in the struggle for existence. Moreover, with the exercise of altruistic forms of action, we must suppose pleasure in its exercise to increase, in so far as we suppose any consciousness at all in the animal performing the action. The greater the degree of exercise, the greater the pleasure connected with the action, and the more readily the organism will respond to conditions permitting its accomplishment; while repetition, again, must increase tendency to repetition. This is true not only of exactly the same form of action, but also of similar forms, that is, of forms having some like elements. The conditions of action are never exactly the same; the environment is continually changing; but the animal tends to choose, among possible forms of action, that which corresponds most nearly to most exercised and pleasurable forms.

At just what period we are to regard the altruistic forms of action as becoming in spirit altruistic depends, as has already been said, on our definition of the degree of disinterested feeling necessary to altruism proper, aside from our theories of the existence and form of consciousness in the case of any particular species at any particular point of development. In the case of even disinterested human action, the altruism is not generally, or at least in very many cases, wholly unmixed with any thought of self, though this thought may not hold first place. If self-sacrifice be the 
test of altruistic feeling, then we must suppose the latter to exist, in some relations, even far down in the scale of being. In this case, just as in other cases where choice is necessary, the stronger tendency conquers even with the result of pain of disappointment in some other direction. The case of altruistic action is hence not unique in this respect, and it might perhaps be argued that such self-sacrifice would therefore be possible without any consideration or consciousness of the good accruing to others through its performance. But if we analyze the development of any habit, we find that the pleasure of the act speedily connects itself with all the constant results of the act that come within the experience of the performer of the act and are recognized as its results. Any result at first unpleasant must, if it is constant, either lead to the discontinuance of the act or else, with time, lose much of its quality of unpleasantness. Either the expected pain of this one factor is sufficient to counterbalance the pleasure awaited in the act, and a repetition of the act is thus avoided, or, as in all other cases of habitual experience, the pain or discomfort gradually diminishes, until, if the habit be long enough continued, pleasure takes its place. The pleasure of others must be a constant result of action that secures their welfare, and if this result comes within the conscious experience of the performer of the action, we can scarcely avoid supposing that, even if his action is in the beginning purely selfish, the pleasure of those benefited must come in time to play a part in the pleasure of the performer. The part it plays will not be, in the beginning, naturally, a very important one, but its importance will increase with time. If this is true in a measure even of the individual, it is doubly true of the species. Wherever, therefore, we may suppose the existence of sufficient intelligence for the inference of pleasure from its outer signs in others, it must be admitted to be possible and even probable that constant habits of self-sacrifice and helpfulness to others will be accompanied by some measure of altruistic feeling. And even if we suppose an insufficiency of intelligence for such inference, it is still possible and even probable that the constant symptoms of pleasure in others will come to be a part of the conditions of the pleasure of the individual or the species in whom habits of self-sacrifice have become constant, although their inner significance is not recognized. It may be objected that, if actual altruistic feeling were present in animals which show a 
certain amount of helpfulness towards others of their kind, this altruism would not desert these others at the very time of their greatest need or when any great peril to self is involved, or that it would show itself in many other acts than just those which, as in the case of the ants, secure the preservation of a society, or in that of some other species give a certain protection to the female during breeding time. The argument is wholly inconclusive, and has already been answered. The action of natural selection in the preservation of those forms of tendency that secure the preservation of the species does not annul the action of the will or render the presence of strong emotion in the direction of the tendency thus preserved impossible; on the contrary, we must suppose all tendency, in man equally with other animal species, to be the result of natural selection. And in man, too, altruism that is sufficient for some degree of sacrifice is insufficient for a greater. In man, as in other species, altruistic feeling and altruistic action vary according to the particular directions in which habit in the species and in the individual has been cultivated. Men and women who are not kind to each other will frequently be kind to little children. The average Englishman is kind to his dog in spite of his total indifference to the pain inflicted on the very nearly if not quite as intelligent fox; and he will grow indignant to the verge of tears over abuse of a horse, while he will regard the like abuse with little or no emotion when it is inflicted on a miserable donkey. I doubt if the average Englishman would shoot horses or dogs, even if they were good for food and useless otherwise, and abounded wild in Great Britain. But this is merely because association and habit have made him acquainted with the capacity of feeling in the horse and dog, and have accustomed him to humane treatment of them.

An argument sometimes advanced against the theory of a derivation of altruism from egoism is that such altruism has no premises or reasons ; if, say the advocates of this argument, a man performs an apparently altruistic act to-day from selfish motives, and performs the same act to-morrow withont calculation of the benefit to self to be gained from it, - if such a change were possible, then this man must simply have forgotten his motives for the act. But this is not altruism proper. Such action is the result of a logical confusion, but it can never be altruism. Altruism proper has a motive, and this motive is the desire to do good to others. 
With regard to this argument it may simply be said that it is wholly untenable from any evolutionist standpoint; it destroys at once the possibility of any moral progress. Intended to defend altruism and moral principle in general from what is designated as degradation, it is itself degrading in its denial of the compatibility of natural and moral advance. It posits the assertion that nothing can ever become that which it was not from the beginning, an assertion utterly inconsistent with any theory of growth, whether evolutional or otherwise. It is contradictory, too, of the directly observed every-day facts of individual experience. The ends with which we perform our acts, and the same acts, certainly change from day to day. The adult would have reason for shame were the ends with which he performs certain acts the same with those with which he performed those same acts when he was a child. The emotions with which we regard life and its various relations alter every day. If the change from egoism to altruism could be pronounced logical confusion, then all mental evolution must constitute an increase of intellectual disorder, a continuous progress towards less instead of greater intelligence. Where is the beginning of feeling and what was feeling in the beginning? Of what nature were the motives of our ape-like progenitors, and of what nature the first motive that appeared in the universe? and how have we ever arrived at the possession of other motives than these? What a confusion worse confounded must be our present motives, and of what a chaos of thought and emotion must the human intellect consist! The origin of any such argument as this, intended to disprove the theory of a derivation of altruism from egoism, is probably in the failure to distinguish the fact that both altruism and egoism, as we know them, are comparative, not absolute. Naturally, absolute altruism could not develop immediately from absolute egoism, that is, the one could not change immediately into the other. But there are very few human beings in whom some degree of altruism does not exist ; and all we may note directly of change of motive in ourselves, as well as all we ever could note of change in external action in other species, is gradual increase in this direction. In the individual case it is quite possible for change to take place in the opposite direction of the development of greater egoism.

In connection with the discussion of the development of motives, we may inquire what is the final end of action; I refer not to the 
ideal end but the actual end, although the two are not always distinguished in the answer to this question. The confusion of the two generally arises from forgetfulness of the fact that an end is the part of the result of an act particularly willed by the performer. The concept is again a teleological one, although often advanced, in some form, by persons of materialistic views. Thus some authors, looking at the process of evolution as continual survival of the fittest, and observing that natural selection thus tends continually towards health, so that the action of existing species is, in a large and ever increasing measure, favorable to health, assert that the latter is the end of action. Others, in like manner and from similar premises, argue that the preservation of the species is the end of action; or sometimes the logical inaccuracy involved in making health or the preservation of species the universal end of action is partly concealed by giving the assertion the form that one or the other of these is "the end attained" by action. To these statements may be answered: The health of the individual, although it sometimes appears as the end willed, is by no means the constant and universal end, but, on the contrary, rather an infrequent end. As to the preservation of the species, the concept has never been heard of by a majority of human beings, and a thing cannot be an end to those who have not heard of it. It is doubtful, moreover, whether even those to whom it is familiar often, if ever, make it the end of action. With regard to pleasure, it has already been said that special calculation of the pleasure to accrue to self is by no means a necessary part of the motive to action. Attention may again be called to the fact that it is not the future pleasure that decides the will to action in the case of struggle of conflicting tendencies, but that it is the more pleasurable representation, and that it is present pleasure which decides in any case. Or, rather, it is not the pleasure, the feeling alone, that decides, for feeling is never found alone; it is always combined with thought-images. 'The strength of pleasurable feeling is the "tone" in which the intensity of the function manifests itself, and according to which it tends to further expression in action. In the imagination of action and its results, or the thought of it, reflection may linger especially on any one of its elements, - on any part of the action or its results as inferred from the analogy of past experience; the pleasure to self is not necessarily the element on which the mind lays stress, and the 
pleasure to others may be the element with which thought is particularly occupied and which turns the scale of choice; just as, also, in the actual action and its results, the pleasure in pleasure or benefit accruing to others may more than counterbalance the pain which some other inevitable phase of the action or its results brings with it.

Much that has been said of the development of egoism from altruism still holds true of the individual, even if the idea of a progress in altruism through heredity be surrendered. The consideration of the question of heredity is, however, necessary to any complete or wide-reaching theory of moral progress. Hitherto, the actuality of the inheritance of altruistic tendency has been assumed on the strength of previous considerations with regard to heredity in general, according to which we could not conceive all the multifarious differences which appear in all the species and varieties of animal nature to have been present in simplest primal organisms, or all the differences of the different species and varieties which have arisen through sexual propagation from common ancestors to have been present as inherent potentialities in the germ-plasm, as such, of their common ancestors, and so cannot consider the lesser variations which go to make up the larger ones as due merely to the germ-plasm. It remains for us to examine the facts more particularly with respect to this special form of tendency. Stephen says : "An unreasoning animal can only adapt itself to new circumstances, except within a very narrow range, by acquiring a new organization; or, in other words, by becoming a different animal. Its habits and instincts may therefore remain fixed through countless generations. But man, by accumulating experiences, can virtually alter both his faculties and his surroundings without altering his organization. When this accumulation extends beyond the individual, it implies a social development, and explains the enormous changes wrought within historical times, and which define the difference between the savage and the civilized man." " "Briefly, society exists as it exists in virtue of this organization, which is as real as the organization of any material instrument, though it depends upon habits and instincts instead of arrangements of tangible and visible objects." ${ }^{2}$ "Children, no doubt, start with infinitely varying aptitudes for moral culture, as they start with stomachs of varying strength of digestion;

1 “The Science of Ethics," pp. 103, I04.

${ }^{2}$ Ibid. p. rog. 
but, in every case, the action of the social medium is an essential factor of the result." " Now, in the first place, objection may be made to the term "unreasoning animal," in that, whatever we may think with regard to inorganic matter and plant-life or even with regard to the lower forms of animal-life, the whole theory of evolution is opposed to the supposition that reason suddenly arises in man; and in that we have, moreover, in the case of many of the higher species, very conclusive evidence of the presence of some degree of reason. Mr. Stephen does not elsewhere make any positive assertion of the entire absence of reason in animals; yet to his remark that "It may be that germs of this capacity [i.e. the capacity to learn by experience and impart this knowledge to others] are to be found in the lower animals " he adds, "but we shall make no sensible error if we regard it, as it has always been regarded, as the exclusive prerogative oi humanity." 2 That is, we make no sensible error if we regard the progress of other animal species than our own to be wholly "organic," that of our own species, on the other hancl, to be wholly an accumulation of common knowledge. The division between man and the rest of the animal kingdom is thus made a very distinct and absolute line. It may be noticed, second, that the third quotation of the three cited consecutively above contains a very different statement from that of the first quotation. And it may be said, third, that the second quotation, while seeming to bear out the first, is in reality a contradiction of it, since it makes social organization dependent upon "habits" and "instincts."

Exactly what is it that is meant by the alteration of organization which is pronounced unnecessary to the "virtual "alteration of human faculties? From the modern spiritualistic, the materialistic, the positivistic, or any modern standpoint at all, it is difficult to perceive how mental alteration can be supposed without the assumption of an exactly corresponding physiological change. In view of the exceedingly minute structure of the nervous system, which is chiefly affected by such change, we may suppose this change to be so fine as to be imperceptible to sense-perception, but, since it must, in any case, be exactly coördinate with the psychical change, I fail to see how we can scientifically regard the one and at the same time ignore the other and pronounce it of no significance. And if we suppose any fixation of psychical altera-

1 "The Science of Ethics," p. 419.

2 Ibid. p. Io3. 
tion, we cannot avoid likewise supposing an exactly coördinate fixation of physiological alteration. Of course the question remains as to the extent to which fixation takes place in either case, and this question we have yet to consider. The weakness of Mr. Stephen's position lies in his assumption of fixation on the one side and his denial of it on the other.

How far are the moral qualities acquired in one generation inherited by the next? Inasmuch as all development is by inappreciable increments, all change of organization gradual, or, in psychical terms, inasmuch as character varies only slowly from the grooves of established habit, there is a general truth in the statement that all habit prominent enough to be noticed as such can generally be traced farther back than the next generation only. Nevertheless, here are a few cases for the Weismannites :-

"Gall speaks of a Russian family in which the father and grandfather had died prematurely, the victims of taste for strong drink. The grandson, at the age of five, manifested the same liking in the highest degree."

"'Trélat, in his work 'Folie Lucide,' states that a lady of regular life and economical habits was subject to fits of uncontrollable dipsomania. Loathing her state, she called herself a miserable drunkard, and mixed the most disgusting substances with her wine, but all in vain; the passion was stronger than her will. The mother and the uncle of this lady had also been subject to dipsomania."

"Charles $\mathrm{X}-$, son of an eccentric and intemperate father, manifested instincts of great cruelty from infancy. He was sent at an early age to various schools, but was expelled from them all. Being forced to enlist in the army, he sold his uniform for drink and only escaped a sentence of death on the testimony of physicians, who declared that he was the victim of an irresistible appetite. He was placed under restraint, and died of general paralysis."

"A man belonging to the educated class, and charged with important functions, succeeded for a long time in concealing his alcoholic habits from the eyes of the public; his family were the only sufferers by it. He had five children, only one of whom lived to maturity. Instincts of cruelty were manifested in this child, and from an early age its sole delight was to torture animals in every conceivable way. He was sent to school, but could not 
learn. In the proportions of the head he presented the character of microcephalism, and in the field of intellectual acquisition he could only reach a certain low stage, beyond which further progress was impossible. At the age of nineteen he had to be sent to an asylum for the insane."

"A man of an excellent family of laboring people was early addicted to drink, and died of chronic alcoholism, leaving seven children. The first two of these died, at an early age, of convulsions. The third became insane at twenty-two, and died an idiot. The fourth, after various attempts at suicide, fell into the lowest grade of idiocy. The fifth, of passionate and misanthropic temper, broke off all relations with his family. His sister suffers from nervous disorder, which chiefly takes the form of hysteria, with intermittent attacks of insanity. The seventh, a very intelligent workman, but of nervous temperament, freely gives expression to the gloomiest forebodings as to his intellectual future."

"Dr. Morel gives the history of a family living in the Vosges, in which the great-grandfather was a drunkard, and died from the effects of intoxication; and the grandfather, subject to the same passion, died a maniac. He had a son far more sober than himself, but subject to hypochondria and of homicidal tendencies; the son of this latter was stupid, idiotic. Here we see, in the first generation, alcoholic excess; in the second, hereditary dipsomania; in the third, hypochondria; and in the fourth, idiocy and probable extinction of the race." 1

It is the general testimony of authorities that mental disease may thus appear in one generation as general tendency to excess, in another as homicidal mania, in another as microcephalism, etc. Here we have examples of the hereditary character of what we recognize as nervous disease, which yet has its moral as well as its intellectual side. There are few who do not recognize the power

${ }^{1}$ Ribot: "Heredity." IIere we have examples which show that disease, as well as healthful organization and function, are subject to variation; and it may occur to us to wonder that no one has thought of referring these variations to some supernatural interference or special inner spontaneity; that theories which assume some transcendental agency or some spontaneously acting vital principle as the cause of normal, healthful variation have yet either left the variations of disease out of consideration or else simply referred them to influence of the environment. The reason for this, as far as transcendental interference is concerned, is evident; any theory of teleology in such cases must point to malevolent not benevolent design. 
of the parent, through injury to his own health, to affect the health of his children; and yet that which we call disease is not more physical than that which we call moral characteristic. However, the physical side of that which we call normal moral characteristic is more withdrawn from observation; that which is recognized as mental disease forms, in this respect, a link between what we term ill-health and mental characteristic. The physical features of what we term ill-health attract our attention especially because of the weakness and incapacity or the distinct physical pain involved; the physical side of insanity comes also more or less distinctly to our notice, but the physical accompaniments of normal characteristic attract less attention. And yet all these three conditions have each a psychical and each a physiological side. It is therefore difficult to understand how the possibility of the inheritance of ill-health from want or excess can be acknowledged and yet the possibility of the inheritance of psychical characteristic acquired by the parent be doubted; the latter has its organic side as much as the former. And no better illustration of this fact can be found than in just such cases as those above cited, where that which appears in the first place as mere excess, that is, moral characteristic as we ordinarily term it, takes finally the form of microcephalism, idiocy, or insanity.

Man's early existence as an individual is distinguished by the length of duration of a condition of helplessness, at the beginning of which, beyond the fundamental so-called organic action, only a few simple activities manifest themselves. The human being is born with almost everything to acquire, and the earlier years, during which habits are slowly accumulating, appear peculiarly adaptive or formative. The human child is peculiarly susceptible, as regards mental and moral acquirements, to the nature of his surroundings. But this fact does not necessarily mean any more than what Stephen asserts in the last of the three quotations above cited, namely, that the social medium is an essential factor of the result; it does not necessarily exclude the inheritance of moral or immoral tendency acquired under civilization or even by near ancestors. Even in cases of the inheritance of the most extreme passion for alcohol, we cannot suppose that the taste would ever have manifested itself, had alcohol never come within the reach of the inheriting individual. The young kitten that has never tasted meat will snatch at a piece as soon as it scents it; but we 
cannot suppose that the evidently inherited taste for flesh would ever appear, did flesh never come within the range of its senseperception. Since a suitable environment must always be conceived as essential to the development even of the most inveterate inherited qualities, and since man's mental and especially his moral superiority has been developed in connection with social conditions, it is conceivable that, these conditions failing, his mental and moral development may show a lack coördinate with the degree of such failure. And here is an answer to those who, in contesting the theory of any moral inheritance, state their views in the final form that if any inheritance at all can be claimed, it can only be as a certain degree of readiness in responding to the conditions of civilization; no inheritance can ever be anything more than this ; the existence, to a sufficient degree, of complementary conditions in the environment is always necessary to the development of tendency. It is, therefore, conceivable that the child of civilized parents of a higher type of morality, if carried off, in infancy, by savages, might fail to exhibit the high character of its parents, just as it is conceivable and more than probable that it would fail to exhibit their higher intellectual gifts. It is also conceivable that the child of moral parentage may inherit the capacity of high moral development and yet fall into crime, if circumstances afford him no education save that of association with hardened criminals. We might only with reason expect to find, in the case of the supposed child abducted by savages, a certain mental acuteness applied to savage affairs and some greater degree of humane feeling, dominated, however, by savage conceptions ; as also greater ease in the acquirement of civilized ideas and customs in case of a return to higher surroundings before maturity; and we might only expect to find, in the case of the child brought up among criminals, a greater degree of that primitive honor and faithfulness which may exist among criminals. Modern reformatories have testified to the possibility of the redemption of a large number of criminals from their evil life, but they have shown, nevertheless, that there is a lust of cupidity, a love of meanness, and an animality from which rescue is almost if not quite impossible. The reaction of men whose past opportunities have been about equal, upon effort for their reform, exhibits also very different degrees of readiness. The testimony of reformatories for the young is especially of worth on this point; and I once heard Mrs. Mary 
A. Livermore, whose interest in reformatories and prisons is well known, describe the faces of many of the children to be found in a certain institution of this sort, as bearing fearful witness to the fact that they had been " mortgaged to the devil before they were born." I remember a number of cases cited by the matron of a certain orphan asylum showing that children taken from their home at too early an age to have learned the sins of their parents by imitation may yet repeat those sins. Out of three children of the same parents, the one of whom was a drunkard and prostitute, the other a thief, one developed, at a very early age, a-tendency to dishonesty, another an extreme morbid eroticism, and the third child appeared to have escaped the evil inheritance; but he was still very young when I last heard of hirn. The two children did not exhibit these evil traits at their entrance to the home, but developed them later.

And here it may be noticed that the fact of the unformed character of the infant does not prove that the tendencies which make their appearance in later life are wholly the result of the environment. It has been remarked by biologists and pathologists that inherited characteristics tend to appear at an age corresponding to that at which they appeared in the progenitor. The caterpillar does not undergo metamorphosis with a less regularity because it is not, in the beginning, a butterfly, and the beard does not the less appear in the adult human male because he was not born bearded. Diseases of the brain often develop, for several generations, at nearly the same age, and there seems to be no reason why we should not suppose the like to be true in the case of many normal characteristics. Ribot cites from Voltaire the following case: " 'I have with my own eyes,' he writes, 'seen a suicide that is worthy of the attention of physicians. A thoughtful professional man, of mature age, of regular habits, having no strong passions, and beyond the reach of want, committed suicide on the 17 th of October, 1769 , leaving behind him, addressed to the council of his native city, an apology for his voluntary death, which it was not thought advisable to publish, lest men should be encouraged to quit a life whereof so much evil is spoken. So far there is nothing extraordinary, since instances of this kind are everywhere to be found; but here is the astonishing feature of the case: his father and his brother had committed suicide at the same age as himself. What hidden 
disposition of mind, what sympathy, what concurrence of physical laws, caused this father and his two sons to perish by their own hand and by the same form of death, just when they had acquired the same year of their age?" "1 Ribot continues :-

"Since Voltaire's day, the history of mental disease has registered a great number of similar facts. They abound in Gall, Esquirol, Moreau of Tours, and in all the writers on insanity. Esquirol knew a family in which the grandmother, mother, daughter, and grandson, committed suicide. 'A father of taciturn disposition,' says Falret, 'had five sons. The eldest, at the age of forty, threw himself out of a third-story window; the second strangled himself at the age of thirty-five; the third threw himself out of a window; the fourth shot himself; a cousin of theirs drowned himself for a trifling cause. In the Oroten family, the oldest in Teneriffe, two sisters were affected with suicidal mania, and their brother, grandfather, and two uncles, put an end to their own lives.' ... The point which excited Voltaire's surprise, viz. the heredity of suicide at a definite age, has been often noticed: 'M. L L - a monomaniac,' says Moreau of Tours, 'put an end to his life at the age of thirty. His son had hardly attained the same age when he was attacked with the same monomania, and made two attempts at suicide. Another man, in the prime of life, fell into a melancholy state and drowned himself; his son, of good constitution, wealthy, and the father of two gifted children, drowned himself at the same age. A wine-taster who had made a mistake as to the quality of a wine threw himself into the water in a fit of desperation. He was rescued, but afterwards accomplished his purpose. The physician who had attended him ascertained that this man's father and one of his brothers had committed suicide at the same age and in the same way.' ...

"A woman named Olhaven fell ill of a serious disorder, which obliged her to wean her daughter, six weeks old. This complaint of the mother began by an irresistible desire to kill her child. This purpose was discovered in season to prevent it. She was next seized with a violent fever which utterly blotted the fact from her memory, and she afterwards proved a most devoted mother to her daughter. 'This daughter, become a mother in her turn,

1 "Heredity," pp. I24, 125. Quoted from the "Dictionnaire Philosophique," article "Caton." 
took two children to nurse. For some days she had suffered from fatigue and from 'movements in the stomach,' when one evening as she was in her room with the infants, one of them on her lap, she was suddenly seized by a strong desire to cut its throat. Alarmed by the horrible temptation, she ran from the spot with the knife in her hand, and sought in singing, dancing, and sleep, a refuge from the thoughts that haunted her. Hardly had she fallen asleep when she started up, her mind filled with the same idea, which now was irresistible. She was, however, controlled, and in a measure calmed. The homicidal delirium recurred, and finally gave way, only after many remedies had been employed."

These are only a few out of the many instances that might be given of recurrence, at the same age or under the stimulation of similar conditions, of so-called pathological states. Science has hitherto given more study to such cases than to the inheritance of healthful conditions, though the line between healthful mental conditions and mental disease is very difficult to draw, and the assumption that all suicides are more insane than many of the people who are regarded as sane is unwarranted; of course if one starts with the premise that suicide is always a symptom of insanity, then the conclusion follows naturally that all suicides are insane; but this is a mere argument in a circle. As far as the inheritance of healthy or normal mental characteristics is concerned, we do know at least, from general observation, that a child often exhibits, as it develops, more and more rather than less and less the characteristics of some progenitor; and this, moreover, in many cases where the possibility of imitation is excluded. Observations might possibly be made here in a line with former reflections on man's adaptability and Haeckel's theory of the prenatal existence of the individual as repeating the history of his species. In the case of postnatal as well as in that of prenatal existence, the action of the environment can no more be left out of account than can that of heredity; and the influence of favorable or of unfavorable conditions at corresponding periods of development may explain the exaggerated growth or, on the other hand, the dwarfed character or non-appearance of tendencies associated in their development with these periods. But at present such observations can be little more than speculation. We may at least say, however, that Mr. Leslie Stephen's statement of the case, namely, that children "start with infinitely varying capacities" 
but that the environment of civilization is that which finally makes them what they become morally and mentally, should rather be reversed ; for it is rather true that children are born into the world on about the same level mentally and morally (for we observe but little difference in the faculties of new-born babes), but that they by no means react, in development, upon the same or a similar environment in a similar manner. The case of the Athenian baby, whose probable equality with the modern infant is used by Mr. Stephen as an argument that the human race has made no progress as far as innate qualities are concerned, would therefore scarcely be a case in point, even if it were capable of proof, - as it is not. But it cannot be called a case in point in any sense, the English baby with which Mr. Stephen compares the Athenian infant not being of Athenian descent. Any comparison of this sort, to be of worth in the discussion of the element of heredity in human progress, must be between the baby of the primitive savage Briton and the modern British infant. The Athenians arrived at a high degree of social development ; but the very fact that neither their civilization nor even that of Rome was acquired by the less civilized races who were their conquerors is rather testimony in favor of the theory of the hereditary, organic character of the habits and capacities acquired in the course of civilization. Nor have the Athenians transmitted their type unmixed; there is no pure Athenian or Greek race at the present day with which we could compare the ancient Greeks, even if we desired to affirm so great an independence of circumstances as would assure to such a race the unimpaired faculties of their ancestors in spite of all the changes in their environment which history records. Not only the environment was changed and mixed; the stock, also, of that race which once regarded all strangers as barbarians became equally impure. And assuredly the comparison of the "average child of to-day" with an Archimedes or a Themistocles is anything but a fair one. ${ }^{1}$ Taken with the qualification of the predicate which Mr. Stephen cautiously introduces in asserting that the innate qualities of the average modern child are not "radically" superior to those of the greatest ancients, it leads us to suspect that Mr. Stephen is not, himself, very thoroughly convinced of what he attempts to prove. We may agree with Mr. Stephen that "If Homer or Plato had been born amongst the Hottentots, they

1 "The Science of Ethics," pp. IO2, $\mathrm{IO}_{3}$. 
could no more have composed the 'Iliad' or the 'Dialogues' than Beethoven could have composed his music, however fine his ear or delicate his organization, in the days when the only musical instrument was the tom-tom" 1 ; for certainly no one can reach the same heights under an unfavorable environment that he might have attained under a favorable one; and that Homer could have expressed, in the ruder poetry which he might still have composed among Hottentots, the sentiments of the "Iliad," or Beethoven have produced his sonatas with the assistance of the tom-tom (provided that remained the only instrument after the appearance of an individual of such musical capacity as a Beethoven), cannot be conceived. But it is also inconceivable that a Beethoven, a Homer, or a Plato, could be born among the Hottentots, if " to be born among them" means to be born of their stock.

In order to make any direct comparison between the capacities of the descendants of civilized parents and those of uncivilized progenitors, we ought to be able to compare average results obtained in savage infants removed, in earliest infancy, to the advantages of civilization, with the average mental and moral acquirements of individuals born under those influences. We need to compare averages, I say, and not one or two individual cases alone; for, in order to assert the organic and hereditary character of human progress up to and under civilization, we are by no means compelled to prove a like advance in all parts of a nation or people, or even advance at all in every part. It is conceivable, and wholly in accordance with the general course of evolution, that types should remain stationary while other types are advancing, that lower types should continue to exist side by side with higher ones that have developed out of them, and even that, in some lines of descent, retrogression should take place while the species or a society as a whole is progressing. But our data for comparison of averages are not, by any means, as satisfactory as could be wished; for nowhere are the direct descendants of uncivilized races given equal advantages with those of the descendants of peoples already civilized. Galton's comparison of the negro with the white man is, for this reason, too extreme in its conclusions as to the hereditary character of intellect. Yet some general facts may be noted. And perhaps no better field for comparison is afforded us than the United States, where the white

1 "The Science of Ethics," p. I07. 
population is not the mere offshoot and tributary of a nation the great majority of whose better representatives inhabit a distant land, but an independent and successful nation, and where the negro race, while yet untutored, was suddenly endowed with a liberty nominally as great as that of the white man, together with a part in the government and a right to state education. This liberty may be, indeed is, in many parts of the South, a mere pretence, though even there toleration is gradually being acquired; but in the North the negro is treated on very nearly the same footing with the white man, the indignities offered him having their origin, for the most part, with former slave-holders, not with the born and bred Northerner. Negro children have free access to the northern schools, where they may often be seen sitting side by side with white children; and the best of American universities are open to negro students. If, then, the average of opinion, even in the North, maintains a certain amount of condescension towards the African, this condescension is no greater in degree than that maintained by the aristocracy of Europe towards the so-called lower (not the lowest) classes, and in spite of which many have risen to prominence from those classes. Indeed, the measure of condescension is rather less than the average manifested by master to underling in many European countries not so democratic as England; it would compare favorably with the attitude of the petty German officials to the ordinary citizen of the less well-to-do classes. It may mean discouragement, but there is no reason why it should, in all cases, mean failure. Yet, as a fact, very few of pure negro blood have risen to any prominence whatever, and the average of intelligence appears comparatively low; the large majority of those who have risen to eminence have had some admixture of the blood of the white race. The American Indian appears to be more capable of cultivation; but he has enjoyed fewer advantages than the negro. The Indian children at the schools provided for them do not, however, appear to exhibit the degree of intelligence possessed by white children. On the other hand, the mixture of white and Indian blood seems to produce, sometimes, rather more than the average of intelligence. The writer is acquainted with two cases of this kind. The first was that of the daughter of an ignorant Indian father, who lived entirely by hunting and fishing, and of an almost as ignorant white mother. The child, who had at first no advantages save those afforded by a primitive district school, nevertheless early 
developed an insatiable love of study, gained access to a higher school, and finally to what was, in her time, the highest school for women in the country. Here she did housework, during a course of four years, in order partly to pay her expenses, supplying the remaining sum for tuition afterwards out of her earnings as a teacher. By clothing herself, summer and winter, in cheap prints, she also saved enough to buy the time of a sister who had been bound out, assisted in the education of the rest of the family, and taught a school whose excellence is remembered and praised to this day. But the Indian is commonly supposed to be of higher stock than the African negro; he certainly exhibits, even in his uncivilized state, a cunning, a courage, and a persistence, of a higher type than that of the African; and the superiority of a mixture between this alert type and the intelligence of the white man is thus explained. I repeat, though the subtle results of many minute accumulating influences of individual environment must undoubtedly be taken into consideration in our judgment of different races, the difference of opportunity does not seem to account fully for the great difference of attainment.

It must be noticed, too, that, in comparing the negro with the white man in the United States, we have not compared a wholly savage people with a civilized one; for the negro has been, for several generations, in contact with civilization, and must have gained something from this contact. It is to be greatly doubted whether the infants of those Siberians of whose pleasure in the suffering of other beings an instance was given above would, even under the best of influences, develop into individuals of much real benevolence. The average child of civilized society is somewhat callous to the sufferings of animals, partly because he does not realize the reality of those sufferings; yet I have seen lost kittens tenderly cared for by ragged little street urchins; and I have more than once heard small boys, playing in the gutter, exclaim at the beating of a donkey or a horse. The child repeats, perhaps, to some extent, the history of his race's origin in savagery. Yet it is to be seriously doubted whether the children of the savages described as delighting in cutting their meat from living animals would attain, even under the most careful training, the average spontaneous humanity of the lad of civilized progenitors, or would ever become truly humane men and women. It is conceivable that superior mental and moral capacity may remain compara- 
tively undeveloped, proper environment lacking, but we begin to see the fallacy of concluding, from such cases, the non-hereditary character of capacity when we suppose such cases as those above, of the rearing of savage infants under civilization. It must be added of the very isolated cases - of which much is often made -in which the children of civilized parents have been stolen by savages, at an early age, (I) that it is not, and cannot be, maintained that all the descendants of civilized progenitors are endowed with superior mental and moral tendency; and (2) that such instances are too few in number to furnish, alone, the basis of any theory. The evidence furnished us by the general results of neglect in the midst of civilization is more to the point; but, even in these cases, it must be shown that the children came of good parentage in order that the evidence may be admitted as telling against the theory of heredity. Every breeder of animals counts with the greatest confidence upon the action of the laws of heredity ; and no reason can be given why these laws should not work in the case of man, why he should be the one species exempt from them. It is impossible to cross the dog with the wolf without perceiving the result of the crossing, in the mental as well as the physical characteristics of the offspring; and the dog does not differ more from the wolf than does civilized man, in the most advanced nations, from the savage. Even his physical characteristics, the contour of the head and face especially, the form of the features as well as the expression, are different and imply a higher type.

And, in discussing lower types in the midst of civilization, we cannot do better than give some consideration to Dugdale's remarkable book on the Jukes, which has already been mentioned. In this book is traced the history of five hundred and forty persons belonging to seven generations of descendants of five sisters, there being much intermarrying among them. Out of two hundred and fifty-two Juke women, whose history is traced, thirtythree were illegitimate, eighteen were mothers of bastards before marriage, twelve the mothers of bastards after marriage, fifty-three were prostitutes (the cases of eight being unascertained), thirteen were barren, eleven kept brothels, thirty-seven had syphilis, fortyfive received, at some time, outdoor relief, the total number of years amounting to two hundred and forty-two, twenty-four received almshouse relief, the time reaching a total of thirty-five 
years, and sixteen were committed for crimes for a total of one and three-fourths years, the number of offences being twenty-four. Out of two hundred and twenty-five Juke men, forty-nine were illegitimate, twenty were prostitutes, one kept a brothel, fourteen were afflicted with syphilis, fifty received outdoor relief, the time being, in total, two hundred and seventy years, twenty-nine were in the almshouse for a total of forty-six years, and thirty-three were committed for crime for a total of eighty-nine and a half years, the number of offences being fifty-nine. The lines with which the Jukes cohabited or intermarried were naturally of a low moral type, but they do not show nearly as high a percentage of crime and pauperism; thus among the marriageable women of the Jukes, we find the percentage of harlotry to be 52.40 , among those of the intermarrying or cohabiting lines only $4 \mathrm{r} .76$. Of the stock of Ada Juke, known to the police as "Margaret, the mother of criminals," nine offenders were sent to prison for a total of sixty years, their crimes constituting fifty-four per cent of all the crimes against property recorded of the Jukes, and including burglary, grand larceny, and highway robbery ; besides one murder and three attempts at rape. Dugdale thus describes his first acquaintance with the "Jukes." "In July, I 874 , the New York Prison Association having deputed me to visit thirteen of the county jails of this state and report thereupon, I made a tour of inspection in pursuance of that appointment. No specially striking cases of criminal careers, traceable through several generations, presented themselves till — County was reached. Here, however, were found six persons, under four family names, who turned out to be blood relations in some degree. The oldest, a man of forty-five, was waiting trial for receiving stolen goods; his daughter, aged eighteen, held as witness against him; her uncle, aged forty-two, burglary in the first degree ; the illegitimate daughter of the latter's wife, aged twelve years, upon which child the latter had attempted rape, to be sent to the reformatory for vagrancy; and two brothers in another branch of the family, aged respectively nineteen and fourteen, accused of an assault with intent to kill, they having maliciously pushed a child over a high cliff and nearly killed him. Upon trial, the oldest was acquitted, though the goods stolen were found in his house, his previous good character saving him; the guilt belonged to his brother-in-law, the man aged forty-two above-mentioned, who was 
living in the house. This brother-in-law is an illegitimate child, an habitual criminal, and the son of an unpunished and cautious thief. He had two brothers and one sister, all of whom are thieves, the sister being the contriver of crime, they its executors. The daughter of this woman, the girl aged eighteen above-mentioned, testified, at the trial which resulted in convicting her uncle and procuring his sentence for twenty years to state prison, that she was forced to join him in his last foray, that he had loaded her with the booty and beat her on the journey home, over two miles, because she lagged under the load. When this girl was released, her family in jail, and thus left without a home, she was forced to make her lodging in a brothel on the outskirts of the city. Next morning she applied to the judge to be recommitted to prison 'for protection' against certain specified carnal outrages required of her and submitted to. She has since been sent to the house of refuge. Of the two boys, one was discharged by the grand jury; the other was tried and received five years' imprisonment in Sing Sing.

"These six persons belonged to a long lineage, reaching back to the early colonists, and had intermarried so slightly with the emigrant population of the Old World that they may be called a strictly Anerican family. They had lived in the same locality for generations, and were so despised by the respectable community that their family name had come to be used generically as a term of reproaich.

"That this was deserved became manifest on slight inquiry. It was found that out of twenty-nine males, in ages ranging from fifteen to seventy-five, the immediate blood-relations of these six persons, seventeen of them were criminals, or fifty-eight per cent ; while fifteen were convicted of some degree of offence, and received seventy-one years of sentence. . . . The crimes and misdemeanors they committed were assault and battery, assault with intent to kill, murder, attempt at rape, petit larceny, grand larceny, burglary, forgery, cruelty to animals."

But this book of Dugdale's, which traces so clearly and thoroughly long lines of criminal descent, makes manifest, also, the influence of environment. We find, for instance, in the line of the illegitimate posterity of Ada Juke, generation five, the case of a male descendant, who was sentenced to Sing Sing for three years at the age of twenty-two, but who, leaving prison at the expiration of his sen- 
tence, abandoned crime and settled down to steady employment. A second case is that of another male descendant of Ada, who assisted his brother in burglary at the age of twelve, and served probably some thirteen or fourteen years in prison, but later reformed and took to stone-quarrying, having learned, says Dugdale, industrious habits in prison. A brother of this man, who had also served sentences in jail for assault and battery, and a term of two years at Sing Sing for burglary (the term beginning at the age of twenty-two), moved at the age of thirty-one into the same county as his brother, and went into the business of quarrying. A female descendant in the illegitimate line of Ada, generation five, who seems to have followed a dissolute life up to the age of fifteen, at this point married a German, a "steady, industrious, plodding man," and settled down into a reputable woman. In the legitimate line of Ada, again, generation five, we find the case of a girl "said to have been born in the poorhouse," who "was adopted out from there into a wealthy family, and is doing well." In all these cases, the reform was the result of contact, during the earlier period of life, with new elements inducing industry and sobriety. Such cases might lead us to doubt the conclusions we should otherwise feel justified in drawing with regard to the action of heredity, and must certainly render us cautious not to impute the whole character of the individual to heredity alone. But the complicated nature of all social relations should restrain us from laying all stress upon any one element in those relations, in any case. Here, again, we recur to the conception of conditions and results in distinction from that of cause and effect. If statistics such as these of the Jukes included minute and careful statements as to mental and physical characteristics and resemblances, they would undeniably be much more reliable basis for conclusions as to the hereditary nature of character. Nevertheless, incomplete though this evidence be, it is by no means such that it can be logically disregarded. It is to be said of such cases of reform and respectability as those noticed under favorable influences (I) that we are not informed as to its exact extent and motive and have no means of knowing what these were; (2) that, if reversion to ancestral types is possible in the sense of deterioration, there is no reason why it should not be possible in the opposite sense also, no reason why better characters should not, through, perhaps, some favorable prenatal influence at exactly the right period of develop- 
ment, occasionally crop out in a line of general baseness $;^{1}$ and (3) that the admixture of a strain of somewhat better blood may produce, or some especial crossing be favorable to, the development of higher character in a part, though not necessarily all, of the offspring. "When the domestic pig and the wild boar or the wolf and the dog are crossed," says Ribot," "some of the progeny inherit the savage, and others the domestic instincts. Similar facts have been observed by Girou in the crossing of different races of dogs and cats." We know quite well that the same law governs the transmission of character in human beings. In a family of children, some will inherit the characteristics of the father, some those of the mother. Mr. Jenkins of the Bureau of Police of Brooklyn, N.Y., related to me a case that had come under his notice. Of a family consisting of father, mother, two sons, and a daughter, the mother was a hard-working, honest washerwoman, while the father was depraved in his tendencies; and of the three children the daughter resembled the mother in character, the sons, on the other hand, their father. One of the sons was sentenced to prison for a bad case of burglary, and was shot while attempting to escape ; and on the same day on which his picture was removed from the rogues' gallery, his brother's was hung in its place, the latter having, with calm deliberation and preparation, murdered a girl with whom he had some relation. A similar case is recorded by Gall, where the mother represented the good, the father the evil stock, and of five children three were condemned to severe penalties for thieving, the other two lived correct lives. It is to be noticed that, of the three cases of better character among the Jukes cited above, the two reformed characters were brothers. It is by no means proved by these cases that all or a majority of the Jukes were capable, even under the best of influences, of a like betterment of character. On the contrary: the general characteristics of extreme licentiousness attaching to the whole family, on which Dugdale lays special stress, - a licentiousness extending even to cohabitation and marriage with the negroes at a time when the latter were yet in slavery and regarded as little more than animals, - as well as the exceeding viciousness and inhumanity exhibited in some of the crimes (witness the attempted rape on the niece of twelve and the pushing of the child over the cliff), show a tendency

1 See previous observations on this subject, p. 408 .

2 “ Heredity," Engl. trans., p. 84 . 
of character much below the average. Nor was the prison discipline which accomplished the reform of the two brothers the only opportunity of steady industry, or the prison the only reformatory environment afforded. Dugdale mentions an " extensive employer of labor, located near the original settlement of the Jukes," who "employs several members of it," treating them "with firmness and unvaryingly scrupulous fairness," interposing his authority and checking them in incipient crime. He acts as their banker and, as school trustee, arranges, "where widows depend upon their boys for support, that they shall work for him and go to school alternate weeks." If, indeed, the family is located, as it seems to be, in the rather sparsely settled districts of northern New York, it is scarcely likely to suffer great isolation, as it might in the midst of a city, or to be excluded from means of honest livelihood. Dugdale mentions, indeed, that this employer "has not taken up this work as a 'mission,' but strictly as a business man, who, finding himself placed where he must employ the rude laborers of his locality, deals with them on the sound and healthy basis of commercial contract, honestly carried out and rigidly enforced." Unfortunately, Dugdale does not furnish us with any exact information as to the result of this very humane course of treatment. We can only revert to his remark that, though the Jukes had lived in this neighborhood for generations where work was evidently not lacking nor kind and judicious treatment absent, their name was used generically, by the reputable community, as a term of reproach.

We have already noticed some inconsistencies in Stephen's theory of human progress as merely that of an accumulation of knowledge. But he practically contradicts, elsewhere in his work, this view of advancement. On page 201 of the "Science of Ethics," he says distinctly: "As men become more intellectual, sympathetic, and so forth, they gain fresh sensibilities, which are not simple judgments of consequences hitherto improved, but as direct, imperative, and substantial as any of the primitive sensibilities." Even if this statement were meant to apply to the individual alone, a great difficulty must lie in the way of any theory that sensibilities so inherent, sensibilities " as direct, imperative, and substantial as any of the primitive sensibilities," will not affect the character of descendants through inheritance, in the same manner as these primitive sensibilities are acknowledged to affect it. But elsewhere Stephen remarks: "An instinct grows 
and decays not on account of its effects on the individual, but on account of its effects upon the race. The animal which, on the whole, is better adapted for continuing its species, will have an advantage in the struggle, even though it may not be so well adapted for pursuing its own happiness." $\mathrm{He}$ is careful to use the word "happiness" here, but the division under which the sentence appears is headed, "Social and Individual Utility," and he distinctly states, on the preceding page, that the social instincts may be a disadvantage to the individual in the struggle for existence. He writes, in this connection: "The process by which the correlation of pernicious and painful states is worked out is one which, by its very nature, must take a number of generations. Races survive in virtue of the completeness of this correlation." 1 This is Darwinism applied to humanity; and, surely, since the human race has existed in the social state for very many generations, we must suppose, according to the theory thus stated, continuous organic advance, even if we did not consider the passage in connection with the assertion of the gain, with increasing intelligence and sympathy, of sensibilities as direct, imperative, and substantial as any primitive ones. Again Mr. Stephen writes: "It is true, generally, that each man has certain capacities for moral as for every other kind of development, and capacities which vary from the top to the bottom of the scale. No process of education or discipline whatezer would convert a Judas Iscariot into a Paul or John.". ${ }^{2}$ Then education, the environment of civilization, is not the only factor in the production of character. Nor is it, according to Mr. Stephen's own words, the only important factor. If capacities vary from the top to the bottom of the scale, then surely this variation cannot be an unimportant element of development. As a matter of fact, Mr. Stephen himself lays especial stress upon inherited characteristic as the basis of character. He says, for example: "The character is determined for each individual by its original constitution, though the character is modified as the reason acts. ... But, after all, we start with a certain balance of feeling, with certain fixed relations between our various instincts ; and, however these may change afterwards, our character is so far determined from the start. Again, it is plain that this varies greatly with different peoples and gives rise to different types." ${ }_{3}$ Surely the formation of types at least cannot be a matter of the

1 “The Science of Ethics," pp. 91, 92.

2 Ibid. p. 432 . The italics are mine.

${ }^{3}$ Ibid., pp. 72, 73 . 
individual alone. Furthermore, Mr. Stephen distinctly asserts a growth of intelligence in the savage - which we cannot suppose to stop short with the beginning of civilization - while he especially emphasizes the fact that the emotions develop concomitantly with the intellect. He says also: "We assume an organic change to occur - no matter how - in certain individuals of a species, and that change to be inherited by their descendants; and thus two competing varieties to arise, one of which may be supplanted by the other, or each of which may supplant the other in a certain part of the common domain. Some such process is clearly occurring in the case of human variations. Everywhere we see a competition between different races, and the more savage vanishing under the approach of the more civilized. Certain races seem to possess enormous expansive powers, whilst others remain limited within fixed regions or are slowly passing out of existence. So far as human development supposes an organic change in the individual [?], we may suppose that this process is actually going on and that, for example, the white man may be slowly pushing savage races out of existence. I do not ask whether this is the fact, because for my purpose it is irrelevant. We are considering the changes which take place without such organic development, not as denying the existence of organic developments, but simply because they are so slow and their influence so gradual that they do not come within our sphere. They belong, as astronomers say, to the secular, not to the periodic changes. Confining ourselves, therefore, to the changes which are, in my phrase, products of the 'social factor,' and which assume the constancy of the individual organism," " etc. The passage is of importance as acknowledging the reality of organic progress; but it is full of the self-contradictions which we have already noticed. It starts with the Darwinian assumption that organic change occurring in individuals is directly inheritable by their descendants; this assumption, having done its office, however, is discarded, and we are told that any organic change cannot be that of individuals but must be that of societies, or at least that it must be of such sort that we have not only no need to consider it with regard to the individual life, but even no need to consider it in the study of the whole development of a society under civilization, or rather that we have no need to study it at all as soon as we have the 
"social medium" to fall back upon for an explanation of progress; and finally, in direct contradiction to the assumption first made, a constancy of the individual organism is asserted. This assertion is also in direct contradiction to the assertion before noticed that character is determined by original constitution and that original capacity differs "infinitely" 1 in different individuals. We are indebted to Mr. Stephen for a very minute analysis of the influence of even smallest details of circumstance upon character; surely, while we are thus emphasizing the delicacy of nervous organization that answers, with the sensibility of a gold-leaf electroscope, to the slightest variations in the environment, we cannot logically leave out of account the results of such variation in inheritance because these, too, are minute. And surely we cannot conceive that an organism so sensitive to the influence of environment is yet so inflexible and unalterable as far as the transmission of its changes to offspring is concerned. On any sound physiological theory, we cannot avoid supposing that all these minute changes in character which Stephen refers to the action of the social environment are accompanied by exact physiological equivalents. Then either these changes of organization are not inheritable, - in which case the organism does not propagate itself but something different from itself, and we have no alternative but to resort to some such theory as that of Weismann, - or else these changes are inheritable (subject, of course, to all the variations which individual circumstances of development must induce), in which case their inheritance must be of quite as much importance as their origin to any theory of social progress. As we have said, Weismann has gradually come to admit some influence of the environment on the germ-plasm. We can indeed conceive of the representation of all previous development of the species in the individual, and of the determination of the degree of importance assumed, in the organism, by any particular acquirement or tendency by the coincidence of circumstance, but we can scarcely conceive logically of a propagation of organization that does not represent all the influences which have made that organization what it is. Even from Stephen's standpoint, it is difficult to understand how the organization of society, which he admits to be no organization on the plane of the higher animal, but of a much lower type, can be of so much importance in the advance of man-

1 See above, p. 400. 
kind, its variations the condition of progress, and yet the much more interdependent organization of the animal body be supposed to remain constant and take no part in this progress. It is difficult to comprehend how so much stress can be laid on the mere external influence of the units of society on each other, and, at the same time, the far more intimate and direct influence of parents on their offspring can be deemed of so little importance as to warrant our disregarding it altogether. It is especially difficult to understand how it is that heredity can be disregarded, not merely in its influence on the individual or even on the generation, but in all its manifold, intricate, and prolonged workings since man first extended family life to tribal organization; and this, too, in spite of the acknowledgment that progress through heredity is real if slow. It is strange that there should always be a tendency to draw a distinct line between social man and all the rest of the animal kingdom, as if, when society began, all former laws ceased from operation. Thus it is sometimes said that natural selection no longer acts on the individual because it acts on societies as wholes also; as well say that it cannot act on inner organization because it acts on the organism as a whole. As a matter of fact, it affects society through individuals, and the individual through, or rather in, his organization. If it is true, as Stephen asserts, that change of social tissue is primary and fundamental to all external social change, it is not the less true that change of individual organization is fundamental to all change of external action. No theory of development which goes beyond the individual life and considers the progress of society as a whole can scientifically disregard the element of heredity in this progress. 


\title{
CHAPTER VI.
}

\author{
CONSCIENCE
}

THE exact circumstances which led, in any particular line of descent, to the final production of self-conscious altruism we cannot know. We may, perhaps, as has been hinted, trace the whole development to the original union of the sexes in lower, asexual species, and of mother and offspring; and we may suppose the final self-conscious altruism to have been led up to gradually by habit, in any case, the history of all function being gradual evolution. Thus we may suppose it possible that, in some cases, the care of offspring may have been preceded by a habit of care, on the part of the female animal, for her eggs, which, as habit, was pleasurable, but was connected with no consciousness of the offspring produced from the eggs until some new circumstance of environment brought them within ken. Of the development of habit in general and of pleasure in it, we have plenty of illustrations in our own individual experience, and we can even watch, in our own case, the process of the increase of altruism along old lines as well as its growth in new directions; and we may thus gain a conception of what must have been the general nature of its earliest development, in any case.

In Volume III of "Mind," Paul Friedmann has an interesting essay on "The Genesis of Disinterested Benevolence," in which he relates the following: "A man had to throw away some water and, stepping out of his house, threw it upon a heap of rubbish, where some faded plants were nearly dying. At that moment, he paid no attention to them, took no interest in their pitiable state. The next day, having again some water to throw away, the man stepped out at the same place, when he remarked that the plants had raised their stems and regained some life. He understood that this was the result of his act of the day before, his interest was awakened, and as he held a jar with water in his hand, he 
again threw its contents over the plants. On the following day the same took place; the benevolent feeling, the interest in the recovery and welfare of the plants augmented, and the man tended the plants with increasing care. When he found, one day, that the rubbish and plants had been carted away, he felt a real annoyance. The feeling of the man was in this case real disinterested benevolence. The plants were neither fine nor useful, and the place where they stood was ugly and out of the way, so that the man had no advantage from their growth. Nor had the man a general wish to rear plants, for there were a number of other plants sorely in want of care, but to which the man did not transfer his affections. He had loved these individual plants." Friedmann says further: "Formerly rather hostile to dogs, now that I have a dog myself, I feel well inclined towards the whole canine species, but most to that part of it which has some characteristic feature in common with my favorite." Features of the first quotation may remind us of some former considerations of ours in which attention and interest were found to run parallel. We may take exception, however, to Friedmann's definition of the extension of benevolent feeling from an individual of a class to the whole of the class or to beings resembling them in any way as "a sort of logical confusion." This view has already been criticised. The adult being at least does not confuse individuals, or even if he may occasionally do so, such confusion is not at all the distinguishing feature of progress in altruism ; it is merely an accident, not anything that is characteristic. The recognition of old features in new objects is the opposite of confusion; it would rather indicate a logical confusion, a lack of intelligence, if we failed to remember that which has formerly given us pleasure, and to find, in similar objects, some renewal of that pleasure. It would have been just as logical, for instance, and more truly benevolent, if the man who tended the plants had cared also for the other plants mentioned as "sorely in want of care," and which he seems to have left to perish.

We may often notice the growth of altruistic from egoistic as well as of egoistic from altruistic motives, in ourselves ; for retrogression as well as progression in altruism is possible with the individual. If we feel bitterly towards some human being, for instance, the best and surest remedy is to perform some act of kindness towards him. We may contemplate and carry out the 
deed with merely a sense of gratification and egoistic elation at our own generosity, but we are more than likely to experience some degree of change of feeling before we have finished. On the other hand, our heart often seems to harden and fill with greater animosity towards those we have injured, the longer we continue this course of injurious action and the more positive the injury inflicted. A certain degree of generosity must, it is true, already exist in order that we may be able to show kindness to an enemy, just as hostility must also be present in order that we may be able to commence a course of injury or unkindness ; but both kindly feeling and animosity increase constantly with their exercise. We are never exactly the same after our deeds that we are before them.

Says George Eliot: "It would be a poor result of all our anguish and our wrestling if we won nothing but our old selves at the end of it - if we could return to the same blind loves, the same self-confident blame, the same light thoughts of human suffering, the same frivolous gossip over blighted human lives." 1 And again: "The creature we help to save, though only a halfreared linnet, bruised and lost by the wayside - how we watch and fence it, and dote on its signs of recovery."

Whatever the particular circumstances that led, in the particular line of animal descent by which the species we distinctively term human finally came into existence, to the extension of temporary to life-long association, and whether this life-long association began only with man, or earlier with his ape-like progenitors, certain it is that increase of numbers must finally condition society. The internal, like the external process, is a gradual one, an evolution; and we cannot, therefore, suppose society as lifelong association to have begun with the existence of no altruistic feeling whatever. In so far, Darwin's assertion that the social instinct led men to society contains a measure of truth ; but it is to be remembered that the social instinct at the beginning of social life cannot have been the same with the social instinct of present civilization, which is the product of long development ; pleasure in function, its ends, and objects, increases concomitantly with exercise. Darwin's statement is, hence, liable to misconstruction. There is a similar truth in Rolph's criticism of Spencer's theory that men adopted social life because they found it advan-

1 "Adam Bede." 2 “ Daniel Deronda." 
tageous, on the ground that men must first have had experience of the advantages of association before they could have been aware of them. But the experience which continually leads to a step in advance may not be, at every point, for every step, the experience of the individual or individuals taking the step; it is quite possible that some steps may be taken from the observance of the experience of others ; at least this is possible if we suppose any degree of intelligence and reason in the individuals taking the step. The introduction of the idea of a calculation of advantages is, furthermore, exceedingly useful. For, while the "social instinct," the desire for and pleasure in all the various function connected with association with other beings, may be of assistance in bringing about any advance in association, the selfish instinct, already in existence before the evolution of any considerable degree of altruistic impulse, may influence and induce the advance, where the social instinct is not, alone, of sufficient strength. At the beginning of social life, as at every later point of advancement, motives are mixed, and selfishness may prepare the way for unselfishness.

At any point of evolution, there must be, among contending species or individuals, some who are stronger or who have, through some circumstance, the advantage over the others; given even a moderate number of individuals, and it is hardly possible that all should be defeated and destroyed in any struggle, like the famous cats of Kilkenny. This being the case, and change of organization being continually conditioned by contact with new elements of environment, advancement, evolution, becomes a necessity, no natural catastrophe occurring to destroy all life. There is no mystery about evolution in this sense. Advancement in society is still more comprehensible to us by the fact of the element of reason involved in it; from the beginning of lifeassociation among human beings or their immediate progenitors, the existence of some more intelligent individuals than the rest, who will perceive the advantages of association, may be assumed. And thus at each step, as the growing density of population continually renders increasing coöperation increasingly advantageous, we may suppose the vanguard to be composed of the more intelligent and the more social.

Sympathy prompts not only to the conferring of pleasure, it prompts also to the prevention of injurious conduct, on the part 
of others, towards the being or beings with whom sympathy is felt. A conception of the advantage of mutual aid may assist as a motive in this. The earliest mutual aid was, to a great extent, one of coöperation against enemies. In one way and another, this mutual defence must have extended to the compulsion of positive beneficial conduct, on the part of others, towards the being or beings with whom sympathy was felt. Such compulsion may be exerted by different tribes, or by different members of the same tribe, on each other; the means of compulsion are revenges of different sorts, benefit, assistance of some sort, being, on the other hand, often the reward of ready compliance. This compulsion may be felt as greater or less according to the degree of reluctance to perform any form of action required under pain of the penalty. If the thoughts are occupied with the possible reward, and not with the punishment, then no outer compulsion is felt, but a choice of advantage is made. This choice again may not be wholly one of selfish calculation; some altruistic feeling may be involved. A form of action at first chosen with reluctance, and merely because of the fear of punishment or revenge, may come to be performed later without hesitation, and more under the hope of reward than the fear of punishment; and this same form of action may come to be performed finally with sympathy as the prominent feeling, the hope of reward becoming more and more secondary. Each increase of sympathy, again, reacts upon the environment as represented by other individuals, and thus the relations and influence of men on each other become more and more complicated. Any habit of cruelty or hostility which has been, at former stages, united with prosperity may thus become, through the action and reaction of increasing altruism, a disadvantage to the individual member of any society; or it is also conceivable that a formerly advantageous egoistic form of action may become disadvantageous through the advent of some new influence from outside the particular society in which it is practised. Father Phil, in Lover's story of "Handy Andy," relates an anecdote of an engagement in Spain, in which the dragoons of a regiment, retreating under hot fire, paused at the crossing of a river to take up behind them some women of the camp-followers, who had difficulty in crossing, and thereupon found themselves followed by cheers, instead of shots, from their French foes. I do not intend to intimate that the motive for the 
deed was self-interest; but it is easy to conceive similar instances in which humanity might become an advantage and be practised at first from self-interest, not by individuals merely but by a whole tribe ; this must be frequently the case when less civilized peoples come in contact with more civilized peoples. And this leads us to remark that habits of sympathy and justice exercised within a people will be likely to manifest themselves in relations with other peoples also, in degree as the sympathy is real and the benevolence inward. But the attitudes of different peoples towards each other remain long hostile, since the partial surrender of tribal or national interests necessary to compact often involves too great sacrifices to be acquiesced in at an early stage of development. And the individual is necessarily influenced, to a great extent, by the feelings of those among whom he is born, with regard to the hostile nation. But this is retracing our analysis.

Altruism is thus increased directly by the perception and choice of coöperation as advantageous, by the spread of altruistic feeling and the compulsion of the social environment, as well as by the higher means of persuasion and affection, in which altruism itself affects the increase of altruism; and it is also increased indirectly by the aid of natural selection between individuals, families, neighborhoods, and groups of all sorts, coöperation becoming more and more advantageous with the increased density of population.

It is scarcely necessary to remark that natural selection acts also with regard to the egoistic or personal virtues; for these have regard, primarily, to the preservation of the individual in the best condition for labor and cheerfulness. It is evident that in this direction also the moral must continually gain the advantage. Either the injurious is perceived and avoided, or the individual failing to perceive and avoid it suffers physical injury and deterioration, and, unless a different course is adopted in time, brings at last destruction to himself or to his stock. But our analysis goes further; for the egoistic virtues are evidently not purely egoistic ; and society will come with time to insist on this fact, and to render these virtues still more advantageous and their neglect still more disadvantageous ; while the growth of the altruistic feelings will infuse the individual with the desire to perform his duty to others in this respect also. The purely egoistic character of so-called personal virtues, for the assertion of which so 
much has been written, is a myth. No man can make a sot of himself or indeed injure himself in any way without reducing his power to benefit society and harming those nearest to him. Selfpreservation and the preservation of one's own health may conflict with altruistic virtues at times; that is to say, virtues both of which are altruistic, though the altruistic character of one is more direct than the other, may conflict; in which case, choice is necessary. And it is strange to note, at this point, that just those systems which lay most stress on individual welfare, that is, emphasize the fact that the preservation of individual health and the development of individual capacity are advantageous to society, are the very ones that also defend the freedom of the individual to practise so-called personal vice. The two theories do not well accord; surely, if the individual is of so much importance to society, his vice cannot be without injurious results to it. Only when egoistic care for health has become infused with the higher altruism, does it become truly virtue; then care for self ceases to be the mere means to isolated pleasure, and becomes the means to the happiness of others where it was often, before, the means to their misery, and even their destruction.

In the evolution of higher animal forms from lower, the lower do not necessarily pass out of existence with the development of the higher; in society, however, the contact is close and continuous, and the competition unremitting; there is, therefore, some elimination, though a very gradual one, of lower types. The lower forms may exist for a long time beside the higher; in other words, society as a whole progresses slowly on account of the immense complication of relations within it. We find it including many grades of altruistic and egoistic virtue, and can testify only to a progress that renders the extremes of vice and cruelty less and less the rule and more and more the exception.

And this brings us to the further consideration of a point not long ago touched upon, namely, the high degree of civilization attained by certain ancient peoples. Not the whole race of man, it is evident, advances together to higher grades of civilization, as not all individuals or all lines of descent in the same society fall under the same influences and advance at a like rate. At the present date, the greater part of Africa as well as portions of other countries are inhabited by rude and savage tribes, the rest of the world, not classed as savage, representing very many dif- 
ferent grades and phases of progress. After the conquest of Greece by Rome and of Rome by the tribes from the North, the higher degree of civilization of the conquered nations was partly lost by them and partly acquired by their conquerors; that is, nothing was really lost, but two different forces met and partly neutralized each other; the resultant represented, in this case as in all others, the complication, the algebraic sum, of the two. In the essay before referred to, Dr. Petzoldt calls attention to the extremely unique character of the productions of Inner-African tribes before they have come in contact with white men, and cites Bastian's testimony that even one short visit from a white man is often enough to destroy the peculiarity of the type. "New tendencies are introduced, and the stability is immediately diminished, though only to progress gradually to a newer, higher form." The comparative sparsity of the human race in ancient times rendered it possible for single isolated peoples to attain to a high degree of culture while the greater part of the earth was inhabited by the uncivilized; and the increase of the species since that time, though necessitating wider contact and closer relations, and so rendering the newer civilization necessarily a wider one, has yet not been sufficient to make isolated savagery in lands not reached by the spreading circle, impossible. The ancient civilization was lost, but not lost in the sense that its force ever perished; it found its full representation - but no more - in the result that arose from blending with a lower grade. The same process is being repeated wherever civilized man, on the borders of civilization, comes in contact with savage or half-civilized man. The two races may dwell side by side, separated from intimate association, but their contiguity is yet marked by a certain amount of change on both sides, - a change the greater the greater the degree of association and the greater the isolation of those on the borderlands from the rest of the civilized world, and the longer this state of things persists. We are here reminded particularly of Fechner's formula of the process of evolution, in which the concepts of isolation as favoring the steady advancement of the process on its own peculiar lines, and of new contact as new disturbance from which issues new development, are most prominent. If we regard especially the ethical features of this contact at the borders, it may be remarked both that savages gain gradually more humanity from contact with civilized nations, and that white men, on 
the other hand, lose, in constant contact with savages, some of the humanity which they have displayed in the midst of their own nation. They grow used to sights of cruelty, much of which it is impossible for them to prevent; they are roused to anger, hatred, and retaliation by acts of deception, treachery, and cruelty, and they find, moreover, that kindness is often mistaken for weakness by the bloody and revengeful people with whom they have to do, who are often used to respect only or chiefly the brute force which can compel obedience. I do not intend here to represent the white man as the incarnation of sympathy and humanity; even in the midst of society, as we have already sufficiently noticed, his apparent altruism may be, to a large degree, the outcome of selfish motives, natural tendency being restrained through fear of punishment or hope of gain of some sort. There are grades within societies as well as grades represented by societies as wholes. But several things are to be taken into account in the comparison of the white man with the savage under circumstances of contact. In the first place, we have to remember that, while the white man is, to a great extent, withdrawn from the control of the society to which he belongs, secure from their judgment for the time being and with the prospect, often, of probable security from it for all time, since reports of his actions may never reach the ears of more civilized societies, the individual savage is still restrained by whatever of law and moral sentiment exists in his own tribe ; his vengeance, whatever it is, is to a great extent under the control of his chiefs. Again, the power of the savage to inflict injury is not so great as that of the white man, who has all the implements of advanced coöperation at his disposal. The mere love of power always presents a temptation, and pleasure in demonstrating superiority is a common human emotion. Furthermore, it must be considered that the opportunities for selfishness afforded or the borders of civilization are likely to attract, in the majority, just those men whose social ties and social instinct are weakest, whose greed perceives here the opportunity of unscrupulous gratification, and is drawn by it. And lastly, it is to be noticed that not by any means all the individuals belonging to more advanced societies who come in contact with savages use them with inhumanity, or even retaliate on treachery and injury. The great differences exhibited, under such circumstances, by persons whose opportunities have been very similar is a strong argument in favor 
of inherent, innate grades of altruism, and so of hereditary character. The same is true of the fact that the Greeks and Romans did retain much of their culture even in contact with lower grades of civilization, handing it down, in a degree, to this day ; and that their conquerors only in the lapse of many generations pulled themselves up to this level, which was attained, at last, rather in countries removed from direct contact with it and so, we may argue, to a great extent, through their own natural evolution. The general analysis of the amalgamation at the borders of civilization still remains true in the long run, however individual savages and individual white men may represent exceptions to it.

- Mr. Stephen's analysis of the development of altruism from egoism, while in the main true and one of the most minute analyses on this subject that we possess, opens, through its ambiguity of terms, the way to inaccuracy of thought and to errors of theory into which I am not at all sure that the author does not himself fall at some points. Starting with an implied definition of sympathy as actual "feeling with" other sentient beings through the intellectual comprehension of their emotions, and acknowledging that sympathy in this sense may not lead directly to altruism, he uses the same word also, later in the analysis, in the higher sense, and at some points appears to confound the two meanings; so that, as there is a similar ambiguity in the use of the word "idiot," or "moral idiot," in the same connection, his theory seems to fall into the mistake of asserting the normal association of intellectual comprehension with altruism. He writes :-

"It is not more true that to think of a fire is to revive the sensations of warmth than it is true that to think of a man is to revive the emotions and thoughts which we attribute to him. To think of him in any other sense is to think of the mere doll or statue, the outside framework, not of the organized mass of consciousness which determines all the relations in which he is most deeply interesting to us." "The primary sympathy is, of course, modified in a thousand ways - by the ease or difficulty with which we can adopt his feelings; by the attractiveness or repulsiveness of the feelings revealed; by the degree in which circumstances force us into coöperation or antagonism; and by innumerable incidental associations which make it pleasant or painful to share his feelings. If by sympathy we mean this power of vicarious emotion, it may give rise to antipathy, to hatred, rivalry, and jealousy, and even to 
the diabolical perversion of pleasure in another's pain." "The pain given by your pain may simply induce me to shut my eyes. The Pharisee who passed by on the other side may have disliked the sight of the wounded traveller as much as the good Samaritan. Indeed, the sight of suffering often directs irritation against the sufferer. Dives is often angry with Lazarus for exposing his sores before a respectable mansion, and sometimes goes so far as to think, illogically perhaps, that the beggar must have cultivated his misery in order to irritate the nerves of his neighbors. To give the order: 'Take away that damned Lazarus,' may be as natural an impulse as to say: "Give him the means of curing his ailments." " 2 "To believe in the existence of a sentient being is to believe that it has feelings which may persist when I am not aware of them. A real belief, again, implies that, at the moment of belief, I have representative sensations or emotions corresponding to those which imply the actual presence of the object. Again, a material object has an interest only so far as it is a condition of some kind of feeling, and, when the sympathies are not concerned, of some feeling of my own, whether implying or not implying any foretaste of the future. To take any interest in any material object, except in this relation, is unreasonable, as it is unreasonable to desire food which cannot nourish or fire which cannot warm. I want something which has by hypothesis no relation to my wants. The same is true of the sentient object so long, and only so long, as I do not take its sentience into account. But to take the sentience into account is to sympathize, or at least the sympathy is implied in the normal or only possible case. The only condition necessary for the sympathy to exist and to be capable therefore of becoming a motive, is that I should really believe in the object, and have, therefore, representative feelings. To believe in it is to feel for it, to have sympathies which correspond to my representations, less vivid as the object is more distant and further from the sphere of my possible influence, but still real and therefore effective motives. Systematically to ignore these relations, then, is to act as if I were an egoist in the extremest sense, and held that there was no consciousness in the world except my own. But really to carry out this principle is to be an idiot, for an essential part of the world as interesting to me is constituted by the

1 "The Science of Ethics," pp. 238, 239. The italics are mine.

2 Ibid. pp. 242, 243 . 
feelings of other conscious agents, and I can only ignore their existence at the cost of losing all the intelligence which distinguishes me from the lower animal." ${ }^{1}$ A similar use of the word "idiot" occurs in the following passage with regard to the relations of moral action to conviction: "It is a simple 'objective' fact that a man acts rightly or wrongly in a given case, and a fact which may be proved to him ; and, further, though the proof will be thrown away if he is a moral idiot, that is, entirely without the capacities upon which morality is founded, the proof is one which must always affect his character if we suppose the truth to be assimilated, and not the verbal formula to be merely learned by rote." " "To learn really to appreciate the general bearings of moral conduct is to learn to be moral in the normally constituted man." Here the author adds, however, "though we must always make the condition that a certain aptitude of character exists." 3 Again he writes: "But it remains to be admitted that there is apparently such a thing as pleasure in the pain of others - pure malignity - which we call 'devilish' to mark that it is abnormal and significant of a perverted nature." 4 And in the same connection - where he is, at first, seemingly intent on proving only the normal connection of pain with the sight of suffering, admitting that this sympathetic pain may lead to brutality instead of altruistic action towards the sufferer - he says: "Sympathy is the natural and fundamental fact. Even the most brutal of mankind are generally sympathetic so far as to feel rather pain than pleasure at the sight of suffering. The scum of a civilized population gathered to pick pockets on a race-course would be pained at the sight of a child in danger of being run over or brutally assaulted by a ruffian, and would be disposed to rescue it, or at least to cheer a rescuer, unless their spontaneous emotion were overpowered by some extrinsic sentiment." ${ }^{5}$ And finally: "The direct and normal case is that in which sympathy leads to genuine altruism, or feeling in accordance with that which it reflects." 6

'The terms in these passages are thus evidently very loosely used, and the charge above made is, I think, substantiated, - that the

1 As above, pp. 255, 256. The italics are mine.

2 Ibid. p. 443.

3 Ibid. p. 441. The italics are mine.

4 Ibid. p. 236 . The italics are mine.

5 Ibid. p. 237.

${ }^{6}$ Ibid. p. 239. The italics are here also mine. 
author himself finally falls into the error following upon a confusion of the various meanings, and comes to assert what he elsewhere distinctly denies, namely, the normal connection of intellect and morality, of the comprehension of suffering with that form of sympathy which issues in altruistic action. The problem is an interesting one, and it may be well for us to look into it a little further.

During the last few years a number of books have been written in which the attempt has been made to prove the general physical, and especially the cerebral, and so the intellectual inferiority of a large number of criminals. There may be a difference of opinion as to the value of exact weights and measures except in so far as they demonstrate an actual nervous deformity of some sort; and it may be said that the cases examined for distinctly cerebral defect are too few to admit of the formation of any universal, definite, theory or law. But some degree of importance must assuredly be attached, by the unprejudiced reader, to the more purely psychological evidence obtained in many cases, as well as to the evidence of the tendency to brain-disease often found in the direct line of descent. Indeed, in the case of some of the photographs issued with Lombroso's "L'Homme Criminel," not more than a glance is needed to convince one that the possessors of such heads and faces cannot be normal men and women. To this testimony from the criminologists may be added that of many eminent specialists in mental diseases, whose evidence goes to show the degeneration of the moral sense in cases of brain-disease. Maudesley says, for instance, of moral feeling: "Whoever is destitute of it is, to that extent, a defective being; he marks the beginning of race-degeneracy; and if propitious influence do not chance to check or to neutralize the morbid tendency, his children will exhibit a further degree of degeneracy, and be actual morbid varieties. Whether the particular outcome of the morbid strain shall be vice, or madness, or crime, will depend much on the circumstances of life." "When we make a scientific study of the fundamental meaning of those deviations from the sound type which issue in insanity and crime, by searching inquiry into the laws of their genesis, it appears that these forms of human degeneracy do not lie so far asunder as they are commonly supposed to do. Moreover, theory is here confirmed by observation; for it has been pointed out by those who 
have made criminals their study, that they oftentimes spring from families in which insanity, epilepsy, or some allied neurosis exists, that many of them are weak-minded, epileptic, or actually insane, and that they are apt to die from diseases of the nervous system and from tubercular diseases." 1 To the history proper of the Jukes, Dugdale has appended a series of tables giving further information as to the stock, environment, and present condition of some two hundred and thirty-three criminals committed for various crimes, each of which crimes heads a separate list. These lists are decidedly interesting, particularly as affording us some considerable information with regard to psychological characteristics and environment, under the headings: "Neglected Chilren," “Orphans," "Habitual Criminals," "First Offenders," "Reformable," "Hopeless," etc. From the table of percentages we remark that, in the "Neurotic Stock," the highest percentage $(40.47)$ is reached in arson and the crimes against persons, or crimes of impulse, as Dugdale terms them, while 23.03 is the percentage of neurotic stock in the whole number of criminals exanined. "This close relationship between nervous disorders and crime," says Dugdale, "runs parallel with the experience of England, where "the ratio of insane to sane criminals is thirty-four times as great as the ratio of lunatics to the whole population of England, or, if we take half the population to represent the adults which supply the convict prisons, we shall have the criminal lunatics in excess in the high proportion of seventeen to one." Dugdale further quotes from Dr. Bruce Thomson, surgeon to the General Prison of Scotland, the following words: "On a close acquaintance with criminals, of eighteen years' standing, I consider that nine in ten are of inferior intellect, but that all are excessively cunning." Dr. Thomson says also: "In all my experience, I have never seen such an accumulation of morbid appearances as I witness in the post-mortem examinations of the prisoners who die here. Scarcely one of them can be said to die of one disease, for almost every organ of the body is more or less diseased ; and the wonder to me is that life could have been supported in such a diseased frame."

But with regard to this last quotation, it may be remarked that, although many modern students of crime tend to look upon the general diseased condition of body among criminals as the cause 1 “" The Pathology of Mind," 102 et seg. 
of their criminality, it is generally, as a matter of fact, a cumulative growth, vicious acts appearing now as condition, now as result, in its increase. Vice is directly connected with disease, and crime against others, even where it does not itself directly involve vice, is still likely to be connected with it, since the man who is immoral in one direction is not likely to be restrained from immorality in what is ordinarily considered a direction of lesser wrong; and the self-gratification of vice always presents a temptation to the man of coarser fibre. Dugdale notices that pauperism often appears in the younger members of a family where crime appears in the elder branches, his explanation being that crime is a sign of comparative vigor, pauperism of greater physical weakness.

We have found some connection between intellectual incapacity and moral lack in the shape of crime, but the cases are extreme ones. The question is not: Are the extremes of criminality connected with mental incapacity? but, Is the power of intellectual comprehension, is intelligence, always associated with sympathy and altruism? Is the connection of these two general? Or, conversely: Is lack of sympathy and altruism in general a sign of mental incapacity, of the power of comprehension for another's suffering?

The individual may be supposed to be naturally endowed with a certain basis of tendency, which, as coördinate with a nervous organization that, as organization, is of definite nature, is also definite. I do not intend, here or elsewhere, to lay especial stress on the physical, as distinguished from the psychical; merely, it is convenient for reference. The individual character and life must be the continual progressive issue of this basis of tendency or capacity and the developing and modifying factors of environment. Individuals will, therefore, but in very different degrees and manners, reflect the moral standard of the society as organization, the class, and the family, to which they belong, the importance assumed by the class or family relations being according to the closeness and duration of association, and the natural aptitude of the individual for one or another sort of influence. Aside from altruistic considerations, the individual will find it to his advantage to conform to the standards of these environments, at least in a considerable degree. The standards may, however, conflict, so that there is also a conflict of advantages. Moreover, circumstances may arise such that conformity to all or any of these stand- 
ards presents much greater disadvantage than advantage, involving great sacrifice, which may reach even to personal destruction. But while a single anti-social act to avert personal destruction may involve greater advantage to the individual, as life represents an advantage over death, and while such an act is more an advantage and less a disadvantage as it involves less conflict with social standards (if it is the theft of food, for instance, rather than murder), any continued course of crime in so-called civilized society must be attended with many risks to the evil-doer, and present gain may mean future loss of a much higher degree. Deeds conflicting with general social standards are punished by penalties which are larger as the conflict is greater in the eye of the state. The individual who lays himself liable to legal punishment or social ostracism is foolish as well as, in very many cases, bad; of course, it is possible that his conduct may rise above the moral standards as well as that it may fall below them. But we are now considering cases where it is, by the assumption, supposed to fall below them. It is easy to perceive, from this standpoint, that great and persistent criminals are likely to be of inferior intellect, as well as wanting in moral aptitude, although, whatever reasoning capacity they possess being developed in the line of their own interest in their accustomed occupation, they may appear to the more moral, who are not practised in this direction, to possess a high degree of cunning.

The honest man has generally a better chance than the habitual criminal, however small his chance may be. Further, education of any sort, which is also intellectual elevation, gives the individual better chances of earning his own living honestly, and so renders the advantages on this side greater, and also endows with the power of perceiving these advantages. But these are only general truths, applying, again, to extreme cases. There may be cases in which there seems, at least, to be no choice left between crime and a life continually on the verge of starvation; and though the crime means also continual risk, and higher risk as the crime is greater and so, in general, more lucrative, the advantage may still be reckoned by the individual as on its side. In this case, the individual may discover, in the end, that his calculation was mistaken; but the mistake may not be so great, the balance of disadvantage on the side of conformity with social standards so excessive, as to prove him below the average of intellect in his 
mistaking. The wisest men make many mistakes in calculating the results of their action. Again, the cleverer a man is, the greater is his power to cope with the risk of detection and to avoid it. It may be objected that the single individual cannot hope to compete continually with the organized action of all society, and that the criminal must, at times, submit to some degree of punishment, even if escaping its worst phases. But if he feels no shame at the disgrace of the punishment, it may not mean to him the greater disadvantage.

But here we come round to the altruistic and moral emotions, for shame is present only where the individual has a desire to please, and is pained at the disapproval of others; that is, shame implies and requires, in the degree in which it exists, social and altruistic capacity. Furthermore, when we come to examine the concept of "advantage," we find that it is as relative as that of "end," and will be judged according to the individual predilections; to the non-sympathetic, shameless man it is an advantage to "get on" at whatever cost to others; to the moral man no gain appears an advantage at the expense of principle. And, as there are all degrees of altruism in the bases of character of different individuals, so the advantage, in any particular case, will lie at very different points according to the individual mind reflecting on it. Only the general truths may be asserted, that, even to the man of less than the average moral aptitude, great punishment must appear a disadvantage, while even to the man of considerable moral principle death for the sake of his convictions is a thing to be hesitated at.

We may return to view the question in the light of the general facts of social evolution. We found that only the general assertion could be made, that the advantages of coöperation, the disadvantages of strife and discord, increase with the closer relations of men, and that the adoption of coöperation follows this line of advantage by individual choice, and by the disadvantage under which the less social as the less fit, labor, the latter tending gradually to disappear leaving the field to the more social. Thus the whole progress is the result of the will of the human being, as well as of the other forces of nature; it is only as the individual chooses, that progress is possible. But lower types survive long beside the more progressive, higher ones. The individual is not so reasonable that he always perceives his own more enduring 
advantage, or always chooses it even when he perceives it; he may choose momentary gratification at the acknowledged risk, and even with the certainty, of great future loss. Nor can it be averred that the individual always suffers seriously from action at variance with even the average standard; simply, the line of survival gradually changes in favor of altruism, so that escape is less frequent and less probable; and the lines of greatest deviation from the altruism demanded at any period by the line of advance tend to disappear; but the altruism demanded by any line of advance is not, up to the present time, an absolute altruism, nor do all deviations from it result in destruction to the individual even in extreme cases. The fact of the growing disadvantage of selfishness, and its destructive tendency, remains, nevertheless. It may be expressed in another form in the statement that power of all sorts is increased by civilization, and where a coördinate increase of self-restraint does not accompany the increased power, it must lead to destruction, either in the case of the individual, or if not so abruptly, then in the case of his descendants. The closer contact of human beings and increased knowledge and coöperation mean growing opportunity of good or evil, to self and others. The destructive forces lie as well in the workings of social organization, in the will of man, as in nature outside man. Legal justice, public opinion, and the opinion of the smaller circle of personal friends and acquaintances, all have their part. Any degree of social instinct developed in the course of social evolution only assists in rendering social punishments of all sorts the more felt; and thus each increment of advance assists in further advance. Men who persist in action antagonistic to social demands, action which they themselves acknowledge to be immoral, may yet feel the condemnation of society so much, that, even while yet persisting, they destroy their vitality by alcoholism or other excesses to drown regret and remorse; habit chains them, in many cases, where the condemnation of others reaches them only late. But the whole process of social evolution is one of very gradual assimilation, and neither in the world as a whole, in the nation or race, or in the tribe, clan, family, locality, or class, is it one of equal advance on all sides. The coöperation adopted may be, at different points, that of individuals against individuals, of tribes against tribes, of nations against nations, or of classes against classes. 
From still another point of view, we may look upon the evolution of man as an intellectual as well as a moral one. We may count the continual gain of new experience, and the variation of thought, feeling, and will in accordance with knowledge, as adjustment to new elements of the environment, and so, as organic progress. Since, indeed, knowledge and the application of knowledge to more and more distant and more and more complex and general ends is just what we designate as higher reason in man as compared with other animal species, we cannot logically regard the further progress of this same sort in the human species itself as other than an increase of reason. Here, again, it is strange that an exact line of division between the human species and the rest of life should so often be drawn; that, although we acknowledge the necessity of an intellectual evolution having taken place from the lower species up to man, and recognize this intellectual evolution as the concomitant of wider adaptation, and although we recognize also man's continuing adaptation or experience as coördinate with progress in knowledge, we yet should be able to regard the human race as stationary as far as reason, intellect, is concerned. Evolution no more stands still in man than it did before his "advent" (if we may still use a word denoting a definite beginning, of the evolution of a species). And the reality of an intellectual evolution at the same time with the moral evolution being acknowledged, it follows that the two must to some extent coincide. $^{1}$ But we have again to remember that the evolution is not on exactly the same lines in all individuals or parts of society, that not all lines of descent may be called also those of progress. Sympathy is a progressive term; there are numberless degrees of it represented by the different individuals who form society, at their different periods of development and in their different moods. Nor can we distinguish between natural sympathy and "extrinsic sentiment" which may interfere with it; since feelings are no separate entities, all sentiment that bears on a subject is intrinsic, and the final sympathy or non-sympathetic feeling is a fusion and not a mere mixture of the various emotions which go to make it. We cannot assert that "genuine altruism" is the normal case, even of the present period of social development, and certainly

1 In this general and limited sense, but only in this general and limited sense, does Spencer's assertion that more moral conduct shows a greater adjustment of means to ends, correspond to the facts. 
not when we are considering morality as an evolution. We may hope that the standard of future generations will come to be as much superior to our present standard as that standard is superior to the savage standard; but it is scarcely to be expected that the men of that better time, although they may look back at this age with as much horror as that with which we regard the savage children roasting their dog for sport, will pronounce it one of general idiocy or even of "moral idiocy." The virtue of Stephen's analysis lies in the especial notice it takes of the different degrees and phases of that which we term "sympathy"; its fault lies in not sufficiently distinguishing between these phases, by definition, throughout the argument; and this fault leads, as we have seen, to a final confusion of the different meanings, the substitution of the one for the other, and so the proving of the higher meaning by the lower. It is scarcely true, even in civilized society, that a comprehension of the feelings of others is naturally associated with a "feeling with" them, even in the lower sense; and it is certainly not true that it is naturally associated with genuine altruism.

The assertion that, in ignoring the sentience of living beings in thought about them, a man is ignoring a thing of importance to himself, is coördinate with the assertion that, in so doing, he is ignoring "an essential part of the world as interesting" to him; for that which appears of importance to a man is that which interests him; and it is true that interest and attention are coördinate. But one thing may appear to one man important, another to another. We generally consider a thing in the relations and phases which interest us, but not all its relations or phases always interest us. We do not follow out all the possible lines of thought connected with a thing, we do not regard it in all its aspects every time we think about it; we think more or less by symbols or parts; and Stephen says that we feel by symbols also. ${ }^{1}$ It is by no means true of all men, or true of any man at all times, that others are most deeply interesting to him in their relations of thought and feeling; there are many cases where they would be quite as interesting if they were mere automata, provided only that they could be depended on to perform the same actions. And it is perfectly possible to regard them in the light of their actions and the significance of these for us, leaving quite

${ }^{1}$ See "The Science of Ethics," p. 62. 
out of account the psychical meaning of the actions, and this also without at all "losing all the intelligence which distinguishes one from the lower animal." Nor is sympathy coördinate with interest in the thoughts and emotions of others; revenge is very normal, yet it rejoices in just the fact that the living being can be made to suffer.

The irritation noticed by Stephen, as sometimes directed against others whose suffering is a source of pain, is of especial interest as bearing on the habit of some animals - wild cattle, for instance - of setting with fury on a wounded comrade, and putting him to a violent death. A recent writer has attempted to explain this habit as a frantic and unintelligent endeavor to render some assistance to a suffering friend; but the explanation seems improbable, especially as we find a corresponding impulse to cruelty even in human society of a higher type. In the action of the animal, there is the possibility and even the probability of still another impulse - that excitement and exhilaration which seems to possess many species at the sight and smell of blood, and which finds its counterpart in the peculiar pleasure that many men of coarser sensibilities derive from bull-fights, prize-fights, cockfights, etc., and that doubtless comes down to us from a time when the struggle for existence was continually a bloody one. Just how the two instincts may be related in the animal, it is difficult, from a human standpoint, to say.

Our analysis has hitherto omitted all definition of morality and conscience. The words should properly, for some reasons, have been defined before this. But any definition must have assumed that which could logically be asserted only at the end of the preceding considerations. The definitions are involved in these considerations. It is evident that morality, as we ordinarily define it, has a very intimate connection with the relations of individuals to each other; and though we may conceive of a morality of the individual passing an entire existence in solitude on a desert island devoid of animal-life, we become aware, when we reflect on the condition of such an imaginary personage, that many of the ordinary grounds of moral action, and moral judgment of action, are wanting in his case. Such a person cannot, by our assumption, beget others who may inherit his psychical and physical qualities, and cannot injure man or beast directly or indirectly. He has only his own welfare to consider, and if he 
chooses rather an animal indulgence in such pleasures as may be within his reach, we may possibly disapprove of his conduct, but we cannot find especial grounds for asserting that he has not a right to his choice. It may be said that this case is only imaginary, and that, in all actual cases of such isolation there is no certainty that the individual may not, at some future time, come in contact with other living animals or with human beings. But this being admitted, we immediately come back again to the conception of morality as dependent upon our relations to others. In spite of all that has been said in favor of egoistic morality, of duties to self as the source and reason of morality, it becomes evident that altruism is a most important element of even that which we term egoistic or personal morality. In fact, we find difficulty in distinguishing, on a higher plane, between the duties of egoism and those of altruism; in both we have to consider others as well as ourselves. And we begin to suspect that we are making a mistake in separating, in a definition, things which must be indissolubly united in actual practice; and we surmise that such a mistake may lie at the root of the many disagreements as to whether the preference is to be given to egoism or to altruism in Ethics. In all evolution, the results of former adaptation are not lost in new; merely the old assumes a higher form. So egoism is not lost in altruism, but assumes a higher form; the care for self becomes identical, according to the degree of altruism, with the care for others. This fact has been utilized for the assertion that all altruism is merely egoism. The argument commits the fallacy of using the word "egoism" in two senses, the one of which, the higher sense, is used to prove the other. We need to remember that the fact of development implies degrees, and that neither egosim nor altruism is an absolute term. A certain care of self, physically and mentally, is necessary to cheerfulness. health, sympathy, and the due performance of labor and kindnesses; just as, conversely, in society, the health and happiness of the individual are dependent upon the aid of others. The antagonistic character of the two principles is gradually modified in evolution and disappears altogether in some cases of action; in the contemplation of the ideal, it vanishes completely. Care for self gains a new significance in the light of love or affection for any other being, and in the action and reaction of character in human society, this newer significance gradually spreads, leav- 
ening the whole of mankind. Our analysis is unable to trace its workings and significance in all the complicated relations of men. In like manner it is difficult to decide, in any particular case, what the exact course is, which, in view of the far-reaching results of an act through the action and reaction of these relations, is the right one. The moral decision must be reached through a consideration which should be nearer the ideal, the nearer it comes to a consideration of all results, a due allowance being made for the uncertainty of distant results. This uncertainty must, other things being equal, diminish the influence of considerations of the far future on the decision, and should properly do so; although relative importance may, again, render the mere possibility of some one result a sufficient reason for choosing or abstaining from an act in the face of all other certainties and probabilities. Again, the power of calculating distant results is increased with the growth of knowledge, and man comes, thus, to obtain greater and greater power to shape the world about him and mould his own life to the attainment of his ends. With this power responsibility is also increased; the adult thief who rears children to theft bears the chief responsibility in the beginning of their career, and a very large share of it later on; the experienced man of the world, who understands whither he is tending, is much more responsible than the ignorant girl whom he seduces.

The highest morality demands, therefore, careful judgment. The factors to be considered are the complicated relations of men in the society of which the judge and actor himself is a member; morality may thus be identified with justice in the highest sense of the word. The decision is always a difficult one on account of the great complexity of the factors concerned; this every man perceives who endeavors, with unbiassed mind, to discover exactly what the most moral course is in any particular case. Some one course may be evidently immoral; but that does not necessarily decide what the moral course is, for there may be very many courses open to choice, or there may be at least more than one other as alternative to the manifestly immoral one. Moreover, the necessity for action forbids that we spend all our time in reflection and choice. Moral responsibility demands, however, that we never cease from the endeavor to discover where justice lies.

A certain constancy in the constitution of society, and the necessity for constancy or consistency in the action of the individual, 
give rise to certain general rules of conduct that develop and change somewhat as society changes; special rules of conduct which supplement these general rules change constantly. In the societies of a primitive sort, held together by only the loosest of bonds, personal retaliation is in vogue and is considered moral. Revenge is a duty. In societies of a higher sort retaliation is taken from the hands of the individual in all matters of importance, at least as far as the revenge consists in definite action, the motive of which can be demonstrated. The Englishman may still knock down the man who insults him, but he may not avenge a murder. Not only the negative morality of abstinence from violence is demanded of the citizen of a so-called civilized society, a certain reliability in the relations of coöperation is also necessary for the general welfare, and thus honesty comes to be encouraged and dishonesty to be discouraged by legal punishment and social contempt. Dishonesty in word is not so often punished directly by law as dishonesty of act, but there are many cases where it is impossible to distinguish between the two, and other cases where the lie is directly punishable because of the consequences which it involves. Beyond this, society begins early to discourage lying in some sort, though the love of and respect for truth obviously grows with social development. Coördinately with the development of coöperation and mutual dependence, constancy in all the multifarious directions and complex relations of that coöperation and dependence, becomes more and more desirable.

But constancy is not to be secured as an outward fact except as it becomes a part of the inward character of men, a constant habit. The man who lies occasionally is in at least some danger of developing a habit in the direction of lying, as he is also in danger of destroying the confidence of others if they discover that he sometimes lies; for they have no means of knowing to exactly what extent untruthfulness is, or is becoming, a habit in his case, or in what instances it may manifest itself, in what not. Moreover, the distrust so engendered may lead to anticipatory deception on their side, and so the circle of distrust and untruthfulness spreads until it is met somewhere by determined truth that demands truth in return. Thus, in spite of all that is said in favor of the occasional lie, we instinctively feel the danger of it, though we may not be able, until after much con- 
sideration, to assign the exact reason for our feeling. We may admit that there are occasions when the lie may be justifiable; but we feel that these occasions must, then, be very exceptional. In general, it is desirable to discipline ourselves to as close an approach to the truth as possible. If I lie in a dozen instances, in what I consider a good cause, I am very likely to lie again when the temptation of some merely personal gain presents itself. The habit of truth or falsehood is, further than this, one of the most subtle and intricate relations in our character: nothing is more difficult than the facing of the exact truth with regard to ourselves; cowardice and self-deception with regard to our own traits and motives are very common, and only the most earnest and constant effort can enable us to gain that moral courage that is the first requisite of self-knowledge and so self-control. Any weakening of the will in the contrary direction is dangerous. Truth is not an easy thing; it is as difficult as justice; in fact, that which is justice in action and the judgment which leads to action, is truth in the premises of which the judgment is the issue. We have most of us known persons who had so accustomed themselves to lying that they seemed no longer able to distinguish between truth and falsehood, facts and mere impressions. Certainly where matters of high importance which deeply concern the public welfare are at stake, we cannot admit falsehood to be desirable for the sake of any personal gain; and even though we may find excuses for the failure of human courage in the face of mortal danger, there are those of us who will still continue to think a Bruno's defiance of death for the sake of his conviction the nobler and better choice. I have heard it argued that this philosopher might have contributed more to the world through a continuation of his life than he did through his death. But surely it was one of the highest services that he could do mankind to show a superstitious and dogmatic age that high moral purpose and steadfastness were not necessarily associated with this or that religious dogma. His death drew the attention of thoughtful and good men as nothing else could have drawn it. But beyond this consideration, and even leaving out of account the desirability of the habit of truth and the necessity of its action in the single instance, it is doubtful whether there is any other benefit we can confer on our fellow-men so great as just the assurance that they can rely on us. The bitter cry of human nature everywhere 
repeats the faithlessness of those on whom trust has been staked; and the rescue of many a man from despair and waste of life has been through the discovery of some one soul whose truth and constancy were steadfast and unchangeable. Belief in others is belief in our own possibilities ; and distrust of others is distrust of self, at least for the most thoughtful and introspective men. The examples of such men as Socrates and Bruno stand to the world as pledges of the power of faithfulness in humanity. They are the rocks on which pessimism must shatter, and the betrayed and sorrowful may build their faith. This is, I believe, the secret of our veneration for such men as these, who died, not in an ecstasy of religious emotion or under the hope of especial glory as a reward for martyrdom, but faithful to a calm conviction, and sustained only by the love of truth and their fellow-men.

And this brings us to a consideration of the sacrifice of the individual. The cases may be few where the highest standard can demand of a man such entire and final sacrifice as the instances we have just noted, even though it may look upon this sacrifice as the highest. But it is evident that some degree of self-sacrifice is often necessary to the welfare of society, and however important we may consider the welfare of the individual, it cannot be regarded as more important than the welfare of the whole of society as an aggregate of many individuals, or even as more important than the welfare of a large number of other individuals, a considerable portion of society. The legitimate degree of sacrifice, where interests conflict and choice is necessary between the sacrifice of the single individual and the sacrifice of many, is a question that can be decided only according to the particular circumstances of the case. Everything depends upon the number of individuals on both sides, whose interests conflict, on the nature of the sacrifices necessary, and the results of these sacrifices to the society as a whole, as well as, in some cases, on the character of the individuals concerned. It is often denied that the nature of the individuals whose interests conflict, between whom choice must be made, can ever affect that choice if it is made under principles of justice. And in general, doubtless, there is danger of injustice in distinctions between individuals; but it is scarcely to be doubted that, if it were necessary to choose between the life of a great philanthropist and that of a persistent and hardened criminal, if, for instance, both were drowning and 
it were possible to save only one, the choice of most would fall, and fall rightly, on the philanthropist. The fact that moral choice must take different directions under different circumstances is sometimes construed into an argument against any fixity of moral commandments, an argument for a narrow expediency. It certainly establishes the rule that obedience to any rule of action should never be blind. Nevertheless, if our preceding considerations be correct, the uniformities in social relations admit of the establishment of certain general rules which the moral man will follow under most circumstances.

We come finally to the definition of conscience. In humanity as a whole, and in the single societies of which it is composed, a certain moral evolution may be perceived which we have found reasons for believing to be internal as well as external, a matter of heredity as well as of instruction. In this internal sense, conscience, as innate capacity, or tendency, may be said to be an instinct. We may not be able to explain how the inheritance takes place in this case any more than we are able to explain how it is possible that the chicken just from the shell may pick at his food without instruction, and just what psychical process, if any, accompanies the first performance of the act ; or to explain how it is that the sexual instinct appears in later life as an inheritance of species, and why it acts uniformly. We can only say that, the proper conditions of stimulation (which are always necessary in the case of any instinct) being present, the action takes place. We are unable to analyze the earliest appearance of sympathy, benevolence, and the sense of obligation, in our individual experience, the power of self-analysis appearing much later in life. That which, when we become capable of reflection, we term conscience, consists in pleasure in forms of action furthering the welfare of society - forms gradually moulded to habit with the development of social relations, - and in a corresponding pain at the realization of having failed of such action; the knowledge of the demand, by society as a whole or by a part of society, of action in accord with the general welfare, and the sense of the justice of this demand, constituting the feeling of obligation and duty. This feeling is early nourished in the family, the obligation we acknowledge being towards our parents first and foremost. We have found motives to be often of a mixed character; and this is often also the case with remorse, the pain we 
experience at having failed in our duty. It may contain an egoistic element of regret or dread at having rendered ourselves liable to punishment or loss of some sort.

Our whole analysis of the course by which conscience is developed tends to show the truth of that which Darwin claimed, namely, that the moral instinct is a development and organization of many special instincts. But there are those who claim conscience to be a special sense, and who generally mean much more than merely that it is, at present, an organization of subordinate instincts. A dim analogy of the special sense organs generally has part in their conception, and religious reference is often made to "the original constitution of man." But evolution knows nothing of an original constitution of man; it knows only of a gradual development of the human. And it must be remembered that, in evolution, that may become inherent which was not so before. Any theory which regards even an organization of special instincts as a special sense may, moreover, be objected to on the same grounds on which the old idea of special faculties of thought, feeling, and will was criticized. The old argument, used to prop the belief in conscience as an original, higher gift, and so, in the original creation of fixed species, - the argument that the same fundamental rules of moral conduct are to be found in all societies, - has already been answered in the demonstration that uniformities of human nature and necessary similarities in all social constitution render the fundamental rules of forbearance, aid, honesty, and truth necessary to all societies alike ; while our analysis of the course of development by which social organization grows more and more complex, shows the necessity as well as the reality of progress in outward and inward observance of these rules. Du Prel argues that even life on any of the heavenly bodies, supposing such to exist, must have some points of resemblance to our own, although the differences due to different planetary conditions may be great; but resemblances must assuredly be considerable where there is a common basis of species.

The Utilitarians are doubtless right in asserting that all rules of morality may be traced to utility. However, there is considerable ambiguity about the word " utility." Mr. Spencer's earlier objections to Utilitarianism, given in "Social Statics," - namely, that we cannot make the greatest good of the greatest number our 
object because it is impossible to perceive, without omniscience, where the greatest good lies, and because the standard of utility is a changing one, cannot be regarded as apposite, for we might as well say that a man cannot endeavor to secure his own health, or that it is not well for him to do so, because he does not possess a knowledge of all the intricate workings of the organs of his body and so may make mistakes, or that he cannot seek it to-day because the conditions necessary to secure it will have changed by to-morrow ; but Mr. Spencer's later objections to Utilitarianism touch an important truth. He says, for instance, in his "Recent Discussions in Science, Philosophy, and Morals": "Utility, convenient a word as it is from its comprehensiveness, has very inconvenient and misleading implications. It vividly suggests uses and means and proximate ends ; but very faintly suggests the pleasures, positive or negative, which are the ultimate ends, and which, in the ethical meaning of the word, are alone considered." Stephen has another pertinent criticism of Utilitarianism, namely that the utilitarian, in his anxiety to have his feet on solid earth, and to assign definite and tangible grounds for every conclusion, is likely to favor the prosaic rather than the poetical, and to leave out of account, or rank as of little importance, finer sorts of pleasure. ${ }^{1}$ The utilitarian is, in fact, liable to fall into a similar error to that already noticed on the part of those who claim that egoism is the foundation of all morality, present as past. While accepting the theory of evolution, the utilitarian fails to perceive, in many cases, that this lends to his terms a progressive and increasingly complex meaning. The error has its source, doubtless, in the fact that the utilitarian school represents a recoil from the older, superstitious Intuitionalism, which not only defended a doctrine of conscience as a sort of supernatural or half-supernatural instinct, on a plane above ordinary instinct, but, relying upon it as of such character, practically denied to reason any authority in matters of morality. In the strong reaction from these ideas, and under the fear of ceding any ground of advantage to the enemy, Utilitarianism has gone to an equally inadmissible extreme of clisregarding "mere impulses" of sympathy, and has tended to reject all conceptions of morality where it was not possible to unravel, beyond the criticism of opponents, the intricate web of social conditions. It is for this reason also that Utilitarianism is often egoistic; in the 1 "The Science of Ethics," pp. 375, 376. 
endeavor to analyze back to tangible grounds of action, it was much easier to adopt the evidently original basis of sympathy and altruism - that is, egoism - as the present basis also, than to trace out later developments in the many-sided organization of society. In rejecting instinct, it was but consistent and natural to overlook also the significance of habit in matters of morality; and thus the poet, the moral enthusiast, the martyr, and the rigid adherent of truth, came to be looked at askance. I do not mean to aver that all Utilitarianism has fallen into these errors, though the tendency is distinctly in this direction; neither the connection of a theory of utility with a disregard of the finer sorts of happiness, and the more distant and complex workings of social forces, nor the connection of a theory of moral instinct with superstition, is a necessary one.

A re-reaction against this bald Utilitarianism has set in; but some of the forms which it takes on can no more be indorsed by the consistent evolutionist than can the system from which it is a revolt. When Sidgwick defends Intuitionalism with the argument that the rightness of some kinds of action is known without consideration of ulterior consequences, we may answer that it is true that tradition furnishes us with many rules that we may follow without consideration of the consequences of our acts, but that it is very doubtful whether we act with the highest degree of morality in so doing. As to the "knowing" of the rightness of the acts, this is surely a matter of judgment, must, therefore, involve the considerations of consequences in some form, though the course of reasoning followed to the attainment of what is often termed "knowledge" in this sense may not be elaborate, and may, indeed, go no farther than a reflection on the approval and disapproval of society.

The terms "higher" and "lower" have been used in our previous considerations with regard to pleasures. The legitimacy of their use in this connection has often been questioned. From an evolutional standpoint, however, either they are legitimate here, or else objection may be made, on similar grounds, to their application to man as distinguished from the brutes or even from the original protoplasmic cell with which evolution began. The later developments of the desires, the newer social ends, are as much higher as the human species is higher than the species from which it has been evolved through continued adaptation. As, in the 
attainment of altruism, egoism is not lost in the sense that the individual no longer seeks that which is most pleasurable to him, but simply reaches a higher plane, so the fundamental animal desires and instincts still move us, but in a quite different form, being closely interwoven, in their later development, with all the ideals and aspirations with which social life has supplied us. The advocates of a "return to nature" make, therefore, a fundamental mistake in theory. Human development is also natural. The same mistake is made when we are told that we must be animals in practice because we are animals by nature, or that we must "copy nature" because we are a part of it. The former assertion ordinarily commits the fallacy of using the word " animal" in two senses. The latter assertion involves the fallacy of first making man a part of the nature, which he is to copy, in order, then, to prove that he must regard himself as something outside nature and must, therefore, slavishly follow. But if man is himself a part of the nature he must copy, one may question why he may not simply copy himself rather than any other part; for obviously he is unable to copy all parts, there being many antagonisms in nature. I have heard the argument used in defence of cruelty to animals; nature is cruel, therefore man must be cruel. But as a matter of fact, there is no more reason why man should copy any other part of nature, than there is reason why the horse should imitate the habits of the hog, or turtle-doves take example by the tiger. Necessity may sometime compel a choice between two cruelties, to which there is no third alternative; but this is a different argument; let us say, in this case, that we are so compelled (if, indeed, there is no other alternative ; for this argument, like the other, is often used as a convenient excuse for mere selfishness, where there are alternatives) ; let us not employ a wholly fallacious and misleading argument which opens the way to the free exercise of selfish disposition.

Objections are often made to theories of the development of higher moral qualities from egoism, on the ground that such a derivation is degrading to that which is best in man. Some color is lent to this view by arguments like that just noticed. But we may question whether facts can be logically chosen or rejected according to their agreeableness, or even their moral utility, in any case. And, again, some of us may fail to discover any 
degradation in this theory of evolution. The flower may grow from carrion, but we do not find it the less beautiful, the less pleasing to our various senses. And we should have exactly as good reason to regard the carrion as elevated by its office as to regard the flower as degraded by the source of its life. As a matter of fact, we merely find the flower pleasing and the carrion abhorrent. We are used to this particular connection of the pleasing with the abhorrent, and accept it as we accept much that may be to us disagreeable in our own physical organization; but we have not yet accustomed ourselves to the ideas of mental and moral evolution, and our recoil from them is an illustration of the displeasing character of the wholly New. The same argument of degradation was at first brought forward also against the theory of an evolution of the human form from that of lower species, and of the "purely intellectual faculties" from the animal mind.

The question as to whether struggle is an essential element of virtue has been so thoroughly answered by Gizycki, Stephen, and others, that it would be superfluous to say much about it here; however, our analysis would not be complete without some consideration of it. "The man is the strongest," writes Stephen, "who can lift the heaviest weight or who can lift a given weight with the greatest ease. But (and it is a proof of the loose argument which has often been accepted in ethical disputes) the two cases have sometimes been confounded. It would plainly be absurd to say, 'The man is strongest who lifts the greatest weight, therefore the man who makes the greatest effort; therefore the man who makes the greatest struggle to lift a given weight.' But it has occasionally been said that a man is most virtuous who resists the greatest temptation; therefore the man who has the greatest struggle; therefore the man who has the greatest difficulty in resisting a given temptation. Though the fallacy does not occur in this bare form, it is not infrequently implied in the assumption that the effort, taken absolutely, is the measure of merit. . . . We are thus led to excuse a man for the very qualities which make him wicked. True, he committed a murder, but he was so spiteful that he could not help it; or he was exceedingly kind, but he is so good-natured that it cost him no effort."

The difficulty lies in the fact that the struggle arising in any 1 “"The Science of Ethics," p. 300. 
particular case may result from any one of several general conditions of character, between which it is often difficult to distinguish. An absence of struggle may mean simply a general weakness of character which makes a man ready to yield to any and almost all momentary influences, good or evil; the agreement with another's argument may signify absence of the power to reason for oneself; but, on the other hand, it may mean the highest intellectual power of unbiassed judgment; the act that follows such agreement as its result may mean will-power, or it may mean vacillating weakness that, if led by a good influence at the present moment, will be as easily or nearly as easily swayed by an evil one, the next. We are all acquainted with persons who invariably agree with all sides, and shilly-shally in a corresponding manner in their action, accomplishing little or no positive good in any direction, though often positive evil. For the reason of this frequent weakness of character in what we call the "good-natured" person, the term "good-natured" has come to have a certain idea of mental and moral inferiority connected with it. In a similar manner, some men who are generally called "good " are swayed to a greater extent by tradition and lack of courage to act for themselves than by strong desire to know and do the right, and thus, very unfortunately, the excellent word "good" even comes to be looked upon with a certain degree of disdain. On the other hand, a man may find much difficulty in doing right in a certain instance, because of the strength of emotions that would be, under ordinary circumstances, morally desirable and are, in themselves, admirable even in the moment of his temptation, although a yielding to this temptation would, nevertheless, involve great wrong. No one could blame the agony and struggle of the switchman who, in the moment when he is about to rescue a passenger-train from imminent collision by switching it to another track, suddenly perceives his baby-girl seated upon the rails. (I Strong and ennobling love between man and woman may involve, under certain conditions, temptation and struggle; even the best of our impulses may not always be followed, if we desire to act morally. Few, if any persons could refuse admiration and respect to the love between Phillip Tredennis and Mrs. Amory in Mrs. Burnett's "Through one Administration." But not all strong feeling is of an admirable nature; the revengefulness of the murderer, the vicious lust of a Joseph Phillippe, the impa- 
tience of the constitutionally belligerent man, are not to be praised, but condemned. Stephen's argument, therefore, that struggle is adjudged an element of virtuous character in many cases because its absence would show "a defect in some faculty of enjoyment," includes too much; for Jack-the-Ripper, and others who especially delight in crime, possess faculties of enjoyment the entire absence of which in other men we do not look upon as a defect. ${ }^{1}$ Stephen restates his position in another form, saying that "If a man resists any inducement because it has no charms for him, his act does not prove virtue unless the inducement be such as to appeal only to the wicked." It is only because, incidentally, those qualities moulded in human society, and therefore fundamentally good, may come into conflict with each other, that we fall into the habit of connecting the idea of struggle with morality; in face of the fact that readier response to moral stimulus must constitute all moral advancement.

And these reflections lead us to remark on the common fallacy that strength of emotion means necessarily a lack of the moral direction of emotion, and that conversely moral self-direction argues weakness of emotional capacity. The direction of emotion is changed with evolution, as we have seen, but this does not mean that emotion is lessened in force. In the man of highest morality, the emotions are merely moulded to a greater harmony with social needs, a harmony that is not weakness but strength, not mere narrow reaction upon momentary impulse or one-sided sympathy with a few to the exclusion of the many, but, in contrast to this lower impulsiveness, an all-sidedness that is the result of reflection and choice. I say this all-sidedness is "the result" of reflection; for I do not mean to intimate that the moral man is less impulsive than the immoral man, or that he is obliged to consider long before every act. Merely his impulsiveness is of a higher sort; in it both racial and individual adjustments to social needs find expression; and reason always stands, figuratively speaking, in the background, ready to suppress the spontaneity where the conditions are such that it ceases to be moral. It has been part of our whole analysis to show that reason and instinct, thought and feeling, are by no means antagonistic. Simply, feeling may take one direction in one man, another in another; in the criminal, it is developed 
in the direction of anti-social acts; in the profligate, it takes the same direction, but in a less degree; the original savage is stronger in him than in the moral man, who belongs to a later and higher type, and finds his pleasure in acts in accordance with the welfare of his fellow-men and fellow-women. As the human being is a higher development than other species because he is adapted to a wider circle of nature, so just as truly the moral man is a higher human development, because function is, in him, adjusted to a wider circle of conditions - to complex social requirements which represent the happiness of his fellow-men. Altruism is not, because a later development, "artificial," as Barratt calls it, any more than man is artificial in comparison with the ape, or the ape is artificial in comparison with original protoplasm. Nor can virtue consist, as Barratt conceives, in a yielding to all emotions, ${ }^{1}$ as long as man has not yet attained the highest summit of morality where all emotions follow moral directions, without conflicts and without constraint. But neither can morality be distinguished as "a constraining power opposed to instinct and emotion in general," 2 as Stephen at one point defines it. Struggle and constraint are not necessarily elements of moral action; kind and moral action often follows upon impulse with no effort whatever; and, on the other hand, the basest characters may know struggle of an extreme nature when the directions of self-interest conflict.

We have already noticed the origin of punishment in revenge, which is the outcome of a fundamental, egoistic instinct of selfdefence ; and we have traced its development up to the monopolization of its extremer forms by society as a whole through state organization. It is impossible for analysis to give any adequate representation of the workings of Reward and Punishment in society, except as we draw an exact line between legal and other forms. But such a distinction, however convenient for particular purposes, is obviously scientifically injustifiable in a general theory of social morals. The constraint of family disinheritance and social ostracism, of threats of all sorts, of vituperation, of disapproval and coldness, are only higher forms of revenge or punishment, by which men influence each other's action, as savages influence each other through physical suffering and the fear of it, in a more primitive and less humane manner; and state reward

${ }^{1}$ See Part I, this book, p. II 7. $\quad 2$ "The Science of Ethics," p. 3 Io. 
for services, praise, and approval, are all forms of encouragement, by which men similarly incite each other not merely to a negative abstention from undesirable acts, but to a positive performance of desirable acts. With the development of sympathy, punishment tends to become less brutal on the one side, while, on the other, the less brutal forms come to have as great influence as the more brutal ones formerly had. Furthermore, the distinct calculation of the attainment of egoistic ends gives place to the impulsive reaction of the sense of justice on the one hand, and, on the other, to the readier response to disapproval and to the desires of others, through social predispositions and affections which are more altruistic than egoistic.

But there are two diametrically opposed schools, neither of which perfectly agrees with the theory of will as stated in a preceding chapter of this work, and both of which may therefore take exception to the theory of recompense which follows naturally upon that theory. The one, the school which asserts Free Will not in a natural, but in a supernatural, or half supernatural sense, may object to the grounds for punishment assumed in our analysis; this school is answered by the demonstration of the actual course of development taken by reward and punishment. The other school maintains, on the ground that man is a part of nature, that there is no merit in conscientiousness, and that evil-doing, being as much dependent upon organization and social environment as disease, cannot, on scientific grounds, be punishable. It is to be noticed, however, that many of the advocates of the theory that state punishment is injustifiable yet inflict punishment upon their own children ; and we may remind them, in this connection, that they can scarcely claim the will of the child to be freer or less the result of general social conditions than that of the adult, and that, moreover, they themselves are the most immediate links in the chain of conditions producing this will. Furthermore, they are inconsistent in their practice if they visit any blame on evildoers or criminals; they are logically restricted to, at most, an "I differ with you in opinion," to Jack-the-Ripper, to the cruelest of slave hunters, or to the Chinese who are said to have regarded with indifference the burning of their fellow-men on the ship "Shanghai," while they exerted themselves to secure the wreckage. Nor, if punishment and blame are inadmissible, on the ground of the determination of the will, can they consistently 
show greater consideration to benevolent than to malevolent men, no matter how great the public benefits these men have conferred, or what aid they have given to the advancement of society? If it is unjust to punish criminals because their acts are determined, then it is also wholly unjust to the rest of mankind to praise a Bruno, or a dying Sir Philip Sidney giving the cup of water offered him to another. If good men might be criminals, had they the criminal organization, it is equally true that ordinary and selfish men might be Brunos and Sir Philip Sidneys if they had the organization of Brunos and Sir Philip Sidneys; why then do ordinary men the injustice of praising and admiring such nobility of character? Nor can a theory of determinism which refuses to blame the individual consistently lay the blame of crime and badness on society as a whole, as it often does; for society as a whole is composed of individuals, all of whom are equally determined in their action. Or, if we choose to regard society as a unit, then it may be said that it is as much the product of nature as a whole as the individual is its product. If it be objected that we do not blame nature as a whole because it is soulless, we may inquire what is meant by soulless; society has no composite soul, no soul except in its individuals. The real significance of the objection is that we cannot influence nature, by our blame, to the production of better characters; but it is also true that we cannot influence society except through the individuals composing it ; and here we have, again, in a nutshell, the real reason and justification of punishment and blame.

The Socialists have been prominent of late in disclaiming the right of the state to punish, on the ground that society as a whole is responsible for the evil of individual characters. But it is not noticeable that all Socialists refrain from blaming non-socialistic and conservative individuals, although it is obviously true that these are quite as much determined, and as irresponsible from a deterministic point of view, as are the criminals. Moreover, even the mildest Socialists advocate the measure of denying food to the man who can work but will not do so. By what right do these determinists make use of the expression "can but will not"? And what right have they, on their own showing, to administer this chastisement to the lazy man? Surely sloth cannot be interpreted as preëminently a power of will, which no other man possesses; and surely sloth is, as much as criminality, the product 
of social conditions. If it be objected that this denial of food is no punishment but merely a letting alone, we may inquire whether the starvation which used to be inflicted on prisoners for some offences was not a positive form of punishment. And if it be said that the slothful man has it in his power, at any time, to escape starvation by beginning to work, we may answer that the state says to the criminal, also, that he has nothing to do with its penalties as long as he abstains from the acts for which they are imposed. Why should the vindictive man, the Joseph Phillippes, the Jukes, and Eyrauds of the future receive sustenance, care, and kindness, in homes set apart for their especial use, while the man who is merely indolent is driven to solitude and the roots and herbs of the forest for the support of existence? Perhaps, in such case, the indolent man may claim society's greater indulgence by taking to crime.

These determinists are sometimes heard to make the assertion that the punishment of criminals is wrong, but that punishment of children must still be resorted to for their own sake as well as for that of society, since their character can be disciplined and bettered by it. When we arrive at this inconsistency, we get at the root of the whole objection to state punishment of criminals. There is a growing dissatisfaction with present methods of punishment, and this dissatisfaction, insufficiently analyzed, takes the form of objection to punishment altogether. Benevolence is progressing beyond present laws, and demands their change; that is the gist of the whole matter.

In the light of our analysis of the evolution of morality, we may repeat the inquiry, left unanswered at the beginning of this work, as to whether, in the province of morals more than in other provinces, we find a supernatural element or an element which, in any way, gives us an intimation of the supernatural or transcendental. The question must be replied to in the negative. If it be objected that we must not expect to find the supernatural in the natural, we may reply that that is just what we have not expected to do. The fallacy of such an expectation does not lie with us. Nature gives us no intimation of a supernature, when we cease to see it with the uncomprehending eye of the untutored savage. Nor can the gross, cruel, and superstitious savage be regarded as, in contrast to more social and humane man, better fitted to be the medium of spiritual truth. 
And this brings us to the discussion of the presence or absence of conscience in lower animal species. We have found that some species have social organization quite as elaborate as that of many savage tribes, and even more elaborate than that of some tribes. We are able to view these organizations only in their external features; we cannot, however, in most cases, suppose the species to be devoid of consciousness of some sort, and consciousness involves, in any case, pleasure in accustomed function and in its constantly experienced results ; the two, action and experience of its results, are, in fact, both functional. The argument of inconstancy, and of inconstancy at points at which it is not found among men, has been shown to be absolutely valueless as directed against any theory of the existence of sympathy and "social instinct" among other animal species. We too are inconstant in our altruism; and habits of altruistic action do not necessarily take the same course with other species that they do with us, differences in social organization rendering differences of habit necessary. If other species fall below us in self-sacrifice for the community in some respects, they often surpass us in others. We may conclude, then, that habits of mutual assistance, habits which we perceive to be externally altruistic, must also be supposed to be connected in many cases with some internal corresponding feelings of the same nature as those which we term, in man, altruistic and social. I do not see how we can avoid this conclusion unless we deny all consciousness to other species ; for consciousness must involve, on any plane, feeling as pleasure and pain. And on the supposition of memory, and of the connection in memory of those things and events which are constantly connected in experience, we must suppose the seeking of ends, also, though they are, probably, in most cases, much nearer ends than our human ones. It may be true, as Professor Morgan thinks, that animals have no general concept of ends and means; but a general concept of ends and means is not necessary to the recognition of the fact that this or that particular form of action will have this or that particular result. It is not necessary to apply the terms "ends" and " means" to events in order to understand their connection as following upon each other with constancy. Moreover, we are accustomed to count only our own ends as ends proper, and so, only our own wisdom as wisdom; and thus we term other species stupid for not understanding just our wisdom 
and acting on a line with us; but certainly there are plenty of human beings whom we do nct term wanting in reasoning powers who seek their own destruction or harm much more stupidly than many animals; and, on the other hand, there are many animals who act much more consistently for their own and others' welfare than a large number of mankind do. If the failure of other species to comprehend our language and understand our action is to be termed stupid, then what shall we term our failure to understand their methods of communication and motives of action? It is time for us to emancipate ourselves from this narrow anthropomorphism in which we are accustomed to live, and to realize and acknowledge that there may be other consciousness than our own, with quite other thoughts, feelings, habits, ends, and motives. It is a part of our customary egoism that we prefer to exalt ourselves ; it is more gratifying to our vanity, as well as more convenient to our conscience, to regard other species as half-automatic and beneath our sympathy; we thus have excuse for using them as we like. So we call the tiger cruel because he is carnivorous as we ourselves are; we call the fox cunning and sly for lying in ambush for his prey ; but when we go out to take, by similar means, our special prey, we call our action a triumph of superior reason. We term the fox a thief, too, when he takes again from us what we are continually taking, and what we took originally, from the beasts. What we regard as right and justifiable and even admirable in ourselves we regard as wrong, cruel, mean, selfish, underhanded, abhorrent, and worthy of all punishment in the animals. As for the faithfulness unto death displayed by many animals, we do not regard that as heroism or worthy our admiration, although we might often take pattern from it. How should we understand other species? We are not accustomed to associate this or that feeling of pleasure in ourselves with a pricking up of ears or a wagging of tail, or our deepest despondency and pain at repulse with this or that peculiar posture or animal cry. A faint trembling of the human hand from fear or pain will stir us with the most profound sympathy; but the sensitive quiver of the whole body in some helpless, hopeless animal, that cannot speak its fear or crave for mercy in the human tongue, touches but seldom an answering chord in our hearts. Shame on our vanity and our hard-heartedness!

The whole of our analysis has tended to lay emphasis on habit. 
And this leads us to comment on a certain disdain and contempt for habit and custom which is continually arising in some quarters. The whole history of mankind is the history of the formation, gradual change, and spread of the change, of habit, and of custom as the social form of the latter. With the progress of society, habits and customs grow old and must be discarded; but only careful consideration can show us when change is desirable. It is, therefore, both stupid and foolish to inveigh against a habit merely because it is habit or because it is of long standing. Originality, intellectual superiority, does not consist in a contempt for custom merely as custom, but in the power to weigh all sides, to view a matter in all lights, without regard to its age or newness, and to decide on its worth according to its inherent merits or defects. In the rebellion from the slavery to tradition as such, the opposite, equally unreasonable extreme of denunciation of all existing custom is often reached. Thus, some followers of Socrates, adhering slavishly to the word of their master but failing to comprehend its inner meaning, dispensed with all the social usages of their nation, and despised its laws. Of late patriotism is denounced as mere race-prejudice founded on habit and association. But all our affections are matters of habit and association. Doubtless, patriotism may often involve narrowness and injustice; so also may a mother's love for her child, or any other of the forms of the preference of affection. However, it does not follow, therefore, that mother-love is to be denounced and rejected; what we need is not less mother-love, or father-love, but a counterbalancing sympathy for other human beings outside the family, also. And so too we do not want less love of country, but the infusion of it with a broader humanity and justice. The love of a mother need not render her less, but may, on the contrary, render her more, sympathetic; and the love of country may be combined with a wide-reaching regard for the welfare of other men outside the nation to which the patriot belongs. In fact, the mother who is incapable of peculiar love for her own child is not likely to be capable of deep sympathy with other human beings; and I am inclined to believe that there must be something lacking in a man's general moral constitution when he feels no peculiar regard for the land to which he belongs. If it is foolish, as is sometimes asserted, to love one country more than another, simply because we happen to have been born in it, then 
it is also equally foolish to love our mother simply because she happens to be our mother. There may be other lands as good as ours, and possibly there may be other mothers as good as ours; but affection does not reason thus.

Is social development the cause of an increase in sympathy, or is the increase of sympathy the cause of social progress and prosperity? Or is increase of population the cause of both by forcing men to companionship? Or is not, rather, increase of population the effect of prosperity? In his work on "Recent Discussions in Science, Philosophy, and Morals," Herbert Spencer writes of the altruistic sentiments: "The development of these has gone on only as fast as society has advanced to a state in which the activities are mainly peaceful. The root of all the altruistic sentiments is sympathy, and sympathy could have become dominant only when the mode of life, instead of being one that habitually inflicted direct pain, became one which conferred direct and indirect benefits; the pains inflicted being mainly incidental and indirect;" and in an essay on "Progress," the author writes: "Social progress is supposed to consist in the produce of a greater quantity and variety of the articles required for satisfying men's wants; in the increasing security of person and property ; in widening freedom of action; whereas, rightly understood, social progress consists in those changes of structure in the social organism which have entailed these consequences." The two paragraphs appear contradictory of each other, the first laying emphasis upon outer conditions as cause of inner change, the second seeming to emphasize inner conditions as cause ; but the terms of the second quotation are somewhat ambiguous. As to the first, to do Mr. Spencer full justice, he corrects this a little farther down, where he says that "sympathy is the concomitant of gregariousness, the two having all along increased by reciprocal aid."

The root of the whole difficulty, with regard to our theories of cause and effect in social development, as with regard to our theories of cause and effect in other parts of nature, lies in our desire for unity and simplicity. Instead of attempting to unravel the intricate web of the conditions, we fix our attention on some one feature or side of the process, and regard the whole development as revolving round this pivot.

It is easy to find examples, in the history of science and opinion, of the errors into which the concepts of cause and effect have led 
men, and of the repeated recurrence of uncertainty to which the unveiling of these errors in the further march of knowledge, has led. For instance, we find some writers on nervous diseases adhering to the view that insanity is sometimes the effect of a weak yielding to a violent disposition; more contending that the violence is itself the effect of incipient insanity; and still others opining that both violence of disposition and insanity are the effect of a general diseased state of the system. Ancient schools of medicine traced all diseases to the blood, and so drained off the fluid; and the patent medicines of to-day generally select some one organ as the source of all disease. I once heard the assertion that a certain woman had died with grief contested by a physician on the ground that the cause of her death was consumption; he added that deaths from sudden mental shock were known to medicine, but the cases were rare; another medical man suggested that the system might not have been in a perfectly healthy condition at the time of the shock, in those cases; and the first man seemed a little puzzled when a third person suggested that there was doubtless a physical basis in every case. 


\section{CHAPTER VII}

THE MORAL PROGRESS OF THE RACE AS SHOWN BY HISTORY

THE necessity of the constant assimilation of savage tribes, of the peopling of thinly inhabited areas, renders social evolution as a whole exceedingly slow. Nor can there be, even in isolated peoples, any sudden leap from savagery to civilization; in other words the term "civilization" is not of absolute but of comparative, progressive, import. Nor can we suppose the social evolution to have been only outward; we cannot suppose that our cavedwelling, man-eating, rude ancestors, if they could have been suddenly transported, in infancy even, into the midst of modern civilization by means of a Carlylean wishing-cap, or by some method of projection in time similar to that by which men promise to " knock each other into the middle of next week," would have been able to equal modern men in mental and moral attainment. We may gain some idea of the gentle manners and moral character of our early progenitors from the customs of savage peoples of the present day; although a very large number of these stand upon a higher plane than did the ancient savages known to geology. I insert a few extracts from Lubbock :-

"Mr. Galbraith, who lived for many years, as Indian agent, among the Sioux (North America), thus describes them: 'They are bigoted, barbarous, and exceedingly superstitious. They regard most of the vices as virtues. Theft, arson, rape, and nurder, are among them regarded as the means of distinction; and the young Indian from childhood is taught to regard killing as the highest of virtues. In their dances and at their feasts, the warriors recite their deeds of theft, pillage, and slaughter, as precious things; and the highest, indeed the only, ambition of a young brave is to secure "the feather," which is but a record of his having murdered or participated in the murder, of some human being - whether man, woman, or child, it is immaterial; and 
after he has secured his first "feather," appetite is whetted to increase the number in his cap, as an Indian brave is estimated by the number of his feathers." "1

" 'Conscience,' says Burton, 'does not exist in Eastern Africa, and "repentance" expresses regret for missed opportunities of mortal crime. Robbery constitutes an honorable man ; murder the more atrocious the midnight crime the better - makes the hero." "' 2

"In Tahiti, the missionaries considered that 'not less than twothirds of the children were murdered by their parents.' Mr. Ellis adds, ' I do not recollect having met with a female in the islands, during the whole period of my residence there, who had been a mother while idolatry prevailed, who had not imbrued her hands in the blood of her offspring.' Mr. Nott also makes the same assertion. Girls were more often killed than boys, because they were of less use in fishing and in war." ${ }^{3}$

"Williams tells us that "offences, in Fijian estimation, are light or grave according to the rank of the offender. Murder by a chief is less heinous than a petty larceny committed by a man of low rank.'"

"Among the Khonds of Central India, human sacrifices prevailed until quite lately. 'A stout stake is driven into the soil and to it the victim is fastened, seated, and anointed with ghee, oii, and turmeric, decorated with flowers, and worshipped during the day by the assembly. At nightfall the licentious revelry is resumed, and on the third morning the victim gets some milk to drink, when the presiding priest implores the goddess to shower her blessings on the people. After the mock ceremony, nevertheless, the victim is taken to the grove where the sacrifice is to be carried out; and to prevent resistance, the bones of the arms and legs are broken, or the victim drugged with opium or datura, when the janni wounds his victim with the axe. This act is followed up by the crowd. A number now press forward to obtain a piece of his flesh, and in a moment he is stripped to the bones.'

"An almost identical custom prevails among the Marimos, a tribe of South Africa much resembling the Bechuanas. . . . Schoolcraft mentions a ... sacrifice to the 'Spirit of Corn' among the Pawnees. The victim was first tortured by being sus-

\footnotetext{
1 “The Origin of Civilization," pp. 397, 398. $\quad{ }^{2}$ Ibid. pp. 402, 403.

${ }^{3}$ Ibid. p. 398.

4 Ibid. p. 407.
} 
pended over a fire. 'At a given signal, a hundred arrows were let fly, and her whole body was pierced. These were immediately withdrawn, and her flesh cut from her bones in small pieces which were put into baskets and carried into the cornfield, where the grain was being planted, and the blood squeezed out on each hill.'

"Human sacrifices occurred in Guinea, and Burton saw 'at Benin City a young woman lashed to a scaffolding upon the summit of a tall blasted tree, and being devoured by the turkeybuzzards. The people declared it to be a "fetich" or charm for bringing rain.' . . .

"Captain Cook describes human sacrifices as prevalent among the islanders of the Pacific, and especially in the Sandwich group.

War captives were frequently sacrificed in Brazil."

"The lowest races have no institution of marriage. True love is almost unknown among them, and marriage in its lowest phases is by no means a matter of affection and companionship. . . . In North America, the Tinné Indians had no word for 'dear' and 'beloved'; and the Algonquin language is stated to have contained no verb meaning 'to love,' so that when the Bible was translated by the missionaries into that language it was necessary to invent a word for the purpose." 3

"The position of women in Australia seems, indeed, to be wretched in the extreme. They are treated with the utmost brutality, beaten and speared in the limbs on the most trivial provocation. ' Few women,' says Eyre, ' will be found, upon examination, to be free from frightful scars upon the head or the marks of spear-wounds upon the body. I have seen a young wornan who, from the number of these marks, appeared to have been almost riddled with spear-wounds." " 4

"Collins thus describes the manner in which the natives about Sydney used to procure wives: 'The poor wretch is stolen upon in the absence of her protectors. Being first stupefied with blows, inflicted with clubs or wooden swords, on the head, back, and shoulders, every one of which is followed by a stream of blood, she is then dragged through the woods by one arm, with a perseverance and violence that it might be supposed would displace it from its socket. This outrage is not resented by the relations of the female, who only retaliate by a similar outrage when they find an opportunity." " 5

${ }^{1}$ See, as above, pp. $368,369$.

2 Ibid. p. 37 I.

8 Ibid. p. 69.

4 Ibid. p. 72.

5 İbid. pp. I 1 2, I 13. 
" Indeed," says Lubbock, " I do not remember a single instance in which a savage is recorded as having shown any symptoms of remorse; and almost the only case I can call to mind, in which a man belonging to one of the lower races has accounted for an act by saying explicitly that it was right, was when Mr. Hunt asked a young Fijian why he had killed his mother." ${ }^{1}$

We have direct evidence, in many present or recent customs, of so-called civilized or half-civilized nations, that the barbarous customs described in "The Origin of Civilization," and in the books of many travellers, are not the original and special inventions of modern savages merely, but that similar customs prevailed among our progenitors. Lubbock notices many of these. The marriage ceremonies of many peoples are particularly suggestive of a time when violent capture was the means of obtaining a wife, and cruelty of treatment was her usual portion. ${ }^{2}$ Human sacrifices were common among many peoples of ancient Europe; and the cancellation of responsibility for murder with fines (often nominal in the case of the murder of a man of lower rank) was a widely spread custom. " "In Russia," writes Lubbock, " as in Scandinavia, human sacrifices continued down to the introduction of Christianity. In Mexico and Peru they seem to have been peculiarly numerous. Müller has suggested that this may have partly arisen from the fact that these nations were not softened by the possession of domestic animals. ${ }^{3}$ Various estimates have been made of the number of human victims annually sacrificed in the Mexican temples. Müller thinks 2500 is a moderate estimate; and in one year it appears to have exceeded 100,000." "In Northern Europe, human sacrifices were not uncommon. The Yarl of the Orkneys is recorded to have sacrificed the son of the King of Norway to Odin in the year 893. In 993, Hakon Yarl sacrificed his own son to the gods. Donald, King of Sweden, was burnt by his people as a sacrifice to Odin, in consequence of a severe famine. At Upsala was a celebrated temple, round which an eyewitness assured Adam of Bremen that he had seen the corpses of seventy-two victims hanging up at one time." 4

1 See, as above, p. 405 .

2 See Lubbock, "Prehistoric Times," also especially Chaps. III. and IV. of "The Origin of Civilization."

${ }^{3}$ Cause or effect, which? Mexico is not a country poor in animal life.

4 "The Origin of Civilization," pp. 372, 373 . 
A peculiar confusion as to the definition of morality sometimes gives rise to such vagaries of theory as the defence of murder committed by savages, and other cruelties practised, on the ground that these things are not considered sins in the moral code of the peoples among which they are practised ; murder is thus excused on the plea that wrecking is also looked upon as permissible ; ${ }^{1}$ and Wallace thinks that savages live up to their "simple moral code" as well as civilized human beings to their elaborate one, so that they are, in reality, as moral as these latter. It should not be forgotten, however, that the moral code is itself the product of the tribe and represents its moral sentiment. Lubbock remarks that if a man's simple moral code permits him to rob and murder, the code is at least an unfortunate one for the victims. ${ }^{2}$ On the other hand, Lubbock himself defends human sacrifice as the result of "deep and earnest religious feeling." 3 But if sympathy were strong, such sacrifices would be impossible, and the religious code would be altered just as the religious code of Christians is altered to keep up with social progress. Opinion and feeling are not two separable things, one of which may advance while the other remains behind; when feeling becomes strong enough, the opinion arises that this or that custom before practised is wrong. As long as man is cruel by nature, however, conscience will not torment him for cruelty, and it is possible for him to regard it as wholly justifiable.

But I am of the opinion that moral progress has been made not only since the time of our savage ancestors, but even also since the time of the great ancients, in spite of the obstacles to such advancement presented in the necessity of the moral assimilation of immense races of savages, - the leavening of the whole of Europe. I believe that modern civilization has caught up to and surpassed the ancient. The knowledge we have of ancient peoples is necessarily most imperfect; nevertheless, we may, I believe, discover considerable evidence of general moral inferiority to the present day. Any advance that has been made will be likely to be most observable in those general virtues which lie at the foundation of all social coöperation - truthfulness in word and honesty in act, and the gradual widening of concepts of justice from individual and class privilege and race prejudice, to the inclusion of mankind as a whole. And the growth of sympathy ${ }^{1}$ See "The Origin of Civilization," p. $396 . \quad 2$ Ibid. p. $398 . \quad{ }^{3}$ Ibid. p. 37 I. 
will be most noticeable in the treatment of those classes of beings which possess least physical means of compelling respect for their rights - animals, children, women, the poor, and ignorant, and sick, and aged.

We may begin with the children. The Lacedemonian custom of giving over the weak and defective children to destruction is familiar to us all. Before Solon, children were often sold by Athenian parents for debt ; and even during the ages of greatest culture, the exposure of children seems to have been a common Athenian practice, regarded with little or no disapproval by the general public. Mahaffy writes: "The cool way in which Plato in his Republic speaks of exposing children, shows that, as we should expect, with the increase of luxury, and the decay of the means of satisfying it, the destruction of infants came more and more into the fashion. What can be more painfully affecting than the practice implied by Socrates, when he is comparing himself to a midwife (Theæt. $\mathrm{I}_{5} \mathrm{I}$ B.). 'And if I abstract and expose your first-born, because I discover that the conception you have formed is a vain shadow, do not quarrel with me, as the manner of women is, when their first children are taken from them. For I have actually known some men ready to bite me when first I have deprived them of a darling folly." "1 That the exposure of children is generally mentioned only incidentally by Greek writers, is perhaps the strongest argument of all that the custom was regarded with indifference by the majority. A considerable number of the exposed children seem to have been rescued to be brought up as prostitutes, but many must have perished miserably. We have reason for doubting whether the average Greek would have shown an equal sympathy to that of Mr. Stephen's modern pickpockets, in the supposed case of danger to a child on the race-course $;^{2}-$ unless, indeed, the child were an especially fine bit of animal flesh.

The same narrow sort of expediency in morals which permitted the exposure of children is exhibited, again, in the lack of regard for the aged shown by the Athenians at all periods of their history ; - in Sparta the old men were treated with some considerable respect. Says Mahaffy: "The strongest case against the Periclean Greeks, and one which marks their parentage most clearly from their Homeric ancestors, is the treatment of their old men. For here it is no inferior class, but their equals, nay 1 "Social Life in Greece," 3d ed. p. $272 . \quad 2$ "The Science of Ethics," p. 237. 
even those to whom they directly owed their greatness, whom they cast aside with contempt when their days of usefulness had passed by.... The Greek lawgivers were accordingly most explicit in enjoining upon children the nurture and support of aged parents who could otherwise expect little from the younger generation. The Attic law alone added a qualification, that the children were to be without responsibility if their parents had neglected to educate them." Aristophanes describes the treatment of the aged in his "Wasps," - " where he declares that the only chance of respect or even safety is to retain the power of acting as a juryman, so extorting homage from the accused and supporting himself by his pay without depending on his children. When he comes home with his fee, they are glad to see him, in fact he is able to support a second wife and younger children, as the passage plainly implies, whereas otherwise the father must look towards his son and his son's steward to give him his daily bread, 'uttering imprecations and mutterings lest he knead me a deadly cake,' a dark insinuation which opens to us terrible suspicions." 1

The women of Greece were comparatively well cared for, as might be expected in a nation and country peculiarly susceptible to the influence of grace and beauty; they were consequently of a comparatively admirable type. However, we are fond, I think, of indulging in this respect, our preference for believing the romantic; so that we usually select carefully the best instances and infer that the standard of all Greece was on this plane. The reasons for this are manifold. We have the habit of imagining, from Greek art, that all Greek women were beautiful ; and it is unpleasant to associate moral inferiority with great beauty, or to imagine its being treated with unkindness or disrespect. Again, we are pleased at discovering examples of love and faithfulness even in the far-away ages, and the pleasure of the discovery exalts the few instances with which Greek literature provides us to a disproportionate importance and significance. Disappointed at not finding their perfect ideal in their own age and nation, men have pleased themselves with the imagination of perfection in an object belonging to another age, with regard to which no sordid reality of every-day relation and common, vulgar needs could intervene to check enthusiasm. Furthermore, it is safer to admire those distant from us in time and place, since we are secure from any

$$
1 \text { "Social Life in Greece," p. } 243 \text { et seq. }
$$


demand of faithfulness and self-sacrifice from their side. Poets and artists have assisted us in this license of agreeable fancy. So we dwell, with special emphasis, on the beauty of Penelope's character, which is not at all exceptionally faithful as measured by modern standards; we warm over the story of Antigone while we pass by, without special enthusiasm, a thousand instances as admirable in our own day and within our own observation; and we read, with delight, the tale of the Greek who encouraged his ignorant child-wife by gentle treatment until she overcame her timidity, became "tame and docile," and was persuaded to discard cosmetics and high-heeled shoes and devote herself to her household duties; though the most of us would regard the forced marriage of such a child, if it occurred in our own day, as no more than child-barter, and the conduct of the husband (doubtless not worsened by his representation of it) as but a moderate exhibition of common decency. Mahaffy says of the Greeks of the Homeric age: "There is ample evidence that the lower-class women, the slaves and even the free servants, were subjected to the hardest and most distressing sorts of work, the carrying of water, and the grinding of hand-mills ; in fact we see them standing to men-servants nearly in the same relation that the NorthAmerican squaw stands to her husband - over-taxed, slave-driven, worn out even with field-work, while he is idling, or smoking, or sleeping." 1 The wives of Athens of all periods were little more than a higher class of household servants, with almost no share, by education, in either the science or the art that was the delight of their nation and made its superiority. The position of the hetairai was betier in some respects; but the apparently widely spread preference of the Greeks of the cultured classes for what we term unnatural crime argues against any considerable degree of education even in their case. Women were sometimes found in the Greek schools of philosophy, but these were evidently isolated cases. The passage from the Theætetus above quoted shows us the unhappy and subservient position of Athenian women in one respect ; and many other passages of Plato throw an unfavorable light upon their lot; though we have, perhaps, to remember that the central figure of the Dialogues had some personal reason for being a woman-hater. "The outcasts from society as we call them were not the immoral and the profligate, but the honorable 
and virtuous. Accordingly, when we consult the literature of the day, we find women treated either with contemptuous ridicule in comedy, or with still more contemptuous silence in history." 1

Human sacrifices were not unknown to the earlier Greeks. Of the later days, of Athenian culture, Mahaffy says : "Plutarch tells us that Themistocles was forced by the acclamations of the army to sacrifice three Persian prisoners of distinction brought in just before the battle of Salamis, though he was greatly affected at the terrible nature of the sacrifice, so that it appears to have been then unusual. But Aristophanes, long after, makes allusions to what he calls фápraкol, as still remembered at Athens, if not still in use (Ran. $73^{2}$ ), and which the scholiasts explain, chiefly from Hipponax, as a sort of human scape-goat, chosen for ugliness or deformity (a very Greek standpoint) and sacrificed for the expiation of the state in days of famine and pestilence, or of other public disaster. I think that Aristophanes alludes to the custom as by-gone, though the scholiasts do not think so ; but its very familiarity to his audience shows a disregard of human life strange enough in so advanced a legal system as that of democratic Athens." ${ }^{2}$

Mahaffy calls attention to the exceeding cruelty practised by the Greeks in the Peloponnesian war, and adds: "It was not merely among Corcyreans, or among Thracian mercenaries, but among the leaders of Greece that we find this disgusting feature. The Spartans put to death in cold blood 225 prisoners whom they took in Platæa after a long and heroic defence. . . . But this is a mere trifle when we hear from Plutarch that Lysander, after the battle of Ægospotami, put to death 3000 prisoners (Alcib. c. $37 \mathrm{cp}$. the details in his Lysander, c. 13), ... Athenians, men of education and of culture. . . . The unfortunate Athenian general, according to Theophrastus (Plut. Lys. 13), submits with dignified resignation to a fate which he confesses would have attended the Lacedemonians had they been vanquished.

"For the Athenians, with their boasted clemency and culture, were very nearly as cruel as their enemies. In the celebrated affair of the Mitylenæans, which Thucydides tells at length in his third book, the first decree of the Athenians was to massacre the

1 Mahaffy: "Three Epochs in the Social Development of the Ancient Greeks," pp. 31, 32.

2 "Social Life in Greece," p. 238. 
whole male population of the captured city. They repented of this decree, because Diodotus proved to them, not that it was inhuman, but that it was inexpedient." Mahaffy argues, in opposition to Grote, that there was no real sentiment of sympathy in the repentance of the Athenians in this affair, for "how could the imagined details of the massacre of 6000 men in Lesbos have been a motive, when the Athenians did, at the same time, have the ringleaders executed at Athens, and they were more than 1000 men (Thuc. III. 30)." These were "executed together, by the hands of Athenians, not with fire-arms but with swords and knives. A few years after, the inhabitants of Melos, many hundreds in number, were put to the sword, when conquered after a brave resistance (Thuc. V. I16), and here, I fear, merely for the purpose of making way for a colony of Athenian citizens, who went out to occupy the houses and lands of their victims."

The practice of torturing witnesses in court was common in Periclean Athens. On this point, Mahaffy writes: "Our best authorities on this question are, of course, the early orators, especially Antiphon, in whose speeches on cases of homicide this feature constantly recurs. It is well known that in such cases the accused might offer his own slaves to be tortured, in order to challenge evidence against himself; and it was thought a weak point in his case if he refused to do so when challenged. It is also well known that the accusers were bound to make good any permanent injury, such as maiming, done to these slaves.

"But there were both restrictions and extensions of this practice as yet but little noticed. It was not the custom to torture slaves who gave evidence to a fact, but only if they denied any knowledge, or appeared to suppress it in the interest of their master (Antiphon, Tetral. A, $\gamma$ ). On the other hand, it was common enough to torture female slaves and also free men. . . .

... " Almost all the orators speak of it as an infallible means of ascertaining the truth. Demosthenes says it has never been known to fail." 2 The restrictions on certain extremities of torture in court diminish in importance when we consider that the poor slave stood, in reality, in all cases, between two alternatives of suffering, that inflicted by the court and that likely to be inflicted by his master in case his evidence displeased the latter. That he was

1 “ Social Life in Greece," p. 234 et seq.

2 Ibid. p. 239 et seq. The italics are mine. 
a piece of property of some value was doubtless no more a safeguard to the Greek slave under the hands of his master than it has been in any modern slave-holding country; the Greek was doubtless at least as liable as the man of to-day to forget ultimate loss in the rage of present anger and the malevolent pleasure of revenge.

The condition of slaves among the Greeks furnishes us, indeed, with one of our strongest arguments against their moral code. We do not need to mention the Helots, whose name has become a synonym of degradation and misery. Slaves formed the greater part of the working population of Athens, and were much more numerous than the freemen. Nor were they necessarily even of inferior race or education. Not only did all prisoners taken in war become slaves, with their descendants forever, except as their masters chose to emancipate them (and the possession of such a superfluity sometimes rendered the Athenians generous in this respect), but, until the time of Solon, freemen might be sold into bondage for debt, - and not alone for a large debt, but also for a small one, and not merely until the debt was paid, but for all time. Nor have we reason to suppose that freemen were treated, even in the days of Athens' greatest culture, with great humanity. "At the opening of the Euthryphro there is a story told which is not intended to be anything exceptional, and which shows that the free laborer, or dependent, had not bettered his position since the days when Achilles cited him as the most miserable creature upon earth. 'Now the man who is dead,' says Euthryphro, 'was a poor dependent of mine who worked for us as a [free] fieldlaborer at Naxos, and one day, in a fit of drunken passion, he got into a quarrel with one of our domestic servants [slaves] and slew him. My father bound him hand and foot and threw him into a ditch, and then sent to Athens to ask of a diviner what he should do with him. Meantime, he had no care or thought of him, deeming him a murderer, and that even if he did die, there would be no great harm. And this was just what happened. For such was the effect of cold and hunger and chains upon him that before the messenger returned from the diviner he was dead. And my father and family are angry with me for taking the part of the murderer and prosecuting my father.'" 1

We have not much evidence as to the treatment of animals in ancient Greece. Race-horses are likely to have been well cared 1 "Social Life in Greece," p. 272 et seq. 
for, - as long as they were young and swift or beautiful. But it does not appear probable, from what we know of the Greek attitude towards slaves and dependents, women and children, that a Society for the Prevention of Cruelty to Animals would have flourished in Greece.

When we come to inquire as to the moral status of the Greeks with regard to honesty, truthfulness, and reliability in general, we find them particularly lacking. Their failure to come up with modern standards in this respect "every schoolboy knows." Ulysses is called the "man of many wiles," with evident intent to compliment. In the poems of Theognis, favorites with the Greek nobility, "it was openly recommended to fawn upon your enemy, to deceive him till he was in your power, and then wreak vengeance upon him. It is usual, among critics, to speak of this as the attitude of Theognis, and of the special aristocracy to which he belonged. They forget that we find the same attitude in the moral Pindar (Pyth. ii. 84). It is expounded by Hesiod as proximate ("E $\rho \gamma$. I65 sqq.), by Thucydides as universal, at a later epoch." " Mahaffy says of the Greeks up to the time of Thucydides, that they "had been often treacherous and cruel, generally dishonest and selfish; but, withal, often generous and gentlemanly, always clever and agreeable, and always carried away by a love of beauty more than by a respect for truth." 2 At the time of Darius, the Milesians, who had involved that king in a bloody and expensive war, and burned his Lydian capital, were yet treated kindly by him when taken prisoners, and settled in his own country. In return they were always trying to beg or embezzle the treasure of the king at Susa. "There was, indeed, a single exception, Scythes, tyrant of Zancle-who asked leave to visit Sicily, and returned to die in Persia. 'Him Darius considered to be the most righteous of all those who had gone up to him from Greece, in that he kept his promise to the great king.'"

"What an evidence of Greek dishonesty. We can well fancy the Aryan barons of Darius' court speaking in the tone of the Roman Juvenal. To them, too, the Graculus esuriens was but too well known, - with his fascination, his cleverness, and, withal, his mean and selfish knavery. I need hardly remind the Greek scholar," continues Mahaffy, "that all through the Ionic 1 “Social Life in Greece," p. $9 \dot{7}$ et seq.

${ }^{2}$ Ibid. p. 157. 
revolt, and through the Persian wars, this treachery and this selfishness were the mainstays of the Persians; in fact, had they depended upon these more completely, the subjugation of Greece would have been a mere question of time." 1

"There was a certain Glaucus at Sparta, celebrated for justice, as well as in other respects, to whom a Milesian, who had heard of his fame, came and entrusted a treasure, wishing as he said, to get the benefit of his justice, since Ionia was disturbed. Of course, such a temptation was too much even for this paragon of Greek honesty. When the heirs of the Milesian came with their tokens and claimed the treasure, he professed to know nothing of the affair," though when they had gone away, he consulted the oracle as to whether he might spend the money, and was so strongly rebuked, that he finally gave it back. ${ }^{2}$ This Mahaffy mentions as an instance where the influence of the oracle was a moral one.

There remains one general and especially significant criticism to be made on Greek morals as a whole; the great mass of the people were little cared for and in a state of unfreedom. Professor Robiou of Rennes aptly remarks that the democracy of ancient times, and that of Athens in particular, had little in common with modern democracy. "The very large majority of the working population were slaves, and had, consequently, no rights of any sort, so that the 'laborers,' at whose political rights Xenophon and Aristophanes jest, were generally what we call patrons. ... .

"As for the laborers and the inhabitants of the environs and villages, since political rights could be exercised only at the Athenian Pnyx and there was no idea of a representative system, it is clear that the presence of many of them in the assembly could be only an exception, in spite of the modest indemnity which was offered them; among the country people the large and middle-class proprietors alone were in a condition to take part regularly. That is to say, one has no difficulty in concluding that, in comparison with other times and other countries, the Athenian democracy was an aristocracy." 3 And we may add that, all things considered, the great mass of the people had less of liberty and privilege, were far more subject to the despotism

1 "Social Life in Greece," p. I6o et seq.

8 "Les Institutions de la Grèce," p. 47 et seq.

2 Ibid. p. 162 et seq. 
and caprice of the few, than in most modern monarchies. In what modern country not inhabited by savages would a man be permitted, at the present day, to throw even a murderer into a ditch and leave him to perish of hunger and cold ? The carelessness of the Greeks in regard to the inner spirit of morals is often excused on the ground that it was at least combined with a large degree of tolerance; but this tolerance appears to be, to a great extent, mythical. The politics of Athens ostracized men whose opinion was feared by the state, or rather by a certain number of citizens, and the Greek religion stained its records with the death of Socrates and the persecution of other philosophers. Stilpo was exiled for doubting whether the Athene of Phidias was a goddess and the books of Anaxagoras and Protagoras were publicly burned. There was, moreover, an inquisitorial bureau at Athens. ${ }^{1}$ However, it is true that the Greeks were, as a people, too little in earnest and too superstitious to fall into doubt of the national mythology.

We have less difficulty in showing the superiority of modern to Roman civilization, and for the reason, partly, that we know more about Roman, than we do about Greek civilization.

The Romans were, from the beginning, a robust and warlike people, and the military discipline which made them conquerors extended into their social relations and even into their family life. The exposure of children appears to have been a common practice, and looked upon leniently even after direct infanticide was visited with some degree of general disapproval. Parents were the absolute masters of their children, having the power to put them to death, or to sell them as slaves; and this was not only true of children in their younger years, but during the whole life of the father. Livy and Valerius Maximus give numerous instances of parents who had put their children to death. It is recorded, however, that Hadrian banished a man who had killed his son, and decreed that whatever a son might earn in military service should belong to himself; while Alexander Severus forbade the killing of adult sons, and Diocletian rendered the sale of children illegal." Lecky however remarks that "the sale of children in case of great necessity, though denounced by the Fathers, continued long after the time of Theodosius, nor does

1 Lecky, “ History of European Morals," I. p. 398.

2 Ibid. p. 299 et seq. 
any Christian emperor appear to have enforced the humane enactments of Diocletian."1

Human sacrifices occurred among the Romans far more frequently than among the Greeks, and continued even down to a late date, says Mahaffy. "In the year 46 в.с., Cæsar sacrificed two soldiers on the altar in the Campus Martius. Augustus is said to have sacrificed a maiden named Gregoria. Even Trajan, when Antioch was rebuilt, sacrificed Calliope, and placed her statue in the theatre. Under Commodus, and later emperors, human sacrifices appear to have been more common; and a gladiator appears to have been sacrificed to Jupiter Latialis even in the time of Constantine. Yet these awful rites had been expressly forbidden в.c. 95 ; and Pliny asserts that in his time they were never openly solemnized." 2

If, however, the direct sacrifice of human victims came in time to be forbidden, there grew out of it, at a comparatively early period, a custom very nearly if not quite as barbarous, which was practised on an immense scale and down to a late date; namely, the gladiatorial contests. The men who took part in these contests were either slaves, criminals, military captives, or men especially trained for the "profession." Many of these last were exposed children who had been rescued for the purpose; their number being also recruited from other ranks. Lecky seems to excuse the condemnation of military captives to these shows, saying that their fate "could not strike the early Romans with the horror it would now inspire, for the right of the conquerors to massacre their prisoners was almost universally admitted." 3 The argument is similar to that noticed and criticised above - one bad principle cannot be an excuse for another, though the two are, doubtless, in this case, coördinate. Every criminal can give us a reason for his crime out of the uniformity of his own character. The question is, simply, whether we are considering the facts from a purely indifferent standpoint, as historical, or from an ethical standpoint; and if from the latter, then we must have some standard of measurement. We may choose to make this, in all cases, the average of the period and nation; though there will be, in that case, considerable

1 Lecky, "History of European Morals," II. p. $3 \mathbf{I}$.

2 "The Origin of Civilization," p. 372.

3 "History of European Morals," I. p. 285. 
difficulty in determining the average. Or we may use some ideal standard, which, as ideal, does not vary with all variations of the society considered, but is constant. But we have no logical right, having assumed the one standard, to confuse it with the other, treating the two as interchangeable. The standard of any age by which men judged their deeds is also part of the morality of the age, by which we may judge it. As for the criminals who fought in the arena, they were sometimes pardoned, when victorious, so that society received back again its most muscular, or skilful and alert criminals. Of all Roman authors and rulers, Lecky mentions only Seneca, Plutarch, Petronius, Junius Mauricus, and Marcus Aurelius, who condemn the games. ${ }^{1}$ Cicero is undecided on the subject ; rather in favor of them. The great satirist, Juvenal, though he repeatedly mentions, does not condemn them. And "of all the great historians who recorded them not one seems to have been conscious that he was recording a barbarity, not one appears to have seen in them any greater evils than an increasing tendency to pleasure and an excessive multiplication of a dangerous class." On the other hand, the attempt to introduce them into Athens was unsuccessful. ${ }^{2}$

An immense increase of gladiators and gladiatorial shows took place in the earlier days of the empire, when the increase of slavery freed a large portion of the Roman population from the necessity of labor, and men came to occupy themselves with amusements, on the one hand as a profession, on the other as means of passing the time. In the days of the Republic, the slaves were comparatively few in number and probably treated with more care, though scarcely with much consideration; all things were permitted the master by law, says Lecky, though probably the censor might interfere in extreme cases. "The elder Cato speaks of slaves simply as instruments for obtaining wealth, and he encouraged masters, both by his precept and his example, to sell them as useless when aged and infirm." ${ }_{3}$ Under Titus and Trajan probably occurred the greatest number of shows that "were compressed into a short time, . . . and no Roman seems to have imagined that the fact of 3000 men having been compelled to fight under the one, and Io, ooo under the

1 "History of European Morals," I. p. 286 et seq.

${ }^{2}$ Ibid. p. $276 . \quad 3$ Ibid. p. 301. 
other, cast the faintest shadow upon their characters." 1 Moreover, "the mere desire for novelty impelled the people to every excess or refinement of barbarity. The simple combat became at last insipid, and every variety of atrocity was devised to stimulate the flagging interest. At one time a bear and a bull, chained together, rolled in fierce contest along the sand; at another, criminals dressed in the skins of wild beasts were thrown to bulls, which were maddened by red-hot irons, or by darts tipped with burning pitch. Four hundred bears were killed on a single day under Caligula; three hundred on another day under Claudius. Under Nero, four hundred tigers fought with bulls and elephants; four hundred bears and three hundred lions were slaughtered by his soldiers. In a single day, at the dedication of the Colosseum by Titus, five thousand animals perished. . . . Lions, tigers, elephants, rhinoceroses, hippopotami, giraffes, bulls, stags, even crocodiles and serpents, were employed to give novelty to the spectacle. Nor was any form of human suffering wanting. The first Gordian, when edile, gave twelve spectacles, in each of which from one hundred and fifty to five hundred pair of gladiators appeared. Eight hundred pair fought at the triumph of Aurelian. Ten thousand men fought during the games of Trajan. . . Under Domitian, an army of feeble dwarfs was compelled to fight, and more than once female gladiators descended to fight in the arena. A criminal personating a fictitious character was nailed to a cross, and there torn by a bear. Another, representing Scævola, was compelled to hold his hand in a real flame. A third, as Hercules, was burnt alive upon the pile. So intense was the craving for blood, that a prince was less unpopular if he neglected the distribution of corn than if he neglected the games; and Nero himself, on account of his munificence in this respect, was probably the sovereign who was most beloved by the Roman multitude. Heliogabalus and Galerius are reported, when dining, to have regaled themselves with the sight of criminals torn by wild beasts. It was said of the latter that 'he never supped without human blood.'" Moreover, the prince was most popular who, at the show of thumbs, "permitted no consideration of economy to make him hesitate to sanction the popular award." 2

1 "History of European Morals," I. p. 287 et seq.

2 Ibid. p. 280 et seq. 
"Even in the closing years of the fourth century, the prefect Symmachus, who was regarded as one of the most estimable pagans of his age, collected some Saxon prisoners to fight in honor of his son. They strangled themselves in prison, and Symmachus lamented the misfortune that had befallen him from their 'impious hands,' but endeavored to calm his feelings by recalling the patience of Socrates and the precepts of philosophy." 1

The conquest of Greece is alleged to have bettered somewhat the position of Roman slaves, since it involved the introduction of many slaves who were the intellectual superiors of their masters. But whatever good this may have effected seems to have been counteracted by the increase in number of the slaves and the consequent diminution in value of the individual slave as a piece of property. On the whole, the position of the slaves of North America, before the war of emancipation, bad as it was in some cases, seems to have been, on the average, quite paradisiacal when compared with that of their Roman forerunners. It has already been mentioned that Cato urged his compatriots to sell their aged slaves. Old and infirm slaves were constantly exposed to perish on an island in the Tiber. It was also customary, in case of the murder of the master, to put all the slaves of the household to death who were not in chains or helpless at the time of the murder. The testimony of the slave was generally received only under torture; he might be tortured in the attempt to compel evidence against his master; but, if he, of his own free will, accused his master of any crime, except treason, he was condemned to the arena. There were different punishments for slaves and for men of rank. "Numerous acts of the most odious barbarity were committed. The well-known anecdotes of Flaminius ordering a slave to be killed to gratify, by the spectacle, the curiosity of a guest; of Vedius Pollio feeding his fish on the flesh of slaves; and of Augustus sentencing a slave who had killed and eaten a favorite quail, to crucifixion, are the extreme examples that are recorded; for we need [ $!]$ not regard as an historical fact the famous picture in Juvenal of a Roman lady in a moment of caprice, ordering her unoffending servant to be crucified. We have, however, many other very horrible glimpses of slave life at the close of the Republic and

1 "History of European Morals," I. p. 287. 
in the early days of the Empire. The marriage of slaves was entirely unrecognized by law, and, in their case, the words adultery, incest, or polygamy had no legal meaning. . . . When executed for a crime, their deaths were of a most hideous kind. The ergastula, or private prisons of the masters, were frequently their only sleeping places. . . We read of slaves chained as porters to the doors, and cultivating the fields in chains. Ovid and Juvenal describe the fierce Roman ladies tearing their servants' faces, and thrusting the long pins of their brooches into their flesh. The master, at the close of the Republic, had full power to sell his slave as a gladiator or as a combatant with wild beasts." 1

Lecky admonishes us that we should not judge the whole institution of Roman slavery by this one side of the picture. $\mathrm{He}$ calls attention to the respect in which learned Greek slaves were often held, as showing a better phase of the system; but it is quite possible that certain slaves or classes of slaves should be held in respect and that the rest of the slaves should be treated, nevertheless, with anything but respect or kindness. The great wonder to the modern mind is that the Romans felt at liberty to hold learned Greeks slaves at all. Lecky points out that slaves were emancipated in great numbers; but we must remember, first, that slaves were very plentiful, further, that freedmen and their descendants remained bound, by a sort of feudal tie, to their former masters until the third generation, and moreover that it was considered an honor to have many freedmen in one's following; so that the advantage of manumission was often, as Lecky himself says, on the side of the master. Slaves were sometimes emancipated to prevent their revealing crimes of their masters under torture, and many slaves were given their liberty especially in order that they might make a show in the funeral train. Augustus, indeed, found it necessary to restrict emancipation by will to one hundred slaves. ${ }^{2}$ Seneca mentions that masters who ill-treated their slaves were the object of public odium; but then it may occur to us to inquire what the Romans considered ill-treatment; some of the laws which Lecky cites in evidence of the improvement of the slave's position in the third or last of the periods under which he considers this position may appear to his readers as much evidence against, as in favor

1 "History of European Morals," I. p. 302 et seq.

2 Ibid. p. 236. 
of, kindness on the part of the masters. "The Petronian law," he says, "which was issued by Augustus, or more probably by Nero, forbade the master to condemn his slave to combat with wild beasts without a sentence from a judge." We may inquire as to how difficult it was to obtain such a sentence. "Under Claudius some citizens exposed their sick slaves on the island of Asculapius in the Tiber to avoid the trouble of tending them, and the emperor decreed that if [!] the slave so exposed recovered from his sickness, he should become free, and also that masters who killed their slaves instead of exposing them should be punished as murderers. . . U Under Nero, a judge was appointed to hear their complaints, and was instructed to punish masters who treated them with barbarity, made them the instruments of lust, or withheld from them a sufficient quantity of the necessaries of life. . . . Domitian made a law, which was afterwards reiterated, forbidding the Oriental custom of mutilating slaves for sensual purposes, and the reforms were renewed with great energy in the period of the Antonines. ${ }^{1}$ Hadrian and his two successors formally deprived masters of the right of killing their slaves; forbade them to sell slaves to the lanistæ or speculators in gladiators; destroyed the ergastula or private prisons; ordered that, when a master was murdered, those slaves only should be tortured who were within hearing; appointed officers through all the provinces to hear the complaints of slaves; enjoined that no master should treat slaves with excessive [?] severity; and commanded that, when such severity was proved, the master should be compelled to sell the slave he had illtreated." 2 The humanity of the last law is open to dispute. Moreover, Lecky does not notice, here, that Constantine nevertheless felt it necessary to limit the punishment of slaves by prohibiting its administration with a cudgel, though not with the lash, and forbidding poison, mortal wounds, various kinds of torture, stoning, hanging, mutilation, or throwing from a height. ${ }^{3}$ But

1 Compare, however, "History of European Morals," I. p. 263: "Ionian slaves of a surpassing beauty, Alexandrian slaves, famous for their subtle skill in stimulating the jaded senses of the confirmed and sated libertine, became the ornaments of every patrician house, the companions and instructors of the young. . . . The slave population was itself a hotbed of vice, and it contaminated all with which it came in contact."

2 "History of European Morals," I. p. $303 \mathrm{et} \mathrm{seq.} \mathrm{The} \mathrm{italics} \mathrm{are} \mathrm{mine.}$

${ }^{3}$ L. O. Pike, "Crime in England," I. p. 20. 
he mentions two facts which indicate some degree of humanity in certain directions, and namely: that, though the law did not recognize the marriage of a slave, "it appears not to have been common to separate his family;" also, that the private property of slaves was recognized by their masters, though part or all of it usually reverted to the master on the death of the slave. The great mass of evidence goes to show, however, that what the Romans termed humanity to slaves would have been, in the eyes of modern "civilized" peoples, extreme barbarity.

Women, among the Romans, were, like their children, under the control of the head of the family - father or husband. "The father disposed absolutely of the hand of his daughter and sometimes even possessed the power of breaking off marriages that had been actually contracted. In the forms of marriage, however, which were usual in the earlier periods of Rome, the absolute power passed into the hands of the husband, and he had the right, in some cases, of putting her to death." "The power appears to have become quite obsolete during the Empire; but the first legal act (which was rather of the nature of an exhortation than of a command) against it was issued by Antoninus Pius, and it was only definitely abolished under Diocletian." 1 Roman women had, at first, no share by law in the heritage of their fathers; but public opinion revolted, in some cases, from the law, and gradually this was considerably altered. When marriage became, under the Empire, a mere matter of mutual consent, divorce a mere matter of repudiation, the daughter, though married, often remained in her father's house, having full control over her own property. Practically, if not always legally, the position of women among the Romans seems to have been considerably better than among the Greeks; Roman wives became, gradually, far more nearly the equals of their husbands than Greek wives ever were, and appear to have received a proportionately greater degree of love. Their position, however, falls far behind that of even German women at the present day, and certainly much behind that of every other civilized nation.

After recording the use of animals in the public games, there is little need of considering the subject of their treatment specially; there can be no doubt as to its probable nature; though certain famous Romans had their brute favorites.

1 "History of European Morals," II. p. 299. 
It is sometimes argued that, though we are morally superior to the Greeks and Romans in some respects, we fall short of their standard in other respects. Doubtless new forms of evil may arise in later periods, which were impossible under old forms of government and the social relations of earlier peoples. Each period and nation will, according to its circumstances, have its own peculiar forms of vice and misery. But the question which we are considering is not whether or not we have some forms of evil which the ancients did not possess, but whether the particular forms which prevail among us are or are not worse than those which prevailed in Greece and Rome, and, in general, whether the average of sympathy and altruistic action in modern times and among the foremost peoples is greater than the average among the Greeks and Romans. And it must be recollected, moreover, in considering the question, that while the evil in our midst is brought very vividly before our eyes through the medium of our many methods of news-carrying and of wide personal observation, - through our railways, our telegraphs, our many newspapers and periodicals, - we have, in reality, when all is told, very scanty knowledge of the daily life of the common people, of the ordinary, every-day miseries and sufferings, among the Greeks and Romans. But there are some features of these facts that tell in favor of modern times; for the ancients were but little impressed by the miseries of the poorer classes; and just the spirit that notes and makes much of our modern inhumanity is evidence of a broader sympathy peculiar to our later times.

Of Europe as a whole in the centuries after Rome's decline and its loss of power, it is not necessary to say much, in order to prove the moral superiority of modern times. IVe are all acquainted with the fierce contests between Christianity and its opponents, with the mutual persecutions, the martyrdoms of Christians and the retaliation of Christians upon "heretics," with the license and bigotry of the clergy, the robbery and oppression of the poor and dependent by these as well as by the titled castle-owners, the burning of "witches," the general intellectual and moral darkness which spread and covered even the lands of former comparative civilization and was lifted only as Europe as a whole advanced to a higher stage.

But without entering into any extended discussion of this 
complicated process of development as a whole, after the disturbance of the old equilibrium, it may not be undesirable to note the general course of events in some one country as typical, not in its special features, but in its general moral import, of the course of development in the other countries of Europe also.

The manner of the growth of state and social recompense for evil out of individual and tribal vengeance has already been touched upon. The enemy within, and the enemy without the tribe, the foe of the battle-field and the criminal were regarded, at many stages, with much the same feeling of animosity, the advantage being rather in favor of the criminal. To the Greek all those who were not Greeks were barbarians, against whom but little justice or mercy was necessary; and, as we have seen, the Romans condemned to the arena their war-captives equally with their criminals, together with slaves who were also, originally, war-captives. Crime is, in ruder societies, hardly distinguished from other forms of aggression that are, later, not included under this head. The definition of crime differs greatly in different periods of a people's history, changing as the conceptions of morality as duty to society as a whole emerge from the crude conceptions of individual and tribal constraint through revenge. It is for this reason that the history of criminal law and the administration of "justice" constitute, in reality, a history of moral evolution. There is nothing that is a clearer index of the moral status of a people than its treatment of those considered to be malefactors.

Cæsar and Tacitus both mention human sacrifices as taking place in England before the Roman conquest; but little is known certainly on the subject. 'The Romans, of course, introduced their own laws and customs, which existed side by side with many ancient ones not wholly abolished. The torture and burning of slaves for various offences was customary. These penalties were gradually mitigated. But the invasion of the Teutonic tribes seems to have introduced many new barbarities. In the first half of the tenth century, for instance, appears a law which condemned to the stake female slaves who had stolen from any but their masters, the wood to be piled about them by eighty other slaves of their own sex; this last office being designed, doubtless, to impress the lesson upon the minds of the eighty attendants. Later, many heretics were burned, and the writ for 
the burning of heretics was not abolished until the reign of Charles II., though it was practically annulled by the laws of I648. However, in 1649 , a number of women were burned for witchcraft in Berwickshire, and burning continued to be practised, much later, in cases of heresy and witchcraft; still later in cases of high and petty treason, and up to the time of George III., for murder. In the thirtieth year of the latter's reign, a statute was passed substituting hanging for burning. In 1784 , a woman was burnt at Portsmouth for the murder of her husband. During the last years, however, in which the sentence was carried out, it seems to have been customary for the executioner to wring the malefactor's neck before the burning. But comparatively trivial offences, among these false coining, were classed as treason, and it is noticeable also that the stake seems to have been a favorite punishment in the case of women-offenders, even in later days. ${ }^{1}$ In the year 1530 , two persons of the household of the Bishop of Rochester having died from poison thrown into some porridge by the cook, an "Act of Poisoning" was passed, according to which offenders coming under its definition were to be boiled to death. 'The statute was shortly afterwards repealed, but the bishop's cook was publicly executed in accordance with its provision. ${ }^{2}$

But simple burning or hanging was, for the most part, considered much too good for the man who had committed high treason ; he was given the mere mockery of a trial, and, if convicted, was hanged, was taken down while yet alive, disembowelled, and his entrails burnt, was beheaded, and quartered. Law modifying this penalty first comes into prominence in the reign of William III. ${ }^{3}$ When Richard I. sailed with his army for the Holy Land, it was ordained that whoever killed a man on board ship was to be tied to the corpse and thrown into the sea, whosoever killed a man on shore was to be burnt alive with the corpse, while simply drawing blood with a knife was to be punished with the loss of a hand, and a thief was to be shaved, treated to a head-bath of boiling pitch and feathers, and put ashore at the first place the vessel touched at. ${ }^{4}$

${ }^{1}$ L. O. Pike, "A IIistory of Crime in England," I. pp. 51, 344 et seq.; II. pp. I $38,176,177,287,379$ et seq.

2 Ibid. II. pp. 81,82 .

3 Ibid. I. p. 226; II. pp. 85, 86, I 74 et seq., 324 et seq.

4 Ibid. I. pp. I68, I69. 
The payment of blood-money was a common custom among the Teutons, and so little distinction was made between greater and lesser crime that, while a murderer could commonly buy off the relatives of his victim, the petty thief often suffered death or mutilation for his offence. Pike says of these punishments in the early history of Britain: "It was for the free man of low estate, for the slave, and for women, that the greatest atrocities were reserved. Men branded on the forehead, without hands, without feet, without tongues, lived as an example of the danger which attended the commission of petty crimes, and as a warning to all who had the misfortune of holding no higher position than that of a churl. The horrors of the Danish invasions had no tendency to mitigate these severities; and those who were chastised with whips before were chastised with scorpions afterwards. New ingenuity was brought to bear upon the art of mutilation, which was practised in every form. The eyes were plucked out; the nose, the ears, and the upper lip were cut off; the scalp was torn away; and sometimes even, there is reason to believe, the whole body was flayed alive." 1 The law of the tenth century, according to which a female slave who had committed theft was burnt alive by eighty women-executioners, has already been mentioned; parallel to this law was the law that a male slave who was a thief was to be stoned to death by eighty slaves, any one of whom, who missed the mark three times, was to be whipped three times. "If a thief was a free woman, she was to be thrown down a precipice or drowned." ${ }^{2}$ The law did not favor women.

The dividing line between mutilation and torture is a difficult one to draw. One of the earlier forms of "trial" was by ordeal. The accused, with his hand bound in cloth, was compelled to snatch a stone from elbow or wrist-depth in a caldron of boiling water, or to lift a weight of heated metal. If, at the end of three days, when the cloth which bound the arm was removed, no scald or burn was visible, the accused was pronounced innocent. These ordeals took place in the church with much sprinkling of holy water and other ceremony. The clergy themselves seem to have had less trying substitutes for these ordeals, often being compelled only to take oath on the sacrament, or to partake of consecrated bread or cheese which was supposed to

$$
1 \text { “History of Crime," I. p. 50. } \quad 2 \text { Ibid. p. } 5 \text { I. }
$$


produce evil results in case of guilt. As Pike suggests, it is quite possible that, as priests had the preparing of this bread or cheese, it may sometimes have come up to expectations in this respect; as it is also possible that the cloths bound on the arm of the layman who was to undergo the ordeal of fire or water may have been differently arranged in different cases. ${ }^{1}$ As late as the reign of King John, trial was made by ordeal, and mention is also made of it in the reign of Henry II. It was not formally abolished until the year I $219 .^{2}$ For remaining mute before accusers in court, the dire penalty of imprisonment with starvation was inflicted, in the reign of Edward I., and to this punishment was added, about the time of Henry IV., torture by the press. ${ }^{3}$ In 1570 , a man found guilty of forging warrants for the arrest of two persons was sentenced to the pillory for two days, on the first of which one ear, on the second the other, was to be nailed to the pillory in such a manner that he must "by his own proper motion" tear it away. " The rack is supposed to have been introduced into England in the reign of Henry VI., and in the reign of Henry VIII. was added "Skevington's Daughter," an instrument by which offenders were compressed rather than extended until "the miserable human being lost all form but that of a globe." Blood was forced from fingers, toes, nostrils, and mouth, and ribs and breast-bone were commonly broken in. The thumb-screw was also in use, and there was a "Dungeon among Rats," and a chamber in the Tower called "Little Ease," in which it was impossible either to stand upright or to lie at full length. ${ }^{5}$ The press was not abolished until the reign of George III. ${ }^{6}$ It is recorded of the case of Burnworth, tried for murder in 1726 , that he bore pressure of nearly four hundred weight, for an hour and three-quarters, before begging for mercy and pleading Not Guilty. He was, however, found guilty and hanged. ${ }^{7}$ In i630, Alexander Leighton was punished for "framing, publishing, and dispensing a scandalous book against kings, peers, and prelates," in the following manner: he was whipped, put in the pillory, had one of his ears cut off and one side of his nose slit, was branded on one cheek with a red-hot

1 " History of Crime," I. p. 52 et seq.

${ }^{5}$ Ibid. II. pp. $87-89$.

2 Ibid. I. pp. 204, 2 IO.

6 Ibid. II. p. 346.

${ }^{3}$ Ibid. I. p. 2 10 et seq.

7 Ibid. II. p. 283.

4 Ibid. II. p. 85. 
iron, was afterwards returned to the Fleet to be kept in close custody, and seven days later was whipped again at the pillory, had the other ear cut off, his other nostril slit, and his other cheek branded. ${ }^{1}$ As late as 1 734, John Durant, who "either was, or pretended to be, deaf and unable to read," had his thumbs tied and the knot drawn hard because he did not answer the accusation of the court; he was also threatened with the press. $^{2}$ Excepting in cases where the press was used, torture was not, according to Pike, practised in England after the first part of the seventeenth century; but the case just cited is a contradiction of so broad an assertion.

The introductions of customs of penance did much towards rendering the differences in the punishment and general treatment of the poor and rich, the humble and noble, more conspicuous. As for the clergy, they had special benefits given them, and were accustomed, in the early days of Britain, to murder, rob, and indulge their passions very nearly as they chose, without interference from the state. ${ }^{3}$ But the Benefit of Clergy, which rendered any one subject to it, "practically exempt from the ordinary punishments for most of the greater crimes," was applicable, in later centuries, not only to clergymen proper, but also to all clerks, the term including every one who had been married and could read. ${ }^{4}$ The position of the slave after the Teutonic invasion has been noticed. The position of the churl was nearly as bad. "The infliction of a penalty which he could not pay, and which none would pay for him, rendered him utterly bankrupt in freedom.... If he left the place assigned to him it was held that he had stolen his own body. He could be summarily hanged when caught, and his life was worth nothing to his lord, or even to his kindred, unless they redeemed him. This was the fate which was continually impending over the free man of low estate if he had the misfortune to make enemies among those who had the power to save or condemn him." ${ }^{5}$ In the reign of Edward I., "a statute was passed which made it a grave offence to devise or tell any false news of prelates, dukes, earls, barons, or nobles of the realm. Others, too, were enumerated as being within the meaning of the act — the Chancellor, the

1 "History of Crime," II. pp. I62, I63.

2 Ibid. II. p. 284.

4 Ibid. I. p. 297 et seq.

${ }^{3}$ Ibid. I. p. 52 et seq., p. 146 et seq.

5 Ibid. I. p. 89 et seq. 
Justices of either Bench, and all the great officers of state." Under Richard II., the statute was reënacted and made more stringent. ${ }^{1}$

For most trivial offences of all sorts, extreme punishment was meted out. Mutilation was often inflicted merely for the killing of game belonging to the King's forests, and though the Forest Charter of Henry III. provided that no one should, in future, lose life or limb for the sake of the King's deer, the penalty does not seem to have gone out of use at this period, for other offences. In the reign of Edward III., a tailor was sentenced, for brawling in court, to imprisonment in the Tower of London for life and the loss of his right hand; "and the rolls of Gaol Delivery of this period show conclusively that the ordinary punishments were hanging, the pillory, and the tumbrel or dungcart." 2 Late in the reign of Henry VIII., an act was passed condemning any person who struck another so that blood was drawn, within the limits of the King's house, to the loss of his right hand. The pillory was in use up to the reign of Queen Victoria; "it could be applied to perjurers and suborners of perjury until the year 1837 . It was even applied to women for no greater crime than fortune-telling, late in the eighteenth century." ${ }^{3}$ "Of the other punishments associated with the old spirit of violence, and inflicted in public, the chief was whipping. It was commonly awarded to men guilty of petty thefts. . . . Instances in which women were whipped were by no means uncommon at the very end of the eighteenth century." Until I808, pocket-picking, until I8II, stealing from bleachinggrounds, were punished with death. In 18 I3 3 I8I6, and I8I8, a bill was introduced to abolish capital punishment for a theft of five shillings from shops; but it was defeated in the House of Lords. In 1820 , the amount necessary to the death-sentence was raised to $£_{15}$. Until I $_{32}$, horse, cattle, and sheep stealing, theft from a dwelling-house, and forgery, were capital offences. In 1833 , house-breaking; in 1834 , returning from transportation before expiration of the sentence; and, in 1835 , sacrilege and letter-stealing ceased to be punished with death. But it was not until I86I that hanging was limited by law to cases of murder and treason. ${ }^{4}$

1 " History of Crime," II. p. 398 et seq.

3 Ibid. II. pp. 82,83, 377 et seq.
2 Ibid. I. p. 2 I 3.

4 Ibid. II. p. $45^{\circ}$ et seq. 
The worst element of the punishment by pillory or in any manner in public did not lie so much in the punishment itself, as in the violence of the mob, which appears to have been regarded as a legitimate part of the ceremony, and against which the criminal seldom received any protection. Sometimes, the man or woman sentenced to the pillory for a petty offence died of stoning at the hands of the onlookers; and Pike writes of the burning of a woman in $172 \mathrm{I}$, for coining: "Her last wish was that she might say a prayer in peace. But the mob which had come out to take its ease and its pleasure had no mind to sacrifice its rights for the comfort of a criminal. A woman at the stake was a good butt for filthy missiles and ribald jests; the yelling rabble would not permit the poor wretch to collect her thoughts, or to hear her own words, and instead of sympathy they gave her stones. When the fire was kindled, even the consuming flames must have seemed less cruel than the men and women standing around." 1

We all know the condition in which Howard found the prisons of his day; and if we possess strong powers of imagination, we may perchance be able partly to conceive what must have been their state in days when the people knew but very little of what passed within prison-walls, and the keepers wielded an almost absolute power over the prisoners. If the abuses which were common even two centuries ago were to occur in only a few instances to-day, the whole English nation would flame with indignation. In the fourteenth century, jail-breaking was frequent in cases where the prisoner could afford to pay for his escape; judges were often bribed; a "clerk" who was delivered over to the bishop before or after sentence, according to the Benefit of Clergy, could still be acquitted by the bishop in case the requisite number of compurgators were found to swear to belief in his innocence; and, moreover, clerks who had been convicted could not afterwards be tried for any offence committed before their conviction. On the other hand, if a woman attempted to obtain sentence against the murderer of a relative, she had not only to fear the revenge of the man's allies, who seem to have had things very much their own way; but in case courage deserted her at the last, and she failed to appear against the accused, she was "waived" or outlawed; again it may be remarked that the laws of

1 See as above, II. p. 288. 
England did not favor women. ${ }^{1}$ Writs were forged, juries were packed, judges, justices, and sheriffs bribed. In the reign of James I., the young countess of Essex, who, having fallen in love with Lord Rochester during the absence of her husband, had obtained a divorce to marry him, became angry with a friend of her lover who counselled him against the marriage, caused him to be imprisoned in the Tower, had the Lieutenant and underkeeper of the Tower replaced by friends of hers, and through the aid of these administered poison to him. The countess and her husband were arrested on charge of causing the death, and the former pleaded, the latter was proved, guilty. Yet the two were pardoned, though some of their accomplices were executed. ${ }^{2}$

It is impossible that such customs should exist, in legal relations, in connection with great justice and sympathy in other relations. Some allowance may be made for idiosyncrasy, for individual and national peculiarities; it is possible that a bloodyminded and cruel ruler may find pleasure in petting pigeons, but his pleasure will be likely to be rather of an egoistic order, and his apparent kindness easily turned to cruelty if anger comes upon him. So, too, the cruel potentate may prove a kind husband and friend, as long as his own interests coincide, and do not conflict, with those of his friends or his family. But the man who is consistently treacherous and unfeeling in any one relation will not, as a rule, show consideration and tenderness in other relations, except in so far as these other relations subserve his own ends of gain or vanity; the point where they part company with such ends is the point where he will resort to another mode of action. The same is true of nations. Accordingly, we find brigandage and open robbery common even down to the end of the last century, and not only on the part of the poorer classes, or rather not so much on their part as on that of princes, nobles, and even the clergy; we find pirating and wreckage common on the sea; we find intrigue upon intrigue at court, nobles and members of the royal family continually plotting each other's murder, but nevertheless escaping punishment and received with adulation; we find the much-praised heroes of the Crusades devasting the lands through which they passed, violating wives and daughters of their hosts, and deserting to the enemy for bribes; we find wholesale massacres of unoffending

$$
{ }^{1} \text { As above, I. p. } 270 \text { et seq. } \quad 2 \text { Ibid. II. p. } 145 \text { et seq. }
$$


Jews; we find perjury a profession, station an excuse for nearly every crime, religion a cloak for extortion and vice, and oppression of the poor and lowly universal. And yet we weep over modern deterioration!

We forget, when we read - perhaps with an exclamation that man is as much a savage as ever-how the onlookers at the burning of the Shanghai made no effort to save lives but only to secure spoil, that it is only a short time since such scenes must have been common enough on all the shores of Europe; we forget, when we shudder with horror at an exceptional case of unjust or brutal punishment on the borders of our civilization, that it is not long since torture and mutilation, barbarities of every sort, were practised among the foremost nations of the world, and for the most trivial offences. Nor do we always remember, when we grow indignant at the hard case of our poor, that there was a time when the excess of indigent population was prevented only by famines and pestilences which killed their thousands upon thousands, and of which we very seldom see the like in modern times; we forget that there was a time when the desperate rising of the continental peasantry against the bitter oppression of the landowners drew from even the reformer Luther the exclamation that the revolters ought to be throttled collectively. I have no intention to underrate present evils or to excuse them by past ones. I see no reason for believing that the present age should rest upon its laurels; on the contrary, I believe that we are only at the beginning of civilization; but I see no need for denying past evolution in order to make this assertion. Starvation is not easier to a man to-day, because it is proved to him that many more men died of hunger in the past than die of it in the present century. But just for this reason, I fail to understand why there should be so much effort expended by certain reformers in the attempt to disprove what history and observation yet so plainly show, - namely, that the condition of the masses at present, taken for all in all, is much better than it has ever been before; that misery is not so extreme or proportionately so widely spread; that the worst sorts of crime are decreasing; that justice is more general, and that sympathy is warmer, than in any previous age. It is true that we have new methods of exploiting the poor; but we need to consider how our ancestors would have used those opportunities had they possessed 
them; and we need also to remember, with regard to a particular form of evil, that some time is necessary for society as a whole to grow to a comprehension of its increase and importance, and to reach unanimity of opinion as to action for its removal. As forms of evil change, some one particular form may increase for a time, swallowing up in itself, as the larger wave accumulates several small ones, various other forms, until the slowly gathered resistance of public opinion brings the reaction.

We may gather valuable evidence as to our progress, even in comparison with recent times, by reference to our artistic literature. True, the great writers have often been far ahead of their times. But if we regard the average, we shall soon perceive the signs to which I refer. The stilted mannerisms of the ancient novel mark the absence of democratic feeling, and witness to the less general diffusion of true kindness, which, wherever it appears, tends to simplicity, having no need of mannerisms. Nothing, too, is more indicative of our advancement than the change in conceptions of humor; for to know what a nation laughs about is to know what are its ideals and shortcomings. Earlier humor is often mere vulgarity or brutality, or a mixture of the two; obscenity, vice, and the heartless torture of the weak and helpless are its favorite themes, and appear in the characters of its heroes and ideals. The truthfulness of Victor Hugo's description of earlier British "fun," in his "L'Homme qui rit," is borne witness to by English literature.

All modern literature marks the progress of the democratic idea. Our history and our art are full of the people. The very unrest and dissatisfaction of the time are signs of a more general and a better education, an increase of sympathy in degree and extent, and, I believe, of better nourishment and a more energetic physique. The higher ideals which were once the property of the few are become the property of the many. Our institutions are grown more democratic and humane. We have our free hospitals and dispensaries, our soup-kitchens and cheap lodging-houses, our asylums for the deaf, the dumb, the blind, old people and orphans, the weak and afflicted of all kinds, our guilds, "Settlements," and "Open-air" charities, our crêches, our refuges and reformatories, our societies for the Prevention 
of Cruelty to Children and to Animals, our "Open Doors," and "Midnight Missions," our trade and industrial schools, and our free schools and scholarships and free libraries. In times of famine, disease, and disaster, we band together to aid, and funds for the distressed pour in from every side, and not only from people of the nation to which the sufferers belong, but often also from those of distant parts of the world. Fancy the Greeks subscribing to a fund in aid of cholera-stricken barbarians; imagine the Romans, even, clubbing together, in every part of the world to which they had wandered, to succour the sufferers by a Johnstown flood; or conceive of the wealthy classes of the Middle Ages furnishing fires and food as did the Parisians during the unusual winter cold of $\mathrm{r} 890-9 \mathrm{r}$ !

Not only has sympathy become more wildly diffused within the state; it has spread outside it also. National narrowness is slowly disappearing. The federation of the states of Europe and of the civilized world is no longer looked upon as a madman's fancy but as a sober possibility or even a probability. It is now agreed that war between the English-speaking nations of the earth, - between England and her colonies, or England and the United States, is very nearly, if not quite, an impossibility. The union of three of the most powerful nations of Europe, not for war but for peace, is assuredly of great political importance in itself; but of even more importance in the influence insensibly exerted by its continuance upon the opinions of the world. The masses of the people themselves are becoming more and more cosmopolitan, and we have an ever-increasing number of international unions and congresses, political, scientific, artistic, and ethical.

On the whole, it is, perhaps, as much a lack of imagination as anything which makes us fall into the mistake of underestimating our own age and overestimating all others. The crimes and abuses far away in times different from our own are difficult to conceive, and stir our blood even less than those distant in space; the sufferings of the Middle Ages, or even of one or two centuries ago, are more difficult to realize and move us less than a famine or flood in China or a murder in the heart of Africa. The things immediately before our eyes affect us most; and it is well, for many reasons, that this is so. Nevertheless, idealization of the past is evil in its consequences. For, if present 
progress is to some men an excuse for easy-going inactivity, the extent of existing evil is even more often an excuse for the same selfish course.

Man has had, in all periods, the tendency, in his discontent with the present, to invest with ideal attributes of every sort some past period in which the special evils he deplores did not, perhaps, exist; the dissatisfied of all times have imagined a golden age somewhere in the past. The old, who look on the innovations of a younger generation with distrust, and are likely to mistake, in remembrance, the gold of their own life's morning for an outer radiance independent of their youth, add to our delusion; while the young confuse their increasing knowledge of the evil of the world with an increase of the evil itself. But the more science progresses, and the greater our acquaintance with the facts of history becomes, the more these delusions tend to disappear. The much-praised simplicity of our ancestors was, in truth, a half-savagery, where the higher forms of justice were not practised, that finer tact and consideration which makes life best worth living was unknown, and many of the faults which we most deplore in our own day were considered rather virtues than otherwise. It is a moral pity that poets and philosophers have lent the beauty of their verse and the dignity of their eloquence to the idealization of the past. Indeed,

"I do distrust the poet who discerns

No character or glory in his times,

And trundles back his soul five hundred years,

Past moat and drawbridge, into a castle-court,

To sing - oh, not of lizard or of toad

Alive i' the ditch there, - 'twere excusable,

But of some black chief, half knight, half sheep-lifter,

Some beauteous dame, half chattel and half queen,

As dead as must be, for the greater part,

The poems made on their chivalric bones." I

It is an especial pity that the reformer should ever devote his effort to the upholding of the old idea of the inferiority of the present to the past. Not in the past, but in the future, lies the Golden Age of man.

1 Mrs. Browning, "Aurora Leigh." 


\section{CHAPTER VIII}

THE RESULTS OF ETHICAL INQUIRY ON AN EVOLUTIONAL BASIS

IN Professor Alexander's statement that "the good man of former days was as good as the good man of to-day," 1 the standard applied to the two cases compared is not the same; the comparison is not a direct one between the two men, according to some common rule, but resembles a mathematical statement of proportion, or comparison of ratios; the man named good according to the standard of one age stands to the social conditions of that age as the man named good by the standard of a later age to the social conditions of his age. The implication of this double standard is, however, easily overlooked, so that the statement stands in danger of the reproach of misleading as a begging of the question; in "the good man of former days," the moral verdict is already delivered. A question of moral expediency arises here. How are we to define "the good man of former days"? Shal1 we declare, for instance, that that cannibal who fulfilled the ideal of pity in his society by sparing his conquered foe to abject and miserable slavery, instead of cooking him for dinner, was good, and as good as the man of highest benevolence of the present day? Or suppose an Australian savage who varies the tribal custom of wooing by carefully carrying home his victim after reducing her to unconsciousness, instead of dragging her over the ground at risk of life and limb, thus fulfilling a high tribal ideal; shall we compare such a man with lovers like Mill or Browning and pronounce him as good as the latter? Or, to take less extreme cases, shall we compare the Spartan of one period, with his ideal of successful theft, with a Socrates or a Bruno dying for sake of what they believed to be the truth, and pronounce one no better than the other? No one denies the right of the individual to fix the significance of his own terms, provided he adheres to this significance consistently; but man-

1 "Moral Order and Progress," p. 292; Part I., this book, pp. 250, $25 \mathrm{I}$. 
kind thinks slowly and painfully, and the double purpose of language, in the communication of thought to others and the registration of it as a stepping-stone to our own further reasoning, is likely to be frustrated by a too peculiar use of terms. In Ethics, this question of expediency takes on a moral aspect; and Alexander's definition of absolute right and wrong as action in accordance with, or opposition to, a standard fixed by the age and nation is likely to lead to moral as well as intellectual confusion - to the excuse of wrong-doing because of circumstances, on the one hand, and the dogmatic assertion of infallibility on the other, or at least to the confusion of the ideal standard with the easy-going standard of the average man of his age.

But it is true that this criticism is scarcely conclusive alone. For the definitions criticised are on a line with the idea of progress as at each moment establishing the equilibrium of the society, and fulfil the demand for self-consistency. A criticism of the use, in ethical theory, of a continually changing standard of moral judgment, must concern the more fundamental idea of a continually established equilibrium.

To the practical considerations of the possible confusion of the ideal with the average standard through Alexander's idea of the judgment of an age by its own standard, it might be objected that the moral standard implied in his theory is not at all the average standard, but the standard as represented by the ideal in the mind of the good man of his age. ${ }^{1}$

To this may be answered that he whom we regard as the good man of his age is by no means necessarily in harmony with his age, as is proved by the persecution that many good men endure; and the statement that the good man is not in harmony with his age means that he does not represent the character of his society as a whole, and cannot, therefore, be said to express an attained equilibrium of the society. His sentiments and ideal are not the sentiments and ideal of the society as a whole considered as an adjustment of sentiments and ideals. If it be replied, to this, that the good men of their age who undergo persecution must be regarded, according to Alexander's theory, as only prospectively good, - as representing an ideal that has not yet been proved to be the victorious variety, ${ }^{2}$ then we are driven to return to the

1 “Moral Order and Progress," p. 287, etc.; Part I. p. 249, this book.

2 "Moral Order and Progress," pp. 307, 312; Part I. pp. 250, 252, 253, this book. 
conclusion that, by the good man of his age who represents the social equilibrium, Alexander designates, not the man who leads the moral van, or he who plans an advance, but he who is carried on by it, the man who represents the preponderating mass of opinion, the ideal of the majority or the average ideal; and the practical criticisms above made hold good. Whatever may be said of our judgment of a past age by present standards, the standard by which we judge present action is not at all the average standard, but the highest moral ideal we can discover; and in this fact lies the whole significance of Ethics.

Or there is another form in which Alexander combines his idea of the good man and that of a social equilibrium. According to this interpretation, the equilibrium the good man represents is not an actually attained equilibrium, but merely one that would be secured were his ideal universally carried out, - an equilibrium realized only in so far as men are good. ${ }^{1}$ In this case, indeed, the ideal may be rescued from the reproach of representing only the average, easy-going morality; but, at the same time, all the remarks that make present morality absolute because it represents and maintains a present social equilibrium, and the argument in a line with such remarks that all maintenance of existence means adjustment to the conditions, or equilibrium, become inapplicable. It might be contended that the whole dilemma is avoided by Alexander in the assertion that wickedness has but little share in the life of society ${ }^{2}$ - that is, that goodness prevails; but such a statement may be disputed, except as morality is judged by the average standard; and, in this case, the argument begs the question, and the old problem recurs. It may further be added that the action of the good man in any other sense cannot represent the course that would be followed by every man, were all men good like himself, for his action takes into consideration the fact that all men are not good like himself and is a compromise with inideal conditions.

There is, in fact, and has been up to the present time, no "full" equilibrium of any society as a whole, and certainly no absolute equilibrium such as must coexist with an absolute right, which would be its expression. Du Prel, to illustrate his conception of the evolution of the systems of the heavens, imagines a group book.

1 "Moral Order and Progress," Book I. Chap. II.; Part I. pp. 231, 232, this

2 “Moral Order and Progress," p. 332. 
of dancers, each of whom sets out to dance a figure of her own without reference to the movements of the others; and he points out that if, in all cases of collision, the colliding parties either withdraw from the group or else move from this point together, a harmony of movement must finally be attained. ${ }^{1}$ We may conceive of momentary equilibrium of small portions of a society, just as, in the case of such a group of dancers, we may conceive of any moment as possibly representing an absence of collision in some one part of the company, although, in other parts, many collisions are taking place. But there is, at present, no general equilibrium of ideals, no common ideal for any society as a whole, but, on the contrary, a mass of conflicting ideals continually at war with one another; although, of course, there may be calculated an average ideal made up from all extremes, and there may be discerned a preponderating ideal in smaller portions of a society that form a body by themselves. The isolation of such portions is, however, only relative, and any equilibrium that can be spoken of as attained by them is most imperfect. The "good man," in so far as we regard his goodness as inherited, may be said to represent an equilibrium; but it is only the equilibrium of some one favored line of descent, and not an absolute, but a relative, equilibrium. In so far as we regard the "good man's." goodness as the further result of especial association with good men, it may be, to a large extent, in harmony with their ideals, and may hence represent a certain equilibrium among men who preserve themselves from intimacy with individuals of low ideals or only average morality, thus forming a partly isolated body; but this equilibrium, again, is only a relative equilibrium, just as the isolation of the group is only partial. If our definition of morality is progressive and not statical, the good man must be he who leads the advance. But such a man is not representative of his society as a whole.

Alexander regards the infliction of incidental pains as of little consequence for the absolute rightness of conduct. But the necessity of these pains has a reactive influence on character. That, in order to do the work which I can do best and which, therefore, I ought to do for society, I must pass many beggars in the street without inquiry into their cases, and much misery of all sorts without materially lessening it, has a certain detrimental

1 See "Die Entwicklungsgeschichte des Weltalls." 
result to myself. All pain, the sight of which is endured without the taking of active measures for its alleviation, vitiates the sympathies; and, on the other hand, a certain hardness of heart is necessary to the endurance of mere existence, at the present time; a certain selfishness to the enjoyment even of a life spent in moral effort; for perfect sympathy would make life unbearable in sight and hearing of the suffering of many of our fellow-creatures. The need for self-defence has been felt at all stages of the world's progress - in olden times for self-defence of a brutal sort, in modern days for a less and less brutal self-defence; such selfdefence is at present imperative, lest the yielding to one person result not only in a lack of fulfilment of our own duties to others than the one, but also in the strengthening, in that one, of a selfishness and dogmatism which may issue in further evil to others. And yet all resistance, where and in so far as carried out, vitiates temper and benevolence.

Alexander's position is positivistic in that it aims not to go beyond the facts; and this position might seem to lead naturally to the judgment of each age by a standard possible to the individuals of that age, that is, existent, in some form, in the society judged; and it might seem to lead, also, to the assertion of an absolute right where the existence of wrong is unfelt. But to this might be answered that, as soon as the higher standard does exist, the wrong may be judged by it; and that the judgment of a right as yet including elements of wrong implies the existence of another and higher standard as one of the facts. If Du Prel's company of dancers were automata, incapable of forecasting collisions, we might regard a momentary absence of collision in some one part of the company, from the standpoint of the automata concerned, as absolute equilibrium, since our judgment would have no regard to the rest of the company or the next move of the figures at present in equilibrium. But human beings are not automata, and the theory which regards the moral evolution from the standpoint of the ideals actually existent in society must take into consideration the actual realization which enters into the practical ideals of a large part of society, of the contrast of those ideals with a conceived higher standard at present impracticable. It is true that the consciousness of past ages, not comprehending in so great a degree the complexity of human interests, or looking 
so far into the future to distant results as does present mankind, had not so strong a sense of this contrast. But the contrast has arisen, was vaguely conceived even in far-distant times, and has continually grown more definite and pronounced in human thought. So far from its being true, as Professor Alexander conceives, that conscience always asserts the possibility of an absolutely right course, ${ }^{1}$ it may be said that, athough doubtless the mind always conceives, amongst the courses open to choice, some best course, there is a growing realization of the evil to conduct and character, of self and others, involved in any course possible under present conditions. The assertion of an absolute right, with an exact boundary-line dividing it from wrong, belongs to past Ethics; the appreciation of present evil doubtless differs in degree in different persons; but it is increasing both in extent and in intent, and is the explanation of the tendency to believe the present age worse than all past ages. It is not the sign of growing evil, but is, on the contrary, a part of a growing good; nevertheless, it registers the existence of present evil. There are few men of the present date, excepting the very young and exceptionally healthy and happy, who would agree with Alexander, that "it is ridiculous to suppose that wickedness occupies a considerable space in the life of a society."

Professor Alexander himself acknowledges the progress of society towards a state of good that shall be good not for a part of the human race merely but for the whole; and he recognizes also the fact that this extension of the ideal to the whole race means a progress in intent also. Such an ultimate state is certainly not ultimate in the sense that it is eternal; but it may be considered permanent in the same sense as the equilibrium of the solar system is permanent - in the sense that it remains practically the same for a period long to human thought. It expresses a perfect, though not an absolute, equilibrium. As such, it does not involve absolute happiness any more than absolute preservation of existence, immortality: it implies only the reduction of pain to a minimum through increasing wisdom and sympathy; through the endeavor, on the one hand, of a far-seeing and sympathetic society to protect the individual from disappointment, and through such increase, on the other, of the ethical pleasures that what Alexander terms "incidental pains" become inappreciable by contrast.

1 “. Moral Order and Progress," p. 270; Part I., this book, p. 247. 
The evolution of human society is not an evolution of one state or country alone but of the habitable globe; a condition of full equilibrium can be reached only when, in one way or another, all countries are gathered into the circle of civilization and sympathy. Until this happens, the isolation of single societies must be repeatedly broken in upon and the process of equilibration disturbed by the introduction of new elements to which adjustment must take place; the new adjustment being in the sense of progress towards a higher system of equilibrium, that is, one of more elements, and the whole process constituting a continual progress in the direction of a full stability of Life upon the earth. While despotisms exist to pour into other, freer countries their hunted and miserable subjects, unused to the responsibilities of self-government, and often as unfit for peace as is the dog who has been always chained and tormented, democracy must feel the evils of tyranny even in her own system. While uncivilized, or mentally, morally, and physically degraded human beings exist in one country, men in other parts of the world are not secure from contact either directly with these lowest orders, or, at least, with those who have been rendered less honorable or more callous to suffering by their influence or habituation to their suffering. And while war rouses hatred, and hatred results in war, there will also be, in societies, internal fluctuations, jealousies, hatreds. Lack of sympathy, violence, or indifference to suffering in one respect or direction is likely to be accompanied by lack of sympathy, violence, indifference, in other respects: while, again, violence is likely to beget violence, indifference indifference, between individuals, classes, parties, or nations. Different degrees of progress may be visible in different countries; but the more facilities of communication increase, the more inevitable it will become that the evils existing in any one nation will affect all, as also that the progress of any one nation will affect all; in other words, progress must tend, more and more, to equalization in all countries. 'Fechner's ideas of the Tendency to Stability thus explain the loss of Greek and Roman civilization, as well as the insoluble mystery which Wallace finds in the fact of the attainment of greatness among earlier peoples, there being "no agency at work, then or now, ${ }^{1}$ calculated to do more than weed out the lower types." 2

1 On the theory of Weismann.

2 "I Iuman Progress, Past and Present," "The Arena" for Jan., 1892. 
Increasing sympathy is a continual accompaniment of the increasingly close relations of men to each other through the gradual peopling of all parts of the earth, but especially through the increasing facilities of communication by which the distant is brought into contact with us; but the sympathy is of gradual growth, and the continual renewal of the struggle for existence induces renewed evils, so that it might seem, at first glance, as if the evil must continue indefinitely and undiminished, only changing its form. As long as no absolute equilibrium has been attained, doubtless evil of some sort must exist; change is inevitably accompanied by disadvantages as well as advantages, everywhere. But several facts are to be noticed. First: The statement which has often been made, that the severity of the struggle for existence is increased in the social state and grows with the growth of society, is erroneous. That is to say, more is doubtless continually demanded of the individual, but it is no abstract "principle" or "law" outside man which makes this demand: it is the increased power of the average of society which makes it; or, that is, the increased requirements of the age are met with increased capacity, and this would still remain true if we reckoned capacity as merely dependent upon the inheritance of knowledge and implements. Coöperation increases resources; and the average length of life is shown to increase with the progress of civilization. There is a lagging minority who suffer, for one reason or another, in the advance; these represent the inherently inferior types, or the types which suffer temporarily from outer disadvantage. The evils of competition in human society are not greater, they are simply more evident to human beings than the evils elsewhere in nature. The tragedies of the woods are bloody but short; death puts a speedy end to sufferings, and the earth quickly hides the victims. In society, on the other hand, coöperation preserves not only the aged and feeble, the deformed and idiotic, of the more privileged classes; it even suffices to enable the most miserable to drag out a forlorn existence somewhat longer. It forbids the mother who finds her child a burden simply to leave it by the roadside as the savage mother does, and it will give a penny or two against starvation where it will not bestow enough for comfort. This prolongation of suffering is thus the sign of an increased but not yet sufficient sympathy; in other words, evil not only changes its form with social 
evolution; it also gradually loses its force. To suppose, indeed, that renewed progress must always be attended with as great evils as to-day attend it, is to make the erroneous supposition that character has no constancy, and the sympathy for one's fellowmen gained in one relation will wholly fail to act in others.

Again, it might possibly be thought that increase in density of population, even as condition of the closer contact necessary to increase of sympathy, must go on ad infinitum, with everincreasing, or at least ever-renewed, misery, until the individual be left with barely standing-room; indeed, the picture of such a denouement has occasionally been drawn. But it is to be remembered that the conditions of mutual comprehension, dependence, and sympathy, come to lie, in later social stages, less and less in mere density of population and more and more in those many devices of modern life which we have termed means of communication. The increase of the human species must tend, in time, to self-correction; the only alternative is the extinction of the race through growing unhealthfulness of conditions. But this alternative is an impossibility; the human species cannot be annihilated as a whole except through some catastrophic event which interferes with the present course of evolution by the destruction of the earth - or through that final gradual decay which must accompany the earth's decline in power of nourishment. From internal causes we cannot expect the species to perish; for again in this case it is impossible that a struggle should be continued until the last individuals are destroyed. Indeed, the idea of destruction through insanitary crowding gives us at once a contradiction of the supposition of limitless increase, and a partial solution of the question. But the later and higher solution of the question is another. The fittest will survive; and the fittest will be those who perceive the evils of overcrowding and take active measures to avoid it. The fittest will be those who perceive that they are acting for the good of their children, and that of society as a whole, if they do not bring into the world more offspring than they can furnish with a healthy constitution, good moral training, and a sufficient education for self-support and comfort under conditions of normal labor. The term "health" is not an absolute one; but if we once suppose a start made in the direction of the decrease of pressure, we must suppose, other things being equal, that those lines of descent and 
parts of society in which it arises will be favored in the struggle for existence, and will come to supplant other parts. 'To suppose that the increase of pressure can go on ad infinitum is, indeed, to reckon - if we look at the matter from the purely psychological side - without man's reason. Social development and moral theory have not favored any limitation of progeny as long as population was sparse. But certain facts are beginning to be recognized: ( $\mathrm{I}$ ) that the propagation of their kind by the criminally constituted and by the hopelessly diseased is immoral; (2) that the propagation of offspring to such poverty and ignorance as stunts them physically, and makes their entrance into the criminal or pauper classes a probability, is also immoral; and (3) that duty does not demand of men and women that they shall sacrifice health and happiness, and drag out a miserable, overworked, joyless existence in illy rearing an over-large and probably weakly family. The greatest favor, privilege, and luxury that parents can confer upon children is that of health, and the next greatest is that of healthy parents, neither ill-tempered with care nor morbid and dull with overwork, but alert to perceive and ready to sympathize in all their trials and aspirations, and endowed with sufficient leisure to give some attention to that quite as important duty as child-bearing - the character-training of children. Selfishness is, of course, possible in the direction of limitation of increase as in every other direction, and in this case it must defeat the end to a great extent; but such selfishness must tend to correct itself as sympathy develops and society, in its approval, recognizes and demands more and more what is for the good of all.

The course of our reasoning does not pretend to predict an absolute social equilibrium, which must include the immortality of man on the earth, together with the prevention of every accident and of every disappointment whatsoever. A word has already been said as to the probable necessity of the death of the individual; and with death are given also disease and age and their attendant mental evils. We may suppose, however, under an increased healthfulness of general conditions, an increase of vitality which shall make death, in an ever greater proportion of cases, rather the issue of a gradual failure of the powers than the result of violent illness. That the tendency is in this direction is demonstrated by the gradual increase 
of the length of life. A high degree of mental, moral, and physical harmony in human society is no more "wonderful" or inconceivable than the high degree of harmony already attained in the movements of our own solar system. On the one hand, social progress means the attainment of results which call less and less for reform; and, on the other hand, we are accustoming ourselves to social change; reforms, the like of which would once have convulsed the world are now accomplished with little inconvenience, and we are able to go forward with a rapidity of which no former age was capable.

We may look at social development from still another point of view, as a process by which the preservation of the individual gradually becomes coördinate with the preservation and welfare of the species. Darwin surmises that the work of the benevolent or intellectually great man for his people may be as important for its welfare and the determination of its conquest in the struggle for existence as is the propagation of offspring. As social organization progresses, and the relations of men become more intimate and complex, all the acts of the individual grow to be of greater and greater significance for his kind, while, reciprocally, the health and happiness of the individual increase in importance for his kind. And thus, from both sides, virtue and health, virtue and happiness, also tend towards coincidence in the individual life, and environment comes more and more to favor the virtuous. Sympathy, which is for the general good in many relations, increases in strength as inward characteristic and acts with more and more certainty and universality, so that the society which has been merciful and helpful in a degree towards many individuals comes to show mercy and helpfulness in a greater degree, and with more uniformity, towards more and more individuals; while, at the same time, the welfare and the happiness of the individual become more and more coördinate with the welfare of society as a whole, and the latter is accordingly more universally sought. This does not necessarily mean that it is sought from motives of self-interest; on the contrary, as society progresses, the individual is more and more moulded to such harmony with its needs that he finds his happiness in seeking its welfare.

The earlier punishments of offenders were extreme and cruel; the majority, in endeavoring to protect itself, had little regard for the individual, as the individual also had little regard for 
the welfare of the majority. With social progress, however, the majority become more humane even towards their enemy, the criminal. The checks which the fear of extreme physical punishment alone could impose at an earlier period are gradually succeeded by the checks furnished in the approval and disapproval of society as a whole, and of those to whom the individual is bound by ties of affection and of respect. That is, in the sympathetic feelings themselves a dependence on others is developed which acts as an effectual preventive and stimulus, and must become more and more effectual as society advances and the range of sympathy widens. This increasingly altruistic form of even the checks to evil is taken no account of by the pessimist. As the necessity for severity decreases, severity even in social disapproval must lessen; as the individual comes to yield more readily and promptly to a slight spur, extremer methods will be discarded. Thus fear will be, by degrees, replaced by hope. This development is seen not only in sectarian matters but also in the history of religious thought; nearly erery religion has had its heaven and its hell, but with social progress and the broadening of sympathy, the hell falls more and more into disrepute, the motive of heavenly reward being rather emphasized.

As sympathy broadens, we come to feel, not alone pain at the pain of others, but in an increased degree and with regard to ever wider circles, pleasure also in their pleasure. The altruistic pleasure afforded by the relief of pain, as the more necessary to the preservation of existence, has been the earliest developed. A great good in its province, it may contain, nevertheless, an element of vanity that opposes itself to a further evolution. There is no doubt that a certain kind of benevolence would greatly miss the gratification and self-aggrandizement experienced in the relief of poverty and suffering. The higher but not yet so universal capacity is that of rejoicing in others' good and happiness as well as sympathizing in their sorrow. This capacity shows itself as yet chiefly in the more intimate relations of love and friendship. In these, too, the influence of approval and disapproval is powerful, and the pleasure we give a friend in being worthy of his esteem may make our best happiness. Here we have a hint of an increasing union of love for the individual and love for the ideal which must tend to raise fricndship itself to the highest plane.

As a result of our considerations, we may deny the truth of 
Rolph's assertion that the stimulus of want will be forever necessary in order to secure exertion - that is, if by want is meant misery or great pain of any sort; if merely desire is meant, which the anticipation and early accomplishment of satisfaction may prevent from becoming pain, we may admit the statement. In this case, however, the argument which Rolph deduces against the possibility of a final state of social harmony is invalid.

But it is not the intention of our argument to assert that all desires without exception will be fulfilled in any future condition of society. What may be said is that, in an increasing degree, sympathy will endeavor to satisfy the wants of the individual, while, on the other hand, the approval and fellow-feeling of society, and the consciousness of having performed his duty, will come to represent to the individual, in a greater and greater degree, recompense for personal loss. This change of direction in desire and gratification is no weakening of it: it is no more necessarily true that the man of perfect principle is poorer in emotion than the man whose passions lead him to sacrifice his fellow men than it is true that the average man of civilized society is poorer in emotion than the brutal savage. Merely, human evolution is a continual development of higher and more complex emotions, which rise into force on the proper occasion to modify the more primitive ones, or, more accurately speaking, the lower emotions of the savage themselves take on a higher form through organization with later ones.

Spencer, in criticising theories of altruistic morals, endeavors to show that time and energy are lost in the distribution, through others, of the happiness or means of happiness which might with more profit, because a better understanding of need, be sought by the individual himself ; and he remarks, that it is a question how much of the happiness which means also vitality the individual may rightly sacrifice to society. But the refusal of individuals to sacrifice anything of personal gratification must lead, under present conditions of desire, to extreme sacrifice on the part of other individuals; so that the principle of the illegitimacy of sacrifice logically contradicts itself. It is not perfectly clear what is meant by a "division and redistribution" of happiness, or the means of happiness, against which Spencer directs his argument. It is probable that the author has in mind, and is especially opposing, a particular school of theorists whose ideas 
we will consider later on. Suffice it to say, at this point, that social harmony can never be reached by the stubborn continuance of each in his line of inharmonious conduct, but can only be attained by such gradual moulding of habit and desire that by natural organization individuals will come to be in harmony with each other. It is the history of social evolution that the individual, though always determining what are his own needs, as it is obvious that he can best do, is increasingly aided in satisfying them by coöperation, while he also gives increasing aid in return. Against the list of the advantages of egoism enumerated by Spencer and others, I would muster the advantages of altruism, for by coöperation alone can the individual attain the pleasures which now so often lie beyond his reach; by it alone can society attain a higher plane; and the pleasures of altruism are the highest and the most unfailing. The selfish man will suffer disappointment and loss as well as the benevolent man, and he will lack the refuge of sympathy and of the power to find happiness in the happiness of others. What man who has felt the joys of sympathy would exchange even the hardships it brings for the brutal liberty and unmoved selfishness of the savage! what man who has known the joys of the higher, the more unselfish love, would exchange them for the ungoverned and quickly-palling pleasures of the profligate! These joys first lend life worth and meaning; through association and altruism, coöperation in action and feeling, man first becomes a power in the world. Yet the man who is capable of the higher sympathy is incapable of a selfish calculation of its personal advantages to him.

Wundt has an objection to Evolutional Ethics as it is understood by this treatise, on the score of the assumptions with regard to moral inheritance involved. "How, out of tendencies stored up in the nervous system, moral conceptions arise, is, and remains, a mystery," he says. ${ }^{1}$ The problem is nothing more or less than that of the connection of brain-function and psychical process, in inheritance; and we may say again that we no more perceive the necessity of explaining the "how" of this before accepting the evident facts, than we see the necessity of explaining, in the same sense, the connection between light and heat, or between the seen vibrations and the heard note. Moreover, the "mystery" belongs as much to the conservation of character 1 “ Ethik," p. 344 . 
in the individual life as to its conservation in the race; if an explanation be necessary before acceptance of the facts in the one case, it is assuredly necessary in the other also; and its necessity must be fatal to Physiological Psychology. It is time that that ancient scarecrow of superstition, "a mystery," were removed from the field of science. When Wundt further proceeds to interpret Spencer's theory of heredity as one of the inheritance of distinct and definite ideas in their original form, he reads into the theory what Spencer himself, with his conceptions of instinct and reflex action, never put there, and what, moreover, no modern writer on philosophy has distinctly asserted. This present treatise is much more open to Wundt's criticism than is Spencer's work, though it makes no positive assertion as to the nature of "instinct" and so-called "automatism," but leaves the question as to their unconscious character open. The appearance of common psychical phenomena at the period of puberty, and with characteristics peculiar, moreover, to the particular lines of descent, would be enough to establish the fact of heredity, if no other testimony were forthcoming; and yet no one can "explain" the sudden appearance of these phenomena at a certain age.

But the most of the objections to Evolutional Ethics are not on such score as this. A while ago, the conservatives in Ethics declared that the theory of Evolution, even if true, had nothing to do with morals, which occupied a region far above the plane of science. Now, the most of the conservative schools content themselves with merely asserting that evolution may be true even in application to Ethics, but that it is useless in this province, since it adds nothing of value to theory or practice. It may be well to examine into this assertion. A priori, we could scarcely suppose that increased knowledge in any branch could fail to be of importance to that branch and to affect it in some manner. Knowledge is power, and we should presume not less so in Ethics than in any other science.

The assertion that Evolution adds nothing to theory would indeed be as just with regard to other sciences as with regard to Ethics; or, rather, it would be more just with regard to the natural sciences. For they at least recognized, before the appearance of the theory of Evolution, the element of constancy ordinarily called law, and attempted to formulate this constancy as a basis 
of thought and action. To these concepts of constancy and the predictions founded upon them, the theory of Evolution merely added greater certainty and a.more extended range, supplying the bond of union between various branches, and showing the inner relation of many before disconnected theories; its whole force was one of clarification. But the work of Evolution for Ethics, though of a similar nature, has been of even greater degree and significance; it has unified and clarified the attempts made to discover a basis for moral principles and has rendered that foundation for the first time secure; it has cleared away, with one sweep, the rubbish of ancient superstition, made exact methods possible, and raised Ethics to the plane of a Science. If it had added anything absolutely new and entirely unconnected with previous theory, it would be as unintelligible to us as Calculus to a Fiji-Islander; if it had no intimate and vital connection with foregoing ideas, it would meet with no comprehension or acceptance. Science, too, is an evolution, not a creation. The value of the theory of Evolution lies in the very fact that it is simply an addition, though a large one, to previous thought, a higher phase of conception which rises naturally out of the old. But the cavillers say on the one hand: "It teaches a theory of conscience as instinct, therefore we may still cling to the old and unaltered doctrine of the veiled and sacred 'mystery of Feeling " ; and on the other hand: "We already accepted a basis of reason and Etility, therefore our theory, not being overthrown, needs no alteration." Both schools forget that, in science as elsewhere, the new develops from the old, but evolution brings with it, nevertheless, a difference of degree that finally issues in difference of kind. It has been said even by one belonging to the advanced school of Ethics, that, if the course of Evolution could be shown to prescribe immoral conduct, the duty of the moral man would be to oppose evolution even if he perished in the attempt. The conception which lies at the basis of this assertion is as erroneous as that which asserts that man must go forward on the path taken by evolution whether he will or no. ${ }^{1}$ To suppose the will of society opposing the course of Evolution is to suppose a self-contradiction. Nature and man's will are not two different things in this process; man is the part of nature which is involved in the evolution considered. Our prediction

${ }^{1}$ See Part I. p. 147. 
of the direction of social development is a prediction of his will; he will will in certain ways constant in the broad sense in which all nature is constant, constant as character and reason are constant. The individual has assuredly the power to oppose himself to all other individuals, if he so wills; and his influence will not be lost; but it is exactly this willing and the mutual influence of individuals upon each other which the theory of Evolution, as applied to Ethics, endeavors to take into account. The result in prediction cannot be properly likened, as it is likened by Stephen, ${ }^{1}$ to the inference of the future of an organic whole from its present parts. It does not define the progress in society as a whole from a study of the individual; it is, on the contrary, an inference of the future of the whole from its past and present considered in the light of general natural laws, and is as legitimate as the computation of the future position of heavenly bodies from their observed past movements and present position; though we can doubtless make only general predictions from general observations. Or, if we approach the question from another side, we may say that the science of Ethics endeavors to ascertain the ideal by which the welfare of all may be attained, and that the solution of this problem cannot be given otherwise than through rules for the attainment of the general health in the broadest sense of the word; for this corresponds to a final harmony of desires through survival of the fittest.

The power of prediction is, thus, evidently not to be interpreted as if the evolution of morality would go on except through the human will, and through this will in individuals. In any assertion to the contrary, the same old contradictory division is assumed, of nature as active opposed to nature as passive; man is first regarded as a part of nature and then again as outside nature and compelled by it. We divide him into two parts: the one necessarily coincident with the nature in himself, the other antagonistic to it; the one absolutely passive, the other active; and yet these two are the same, and we regard them as the same from other points of view. Nor does prediction impose any "laws" upon the will from without; it is simply inference from the observed relations in the action of individuals: it does not create or alter those relations. It reckons, not from man as compelled by "Necessity," but from man as possessing will and acting from

$$
1 \text { “The Science of Ethics," pp. 32-34. }
$$


reason. If man is reasonable, he will perceive that it is for the good of himself as well as for that of the rest of his race to attain a state of harmony; as he is reasonable, he will perceive that social progress is for his benefit as well as for that of others. The increasing solidarity of society continually rendering progress desirable, and the line of the fittest, that is, of those who will in a manner that best fits them for social conditions, continually tending to coincidence with the line of moral progress, the final triumph of the moral is assured. It is not in any way denied that man chooses this course of advancement. On the contrary, wherever we begin in our analysis, we come round finally to the variation of reason, emotion, and will.

As above noticed, the false interpretation of the significance of Evolutional Ethics on the subject of man's will in relation to progress sometimes gives rise to the opposite erroneous impression to that just noticed, to the impression, namely, that progress will go on whether men strive for it or not, and that it is of no particular consequence what the individual does, or at least that Evolutional Ethics can furnish nothing but statistics and predictions, never motives to right-doing. This confusion has caused much self-contradiction, has given rise to the most of the discussion on the subject of Absolute and Relative Ethics, and has impelled certain authors to close their books with something very like a half doubt of the efficacy of their own method except as one of observation. But the value of Evolutional Ethics lies not only in the fact that it goes deeper than any other system and analyzes more clearly the ground of moral conduct, - thus removing doubt with those who are open to conviction, and furnishing a less fallible criterion to those who desire to perceive where right lies in order to perform it, - but in that it also renders obvious the fact that conduct opposed to the welfare of society becomes, with time, more and more disadvantageous. The individual may escape punishment for his misdeeds : but the chances against him are greater, the greater these misdeeds and the longer they are persisted in; it is the "average of the line of moral progress" that is favored by natural selection. A system of Ethics is a part of the environment which acts on the individual; its force is no more lost than is that of any other part of the environment, although the result in the particular case will depend, also, on the character of the individual appealed to. But if Evolutional 
Ethics cannot bring any such force to bear on the individual as will change his character in an instant, rendering him apt and ready to act according to the ideal, whatever may have been his previous character, there is neither any other system of Ethics which can do this, and there has seldom been one so sanguine as to hope to do it. Theological Ethics, or rather, Theology, has asserted the possibility of such instant transformation, and the doctrine of Socrates that the knowledge of right will secure its performance is a much less extreme instance of a similar idea. But Evolutional Ethics, while rendering manifest the necessity of unceasing endeavor, affords us encouragement by its assurance of the possibility of progress, and its demonstration of the fact that the force of endeavor can no more be lost than any other force. It adds dignity to the smallest acts, and lends earnestness and worth to life. It neither contains any excuses for inaction nor leaves any reason open to pessimism except a selfish one; to the man to whom his own selfish gratification is all in all, the knowledge of social evolution is not a matter of encouragement and rejoicing; but to the lover of his kind it must be. Evolutional Ethics admonishes us to labor, yet teaches us the necessity of patience, since, however the individual will, nothing arises all at once, and the evolution of morals in society as a whole must, like all other evolutions, be a gradual, because a many-sided one. It admonishes us, too, - and this is well, that we cannot sin without leaving ineffaceable stains upon our own character. The past is never dead, either in its results outside ourselves or in our habit; and it is not the drunkard only who one day awakens to find himself irrevocably moulded, by steps of habit so slight as to have been almost imperceptible, to that which he once loathed and detested. "Our deeds are like children that are born to us; they live and act apart from our own will. Nay, children may be strangled, but deeds never; they have an indestructible life both in and out of our consciousness."1 We may not be a mere spectator of the struggle for existence even if we will; the dead weight of inaction is itself a force opposed to other force. Willy, nilly, so long as we live we must bear the responsibility of taking a part for or against the progress and welfare of the world.

But there is, as I have said, a system which asserts the possi1 George Eliot, " Romola." 
bility of instant entire change of character, as well as of the forgiveness and obliteration of past sins. What manner of obliteration is this? Not the obliteration of the consequences of the acts, since that is impossible, but an obliteration of responsibility for them such that the doer may erase them from his conscience. The innocent on whom the evil results fall are, then, according to this view, the only ones who shall suffer for them. The doctrine of the Atonement takes away that sense of personal responsibility which is most essential to morality, and this removal of responsibility explains the ease with which Christians of all ages have combined a fervid religiosity with vice and crime. Christian theories of morals of the present day forbid the issue of indulgences; but the consciousness that full and free forgiveness is always waiting to receive the offender whenever he gets ready to repent, even if it is not until his death-bed, is most pernicious in its results. So we learn, for instance, that the "Mollie Maguires," a league formed in the mines of Pennsylvania a few years ago, for the express purpose of murder by coöperation, were in the habit of opening their meetings with prayer, and of withdrawing regularly from the society, for one quarter of the year, to attend church, in order then to murder with an easy conscience for the other three quarters. The senior member of Conan Doyle's "Firm of Girdlestone" is no mere fiction of the imagination. I have no desire to join with those who pronounce all Christians, or everything in Christian doctrine, morally unsound; I only maintain that the doctrine of the Atonement is in itself pernicious, and is shown to be so by its easy reconciliation with evil action.

Theological Ethics is defective in other respects also. A system which represents God as accomplishing his own will in the world in "mysterious ways," to question which is sacrilege, has necessarily led to the excusing of much evil as punishment or discipline, and so to inaction against it. "Men can do so little themselves to make the world better," said a fervent Christian to me not long since; "we must leave these things to God." So, poverty has been held to be a mysterious dispensation of Providence which it was not necessary to do away with even if its abolishment were possible, but the slight alleviation of which was counted among the means of atonement for other sin. Thus it has been in other ways than in itself a curse to mankind, furnish- 
ing a sort of indulgence for the immoralities of the rich. Poverty has even been represented as a blessing, since it was to be compensated with double joy in the hereafter. The Christian, pointing the miserable and starving to Heaven as a recompense for pain, experienced, without largely inconveniencing himself, a sense of his own piety and desert, and exerting himself to no radical cure but only to a meagre dole of charity, shifted all responsibility of the cure or its omission, by prayer, to God. So Salter is led to exclaim: "If we must pray, let us pray to men; for there all the trouble lies. Could you, O churches, but open the hearts of your worshippers as you seek to move the heart of God, the need for all other prayer would soon be gone." 1

Again, 'Theology has continually taught that man's first duty was to save his own soul from hell, and in this doctrine, ideas of repentance and redemption, faith and worship, have played a larger part than "mere morality." The tendency has, therefore, been towards an "other-worldliness," an egoism of the Hereafter, rather than a fulfilment of the commandment of love. Faith has been exalted above love of Truth, and blind obedience above reasoning morality. Thus it was that Christians entered, with such zeal, into the persecution of heretics. Had the commandment of justice: "do unto others as ye would that they should do unto you," been followed, the Inquisition could never have taken place. But Christians forget, when they point to this commandment in evidence of the superiority of Christian Ethics, that it is not the only command or doctrine that the Bible contains. Nor is this conception of love to others, which Christians have continually cited as testimony of the divine origin of their religion, confined to Christianity or even original with it. Many other religions contain it. The Buddhist religion enjoins towards all creatures such love as that with which a mother "watches over her own child, her only child."

It is true that the majority of the objectionable points of Christian Ethics are found in the Old Testament. This testament is, however, accepted as the exponent of divine truth, though the authority it now possesses is slight in comparison with that which it formerly held. Yet Christ himself says: "Think not I am come to destroy the Law (i.e., the Pentateuch), ${ }^{2}$ or the

${ }^{1}$ Salter, "Ethical Religion."

2 It is strange that even enlightened Christians often, without thinking, in- 
Prophets, I come not to destroy, but to fulfil. For, verily, I say unto you, Till heaven and earth pass, one jot or one tittle shall in no wise pass from the Law till all be fulfilled. Whosoever, therefore, shall break one of these least commandments and shall teach men so, he shall be called the least in the kingdom of heaven; but whosoever shall do and teach them, the same shall be called great in the kingdom of heaven." Repeatedly, Christ shows himself a strict conformant to the Jewish code. But if we examine the Pentateuch, the Jewish Law, we shall easily find on what grounds the burning of heretics and witches, and all the other cruelties of the Middle Ages were committed in the name of Christianity. Lubbock writes, for instance: ${ }^{1}$ "Among the Jews, we find a system of animal sacrifice on a great scale, and symbols of human sacrifice which can, I think, only be understood on the hypothesis that the latter were once usual. The case of Jephthah's daughter is generally looked upon as exceptional; but the twenty-eighth and twenty-ninth verses of the twenty-seventh chapter of Leviticus appear to indicate that human sacrifices were at one time habitual, among the Jews." See also 2 Sam. xxi. I, 5-9, I4. In Lev. xx. 27 ; Ex. xxii. I8, the stoning of witches is commanded. In Ex. xxii. 20 ; Deut. xiii. I-5, 6-10, I4, 15; xvii. I-5; xviii. 20 , it was commanded that men be put to death for idolatry or heresy or for "dreaming dreams" in the service of another god, and that idolatrous cities should be utterly destroyed even to the cattle within them. Superstition and insanity must have fared ill among the Jews. Ex. xxxi. 14,$15 ; \operatorname{xxxv} .22,3$; sentence of death is pronounced on any who shall perform even so much labor as the kindling of a fire on the Sabbath; and Num. xv. 32-36, describe how a man was put to death, by God's command to Moses, for gathering sticks on that day. Death was also commanded for murmuring and for all sorts of ceremonial offences; see, for instance, Ex. xii. 15, 19; xxx. 33-38; Lev. vii. 20-27; xvii. 8-10, I3-16; xix. 5-8; xxiii. 29, 30; xxiv. 10-16, 23 ; Num. i. 5 I ; iii. 10,38 ; iv. 15 , 18-20; xi. I; xvii. I 3 ; xviii. $3,7,22$; see also especially Deut. xxviii. 15-68; xxxii. 22-42. Command of subjection to the priesthood on pain of death is found in Deut. xvii. 8-12, and examples of terpret the "Scriptures" referred to by Christ as if they, in some way, included the New Testament, which was not written till long after his death.

1 "The Origin of Civilization," p. 373. 
fearful punishment for protest against its supremacy are given in Num. xvi. 3-1 5, 20, 2 I, 26-35, 4 I-47, 49. It may be noticed, that here the children are represented as perishing with the parents by God's express command and miracle. Many instances of the stoning and putting to death of whole families for the sins of some member or members of the family are recorded in the Old Testament, and prove that the expression "visiting the sins of the fathers upon the children, and upon the children's children, unto the third and to the fourth generation," is not to be interpreted as a mere reference to heredity, as many have endeavored to prove it to be. See on this point Is. xiv. 2 I ; also Ps. cix. 7-20; cxxxvii. 9. The origin of ordeals may be traced to Num. v. I I-3I.

The Old Testament also sanctions slavery, and makes no protest against the selling of children into slavery; see Ex. xxi. 2-6, 7; Lev. xxv. 44-47; although the Israelites were to treat slaves and servants of their own nation with much greater kindness than that used towards those of other nations. Ex. xxi. 20, 21, prescribes that a man shall not be punished for beating his servant to death, provided the servant does not die directly under his hand, but linger a day or two; "for he is his money." Christians have often protested that their religion cannot be held responsible for the sins of the prophets, - for David's murder of Uriah in order to obtain the wife with whom he had already committed adultery; for his torture of the Ammonites with saws and axes and harrows and fire, and his houghing of the horses of a thousand Moabitish chariots; for Solomon's concubinage and his slaughter of Joab according to David's last orders; for Elijah's wholesale slaughter of the priests of Baal; or for the thousand other vices, crimes, and atrocities described in the Old Testament as committed by God's chosen men, generally without punishment or protest from him. However, the case is not so easily dismissed when we find just as great cruelties and atrocities directly ascribed to God's express command or miraculous interposition. A large number of such are included in the passages already noticed; and we further find descriptions of a destruction from God for the crime of census-taking ${ }^{1}$ - I Chron. xxi. I, I I-I 5 - for touching the ark in the endeavor to save it from a fall -2 Sam. vi. $6,7,-$ and

1 Superstitious fears are often awakened in savage tribes, and among the ignorant of our own more advanced societies, by attempts at census-taking. 
for many other trifling offences. God is always represented as favoring the Israelites in their wars and massacres, and often as commanding the slaughter of thousands; so that we can easily understand how it happened that the cowardly murderers of the Duke of Gloucester, in the time of Richard I1., swore "upon the Body of Christ before a certain chaplain of St. George in the church of Our Lady of Calais, that they would not disclose the murder they were about to perpetrate," ${ }^{1}$ as also, on what precedent Russia, at the present day, has her war-engines blessed by priests of the "God of Battles." Deut. xx. IO-I5, commands the slaughter of males captured in a siege, but the sparing alive of women and children as booty; and Num. xxxi. describes a case in which the command was carried out, with the reservation of a certain portion of young girls for the priests. See also Deut. xxi. ro-r4. Furthermore, a religion that makes man absolute ruler of the earth and all living things, and sanctions animal sacrifice, cannot conduce to a sense of the duty of self-restraint towards other species, and is, in fact, often used as an excuse for the autocracy and cruelty of man.

It is, indeed, strange to see civilized peoples of the nineteenth century proclaiming the divine origin of laws and beliefs like these - laws and beliefs at least as barbarous as those of the Greeks and Romans whose gods the Christians deride, and far behind the Ethics of some philosophical systems produced among those "heathen" peoples. As has been said, various attempts have been made to explain away these barbarities, or to withdraw all responsibility for them from God, to whom the Old 'Testament often directly ascribes them. But in the light of what we know of other primitive peoples the customs of the Jews are only too easily comprehensible; the same barbarities of human and animal sacrifice, slavery, murder without pity, and unscrupulous cruelty of every sort, were to be found, as we have seen, among many other ancient peoples. As for withdrawing the responsibility from the God of the Jews, Christians forget that, in denying the divine origin of the cruel, brutal, and obscene laws ascribed to God together with other laws of less barbarity but of organic growth with these, they are forever destroying the grounds of belief in any assertion of divine supervision, and throwing doubt, by implication, on the New Testament as well, since Christ and

1 Pike, "I History of Crime," I. p. 405. 
his followers were believers in the Law and the Prophets, and often refer to their assertions and accounts of divine direction. But most religions have claimed, and do claim, the divine origin and ratification of their laws, as a means of enforcing them.

The God of the Jews, Jehovah, was originally a nature-god, the god of the heavens, like Zeus, Jupiter, and many other of the greatest gods of other peoples. Science has exploded ancient ideas of the sky; but the Christians still cling to the old terms brought into use at a time when men believed in a flat earth and a region of spirits above floored by an opaque heaven. The God of the Jews was, like the gods of all primitive peoples, a "jealous" and revengeful god, rather to be "feared" than loved; for to such peoples, possessing few resources against the powers of nature and ignorant of their character, the destructive forces of the elements appeared at first rather evil than good, and therefore to be conciliated and appeased; the gods take on their friendly character only as man comes to learn how the forces of nature may be employed for his benefit, and as he slowly attains, in himself, to sympathetic and moral feeling. Accordingly, the Jews were continually occupied with all manner of propitiatory offerings of their most valuable possessions - their herds and the fruits of the earth; and these were burnt under the impression common to nearly all primitive and savage tribes, that they suffered by fire a sort of death and entered the spiritual world. Gradually, the Jews became more civilized, and took on the higher ideals of Eastern religions with which they came in contact; but even to very recent date, the "fear" of God was regarded as the chief essential emotion on the part of the worshipper. Of late, as social ideals have become higher, and sympathy more general, the idea of love, lost for a time through the mixture of Eastern peoples with more barbaric ones, has come to the fore. That a doctrine of polytheism is clearly taught in Gen. iii. 22 ; vi. $1-4$, Christians do not generally even notice. The idea of demigods, found in the latter verse, is called by them, when they meet with it in the Greek or Roman religion, a "myth "; and the idea of sexual intercourse between men and gods, also taught in these verses, is held worthy of all abhorrence, when these "heathen" religions are under consideration. The fact is, that exegesis, forced to advance by progressing civilization, has left far behind the simple original meaning of bible-texts, - such 
obvious meaning as Christians find in the Buddhist, Persian, or Egyptian Scriptures, when they peruse them. This is true of the New Testament as well as of the Old. The Christian religion has indeed developed into a system of Christian philosophy as different from the Christianity warranted by the Old and New Testaments as were the later Buddhist philosophies from original Buddhism.

When Christ conferred upon his Apostles the power to forgive sins, he laid the foundation for papal authority, and confirmed the ancient authority of the priesthood, preparing the way for that organization of priestcraft which figured so prominently in all the sorrowful history of the Middle Ages. Moreover, the vein of sadness and the subordination of natural modes of life which mark his teaching as they mark only in a greater degree those of the Buddha, easily led to the celibacy and mortification of the flesh which so long condemned the most aspiring from a moral point of view, the most gentle and conscientious, to a life of loneliness, and peopled the world with the progeny of the less moral. Indeed, if we read Matt. xix. I 2 correctly, Christ distinctly taught emasculation as a high religious virtue.

The New Testament tolerated the slavery upheld by the Old Testament, and we not only find no protest whatever against it, but we even find Paul returning a runaway slave to his master. Not only Paul, but John also, taught both predestination and hell-fire for idolaters and unbelievers, as well as for the fearful and doubtful, equally with murderers, whoremongers, and liars: Rev. xvii. 8; xx. I5. Christ himself plainly proclaims the damnation of unbelievers - Matt. xxii. I3, I4; xxiii. I4, 33; Mark xvi. I6; etc. - and he at the same time asserts a very positive doctrine of predestination, avowing that he himself takes special pains that many of those to whom he preaches shall not be able to understand him, believe, and be saved: Mark iv. I I, I 2; John xii. 39, 40. His language on these subjects is very clear, and bears no sign of being intended as figurative, though modern Christians prefer to regard it as such rather than to relinquish a religion the morals of which would, by other interpretation, be proved inadequate to the demands of the standards of higher civilization; the same method of exegesis applied to the sacred books of Confucianism or of Buddhism, from which it now appears probable that very-many of the 
Christian ideas were derived, would suit them ill. But even if Christ's language were figurative, it must have some meaning; the wrath and vengeance of God are continually spoken of in the New Testament as well as in the Old. Such expressions were not looked upon, until of late, as figurative, and they doubtless did much to justify, to the minds of earlier Christians, the burning of heretics. The justification of all sin in God's elect, a permanent indulgence, is plainly taught by Paul, Rom. viii. 33; iv. 5-8; r Cor. vi. 12. Let us take the Buddhist Scriptures, and, in the light of the better passages, or in the light of Siddhartha's devotion to truth and to his fellow men, interpret the passages which, morally, we find wanting, and we shall find this religion as beautiful as the Christian.

A chief reason often advanced by Christians for continued faith in their religion, is the comfort conferred by a belief in immortality and the forgiveness of sins through Christ; that is, the rescue of men from the "wrath of God" through the offering of an innocent being, a "human sacrifice," which was to bear this wrath, and appease it, according to the old Jewish idea of the scapegoat. The morality of the last doctrine we have already condemned; there is no real making atonement in this world; we should recognize this fact, bear the responsibility of our deeds, and in the light of past experience, avoid the repetition of our old sins. And the moral question as to mortality or immortality is not: "What is the pleasanter to believe?" but "What is the truth?" In this recommendation of the pleasant in belief, we have but an illustration of one of the chief defects of Christian theory, which lays most stress upon faith and far less upon a love of the Truth at all costs. The peace of the Christian's death-bed is often made one of the chief arguments in favor of the Christian religion. But the mind in which there exists the noble love of truth will seek this only at the cost of all peace and blind content.

On the general connection of faith and morals, Clifford writes: "Belief in God and in a future life is a source of refined and elevated pleasure to those who can hold it. But the foregoing of a refined and elevated pleasure, because it appears that we have no right to indulge in it, is not in itself, and cannot produce as its consequences, a decline of morality." 1 Indeed, Christianity, as

${ }^{1}$ Essays and Lectures, "The Influence upon Morality of a Decline in Religious Belief." 
has been already remarked, and as is conclusively shown by any conscientious and unprejudiced examination of the Bible itself, leaves room for an ease of conscience and a self-excuse in even very great sins, which no high standard of morals can tolerate. How many of those who attend church regularly, on Sunday, are restrained by their religion from practising vice and injustice on week-days, under the consolation, if their conscience troubles them at all, that their prayers for forgiveness and the bestowal of charity, or even, in extremity, a death-bed "repentance" will make their peace with God? In place of an attempt at reparation towards men, against whom sin is really done, Christians are taught to seek the "forgiveness" of God. Some there are, indeed, who remember only the law of love and endeavor to follow it. All honor to them. But they are adherents of a modern Christian Philosophy, the product of many good men who have winnowed out the wheat of their religion and left the chaff; they are not followers of the Bible, or even of the New Testament, as a whole. Many there are who are perceiving this, and the old system needs replacement with a newer and higher - with a system which affords clear and evident grounds for moral action, leaves no room for mysticism, self-justification, or inaction, offers no opiate to conscience. Such a system must be founded on the solid rock of scientific Truth; not on any doctrine of blind obedience to traditions; it must take into account man's evolution, that it may progress with his progress.

Many term the Ethics of science dry and uninspiring, and turn, with preference, to religions which, if they give us mysticism or pessimism, give us poetry also; for man is an emotional as well as an intellectual being; and there may be much poetry in pessimism. But again, it may be said that the Truth is that which we should first seek. And especially let it be remembered that, if poetry is lacking, it may be that the deficiency is in ourselves. It is a history many times repeated, that men call their age and its ideas dry and uninteresting, and seek their ideals and inspirations in the past, until the master-mind arises, who boldly faces and interprets the realities about him; and then men exclaim and wonder, and find that their own blindness, and not the age, was at fault. We cling by habit to the old and fear the new; and so we have yet to inspire these new ideals with the beauty gained by association and habit; in themselves, they do not lack beauty. 
In truth, as I believe that there is more of poetry in the gray wires strung across our streets and guiding the swift, silent, fearful forces in which lies power to light a city or destroy a life, than ever was in any feeble-flamed Grecian lamp, so I believe also that, in the dry, hard, cold-seeming facts of modern science there lurks more poetry than all the ages gone have known; though we may need the poet to interpret it to us. The highest poetry is that of love; and it is the realization of this poetry that the Ethics of Evolution teaches, promises, and enjoins. Certainly the superficial Utilitarianism which looks only at external forms of government and customs and the arithmetically calculated relations of men, not at their inner character and the organic complexity of moral questions, cannot satisfy in the long run. Nor can the bald Materialism satisfy which, standing by its analysis in physical terms like the physiologist in the dissecting-room with his chemicals about him and the dead nerves and muscles in his hand, exclaims with a triumph that is half a sneer: "This is all." It is not all. The synthesis of nature and of life cannot be represented by its parts merely; the bond of organization wanting, all is wanting. Nor is the action in the brain more real, more forceful, more spontaneous, or freer, than the love for a friend, the thought of him, or the will to do him a kindness. 


\section{CHAP'TER IX}

THE IDEAL AND THE WAY OF ITS ATTAINMENT

Mr. STEPHen questions the possibility of our determining at all what a state of ideal morality should be. I should contend, on the contrary, that there would be little disagreement in opinions as to what the ideal should be, but that rather our chief difficulties must lie in the determination of the course to be pursued in order to attain to the ideal. The profligate, it is true, will not be likely to acknowledge that self-control and faithfulness are parts of an ideal condition if he thinks that the acknowledgment binds him in any way to faithfulness and self-control in his own conduct; and the dishonest man will be chary of admitting that honesty is desirable if his consciousness suggests that he ought therefore to practise unvarying honesty himself. But the dishonest man is generally very thoroughly convinced of the desirability of honor and uprightness in every one else; and the profligate also is generally both among the londest in his denunciation of unfaithfulness in those he feels should be true to him, and sufficiently ready to acknowledge the social advantages of principles opposite to his own, if you can but convince him that it is only a matter of pure theory you are discussing, which will doubtless never be put in practice by society as a whole, and which in no way interferes with your thorough approval of his own action. So, too, the cruel, the rough, and the rude, will easily confess that unselfishness, unfailing kindness, tact, and consideration in the rest of society, are what the world needs. Did these virtues exist, there would be no need of the choice between evils now necessary. That which really troubles us is this choice, the difficulty of ascertaining just what course is the best, which brings us nearest to our ideal, assists most effectually in hastening development towards that goal. For there is no course, under existing conditions, which is wholly advantageous to society, 
none which does not involve some evil. It follows, from this, that it is insufficient to show that any particular course involves some advantage to some one in order to demonstrate that it is the right one, as also that it is insufficient to show that a course involves evil to some one in order to demonstrate that it is wrong. It is not proved that, because the restraint of any particular desire or passion is attended with pain to the individual, it is wrong. The argument has often been, and is still, advanced - seemingly with the idea that it is conclusive - that the indulgence of physical passion in youth tends to sobriety and steadiness in later years; and, with a similar idea apparently, a dramatic critic falls into a rhapsody over the manner in which the characters in a recent play come out "purified by the evil " they have wrought or endured. ${ }^{1}$ But even if this argument were scientifically sound, it would not prove the desirability of self-indulgence, since not the individual alone is to be considered. The argument is, however, erroneous. With advancing years comes in general, in any case, a diminution of passion, or at least a greater admixture of reason; but apart from this, indulgence tends to increase desire and tendency, except as excess may lead to morbid conditions, or the disregard of higher instincts to disappointment and cynicism. When we are told, in another play than the one mentioned above, and apparently with the idea that the statement is an excuse, that the hero could find no other outlet for the exuberance of his youth than the seduction of an innocent girl, we may see no reason to doubt the assertion, but we may question whether society has not a right, nevertheless, to suppress a little of such exuberance or turn it into other channels. The man born with fierce and ungovernable fury in his disposition may likewise feel a strong propensity to express the exuberance of his youth in a murder or two; but I see no reason why society should permit him to do so. The passion of anger is also a perfectly natural one, and the ungovernable fury which led to murder was not an exception with our ancestors of the savage plane, but the rule. Not all natural passion is to be indulged simply because it is natural; and even the fact that a tendency is good in moderation and under certain restrictions is no proof that it is good or to be indulged in immoderation, or without these restrictions. It can

${ }^{1}$ It should be said, in justice to the play in question, that the idea of purification by evil was evidently not present to its author. 
have been only by restriction of the natural savage fury that this fury grew less prominent in character. The cannibal transported into civilized society may still have a strong and perfectly natural hunger for my spareribs, but that is no sufficient reason why he should get them. Jack the Ripper is endowed, evidently, with a very passionate love for his human vivisection, and finds it an outlet for an exuberance which also bubbles out otherwise in many ways; yet I think society will be justified in putting a peremptory end to that exuberance, when it gets the opportunity.

Morality is indeed a matter of welfare, and so, of the gratification of desire and tendency; but neither the present alone, nor the single individual in preference to all the rest of society, is to be considered. Effort should be exerted continually for the reduction of pain to a minimum, in every respect possible, with regard to the individual and the minority as well as with regard to the majority, though the greater good and the greater number must always take precedence. The rule of the majority may be asserted to be moral in that it is the best possible expedient where there is disagreement of desires. The necessity for choice between evils is the origin of the principle of the Greatest Good to the Greatest Number, and this, as has been said, covers all the ground, if rightly applied. But it offers a temptation to stop with the mere comparison of two sums of individuals and degrees of happiness for the time being, without taking into the problem the wider results of a particular choice to society as a whole, through habit and personal influence. The consideration of these last important factors has led, on the other hand, to such rules as that of Kant, - "Act so that the maxims of thy will might be taken as the principle of universal action" ; and this rule, because it goes deeper, is less likely to lead to error. The moral requirement of continual effort to find the best method of reducing the evil still remaining, of recompensing the individual and the minority for the good of which they are necessarily deprived, needs especial emphasis; for the continual direction of attention to effort for progress, even where no outward change is, for the moment, possible, constitutes an inward progress in character which is ever ready to issue in external progress the instant opportunity presents itself. Present pain to individuals is the sign of imperfection in those permitting it and those suffering it, and must result in increase of tendency 
in this direction of imperfection unless it takes place only in spite of the most vigorous effort for its prevention. Even the reformer must choose that to which he would chiefly apply his endeavor, with some necessary withdrawal of effort from other directions. Yet the neglect of any present opportunity of reform or benefit, though it may sometimes be necessitated for the gain of some more important future good, is still an outer, and also, especially, an inner evil, which can be compensated only by a high degree of superiority in the future good to be obtained. As the man who, perhaps from the fear of failing in thoroughness, leaves all original work until middle age, is likely to find his power of originality much deteriorated by that time, so the man who is cruel to-day, in order to be kind in some wider respect later on, is likely to find, on the final arrival of opportunity, if the period through which the unkindness is exercised be a long one, that his capacity for kindness has diminished. Every neglect of present opportunity is a loss to character as well as an external loss. When the present good passed over for the sake of the future includes the welfare of whole lives, the question of choice and the postponement of good becomes still graver; when it includes generations, we need to consider earnestly before we take on ourselves the responsibility of a choice that shall prefer the future. I cannot agree with those who believe or practically live out the idea that the present generation is only or chiefly for the sake of the future generation, the parents only for the sake of their children, or the individual only for the sake of society as a whole. We need to remember that the race includes present and future, and parents and children, and has no existence outside the individuals that compose it. It is difficult to reconcile the many conflicting principles; and thus it appears that morality is not easy, even where earnest desire for it exists, and that different views with regard to it may be conscientiously held. The difficulty only increases the duty of continual endeavor to reconcile the many different conditions of happiness and welfare.

We come thus naturally to a question of the day, - the contest between the Individualist and the Socialist.

What has already been said makes it sufficiently evident that, if Individualism is to be maintained at all, it cannot be upheld on the ground that the doings of the individual are of no importance to society, and his sins may therefore not be interfered with by 
society. In "Social Statics," Mr. Spencer secures freedom for "personal vice" by turning his principle that a man has a right to seek his own ends as long as he does not prevent others from the pursuit of their ends, into the entirely different one, that a man has a right to seek a certain end if he does not prevent others from seeking the same end. ${ }^{1}$ The argument in this form is applied to drunkenness, but it could as well be used to prove the moral rightness of murder or any other crime, the sole condition being that the murderer did not prevent others from committing the crime also.

Nor is the Individualism less self-contradictory which bases its theory on the principle that it is the office of civil law to guard the rights of the individual. What individual? All individuals? If so, then assuredly it is the duty of the State to see that the laborer is paid a fair price for his work.

Nor can it be shown, as Höffding asserts, that intellectual labor benefits the whole of society, while manual labor is less valuable because it is for a few. The intellectual laborer knows well of what value to him and his ilk is the manual labor which feeds him, clothes him, and manufactures the thousand and one things necessary for his comfort, leaving him leisure to pursue his studies with all material wants provided for. The satisfaction of our material wants is the very first requisite of life, without which intellectual labor would be an impossibility.

There are, however, many degrees and shades of Individualism. As Höffding says, Individualism may be identical with Egoism, but it need not be so. And, moreover, as has been noticed, the adherents of theories of Egoistic Morals are not necessarily adherents of any theory of selfishness.

The theories bearing the name of Socialism are also very various, - quite as much so as those included under the head of Individualism. It is, therefore, both confusing to consider Socialism without some notice of the distinction between these various phases of theory, and is likely to lead to protest from one side or the other. But no single party of Socialists can be treated exclusively as "the" Socialists; a minority of the party cannot expect to be regarded as anything but a minority.

Of the tendency to represent the whole of the present order of society as utterly bad,--a tendency not confined to the Socialist

1 See Part I. p. 33, this book; "Social Statics," 87-89. 
party, but nevertheless strongly developed in many parts of it, considerable has already been said. As Höffding remarks, it is difficult to perceive how, in an utterly corrupt society, any foundation may be found on which to build the almost flawless society the Socialist proposes to institute. If the course of evolution has hitherto been propitious to the increase of evil, it is difficult to find any scientific grounds for a belief that evolution will now proceed to favor the good. If man, as a being possessing reason, has hitherto chosen, in increasing degree, injustice towards his fellow-man, it is scarcely possible for any one who proceeds upon the supposition of constancy in the action of man as a part of nature to hope that future events will exhibit exactly opposite characters. Assuredly, we are far enough from the goal yet, but in order to demonstrate this fact it is not necessary to prove that we are worse than any previous age has been. The tendency to lay stress, by every means, on present evil, in the endeavor to impress its reality and undesirability upon the mind of society, is comprehensible; and doubtless, too, as the troubles of the individual are likely to appear to himself among the hardest possible, so to those on whom the evils of the age press most severely these are likely to seem greater than the evils of any other times. But this method of regarding history is not the less erroneous. "In the age of chivalry men had at least a common ideal," said a Socialist to me, not long since. But what an ideal! And unity of purpose is not by any means necessarily a sign of a high plane. It may, on the contrary, signify stupidity, lack of the power of independent thought. The first result of thought on any particular subject is sure to be a division of opinion, although mutual criticism gradually evolves harmony from the strife, and brings about a degree of unity again, on a higher plane; for the mutual criticism is sure to have been of intellectual use. The Socialists themselves have demonstrated the fact that division of opinion necessarily arises when men begin to think upon any question, for with the development of their party many different phases of socialistic theory have appeared. The history of the division of the Church into sects, and of the mutual criticism of these sects, has been the history of religious progress.

With some Socialists, again, the already criticised idea of a " return to nature" plays a conspicuous part. But we have never departed from nature; we are as much a part of nature, as natural, 
as we ever were. Or, if we are to return, who shall tell us at just what point we leave the "artificial" and arrive at the "natural"? There are no stopping-places, no stations or pauses, in the scale of evolution. There is only continual change by inappreciable increments. The theory of evolution carries with it no significance which could authorize us to consider that we had arrived at our goal at one point rather than at another. And, again, if we are to give up the artificial customs of later development and return to earlier habits, then customs of altruistic action, as the most distinctive and characteristic of later forms of conduct, must be chiefly affected. If, however, by a return to nature is meant the adoption of a simpler mode of life in some classes in order that a less simple but more healthful one may become possible in other classes, the question of the desirability of such a change is, of course, open to discussion; but let us consider it under these terms then. To designate the proposed mode of life as a return to the natural, thus making present modes of life artificial, is to smuggle in an illegitimate assumption against the latter.

It is the habit of a portion of the Socialist party to represent the laborer as the epitome of all the virtues, the capitalist as his moral opposite. This view cannot be other than erroneous, considered from any standpoint. Moral evil cannot affect one part of a closely united society without affecting the other parts also, though it may assume different forms in different parts. This should be, in reality, the Socialist's strongest argument, and is, indeed, one which he constantly makes use of in other connections. If the steady labor of one class is often associated with certain virtues, there are many elements of its surroundings which tend to develop and encourage certain vices also; and if, on the other hand, excessive wealth is often the condition, as well as the result, of selfishness, still the relief from material anxieties may be used, on the other hand, as opportunity for other useful labor, and leaves room, indeed, for a development of finer intellectual and moral qualities. To reply that much greater good would accompany other conditions is irrelevant ; for we are not now comparing actualities with ideals, but one class of people with another under existing circumstances.

A somewhat similar phase of idea to that just considered is found in the agitation against machinery. This agitation is not of recent date, however; it began over two centuries ago, and 
would, if it had succeeded, have deprived the world of nearly all the comforts and conveniences which have, since then, become possible. Doubtless the abolishment of machinery would temporarily furnish labor to all the unemployed. Indeed, it has been computed, from facts supplied by the statistical bureau of Berlin, that it would require about double the number of inhabitants now on the face of the globe to perform the labor accomplished by the steam works of the principal civilized lands. But the increase of the earth's inhabitants depends, to a great extent, on the favorable or unfavorable circumstances of the environment; and we cannot suppose otherwise than that the sudden accession of abundant means of livelihood would cause a very great acceleration of the rate of increase and so a speedy return of the old problem. Even supposing that a certain recklessness of sexual indulgence would be done away with under better circumstances which afforded access to other means of pleasure than the purely physical, this over-indulgence leads quite as often to sterility and disease as to excess of offspring. Habit and opinion not being matters of instantaneous or even rapid change, the new order of society would very largely depend upon the character and ideas acquired under the old order, and population must increase with a rapidity fostered by an immense multiplication of regular marriages, and by more healthful surroundings for offspring at all ages. Unchecked, as hitherto, by the excessive mortality due to fainine, filth, and neglect, it must soon arrive at a point where the questions of competition again present themselves. But machinery is a relative term. Every tool and device for lightening labor is, in fact, a machine, and takes, by definition, from the labor of the world. When, therefore, we should find ourselves face to face with the former conditions, I do not see that any consistent course would lie before us but the doing away with our more complicated tools, and, later, with our less complicated ones, and so on, as the increase of the world's inhabitants brought again and again the recurrence of questions of competition, until we should arrive, at length, at that ancient state of things where all transport would be made by porters, land ploughed by the pointed stick, and clothes - if we consented to withdraw labor from the cultivation of the earth for the manufacture of such luxuries - would require for the preparation of each garment several weeks, months, or even years of work. I do not see where else the theory of the abolish- 
ment of machinery for the sake of supplying labor to the unemployed can logically and practically lead, especially as the withdrawal of machinery must mean, in the end, the withdrawal of those opportunities for cultivating the arts and sciences which the leisure from merely mechanical pursuits alone can give. Under more primitive conditions of labor, the ignorance of the masses must spread more and more, until its widening circle must take in the great majority of men, as was the case when these primitive conditions prevailed. In other words, the abolishment of machinery means social retrogression, and, if affording temporary relief, leaves the race, in the end, on a lower plane of evolution, with the work of advancement to its former plane all to do over again.

And this brings us to the consideration of another point, namely, the agitation against luxury, - an agitation carried on not, like that against machinery, by only a portion, if a considerable portion, of the Socialist party, but by that party as a whole. We may inquire, then, as to what luxury is. The Socialists find considerable trouble in defining it; they generally content themselves with the word alone, leaving it undefined or referring, with a general indefiniteness, to "velvets, jewels, and laces," or "diamonds and silks"; the German Socialists have sometimes shown particular antipathy to the glacé glove; and a society of English Socialists listened, not long ago, to a lecture in which, as an example of the reforms proposed by Socialism, it was prophesied that the evening-dresses of the future would be made of more lasting though not less delicate and beautiful material. This last would assuredly be desirable, if it could be carried out; but it remains to be seen in how far it is practicable. The things which are the most delicate, whether they be clothing or other articles, are ordinarily likewise the most perishable; the union of delicacy of texture with endurance is a problem that can be solved only by gradual improvement if at all; and it is probable that it can be solved only relatively in some cases and not at all in others; yet there are few people who will not find delicacy an attribute of beauty. Few will disagree with $M$. de Laveleye that beauty of costume must consist rather in harmony of colors and purity of line than in the mere costliness of the goods; however, in a large number of cases, excess of price corresponds to some actual superiority of color, durability, or texture, in the goods. Doubtless it is true that some things (M. de Laveleye 
instances opium) may cost much money and yet be useless or even harmful; but this very limited assertion cannot, by any logical method, be converted into an assertion that the price of an article is an argument against it. Even the extra price demanded and paid for novelties corresponds to an actual, general desire for variety, and if this is often carried too far, the fact still remains that the want is inherent in all human nature, indeed, in all life, and cannot be entirely disregarded. The proposal of M. de Laveleye to reinstitute a national dress is, for this reason, a foolish and inartistic one. No two people are suited to exactly the same costume; and the more society develops the more the individual shows a desire for individuality in dress. No nation with a sense of beauty will ever consent to eternal sameness.

Luxury is relative, as M. de Laveleye himself acknowledges. We might define it, as he does at one point, ${ }^{1}$ by excess of price or labor expended. In that case, such articles as those African dresses which it takes several years to manufacture would assuredly come under the head of luxuries, and must, as such, be condemned from the standpoint of the tribal plane of advancement; though they are not equal in texture or taste of ornamentation to many of the cheapest of English goods, within the reach of all but the very poorest. What are, with Europeans, the bare necessities, or comforts of lowest grade, represent the extreme of luxury to the Africans on whose plane our ancestors once stood. Many of the things which are regarded by the average individual of to-day as indispensable - every-day comforts - were within the reach of only the wealthy few, a century ago, and could be had only as rare and choice articles, to be preserved with the greatest care. The comforts of a century ago represent, again, the luxuries of a preceding age, and so on. Almost all products of labor are costly and rare before they can become cheap and abundant. Had our ancestors entertained a socialistic prejudice against the luxuries of their age, and resolved, with one accord, to forego their manufacture as supplying only artificial needs, we should not have had them to-day; but it is doubtful whether the social problem would be any nearer solution than it is. The agitation against machinery, at least, is ill combined with an agitation against luxury; for every removal of machinery must make luxuries out of what were, before, mere comforts, and advance the things

$$
1 \text { “Le Luxe," p. } 2 .
$$


now regarded as necessities to the plane of the present comforts, as far as expenditure of labor is regarded. M. de Laveleye distinguishes between rational and primitive needs and irrational, "superfluous," or "spurious," ones; and he defines the rational ones as those which reason asserts and hygiene determines. ${ }^{1}$ But from the merely hygienic point of view, every need bears with it, by its very existence, a title to some consideration, health and the gratification of desires being most intimately connected. Certainly luxury is not necessarily inconsistent with the most healthy physique, or the longest life. Many of the things ordinarily looked upon as luxuries present unusually favorable conditions for health. Nor can the question be decided by arbitrarily pronouncing all desires for luxury "spurious." To M. de Laveleye and a minority of others they may appear so; but what right has the individual to the assumption that all needs beyond his own are spurious? Even the poorer classes of society would, for the most part, be very glad to possess the luxuries of the rich, and find them desirable; in other words, those desires which M. de Laveleye pronounces spurious appertain to very nearly all human beings who have at all formed a conception of their possibility. The savage does not desire what we term luxury in as far as he knows nothing of it. The argument that luxury is wrong or irrational simply because men once were able to do without it is by no means conclusive. The conditions of life, the employments of human beings, are far different now from those of the time when men "lived in houses of osier." "Primitive" the desire for luxury may not be; but if we attempt to determine what is primitive in man, we shall meet with excessive difficulties. And again, if we decide the question on the basis of any assumption against the non-primitive, we must, in all consistency, exclude, as has already been said, all higher ethical emotion and the love of art and science; none of these can be pronounced primitive. Possibly we might define hunger, thirst, sexual appetite, and the desire for a comfortable degree of warmth, as the most primitive human needs; and these, indeed, are soon satisfied; but the man who has no needs beyond these can not represent the social ideal. The whole history of civilization from century to century is the history of the formation of new needs and the gradual satisfaction of these in larger and larger circles, until their objects, from costly

$$
1 \text { “Le Luxe," p. } 12 .
$$


and hardly obtainable rarities, have become articles of common use. With this course of development, coarseness has decreased, refinement and taste have become more general. Nor can we, as has before been stated, divide the human being into his separate desires and functions, and assume that he can get rid of this or that one without influencing all. The desires of the human being are of organic growth, and the desire for luxury has an organic connection with the taste and refinement with which it has grown. It is impossible that the love of beauty in general should develop without the appearance of a desire for beauty in the details of every-day life, - in utensils, clothing, surroundings of every sort; as it is impossible, also, that this desire for beauty in particulars should be dispensed with without a corresponding retrogression in refinement and love of beauty in general. One of the chief expenses of American entertainments is the profusion of flowers used in decoration, and often most artistically arranged; and whatever else may be said on the subject, the pleasure derived from them can scarcely be termed spurious or irrational. Not all large sums spent by the rich are given for mere display or for sensuality; they may be spent for scientific experiments on a large scale, like those of Edison, for travel, for books, for statuary and fine pictures, for fine architecture, for rich tapestries and carpets, and even in great measure for appliances and methods that secure greater cleanliness and more healthful ways of living altogether. Nor are the appliances of art and culture as desirable in huge museums or draughty and ill-ventilated libraries, or anywhere else where the individual is forced into the noise and numerous other annoyances of a promiscuous crowd, as in his own home, arranged according to his own peculiarities of taste, and associated with all the joys of love and domestic freedom. When sympathy has become so general and so strong that not only men but women also can find their best intellectual enjoyment in public places, these reasons will cease to be of any force, but at present they have even moral force; and since inherent character is a matter of evolution, a condition of general sympathy and mutual consideration, and even of universal common decency, must be of slow growth. It may further be said, in particular, that there is no material more used by artists than the so-muchdecried velvet; again, many people of taste, who otherwise spend money for little more than the necessities of life, find a peculiar 
delight in the delicacy of fine laces, and are willing to forego many other pleasures in order to possess them. George Eliot's Dorothea, otherwise simple of habit, content with her plain wool gown, found a peculiar fascination in the colors of an emerald bracelet, and numerous persons confess to a similar pleasure in the changing rainbow of the diamond, or the clear blue of the sapphire. These desires and pleasures exist; they exist in people of comparative taste; they exist as the result of human progress; they are not confined to a few individuals; and they cannot be dismissed with a mere arbitrary definition of them as "artificial," "superfluous," "irrational," or "spurious."

The more cultivated Socialist complains of the lack of taste in society; and an artist who is also a Socialist not long ago expressed his regret that art was at present " unable to prevent" the wearing of unbecoming forms of dress, etc. But we trust that this is not a hint that socialistic government would undertake to decree what forms of dress should be adopted; and we scarcely think that it could supply taste itself to all people, or render differences of taste impossible. Taste is, like everything else, a matter of evolution; it must make its experiments, and undergo many failures for every step in advance. The modern average of taste is as much in advance upon the average of our savage ancestors as the modern average of morals is an advance upon savage morals. The ideal of taste is, by definition, above the average; and it may be doubted whether the time will ever come when there will not be both degrees and differences of taste, and also an æsthetic superiority of taste among those who devote their lives to art that will render the average "poor" to them.

If, then, we are to condemn luxury on any tenable scientific grounds, we must face the fact that it is an organic feature of the progress of human society in intellectual and moral character, and a part of human happiness; and we must show, over against these undeniable facts, outweighing reasons for condemning it. The matter is more difficult than a superficial Utilitarianism perceives.

The question seems to be one of the relinquishment of certain things on the part of one class, in order that another may be elevated to a higher plane. Certainly, no one can deny that the present misery and degradation in society is a moral wrong, and 
that it is our duty to seek some method by which it may be removed as speedily as possible. But what is the degree of relinquishment which will suffice to raise all the poor to a plane of comfort? livithout defining the tastes for the refinements or elegancies of life as "spurious," or, except as they are personally injurious or associated with idleness, as in themselves bad, we must admit that there are many exaggerations of expenditure for the mere pleasure of the moment to a very small minority of individuais, which, in view of the joys the same sums might secure for multitudes, cannot be justified. But suppose that we do away with the spending of immense sums for the entertainment of princes and potentates, with the lavishing of wealth on a single dinner, on a single reception, on carriages built for the mere purpose of carrying a single millionaire bride to the church-door, and with the other expenses of this order; shall we be able, as a result, to supply all the destitute with comforts? Or to what length must we go, to what grade of luxury must we descend in our reforms, in order to secure this? It would certainly not be for the general good that society as a whole should relinquish all the refinements that it has won in its evolution and be reduced to a mere bread-and-butter level in the equalizing process. Beyond the superficial utilitarian comparison of the two classes we have to consider also the welfare of society as a whole. If we cannot morally defend the sacrifice of the general good to one class, neither can we defend its sacrifice to another class.

And here we come again to the population question. It is foolish to suppose that character, as already formed, at any period, in adults, as inherited correlative with physical organization, and as further influenced by the contact of children with parents, husbands with wives, friends with friends, and classes with classes, could be changed in the twinkling of an eye. It is foolish to suppose that men would become all at once, with the accession of comfort, wise, prudent, self-controlled, and unselfish. On the contrary, those unused to prosperity are generally the ones who use it least well when their lot is suddenly changed. Many would not perceive or realize what results their action would have on the condition of future generations, and many would not care as long as they themselves escaped those results. We cannot, therefore, conceive otherwise than that the rate of increase of population would suffer an immense acceleration, were pros- 
perity to be all at once secured to all classes. Supposing, then, that the equalization of wealth, or that even comfort to the poorer classes, were possible without a return to too primitive a standard of life for all society, would the reform be a permanent one?

The population question is one that the majority of Socialists systematically avoid. But however avoided theoretically, it cannot be avoided when we come to practice; and for this reason practical men are likely to steer clear of theories that take no account of it. There is a reason for this almost universal avoidance of the population question by Socialists; it is, in fact, a question which stands in the way of the very large majority of socialistic projects. But even the more advanced of Socialists take but little notice of its importance. At a recent meeting of the London Fabian Society, a large number present seemed to agree with a member who argued that population might be left to take its own course since "there is only a tendency" to too rapid increase. Naturally, there is only a tendency to increase beyond the food supply, since beyond this limit comes - death from privation and disease; and since even beyond the limit of comfort come morbid conditions which gradually bring death. If the theory of the Fabian in question is not laisser faire, then I do not know what is. But the population question never has solved itself and never will; it can only be solved by definite intention.

At the same discussion mentioned above, another debater objected to any decrease in the size of the families of laborers, on the ground that such decrease would tend to lower wages and so also to lower the standard of life. But the payment of higher wages, either on an average to correspond with an actual average. of larger families, or in particular cases in view of the size of family in these cases, can never constitute a raising of the standard of life; on the contrary, the wages would be paid on the old standard for the individual, and competition would be increased by the actual increase of population. The standard of life is, and can be, raised only as a higher standard for the individual is demanded and obtained.

But to these various arguments may be objected by the Socialists that under socialistic government the whole environment of human society would be changed, and so the old rules would be of no force. And this brings us to another point.

A word continually in the mouth of certain of the Socialists is 
"environment." Man is what he is, say they, by virtue of his environment. Change the environment, and he must change. The present bad condition of things is due to the environment; crime is the effect of poverty, selfishness of competition; therefore, we have but to introduce the socialistic form of government in order to do away with poverty and crime at the same time with competition. The argument is attractive and seems to solve the question as easily and indisputably as if it were a mere elementary problem in Geometry. But the solution does not at all harmonize with the course of analysis followed in this essay. From the idea of an individual introduced into social conditions where poverty is absent, it generalizes to the whole of society introduced to a new set of laws. It forgets, in its definition of environment, that men themselves are the most important factor of the environment, and that, in order to change the environment, one must change the moral character of men with respect to each other. The whole argument makes the mistake of choosing the one of two concomitants as alone cause and regarding the other as alone effect. It is perfectly true that, if you can abolish poverty, you will also have abolished crime and sin; and, without looking farther, the Socialist regards this as conclusive evidence that the system he proposes is logically demonstrated to be the right and sure cure for present evil; but it may be added that it is quite equally true that, if you can abolish crime and sin, you will have abolished poverty, also; and then it may be further said that neither can be abolished, as a whole, first, in order that the other may be gotten rid of through its disappearance. Competition is no more the cause of selfishness, than selfishness is the cause of competition; the present legal system, the present form of government is no more the cause of the evils in society than the other evils in society are the cause of the defects in the present form of government. Man's nature is no more the effect of the social environment than the social conditions are the effect of his nature. Extreme poverty and crime or vice work reciprocally for each other's increase, or they increase and decrease with what may be termed oscillations; poverty results in vice and vice in poverty, or vice in poverty, and poverty again in vice; in the individual, either may be primary, may precede the other. It is as true that you must change men's characters in order to change all the outer evils of the environment as it is that you 
must change the outer evils in order to change men's characters. It is as true that you must get rid of crime and vice in order to get rid of poverty as it is that you must get rid of poverty in order to get rid of crime and vice. Here is the new version of the serpent with its tail in its mouth; but here it is not a symbol of eternity, but of evolution. There is no one cause of the evils in society, but all existing things are interdependent conditions. There is, therefore, no possibility of getting rid of any one of them at one stroke, its abolishment to be followed by the disappearance of the others; as they increase, so they must decrease, - by reciprocal action, or complex action and reaction.

If we imagine, for a moment, a whole society of savages suddenly introduced to a set of ideal laws by - we will say - some one individual from out an ideal society, who proclaims these laws and then returns to his own land, we shall not be able to imagine such laws remaining in force for any great length of time. If we suppose our own ancestors of the stone age introduced to our own laws by some one from out the present century returning to them as Mark Twain's Yankee returned to the court of King Arthur, we shall not imagine those laws as very long binding; and nothing could be truer to facts of psychology than the gigantic tragedy with which Mr. Clemens' book closes. No set of ideal laws introduced to an inideal society can be regarded as the "environment" of that society, which shall render it ideal. 'The more democratic a country, the more the passing, even, of a law or measure depends on the general sentiment; but many laws have been passed and many measures of government projected which have failed completely in administration because they were too far in advance of the general moral status. External morality of institutions and internal morality of character in society as a union of many individuals can only increase together, and gradually, by reciprocal action. In other words, the evolution necessary to the attainment of any ideal condition where poverty and crime are eliminated must be internal as well as external; and this is a fact that few Socialists recognize, at least practically, and that even the Fabians, accepting as they do the theory of evolution, continually fail to take account of in the application of their theories. They have indeed received the theory of evolution as regards external institutions; but, with perhaps a few exceptions, they have not regarded it in its inner, psychical significance. This is made evi- 
dent by the continual recurrence of such references and remarks as we have criticised, which trace all evil to our "artificial system," refer to character as bad because "saturated with immoral principles by our commercial system," ${ }^{1}$ and reckon upon a change in this "artificial system" which, first accomplished, will cause a revolution in character. The acknowledgment of the necessity of evolution is, for the most part, forgotten in practical discussion; and the reason of this forgetfulness is easily understood from just the fact noticed - that the evolution, the necessity of which is recognized, is the mere external one of state institutions. Character is regarded in any case as a dependent, an effect; and this is in accordance with the old theory of the will as passive and as determined by the rest of nature, never as the active and independent factor determining and instituting. Thus, even a Fabian is likely to look with only half-approval at institutions like the Society for Ethical Culture, which has for its first object the cultivation of character; and many Socialists, until very lately the great majority, have regarded all improvements which did not bear directly towards Socialism as mere temporizing. The socialistic government was to be first established, and this would perform all the reforms necessary; or, rather, evils would disappear of themselves when once it was established. Fortunately, Socialism is itself undergoing an evolution.

But again, even those Socialists who talk of an evolution up to "socialistic forms" are continually found representing the ease with which government might, at present, take over the business of the nation. This is the natural result of the fact that the evolution recognized as necessary is only that of institutions, not that of character. The perception, on the other hand, that character is not, at present, capable of receiving or administering a socialistic form of government, is the reason of much of the resistance cpposed to a party which, whatever a very small minority may claim as to theory, is practically endeavoring to force a system of government upon peoples not prepared for carrying it out with success. There are few governments, as yet, where even the democratic idea has sufficiently taken root to render the people at all used to self-government; and where they exist, the good they confer is not unmixed. I am not advancing an argument against democracy; but the defects of human nature which render

1 "Fabian Essays in Socialism," pp. 27, 145, etc. 
its benefits of a mixed character must hinder in an incomparably greater measure a scheme which would place all power, even to the control of all wealth, in the hands of the administration; in other words, Socialism, if introduced to-day, could no more get rid of poverty and crime than democracy can get rid of them; and the gulf between the old and the new order being so great a one, the danger attending the new institutions would be particularly great. As Höffding remarks, it is not proved, because we intrust many things to state-government (with mixed good and evil) that it would be well to intrust the management of all matters to it. The Socialists propose to secure the perfection of system by making the government responsible to the people and the executive responsible to the government; but in democratic governments this principle is already carried out. Are we to suppose that the possession of still greater power and so still larger opportunities for fraud would afford the people greater security? Or how could the responsibility of the legislative and administrative functions to the people be still better secured than it is anywhere at present? The power of the people might be extended to include interference with both functions. But the socialistic government must, in any case, be excessively complicated; even Bellamy, whose government is much simplified by the supposition of the immediate attainment of an ideal character through the action of the social "environment," designates the scheme as "very elaborate." The difficulties of direct interference with the legislative functions in countries larger than Switzerland (where the referendum is occasionally resorted to), the difficulties of deciding on evidence before the court of the whole country in cases where the power of deposition might be used, the labor of arriving at a general verdict about which there should be no dispute, the strife and party feeling which must be thus continually engendered in the contest of opinions as long as men have not attained to an ideal character, would be likely, if such powers of national interference were often exercised, to keep the country in a state of continual uproar; while, on the other hand, if peace were purchased at the sacrifice of the power of direct interference, the machinery of state would no more than at present secure the nation from fraud, which must be greater as the power in the hands of a socialistic government would be larger. To the man of principle, it would doubtless appear foolish 
as well as wrong to sacrifice position, comparative comfort, and the esteem of fellow-citizens, for mere gain in wealth by dishonest means; but as long as there are many men by whom temporary gratification is often preferred even at the sacrifice of more lasting pleasure, and selfish pleasure is of more account than public esteem, as long as there are men to whom the element of excitement in crime is an attraction, as long as women are often unscrupulous and men the slaves of passion, as long as there are those who find the power to command by means of wealth more desirable than security in moderation, and as long as there remain others who will bow down to wealth fraudulently acquired, as long, too, as there are countries anywhere upon the earth in which malefactors may find refuge, the chances of fraud under a socialistic government are large. They must be particularly large where " inordinate luxury and the hope of it" are abolished; for, leaving out of account all question as to the morality of luxury, there are undoubtedly many men who desire as much of it as they can obtain. Bellamy discreetly supposes his ideal government to be adopted at once by all nations, thus paying no attention to the obviously very different degrees of social development represented by those different nations. But as long as any communication of trade whatever existed with nations still under the old régime, ingenuity could devise ways of theft, and foreign lands would constitute a goal for the enjoyment of the spoil. There are, and will be for very many years yet, plenty of places of refuge for the clever thief. Moreover, communication and commerce with other lands not only being necessary but becoming daily more and more desirable, a law excluding all foreigners would be difficult to establish; and this being the case, the social equilibrium must be continually disturbed, and inner character affected by the influx from other nations.

There is another general objection to socialistic schemes which bears on the point of their application to present conditions, namely, their arbitrary nature, the manner in which they would decide summarily many questions on which society is at present most at variance and different individuals entertain the most conflicting opinions, the comparative value of which can be tested only by experiment. This feature of Socialism is inseparable from the general condition of things. Many feel, therefore, and feel with reason, that sympathy is not yet sufficiently general and 
strong to warrant the entrusting of all interests of the individual to a majority of his fellow-men. It is even a question whether free scientific investigation would not be imperilled if some Socialists had their way. It is not long since that I heard an " evolutionary" Socialist expressing his opinion emphatically that the waste of time and energy in the pursuit of ambitions never to be realized was so undesirable that he questioned whether the individual ought to be permitted to choose a vocation in which it is believed he will fail. But the element of interest that causes a man to choose a given occupation is the very factor which most often results in efficient labor; and it is the testimony of many that the perseverance possible through love of their work has prevailed in direct opposition to the predictions of onlookers. Thousands of men have succeeded against all expectations. It is by no means those who apparently possess most ability who succeed best or profit the world most by their work. There are projects of arbitrariness very similar in sort and nearly as great in degree in all the Socialistic schemes in which the questions of the day are furnished with cut and dried answers. It is strange, for instance, that American advocates of women's right to a free choice of a vocation have failed to discover with what dexterity Bellamy avoids the whole question of women's capacity, by the discreetly blind remark that they are not only inferior to men in strength, but "further disqualified in special ways" (a formula which the author finds so successful that he repeats the words in a subsequent essay), while he appears practically to side with the Conservatives in thought on the matter. The government of Bellamy provides, furthermore, that one can change his vocation only up to the age of thirtyfive, and even to this date only "under proper restrictions"; the experience of mankind has shown, however, that a man's best inspirations may come to him after this age, and lead to a development of talents heretofore unsuspected even by himself. The "aids to choice" in a state may be as numerous as you like; but they can never give a man of thirty the experience and mental development of the man of thirty-five, thirty-seven, or forty. The assistance which the judgment of others can give in the choice of a vocation is, for the most part, of little use to the adult; and whatever the minor advantages of an elimination of the certain amount of disturbance consequent on changes of 
occupation, the harm to society of restriction on efforts in any direction of useful labor must more than counterbalance these.

The method of newspaper-editing in Bellamy's state is also peculiar. The people who desire any special interest to. be brought before the public choose an editor, establish a newspaper "reflecting their opinions and devoted especially to their locality, trade, or profession," and when the editor fails to give satisfaction in his publications, simply "remove him." This method would, I fear, scarcely meet the desires of any editor possessed with a brain, and to whom his profession was something more than a matter of mere automatism.

Indeed, the whole order of Bellamy's state is of too military and automatic a character; though it is easy, in a work of fiction, to represent the members of his industrial army as universally content and universally virtuous.

It is in consequence of the more or less distinct perception that, for all these reasons, human nature of the present time is unsuited to the absolute coöperation involved in Socialism, that many Individualists advocate a continuation of the system of competition. From ancient savagery up to our present half-civilization has been a gradual evolution, not of government with character as its effect, but of government and character as coördinates, or (if we view them in another light) as advancing by mutual action and reaction; and our future must constitute a like gradual evolution (though with continual acceleration of velocity) of character and government as coördinates; the attempt of individuals or parties to force one of these coördinates before the other must always result in failure. It is true, as Mr. Grant Allen stated in a lecture before the London Fabians - designed as refutation of the Individualistic theory that competition is necessary for the best social evolution - that natural selection favors coöperation, ${ }^{1}$ that is, that those societies in which the efforts of individuals are most supplemented by the aid of others, have the best chance of life and health both as wholes and in their individual units; but this fact does not do away with the necessity of the evolution of coöperation coördinate with character. "We know now," says another Fabian, "that in natural selection at the stage of development where the existence of civilized man is at stake, the units selected from are

${ }^{1}$ I have used the word here as elsewhere in its more general, not in its specific, technical sense. 
not individuals but societies." 1 This, however, we do not know. Natural selection acts on cell, on individual, and on all the various social units to which men combine, in their multiplicity of relations. It does not cease to act on individuals because it acts also on social organizations, any more than it ceases to act on cells in acting on organisms as wholes; it is only true that the line of the preservation of the individual and that of the preservation of the whole of society approach each other more and more nearly with social progress. The tendency of the whole of social evolution has been one of increasing coöperation coördinate with increasing social instinct or sympathy in all its complex relations and dependences; and with the attainment of the maximum of sympathy we can not well imagine or suppose anything else than the maximum of coöperation. On the other hand, the gradual nature of social evolution up to this maximum, and the contest of differing opinions, secures a sufficient experiment, and so the protection of the people from tyranny under another name; for it is not the emotional nature of man alone which must grow to greater harmony, it is also his intellectual nature; as opinions are brought nearer and nearer to each other by mutual criticism, men become more capable of coöperation; and this intellectual agreement represents the line of adjustment or natural selection, since it is the conclusion reached by means of experience - the common knowledge bought through the practical application of various principles. A tribe of savages would be incapable of administration of the government of our so-called civilized states, as also of obedience to it:- both because the individual would rebel in opinion and in emotion at the barriers imposed by it, and because the functions of administration in the hands of savages would tend to injustice that would be greater as the sphere of government exceeded that to which the tribe had been used; and for similar reasons, the present age is incapable of that maximum of coöperation in all relations which is involved in Socialism. Even the æsthetic use of wealth, moderation and taste in enjoyment, must be learned by degrees ; it cannot be infused by any government. The savage envies, in our more civilized states, chiefly the opportunities for the gorging of good things and for self-adornment which they afford; and the savage lack of self-control where alcohol is concerned, is proverbial; the

1 “ Fabian Essays," p. 57. 
average of more civilized societies shows a much greater selfcontrol and moderation in the face of opportunities of purely sensual gratification, and a much greater love of more æsthetic and more moral pleasures. Or rather, we should perhaps say, as before, the sensuality becomes more refined, and is gratified in more moral ways, through its organization with higher instincts. It is not among the wealthier classes, who have had the use of wealth, that taste is poorest; on the contrary, the average of taste is smaller, the outlay for foolish ornament of all sorts larger in proportion to means, in the poorer classes; and were these classes to come without change of character into possession of considerable means of enjoyment, it is to be suspected that expenditure for tasteless adornments would, in many cases, and especially among the women, precede and exceed expenditure for higher things.

And this brings me to a more especial consideration of that very large portion of the Socialist party who acknowledge no necessity for an evolution up to Socialism in any sense, but desire a revolution. Bellamy distinctly denies the necessity of an evolution, and many of his followers agree with him on this point ; but the revolution he believes in and hopes for is a bloodless and peaceful one. To this conception the preceding objections sufficiently apply.

A revolution in the ordinary sense of the word is always, however, the sign of powerful opposition between two parties, of which one may gain the immediate ascendancy by force; but will surely be exposed, afterwards, to the long-enduring hatred, opposition, and revenge of a strong minority, that will make itself felt with an energy greatly increased by the vindictiveness which naturally follows on war and defeat. France is still suffering from her revolutions even at this length of time after their occurrence. Where the people have no vote and real influence upon the government, and even the expression of opinion is restricted by law, so that to gain an influence is practically impossible, a political revolution may take place; but its results, both immediate and remote, must contain a very large modicum of evil even if some advance is accomplished by it. A revolution to obtain the establishment of absolute coöperation would be self-contradictory, and the self-contradiction of character implied in it would result in its failure ; it could not happen in a country at all prepared for absolute coöperation, or even for a very high degree of coöperation. A revolution in any country at the present time would have to reckon with all sorts of 
depraved tastes and vicious characters, matters of organization and inheritance which neither in the individual, nor in the line of descent, could be gotten rid of in a day; which must, indeed, affect society for many generations, and before they could be eradicated would do away with Socialism or destroy its success. Poverty and crime cannot be banished by any device of mere legislation; only with time and by gradual means can they be gotten rid of.

Socialism is, then, as a whole, too impetuous, if Individualism is, as a whole, too reluctant. But Socialism is undergoing an evolution, as has been said. Arising as the voice of the poor, the oppressed, the miserable, the hungry, it has made itself heard and has materially modified public opinion, while it has, at the same time, been itself modified, according to the universal law of the equilibration of forces. Forced by necessity practically, and gradually altered by criticism as to theory, it is coming to give its energies less and less to a consideration of the final socialistic government which should do away with the necessity of further reforms because accomplishing an immediate and universal one, and devoting them more and more to present measures of reform, many of which are simply liberal measures proposed by non-Socialists and such as would have had no meaning to the majority of Socialists of a few years past, or would have been regarded by them as useless temporizing. In its mutual action and reaction with Individualism, it will doubtless still more modify and be modified, so that more and more ground for united action will be won. The cause of the laborer is the most urgent of our times; but increase of wages will be of very little use except as it is steadily accompanied by aids to knowledge and self-direction, aids in the formation of character, in the use of self and of the means of enjoyment; otherwise, the laborer must continually defeat his own cause, and renew the old problems.

The education of self-control must begin with the child. The education of the child is never to be considered by itself; the child is not one individual and the adult another, neither is there any dividing line between childhood and maturity; and that which the individual is to become in later life he must grow towards as a child. The habits which the man would exercise the child must learn. In Germany, where the military spirit prevails, implicit obedience to authority is ranked among the 
highest virtues, and habits of strict military discipline are carried into the family as well as exercised in all public relations. In countries where more democratic ideas are strong, the older methods are giving way to milder ones. These sometimes degenerate into the opposite extreme of careless indulgence, with bad results; but taken on the average, their beneficial influence is seen in the greater alertness, originality, and openness of the children brought up under them. Frankness and originality are on the average incompatible with harsh or stern treatment; the latter is more likely to generate craftiness, fawning hypocrisy, or an unloving and unlovable rigidity of character; and any of these qualities is compatible with secret self-indulgence in any form, wherever this is possible. Only an education in freedom can teach the use of freedom. The old, hard, religious idea of "breaking the will" (the natural outcome of a religion based on blind faith, "fear," and unquestioning obedience) was a sad blunder; what we need is not less but more will, with better direction of it. True, the wisdom of experience must always guide the young; but its guidance, to attain the best results, should make itself as little felt as authority as possible, and should withdraw into the background as early as possible. Not that it should degenerate into slipshod yielding to importunities, but that it should endeavor to give reasons rather than mere rules of conduct, to instil principles and ideas rather than laws, and so to develop the power of self-direction. It is often objected that the young child is incapable of comprehending principles; but so is the infant incapable of comprehending speech, and yet it is through the use of speech to the infant that comprehension is gradually attained; as sounds are fixed in the receptive memory of the infant, and slowly acquire meaning, so ethical principles, simply stated, may be communicated, and will be better and better understood as the child develops. This method of instruction is, rightly understood, as far from weakness as it is from tyranny and dogmatism; indeed, no method demands in the instructor so much care, thought, and patience. It must be judicious and consistent, never capricious, and its fundamental principle must be the cultivation of justice through justice, and so of kindness through kindness. Especially should the young be prepared in the home, by self-knowledge, for the trials and temptations which menace in the world outside, through the passions of maturity. To the 
earnest man or woman, nothing appears more trivial than the false shame which hinders, even in the home and between parents and children, the moral discussion of some of the most important of human relations for good or evil. To the pure all things are pure; but, unfortunately, it is also true that to the impure all things are impure. Nothing is more injurious to children than the morbid curiosity stimulated through the secrecy and deception which are ordinarily practised, and which inspires them with the sense of a mystery that is half criminal, half sacred. Curiosity grows under such tuition, a disproportionate interest is awakened and often comes to be satisfied from sources outside the home, with an admixture of deplorable vulgarity, the influence of which is not soon lost. Such a tuition tends, not to purity of thought, but to impurity, and often directly to vice. The mystery with which natural, and what may be perfectly moral, relations is thus invested, is often the source of a fatal attraction to ignorant youth. What we need to make out of our children is not puppets of which the world as well as ourselves may pull the wires, but earnest and self-comprehending men and women, self-reliant and fearless because life is no strange country filled with unknown shadows and pitfalls, but a pleasant land, whose dangers, known, may be avoided, and the road through which leads to a comprehended and desirable goal.

Parental power was once held sacred and beyond interference; nevertheless the use made of it does not seem to have been always a sacred one. The Roman law allowed parents to put their children to death. The modern state has tended, on the other hand, to take away more and more power from the parents, extending its protection to the helpless child. And this is well; the child, as well as the adult, should have the right of protection against abuse. Nevertheless, the theories which would relegate the whole education and care of the child to the state must be regarded as too extreme. Whatever disadvantages there may be in the government of parents, especially at the present day when the education of women is still so inadequate, there is yet nothing which the child cannot better miss out of his education than the influence of parental love, the lack of which no state institution can ever supply. Granted that parental government is of a most mistaken sort in some cases, and that it is not perfect in any case, it still remains true that family affection furnishes one of man- 
kind's greatest joys, and that the love of the parent should, and even does, on the average, make the best protection and educator weak and clinging childhood can have. No one who has at all studied the condition of children in orphan asylums and other institutions under the care of the state, can have failed to notice, even in those institutions managed with the greatest kindness, the immense difference in happiness and attractiveness between their inmates and the children used to family love and mother's caresses. The lack of love makes the child unlovable. The fundamental method of reform lies, not in the withdrawal of all power from parents, but rather in the better preparation of men, and especially of women, to fulfil the duties of parentage. Such a preparation must consist, however, less in any particular study than in such general physical, intellectual, and moral discipline and education as shall expand all the powers in health and harmony, thus securing to children a good physical inheritance and an early guidance both wise and moral. A higher morality must particularly emphasize the fact that not self alone or even merely the two parties to a marriage are to be considered; that the welfare of possible offspring must be regarded; and that, therefore, marriage with the morally unfit is a crime against future generations as well as against self, and marriage of the physically unfit, where offspring are permitted, is equally a wrong. The old idea, encouraged in women, that it was a good and noble use of life to "marry a man in order to reform him," is beginning to go out of vogue; and future standards will not tolerate the present social dogma that, however much of a profligate a man may have been, whatever associates he may have affected, however he may have betrayed the innocent and debauched his own moral sense, he is still fit to mate with any pure and good woman.

The necessity of a better physical and intellectual education for the mothers of the race, as a preparation for the adequate performance of their duties, must be, at the present time, especially emphasized. The task of the mother in the early training of children is one that requires practical knowledge of the world, broad views, and that power of judgment which is possible only through mental discipline. Superstition, narrowness, subjection to tradition and dogma, are incompatible with efficient motherhood. The education must, then, be real, no cramming with stale facts and staler theories; it must advance with the science of the day, and deal with its vital questions. 
But the standpoint which regards women only as means to ends outside themselves, which calculates all the advantages to be permitted them by the measure alone of their usefulness to husbands or children, is a poor one. To afford to all individuals the full and free development of capacity must be the ideal of society. The ancient conceptions which laid little emphasis practically, whatever they might do theoretically, upon the woman's right to opportunities for her own sake, which made meekness and self-abnegation her chief virtues, and fixed its regard always upon future generations in her case, is one that cannot be defended from a higher ethical standpoint. If no man lives unto himself alone, neither should any man, or woman either, be expected to spend his life merely as a means to others and having no end in himself. Every human being has a right to a share in the general privileges and pleasures. For their own sake, and that of society as a whole, as well as for that of their immediate friends and family, women should share equally with men the benefits of mental culture, its æsthetic enjoyments, its consolations and distractions, and the calm and self-poise bestowed by its broad outlook. 'To women as well as to men applies what has already been said of the folly and sin of ignorance of the world. We have only to look at France in order to perceive the evils of a system which brings girls to maturity in a condition of seclusion, ignorance, and dependence, and then suddenly launches them upon society wholly unprepared to withstand the temptations it presents. The evil results of a less degree of the same system are visible all over the world. On the other hand, it is in just that country - America - where women have had the most freedom, that they are also most capable of enduring freedom, and that their civilizing influence is most visible. They are not the less womanly for this liberty, and society is very much the better for it. Indeed, their attractiveness and the power they wield through it is not equalled in any other country. "I wonder," writes George Eliot, "whether the subtle measuring of forces will ever come to measure the force there would be in one beautiful woman whose mind was as noble as her face was beautiful - who made a man's passion for her rush in one current with all the great aims of his life." "It is terrible - the keen, bright eye of a woman when it has once been turned with admiration on what is severely true; but then the severely true rarely comes within its range of vision." 
The questions of marriage and prostitution may be reduced to the single question of the desirability of monogamy. No one can well deny the evils attending the existence of a class of prostitutes isolated from moral associations, despised and ill-treated, daily sinking lower and lower through this isolation, and contaminating, by their influence, those who come in contact with them. The practical question is, then, would it be well for society as a whole to assume another attitude, of open approval, towards prostitution, to admit those who are now outcasts to a position on a par with faithful wives and pure maidens. This was the position of Athenian prostitutes, and it existed together with, we may suppose, comparative chastity on the part of maidens and faithfulness on the part of wives. These, however, did not take part in the social life of the men, but lived in seclusion in their homes; it would be impossible to accord a similar position to prostitutes in modern society unless with the practical surrender of any demand or expectancy of faithfulness on the part of wives, or of chastity on the part of maidens. Even in France, where the position of prostitutes most nearly approximates the Athenian, a very distinct dividing-line is drawn between the demi-monde and the rest of society; and, indeed, special precautions are taken to secure the chastity of girls. In like manner, purity might perhaps still be secured in girls, after the admission of prostitutes to a position of equality with other women, by a convent education and the greatest watchfulness; but the lack of self-dependence would be likely to be followed, as it now so often is in France, only in far greater degree, by excesses after the attainment of comparative self-direction with marriage. The profligate soon tires of the prostitute, and desires higher game; unbridled license begets morbid passion; the sense of honor is blunted; the pure cease to be safe except as far as they are able, by self-control and self-defence, to protect themselves; and for such self-poise only an education of freedom, of knowledge of the world and of self, can prepare. Nor could even such a system of seclusion as we have imagined exist for any length of time side by side with the full acceptance of prostitution as perfectly honorable and right; the two things are self-contradictory and incompatible; in France, faithfulness is not less desired of wives than in other countries. Indeed, the majority of men in civilized countries would never consent to a system of general promiscuity; they desire women. 
that is, a large number of women, a sufficient number to supply them with wives, to remain pure, whatever liberty they demand for themselves. The whole progress of society has been in the direction of monogamy, and the reason of this is obvious: as reason and taste develop, man ceases to be satisfied with the mere enjoyments of the animal; he develops higher powers and instincts which also demand their satisfaction; these powers, too, are not separate entities, but are organized with the more primitive capacities and the whole organization becomes another through their appearance. As the social instinct grows, and intellect comes to take a higher place, the mere or chiefly physical passion felt between the sexes of lower species becomes the higher human love, an organized instinct in which all the moral and intellectual desires, the highest aims and emotions of the individual are fused to a whole. Moreover, momentary pleasure becomes, with social progress, indeed with all evolution, less and less the ruling power; man, above all creatures, comes to demand enduring sources of satisfaction. Faithfulness in love is as necessary to perfect satisfaction as is faithfulness in friendship; and the long as well as the close companionship of congenial natures is now, and must more and more become, the spring of our highest human joys. Disappointment in marriage may incline the individual to doubt, by a universalization from his own case, - to which disappointment is prone,- whether life-long love and faithfulness are possible; but he still must feel that this is the ideal. It has been said that men are naturally polygamous, women monogamous; but this statement is obviously erroneous, since men by no means favor general polygamy; even the savage is capable of jealousy, and men have continually used the superior power they have possessed in law and public opinion to emphasize the exclusive claim they have upon the women they take to wife. It is only true that, having also had the power in their hands of refusing a like faithfulness to that which they demand from women, they have used this power to their own advantage. Women desire faithful love on the part of men quite as much as men desire it on the part of women; and women are quite as capable of physical excesses and of fickleness as are men, when the restraints of public opinion and social law are once broken over.

A condition of promiscuity is impossible in an ideal society, and can never be the goal towards which we tend. Men would 
not submit to it in the women they loved; and if it is not possible for wives, then we have left us only the alternative of prostitution in its present form, increasingly worse in character as the ideal of faithfulness is more universally demanded and more completely carried out in wives, and the necessary coördinate social ostracism and disgrace of the prostitute increases. But this also cannot assuredly be our ideal; the increasing misery of the class of prostitutes is not a thing to be sought. The whole theory which tolerates prostitution is, in fact, illogical and only devised as a prop for the selfishness of men, who are content to take their pleasure at the expense of so much misery. The same thing cannot be, as some one has said, at once right for the man to demand and infamous for the woman to permit. Where the act is one to which both sexes are necessary, it must, if it be right at all, be right for both, and if it is wrong, then wrong for both. And this would remain true even if it were proved that, because of greater strength or for any other reason, the sexual passion of men ought not to be restrained; for, the responsibility of the prostitute's misery is thus laid at the door of men; if the women who ply this traffic are prompted by no passion, but only compelled by destitution, then the blame of their unhappy compulsion to such a traffic rests more than ever on the heads of those who furnish the demand to which their supply answers. In any case, the man is an accessory before the fact to a thing which he acknowledges wrong on the part of its performer.

But the plea that passion is stronger in the man for an act which dates back to the point in evolution where sexual propagation first began, and which has been performed equally by both sexes through all the range of species up to man, and even equally by both sexes of the human species except during the comparatively short period of higher civilization, is absurd. The difference between the sexes in degree of sexual gratification is, among those who transmit their instincts to offspring, not great even under civilization. There is probably more excess in marriage than outside it. But apart from this fact, the fact of cross-heredity is to be taken into consideration. The sexual is no more than any other instinct a separate part of the individual character; it is organically interwoven with all other instincts and tendencies; and it is scarcely supposable that thus fused with the rest of character, it would not be subject, as all other traits, to cross-inheritance 
from father to daughter as well as from mother to son, - that the father's life would not, in many cases, affect his daughter's propensities, and the mother's life her son's. This a priori reasoning is supported by facts of observation, among which those of pathology and criminology are naturally the most marked. Man is an animal; but, as we have said before, he is not a beast, nor does he need to imitate the beasts. - He has his own social organization and must determine his own moral laws. The old theory, that any restraint at all of sexual passion is a crime against nature, and likely to result in great physical evil, is now exploded. Even if it were true that some evil to the individual was always the result of any restraint, the good of the individual is not the absolute criterion of right, and cannot stand against the claim of society as a whole; the unrestrained indulgence of sexual passion could no more be justified on this ground, and because of the fact that it is a natural instinct, than the absolute indulgence of anger can be justified because anger is a natural passion, and its expression doubtless a great satisfaction and relief to the individual. But very many medical men, and among them such men as Professor Krafft-Ebbing, the German authority on nervous diseases, are now denying that self-restraint has such evil results as have been attributed to it. Krafft-Ebbing says, on the contrary, that while physical excess is very often the precursor of harm, self-restraint is seldom so, except in cases of abnormal and morbid appetite. ${ }^{1}$

In other countries than the United States and England, the plea of "poetry" or "romance" is often heard in defence of prostitution, and as an excuse for the seduction of pure women. But if this is poetry, which must so end in the bitter misery, the shame, degradation, despair, and even often the utter destruction of its heroines, then, in the name of pity, let us have less of poetry and more of common humanity. To a man of anything but selfish instincts, "poetry" or "romance" could never be an excuse for connivance at such misery, either by direct act or in any way by influence. Nor is the poetry or romance of the highest order, in any case. There is no romance so powerful, no poetry so thrilling, nor any passion so strong, as that to which all the springs of intellectual aspiration and moral aim converge,

${ }^{1}$ See "Jahrbǔcher für Psychiatrie," I889, "Ueber Ncurosen und Psychosen durch sexuelle Abstinenz." 
and which draws its sweetness and force from a purity tainted by no degradation of ideals, galled by no bitter and humiliating recollections, checked by no self-consciousness of concealment and deceit. Compared with such a feeling, the romance of the "man of the world" is tame and flat, his poetry but the doggerel jingle of the third-rate variety-show. Physical passion the human being shares with every dog and other brute down to nearly the lowest forms of animal life; love is as truly of higher species as the æsthetic sense of the artist is of higher nature than the delight of the savage in gauds. The old idea that strong emotion of any kind was incompatible with perfect morality has already been sufficiently discussed. But this delusion has been the excuse of many a life of profound selfishness. It has led to the theory that the artistic nature must necessarily be unrestrained in the gratification of its impulses, and has furnished the libertine with a fine sense of kinship with the poet through the imitation of his sins. Perhaps the poetry of the lives of Robert and Elizabeth Barrett Browning has been to the world as great a gratification and of as high worth as any that they ever wrote on paper. It has dispelled once and forever the false theory of the necessities of the artistic temperament, and has enabled us to perceive the higher beauty of enduring love.

It is often urged in defence of the sexual sins of the poet or the musician, that they are natural to his temperament and that, moreover, he must be acquainted with all phases of life. But why is it not also urged, then, that he ought to be at liberty to give way to ungoverned fury, if he has inherited a tendency in that direction, or that he is justified in committing murder, arson, and all the other crimes in the catalogue for the sake of the experience and the greater power of portrayal thus gained? If the excuse suffices for one crime against the welfare of human beings, it should suffice also for others. Dickens might possibly have been able to draw the character of Bill Sykes, to depict his crime and the succeeding emotions with greater power and faithfulness, had he himself experienced all that which he wished to portray; nevertheless, society cannot concede that he would have been justified in killing for the sake of his art; and neither can it concede, from a higher ethical standpoint, that any other act in direct opposition to the general welfare is justifiable for the sake of art. It may be possible for the artist, by torturing a slave 
to death, to paint a more realistic picture of dying agony; but however glorious the art, the man of finer sense and stronger sympathies must be revolted by it. Society can even better miss a little of its art than take it at the price of human misery.

But it is to be questioned whether the artist does not lose as much as he gains, or even more, by an immoral license of any sort. True, the artist must know human nature; but the best portrayers of criminal characters have not themselves been criminals; and if ever we should have a murderer-poet, we should in all probability feel the lack, in his verse, of various things, among these of the higher realism which comprehends higher as well as lower types. It is impossible to be merely the spectator of one's own life even if one is an artist; and especially is this true where passion is concerned. The emotions one feels, the acts one performs, must mould one's character, one's thought, opinion, the mental world in which one lives, and so one's creative genius. Nature is by no means all dunghill or reptile-haunted swamp, or even common kitchen; she has also her seas and mountains, and skies, her fields and woods, and even her sunny gardens and dainty parlors. The snow-mountain glowing under the flush of dawn is as real as the reeking dunghill; but the power to appreciate and portray the one may be lost by too close association with the other, as the fine sense of smell is dulled by sojourning in foul odors. To the rake, the character of the self-controlled and virtuous becomes incomprehensible and chimerical; and his attempts to represent it are likely to be tinged with an atmosphere of unreality. Of this we have much evidence in literature. To raise oneself to the higher standard in practice and comprehension requires an effort; but it is comparatively easy to allow oneself to sink to a level for which generations of one's ancestors has prepared innate if latent tendencies. On the other hand, though we desire to know men and things through art, we desire to keep with us through its aid, above all, that which most pleases us in the actual world - the beautiful in form, coloring, and idea, in nature outside man and in man himself; the good, if it is the truly good, and not cant or hypocrisy, is also the beautiful, and the loss of the power to portray it is a large one. And beyond the more easily definable loss which we have noticed, there is a still further one, felt in a subtle tone, a shade, an atmosphere; and which, if closely knit with our moral perceptions, is still an 
æsthetic as well as a moral one. The evolution of morality, could, indeed, no more take place without leaving its impress on art than without leaving it on humor. The higher sense of humor, in very proportion to its keenness, experiences a revulsion at the grotesque and gross vulgarity which passes for humor among the savage and half-civilized; and with time, the immoral comes to revolt too much to permit of æsthetic enjoyment. Had Dickens been a murderer himself, instead of the tender-hearted man he was, the world would doubtless have lost in every way æsthetically as well as morally by the fact. The old theory of the total emancipation of art from all claims of morality cannot be maintained from even the æsthetic standpoint, and certainly not from the ethical standpoint. Art has every right to be non-moral (if that which delights innocently is ever anything but positively moral), but it has none to be immoral, - to use the mighty power it possesses in the cause of evil of any sort.

Nor is it even true that all nature belongs to art. In all its history, sculpture has never, except in a few isolated cases, reproduced the forms of the withered and decrepit. The painter of the extreme realistic school may occasionally portray the scenes of the dissecting-room, but pictures of sores and ulcers are left to adorn the pages of medical works or patent-medicine advertisements. There are moral sores and ulcers as little suited to artistic literature, and belonging properly to works on social healing alone. The depiction of evil in due proportion and with such limitations belongs to the accurate representation of human character. But let its portrayal include no sin against man; let not the artist dip his hands in the dunghill, for humanity's sake and also for his art's sake; lest his picture reek of it, and we find the offal mixed with the colors.

The cant and superstition with which marriage has often been invested has doubtless been the source of the rebellion of many vigorous and original minds from the old morality; the morality founded on tradition and not on reason and sympathy has always this disadvantage. Undoubtedly, the sale of human flesh for gold or any other sordid consideration, is evil, whether done under the sanction of the marriage-law or without it. Undoubtedly also, the marriage-rite performs no miracle or magic spell, as the superstition of the past has imagined. Nevertheless, it is of importance as a civil contract, a public acknowledgment, which 
furnishes data to the state, and places it in a position to protect any injured party, and to fix the responsibility for the maintenance and education of offspring. Considering the number of individuals whose welfare is seriously concerned in these most intimate relations of life, with all their passions, the state cannot relinquish this right of arbitration, which should especially be employed for the protection of the weaker individuals concerned - the wife and children. Unfortunately, it has, as yet, too often been used rather in securing the power of tyranny and abuse than in protecting. This fact is perceptible even in modern law, as, for instance, in the unequal divorce-laws of England, and in the fact that wife-beaters are often treated with great leniency by English magistrates, while the man who abuses his mistress is liable to relatively severe punishment as having no especial power over the latter. It is, undoubtedly, the result of such laws, together with other evils incidental to the average of marriages under the present conditions of human character, that on some sides a theory has grown up in favor of the total abolition of marriage. But neither in its general application, nor in this particular instance, is the Anarchistic conception which finds the source of all evil in law, scientifically justifiable. The conditions of the evil lie in human nature itself, in the incompleteness of its evolution; of the present stage the injustice of present law is a part. The remedy lies, therefore, as far as the law is concerned, in its correction, not in its abolishment.

The ideal of love is enduring faithfulness. But when that ideal is not only unfulfilled, but marriage brings, instead of happiness, only misery, shall the bond be indissoluble, difficult, or easy to loose?

In countries where women are wholly dependent upon men, perfect facility of divorce means substantially the power of repudiation on the part of men. As long as women are incapable of efficient self-support, the advantage of very easy divorce lies largely on the side of the husband. Marriage concerns, in any case, the welfare, not of one person alone but that of husband, wife, and children, and society as a whole must place some restrictions on the selfish action of the individual which may be to the lasting disadvantage of all others concerned. But as society advances, as the education and social independence of women increase, too great stringency becomes undesirable, its advan- 
tages continually diminish in comparison with its disadvantages. Forced family relations where all the affection that might render them for the good of those thus related is lacking, are obviously in themselves undesirable, and in most cases where wife and children can be provided for independently of such relations, an evil to be avoided. Assuredly, it is undesirable that the moral should be tied indissolubly, or practically so, to the immoral, that a mother, for instance, should not only be forced to bring forth children to a father whose evil qualities they may inherit, but be compelled to endure the further ruin of their character through his influence, besides bearing the personal agony of the enforced companionship with a man whose principles she can but despise. But all character is at present faulty; and a desire for perfection in husband or wife therefore certain to disappointment; hence, the relinquishment of all divorce-restrictions whatsoever is too likely to lead to promiscuity; and unless such appears desirable to society, neither public opinion nor state-law can place the power of repudiation in the hands of individuals. It is a choice of evils; the state must take human nature as it finds it, and deal with it on this basis. It has sometimes been proposed to make some substitution for the old form of marriage, as, for instance, by the adoption of a period of probation, of two, three, or five years' marriage before the signing of the final life-contract; by this method, it was proposed to obviate the necessity for divorce. As far as this last proposal is concerned, it may be remarked that applications for divorce are by no means always made in the earlier period of married life, and that, furthermore, any such arrangement would offer the very best opportunities for the unscrupulous libertine.

But beyond this, it may be repeated that, as Höffding has said, it is not in the nature of love worthy the name to calculate the possibility of its own ending, and that the highest form of love is enduring. Enduring relation must, then, form the ideal on which we must fix our eyes, even while failing to attain it; divorce, while given in cases where union seems no longer desirable, must be looked upon as indicating a failure of marriage to fulfil its end. The influence of an ideal held in mind is the continual moulding of reality to a form more nearly resembling it. But to descend to a form of contract which starts with the assumption of separation as possible or probable is to lose sight of the ideal, 
to relinquish it from imagination, and to do away with its influence upon public opinion, and so upon the evolution of institutions and habits. We certainly need better divorce-laws and the wider recognition of the desirability of divorce in many cases, but not the practical acceptance of an ideal of promiscuity.

The plan of such short contracts could never be carried out practically for any length of time, in any modern civilized society. Even if adopted for a time, it would speedily be abolished. Man naturally desires and takes means of enforcing, at first with the lower means of compulsion, then with the higher through the sympathies themselves, faithfulness in woman; woman also, and equally, desires faithfulness in man, but is not able to secure it. 'The gradual growth of woman's social independence must, however, place her more and more in a position to know of the life of men and to enforce the faithfulness she desires; that is, to punish unfaithfulness with the same penalties of disability for marriage by which men have hitherto enforced faithfulness in women. We may easily perceive that this is the direction of development. In countries where women are wholly dependent upon men, the character of a suitor in any respect is a thing little inquired into, the chief object of the parents, who ordinarily have the most to say about the matter, being to secure a husband for the girl at any cost. With the progress of society, women become less and less ready to accept the known drunkard or the confessed libertine, and it is only the seclusion of women and their consequent ignorance of the lives of men that makes marriage, at present, still comparatively easy to the discreet and clever profligate. The coördinate increase of regard for purity in wives with the aggravation of the character of prostitution, supposed above for the sake of the discussion, is possible only up to a certain point, as an oscillation in one direction resistance to which is continually accumulating, and must result in reaction in the opposite direction. The two principles are mutually contradictory, incompatible, and impossible as enduring factors in the same society. The growth of a more widely diffused and stronger sentiment against prostitution and in favor of faithfulness has, indeed, as yet led chiefly to the greater exclusion of prostitutes from association with the rest of society, and made profligacy more and more secret; but, at the same time, the gradually increasing sympathy has formed an accumulating resistance which 
is rapidly taking shape in the realization that the prostitute is not more guilty in furnishing the supply than is the man whose demand makes self-profanation a source of income, that the misery of prostitution is immoral, and that the only remedy is prevention. There is no alternative to this remedy that progress can realize except, as has been shown, general promiscuity. It is best, then, that we should make up our minds between these two and act accordingly ; for the action of every individual tells, for good or ill, upon society as a whole. What is the ideal? I think the answer is plain; no man who has any conception of the higher joys of love which is also friendship, intellectual conpanionship, can hesitate; and if this is so, then duty is plain also. No man has a right to deplore the evil by word who encourages it in any way by his act.

It is sometimes averred by those who oppose the economic independence and educational equality of women with men, that women can mingle with the world on a plane of equality with men only at the sacrifice of all the chivalry and admiration which men now give to women. But this objection opposes every step of women's progress, from the harem upwards, and every step has proved its falseness. True, in the lands where women are freest, they are less favored with insincere and fulsome compliments, with vows and protestations which, when put to the test, mean nothing, or worse than nothing. The case is, however, far otherwise with the attentions which mark sincere regard, and the consideration paid by physical strength to comparative weakness. It would, indeed, be peculiar if higher intellectual powers, a clearer insight into the "severely true," the cultivation of that nobility of character which results from self-knowledge through knowledge of others and the habit of self-reliance, should render women less attractive. The pioneers in any cause need to be the hardier individuals, and so are often those who please little æsthetically; and the kicks and scoffs of the world may take from the disposition what little grace it at first possessed; but this does not prove the moral rightness of the kicks and scoffs, or the moral culpability of those who dare to adhere to their purpose in spite of them. In the countries where excessive difficulties are placed in the way of women's work in the higher professions (there are very few placed in the way of her overwork in other directions), these have resulted naturally in the suppression of effort on the part of the majority of the more 
finely constituted and more sensitive, and have left the field to the hardier and less fine; but in the United States, where women are freest in every way, they have lost neither in natural grace nor in the attention and regard of men; on the contrary, they have gained in both, and they have, furthermore, left the mark of their refining influence on the whole civilization of the country. As long as women are weaker than men physically, a higher moral standard must have regard for this weakness. When, through a more healthful life, women become more nearly equal to men in endurance, certain forms of attention will be less necessary, and will, doubtless, fall off somewhat, only to make room for a higher plane of mutual helpfulness. Yet I doubt whether the time will ever come when the grace and beauty of women, the associations of love and the memories of family affection, will not stir men of finer fibre to peculiar kindness, repaid as the appreciation of women can well repay.

There is another protest - which comes especially from the party that most exclaims against the evils of competition - against the "superstitious" respect for age. The reason is, obviously, that age tends by nature to conservatism. But the evils of the struggle for existence are not those alone of outward conditions; these are often far less hard than the bitter spirit of mental antagonism that sears and saddens the heart. Youth is daring and originative; middle age is less venturesome, but it possesses, on the other hand, a wider range of experience. Between youth and youth, or youth and middle age, the battle is more equal. But age no longer possesses the power to cope with the world physically or mentally ; it is fixed in habit, and apt to follow one accustomed round of thought ; we are certainly not likely to convince it by violence. It has borne its share of violence and has done its part in the battle. It has advanced with its generation, though it may not be able to advance any longer with ours. Our ideal should certainly be that of forbearance, not of intolerance towards it.

Modern opinion is becoming dissatisfied with the old methods of dealing with criminals - with the methods which continually return the criminal to society not bettered by incarceration, and ready to commit all manner of crimes again. Both the protection of society and the welfare of the criminal would be better served by a course of discipline that should only then give him back to 
society when he is fitted to live in harmony with it and to enjoy the advantages conferred by such harmony. Recent experiments in reformatories have demonstrated the immense advantage of methods which attempt something like this. Among the improved reformatories for children, many of them without walls, bolts, or bars, some have sent out cured from eighty to eighty-five per cent of the offenders committed to them. The Elmira reformatory deals especially with offenders sentenced for their first state's prison offence, and its method is at once eminently humane and remarkably successful. Offenders may be sent to it at the discretion of the judges. It contains three grades. Members of the first of these wear better clothing, eat better food, enjoy various special privileges, and are used, to some extent, as officers and monitors for the other grades. Members of the second grade are less well provided for and honored than those of the first; and members of the third grade are worst clothed and fed, and have the fewest privileges. Every man who enters the prison is submitted to a minute examination as to his antecedents, his mental, moral, and physical condition and capabilities. $\mathrm{He}$ is then placed in the second grade, from which he may go up or down, according to his work and conduct. Eight hours' work a day are required, and compulsory school is held in the evening, at which the common English branches are taught, and elementary instruction given in Law, Political Economy, Ethics, etc. Discussion and thought on the subjects taught are encouraged, and everything possible is done to awaken interest. "Perfect" work and conduct for six months - the standard of "perfection" is high - and a mark of 75 in a scale of roo in the school secure a man advance into the next higher grade; and the same standard maintained for six months in the highest grade entitle a man to release on parole; so that the term of imprisonment need not exceed a year. The man must be willing, industrious, good-tempered, obedient, energetic, who gets release in this time. Work is found for every man released; he is closely watched for six months more, and if his conduct does not keep up the standard required, he is returned to the reformatory and must begin over again; if, on the other hand, his conduct and work, an attested report of which must be handed in each month, is satisfactory for these six months, he is honorably discharged. The obdurate malefactors serve out their full sentence, as they would in state's prison. Of those who go out 
from the institution, eighty per cent return to society reformed; and the superintendent is of the opinion that this percentage could still be raised were the time of detention made indeterminate and wholly dependent upon reform. All prison reformers are coming to recognize the desirability of such indeterminate sentences. The work of the men at Elmira pays over two-thirds of the expenses of the institution, and even if we consider only dollars and cents, this method of dealing with crime is evidently the cheapest; for under the old method we have to take into account the expenses of the later crimes of the men released without improvement of character. 'The method of parole of first offenders, newly introduced into France, and in use to some extent in other countries also, seems to have rather less to recommend it, except in special cases; since the moral, intellectual, and industrial discipline of the reformatory are lacking.

In all such reformatory work it may be remarked that hard labor and stringent discipline, as well as consistent kindness, are found absolutely necessary; and it is to be noted that the disinclination of criminals for labor and regularity of life is one of the greatest obstacles in the way of their reform. ${ }^{1}$ Judge Green quotes from Mr. Hough on this point: "Those who are in control of penal institutions meet with no more pernicious influence than that exerted by certain well-meaning but mistaken philanthropists who are impelled by kindly hearts to slop over with sentiment. No criminal is so hard to reach as the one who fancies himself injured or has a grievance against society. Aside from treatment that compels him to feel resentment, there is no one thing that will so quickly bring this feeling as to have some tender-hearted, benevolent person tell him that they think his penalty is far more severe than his offence warrants, especially now that he has promised to pray regularly and abandon his wicked ways." 2 In connection with this point, we may notice Bellamy's theory of crime as Atavism, to be treated in the hospitals. Whether or not we regard crime as disease, a distinction must be drawn between the disease that may be regarded as physical weakness and that which does not necessarily imply such weakness, though it may imply some physical defect in the sense that the psychical characteristic

${ }^{1}$ See essay by Charles Dudley Warner in the "North American Review" for April, 1885 .

2 S. M. Green: “Crime," Art. III. Chap. V. 
has always its physical coördinate. We may call the places where our criminals are treated prisons, or we may call them hospitals; but the name will not alter the fact that crime, and even the crime the tendency to which manifests itself early in life and is most incorrigible, needs, for the most part, a wholly different treatment from that pursued with the sick or the insane. Discipline and labor may come into play in the insane asylum, and medicine and hygiene in the prison; but the methods are, nevertheless, widely separated, and need to be so in order to attain any success. Bellamy's conception of the character of the criminal by nature - such as he imagines as alone existing under the conditions of his ideal state - as rarely untruthful, does not at all accord with the facts of Psychology and Criminology. Total unreliability is one of the chief characteristics of the criminal by nature. He lies even where there is nothing to be gained by lying and often much to be lost ; he lies apparently for the mere pleasure of lying; or he is crafty and cunning, and the smallest gain suffices to furnish him with a motive for falsehood. In mankind, as a whole, the love of truth, one of the latest developments of the moral sense, is likewise one of those earliest lost in any moral deterioration; and to suppose men, as a rule, strictly truthful and yet capable of committing crimes of any sort, especially in a general ideal state of society and morals, is to suppose a psychological contradiction. Moreover, the antipathy of the criminal to undergoing the penalty of his crime would still remain as long as the discipline and labor of the places for criminal treatment were not abolished; and even the restrictions of incarceration would render the penalty disagreeable, since liberty is always preferable to confinement. And if we consider the indefinite sentence, which all prison reformers now regard as the first condition of the successful treatment of crime, to be introduced, the reasons for pleading "Not Guilty" would by no means be removed. But I doubt whether a society of high moral development would sanction the doubling of the penalty which Bellamy conceives, as the punishment of simply a lie to escape it.

The question of capital punishment is more difficult than at first glance appears. One of the arguments often advanced in opposition to this form of punishment is that the fear of it is no preventive of the crime of murder (for which alone, in times of peace, it is still imposed in civilized countries), since murder still takes place. But 
the argument in this form is practically worthless; we might as well say that art exhibitions do nothing to form taste, since many people who visit them are still lacking in æsthetic feeling. The fact that men have gone away from public executions and committed murder is more to the purpose, as an indication that the influence of the spectacle is probably a bad one. As to the private execution within prison-walls, it is difficult to suppose that the mere knowledge of it could arouse a desire for blood, as the sight of it may be imagined to do. If we abandon capital punishment on this ground merely, ought we not, in consistency, to do away with all representations of violent death on the stage and all description of it in fiction, since these things must affect the imagination full as vividly. The gladiatorial shows of Rome were doubtless undesirable from a humanitarian point of view, not only in themselves, but also in their results; and it might be undesirable for most individuals to accustom themselves to the spectacle of the butchering of their meat; but, whether or not we agree with the vegetarians as to the social significance and influence of the use of animal-food (necessarily, of course, we must concede that every fact has an influence of some sort, and in some degree, upon the mind), it can scarcely be claimed that the mere knowledge that beeves are slaughtered somewhere is likely to influence the mind to such an extent as to lead to a morbid desire to imitate the deed ; nor, the stimulating excitement of the actual spectacle of execution lacking, is it likely that the mere knowledge of its actuality should incite to the taking of human life. On the contrary, it appears far more likely that the would-be murderer should connect the thought of it with the possibilities of his own future in case of detection and arrest, and that he should, thus, be rather deterred from crime by it.

The vital questions appear to be whether we have a right thus to sacrifice life, and whether the evil which the murderer brings upon society may not be better prevented in some other way. Leaving out of consideration, for a moment, a point which will be considered later, the two questions will be seen to resolve themselves into one. If I should perceive an innocent man about to be murdered by a villain, who was on the point of plunging his knife into his victim's heart, and I had in my hand at the time a loaded revolver, my duty would be plain. I should have no choice as to the responsibility for one man's life; only the choice would 
be left me as to which life I would be responsible for; and to spare the murderer would be to make myself an accomplice in the murder. The responsibility lies with every society to do the utmost in its power to prevent the murder of citizens who are, in the majority of cases, better men than their murderer; and the life, even, of the murderer cannot stand out against the life of better men. If, then, the death sentence is the best preventive of murder, and society refuses to inflict it nevertheless, it makes itself the accomplice of the murderer as much as is the man who stands by and permits the knife to be plunged into the victim's heart, rather than shoot down its wielder. It is not mercy that spares the guilty to sacrifice the innocent. If, then, we must be responsible for the death of any man, let it be for that of the murderer rather than for that of his victims. It is easy enough to say, as do some on this point, that it should never become a principle of society to do evil in order that good may come; but as long as there are conflicting conditions in society, there can be no choice of absolute good; the only choice is between lesser and greater evils. Forgetting this, and looking only on the one side of the question on which their sympathy has especially been excited, reformers are sometimes guilty of choosing the greater evil in order that a lesser good may come. It is, therefore, not sufficient to brand capital punishment "a relic of barbarism," in order to prove that it should be abolished.

The problem of prevention of murder includes various elements: it includes the question of the possible repetition of the crime by the individual on trial, the question of his influence by precept and example, and that of his possible propagation of offspring who may inherit his evil propensities; and it also includes the question of the check of fear in other would-be murderers.

It has been claimed that imprisonment for life would act as an effectual preventive in all these respects. There may be, however, various objections to this penalty. In the first place, an unconditional life-sentence without hope of pardon is difficult to establish, especially in democratic countries; and its justice is doubtful, in case it were possible. Even if sentences of this sort were to be passed, pity would be likely to interfere later with their execution. And then the momentous question arises as to whether it would always be well-directed pity. The men in whom the right of pardion is vested are not always wise in their use of it, and in demo- 
cratic countries they are guided to a considerable extent by the will of importunate portions of society which is often still less wise. The sentimentality which now vents itself in loading down violent criminals with flowers, fruit, gifts of all sorts, letters, photographs, commiserations for their "misfortune," and even offers of marriage, is likely to stand in the way of the safety of society in case the murderer lives. 'This sentimentality, which in many countries exalts the criminal into a hero, and in France turns the police court into a fashionable place of amusement, were it not to be followed by the dread ending which the sterner members of society exact, and were the hope of pardon still open, might invest arrest with even some attractions to the murderer, who is frequently a hero in his own eyes. The prominence of a desire for notoriety is evident in criminals of the Jack-the-Ripper and other types. The sentimentality which is unable to distinguish between a legitimate mercy, and the mercy to the individual which amounts to the worst of cruelty to many others, is, indeed, a continual danger to society and a hindrance to useful reforms.

Again, if the criminal be condemned to life-imprisonment, there is always the possibility of his escape to be considered, and the fact that he will probably stick at nothing to accomplish his escape. The dangers of ultimate success may not be so large; our prisons are nowadays strongly built, the warders and other officers are very seldom open to bribes, and the proportion of escapes is extremely small. Nevertheless, the hopelessness of a lifesentence must constitute a strong motive for the stinulation of effort and ingenuity; and it can scarcely be hoped that a man who has not before hesitated at murder, and who has no greater penalty to fear in case of any number of repetitions of the crime, will hesitate when his liberty and all it means to him of freedom from irksome discipline and restraint of vice, is at stake. And in case of escape society has to fear, not only repetitions of the crime, but also the numberless and complex workings of the criminal's influence on others, and the propagation of offspring who may inherit his evil propensities.

And, furthermore, if the sentence of life-imprisonment is carried out, the murderer's influence on the other tenants of the prison is to be considered, in case he is not kept in solitary confinement. The preservation of a large number of desperate criminals, in contact with the less corrupt ones whose reform is being attempted, 
has many objections. Criminals have more than once stated that they learned their worst principles from companions in prison, and many of our prisons and many of our reformatories have been called mere schools of vice. Moreover, in maintaining our desperate criminals, we are spending large sums for their comfort while hundreds of better men are left to starve, and thousands are more poorly clothed and fed.

The fact that murder has not increased in some countries where the death-sentence has been abolished may be admitted as evidence in the matter, but cannot be regarded, alone, as conclusive. For, first, that which is for the general good in one country may not be so in another, the national temperament, form of government, and general habits of which are different. And, furthermore, it may be said that, although statistics undoubtedly must have some meaning in all cases, the complication of social conditions renders it often difficult to say just what the significance may be in the particular case. In the diminution of murders, other circumstances may have been at work which would have lessened the number even if the death-sentence had not been abolished. At least, experiments with regard to the abolition of the death-penalty have been too few to render any categorical assertion on the subject possible.

- But some of the above-stated objections to the abolition of capital punishment might be removed by the provision of separate prisons for malefactors condemned to life-imprisonment, with separate wards according to the moral condition of the prisoners, little communication being allowed between even those in the same ward, or communication only under supervision, and such instruction being given as would enable the individual to occupy the hours not devoted to labor in study, reading, or other mental recreation.

Green, in his book on crime, calls attention to the very undesirable vindictiveness sometimes aroused, by sentence of death, in the minds of the condemned and of his friends, and notices the general evil of the feeling in the minds of criminals that the state is their deadly foe, defiance of the laws being thus raised to the plane of legitimate warfare upon an enemy. The Hon. John J. Wheeler, in a paper quoted by Green, lays especial stress on the desirability of convincing the criminal that not revenge but the protection of society is aimed at in state-punishment.

Again, the question may be asked whether the sentimental ten- 
dency to regard the criminal as a hero is not fostered by the deathsentence - whether the pity aroused at so extreme a fate would not be inclined to take a less harmful form if the treatment of the criminal were at once firm and humane but less sensational. Doubtless, the glory of crime and half its attractiveness for a large class of morbid criminals would be departed, if we could come to regard the latter with commiseration as of a lower and abnormal type of humanity and to treat them as such. But it must be remembered that society, as a whole, is yet far from so scientific a conception; and that combined firmness and kindness of treatment is difficult to secure, both in prison-officials and in those officers who have the power of pardon at present placed in their hands. We need obviously many reforms in our system of sentence and pardon, as well as in the management of our prisons. We need more men like Mr. Brockway of Elmira, Mr. Wardwell of Virginia, and those other modern reformers of prison-life whose office is to them a matter of humanity and not merely of business. And especially, we need more firmness in society as a whole; sympathy and mercy may be evils in the path of human progress when they deteriorate into a weakness which sacrifices the innocent in a mistaken humanity towards the guilty. In order to be well directed, sympathy must consiler all men, and not the individual alone; only then is it an unmitigated good.

But as for the argument noticed above with regard to the employment of large sums of money for the maintenance of the criminal classes while the class of honest laborers is yet in destitution, it cannot be considered, on close inspection, as of great weight. Certainly it would not be well to maintain the criminal in luxury while other reforms were waiting. But if we act on the principle of deferring all less important reforms until all the more important ones are accomplished, we shall be in danger of not reforming at all. Any reform that is well-timed and possible is important; for the complication of social relations makes all reforms of weight in their wider significance. No reforms can or should be made in a lump; improvement must come from all sides and little by little; sympathy must be consistent and influence social conditions in every direction gradually as it gradually increases. It is the superficial Utilitarianism which bids us wait such a reform as this, though possible, for another, - the same sort of Utilitarianism which advocates the introduction of the Spartan custom of 
preserving only well-formed and vigorous infants, and advises the administration of painless poisons to those hopelessly ill and suffering. All these things have their relation to character, and, therefore, to other social evils, or reforms.

And here we are brought finally to the consideration of the point hitherto left out of account, - a point which bears, however, a strong argument ; namely, the fact of the possible condemnation of innocent men to death. Even since the limitation of capital punishment to cases of murder the innocent have been hung or guillotined in mistake for the guilty. And for such mistakes there is no reparation; the grave never gives up its dead. Men have sometimes been discovered to be innocent in spite of the strongest evidence against them ; human observation is defective, human memory fallible, human character - especially such as often appears in evidence against the murderer - by no means always strictly honorable and honest. Even confessions of guilt have sometimes been proved false. As with regard to other propositions to place the power of the life or death of individuals in the hands of their fellow men, the question presents itself as to whether the use of so great power is not dangerous. And this appears to me the decisive point of our inquiry.

Societies are being formed for the abolition of capital punishment, and feeling is growing strong in its favor. Let us hope, however, that the reformers will adopt a policy stringent and judicious as well as merciful; - that they will not forget that, in order to render the preservation of the murderer harmless to society we need other reforms in law and prison management.

In general, it may be said of all questions, that the conflict between the principles of justice and mercy, known to theological Ethics, resolves itself, from a higher point of view, into the question of justice only. The mercy which is not justice, is either mercy to one at the expense of others, or mercy that spares the offender in one respect to his own greater disadvantage in another. The ideal character is thus at once gentle and strong.

We have followed the development of altruism from egoism up to the point where the thought of punishment ensuing upon the non-performance of duty ceases to play a large part in the motive to action, the reward of the pleasure of others and of their gratitude and love forming a complex motive. But beyond even the incentives of love there lies still a higher motive which, in 
cases of conflict, must figure as the highest morally. In an ideal state, the social sanction could not conflict with duty; but until we reach such a state, the independence of moral motive must be observed, the moral man must do what appears to him right, in spite of public opinion. The course has its dangers, and the principle must be carried out with caution, the questions involving such a course be carefully considered from all sides and in all lights. But when this has been done, the sense of duty remains supreme. In the ideal man, the consciousness of duty performed should constitute the strongest pleasure, the consciousness of failure in duty the severest pain. This is the solution of the problem Ibsen gives us in "Rosmersholm"; society has not advanced from savagery by permitting all pleasures which the individual desires; nor can it advance further towards the ideal by permitting the individual to choose those pleasures which the future shall regard as evidence of our present semi-barbarous state, since they are pleasures inimical to the peace of others and the general good of society; as in the past, so in the present and future, the harmony between pleasure and duty (that is between the conflicting pleasures of individuals) can be attained only by habit which shall bring the desires of the individual into harmony with duty. Thus only can all desires, the happiness of all individuals, attain to harmony, - to "full " equilibrium.

And this leads me to remark that we have reason to doubt the moral conviction of very many who protest against the "immoral " and "superstitious" restriction of personal pleasure in certain directions. Were such individuals morally convinced, were duty to their fellow men really uppermost in their minds, they would not choose darkness and secrecy for their deeds, but after careful and thorough statement of their opinions and reasons would show the earnestness of their belief by open act. The man whose moral conviction is to him the highest duty does not fear public opinion, but dares to follow that which seems to him right, in the face of slander; therefore, we suspect the man who hides his deeds, of seeking his own pleasure and not that of society as a whole.

"Conscience is harder than our enemies,

Knows more, accuses with more nicety,

Nor needs to question Rumor if we fall

Below the perfect level of our thought.

I fear no outward arbiter,"

says Don Silva in "The Spanish Gypsy." 
But for our encouragement, let us contemplate the heroic characters which progress has developed. From these we may take hope and courage, in these we may find the best results of the moral evolution of our race, and the promise of the better future which man alone can work out by ever-renewed effort. The love of such characters, and even the knowledge that they exist, is the highest joy of human association, a joy which the present age may feel in a degree that no former age has known; and herein lies the greater beauty of the present time over all others. The thought of such characters can sustain us even in our own self-doubt. What man has done, man can do. Nay, he shall do more, much more.

The question as to the final destruction of the human race, whether by sudden catastrophe or slow decay, can little affect happiness, at present, or for very many ages to come. As yet, evolution is in the direction of a greater harmony that means continually greater pleasure to life. We have not reached our maximum, we are evolving upwards towards it. The pessimist is fond of making much of the final end of our planet; but the healthy and successful will be happy in spite of future ages, and the extent and degree of happiness will continue to increase for such an immense period of time that there is no reason for considering the destruction of our race as exerting any important influence on ethical theory. The loss of our faith in individual immortality is a far greater source of present pain. It leaves death a harder sorrow.; - but it lends life new meaning. The good we strive for lies no longer in a world of dreams on the other side the grave; it is brought down to earth and waits to be realized by human hands, through human labor. We are called on to forsake the finer egoism that centred all its care on self-salvation, for a love of our own kind that shall triumph over death, and leave its impress on the joy of generations to come. There is something lost in the dissolution of the old faith to us who were reared in it. The hope of restitution, to the individual, from supernatural cause, here or hereafter, is forever done away with. There is no restitution. In our favorite novel, when the doors are closed and the lights extinguished, that some unspeakable sorrow may hide itself in darkness and silence, we can always turn back the leaves till we are again in the midst of light and music and dancing, and the heart for which the tragic knife is pitilessly sharpening in the hand 
of Destiny, is yet untouched. But in the book of Reality, there is no turning back; the pages are burned before our eyes as we read. Sooner or later, we all of us reach the point where that which made life most worth living has passed away from us forever. There is no help save the knowledge of the fact, that shall make us all draw closer in sympathy and by mutual kindness render loss less bitter. As we accept the Truth, and bow our head to the Inevitable, we may learn a less narrow happiness for this life and for the Hereafter, from the great pioneers of Scientific Doubt and pure Humanitarianism, one of whom has written :-

"Oh, may I join the choir invisible

Of those immortal dead who live again

In minds made better by their presence; live

In pulses stirred to generosity,

In deeds of daring rectitude, in scorn

For miserable aims that end with self,

In thoughts sublime that pierce the night like stars,

And with their mild persistence urge man's search

To vaster issues.

So to live is heaven :

To make undying music in the world, Breathing as beauteous order that controls With growing sway the growing life of man.

This is life to come,

Which martyred men have made more glorious

For us who strive to follow. May I reach

That purest heaven, be to other souls

The cup of strength in some great agony,

Enkindle generous ardor, feed pure love,

Beget the smiles that have no cruelty, -

Be the sweet presence of a good diffused,

And in diffusion ever more intense.

So shall I join the choir invisible,

Whose music is the gladness of the world." 



\section{Works on Philosophy}

PUBLISHED BY

\section{MACMILLAN \& CO.}

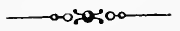

\section{ETHICS.-METAPHYSICS.-LOGIC.-PSYCHOLOGY.}

ARISTOTLE: Outlines of the Philosophy of Aristotle. Compiled by EDwin Wallace, M.A. Third edition enlarged. Pitt Press Series. $16 \mathrm{mo}$. \$1.10, net.

BACON : Novum Organon and Advancement of Learning. Edited with notes by J. DeveY, M.A. Bohn Library. \$I.5O, net.

Novum Organon. Translated by G. W. Krtchin, M.A. 8vo. Bohn Library. \$2.50, net.

BALFGUR (A. J.): A Defence of Philosophic Doubt. An Essay on the Foundations of Belief. Svo. $\$ 3.50$, net.

BAX. Works by E. Belfort BaX:

A Manual of the History of Philosophy, for the Use of Students. Bohn Library. \$I.5O, net.

The Problem of Reality. I2mo. 90 cents.

BIRKS. WORKS BY THOMAS R. Birks:

First Principles of Moral Science. $12 \mathrm{mo}$. $\$ 2.50$.

Modern Utilitarianism; or, the Systems of Paley, Bentham, and Mill Examined and Compared. 12mo. \$2.00.

Modern Physical Fatalism and the Doctrine of Evolution. Including an examination of Herbert Spencer's “First Principles." I 2 mo. \$2.00.

BOOLE (G.): A Treatise on the Calculus of Finite Differences. Third edition, $12 \mathrm{mo}$. \$2.60, net.

BOSANQUet. Works by Bernard Bosanquet, M.A.:

Logic; or, the Morphology of Knowledge. 2 vols. $\$ 5.25$, net.

The History of Esthetics. The Library of Philosophy. 8vo. \$2.75, net. 
BURNET (J.) : Early Greek Philosophy. 8vo. \$2.50, net.

CAIRD (E.): The Critical Philosophy of Emmanuel Kant. 2 vols. 8vo. $\$ 7 \cdot 50$, net.

Essays on Literature and Philosophy. 2 vols. $\$ 3.00$.

CALDERWOOD. Works by Henry Calderwood, LL.D.:

A Handbook of Moral Philosophy. Fourteenth edition. I 2mo. \$I.5O, net.

The Relations of Mind and Brain. Third edition. 8vo. $\$ 4.00$.

CLIFFORD. Works BY William Kingdon Cliffokd:

Lectures and Essays. Edited by Leslie Stephen and F. Pollock, with an Introduction. New edition. \$2.50.

Seeing and Thinking. With Diagrams. Nature Series. \$1.50.

COMTE'S Philosophy of the Sciences, being an Exposition of the Principles of the Cours de Philosophie Positive. By G. H. LEwEs, author of "The Life of Goethe," "Biographical History of Philosophy," etc. Bohn Library. \$I.50, net.

DEVEY (J.) : Logic; or, the Science of Inference. A Systematic View of the Principles of Evidence and the Methods of Inference in the Various Departments of Human Knowledge. A Popular Manual. With Index. Bohn Library. \$I.50, net.

ERDMANN (J. E.) : A History of Philosophy. English translation edited by Williston S. Hough, Professor of Philosophy in the University of Minnesota. The Library of Philosophy. 3 vols. 8vo. \$10.50, net.

An Outline of Erdmann's History of Philosophy. By Henry C. KING, Professor of Philosophy in Oberlin College. 30 cents.

FOWLER (T.) : The Elements of Logic, Deductive and Inductive. I6mo. $\$ \mathrm{I} .75$, net.

- Progressive Morality. An Essay in Ethics. I 2mo. \$I.50.

FOWLER (T.) and WILSON (J. M.): The Principles of Morals. 8vo.

PART I. (Introductory Chapters.) \$1.25.

II. (Being the Body of the Work.) \$2.75.

GREEN (T. H.) : Prolegomena to Ethics. Edited by A. C. Bradley, M.A. Third edition. $8 \mathrm{vo} . \$ 3.25$, net.

HARTMANN (E. vON): Philosophy of the Unconscious. Speculative Results accorded to the Inductive Method of Physical Science. Translated in English by W. C. Coupland, M.A. 3 vols. 8vo. \$7.50, net.

HEGEL : Logic. Translated from the Encyclopædia of the Philosophical Sciences. With Prolegomena by W. Wallace, M.A. 2 vols. 8vo.

Vol. I. Prolegomena. [New edition in preparation.]

II. Translation. New edition. \$2.50, net. 
HEGEL : Lectures on the Philosophy of History. Translated by J. SibreE, M.A. Bohn Library. \$1.50, net.

HÖFFDING (Prof. H.) : Outlines of Psychology. Translated by M. G. LOWNDES. $12 \mathrm{mo}$. \$1.50, net.

JARDINE (R.): The Elements of the Psychology of Cognition. Second edition, revised. I $2 \mathrm{mo}$. \$1.50, net.

Jevons. Works by W. Stanley Jevons.

The Principles of Science. A Treatise on Logic and Scientific Method. 12mo. \$2.75, net.

Elementary Lessons in Logic: Deductive and Inductive. With copious Questions and Examples, and a Vocabulary of Logical Terms. New edition. $18 \mathrm{mo}$. 40 cents, net.

Studies in Deductive Logic. A Manual for Students. Second edition. I 2 mo. I.6o, net.

Pure Logic; and other Minor Works. Edited by Robert Adanson, M.A., LL.D., and Harriet A. Jevons. Preface by Prof. Adamson. 8vo. \$2.50, net.

KANT : Critique of the Pure Reason. Translated into English by F. MAX

Müller. With an Introduction by Ludwig Noiré. 2 vols. 8vo. \$8.oo.

The Translation. Complete. Sold separately. $\$ 3.50$.

Kant's Critical Philosophy for English Readers. By JонN P.

Mahaffy, D.D., and John H. Bernard, B.D. A new and complete edition.

VOL. I. The Kritik of the Pure Reason Explained and Defended. \$1.75, net.

II. Translation of the Prolegomena. With Notes and Appendices. $\$ \mathrm{I} .5 \mathrm{O}$, net.

Critique of Judgment. Translated by J. H. Bernard. 8vo. $\$ 3.50$. Critique of Pure Reason. Translated by J. M. D. Meiklejohn. Bohn Library. \$I.50, net.

Prolegomena and Metaphysical Foundations of Natural Science. Translated, with Biography and Memoir, by E. BeLfort Bax. Bohn Library. \$I.5O, net.

The Philosophy of Kant. As contained in Extracts from his own Writings. Selected and translated by John Watson, LL.D. \$I.75, net.

KEYNES (J. N.): Studies and Exercises in Formal Logic. I 2 mo. $\$ 2.75$, net.

KING (Prof. H. C.) : An Outline of Erdmann's History of Philosophy. By Henry C. King, Professor of Philosophy, Oberlin College. 30 cents.

LAURIE (S. S.): The Institutes of Education, comprising a Rational Introduction to Psychology. $16 \mathrm{mo}$. \$1.00. 
LEIBNITZ : Critique of Locke. New Essays on the Understanding. By the Author of the System of Pre-established Harmony. Translated from the French by Alfred G. Langley, A.M. I 2 mo. [In the press.]

LIBRARY OF PHILOSOPHY (THE) : Edited by J. H. MUIRHEAD, M.A. A History of Philosophy. By Johann Eduard Erdmann, Professor of Philosophy, University of Halle. English translation edited by WILListon S. Hough, Ph.M., Professor of Philosophy, University of Minnesota. 3 vols. Large 8 vo. $\$ 10.50$, net.

Development of Theology. In Germany since Kant, and Great Britain since 1825 . By OTto Pfleiderer, D.D., Professor of Theology in the University of Berlin. Translated, under the author's supervision, by J. Frederick Smith. Large 8vo. \$2.75, net.

The History of Esthetics. By B. BosanQUet, M.A., Author of "Logic; or, the Morphology of Knowledge "; Translator of Lotze's "System of Philosophy." \$2.75, net.

LOCKE : Philosophical Works. With Preliminary Discourse, Analysis of Locke's Doctrine of Ideas, Notes by J. A. St. John, Index, and Portrait of the Author. Bohn Library. 2 vols., each 1.00, net.

\section{LOTZE'S SYSTEM OF PHILOSOPHY.}

PART I. Logic. In Three Books. Of Thought, Of Investigation, and Of Knowledge. English translation by Bosanquet. 2 vols. 12mo. $\$ 3.00$, net.

PART II. Metaphysic. In Three Books: Ontology, Cosmology, and Psychology. English translation by Bosanquet. 2 vols. $\$ 3.00$, net.

Outlines of a Philosophy of Religion. By Herman Lotze. Edited by F. C. Conybeare, M.A. 90 cents.

MACKENZIE : An Introduction to Social Philosophy. By JoHn S. MACKenzie, M.A., B.A., Assistant Lecturer on Philosophy in Owens College, Manchester, formerly Examiner in Philosophy in the University of Glasgow. 8vo. \$2.6o, net.

MAHAFFY (J. P.) and BERNARD (J. H.): Kant's Critical Philosophy for English Readers.

Vol. I. The Kritik of the Pure Reason Explained and Defended. \$1.75, net.

II. Translation of the Prolegomena. With Notes and Appendices. $\$ 1.50$, net.

MARSHALL: A Short History of Greek Philosophy. By JohN MARSHALL, M.A., Oxon., LL.D. I 2 mo. \$1.10, net.

MARTINEAU. Works by JAMES Martineau, LL.D.:

Types of Ethical Theory. New and cheaper edition. In one volume.

I 2 mo. \$2.6o, net.

Spinoza: A Study of. With portrait. Second edition. $\$ 2.00$. 
MASSON (D.) : Recent British Philosophy. A Review with Criticisms. Third edition. \$1.75.

MAUDSLEY (HeNkY, M.D.) : Body and Mind. An Inquiry into their Connection and Mutual Influence. Second edition, enlarged. \$2.00.

MAURICE (F. D.) : Moral and Metaphysical Philosophy. 2 vols. 8vo. $\$ 6.00$.

Vol. I. Ancient Philosophy from the First to the Thirteenth Centuries.

11. Fourteenth Century and the French Revolution, with a Glimpse into the Nineteenth Century.

MAYOR (J. B.): A Sketch of Ancient Philosophy from Thales to Cicero. Pitt Press Series. 16 mo. 90 cents, net.

MILLER (Professor): History Philosophically Illustrated, from the Fall of the Roman Empire to the French Revolution. Bohn Library. 4 vols., each $\$$ r.oo.

MURPHY (J. J.) : Habit and Intelligence. Essays on the Laws of Life and Mind. Second edition, revised and rewritten. With illustrations. 8 vo. $\$ 5.00$.

PFLEIDERER: The Development of Theology in Germany since Kant, and its Progress in Great Britain since 1825. By Otto Pfleiderer, D.D. Translated, under the author's supervision, by J. Frederick SMith. The Library of Philosophy. 8vo. \$2.75, net.

RAY (P. K.) : A Text-Book of Deductive Logic for Students. \$1.25, net. RYLAND (F.): The Student's Manual of Psychology and Ethics. Cloth, red edges. $5^{\text {th }}$ edition, revised and enlarged. 1 2 mo. \$1.0o.

SCHLEGEL. Works by F. Schlegel:

On the Philosophy of History. Translated, with a Memoir of the Author, by J. B. Robertson. Bohn Library. \$1.00, net.

On the Philosophy of Life and The Philosophy of Language. Translated by A. J. W. Morrison, M.A. Bohn Library. \$r.oo, net.

SCHOPENHAUER. WORKS BY A. SCHOPENHAUER:

On the Fourfold Root of the Principle of Sufficient Reason and On the Will in Nature. Translated from the German. Bohn Library. $\$ 1.50$, net.

Essays. Selected and translated by E. Belfort BAx. Bohn Library. $\$ \mathbf{r} .50$, net.

Essays. Selected and translated by T. Bailey Saunders. Five volumes in a box, $\$ 4.50$; or, 90 cents each:

The Wisdom of Life.

Counsels and Maxims.

Religion: A Dialogue.

The Art of Literature.

Studies in Pessimism. 
SIDGWICK. Works by Professor Henry Sidgwick:

The Methods of Ethics. Fourth edition. 8vo. $\$ 3.50$, net.

Outlines of the History of Ethics for English Readers. \$1.25, net.

SPINOZA: A Study of. By Janes Martineau. \$2.00.

Chief Works. Translated, with Introduction, by R. H. M. Elwes. 2 vols. .

Vol. I. Tractatus Theologico-Politicus; Political Treatise. \$1.50, net.

II. Improvement of the Understanding; Ethics; Letters. \$I.5O, net.

STEWART (J. H.): Notes on the Nicomachean Ethics of Aristotle. 8 vo. 2 vols. \$8.oo, net.

STEWART and TAIT. Works by Professor Balfour Stewart and P. G. TAIT :

The Unseen Universe: Physical Speculation on a Future State. $\$ 1.25$.

Paradoxical Philosophy: A Sequel to "The Unseen Universe." $\$ 1.75$.

THORNTON (W. T., C. B.) : Old-Fashioned Ethics and Commion-Sense Metaphysics. 8vo. \$2.5\%.

VENN. WORKS BY John VenN, M.A.:

The Logic of Chance. Third edition. \$2.75, net.

Symbolic Logic. $\$ 2.75$, net.

Principles of Empirical or Inductive Logic.. 8vo. \$4.50, net.

WARNER (F.) : A Course of Lectures on the Growth and Means of Training the Mental Faculty. Delivered $\dot{*}$ rsity at Cambridge. I 2 mo. Cloth. 90 cents, net.

WATSON. WORKS BY JoHN WATSON, LL.D

Kant and his English Critics. A Comparı

.nd Empirical

Philosophy. 8vo. \$4.0o.

The Philosophy of Kant, as contained in

Writings. Selected and Translated. \$I.75, net.

WILlIAMS (C. M.): A Review of the Systems of Ethics founded on the Theory of Evolution. I 2mo. [Shortly.]

WILSON (J. M.) and FOWLER (T.): The Principles of Morals. 8vo.

PART I. (Introductory Chapters.)

II. (Being the Body of the Work.) \$2.75.

ZIEhEN (Prof. T.) : Introduction to Physiological Psychology. Translated by C. C. VAN Lieuiw and Dr. Otto Beyer. \$1.50, net. 




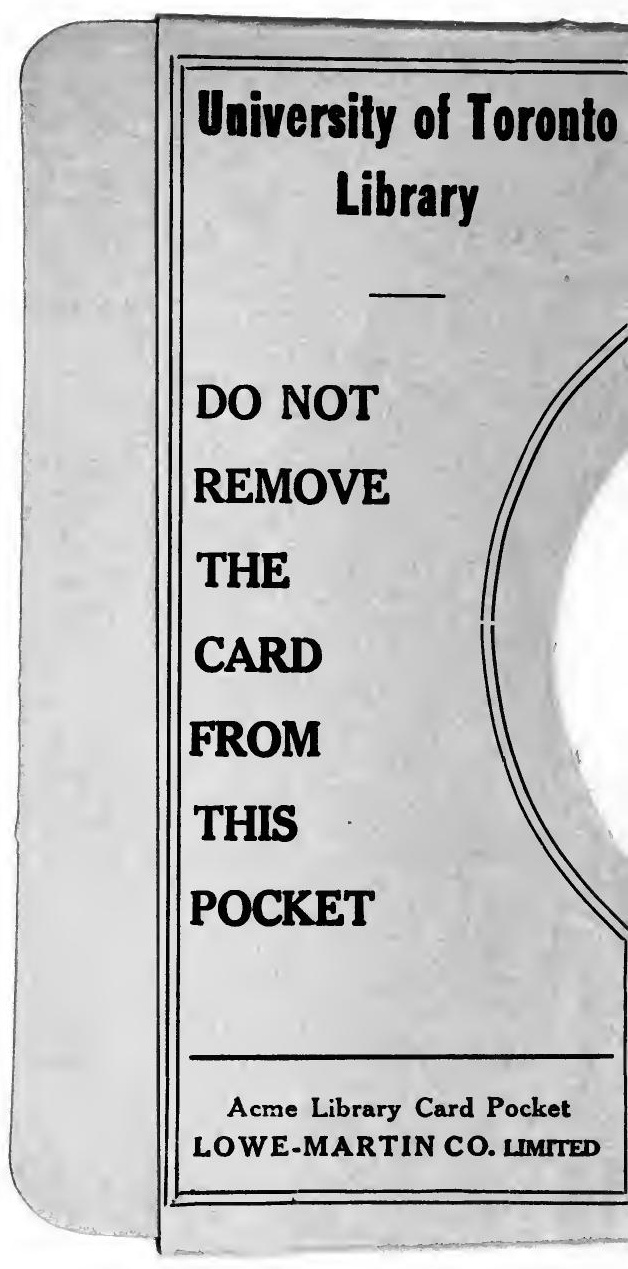




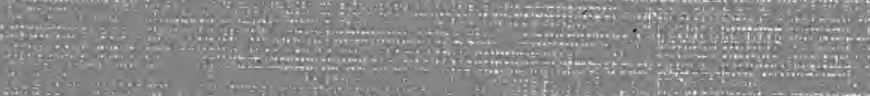

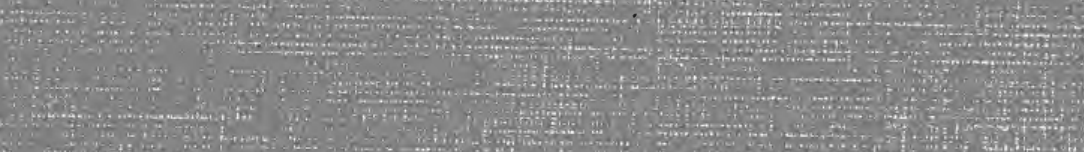

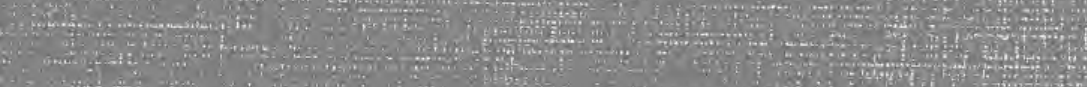

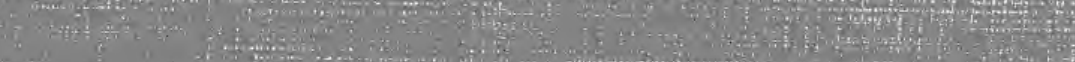

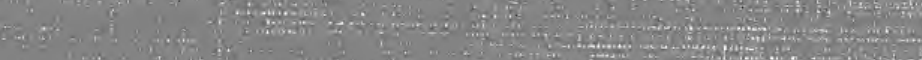

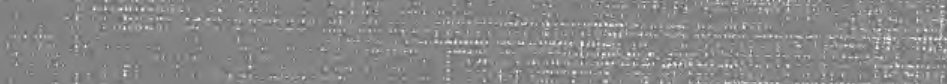

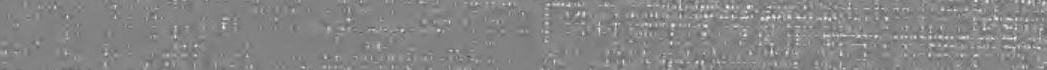

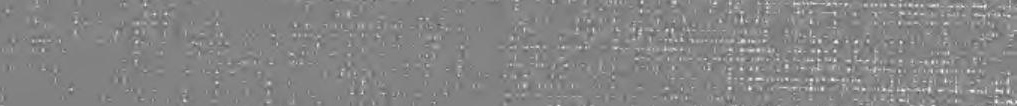

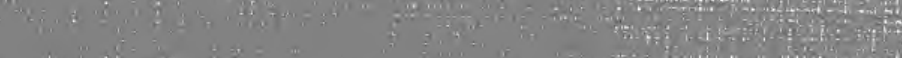

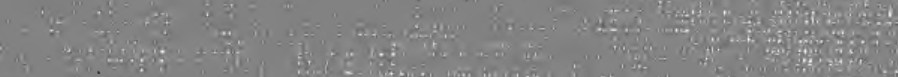

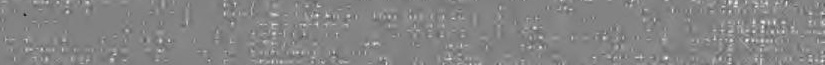

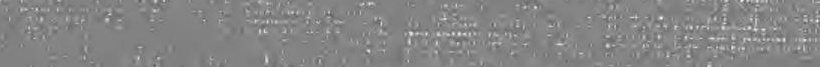

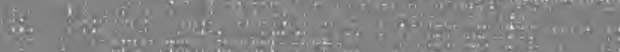

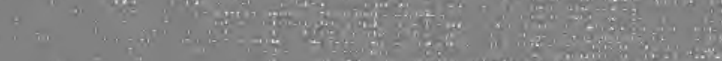

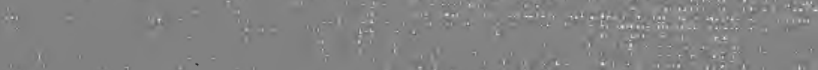

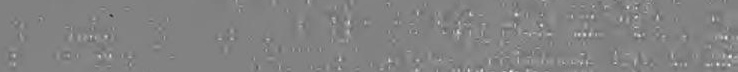

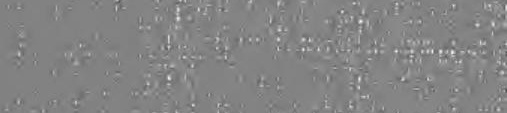

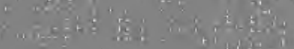

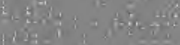

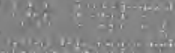

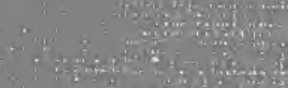

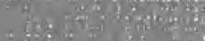

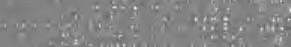

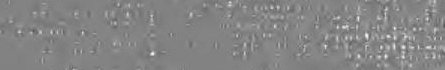

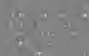

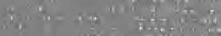

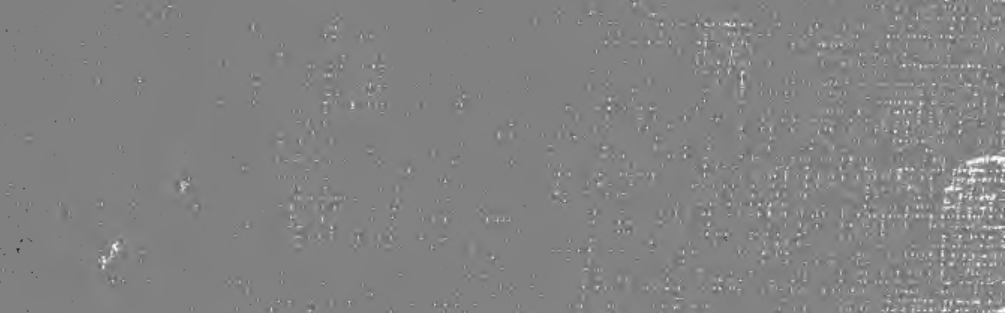

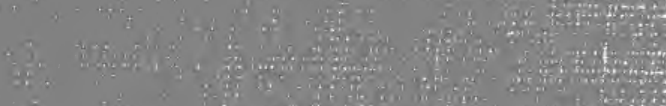

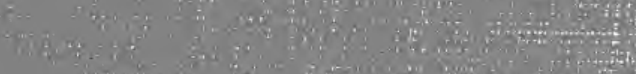

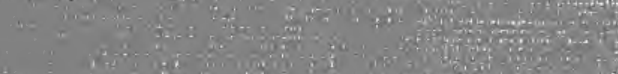

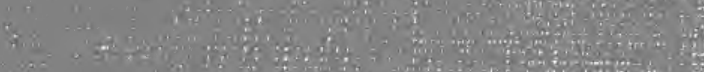

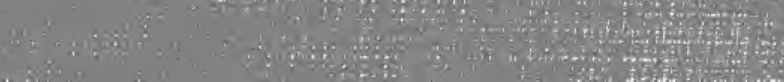

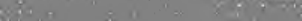
$\frac{8}{4}$ 